\title{
Aufgeklärte Apokalyptik: Religion, Gewalt und Frieden im Zeitalter der Globalisierung
}

Edition Weltordnung - Religion - Gewalt 1

The

innsbruck university press

in series 



\section{SERIES}

\section{Edition Weltordnung - Religion - Gewalt}

Editor-in-Chief: Wolfgang Palaver

Editorial Board:

Andreas Exenberger, Wilhelm Guggenberger, Peter Haider, Johann Holzner, Brigitte Mazohl, Dietmar Regensburger, Alan Scott, Roman Siebenrock, Kristina Stöckl, Claudia von Werlhof

Band 1

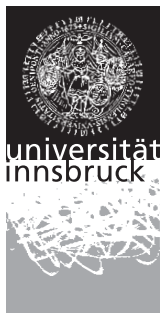


(C) 2007 innsbruck university press

1. Auflage

Alle Rechte vorbehalten.

innsbruck university press

Univ.-Prof. Dr. Dr.h.c.mult. Tilmann Märk

Universität Innsbruck

Christoph-Probst-Platz, Innrain 52

A-6020 Innsbruck

www.uibk.ac.at/iup

Herausgeber: Wolfgang Palaver, Andreas Exenberger, Kristina Stöckl

Verlagsredaktion: Carmen Drolshagen

Umschlaggestaltung: Alexander Eberharter

Lektorat: Alexander Eberharter

Satz: Alexander Eberharter, Andreas Exenberger

Herstellung: Fred Steiner, Rinn

ISBN: 978-3-902571-41-0 


\section{Aufgeklärte Apokalyptik: Religion, Gewalt und Frieden im Zeitalter der Globalisierung}

Wolfgang Palaver, Andreas Exenberger, Kristina Stöckl (Hg.)

Edition Weltordnung - Religion - Gewalt 1 



\section{Inhaltsverzeichnis}

\section{1}

11 Einleitung

Wolfgang Palaver, Kristina Stöckl

23 Aufgeklärte Apokalyptik. Jean-Pierre Dupuy als möglicher Referenzautor für das interfakultäre Forschungsprojekt „Weltordnung-Religion-Gewalt“

Raymund Schwager $\uparrow$

\section{2}

43 Wessen Frieden? Zur Frage nach der Transrationalität in der Friedensforschung

Wolfgang Dietrich

67 Islam und Gewalt

Rüdiger Loblker

85 Theologie und Volkssouveränität oder Vom Nutzen der Theologie für die Politik

Mariano Delgado

109 Glaube und Krieg. Gedanken zur Antriebsmotivation zum Krieg bei den Hussiten und in der New Model Army

Robert Rebitsch 
135 Globalisierung von Ausbeutung(ssystemen) im Kongo. Akteure und Beziehungen im Kontext ,gewalttätigen Handelns“

Simon Hartmann

165 Organisation des Hungers. Ein apokalyptischer Reiter im Lichte von Weltordnungs- und Globalisierungsprozessen

Andreas Exenberger

199 Die Informationsrevolution frisst ihre eigenen Kinder. Internationale Medienpolitik zwischen Terror, Militarisierung und totaler Entgrenzung Jörg Becker

229 Die Ethik der Technologie im Zeitalter der drohenden Apokalypse Jean-Pierre Dupuy

3

253 Gewalt und das kulturelle Unbewusste. Eine Archäologie des Abendmahls Aleida Assmann

279 Wandlung. Die christliche Eucharistiefeier als Transformation der „kotigen Wurzeln unserer Kultur“. Eine Antwort auf Aleida Assmann

Roman A. Siebenrock, Wolfgang Palaver, Willibald Sandler

321 Ursprünge der Gewalt. Eine kritische Auseinandersetzung mit der Theorie matriarchaler Gesellschaft aus Sicht der mimetischen Theorie

Wilhelm Guggenberger, Wolfgang Palaver, Willibald Sandler, Petra SteinmairPösel

355 Satanologie angesichts der Apokalypse. Wovon René Girard (nicht) spricht und was daraus folgt

Claudia von Werlhof

391 Besessenheit und Exorzismus. Gedanken zu einem psychiatrisch (und theologisch) obsoleten Thema

Hartmann Hinterbuber 
435 Zur Rede vom Bösen, Dämonen und dem Teufel in der Theologie. Eine theologische Orientierung zum Text von Hartmann

Hinterhuber

Roman A. Siebenrock 



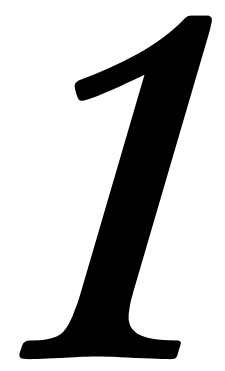





\section{Einleitung}

Wolfgang Palaver, Kristina Stöckl*

Die Idee für eine interfakultäre Forschungszusammenarbeit zum Thema Weltordnung, Religion und Gewalt an der Universität Innsbruck wurde im Frühjahr 2002 von Raymund Schwager SJ, Professor für Systematische Theologie an der Katholisch-Theologischen Fakultät und Begründer des seit den frühen 80er-Jahren des 20. Jahrhunderts bestehenden theologischen Forschungsschwerpunktes „Religion - Gewalt - Kommunikation - Weltordnung“, geboren. Unter dem Eindruck der Terroranschläge vom 11. September 2001 und der damit einhergehenden politischen und gesellschaftlichen Entwicklungen stellte er sich und seinen Kollegen und Kolleginnen an den Instituten der Universität Innsbruck die Frage, wie die Wissenschaft diese Ereignisse verstehen und auf die Herausforderung von religiösem Fundamentalismus und Gewalt reagieren könne. Diese Frage und das bekundete Interesse an ihrer Bearbeitung seitens einer Reihe von Vertreter(inne)n der Theologie, Geschichte, Literaturwissenschaft, Philosophie, Politologie, Sozial- und Wirtschaftswissenschaften wurden zum Ausgangspunkt für eine rege For-

* Wolfgang Palaver ist seit 2002 Professor für Christliche Gesellschaftslehre am Institut für Systematische Theologie der Universität Innsbruck und seit 2004 Sprecher jener Initiative, die seit 2007 die Forschungsplattform „Weltordnung - Religion - Gewalt“ ist. Kristina Stöckl ist wissenschaftliche und administrative Koordinatorin der Plattform, ihre Forschungsschwerpunkte sind Theorien der europäischen Integration und Governance mit einem Fokus auf Religion. 
schungszusammenarbeit, die 2007 letztlich zur Institutionalisierung der Forschungsplattform Weltordnung - Religion - Gewalt geführt hat. Schwagers Bemühen um diese interdisziplinäre Zusammenarbeit zeigt sich deutlich im ersten Beitrag des vorliegenden Bandes, der in den Arbeiten des französischen Sozialphilosophen Jean-Pierre Dupuy eine wichtige Brücke zwischen den verschiedenen Disziplinen angesichts aktueller Katastrophenpotenziale nachweist und diese für die Zusammenarbeit fruchtbar zu machen versucht. Eine „aufgeklärte Apokalyptik" nimmt Stellung zu den Katastrophenpotenzialen unserer Zeit, zu Gewalt, Hunger, religiösem und anti-religiösem Fundamentalismus und zu technologischen Entwicklungen, die bedrohliche Formen annehmen. Die Beiträge in diesem Band mit dem Titel „Aufgeklärte Apokalyptik: Religion, Gewalt und Frieden im Zeitalter der Globalisierung" möchten die Tragweite der angesprochenen Problematiken weder verschleiern noch vor ihnen kapitulieren.

Seit Beginn der Forschungszusammenarbeit, aus denen die Beiträge in diesem Band hervorgegangen sind, steht das Generalthema Weltordnung - Religion - Gewalt für die kritische Betrachtung von aktuellen Herrschafts- und Machtverhältnissen, für das Studium von Religion im Spannungsfeld zwischen Konfliktlösung und Konfliktpotenzial sowie für die Analyse von Gewaltphänomenen sowohl direkter als auch struktureller Art. Die beteiligten Forscher(innen) teilen den Anspruch, mit ihrer Arbeit Stellung zu den drängenden sozialen und politischen Fragen der Gegenwart zu nehmen, insbesondere zu der Frage nach einem friedlichen Zusammenleben in einem religiös und weltanschaulich pluralen Europa.

Die Bestandsaufnahme eines sich ausdehnenden Forschungsvorhabens, als welches sich die Plattform Weltordnung - Religion Gewalt nicht zuletzt seit ihrer Institutionalisierung als einer von vier Forschungsplattformen an der Universität Innsbruck im Januar 2007 präsentiert, ist ein notwendig unabschließbares Unterfangen. Trotzdem ist an dieser Stelle aus Anlass der Gründung der Publikationsreihe der Plattform eine solche Bestandsaufnahme angebracht, nicht zuletzt zur Würdigung der erfolgreichen Arbeit der letzten Jahre, die die mit ihrem ersten Band vorliegende Edition Weltordnung - Religion Gewalt und die Etablierung der interfakultären Forschungsplattform erst möglich gemacht hat. 


\section{Die institutionellen Rahmenbedingungen}

Zunächst jedoch eine Anmerkung zu den institutionellen Rahmenbedingungen: Die Forschungsplattform WRG reagiert auf die mit dem Universitätsgesetz 2002 neu definierten Spielregeln für die heimischen Universitäten. Universitäten stehen heute verstärkt im nationalen und internationalen Wettbewerb, in dem es gilt, sich durch die Bildung von Forschungsschwerpunkten und durch die Akzentuierung des Studien- und Forschungsangebots zu behaupten. Forschungszentren, Forschungsplattformen und Forschungsschwerpunkte geben der Universität nach innen und außen ein strategisches Profil, sie erlauben eine gezielte Förderung von Exzellenz und sind die Voraussetzung für die erfolgreiche Akquirierung von Drittmitteln. Mit der Gründung der interfakultären Forschungsplattform Weltordnung - Religion - Gewalt wurde an der Universität Innsbruck eine Bündelung und Vernetzung geistes- und sozialwissenschaftlicher Kompetenzen zum Thema Religion in Politik und Gesellschaft eingeleitet, die national und international Standards setzen möchte.

Nach den Anfängen einer von Interesse und Enthusiasmus getragenen Forschungszusammenarbeit stellte sich für die beteiligten Wissenschaftler(innen) die Frage nach einer passenden Institutionalisierung ihres gemeinsamen Forschungsinteresses. Während die Gründung eines Forschungsschwerpunktes zunächst noch naheliegend schien, wurde rasch deutlich, dass die breit gestreuten Anliegen und die interdisziplinäre und interfakultäre Zusammenarbeit eine andere Art von Koordination verlangten. Fragen zu Weltordnung, Religion und Gewalt sind in den verschiedensten Forschungsbereichen der Geistes- und Sozialwissenschaften relevant. In den methodisch und theoretisch klar definierten Parametern der Forschungsschwerpunkte sind diese Themen wissenschaftlich zwar gut verankert, doch oft fehlt es an einer über die Forschungsschwerpunkte hinausgehenden Vernetzung. Gerade eine solche hat sich die Forschungsplattform WRG zum Ziel gesetzt. Die Plattform vernetzt, präsentiert und fördert Forschungsvorhaben aus allen Bereichen der Geistes- und Sozialwissenschaften an der Universität Innsbruck, die sich mit dem Thema Politik, Religion und Gewalt beschäftigen. Sie möchte Forschungsergebnisse auf Universitätsebene und außerhalb der Universität sichtbar machen und Anlaufstelle für Studierende und Wissenschaftler(innen) sein, die sich mit ihren Forschungsinteressen in der Fragestellung der Plattform wiederfinden. 
Die Forschungsplattform WRG besteht in ihrer derzeitigen Form seit Januar 2007. Getragen wird sie von einem Gremium aus etablierten Wissenschaftler(inne)n an der Universität Innsbruck, dem WRG-Rat. Diesem steht der wissenschaftliche Leiter der Plattform vor, der in seinen Aufgaben von einer eigens für die Plattform eingerichteten Koordinationsstelle unterstützt wird. Die Plattform WRG zählt aktuell an die achtzig Mitglieder aus über zehn Instituten und vernetzt Forschungsschwerpunkte und Einzelforscher(innen) aus allen geistes- und sozialwissenschaftlichen Fakultäten an der Universität Innsbruck.

\section{Forschungsförderung im Rahmen der Plattform}

Unter den zahlreichen Aktivitäten der Forschungsplattform, auf die im Folgenden eingegangen werden soll, kommt der Forschungsförderung und der Akquirierung von Drittmitteln eine besonders wichtige Rolle zu. Einerseits verfügt die Plattform selbst über ein Budget, mit dem Forschungsvorhaben ihrer Mitglieder gefördert werden, andererseits unterstützt sie Ansuchen bei externen Forschungsfördereinrichtungen. Peer-Review und Coaching von Forschungsprojekten in der Antragsphase sind eine wesentliche Aufgabe der vierteljährlich stattfindenden Klausurtagungen der Plattform. Vor allem Nachwuchswissenschaftler(inne)n kann die Plattform bei der Themenfindung und wissenschaftlichen Vernetzung gute Dienste tun, da sie Doktorand(inn)en eine Perspektive über die Grenzen der jeweiligen Institute hinaus eröffnet. Auch die Plattform selbst kooperiert in ihren Aktivitäten mit verschiedenen Fördereinrichtungen und Forschungszentren und holt somit Drittmittel ein.

Die inhaltliche Arbeit der Plattform findet auf zwei Ebenen statt, einerseits auf Plattform-Ebene bei den Klausurtagungen und bei wissenschaftlichen Veranstaltungen, andererseits auf der Ebene von Forschungsclustern und Einzelprojekten. Auf Plattform-Ebene organisiert die Plattform neben den Klausurtagungen auch regelmäBig wissenschaftliche Konferenzen, sie ist Trägerin der nach ihrem Gründer benannten „Raymund Schwager - Innsbrucker Religionspolitologischen Vorlesungen“ und sie gibt, neben den Innsbrucker Diskussionspapieren ₹u Weltordnung, Religion und Gewalt, nunmehr auch die Buchreihe Edition Weltordnung - Religion - Gewalt heraus. 


\section{Vorlesungsreihe}

Die 2004 begründeten „Raymund Schwager - Innsbrucker Religionspolitologischen Vorlesungen" möchten aktuelle Fragestellungen zum Verhältnis von Religion und Politik in einer sich globalisierenden Welt in den Mittelpunkt der Diskussion stellen. Dafür werden renommierte Wissenschaftler(innen) und anerkannte Vertreter(innen) von Kunst und Literatur zu öffentlichen Vorträgen nach Innsbruck eingeladen, bei denen sie ihre Positionen und Thesen mit einem interessierten Publikum und Mitgliedern der Plattform Weltordnung - Religion - Gewalt diskutieren. Die Vorlesungsreihe umfasst vier bis sechs Gastvorlesungen im akademischen Jahr und zeichnet sich durch eine breite thematische Streuung aus, die die Interdisziplinarität der Plattform widerspiegelt. Dabei kommt der hochaktuellen Frage nach dem Verhältnis von Islam und westlicher Moderne eine Sonderstellung zu; es werden verstärkt Vortragende zu diesem an der Universität Innsbruck selbst bisher unzureichend vertretenen Thema eingeladen. Der vorliegende erste Band der Edition Weltordnung - Religion - Gewalt gibt einen Einblick in die Inhalte und Diskussionen der „Raymund Schwager - Innsbrucker Religionspolitologischen Vorlesungen“".

Die Beiträge von Rüdiger Lohlker, Mariano Delgado, Jörg Becker, Jean-Pierre Dupuy und Aleida Assmann sind schriftliche Fassung von im Zeitraum 2004 bis 2006 gehaltenen „SchwagerVorlesungen“. Lohlkers Beitrag ist ein Beispiel für das Interesse der Plattform an einer intensiveren Beschäftigung mit Fragen des Islams. Jörg Becker steht für den heute wichtigen Zusammenhang von Medien und Gewalt. Jean-Pierre Dupuy betont in seinem Beitrag die apokalyptische Dimension, die jedes Nachdenken über die Technik heute berücksichtigen muss. Eine wichtige Kontroverse löste Aleida Assmanns Vorlesung aus. In diesem Band kann nicht nur ihre kritische Auseinandersetzung mit der Geschichte des Abendmahls nachgelesen werden, sondern auch eine theologische Stellungnahme, die im Kreis der auf Schwager aufbauenden „Dramatischen Theologie“ erarbeitet wurde.

\section{Diskussionspapiere}

Neben den Religionspolitologischen Vorlesungen finden sich auch Beiträge aus den Innsbrucker Diskussionspapieren ₹u Weltordnung, Religion und Gewalt (IDWRG) in diesem Sammelband. Die IDWRG verste- 
hen sich als unregelmäßige Reihe zur Veröffentlichung von wissenschaftlichen Arbeiten, die im Umfeld der Plattform entstanden sind. Oft dokumentieren diese Texte aktuelle Debatten sowie work in progress und dienen dazu, die Diskussion von aktuellen Fragen im Spannungsfeld von Politik, Religion und Gewalt auf hohem wissenschaftlichem Niveau anzuregen. Im vorliegenden Band sind die Beiträge von Robert Rebitsch und Simon Hartmann Beispiele solcher wissenschaftlicher Arbeiten, die in schriftlicher Form zur Diskussion gestellt wurden. Noch direkter als Diskussionspapiere sind die Beiträge von Wolfgang Dietrich und Andreas Exenberger zu verstehen, denn beide waren auch Bestandteil von Diskussionen im Rahmen von Klausurtagungen der Plattform.

Wie kontrovers solche Debatten geführt werden können, zeigt vor allem Teil 3 des vorliegenden Bandes. Er enthält drei Textpaare, die an Diskussionen im Umfeld von Klausurtagungen und Schwager-Vorlesungen ansetzen, darunter Auseinandersetzungen mit dem Thema des Bösen. Hier wird einerseits die schriftliche Fassung des Referats von Hartmann Hinterhuber wiedergegeben und andererseits die von Roman Siebenrock ausgewählten Thesen von einer Gruppe um Ulrich Niemann, der im Juli 2006 Diskussionspartner von Hinterhuber war.

\section{Konferenzen und Fachtagungen}

Ein weiterer Aufgabenbereich der Plattform ist die Organisation von wissenschaftlichen Konferenzen und Fachtagungen. Wichtiger Partner in diesem Zusammenhang ist die österreichweit und international vernetzte Arbeitsgemeinschaft (ARGE) „Politik - Religion Gewalt" der Österreichischen Forschungsgemeinschaft, mit deren Unterstützung im Zeitraum von 2006 bis 2012 jährlich eine Konferenz zum Thema Politik und Religion organisiert wird. Inhaltliche Schwerpunktsetzung des auf diese Art und Weise gemeinsam organisierten Konferenzzyklus ist die kritische Befragung maßgeblicher sozialer und politischer Theorien der Moderne in Hinblick auf die Frage, wie mit der Rückkehr der Religion in die westliche moderne Gesellschaft umzugehen sei. Die Ergebnisse dieser Konferenzen werden in Zukunft als weitere Sammelbände der Edition Weltordnung Religion-Gewalt erscheinen. 


\section{Forschungscluster und Einzelprojekte}

Die Aktivitäten der Forschungscluster und Einzelprojekte bilden die eigentliche Basis der Plattform. Die Forschungscluster bestehen aus Gruppen von Wissenschaftler(inne)n, die einen methodischen und theoretischen Ansatz teilen und aus dieser Perspektive verschiedene plattformrelevante Thematiken behandeln. Die vier Forschungscluster der Plattform sind „Anthropologie und Gewalt“, „Konflikt und Kultur“, „Hegemonie und Massentod“ und „Matriarchatsthese und Patriarchatskritik“. Die Arbeitsweise in diesen vier WRGClustern, die im Folgenden einzeln beschrieben werden, ist unterschiedlich; Konstanten sind jedoch die regelmäßige Einberufung von Cluster-Treffen, die Teilnahme an den Klausurtagungen, eine jährliche Berichterstattung auf Plattformebene und die Repräsentation der Cluster durch die jeweiligen Cluster-Sprecher im WRG-Rat.

Der Cluster „Anthropologie und Gewalt“ stellt so etwas wie die Keimzelle der gesamten Plattform dar. Er ist aus einer aktiven Gruppe von Theolog(inn)en, Sozial- und Geisteswissenschaftler(inne)n hervorgegangen, die bereits seit den frühen 80er-Jahren des 20. Jahrhunderts das Thema Gewalt ins Zentrum ihrer Forschung stellen. Die Arbeit dieser Gruppe und insbesondere ihres Leiters Raymund Schwager wurde maßgeblich durch die rege Zusammenarbeit mit dem französisch-amerikanischen Literaturwissenschaftler und Anthropologen René Girard bestimmt. Girards Thesen zu gesellschaftlich und theologisch zentralen Themen wie Konflikt und Gewalt, Riten, Opfer und Sakralität, Ausstoßung und Versöhnung sowie Friede und Offenbarung sind an der Universität Innsbruck auf vielfältige Weise weiterentwickelt und ergänzt worden. Der Forschungsschwerpunkt „Religion - Gewalt - Kommunikation - Weltordnung“ (RGKW) und das der Arbeit Girards verpflichtete „Colloquium on Violence \& Religion“ sind Ausdruck einer international anerkannten Kompetenz in Fragen von Religion und Gewalt an der Universität Innsbruck.

Der gemeinsame Ausgangspunkt des Clusters „Anthropologie und Gewalt" besteht in der mimetischen Theorie René Girards. Diese als Hypothese verstandene Theorie, die von den Clusterteilnehmer(inne) $n$ in unterschiedlicher Weise aufgenommen wird, dient der inhaltlichen Fokussierung einer Untersuchung des systematischen Zusammenhangs von Weltordnung, Religion und Gewalt in Gegenwart und Geschichte. Die mimetische Theorie bietet den Vorteil, dass sie anschlussfähig für anthropologische, historisch-kultur- 
wissenschaftliche, sozialwissenschaftliche, religionswissenschaftliche und theologische Fragestellungen ist. In der Arbeit des Clusters geht es, in Übereinstimmung mit der grundlegenden Fragestellung der Gesamtplattform, in erster Linie um die Beantwortung der Frage, ob und wie ein friedliches Zusammenleben in der Welt denkbar und möglich ist. Aufbauend auf der mimetischen Theorie arbeitet der Cluster an der Schärfung eines Instrumentariums, das - neben anderen - innerhalb der Plattform WRG zum Einsatz kommt und der Bearbeitung jenes Problemfeldes dient, das durch die Titelwörter „Weltordnung“, „Religion“, „Gewalt“ abgesteckt ist.

Der Cluster „Kultur und Konflikt" ist eng mit dem Forschungsschwerpunkt „Politische Kommunikation und die Macht der Kunst" an der Historisch-Philosophischen Fakultät verbunden und organisatorisch am Brenner-Archiv verankert. Die Forscher(innen) in diesem Cluster beschäftigen sich mit der Frage nach Konfliktpotenzialen und ihren Lösungen im Studium der Geschichte, der Literatur, der Philosophie und der Kunst. Themen wie Erinnerungskultur und Gedächtnispolitik, Literatur als Erinnerungsarbeit, Konflikte vermeidende Interaktionsformen, Ethik und Politik oder christliche Symbolik im politischen Raum werden in diesem Cluster anhand von konkreten Fallbeispielen bearbeitet. Die Vielfalt der Themenstellungen spiegelt sich in der von diesem Cluster geplanten Ringvorlesung „Kunst und Kultur als politisches Konfliktpotenzial“.

Der Cluster „Hegemonie und Massentod“ stellt eine interdisziplinäre Zusammenarbeit zwischen Vertreter(inne)n der HistorischPhilosophischen Fakultät, der Fakultät für Volkswirtschaft und Statistik, der Fakultät für Politikwissenschaft und Soziologie und der Philologisch-Kulturwissenschaftlichen Fakultät dar. Der Cluster möchte in einem historischen Vergleich von „Anfang“ (Antike) und „Ende“ (Moderne) der dokumentierten Geschichte an konkreten Fallbeispielen exemplarisch und auf Grundlage empirischen Quellenmaterials den direkten oder indirekten Zusammenhang zwischen unterschiedlichen hegemonialen Herrschaftsformen (Imperien, Kolonialreiche, Dominanzbeziehungen, ...) und diversen Arten des Massentodes (Massenmord, Hunger, Seuchen, Kriege, ...) erforschen. Dabei nimmt im aktuellen Teil auch die Analyse von multidimensionalen Konfliktsystemen breiten Raum ein, speziell von solchen in Afrika, und eine Vernetzung mit Forschungen zur Sklavereigeschichte. Der Cluster zieht seinen spezifischen Mehrwert gerade aus dem Dialog zwischen sehr unterschiedlichen historischen Kon- 
texten und dem Zusammentreffen von Forschungsströmungen, die aus unterschiedlichen methodischen Richtungen kommen.

Im Cluster „Matriarchatsthese und Patriarchatskritik“ geht es um die Frage, in welche Richtung sich die Zivilisationen verändern und welche Zivilisationspolitik zu entwerfen wäre, um diese Richtung zu bestimmen. Es geht also um Maßstäbe für eine politische Zivilisationstheorie ebenso wie um eine konkrete Zivilisationspolitik. Neben grundsätzlichen theoretischen Arbeiten zur Zivilisationstheorie beschäftigen sich Mitarbeiter(innen) des Clusters mit der Analyse von Fallstudien aus Europa, Afrika, Asien und Lateinamerika, in denen sich - wie z.B. im Fall von Kolonialisierung und Modernisierung - Zivilisations-Wandel manifestiert. Gemeinsamer Ausgangspunkt ist dabei die Annahme, dass historisch zwei grundlegend verschiedene Gesellschaftsordnungen voneinander zu unterscheiden sind, eine matriarchale und eine patriarchale. Die ältere, matriarchale Ordnung ist geprägt vom Mutter-Kind-Zusammenhang und stellt somit eine mütterliche, am Leben orientierte, egalitäre, friedliche, kooperativ mit Natur umgehende und spirituell mit allem Sein in Himmel und Erde verbundene Ordnung dar. Die patriarchale Ordnung hingegen ist gekennzeichnet durch Krieg, hierarchische Herrschaft, Religion (insbesondere Monotheismus), Unterwerfung der Frauen, Ausbeutung, Generationenkonflikte und ökologische Probleme. Der Cluster "Matriarchatsthese und Zivilisationskritik" geht davon aus, dass die im Westen dominante patriarchale Ordnung, die die matriarchale historisch ablöst, sich nicht nur in der Ausbreitung („Globalisierung"), sondern gleichzeitig auch in einer tiefen und grundlegenden Krise befindet. Ziel des Clusters ist es darum, über eine radikal andere Art der Zivilisation nachzudenken und mögliche Ansätze dafür zu beschreiben.

Schon diese kurze Darstellung der einzelnen Forschungscluster macht deutlich, wie sehr sich diese in ihren inhaltlichen und methodischen Zugängen zur Thematik der Plattform voneinander unterscheiden. Diese Unterschiede bestimmen auch die Zusammenarbeit der Plattform, die kritische Auseinandersetzungen zwischen den verschiedenen Zugängen fördert. Als Beispiel in diesem Band sei auf die Kontroverse um die Frage des Matriarchats/Patriarchats verwiesen. Während Vertreter des Forschungsclusters „Anthropologie und Gewalt" aus der Sicht der mimetischen Theorie kritisch zur Theorie matriarchaler Gesellschaft Stellung nehmen, geht Claudia von Werl- 
hof umgekehrt von der Matriarchatsthese aus, um auf blinde Flecken und problematische Hintergründe der Theorie Girards hinzuweisen.

Neben den Forschungsclustern gibt es auch verschiedene Einzelprojekte, die von Mitgliedern der Plattform verfolgt werden, ohne jedoch in die Arbeit eines Clusters eingebunden zu sein. Einzelprojekte werden in der Regel durch die Sprecher der in der Plattform vertretenen fakultären Forschungsschwerpunkte - „Governance and Civil Society“, „RGKW“ und „Politische Kommunikation und Macht der Kunst" - im WRG-Rat vertreten und ermöglichen eine flexible Projektkoordination innerhalb der Plattform.

\section{Die Edition Weltordnung - Religion - Gewalt}

Die Publikationsreihe Edition Weltordnung - Religion - Gewalt ist der wissenschaftlichen Auseinandersetzung mit den drängenden sozialpolitischen und anthropologischen Fragen unserer Zeit verpflichtet. Nach dem Ende des Kalten Krieges machten zwei politische Weltdeutungen die Runde, die unterschiedlicher nicht hätten sein können. Während die einen optimistisch von einem „Ende der Geschichte" und dem Sieg des Liberalismus und der Demokratie sprachen, warnten die anderen vor einem „Kampf der Kulturen“. Die Forschungsplattform Weltordnung - Religion - Gewalt vertritt die Ansicht, dass weder die eine noch die andere These wirklich geeignet ist, die komplizierter gewordene Welt zu Beginn des 21. Jahrhunderts zu fassen. Insbesondere unter dem Eindruck einer allgemeinen Rückkehr der Religion, ablesbar an klaren Tendenzen zur Entsäkularisierung in modernen Gesellschaften und zu religiösen Fundamentalismen, ist es notwendig geworden, Weltordnung, Religion und Gewalt in ibrer gegenseitigen Abbängigkeit zu einem Thema für die Geistes- und Sozialwissenschaften zu machen. Während über einen langen Zeitraum das Thema Religion an den Theologischen Fakultäten gut aufgehoben schien, steht Religion nunmehr im Zentrum der Aufmerksamkeit auch anderer wissenschaftlicher Zweige. Das Selbstverständnis der Forschungsplattform mit ihrer Publikationsreihe Edition Weltordnung - Religion - Gewalt liegt in einer Verknüpfung fundierter Kompetenzen und neuer Fragestellungen, die wichtige Erkenntnisse und ein erweitertes Problembewusstsein in Sachen Weltordnung, Religion und Gewalt verspricht. 
Abschließend möchten wir allen Autorinnen und Autoren dafür danken, dass sie ihren Beitrag zum Gelingen dieses Vorhabens geleistet haben. Ganz besonderer Dank gebührt zudem Alexander Eberharter für das sorgfältige Lektorat des Bandes sowie die Gestaltung des Buchumschlags und des Layouts, Mitherausgeber Andreas Exenberger für die umfangreiche „Inneneinrichtung“ und Carmen Drolshagen von der „innsbruck university press“ für die gute $\mathrm{Zu}$ sammenarbeit bei der Begründung dieser neuen Buchreihe. 

Aufgeklärte Apokalyptik. Jean-Pierre Dupuy als möglicher

Referenzautor für das interfakultäre Forschungsprojekt

„Weltordnung-Religion-Gewalt“"

Raymund Schwager ${ }^{*}$

Jean-Pierre Dupuy ist Professor an der École Polytechnique in Paris und zugleich an der Stanford University (USA). Er war Gründer und von 1982 bis 1999 auch Leiter des an der École Polytechnique installierten Centre de Recherches en Epistémologie Appliquée, an dem vor allem zwei Richtungen verfolgt wurden, die theoretische Wirtschaftswissenschaft und die Kognitionswissenschaften. Beide Bereiche gehören zu den zentralen Arbeitsgebieten von Dupuy, der sich aber vor allem dadurch auszeichnet, dass er sich noch in zahlreiche andere Arbeitsgebiete eingelesen und dabei die erstaunliche Fähigkeit entwickelt hat, jeweils scharf und präzise die grundlegenden Argumentationsstrukturen herauszuarbeiten. Auf diese Weise kann er aufzeigen, dass von Arbeitsbereich zu Arbeitsbereich und oft sogar von Schule zu Schule innerhalb des gleichen Arbeitsgebietes ganz anders und nicht selten widersprüchlich argumentiert wird. Aus seinen Ausführungen erhellt ferner, wie in unterschiedlichen Disziplinen immer mehr auf mechanistische Modelle zurückgegriffen wird, gleichzeitig

\footnotetext{
* P. Raymund Schwager SJ (1935-2004) war seit 1977 Professor für Dogmatische und Ökumenische Theologie an der Universität Innsbruck. Zuletzt war er Dekan der Katholisch-Theologischen Fakultät und - neben vielen anderen akademischen Aufgaben - Initiator und Leiter dessen, was schließlich die Forschungsplattform „Weltordnung - Religion - Gewalt“ werden sollte. Der vorliegende Text war diesem „Kind“ gewidmet und wurde am 3. Oktober 2003 bei der 5. Klausurtagung der Plattform zur Diskussion gestellt. Das war, etwa ein halbes Jahr bevor Raymund Schwager am 27. Februar 2004 völlig unterwartet verstarb. Wir alle verdanken ihm viel.
} 
aber die Prinzipien der Gleichheit, Gerechtigkeit und des Friedens verfochten werden. Daraus ergibt sich für ihn, dass die Problematik des Bösen (die zur Selbstzerstörung führt) nicht bloß eine moralische Frage ist, sondern als analytische Kategorie zur Deutung auch der modernen Gesellschaft notwendig ist. Mechanistische und strukturalistische Modelle sind deshalb im Blick auf Subjekte und Entscheidungen und im Blick auf die Zeit und geschichtliche Fragestellungen von innen heraus kritisch zu befragen und zu öffnen.

\section{Grundmodell der Wirtschaftswissenschaft und das Prinzip der Gerechtigkeit}

Das Grundmodell der Wirtschaftswissenschaft ist für Dupuy insofern zentral, als es seiner argumentativen Struktur nach zum Grundmodell in vielen anderen Bereichen geworden ist. Es dominiert nicht nur die Sozial-, sondern auch die Kognitionswissenschaften und weite Bereiche der Humanwissenschaften bis hinein in die moderne Biologie. Für Dupuy ist es deshalb zentral, dieses Modell in all seinen Aspekten präzise zu kennen, und zwar nicht um ihm dogmatisch zu folgen, sondern um fähig zu werden, es von innen heraus zu kritisieren. Zu diesem Grundmodell gehören folgende zentrale Elemente:

- Die Gesellschaft ist nicht ein vorgegebenes Ganzes, wie es die traditionelle und hierarchische Sicht vertreten hat (gesellschaftlicher Holismus), sie ergibt sich vielmehr aus den Interaktionen ihrer vielen einzelnen Mitglieder (methodischer Individualismus).

- Auch wenn die Gesellschaft auf der Interaktion Einzelner ruht, kennt sie übergeordnete Größen, die sie funktionsfähig halten.

- Diese übergeordneten Größen sind nicht von der Natur (oder von Gott) vorgegeben, sondern das automatische und unbeabsichtigte Produkt der vielen Interaktionen, deren Komplexität niemand im Einzelnen durchschauen kann und die deshalb einen Effekt der Selbsttranszendenz oder Selbstobjektivierung erzeugt.

- Das klassische Beispiel dieser Selbsttranszendenz ist der Markt, bei dem die Preise einerseits durch das Kaufen und Verkaufen aller Marktteilnehmer(innen) erst entstehen, anderseits für jeden Einzelnen aber doch vorgegebenen sind. Ähnliches gilt - gemäß diesem Modell - für die Emergenz oder Selbsttranszen- 
denz des Staates oder religiöser Vorstellungen aus den Interaktionen der Einzelnen.

- $\quad$ Die Gesellschaft wird deshalb - gemäß diesem modernen, zunächst in der Wirtschaftswissenschaft entwickelten Modell weder geplant noch von vorgegebenen Zielen geführt. Die Ordnung ergibt sich vielmehr von selber aus den undurchschaubaren Interaktionen vieler Einzelner (Ordnung durch eine „unsichtbare Hand“ [A. Smith]).

- Auch der Friede unter Menschen entsteht - so Kant in seiner Schrift Zum ewigen Frieden - dank eines Mechanismus der Natur, nämlich dank des Handelsgeistes, der aus der Zwietracht der Menschen wider ihren Willen Eintracht entstehen lässt und die selbstsüchtigen Neigungen, die natürlicherweise gegeneinander stehen, zum allgemeinen Frieden zusammenführt. ${ }^{1}$

Neben diesem Grundmodell der Gesellschaft gehört zum modernen Denken, dass alle Menschen gleich sind und dass einzelne Menschen oder Minderheiten nicht im Interesse der Mehrheit geopfert werden dürfen (soziale Gerechtigkeit). In Le Sacrifice et l'envie. Le libéralisme aux prises avec la justice sociale ${ }^{2}$ zeigt Dupuy aber, dass es den großen Denkern des Sozialen (vor allem A. Smith, J.J. Rousseau, F. Hayek, J. Rawls, R. Nozick) nie gelingt, das skizzierte gesellschaftliche Grundmodell mit den Forderungen der sozialen Gerechtigkeit zu verbinden. Auf theoretischer Ebene entstehen Widersprüche, und auf praktischer Ebene zeigt sich, dass die beschriebene Ordnung nicht so friedlich und gerecht ist, wie sie vorgibt. Die Problematik der Opfer, obwohl sie nicht vorkommen dürfte, lässt sich in diesem Modell nicht vermeiden. Es gilt vielmehr: „Le marché contient la panique (la violence)“3, wobei das Wort „,contenir" einen doppelten Sinn hat. Der Markt enthält die Panik (Gewalt), und er dämmt sie ein.

$\mathrm{Zu}$ einer ähnlichen Position kommt Dupuy in La panique. ${ }^{4} \mathrm{Er}$ geht dort zunächst auf die französische und die amerikanische Schule ein, die sich mit der Panik-Forschung beschäftigen, und er arbeitet heraus, dass beide von unterschiedlichen, ja widersprüchlichen Voraussetzungen - vor allem im Bezug auf die Massenpsychologie -

1 Kant (1795). Der letzte Nachdruck dieses Klassikers erschien 2005 bei Reclam.

2 Dupuy (1992).

3 Dupuy (1992), 318-329.

4 Dupuy (1991). 
ausgehen. Durch eine präzise Analyse der vorgetragenen Argumente und ihrer Widersprüche versucht Dupuy dann nachzuweisen, dass es eine Kontinuität zwischen Massenphänomenen und dem wirtschaftlichen Leben gibt, und zwar über das Phänomen der Panik, das sich vor allem an der Börse immer wieder einstellen kann. Die Folgerung auch hier: Der Markt enthält die Panik, und er dämmt sie ein.

\section{Selbstreferenz und verwickelte Hierarchie}

Aufgrund des Pendelns zwischen Paris und Stanford und zwischen den Geistes- und den Sozialwissenschaften bietet sich Dupuy über die Wirtschaftswissenschaft hinaus folgendes widersprüchliche Bild in zahlreichen wissenschaftlichen Disziplinen: „Einerseits zelebrieren Studenten der Literatur, die in die Geheimnisse des französischen Strukturalismus und seiner Dekonstruktion durch die zahllosen Schüler Jacques Derridas eingeweiht sind, den Tod des Subjekts Mensch und wiederholen, ad infinitum, dass der Mensch nicht sein eigener Herr sei und dass das Bewusstsein, das er von dem hat, was ihn betrifft, unvermeidlich von außen, von einer Art Unbewusstem bestimmt ist. Andererseits lernen ihre Kollegen in den Wirtschaftswissenschaften, den politischen und den Wissenschaften von der Wahrnehmung, soziale Institutionen systematisch auf eine freiwillige Übereinkunft zwischen durchaus bewussten und freien Individuen zurückzuführen. “5 Dupuy lässt dann in seiner Arbeit zur SelbstDekonstruktion von Konventionen eine fiktive und intelligente Studentin durch die verschiedenen Disziplinen wandern. Dabei entdeckt sie mit Erstaunen, dass in der Literaturwissenschaft mit ihren Erzähltheorien, in der Anthropologie der Religionen, in der Rechtsphilosophie, in der postmodernen Philosophie (Derrida) und in den wirtschaftswissenschaftlichen und strategischen Spieltheorien letztlich immer wieder die gleiche selbstreferentielle Denkfigur auftaucht, die eine Umkehrung der Hierarchie innerhalb ihrer selber enthält („,verwickelte Hierarchie“). Im Bereich der religiös-politischen Ordnung und am Beispiel Indiens dargestellt bedeutet dies: „Der Brahmane verkörpert das Heilige, die umfassende Ebene, und ist dem König hierarchisch übergeordnet. In bestimmten Bereichen aller-

5 Dupuy (2002c), 85. - Dupuy stellt auch in seinem Artikel „Self-reference in Literature“ über den Begriff der Selbstreferenz eine Verbindung zwischen den Literaturwissenschaften und den Sozial- und Wirtschaftswissenschaften her. Siehe Dupuy (1989). 
dings, denen in der sozialen Hierarchie ein niedriger Rang zukommt, wird die Hierarchie umgekehrt, und der König steht über dem Brahmanen. [...] Der Brahmane steht über dem König, weil der König nur auf niedrigeren Ebenen über dem Brahmanen steht. "6 Im Bereich der Philosophie und auf das Beispiel Derridas über das Verhältnis von gesprochenem Wort und Schrift angewandt heißt dies: „Im Reich des Logos hat das Wörtliche Vorrang vor dem Übertragenen; im Bereich des Schreibens, das seinerseits in Bezug auf den Logos sekundär ist, steht das Übertragene über dem Wörtlichen. Das, was auf einer höheren Ebene höherwertig ist, wird auf einer niedrigeren Ebene minderwertig. "7 Das Verwirrende und Überraschende besteht nun darin, dass die gleiche Denkfigur der selbstreferentiellen verwickelten Hierarchie in gewissen Bereichen benützt wird, um Autonomie zu begründen, in anderen, um Autonomie zu entmystifizieren, und in wieder anderen, um auf Paradoxe hinzuweisen. Jene, die nur einen Bereich kennen, scheinen folglich ihre eigene Denkfigur nicht zu durchschauen. Für Dupuy selber besagt die verwickelte Hierarchie, „dass konventionelle Ordnung, sei sie nun religiös, modern oder postmodern, ihre mögliche Umkehrung, Negation, Verletzung oder Zerstörung einschließt. ${ }^{\text {' }}$ Dabei hat das Verb „einschließen“ („,contenir“) - wie beim Markt - die bekannte Doppelbedeutung von ,in sich selbst enthalten, aber auch unter Kontrolle halten" $"$.

In einer gemeinsamen Arbeit mit Francisco Varela geht Dupuy noch einen Schritt weiter, und beide zeigen, dass die moderne Biologie es mit der gleichen selbstreferentiellen Ordnung und verwickelten Hierarchie zu tun hat. Der Begriff des genetischen Programms schließt nämlich eine selbstreferentielle Schleife ein. „Es handelt sich um den Fall eines Programms, das seine eigene Herstellung erfordert, um durchgeführt zu werden. In der Tat wird jeder Schritt der Aufrechterhaltung und Transkription der DNA durch Proteine geleistet, die genau das sind, was codiert ist. Um das Programm durchzuführen, muss es schon durchgeführt sein!“10 Dupuy und Varela

6 Dupuy (2002c), 90.

7 Dupuy (2002c), 93

8 Dupuy (2002c), 94.

9 Dupuy (2002c), 94.

10 Dupuy/Varela (2002), 251. - Oder auf Seite 253: „Es fällt auf, daß diejenigen Theoretiker natürlicher autonomer Systeme, die sich mit der ursprünglichen Begründung von Leben 
verstehen dies nicht als logischen Widerspruch, sondern als kreativen Zirkelschluss und verwickelte Hierarchie, die im Bereich des Lebendigen zum Entstehen von Lebewesen mit labiler Autonomie führt. Das gilt allerdings nur, wenn man die selbstreferentielle Struktur nicht als abstrakte Logik, sondern als zeitlichen Prozess versteht, bei dem viele Elemente komplex interagieren und - mit zeitlichem Abstand - auf sich zurückwirken. So ergibt sich auch von dieser Seite her - wie beim Markt - ein Modell, bei dem viele Elemente interagieren und aus der Interaktion eine Grenze erzeugen und Selbsttranszendenz oder Selbstobjektivation schaffen. Entscheidend ist aber der zeitliche Prozess, bei dem durch Selbstorganisation Ordnungen mit einer neuen hierarchischen Ebene entstehen, die an die untere zurückgebunden bleibt und die - je nach der Betrachtungsweise - auch als die höhere gelten kann.

\section{Der 11. September 2001 und das Böse}

Dupuy bleibt nicht bei abstrakten wissenschaftlichen Modellen stehen, sondern geht auch auf aktuelle Fragen ein. Der Terrorismus interessiert ihn aber nicht deshalb, weil er gerade aktuell ist, sondern weil er an ihm eine Problematik aufzeigen kann, die in den üblichen wissenschaftlichen Modellen seiner Ansicht nach verdrängt wird. Er geht auch ganz anders vor als die üblichen Arbeiten zu diesem Thema, denn er zieht zunächst Linien durch zentrale Bereiche des französischen modernen Denkens und Forschens, um schließlich die Bedeutung der Frage nach dem Bösen hervortreten zu lassen. ${ }^{11} \mathrm{Er}$ beginnt mit einem berühmten Essay von Marcel Mauss über das Geschenk und den Tausch in archaischen Gesellschaften $(1923 / 24)^{12}$, in dem der französische Ethnologe zeigt, dass es in diesen Gesellschaften eine strikte Verpflichtung zum Geschenk und zum Gegengeschenk gab, das Geben aber so geschehen musste, dass die Gegengabe zugleich als freiwillig erschien. Mauss fragte deshalb, welche

auseinanderzusetzen versucht haben, schließlich bei einer Logik anlangen, die die Derridasche Logik der Ergänzung widerspiegelt, die doch eigentlich die wichtigste Waffe darstellt, um jeglichen Anspruch auf autonome Begründung und Autarkie zu widerlegen! Eines der Hauptanliegen dieses Essays ist es, die akademischen Mauern einzureißen, die diese beiden unterschiedlichen Vorgehensweisen künstlich getrennt gehalten haben, sie einander gegenüberzustellen und zur weiteren Aufklärung beizutragen.“

11 Dupuy (2002b).

12 Zuletzt erschienen als Mauss (2005). 
Kraft in den Geschenken später zu einem Gegengeschenk verpflichte, und er fand sie nach dem Zeugnis der von ihm untersuchten Gesellschaft in einer magischen Kraft, die dem Geschenk innewohne („hau“). 1950 hat C. Lévi-Strauss in seiner Einleitung zum Werk von M. Mauss, die ebenfalls berühmt und sogar zum „Gründungstext“ des französischen Strukturalismus wurde, eine andere Deutung vorgeschlagen. ${ }^{13}$ Mauss habe sich von seinen Informanten mystifizieren lassen. Gabe und Gegengabe würden als Tausch eine ursprüngliche Einheit bilden, die durch keine mythische Kraft zusammengehalten werden müsse. Die Einheit ergebe sich vielmehr aus den unbewussten mentalen Strukturen, die ihre eigene klare Logik haben und die alle archaischen Gesellschaften dominieren. ${ }^{14}$ Gemäß den weiteren Arbeiten von Lévi-Strauss gilt dies nicht nur für frühere Kulturen, er will auch das moderne Subjekt durch unbewusste mentale Strukturen ersetzen. - Diese strukturalistische Sicht hat P. Bourdieu, ein Vordenker der kritischen französischen Soziologie, seinerseits kritisiert. ${ }^{15}$ Bourdieu bezweifelt zwar in keiner Weise das Prinzip der Wechselseitigkeit bei Gabe und Gegengabe, wie es Lévi-Strauss betont, er meint aber, die Eingeborenen hätten das selber schon gewusst. Das sei aber nicht die ganze Wahrheit, denn dazu gehöre, dass die Wechselseitigkeit auch verschleiert werde, denn das Tauschsystem könne nur existieren, wenn es nicht direkt in Erscheinung trete. Diese letzte Aussage benützt nun Dupuy, um seinerseits Bourdieu kritisch zu befragen. Dieser erkläre in keiner Weise weshalb die Wechselseitigkeit verdeckt bleiben müsse. Dupuy versucht - gestützt auf M. Sahlins ${ }^{16}$ und R. Girard ${ }^{17}$ - auf diese Frage selber eine Antwort zu geben. Es gebe nämlich eine doppelte Wechselseitigkeit, die von Geschenk und Gegengeschenk und die von Schlag und Gegenschlag, wobei die letztere sich viel spontaner und direkter einstelle. Um die negative Wechselseitigkeit zu verhindern, müssten in der positiven der zeitliche Abstand und die Freiwilligkeit bewusst betont werden. Das Paradox von Freiwilligkeit und Verpflichtung sei nichts anderes als ein Vertrag gegen die Gewalt. Zur kritischen französischen Soziologie bemerkt Dupuy ferner, dass sie zwar den herrschenden Ökonomis-

\footnotetext{
13 Vgl. Mauss (2005).

14 Vgl. Lévi-Strauss (1994).

15 Bourdieu (1972).

16 Sahlins (1972).

17 Vgl. Girard (1988).
} 
mus kritisiere, aber von der gleichen Voraussetzung wie dieser ausgehe, nämlich von der Annahme, Menschen würden letztlich nur aus wirtschaftlichen Interessen handeln.

Zur Deutung der negativen Wechselseitigkeit und zur Kritik des Ökonomismus geht Dupuy auf große Texte von Jean-Jacques Rousseau, Adam Smith und Alexis de Tocqueville ein, die deutlich machen, wie Menschen letztlich das begehren, was vorbildhafte „Andere" erstreben. Erst in einer Welt, in der das Geld als besonders begehrenswert angesehen wird, werde es auch dominant, und selbst hier können Nachahmung und Rivalität leicht Konflikte provozieren, die ökonomisch selbstzerstörerisch sind. Diese negativen Tendenzen müssten eigens erklärt werden, und dies geschehe weder durch die kritische Soziologie noch durch die übliche Wirtschaftswissenschaft. Das Selbstzerstörerische oder das Böse sei nicht bloß eine moralische, sondern auch eine analytische Kategorie zur Erklärung menschlichen Verhaltens.

Von diesem Ausgangspunkt her versucht Dupuy eine Anatomie des 11. Septembers 2001. Nachahmung und Rivalität hält er für zentrale Faktoren, während Erklärungen mittels „absurder religiöser Vorstellungen“ ihm oberflächlich erscheinen. Nicht nur einzelne Menschen vergleichen sich, auch Völker, Kulturen und religiöse Gemeinschaften blicken auf andere, sobald die Grenzen der Wahrnehmung zwischen ihnen abgebaut werden. Wenn die Konkurrenz weltweit wird und einige systematisch verlieren, dann entstehe, so Dupuy, unvermeidlich ein Ressentiment mit den entsprechenden verheerenden Folgen (Prinzip der negativen Wechselseitigkeit). Der Terror sei die Reaktion von Verlierern auf ein Vorbild, das fasziniere und zugleich verhasst sei. Ossama bin Laden habe, wie entsprechende Zitate belegen, ganz nach dem Prinzip der Wechselseitigkeit gehandelt und sich dabei ausdrücklich auf jene Logik berufen, die LéviStrauss für universal erklärt hat. Dass die Islamisten in erster Linie auf den erfolgreicheren Westen reagieren, belege auch die Tatsache, dass sie mit dem Wort „Opfer“ - wie das Christentum - immer ein „Selbstopfer“ bezeichnen. Schließlich stelle sich auch die Frage, weshalb die Amerikaner den Ort des Terrors spontan „Ground Zero" nannten und ihm also den gleichen Namen wie dem Ort der ersten Atombombe gaben und weshalb sie diesen Ort des Schreckens, wie viele Einzelheiten zeigen, zu einem „sakralen Ort" machen. Aufgrund solcher Überlegungen optiert Dupuy für die These, der 11. September lasse sich am ehesten von der religiösen Anthropologie 
her erklären. Damit meint er aber nicht, die Terrorakte seien die Folge abstruser religiöser Vorstellungen, vielmehr seien die archaischen Opfer aus ähnlichen Problemen entstanden wie die heutigen Terrorakte. Das Probleme liege im Bösen, in der negativen Wechselseitigkeit.

Diese Frage nach dem Bösen verfolgt Dupuy auch unter dem Stichwort „Verkünstlichung“" (,artificialisation“) der Ethik, wobei er mit dem Neologismus an die Rede von der künstlichen Intelligenz anschließt. Sachlich meint er damit sowohl das große Paradigma der Wirtschaftswissenschaft, das die Ethik durch einen Mechanismus ersetzen will, als im Speziellen auch das Werk $A$ Theory of Justice von John Rawls, das er früher trotz kritischer Vorbehalte so schätzte, dass er es ins Französische übersetzen ließ. Dupuy gesteht, dass sein Urteil über diesen amerikanischen Sozialethiker sich nach dem 11. September 2001 massiv verändert habe. In der „ursprünglichen“, theoretisch angenommenen Situation, aus der heraus Rawls die Gerechtigkeit ableitet, kämen nämlich die Menschen nur als ,künstliche Personen“ (,artificial persons") vor, die keine Vorlieben und keinen Neid kennen würden. Zwar bemühten sie sich, den am schlechtesten Gestellten innerhalb der Grenzen des Systems eine klare Priorität zuzuerkennen, fragten sich aber nicht, ob die Differenzen, die dennoch blieben, von den defavorisierten Menschen aus Fleisch und Blut auch tatsächlich angenommen würden und ob Unterschiede nicht ein massives Ressentiment erzeugten, das die theoretisch gerechte Gesellschaft à la Rawls de facto auf Dauer doch unlebbar mache. Gerade der Anspruch, eine von Menschen gemachte und gerechte Gesellschaft zu sein, müsse bei den Defavorisierten umso mehr Ressentiments wecken, als sie ihre schlechte Position durch keine äußeren Ursachen (Natur, göttliche Ordnung) mehr erklären könnten. Der fundamentale Fehler von Rawls liege darin zu meinen, es gebe eine echte Lösung für das Problem der Gerechtigkeit und diese Lösung beseitige zugleich die Frage des Bösen. - Eine weitere Verkünstlichung der Ethik findet Dupuy schließlich bei NeoHobbesianern, die nach dem Modell der Evolution nachweisen möchten, wie aus einer Menge von egoistischen Individuen nur durch rationale Entscheidungen im Sinne des Eigeninteresses ein altruistisches Verhalten entstehe. Das abstrakte Modell, das dabei entworfen werde, funktioniere zwar auf niederen Ebenen gut, in seinem Zentrum stehe aber eine mathematische Formel, und damit habe 
man noch nie den Stolz und den Neid der Menschen erklären können.

In einem weiteren Schritt seiner Untersuchung zum Bösen geht Dupuy auf ein Thema ein, das zunächst überrascht, nämlich auf die Lotterie und das Würfelspiel. Er kann aber rasch zeigen, dass damit nur ein weiterer Aspekt der genannten Problematik angesprochen wird. Alle traditionellen Gesellschaften hätten angesichts des moralischen Problems der Gerechtigkeit und des politischen, wie menschliches Zusammenleben möglich sei, auf einen transzendenten Grund verwiesen. Die moderne Gesellschaft wolle in ihrem Streben nach Autonomie jedoch alles aus sich selber erklären und bediene sich dazu des Mechanismus der Selbstobjektivation oder Selbsttranszendenz. Doch dieser Mechanismus funktioniere nie ohne ein Element der Lotterie. Dupuy referiert Arbeiten, die die Rolle des Zufalls bei politischen Wahlen nachweisen, und er analysiert die letzten Wahlen in den USA, durch die Bush an die Macht gekommen ist und bei denen der Unterschied in der Stimmenzahl geringer war als die Wahrscheinlichkeit von Irrtümern beim Zählen. So gab es nach dem anerkannten Wahlsystem, das bereits Elemente der Lotterie einschließt, nur eine Lösung durch eine dem Wahlsystem äußere Instanz (Gericht). Dupuy schließt aus den Analysen um das Wahlsystem als solches und aus den Diskussionen um die letzten amerikanischen Wahlen, dass demokratische Wahlen wesentlich Riten seien mit einem paradoxen Element. Gerade im Augenblick der Wahl, bei der das Volk seinen gemeinsamen Willen ausdrücken solle, handle jeder Wählende ganz für sich allein: Die Zahl tritt an die Stelle der Substanz - wie beim Mechanismus des Marktes, der das soziale Leben auf zählbare Werte (Preise) reduziert. Jeder Mechanismus der Selbstorganisation enthalte aber normalerweise mehrere mögliche Attraktionspunkte, auf die er zulaufen könne, und es sei zufällig, auf welchen er sich tatsächlich einspiele. Der Zufall sei ein wesentliches Element der Selbstorganisation. Im gesellschaftlichen Bereich müsse er aber irgendwie gedeutet werden, und es wäre rein Despotie, wenn die Macht nur ihm und der Zahl entspringen würde. Der Versuch der modernen Gesellschaft, sich selber total zu beherrschen, und damit die Versuchung des Totalitarismus könnten nur vermieden werden, wenn der Ort der Macht auch dieser Gesellschaft letztlich 
äußerlich bleibe und, wie C. Lefort betont ${ }^{18}$, leer gehalten werde. Durch den Ritus oder durch die Lotterie der Wahlen werde nur bestimmt, wer für eine begrenzte Zeit diesen Ort, der nicht in Besitz genommen werden dürfe, repräsentiere. Wenn aber die Wahlen mechanischen Selbstorganisationsprozessen mit zufälligen Attraktionspunkten gleichen, stellt sich die Frage, wer dann die Verantwortung für die großen drängenden Probleme übernimmt, die heute auf die Menschheit zukommen und die eine richtige und nicht bloß eine zufällige Antwort erfordern (Folgen der Technik, wissenschaftliche Waffen, Umweltproblematik).

Der „Verkünstlichung“ oder Mechanisierung der Ethik liegt eine weitere Tendenz der modernen Gesellschaft zugrunde, auf die Dupuy in seiner Untersuchung zum Bösen abschließend eingeht, nämlich die Mechanisierung des Geistes, über deren moderne Formen er mehrere Arbeiten geschrieben hat. ${ }^{19}$ Boten seit der Aufklärung zunächst die Uhr und dann die Hydraulik Bilder an, um den Menschen und die Gesellschaft zu verstehen, so steht heute eine andere Mechanik im Zentrum, der Computer mit dem Algorithmus: Denken ist Rechnen. Im Laufe der letzten Jahrhunderte wurden immer mehr Bereiche mechanisch gedeutet, und heute bestehe die Tendenz, den letzten widerständigen Bereich, das menschliche Subjekt, zu erobern. Wie weit die Mechanisierung fortgeschritten und wie komplex die Problematik ist, zeige sich - so Dupuy - darin, dass für Heidegger und vor allem für seine vielen Anhänger in Frankreich der Humanismus, der früher die Mechanisierung kritisiert hat, selber nichts anderes als eine Form der Technologie im Kleid der Metaphysik sei. Paradoxerweise bedienen sich aber die französischen Kritiker des metaphysischen Humanismus (Lacan, Levi-Strauss, Althusser etc.), der ihrer Ansicht nach mechanisiert war, selber subtiler mechanischer, nämlich kybernetischer Modelle, mit deren Hilfe sie den Begriff des Subjekts und der Person dekonstruieren möchten. Das Unbewusste von Freud wird bei Lacan zu einer automatischen und selbstreflexiven Rechenoperation und das Symbolische bei LéviStrauss zu einer unbewussten und automatischen Sprachstruktur. So ergibt sich von mehreren Seiten her (artificial intelligence, Kognitionswissenschaften, Neurobiologie, strukturalistische und konstruktivis- 
tische Human- und Sozialwissenschaften) die Tendenz, mittels der Kybernetik ein Denken zu schaffen, das ganz ohne Subjekte auskommt. Die Menschheit tendiert dahin, sich selber total zu beherrschen, indem sie sich gleichzeitig selber zur Maschine reduziert. Warum tut sie dies? Diese Frage begleitete Dupuy durch seine ganze Untersuchung hindurch, und er glaubt folgende Antwort gefunden zu haben: „Als Opfer des Ressentiments, des Neides, der Eifersucht und des zerstörerischen Hasses benehmen sie [die Menschen] sich, wie wenn sie an Mechanismen gebunden wären. Die Versuchung kann dann groß sein, einen Schritt weiter zu gehen und sich wirklich zur Maschine zu machen, um dem Leiden zu entrinnen, das ein maschinen-ähnlicher Mensch immer noch spürt.“"20

\section{Aufgeklärte Apokalyptik}

Die Problematik des Bösen hat in der Vergangenheit oft zu apokalyptischen Vorstellungen geführt. Auch Dupuy geht darauf ein, ohne allerdings die religiöse Rede zu übernehmen. Er entwirft vielmehr einen aufgeklärten „Katastrophismus“21. Sein entsprechendes Buch wurde vor dem 11. September 2001 geschrieben, aber erst danach veröffentlicht. Es geht auf einen seiner Vorträge vor dem Commissariat général du Plan ${ }^{22}$ in Paris zurück und behandelt das Problem der großen Katastrophen, von denen eine kleinere dann kurz danach eingetreten ist. Wie üblich arbeitet Dupuy zunächst vorliegende Theorien auf, diesmal zur Frage der rationalen Entscheidung, zum Problem des Risikos, der Vorsicht/Vorsorge („precaution“) und der Prävention („prevention“). In der modernen Gesellschaft gebe es kein göttliches Gericht mehr, aber die Rache („nemesis") geschehe dennoch durch die kontraproduktiven Folgen gesellschaftlicher Prozesse, wie Ivan Illich immer wieder betont habe. Die Hauptschwierigkeit liegt, wie Dupuy nach der Lektüre von Tausenden von Seiten glaubt feststellen zu können, nicht darin, Katastrophen richtig vorauszusehen, sondern daran zu glauben. Je größer sie nämlich erscheinen, für umso unwahrscheinlicher werden sie gehalten, bevor

20 Dupuy (2002b), 159.

21 Dupuy (2002a).

22 Dupuy ist auch Mitglied des Comité d'Éthique et de Précaution de l'INRA (Institut national de la recherche agronomique), zu dem 257 Forschungseinheiten mit einem jährlichen Budget von 573 Millionen Euro gehören. 
sie eintreten, aber umso selbstverständlicher sind sie, sobald sie eingetreten sind, eine Erfahrung, auf die bereits H. Bergson im Zusammenhang mit dem Ersten Weltkrieg hingewiesen hat. Die heutige Gesellschaft enthält nun Dynamiken, die auf noch weit größere Gefahren zulaufen. ${ }^{23}$ Aber gerade weil die möglichen Katastrophen so groß sind, werden sie, bevor sie eintreten, nicht geglaubt und auf der Ebene des praktischen Handelns für unmöglich gehalten. „Alles legt nahe, dass wir die gegenwärtige Art des Fortschritts nicht räumlich und zeitlich grenzenlos verlängern können. Aber das, was wir über den Fortschritt gelernt und uns angeeignet haben, in Frage zu stellen, hätte so phänomenale Konsequenzen, dass wir das, was wir wissen, nicht glauben." 24

Dupuy möchte nun nachweisen, dass dies nicht bloß ein psychologisches und ein ethisches Problem ist, obwohl er sich sehr an ethischen Fragen interessiert. ${ }^{25} \mathrm{Im}$ vorliegenden Buch geht es ihm vor allem um den Nachweis, dass die Problematik möglicher, kommender Katastrophen und der vorausgehenden Reaktionen darauf nicht selbstwidersprüchlich ist, dafür aber einer entsprechenden Metaphysik der Zeit bedarf (vgl. H. Bergson). Im Unterschied zu einer Ethik der Konsequenzen, die von der Gegenwart in die Zukunft schaut, gehe es darum, eine Ethik der Zukunft zu entwerfen, die von dort her auf die Gegenwart zurückblickt, wie dies bereits Hans Jonas vorgeschlagen hat. Dabei liege der entscheidende Unterschied darin, dass im ersten Fall die Gegenwart einlinig in die Zukunft verlängert wird und so keine genuinen neuen Handlungsmöglichkeiten erschlossen werden, während im zweiten Fall von einer hypothetischen Zukunft ausgegangen wird, die, gerade wenn sie mit ihren Katastrophen von den Menschen ernst genommen wird, verhindert werden kann und nicht eintritt, wie schon das Beispiel des biblischen Jonas zeigt, der gemäß der alttestamentlichen Erzählung den Untergang Ninives ankündigt und durch die darauf erfolgende Bekehrung seiner Bewohner verhindert, dass die Stadt tatsächlich vernichtet wird. Damit eine angesagte Katastrophe aber ernst genommen wird, muss sie als sicher vorausgesagt werden. Wie ist dies aber möglich, wenn sie vom Tun der Menschen abhängt und gerade verhindert

23 Vgl. Joy (2000) und Rees (2004).

24 Dupuy (2002a), 144.

25 Seit 2000 ist Dupuy an der École Polytechnique in Paris Leiter der GRISÉ (Groupe de Recherche et d'Intervention sur la Science et l'Éthique). 
werden soll und auch keine Berufung auf Gott mehr möglich ist wie beim biblischen Jonas? Nach Dupuy bedarf es dazu einer Metaphysik der Zeit, die zwischen der Zeit des Entwurfs (,projet") und der geschichtlichen Zeit unterscheidet. Voraussagen können bewirken, dass Menschen gerade wegen der Voraussage anders handeln und das Vorausgesagte deshalb nicht eintritt. Das Vorausgesagte war folglich nicht bloß eine leere Möglichkeit, die nie Wirklichkeit wurde, sie hat vielmehr tatsächlich gewirkt und die Geschichte verändert. Die Zeit des Entwurfs ist etwas Reales und eröffnet den Raum der Geschichte.

Gemäß dem Modell des Marktes, bei dem die Preise einerseits vorgegeben sind, obwohl sie anderseits aus dem Kaufen und Verkaufen der vielen Teilnehmer erst entstehen, scheint die Voraussage kommender Ereignisse auch möglich zu sein, selbst wenn diese vom gegenwärtigen Tun der Menschen abhängen. Das kollektive Handeln hat eine Eigengesetzlichkeit gegenüber dem individuellen Tun. Für das Problem der Zukunft der Menschheit bedeutet dies: „Die Menschen müssen ihr Tun im Blick auf ein negatives Zukunftsbild, das für fix gehalten wird und das man nicht will, koordinieren." ${ }^{26}$ Wie kann das Zukunftsbild aber für fix gehalten werden, wenn es gerade verhindert werden soll? Widerlegt die sichere Ansage einer Katastrophe mit der Annahme, dass die Menschen sich dadurch ändern und die Katastrophe verhindern, nicht sich selber? Hier setzt Dupuy nochmals mit komplexen Überlegungen zum Zirkel zwischen Zukunft und Gegenwart an und konfrontiert diese mit den ebenso komplexen Überlegungen zur atomaren Abschreckung, um schließlich zu folgender Einsicht zu kommen: Aufgabe der wissenschaftlichen Futurologie und der Meditation über die Ziele des Menschen ist es, ein Bild der Zukunft zu entwerfen, das einerseits genügend katastrophenhaft ist, um abstoßend zu wirken, und anderseits als genügend glaubhaft erscheint, um Aktionen auszulösen, die seine Realisierung wahrscheinlich verhindern. ${ }^{27}$ Dabei ist das Wort ,wahrscheinlich“ entscheidend. Eine letzte Ungewissheit öffnet den Raum für freie Entscheidungen. 


\section{Geschichtliche Hermeneutik}

Die Arbeiten von Dupuy beschäftigen sich nicht direkt mit der Geschichte, sondern vor allem mit den vielfältigen und mächtigen Mechanismen in der heutigen Gesellschaft. Sein kritisches Nachfragen führt ihn aber zu Themen wie Zeit und Voraussage, Freiheit und Subjekt, Gerechtigkeit und Verantwort, Hierarchie und Autonomie, Böses und Apokalyptik. All diese Themen sind zentral für das Verständnis der Geschichte, und sie müssen heute, soll eine Geschichtsschreibung unter gegebenen Umständen glaubhaft sein, mit den mächtigen Mechanismen, die jede Gesellschaft beherrschen und die Dupuy bis in ihre vielen Verästelungen hinein verfolgt, kritisch konfrontiert werden.

Um geschichtliche Zusammenhänge aufzuzeigen, müssen unter den vielen Einzelfakten entscheidende Linien herausgehoben werden. Solche Linien lassen sich aber nur ziehen, wenn eine Zielrichtung angenommen wird. Die religiöse christliche Geschichtsschreibung war deshalb auf die Endzeit ausgerichtet. In Konkurrenz zu dieser Sicht hat der klassische Historismus die europäische Kultur oder gar die Kultur einer einzelnen Nation für den Höhepunkt der menschlichen Entwicklung gehalten und die Geschichte entsprechend stilisiert. Im Gegensatz zum Historismus hat der Marxismus die Geschichte ganz auf die klassenlose Gesellschaft zulaufen sehen. Nach dem Ende des sowjetischen Imperiums und dem Zusammenbruch des offiziellen Marxismus hielten manche die liberale westliche Gesellschaft mit ihrer Marktwirtschaft für die Siegerin der Weltgeschichte. ${ }^{28}$ In diesem Zusammenhang begannen vor allem in Amerika zahlreiche Historiker beim Studium der Vergangenheit jene Elemente hervorzuheben, die auf den Markt zuliefen oder zuzulaufen schienen. ${ }^{29}$ Die ganze Kultur droht so zu einem Phänomen des Marktes zu werden. Die Geschichtsschreibung wird dabei zu einem Mittel der Immunisierung, durch das gezeigt wird, dass alles so kommen musste und es keine Alternativen für die Zukunft gibt.

Eine aufgeklärte Apokalyptik, wie Dupuy sie zeichnet und die all die komplexen Mechanismen der modernen Gesellschaft bedenkt,

28 Fukuyama (1992).

29 „In der US-amerikanischen Geschichtswissenschaft sind seit einigen Jahren Begriffe wie „Markt', ,Kapitalismus' und „Konsum` zu herausragender Prominenz gelangt und bestimmen inzwischen über weite Strecken die Debatten über die Deutung der amerikanischen Geschichte vom frühen 17. bis zum späten 20. Jahrhundert insgesamt.“ Nolte (1997), 359. 
versucht die Gegenwart differenzierter zu sehen und damit auch ein weit komplexeres Bild der Vergangenheit zu zeichnen. Ein aufgeklärter Katastrophismus sieht zwar all die komplexen Mechanismen, in die die menschliche Gesellschaft verstrickt ist und die dennoch den Raum für freie Entscheidungen offen lassen. Entsprechend erscheint auch die vergangene Geschichte nicht als ein notwendiger Ablauf, sondern als ein Gang der Menschen und Völker, der immer auch andere Möglichkeiten, die nicht gewählt wurden, offenließ.

\section{Literatur}

Bourdieu, Pierre (1972): Esquisse d'une théorie de la pratique. Genève: Droz.

Dupuy, Jean-Pierre (1989): „Self-reference in Literature“, in: Poetics 18, 491 515.

Dupuy, Jean-Pierre (1991): La panique. Paris: Laboratoires Delagrange.

Dupuy, Jean-Pierre (1992): Le Sacrifice et l' envie. Paris: Calmann-Lévy.

Dupuy, Jean-Pierre (1994): Aux origines des sciences cognitives. Paris: La Découverte et Syros.

Dupuy, Jean-Pierre (2000a): The Mechanization of the Mind. Princeton: Princeton University Press.

Dupuy, Jean-Pierre (2000b): Les savants croient-ils en leurs théories? Une lecture philosophique de l'histoire des sciences cognitives. Paris: INRA Éditions.

Dupuy, Jean-Pierre (2002a): Pour un catastrophisme éclairé. Quand l'impossible est certain. Paris: Seuil.

Dupuy, Jean-Pierre (2002b): Avions-nous oublié le mal? Penser la politique après le 11 septembre. Paris: Bayard.

Dupuy, Jean-Pierre (2002c): „Zur Selbst-Dekonstruktion von Konventionen", in: Krieg, Peter/Watzlawick, Paul, Hg.: Das Auge des Betracbters. Beiträge zum Konstruktivismus. Heidelberg: Carl-Auer-Systeme, 85-115.

Dupuy, Jean-Pierre/Varela, Francisco (2002): „Kreative Zirkelschlüsse. Zum Verständnis der Ursprünge“, in: Krieg, Peter/Watzlawick, Paul, Hg.: Das Auge des Betracbters. Beiträge zum Konstruktivismus. Heidelberg: Carl-Auer-Systeme, 247-275.

Fukuyama, Francis (1992): Das Ende der Geschicbte. Wo stehen wir? München: Kindler.

Girard, René (1988): Der Sündenbock. Zürich: Benziger.

Joy, Bill (2000): „Why the Future Doesn't Need Us. Our Most Powerful 21st-century Technologies - Robotics, Genetic Engineering, and Nanotech - are Threatening to Make Humans an Endangered Species", in: Wired 8.04, 238-262.

Kant, Immanuel (1795): Zum ewigen Frieden. Ein philosophischer Entwurf. Königsberg: Nicolovius.

Lefort, Claude (1986): Essais sur le politique. Paris: Seuil. 
Lévi-Strauss, Claude (91994): Das wilde Denken. Frankfurt/M.: Suhrkamp.

Mauss, Marcel (52005): Die Gabe. Form und Funktion des Austauschs in archaischen Gesellschaften. Frankfurt/M.: Suhrkamp.

Nolte, Paul (1997): „Der Markt und seine Kultur - ein neues Paradigma der amerikanischen Geschichte?", in: Historische Zeitschrift 264, 329-360.

Rees, Martin J. (2004): Our Final Hour. A Scientist's Warning: How Terror, Error, and Environmental Disaster Threaten Humankind's Future in this Cen-tury - on Earth \& Beyond. New York: Basic Books.

Sahlins, Marshall (1972): Stone Age Economics. New York: Aldine de Gruyter. 



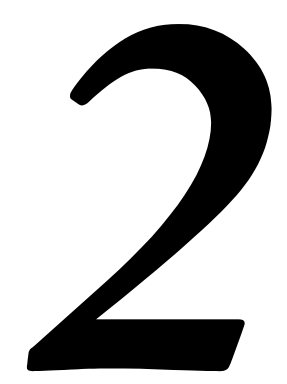





\title{
Wessen Frieden? Zur Frage nach der Transrationalität in der Friedensforschung
}

\author{
Wolfgang Dietrich
}

\section{Einleitung}

Vor zehn Jahren habe ich mich mit meinem Call for Many Peaces ${ }^{1} \mathrm{zu}$ Frieden als einem Kulturbegriff bekannt, den viele - und das nicht zu Unrecht - als postmodern bezeichnet haben. Seither hat mich meine Erfahrung in interkulturellen Programmen zur Friedensforschung - vom renommierten UNESCO Chair for Peace Philosophy an der Universität Jaume I. in Castellón de la Plana (Spanien) bis zur Friedensuniversität der Vereinten Nationen in Ciudad Colón (Costa Rica) - in dieser Haltung bestärkt. Mehr noch, sie hat mich weit darüber hinaus geführt, sodass ich heute den Lehrgang für Friedensstudien an der Universität Innsbruck ${ }^{2}$ in einer Weise leite, die versucht die Postmoderne zu durchschreiten und einem transrationalen Ansatz zu folgen.

Mit dieser simpel scheinenden Feststellung befinde ich mich bereits in einer äußerst komplexen Diskussion, denn jeder der eingangs erwähnten Schlüsselbegriffe schreit nach einer genaueren Bestim-

\footnotetext{
* Wolfgang Dietrich ist Programmdirektor des Masterprogramms „Peace, Development, Security and International Conflict Transformation" an der Universität Innsbruck und akademischer Direktor des Österreichischen Lateinamerika-Instituts. Zudem ist er Gastdozent an der Universität Wien und Mitglied des Centro Internacional Bancaja para la Paz y el Desarrollo an der Universidad de Castellón (Spanien). Seine Arbeitsschwerpunkte sind Friedensforschung und internationale Beziehungen. Der vorliegende Text schließt an einen Vortrag bei der 17. Klausurtagung der Plattform am 13. Oktober 2006 an.

1 Neu aufgelegt in: Dietrich et al. (2006).

2 Vgl. etwa http://www.tirol.gv.at/peacestudies.
} 
mung und einer Rechtfertigung für seine Verwendung im Kontext akademischer Programme, die sich mit den Frieden befassen. Wenn ich heute für Transrationalität in der Friedensforschung plädiere, so greife ich damit eine von fünf Grundkategorien auf, in welche ich die mir bislang empirisch zugänglichen Friedensbegriffe einzuteilen begonnen habe: energetische, moralische, moderne, postmoderne und transrationale.

\section{Zur postmodernen Rebellion gegen die moderne Chronosophie der Frieden}

Ich sage Kategorien, weil ein modernes europäisches Verständnis leicht dazu verführen könnte, diese Einteilung chronologisch zu interpretieren. Chronologie im Sinne eines vektoralen Zeitverständnisses ist ihrerseits aber keine natürlich Gegebenheit, sondern eine Ideologie, die bezeichnend für die Moderne ist. Deshalb würde diese - in hegelianischer Weise etwa - das energetische Friedensbild einer magischen Weltsicht zuordnen, das moralische einer mythischen und das moderne einer rationalen. ${ }^{3}$ Da jenseits einer so verstandenen Moderne nur noch das Ende der Geschichte warten kann, das etliche Autoren am Ende des zwanzigsten Jahrhunderts auch beschworen haben, ${ }^{4}$ gelten einer solchen Weltsicht Postmoderne und Transrationalität zwangsläufig als irrationale Verirrungen, temporäre Verfallserscheinungen. Postmoderne Friedensbegriffe pflegt sie daher dem Durkheim'schen deréglèment ${ }^{5}$ zuzuordnen und transrationale mit prärationalem Okkultismus oder neokonservativer New-Age-Spiritualität zu verwechseln.

Stelle ich den Begriff der Frieden - und damit wohl das zentrale Anliegen jeder Gesellschaftswissenschaft - in den Mittelpunkt meines Interesses, so wird die begrenzte Reichweite moderner Friedensinterpretationen aber bald einsichtig. Um das näher zu erläutern, muss vorerst geklärt werden, wie hier der Begriff Moderne verstanden wird.

Das in der französischen Umgangssprache verwendete „temps modernes" bezeichnet das, was man in der deutschen Sprache Neuzeit zu nennen pflegt. Diese Verwendung geht auf das lateinische

3 So macht das etwa Wilber (1995)..

4 Am bekanntesten wohl Fukuyama (1992).

5 Durkheim (1895). 
Wort „modernus“ für neu, neuzeitlich oder gegenwärtig zurück und stammt vom Adverb „modo“ für eben, eben erst ab.

Die Verwendung des Begriffs Moderne im Deutschen ist weniger klar. Da kann die Moderne des achtzehnten Jahrhunderts und die sogenannte Aufklärung (selbst wiederum ein höchst verwirrender Begriff) gemeint sein, aber auch die Moderne des neunzehnten Jahrhunderts, also das Fortschrittsprogramm des Industrialisierungsprozesses, oder die Moderne des zwanzigsten Jahrhunderts mit ihren künstlerischen Avantgarden, der Grundlagenkrise der Wissenschaft, den politischen Totalitarismen und den Lifestylediktaten. ${ }^{6}$

In dieser Verwendung meint modern im Wesentlichen neu als Gegensatz zu traditionell, alt. In einer Weltsicht, welche die soziale Zeit linear wahrnimmt, in einer vektoralen Chronosophie also, ergibt sich daraus zwangsläufig, dass das Moderne von heute zwar auch das „Gute“, aber schon morgen das Traditionelle und Überholte und damit „Schlechte“ ist, womit sich in einer derart dualen Welt das Moderne permanent neu erfinden und definieren muss, indem es sich vom Alten abgrenzt. So verstanden ist der Begriff als historische Kategorie schwer fassbar und kaum tauglich.

Aus diesem Grund gibt es etliche Vorschläge, welche die Moderne nicht als Epoche definieren wollen, sondern sie qualitativ zu erfassen trachten. Schon Ferdinand Tönnies, einer der Begründer der deutschsprachigen Soziologie, schlug als Definitionskriterium der Moderne die gesellschaftliche Organisationsform vor, welche er von der gemeinschaftlichen unterschied. ${ }^{7}$ Dabei haben wir aber dasselbe Problem wie zuvor. Gemeinschaftlich ist traditionell, alt und letztlich schlecht, gesellschaftlich neu(zeitlich), modern und gut. Der berühmte Widerspruch von Ivan Illich ${ }^{8}$ mit seiner Sicht des Vernakulären drängt sich da mächtig auf. Dem trägt Fritjof Capra ${ }^{9}$ mit seiner Unterscheidung zwischen dem organischen und dem mechanistischen Weltverständnis Rechnung.

Immanuel Wallerstein lehnt die Dualitäten von Rationalität und Aberglaube oder Freiheit und geistige Unterdrückung als Unterscheidungskriterien überhaupt ab und setzt das moderne Weltsystem mit dem Kapitalismus gleich. Er sieht die Vorstellung von der Tradi-

6 Welsch (1994), 2-3.

7 Tönnies (2005).

8 Illich (1982), 114-122.

9 Capra (1983), 52. 
tion selbst als eine Schöpfung der Moderne, Teil deren großer Erzählung und in die Welt gesetzt, um auf diese Art die Segmentierung der Weltbevölkerung und die Zurichtung einer entsprechenden Billigstarbeitskraft für den Zweck der Kapitalakkumulation zu ermöglichen. Der Universalismus ist ihm die Voraussetzung dafür, die Globalisierung die Konsequenz.

Der Universalismus ,ist eine Sammlung von Glaubenssätzen darüber, was erfahrbar ist und wie es erfahrbar ist. Der Kern dieser Ansicht ist, dass es sinnvolle generelle Feststellungen über die Welt gibt [...], die universell gültig sind, jetzt und immerfort, und dass das Ziel der Forschung die Suche nach diesen generellen Feststellungen in einer Form ist, die alle subjektiven, das heißt, alle historisch beschränkten Elemente aus seiner Formulierung ausschließt." ${ }^{\prime 10}$

Wallerstein stößt also auf das sensible Thema der universellen Wahrheit. Aber wenn er es als Charakteristikum der Moderne definiert, so stellt er es nicht etwa einer Tradition der Vielheit gegenüber, sondern verweist auf seinen Einsatz für die Schaffung eines weltweiten bürgerlichen Rahmens, der auf verschiedene ,nationale“ Varianten verpflanzt werden kann, was besonders im Bereich der Wissenschaft und Technologie, aber ebenso hinsichtlich der politischen Ideen entscheidend wäre.

„Die Überhöhung des Fortschritts und später der Modernisierung faßte diese Ideensammlung zusammen, die weniger als wahre Normen sozialen Tuns denn als Statussymbol von Ehrerbietung und Partizipation an den weltweiten Oberschichten diente. Der Abfall von den vermeintlich kulturell engen religiösen Wissensgrundlagen zugunsten von vermeintlich überkulturellen wissenschaftlichen Wissengrundlagen diente als Selbstrechtfertigung einer besonders bösartigen Form von Kulturimperialismus. Er herrschte im Namen der geistigen Befreiung; er betrog im Namen des Skeptizismus." "11

Für Wallerstein ist Kapitalismus die Verwandlung aller Dinge in Waren, und deren Einsetzen ist ihm der entscheidende Wendepunkt, den er als Beginn des modernen Weltsystems sieht. Dieser Vorgang ist aber kein Faktum, sondern eine Interpretation, welche sozialmächtig gemacht wird. In unserem Kontext ist dabei besonders sein Hinweis auf das Postulat der einen Wahrheit, wie sie das mittelalterli- 
che Christentum transportiert hat, wichtig, denn es zeigt, dass die Wende zur Moderne nicht zu neuen Freiheiten sui generis geführt hat, sondern zu einer eindimensionalen Umkehr des vorgestellten Vektors sozialer Orientierung vom vorgestellten Jenseits auf ein vorgestelltes Diesseits. Die Umwandlung aller Dinge in Waren ist nur ein anderes Wort, ein anderer Fokus eines transzendenten Gottesbildes.

Deshalb ist es so schwer, die Moderne zu periodisieren. Weder die Erfindung Amerikas noch der Westfälische Frieden, die Aufklärung oder die Französische Revolution ist ein materieller Wendepunkt in der Zeit, der es gestatten würde, sie ab da faktisch auszurufen. Jean-Francois Lyotard bezeichnet sie als einen Gemüts- und Geisteszustand, für den gesellschaftliches und individuelles Tun der Herrschaft eines Meta-Textes unterliegt, der diesem Tun Sinn gibt. Er fasst die Moderne als jenes zeitlich nicht exakt begrenzbare Gesellschaftsprojekt, das auf der Newton'schen Physik, dem cartesianischen Reduktionismus und dem Nationalstaatsdenken des Thomas Hobbes fußt. Diese Säulen geben dem politischen Handeln in der Moderne seinen Sinn, bewirken eine als real erlebte Selbstverständlichkeit von Zielvorstellungen, Handlungsanleitungen und deren Befolgung. ${ }^{12}$

In diesem Sinne hat die Moderne freilich überhaupt nie existiert. Ein solches Selbstverständnis ist an keinem Ort und zu keinem Zeitpunkt jemals unwidersprochen aufgetreten. Deshalb meinen viele, die Postmoderne wäre seit dem ersten Moment modernen Denkens als rationaler, kritischer und inhärenter Gegenpart in der Moderne selbst angelegt gewesen. Lyotard schlägt daher vor, bestenfalls von einer Klassik zu sprechen, in welcher mit der Zukunft und der Vergangenheit so umgegangen wird, als ob sie zusammen genommen die Totalität des Lebens in einer Sinneinheit umfassen würden. ${ }^{13}$ Das heißt, in Lyotards Klassik sind Anfang und Ende einer erzählten Geschichte so glaubhaft organisiert und strukturiert, dass darin gleichsam ein stabiles, verlängertes Jetzt wahrgenommen wird.

Lyotards Klassik ist so etwas wie eine „kleine Moderne“, örtlich, zeitlich und personell begrenzt, in diesem Rahmen aber „wahr“ und weit über ihn hinaus wirksam in Kontexten, die sich selbst nicht 
mit ihr identifizieren. Deshalb lassen sich Klassiker des modernen Denkens benennen, moderne Verhältnisse, Produktionsweisen und Friedensbegriffe beschreiben, auch wenn die Moderne selbst ein in ihrer Gesamtheit unfassbares und widersprüchliches Phänomen bleibt.

Folgen wir dieser Definition, so wird einsichtig, dass moderne Friedensbilder nicht in der Lage sind, andere Friedensbegriffe als den einen eigenen zuzulassen. Widersprüchliche Evidenz wird entweder in die Vergangenheit verlagert oder kraft der diagnostischen Eigenmacht Kontexten zugeschrieben, die als rückständig, unzivilisiert, unterentwickelt, und damit unzeitgemäß, also auch der Vergangenheit zugehörig, bezeichnet werden. Und da sich in der Moderne die Geschichte vollendet, wird folgerichtig ausgeschlossen, dass sich je nachmoderne Friedensbegriffe formieren könnten.

Gegen diese Anmaßung rebellierte die postmoderne Philosophie und ein Teil der Friedenswissenschaft folgte ihr mit jenem Plädoyer für die Öffnung der Friedenvorstellung für Begriffe und Deutungen, welche dem in diesem Sinne modernen Denken mit seinem permanenten Fortschrittsgebot folgen konnten oder wollten.

Im Grunde hat die Moderne selbst, insbesondere durch die Erkenntnisse der Quantenmechanik, welche untrennbar mit Namen wie Max Planck (1858-1947), Albert Einstein (1879-1955), Niels Bohr (1885-1962), Erwin Schrödinger (1887-1961) und Werner Heisenberg (1901-1976) verbunden sind, die Grundlagen ihres Weltbildes zertrümmert. Ich will kurz argumentieren, wie und warum:

Die Vorstellung vom Universum als einem ineinander verwobenen Netz von Zusammenhängen ist eines der Themen, die in dieser neuen Physik, der Chemie und der Biologie immer wieder aufgeworfen werden. Wenn das für die kleinsten Teile gilt, so dürfen wir es in unserer Sinneswelt zwar anders wahrnehmen und deuten, aber unsere eigenen kleinsten Teilchen und damit das, was wir als unser Selbst betrachten, kann diesen Zusammenhängen nicht entkommen. In jedem Fall ist die mechanistische Annahme von kleinsten Teilchen, die als Staubkörner verdichtet oder als einsam herumschwirrende Billardkugeln ihre Bahnen ziehen mit der Quantenphysik widerlegt. Darauf kann kein Weltbild mehr gebaut werden.

Die zweite große Erkenntnis jener Zeit war die, dass dieses kosmische Gewebe von Natur aus dynamisch ist. Der dynamische Aspekt der Materie ergibt sich aus der Wellennatur der subatomaren Teilchen. Mit der Ausstattung unserer Sinne betrachtet mögen man- 
che materielle Objekte um uns herum passiv und tot erscheinen. Vergrößert man aber etwa einen „toten“ Stein bis seine Teilchen sichtbar werden, so ergibt sich, dass er voller Aktivität ist. Je näher wir hinschauen, je mehr wir ins Detail gehen, umso mehr lebt er. Die neue Physik beschreibt Materie also keineswegs als passiv und träge, sondern als in unaufhörlich tanzender und vibrierender Bewegung begriffen, wobei die rhythmischen Muster durch die molekulare, atomare und nukleare Zusammensetzung bestimmt werden. Es existieren in der Natur keine statischen Strukturen. Zwar gibt es Stabilität, aber das ist eine Stabilität dynamischen Gleichgewichts. Die wichtigste Folge dieses damals neuen relativistischen Rahmens war die Erkenntnis, dass Masse nichts als eine Form der Energie ist. Selbst ein ruhender Gegenstand hat in seiner Masse Energie gespeichert, und die Beziehung zwischen beiden wird in Einsteins berühmter Formel $\mathrm{E}=\mathrm{mc}^{2}$ ausgedrückt.

Diese Erkenntnis stellte einen radikalen Bruch mit dem traditionellen Geist der Grundlagenforschung in der Physik dar, die immer darauf ausgerichtet war, die Grundbausteine der Materie zu finden. Zugleich ist sie der Durchbruch zur Vorstellung von der materiellen Welt als einem dynamischen Gewebe von Zusammenhängen. Es muss nicht nur der Gedanke an fundamentale Bausteine der Materie aufgegeben werden, sondern auch der an fundamentale Einheiten irgendeiner Art. Das Universum wird als ein pulsierend expandierendes Netz untereinander verbundener Geschehnisse betrachtet. Keine der Eigenschaften irgendeines Teiles dieses Gewebes ist fundamental.

Die Eigenschaften aller Teile ergeben sich aus den Eigenschaften der anderen Teile. Und die folgerichtige Gesamtübereinstimmung ihrer Wechselbeziehungen determiniert die Struktur des gesamten Netzes. Wenn alle Eigenschaften der Teilchen von Prinzipien bestimmt werden, die von den Beobachtungsmethoden abhängen, bedeutet das, dass die Strukturen der materiellen Welt letztlich durch die Art und Weise bestimmt werden, wie wir diese Welt sehen. Die beobachteten Strukturen der Materie wären somit Spiegelungen der Strukturen unseres Bewusstseins.

Mit der Annahme dieses naturwissenschaftlichen Kanons musste die Welt grundlegend neu verstanden werden. Doch bis sich daraus eine postmoderne Philosophie entwickelte, dauerte es Jahrzehnte, will man Visionäre wie Nietzsche und Wegbereiter wie Husserl oder Heidegger noch nicht mit diesem Emblem versehen. Die Ge- 
sellschaftswissenschaften und mit ihnen die Internationalen Beziehungen als wissenschaftliche Disziplin und der Mainstream der Friedensforschung scheinen noch länger zu brauchen, um die ganze Tragweite jener Weltsicht zu begreifen. Dabei ist die Botschaft eindeutig: Wenn die Welt schon in ihren kleinsten Teilchen nur über Beziehungen wahrgenommen werden kann, so muss dies auch für jenen Bereich gelten, der mit den menschlichen Sinnen fassbar ist.

Frieden kann folglich weder als Zustand noch als Pakt oder Norm gedacht werden, sondern nur als dynamische Beziehung, wie dies zahlreiche energetische vor- und außermoderne Friedensbilder seit Jahrtausenden vorschlagen. In diesem Licht verwandelt sich das postmoderne Plädoyer für die vielen Frieden von einem idealistischen Appell für einen etwas respektvolleren Umgang mit „dem anderen“ zu einem Akt der Befreiung der eigenen Wahrnehmung aus der Begrenztheit einer als statisch und absolut missdeuteten Rationalität. So wie sich die Moderne über den kartesianischen Begriff des erkennenden Subjektes und dessen Objektivität erst konstituieren musste, verlangt der Versuch einer solchen Befreiung nun aber auch nach einem neuen Selbstverständnis des Menschen als erkennendes und die Frieden konstruierendes Wesen. Wenden wir uns daher in einem weiteren Schritt der fundamentalen Frage zu, was nun der Mensch als Individuum, Subjekt, Person, Persönlichkeit, Ich oder Selbst überhaupt bedeutet, um von da aus die weitere Frage nach den Möglichkeiten transpersonaler und in der Folge transrationaler Frieden stellen zu können.

\section{Individuum, Subjekt, Person, Persönlichkeit, Ich, Ego, Selbst}

Im fünften Jahrhundert definierte der richtungsweisende christliche Philosoph Boethius die Person als individuelle Substanz von rationaler Natur. ${ }^{14}$ Er hat den Begriff natürlich nicht erfunden. Er verwendete das lateinische Wort „per-sonare“, das etymologisch „durch eine Maske klingen“ meint und entweder im griechischen „prosôpon“ oder im etruskischen „phersu“ wurzelt. Beide bedeuten „Maske“. Die Maske wiederum repräsentierte in den frühen griechischen Ritualen und Tragödien den formellen Aspekt des Göttlichen. Die Maske oder die Rolle stellt also nur die sichtbare Oberfläche von et-

14 Boethius (o.J.). 
was Größerem dar. Im dionysischen Ritual und der vorsokratischen Tragödie bestimmten aber die Energie, ausgedrückt durch die Musik, den Dithyrambus, das Geschehen, nicht umgekehrt. ${ }^{15}$ In seinem materiellem Aspekt (Apollo) ist es nicht vollständig, es benötigt die Energie (Dionysus), welche durch die Maske klingt.

In der christlichen Tradition wurde diese Energie als Seele überliefert. Die Person besteht demnach aus Körper, Geist und Seele. Boethius führte die rationale Natur in diese Debatte ein, welche er unter allen existierenden Wesen nur dem Menschen zuschrieb. Der Mensch ist nach ihm das höchste aller existierenden Dinge, ausgestattet mit einer besonderen Würde und mit Rechten. Daher macht für Boethius noch keiner der genannten Aspekte allein einen Menschen aus, sondern erst das Zusammenwirken aller drei. Nach dieser Definition erkennen wir im Menschen eine substanzielle Erscheinung, welche auf rationale Weise eine sozial wahrnehmbare Rolle spielt, eine Funktion wahrnimmt, und dabei von ihrem metaphysischen Aspekt, der Seele, welche sie mit Gott verbindet, geleitet wird. Das wurde durch Jahrhunderte herrschende Lehre, obwohl der metaphysische Aspekt stets Raum für Zweifel, Widersprüche und Manipulationen offen ließ.

Wie wir gesehen haben, benötigte Boethius für die Definition der Person eine ,individuelle Substanz“, da Materie die Grundlage für die Individuation bildet. So könnten wir sagen, dass das Individuum den materiellen Aspekt der Person darstellt. Es ist weniger als eine ganze Person und der Begriff lässt sich auch auf nichtmenschliche Lebensformen anwenden. Doch was macht eine lebende Substanz „unteilbar“? Wie kann das Individuum von seiner Herde, seinem Schwarm, seiner Schar oder seiner Umwelt unterschieden werden? Wo hört es auf? Wo fängt es an? Ist die Luft, die es einatmet, die Nahrung, die es verdaut, Teil von ihm? Oder sind das eigene Dinge, obwohl man sie im Körper findet und sie in einer dauernden Abfolge in ihn integriert, transformiert und wieder ausgeschieden werden?

Das Wort Individuum unterstellt, dass etwas nicht mehr geteilt werden kann, dass man die kleinstmögliche Einheit einer entsprechenden Lebensform erreicht hat. Doch das wirft gleich einen zweifachen ethischen Zweifel auf. Einerseits stellt sich die Frage, ob man 
irgendeine Lebensform von ihrer Umgebung trennen kann, ohne sie zu töten. Falls nicht, dann ist wohl die Natur oder der Kosmos, das All-eine, das einzig existierende Individuum und jedes Konzept der Trennung ist zumindest einmal schiere intellektuelle Gewalt. Für eine wirkliche Individualität wäre weiters Voraussetzung, dass kein abgetrennter Teil des Organismus für sich allein leben könne. Doch unter dieser Voraussetzung wäre die Reproduktion unmöglich. Das Konzept der Individualität trägt einen inhärenten Widerspruch in sich. ${ }^{16}$ Bergson stellte fest, dass Individualität jede beliebige Zahl von Ebenen zulässt und auf keiner vollständig realisierbar ist, auch nicht im Menschen. ${ }^{17}$ Das hat ernste Folgen für den Individualismus in der Moderne.

Man könnte aber auch argumentieren, dass der Körper gar nicht die kleinstmögliche Einheit von Leben bildet. Was geschieht, wenn wir Teile des vermeintlich unteilbaren Körpers vom Rest abtrennen und künstlich am Leben erhalten? Ist das dann keine ,individuelle Substanz" mehr? Und was für ein Individuum bekommen wir, wenn wir diese Teile mit anderer lebender Substanz zusammensetzen, wie das die moderne Medizin laufend macht? Individualität mag in seiner ganzen Geschichte ein Irrlicht gewesen sein, doch wenn wir es aus rein technischen Gründen als solches erkennen, verlangt dies nach einer neuen ethischen Orientierung. Das ist eine der Herausforderungen unserer Zeit.

Das alles wurde nicht gerade dadurch erleichtert, dass René Descartes 1641 in seinen Meditationes de prima philosophia das klassische Konzept der Seele zertrümmerte, indem er die moderne Subjektphilosophie entwarf. Sein Schlüsselwort leitet sich aus dem lateinischen „subiectum“ ab und meint das „Fundamentale“, den „Grund“. Nach Descartes ist der Verstand der Träger von „cogitationes“, also des Denkens, der Erinnerung, der Idee und der Vorstellung. Der Verstand schafft das Subjekt, denn er sorgt für die Gewissheit einer konstituierenden, andauernden und bewussten Selbstreferenz. Ein Subjekt ist demnach ein Wesen, welches eigene Erfahrungen hat und in der Lage ist, diese zu erinnern und anzuwenden. Aus der Sicht des Subjektes ist alles außerhalb ein Objekt. Das Subjekt ist der bewusste Beobachter und das Objekt alles Beobachtete. 
Damit könnte ich also sagen, dass das Subjekt ein bewusstes, wahrnehmendes und agierendes Individuum ist. Oder in anderen Worten, es ist eine Person, welche keine Seele oder Beziehung zu Gott benötigt. Descartes selbst erkannte den dogmatischen Skandal und die logische Schwäche in seinem Vorschlag, den man als ,gottlose Person" bezeichnen könnte. Das wurde mit Recht angegriffen, denn auch wenn ein solches Subjekt keinen Gott für das Wissen benötigt, braucht Descartes doch Gott, um seine bloße Existenz zu erklären. Die Erfahrung der Beschränktheit im Wissen des endlichen Subjekts provozierte ein latentes Gottesbewusstsein. ${ }^{18}$ Descartes' Philosophie benötigte daher immer noch einen transzendenten Gott als letzten Grund, weshalb er verzweifelt versuchte, dessen Existenz zu beweisen, um seine Philosophie zu begründen.

130 Jahre später half Immanuel Kant, indem er feststellte, dass objektives Wissen nur möglich wäre, wenn die Objekte in der Erkenntnisfähigkeit des Subjekts begründet wären. ${ }^{19}$ Das autonome Subjekt wurde auf diese Art die Grundlage für die Definition des Wissens in der modernen Wissenschaft und ersetzte die argumentative Notwendigkeit Gottes. Damit wurde die Person endgültig zum Subjekt reduziert.

John Locke wiederum definierte eine Person als ein lebendes Wesen, welches sich über die Zeit hinweg seiner selbst bewusst wäre und daher in der Lage, bewusste Entscheidungen über die Zukunft zu fällen. Er definierte sie als: "a thinking intelligent Being, that has reason and reflection, and can consider it self as it self, the same thinking thing in different times and places; which it does only by that consciousness, which is inseparable from thinking, and as it seems to me essential to it." 20

Diese rationale Definition verlangt noch immer nach einem Grund. Die Aufklärung löste das Problem, indem sie diesen Grund säkularisierte. Sie setzte Vernunft und Normen an die Stelle Gottes und erreichte so ein scheinbar stabiles Fundament. Eine Persönlichkeit ist nun auf dieser aufgeklärten Basis ein Individuum, ein Subjekt oder eine Person, welche durch das Gesetz anerkannt und geschützt ist. Dieses normative Prinzip wird oft mit dem der Gleichheit vor dem Gesetz verbunden, auf welchem Bürgerrechte, Nationalität, 
Gemeinschaft, Rechte und Pflichten beruhen. Es fand häufig Eingang in die verschiedenen Menschenrechtskodifikationen.

Die Eigenschaft, welche nach dieser Vorstellung alle Persönlichkeiten teilen, ist der Wunsch, die Welt zu verändern. In ihrem Umfeld versucht eine Persönlichkeit alle Faktoren zu verändern, welche ihr missfallen, um jene Bedingungen zu erreichen, die sie glücklicher machen. Das führt zur Beurteilung dessen, was richtig oder falsch ist. Das Richtige zu tun, um die gewünschte Position zu erreichen, resultiert daher aus den Möglichkeiten der Persönlichkeit, ihrem Wissen, ihrer Erfahrung und ihrem Besitz, welche sie alle erworben hat, um möglichst erfolgreich nach Glück zu streben. Daher sind Anerkennung und Schutz der gesetzlichen Stellung substanziell für die Persönlichkeit, weil sie ihr nach dieser Vorstellung erlauben, zum Besten der Gesellschaft selbst zu prosperieren.

Friedrich Nietzsche zertrümmerte auch dieses Konzept, als er feststellte, dass das Subjekt nichts als eine grammatikalische Fiktion wäre, dass es hinter der Maske keinen Akteur gebe. Seine Kritik richtete sich dahin, dass es reine Substanz nicht gebe, weil alles aus oszillierenden Energieformationen gebildet würde, welche sich gegenseitig beeinflussten, für einen Moment kristallisierten und sich dann gleich wieder auflösten. ${ }^{21}$ Demnach gäbe es nur Erscheinungen, keine Fakten. Er betrachtete daher die subjektive Erfahrung als jenseits aller modernen Wissenschaftlichkeit angesiedelt, weil wissenschaftliches Verstehen in der Moderne nach einer objektiven Perspektive verlange, welche dem subjektiven Standpunkt diametral entgegengesetzt wäre.

Gemeinsam mit den Ideen von Karl Marx und wenig später der Strukturhypothese Sigmund Freuds schuf dies den Ausgangspunkt für die Hinterfragung der Bedeutung eines einheitlichen, autonomen Subjekts, der Grundlage des modernen Menschenbildes. All diese Denker öffneten den Weg für die Dekonstruktion des Subjektbegriffs, indem sie feststellten, dass Moral(en) und Ethik nur auf kollektiver, intersubjektiver Ebene konstruiert würden. Einem unabhängigen Individuum kann so etwas wie Moral in keiner Weise helfen.

Freud revolutionierte schließlich die Vorstellung einer dreifaltigen Struktur der Person. Nietzsches Dionysos taucht bei ihm in der Form des triebhaften „Es“ auf, Apoll im „Überich“ und zwischen 
beiden vermittelt das maskenhafte, vernünftige und vorsichtige „Ich“. Doch während Boethius die Person über die metaphysische Seele mit dem Universum, Gott oder dem All-einen verbunden hat, verbindet Freud sein „Überich“ mit der säkularen Welt der Gesellschaft und lässt die Lebensenergie über die Triebe des Individuums fließen. Daher weicht seine Matrix für die interpersonelle Ebene, auf der wir die Frage der Frieden stellen, signifikant vom Modell des Boethius ab, weil jedes Wesen Einfluss auf das „Überich“ aller anderen hat. Somit ist es gleichsam die „Struktur“, die agiert, und nicht die Person als autonomes Subjekt. Das Ich ist somit in diesem Konzept der bewusst wahrnehmungsfähige Aspekt einer strukturell eingebetteten Person.

Während Ich und Ego oftmals als synonyme Begriffe verwendet werden, differenziert Sylvester Walch zwischen dem Ich als lebenserhaltende Struktur im Sinne Freuds und dem Ego als Schattenaspekt des Ich, das seine Ziele gegen die berechtigten Ansprüche anderer durchsetzt, die Grenzen nicht respektiert, kontrolliert und manipuliert, um das Beste für sich selbst herauszuholen. Das Ego kreist vorwiegend um sich selbst und muss daher zum Heil der Person früher oder später transformiert werden..$^{22}$

Das größere, höhere und mystische Selbst $^{23}$ wiederum entspringt dem Weltbild des Buddhismus und anderer östlicher Konzepte als leiblich-selisch-geistige Einheit, als unlokalisierbarer Seinsgrund der Person. Sie interpretieren das Ego weitgehend so wie Locke die Persönlichkeit, die hier allerdings am Weg zur Erkenntnis überwunden werden muss. Was Locke hochleben lässt, gehört im Buddhismus zu den drei Geistesgiften. Daher enthält buddhistische Weisheit die Einladung, das Ego von seinem weltlichen Verlangen zu lösen, von den materiellen, subjektiven Leidenschaften zu befreien und dadurch den Weg zum Bewusstsein für das mystische Selbst zu öffnen.

Der Widerspruch zwischen dem autonomen Subjekt der Aufklärung und dem östlichen Selbst scheint fürs Erste unüberwindbar. Er beschäftigte zahlreiche namhafte Autoren von Carl Gustav Jung $(1875-1961)^{24}$ über Roberto Assagioli (1888-1974) ${ }^{25}$ bis zu Karlfried 
Dürkheim (1896-1988), ${ }^{26}$ die aufgrund ihrer Einsichten allesamt als Wegweiser und Vorläufer der transpersonalen Psychologie angesehen werden. Zwar verwendeten sie alle unterschiedliche Begriffe, stimmten aber in der Ansicht überein, dass jedem Menschen transpersonale Erfahrungswelten des Selbst, die wir hier Frieden nennen, grundsätzlich zugänglich wären. Voraussetzung dafür, dass diese Suche auch als ein heilsamer Prozess erlebt würde, sei aber die vorangehende, vollständige Ausbildung des Ichbewusstseins. Sie sahen also transpersonale Erfahrung als eine Frage des persönlichen Wachstums. Ich darf hinzufügen, dass Transpersonalität überhaupt nur unter dieser Voraussetzung Frieden bedeuten kann. Nichts steht den Frieden mehr im Wege als das Ego. Anders ausgedrückt heißt dies, dass dem Verständnis der Frieden eine gründliche Befassung mit dem Ich und eine Transformation des Ego vorausgehen muss.

Spontane Überschreitungen des Ichbewusstseins hängen hingegen zumeist mit traumatischen oder krisenhaften Erlebnissen zusammen und gehören in den Bereich der Unfrieden. Ein stabiles Ichbewusstsein ist von größter Bedeutung für jede Form der Friedensarbeit und Konflikttransformation. Es muss daher ein primäres Ziel der Curricula entsprechender Ausbildungsprogramme sein.

\section{Ethik und Ästhetik der Friedensforschung}

Nach diesem kurzen Überblick möchte ich ebenso kurz einige Überlegungen zur Ethik und Ästhetik der Frieden als beziehungshaftes Phänomen anstellen. Innerhalb der Ethik von Frieden sind Menschen physische, über ihr Überich verbundene Wesen. Das Individuum bezieht sich hier nicht auf eine Person, sondern auf eine Struktur, ein Gewebe von Beziehungen wie Familien, Klans, Gemeinschaften, Firmen, Verbände, Vereinigungen, Dörfer, Städte, Staaten, die Weltgesellschaft oder etwa auch ein Universitätsprogramm. Diese Struktur leitet Frieden aus sozialer Wahrheit ab. Doch diese Wahrheit ist nicht absolut in einem platonischen oder christlichen Sinne, sondern sie entspricht eher der hinduistischen Vorstellung von Dharma, das in seiner ganzen Größe jenseits der menschlichen Wahrnehmungsmöglichkeit liegt. Mensch kann aus seiner beschränkten irdischen Perspektive stets nur einen kleinen 
Ausschnitt von ihr interpretieren. Die Struktur und ihre Wahrheit sind daher weder festgeschrieben noch teilbar. Ihr beziehungshafter Charakter bedeutet, dass sie ständig oszillieren. Friedensethik anerkennt das und fokussiert auf ungehinderte Transformation. Daher ist eine globale Ethik nur friedlich, wenn sie von letztgültigen Normen gelöst ist, wie das schon die postmoderne Philosophie festgestellt hat. Sobald mensch die Wahrheit dualistisch mit der absoluten Bedeutung von gut und böse, richtig und falsch belegt, verliert sie ihren friedlichen Charakter. Friedensethik verbindet, aber sie bindet nicht.

Auch die Ästhetik der Frieden zielt auf menschliche Beziehungen, aber hier geht es um die energetische Ebene. Sie leitet Frieden aus Harmonie ab. Harmonie ist, wenn die Energie des Lebens ungehindert fließen kann. Daher geht es bei der Ästhetik der Frieden um die Beziehung der Strukturen, die wir Seele, atman oder Es nennen, zueinander und zum All-einen, welches auch Gott, brahman, Existenz, Kosmos oder Universum genannt werden kann. Das ist der dionysische Aspekt des Seins, der unter vielen Namen bekannt wurde - als unio mystica in der jüdischen, christlichen und islamischen Tradition, als satori im Zen, shunyata im Buddhismus oder samadhi im Yoga.

Die Ästhetik der Frieden bezieht sich also auf transzendentale Erfahrung. Sie ist zu einem gewissen Grad metaphysisch, und weil sie energetisch ist, errichtet sie ein individuelles System. Doch das bedeutet keine esoterische Spekulation, denn die Ästhetik der Frieden kann in der physischen Welt als Eigenschaft der oben erwähnten Strukturen wahrgenommen werden. Sie tönt durch das Ego der personae, ob diese das nun zulassen wollen oder nicht, und manifestiert sich in den Eigenschaften ihrer Beziehungen.

Ethik und Ästhetik der Frieden sind also keine ausschließenden oder getrennten Dinge. Frieden sind zugleich ethisch und ästhetisch. Frieden sind gleichzeitig Gegenstand und Eigenschaft von Beziehungen, aber aufgrund der Begrenztheit des Wissens des endlichen Subjekts hängt es vom Erkenntnisinteresse $a b$, ob sie als das eine oder das andere erscheinen, so wie es in der Quantenphysik von der Position des Beobachters abhängt, ob er ein Teilchen oder eine Welle wahrnimmt, obwohl beide nur Aspekte ein und desselben Phänomens sind.

Für die Friedensforschung hat das weitreichende Folgen. Im Grunde müssen auf dieser Basis die in der Geschichte faktisch erfolglosen Ansätze des Realismus wie des Idealismus verworfen werden, da sie auf falschen Annahmen fußen. Weder existieren die auto- 
nomen Subjekte, die ihren Axiomen zugrunde liegen, als solche, noch konstituieren sich Gesellschaften entlang der von ihnen angenommenen Regeln.

Der erkenntnisleitende Antrieb realistischer Zugänge ist die Angst. Böse Erinnerungen oder Erzählungen aktivieren auf der energetischen Ebene Emotionen, welche sich als rationale Überlegungen zu vergegenständlichen trachten. Innerhalb dieses Rahmens mag das auch stimmig sein, doch aus transpersonaler Sicht steht auBer Zweifel, dass Angst als Eigenschaft von Beziehungen den freien Fluss der Lebensenergie blockiert, was eine Vergegenständlichung von Friedensethik unterbindet. Deshalb sind angstgetriebene Theorien oder gar Ideologien weder der Friedensforschung noch der Friedenspraxis dienlich. Sie benötigen sehr viel Resonanz, um transformiert zu werden.

Der Idealismus hingegen speist sich energetisch aus dem Prinzip Hoffnung, das der Ästhetik der Frieden sehr zuträglich ist. Es geht allerdings mit einer Ethik des Wissens und Rechthabens einher, aus dem die Idee eines Sollens resultiert, das als Gegenstand von Beziehungen höchst gewaltträchtige Formen annehmen kann. ${ }^{27}$ Der Hoffende glaubt zu wissen, was getan werden muss, damit die Welt eine bessere würde, und blockiert mit diesem Anspruch just die Ethik der Frieden.

Wenn der Gegenstand, das „Thema“ von zwischenmenschlichen Beziehungen zugleich seine Eigenschaft ist, dann ist die einzige Möglichkeit zur Veränderung der Beziehung der Positionswechsel des Beobachters, sei der nun ein bewusst an dieser Beziehung teilnehmender oder ein vermeintlich passiver. Dass der Positionswechsel eines aktiven Beobachters die Beziehung verändert, versteht sich von selbst. Nur vermeintlich passiv ist in einem geschlossenen System allerdings jeder sich so einschätzende Beobachter deshalb, weil keine Energie verloren geht. Das heißt, verändert der vermeintlich passive Beobachter die Position, so verändert sich nicht nur diese und seine eigene Sichtweise, sondern auch die Beziehung selbst. Zwar ist jede Wahrnehmung des Beobachters nichts als eine Projektion auf seinen eigenen Vorstellungshorizont. Da dieser aber wieder selbst Teil des Gesamtsystems ist, verändert sich durch seine neue Projektion auch das System insgesamt. 
Weniger blumig und mehr praktisch gesprochen heißt das, dass die Analyse eines Konfliktes und eine allfällige Mediation unter transpersonalen Grundannahmen nicht primär auf eine materielle Intervention in die konfliktive Lage gerichtet sein kann, sondern primär auf die Wahrnehmung des Beobachters oder Mediators selbst, der die Konfliktlage dadurch energetisch und gegenständlich beeinflusst.

Genau das ist der Punkt, an dem ein transpersonales Verständnis von Frieden und Konflikttransformation an die Stelle eines modernen oder postmodernen tritt. Beispiele dazu gibt es aus der Kommunikationspsychologie zuhauf. Der Einfluss der Kriegsberichterstattung etwa auf den Verlauf von Kriegen kann kaum überschätzt werden, ${ }^{28}$ und die Geheimdienste aller Welt arbeiten mit diesem Wissen. Nach der transpersonalen Logik ist jedes Wort, jeder Gedanke über einen scheinbar unabhängigen Konflikt Dritter bereits ein Beitrag zu ihm. Der Konflikt anderer kann ebenso herbeigeredet oder herbeigedacht werden, wie er umgekehrt durch Reden oder Denken verhindert werden kann, womit es zu einer wesentlichen Frage der Friedensethik wird, wie wir ästhetisch mit Konflikten umgehen.

Mit der entsprechenden Distanz hat eigentlich jeder Konflikt etwas Lächerliches an sich. Ob es um materielle Interessen geht wie Öl, Gold, Wasser, Weidegründe, Zugang zum Meer, um ideelle wie Ehre, Reinheit von Rasse, Sprache, Religion oder Kultur, um emotionale wie Liebe, Eifersucht oder Hass: Mensch braucht immer nur einen Schritt zurückzutreten und tief durchzuatmen, um die offensichtliche Irrationalität vermeintlich rationaler Argumente für Krieg, Mord und Totschlag auf allen Ebenen zu erkennen. Genau das versucht der transpersonale Ansatz der Friedensforschung, indem er die transformative Kraft einer alternativen Erzählung, Bewertung oder Erinnerung aktiviert.

Ein transpersonaler Ansatz ist freilich immer auch ein transrationaler, denn durch seine ästhetische Komponente durchschreitet er die Beschränktheit eines bloß rationalen Sollens, für das der Idealismus plädiert, oder eines ebenso rationalen Müssens, für das der Realismus steht. Er setzt an deren Stelle ein relationales Können, das nichts als die Beziehung selbst benötigt, um gegenständlich zu wer- 
den. Die Transrationalität leugnet sohin die Rationalität nicht, sie überwindet sie auch nicht, sondern sie durchschreitet und ergänzt sie um die ästhetische Komponente, die zwischenmenschlichen Beziehungen immer innewohnt, die die Moderne aber nicht allzu aufmerksam beobachtet hat. Sie holt auf diese Art ein definitorisches Moment in die Gesellschaftswissenschaften zurück, welches die Aufklärung offensichtlich zurückstellen musste, um die große Einsicht in den Wert der Vernunft durchzuargumentieren. Nachdem das unter den kritischen Augen der Postmoderne vollzogen worden ist, dürfen wir im respektvollen Andenken dieser Leistung und der aus ihr resultierenden Errungenschaften den Menschen wieder mit all unseren Sinnen und all seinen Potenzialen wahrnehmen. Das bedeutet keine Rückkehr zu vormoderner Bigotterie, sondern den Durchbruch zu einer holistischen Transrationalität, welche den Menschen als Gattungswesen untrennbar mit der Natur und dem Kosmos verbunden versteht. Sie begreift, dass Fragen des Friedens oder Unfriedens nichts anderes sind als jene nach eventuellen Störungen im sozialen System Mensch selbst oder in seinem Wechselverhältnis mit der ihn umgebenden Physiosphäre, Biosphäre oder Noosphäre, welche sich auf ethische wie ästhetische Weise äußeren können.

Die Befassung mit diesen Beziehungen und ihren eventuellen Störungen, welche wir als Unfrieden wahrnehmen, ist das definitionsgemäße Aufgabengebiet der Friedensforschung. Da es hier um nicht weniger als um die Existenzfrage der ganzen Spezies geht, steht es auch ihr mehr als jeder anderen Disziplin an, sich auf das bislang wenig beachtete und wenig erforschte Gebiet der systemischen Beziehungen aus einer transrationalen Sicht zu begeben. Und nochmals: Auch ohne materielle Intervention verändert sie das System bereits dadurch, das sie das tut.

\section{Schlüsse aus Innsbrucker Sicht}

Der Innsbrucker Lehrgang für Friedenstudien ist nicht als einer entworfen worden, der sich anmaßt, diesen innovativen Ansatz zur Gänze umzusetzen. Er wurzelt vielmehr in jenen poststrukturalistischen Überlegungen, welche am Beginn der 90er-Jahre des 20. Jahrhunderts mit der idealistischen Tradition der Friedensforschung, vor allem im deutschen Sprachraum, gebrochen haben. Mit der zunehmenden Bedeutung des Kulturbegriffes, dem Übergang vom Strukturalismus zum Poststrukturalismus und seiner Orientierung an den 
Randkulturen erfolgte auch der Übergang von der post-jungianischen Transpersonalität zur Transrationalität. Unser Friedensdenken hat sich nicht nur von der Hermetik des modernen Wahrheitsbegriffs ab- und einer relationalen Deutung sozialer Vorgänge zugewandt, sondern darüber hinaus nach einem Verständnis zu suchen begonnen, welches die Beschränktheit des rationalen Denkens ,,aufhebt". Es bewahrt sie erstens (weil Rationalität eine wichtige Kulturleistung des Menschen als soziales Wesen ist), zweitens neutralisiert es sie (entkleidet sie also ihres aggressiven Wahrheitsaspekts) und hebt sie drittens auf eine höhere Bewusstseinsebene, auf der energetisches Friedensverständnis und Rationalität wieder korrespondieren können.

Wir fanden in Kenneth Boulding, Ken Wilber ${ }^{29}$, Fritjof Capra oder Ervin Laszlo ${ }^{30}$ wichtige Vordenker dieser Richtung. Als Vorlage für unseren Lehrplan diente aber vorerst das sogenannte „HawaiiCurriculum" von Johan Galtung, welches als dynamisch weiterentwickeltes Vorbild für das Innsbrucker Modell unschwer ausgemacht werden kann.

Transrationalität scheint uns weiters für Gesellschaften, welche die Postmoderne durchleiden mussten, zugleich attraktiv und erschreckend. Sie ist attraktiv, weil sie jene Leerstelle füllt, die der „Tod Gottes“ in der Moderne und der Verlust des modernen „Sinns“ in der Postmoderne hinterlassen haben. Sie gestattet erfahrbare Spiritualität und vermittelt soziale Wärme. Zugleich droht sie wie spirituelle Lehren aller Zeiten und Richtungen mit der Entschleierung der Konstruiertheit der Individualität in der manifesten Welt, ohne die Leerstelle, welche „Gott“ und „Sinn“ hinterlassen haben, mit einer neuen Teleologie zu besetzen. Das Individuum wird auf der Suche nach transrationalen Frieden erfahren, dass es bloß ein Dividuum ist.

Daraus ergibt sich, dass in einem transrationalen Rahmen Friedenskonzepte der herkömmlichen Art, seien sie nun idealistisch oder realistisch orientiert, nur eine begrenzte Reichweite haben. Ihre Teleologie verhält sich zur Transrationalität wie ein Faden zum Gewebe. Wo das erkannt wird, schlägt es sich zwangsläufig auch in den Leitfragen der Friedensforschung und den Curricula der Friedens- 
studien nieder. Die zielen dann nicht mehr auf ein mechanistisches, idealistisches und handwerkliches „Frieden-Machen“ ab, ${ }^{31}$ sondern auf einen holistischen Erkenntnisprozess im Einzelnen, der in diesem Sinne eher als Suchender denn als Studierender zu verstehen sein wird. Transrationaler Frieden vertraut auf die transpersonale Wirkung dieses Suchens und Erkennens, so wie ich es zuvor beschrieben habe.

Die entsprechenden Curricula begleiten daher eher die studierend Suchenden auf dem Weg des Erkennens und vermitteln nur ein begrenztes $\mathrm{Ma}$ an kognitivem Wissen, das dafür unerlässlich zu sein scheint. Ein derartiges Curriculum beschreibt somit im eigentlichen Sinne des Wortes einen Weg, es schreibt aber nicht die Erfahrung vor, welche jene machen, die ihn selbst beschreiten. Transrationale Erfahrung mag wohl dann und wann zu einer friedensstiftenden Meisterschaft führen. Meistens aber bleibt sie ein heilsamer und unvollendbarer Versuch, und es ist unwahrscheinlich, dass sie jemanden dazu animiert, emsig von einem Krisenherd zum anderen zu jetten, um die eigene Expertise als Friedenswalterschaft zu verkaufen.

Das mag aus der Sicht des idealistischen Mainstreams unserer Tage wenig spektakulär, ja vielleicht sogar langweilig und enttäuschend klingen. Wo bleibt nun das Heil? Gibt es nicht unendlich viel zu tun auf dieser Welt? Erfordert ihr erbärmlicher Zustand nicht ein rasches und konzertiertes Handeln, wenn wir sie überhaupt noch retten wollen? Können wir es uns angesichts des schreienden Unrechts und der allenthalben beobachtbaren Grausamkeiten denn überhaupt leisten, uns in transrationaler Spiritualität zu ergehen? Ist das moralisch zu rechtfertigen?

Ich meine Nein, moralisch gesehen nicht. Aber könnte es nicht sein, dass uns ebenjene moralischen Tiefencodes die kritische Sicht auf die Rationalität jenes Handelns verstellen, das zu diesem Zustand geführt hat? Erfahrungsgemäß hat Friedensarbeit nicht dort ihren größten Effekt, wo Konflikte augenblicklich mit physischer Gewalt ausgetragen werden, sondern da, wo die materiellen Umstände eine konstruktive Bearbeitung von Tiefenkulturen und Tiefenstrukturen erlauben. Da also, wo eine entsprechende Kommunikationspsychologie hörbar eingesetzt und entsprechende Selbst-Reflexionsprozesse 
angeregt werden können, bevor sich posttraumatische Befindlichkeiten zu neuen Zyklen der Gewalt aufbauen.

Wie Kenneth Boulding ${ }^{32}$ oder Francisco Muñoz ${ }^{33}$ festgestellt haben, ist es ja erstaunlich, wie sehr unsere Aufmerksamkeit stets den gewaltsam misslungenen Akten der Konflikttransformation gilt und nicht der weit überwiegenden Mehrzahl der völlig unspektakulär gelungenen. Sie sind die eigentliche, weil kooperative und nicht kompetitive Erfolgsstory der Spezies Mensch und gehören deshalb gefördert. Menschen, auf der Höhe des Bewusstseins ihres rationalen und energetischen Potenzials, sind die aus ihrem Inneren heraus in die Allgemeinheit wirkenden Schlüsselakteure der transrationalen Frieden. Sie brauchen nicht im Rampenlicht zu stehen, werden selten über Schlachtfelder hetzen oder politische Forderungen stellen, sie retten nicht die Welt und halten sie doch im Gleichgewicht. Transrationale Frieden nicht einfach anzunehmen, sie zu lehren und zu lernen erscheint mir dann sinnvoll, wenn wir das Gefühl haben, dass dieses Gleichgewicht ernsthaft bedroht ist. Da offensichtlich viele Zeitgenossen aus ihrer postmodernen Stimmung heraus ein solches Gefühl beschlichen hat, haben wir uns an der Universität Innsbruck an ein solches Projekt transrationaler Didaktik und Methodik der Friedensstudien gewagt.

Seit der Implementierung dieses Curriculums im Jahr 2001 ist es daher ein Anliegen unserer Arbeit, uns gemeinsam mit unseren Studierenden diesen transrationalen Zugängen anzunähern. Das erfolgt im Rahmen eines überaus spannenden Austauschs, der inzwischen eben nicht mehr nur prägender Charakter ist, sondern auch zentraler Gegenstand dieser Lehrbeziehungen geworden ist.

\section{Literatur}

Assagioli, Roberto (1927): A New Method of Healing. New York: Academic Press.

Bachir Diagne, Souleymane (2007): „Iqbal - Philosophie des Neuseins“, in: polylog 17, 49-60.

Bergson, Henri (1944): Creative Evolution. New York: Random House. 
Boethius (o.J.) „The Consolation of Philosophy“, University of Virginia Library, online unter: http://ccat.sas.upenn.edu/jod/boethius/boetrans.html (Zugriff am 14.5.2007).

Boulding, Kenneth E. (1989): „A Proposal for a Research Program in the History of Peace“, in: Peace \& Change. A Journal of Peace Research 14 (4), 461-469.

Capra, Fritjof (1983): Wendezeit. Bausteine für ein neues Weltbild. BernMünchen-Wien: Scherz.

Dietrich, Wolfgang/Echavarría, Josefina/Koppensteiner, Norbert, Hg. (2006): Schlüsseltexte der Friedensforschung. Wien-Münster: LIT.

Durkheim Emile (1895): Les regles de la methode sociologique. Paris: Alcan.

Dürkheim, Karlfried (1992): Erlebnis und Wandlung. Frankfurt/M.: Suhrkamp.

Fischer, Mark (2005): The Foundations of Karl Rahner. A Paraphrase of the Foundations of Christian Faith with Introduction and Indices. Freiburg/B.: Herder.

Freud, Sigmund (1927): The Ego and the Id. London: Woolf.

Fukuyama, Francis (1992): Das Ende der Geschichte. Wo stehen wir? München: Kindler.

Illich, Ivan (1982): „Der gemeine Frieden“, in: Illich, Ivan: Vom Recht auf Gemeinheit. Reinbeck/H.: Rowohlt, 114-122.

Ingruber, Daniela (2007): der blick als waffe, manipulation von und durch kriegsphotographie. Politikwissenschaftliche Dissertation, Universität Wien.

Jung, Carl Gustav (1971): Die Beqiehung zwischen dem Ich und dem Unbewußten. Freiburg/B.: Herder.

Kant, Immanuel (1974): Die Kritik der reinen Vernunft. Frankfurt/M.: Suhrkamp.

Laszlo, Ervin (1996): The Whispering Pond. Rockport: Element.

Laszlo, Ervin (2005): Science and the Akashic Field. Rochester: Inner Traditions.

Locke, John (1975): An Essay Concerning Human Understanding. Oxford: Clarendon Press.

Lyotard, Jean-Francois (1994): „Die Moderne redigieren“, in: Welsch, Wolfgang, Hg.: Wege aus der Moderne. Schlïsseltexte der Postmoderne-Diskussion. Berlin: Akademie-Verlag, 204-214.

Muñoz, Francisco: „La Paz Imperfecta“, in: Dietrich, Wolfgang/Echavarría, Josefina/Koppensteiner, Norbert, Hg.: Schlüsseltexte der Friedensforschung. Münster-Wien: LIT, 392-434.

Nietzsche, Friedrich (1983): Die Geburt der Tragödie aus dem Geiste der Musik. Salzburg.

Rosenberg, Marshall B. (2003): Nonviolent Communication: A Language of Life. Encinitas: Puddle Dancer Press.

Senghaas, Dieter, Hg. (1997): Frieden machen. Frankfurt/M.: Suhrkamp. 
Swami Veda Bharati (1986): Yoga-Sutras of Patanjali with the Exposition of Vyasa. Honesdale: Himalayan International Institute of Yoga Science and Philosophy.

Tönnies, Ferdinand (2005): Gemeinschaft und Gesellschaft. Darmstadt: Wissenschaftliche Buchgesellschaft.

Walch, Sylvester (2002): Dimensionen der menschlichen Seele. Transpersonale Psychologie und holotropes Atmen. Düsseldorf-Zürich: Walter.

Wallerstein, Immanuel (21989): Der historische Kapitalismus. Berlin-Hamburg: Argument-Verlag.

Welsch, Wolfgang (1994): „Einleitung“, in: Welsch, Wolfgang, Hg.: Wege aus der Moderne. Schlüsseltexte der Postmoderne-Diskussion. Berlin; AkademieVerlag.

Wilber, Ken (1995): Sex, Ecology, Spirituality. Boston: Shambhala. 

Islam und Gewalt

Rüdiger Lohlker ${ }^{*}$

Um die übliche Betrachtungsweise des Verhältnisses von Islam und Gewalt etwas zu verschieben und zu dezentrieren, lassen Sie mich mit einem Zitat aus einer chinesischen Quelle des 10. Jahrhunderts beginnen:

„An jedem siebten Tag sitzt der König [der Araber] hoch oben und spricht zu denen unten und sagt: ,Die, die vom Feind getötet werden, werden in den Himmel oben gebracht; die, die den Feind erschlagen, werden Glück gewinnen.' Deswegen sind sie üblicherweise tapfere Kämpfer." ${ }^{\text {1 }}$

Die Perzeption der arabisch-muslimischen Expansion als gewaltsam und kriegerisch erscheint also nicht als eine europäische Spezialität.

Einer der Begriffe, mit denen ich mich hier beschäftige, ist der „des Islam“. Mit Salman Sayyid können wir sagen, dass die islamische Welt aus einer Gruppe von Kulturen, Gesellschaften, Netzwerken und Geschichten besteht, die zusammengefasst werden eben im

* Rüdiger Lohlker ist seit 2003 am Institut für Orientalistik der Universität Wien Professor für Arabistik und Islamwissenschaften. Er war zuvor an den Universitäten Göttingen und Kiel tätig. Seine Forschungsschwerpunkte liegen u.a. in islamischer Ideengeschichte, islamischem Recht, der Erforschung islamischer sozialer Bewegungen und dem Islam im Internet. Der vorliegende Text basiert auf seiner Schwager-Vorlesung vom 23. November 2006, eine frühere Version ist als Nr. 15 der Innsbrucker Diskussionspapiere zu Weltordnung, Religion und Gewalt erschienen.

1 Hoyland (1997), $250 \mathrm{f}$. 
Begriff des Islam;2 Muslime und Musliminnen werden von anderen und sich selber unter einen einzigen Islam subsumiert. Diese Zuordnung können wir allerdings nicht verstehen ohne die Kämpfe und Anstrengungen, den Islam zu interpretieren, eine bestimmte Art von Beziehungen, Werten und Praktiken anderen gegenüber vorzuziehen, sich das symbolische Kapital (Bourdieu) islamischer Legitimität anzueignen. „Islam“ ist also als master signifier zu verstehen, an den sich Beziehungen, Kooperationen und Konflikte darüber, was sein Wesen ausmacht, knüpfen. Der Islam ist also ein höchst dynamisches Feld von Signifikationsprozessen.

Der zweite Begriff der Gewalt ist ebenfalls diffizil. Für den Moment möchte ich Fragen nach struktureller Gewalt im Galtung'schen Sinne ausschließen und mich auf Gewalt im Sinne physisch gewaltsamen Handelns beschränken. Als mögliche Ursachen individuellen und kollektiven gewaltsamen Handelns können wir aus der ethnologischen Forschung vielleicht folgende benennen:

„1.) Bei der Analyse gewaltsam ausgetragener Konflikte gilt es, gegenstandsbezogen zwischen den Ursachen der Konfliktentstehung und denjenigen Ursachen zu unterscheiden, die die Akteure zur Wahl einer unfriedlichen Austragungsstrategie veranlasst haben." ${ }^{\text {"3 }}$ Hier ist kritisch einzuwenden, dass ein solcher Rational-ChoiceAnsatz die Macht inkorporierten Habitus verkennt.

„2.) Menschen verfügen über ein genetisch zur Disposition gestelltes Aggressionspotential, auf das sie in Konfliktsituationen zur Ausübung von Gewalthandlungen zurückgreifen können; sie müssen es jedoch nicht.

3.) Das Ausmaß des individuellen Aggressionspotentials wird im Sozialisationsprozess kulturspezifisch modelliert, d.h. mit unterdrückenden, geduldeten oder aber geförderten Maßnahmen gelehrt und gelernt. Die diesen jeweiligen Maßnahmen zugrunde liegenden [...] Ursachen sind daher in den kulturspezifischen Überzeugungsbereichen in Form kognitiver Vorbilder oder Modelle verankert.

4.) Als letztendliche [...] Ursache von Aggression wird ihre Funktion zur Sicherung des Überlebens gesehen, sei es im generellen Sinne einer Anpassung an die Erfordernisse der sich ändernden Umweltbedingungen (kulturökologische Perspektive) oder im spe- 
ziellen Sinne einer Maximierung bzw. Optimierung individueller Fitness zur erfolgreichen Reproduktion, d.h. die Verbesserung der genetischen Repräsentanz in der Folgegeneration (soziobiologische Perspektive).“4

Gehen wir von einer kulturellen Modellierung individueller Aggressionspotenziale aus, lässt sich annehmen, dass diese Modellierung in den kulturellen Überzeugungssystemen erfolgt. ${ }^{5}$ Dies führt uns direkt zur Betrachtung des dominanten Überzeugungssystems muslimischer Gesellschaften, eines Ensembles von Phänomenen, das unter dem Begriff des Islam zusammengefasst werden kann. Eine Einschränkung ist noch erforderlich. Die Vielzahl Aggression fördernder sozialer Strukturen muslimischer Gesellschaften in Form von Ehrenökonomien u.a. muss außerhalb unserer Betrachtung bleiben.

Wir könnten bei der Reflexion über das Verhältnis von islamischer Religion/Religiosität und Gewalt ausgehen von der Aussage Jan Assmanns, später modifiziert, über den Monotheismus: „Wenn man die monotheistische Idee retten will, dann muss man sie ihrer inhärenten Gewalttätigkeit entkleiden.“6

Können wir von einer inhärenten Gewalttätigkeit des Islam denn sprechen? Eine einfache Antwort ist zu einfach. Muslime mögen nicht nur im Westen als tatkräftige Kriegsleute erschienen sein auch im Osten war dies der Fall, dies haben wir gesehen. Diese Gewaltsamkeit wird reflektiert im Begriff des Dschihad, der höchst wechselvolle Geschichten hat, die wir nicht annähernd ausschöpfen können. ${ }^{7}$ Allerdings wird eine Reflexion dieses Begriffes uns dem Verständnis unseres Themas näher bringen.

Wenig befriedigend sind einige Versuche, sich dem Problem der Gewaltsamkeit von der Seite zeitgenössischer muslimischer Positionen aus zu stellen. Ich darf auf die Stellungnahme des Münsteraner Islamtheologen Muhammad Kalisch verweisen, der sich im Kern auf eine islamrechtliche Perspektive beschränkt, die die eigentlichen Probleme nur am Rande berührt. ${ }^{8}$ Hier werden weitere Diskussionen notwendig sein. Deutlicher wird die Kairiner Politologin Nadia

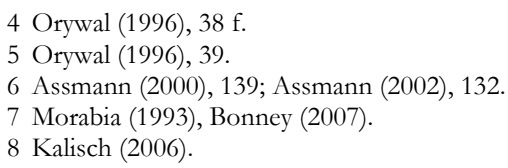


Mahmoud Mostafa, die von der Notwendigkeit der Entwicklung eines neuen fiqh, einer neuen Form islamischen Rechtsdenkens, ausgeht, die die Extreme einer absoluten Befürwortung und einer absoluten Verwerfung von Gewalt vermeidet und eine situationsbedingte Untersuchung der Notwendigkeit des Gebrauches von Gewalt in internationalen Beziehungen ermöglicht, die nicht notwendigerweise gegeben sein muss. ${ }^{9}$ Auch hier wird allerdings grundlegenden Kategorien nicht befriedigend nachgegangen. ${ }^{10}$ Wenden wir uns also diesen Kategorien zu.

\section{Zum Begriff des Dschihad und seinen Geschichten}

Wenn wir auch nicht erwarten dürfen und sollten, dass der Koran die Matrix für das Verständnis der Dinge ist, die als Islam bezeichnet werden, wollen wir doch einen kurzen Blick in die Offenbarungsschrift der muslimischen Gemeinschaften werfen. ${ }^{11}$ Angesichts fundamentalistischer Lesarten muslimischer wie nichtmuslimischer Art erscheint dies mehr als notwendig.

Dschihad finden wir im Koran des Öfteren vertreten, aber nicht in dem Sinne, der ihm heute meist zugeschrieben wird. Wenn wir uns zunächst den Stellen zuwenden, in denen wir tatsächlich den Begriff „Dschihad“ finden, so sehen wir, dass sie sich nicht direkt auf die Kriegsführung beziehen. Sie beziehen sich vielmehr auf Disputationen und den Einsatz für die Sache Gottes (25.52, 22.78). Auf allgemeinerer Ebene finden wir die arabische Wurzel „dsch - h - d“, die ein Wortfeld bezeichnet, das Begriffe wie „Anstrengung“ umfasst, 41-mal, darunter die zwei bereits genannten Stellen. Nur zehn dieser Stellen beziehen sich eindeutig auf Kriegsführung. An allen einschlägigen Stellen ruft der Koran zur Verehrung Gottes, zu rechtem Verhalten und auch zur Selbstaufopferung. Dies kann zweifelsohne den physischen Kampf einschließen, in den meisten Fällen ist allerdings nicht klar, was gemeint ist.

Kampf und Krieg bilden aber auf jeden Fall einen wichtigen Themenkreis im Koran. Derartige Aktivitäten werden mit einem

9 Mostafa (2006).

10 Trotz vieler Versuche fehlt doch eine Geschichte der Genealogie des Begriffes des Dschihad. Zu Techniken der „Entschärfung“ Gewalt fördernder religiöser Texte siehe Scheffler (2006).

11 Die folgende Darstellung schließt an Bonner (2006) an. 
Vokabular beschrieben, das aus anderen Wurzeln stammt als der bereits erwähnten (,dsch $\left.-\mathrm{h}-\mathrm{d}^{\mathrm{d}}\right)$. Die betreffenden Wurzeln bezeichnen Wortfelder wie „Kämpfen, Töten“ oder „Kämpfen, Kriegführen“. Es geht dabei um Aufrufe, die Waffen zu ergreifen, Anweisungen, zu kämpfen oder davon abzustehen, die Aufteilung militärischer Pflichten, die Verteilung der Kriegsbeute, die Behandlung von Nichtkombattanten und Kriegsgefangenen etc. Wir können nicht sagen, dass es sich dabei um eine zusammenhängende Doktrin handelt.

Aus Gründen, die wir heute nicht genau erkennen können, wurde der Begriff „Dschihad“ verknüpft mit einem komplexen, höchst dynamischen System von Lehren und Praktiken der Kriegsführung. Diese Entwicklung dürfte irgendwann in der Zeit zwischen der Offenbarung und der Sammlung des Korans stattgefunden haben. Wichtig ist aber, dass die Vorstellung des Dschihad im Koran nicht hauptsächlich mit der von Krieg und Kampf verknüpft war. Der „innere“, „spirituelle“ Dschihad kann sich also mit gleichem Recht auf den Koran berufen wie sein ,äußeres“, „kriegerisches“ Gegenstück.

\section{Großmut}

Neben diesem Gedankenfeld - und häufig dieses Feld berührend finden wir im Koran einen weiteren Gedankenkomplex, der mit Generosität, mit Großmut und dem Geben von Gaben zu tun hat.

Das Speisen der Armen macht eine Person zu einem „der Gefährten der rechten Hand“ (90, al-balad, 18). Gaben werden aus dem Eigentum des Gebenden genommen, um es zu reinigen (9, at-tauba, 103). Es wird also ein Teil des Eigentums gegeben, um den Rest zu erhalten. Für das Geben, das sich auch auf Kriegsbeute beziehen kann, wird generell eine Richtung vorausgesetzt, die von den Reichen zu den Armen verläuft. Durch das so ausgerichtete Geben wird die muslimische Gemeinschaft konstituiert. Auch die Aufwendung des persönlichen Eigentums zur Unterstützung des Kampfes wird zum Thema.

Damit wird die vorislamische, arabische Vorstellung der Hochschätzung des Gebenden, die wir in der altarabischen Dichtung finden, aus dem Kontext des Lobes und des Nachruhms Einzelner und 
ihrer Familienverbände ${ }^{12}$ transformiert in eine Praxis zum Nutzen einer sich universalisierenden Gemeinschaft.

Ein anderer Komplex von Taten konnte in altarabischen Zeiten gleichfalls den Nachruhm sichern: kriegerische Taten gegen Feinde des eigenen Familienverbandes. Dies wurde in die entstehende frühe islamische Gemeinschaft integriert und jetzt nach außen gewendet gegen die Feinde Gottes und der Gemeinschaft. Der Koran reformuliert auch die Grundlage des Kampfes. Es ist nicht mehr die individuelle Tapferkeit, die Kämpfenden müssen sich nun durch eine fromme Haltung auszeichnen, die ihnen die paradiesische Belohnung sichert.

Die großartigen militärischen Erfolge der frühen muslimischen Gemeinschaften begründeten eine Eroberungsgesellschaft, die die Grundlage für das klassische islamische Steuersystem und die Behandlung von Nichtmuslimen unter muslimischer Herrschaft legte. Allerdings brach dieses expansionistische Reich bald zusammen und mit ihm die Eroberungsgesellschaft, die nur noch als Phantasie, als eine Idee existieren sollte. In der Zeit, als die Anpassung an diese neuen Umstände erfolgte, gegen Ende des 8. Jahrhunderts christlicher Zeitrechnung, entstand auch die Doktrin des Dschihad und die um sie angeordneten Praktiken. Diese Wandlung fand z.B. ihren Ausdruck in Theorien, die die Abrogation von frühen gemäßigten Äußerungen des Korans formulierten. Es wird so von späteren Theoretikern gesagt, dass der "Schwertvers“ (9, at-tauba, 5), der nicht lange vor der Eroberung Mekkas offenbart wurde, bis zu 124 frühere Verse stillgelegt habe. ${ }^{13}$

Der Dschihad wurde zum Teil einer ganzen Reihe von frontier societies, Grenzgesellschaften. Eine dieser Grenzgesellschaften war Syrien, wo der Dschihad eigentlich zum Inhalt der Religion der dort im 7./8. Jahrhundert einfallenden frühen Muslime (und Musliminnen) wurde. ${ }^{14}$ Dies fand seinen Ausdruck in Hadithen, in denen keinerlei Bezug auf den Koran genommen wurde. Mittels dieser Hadithe wurde um den Rang der einzelnen Glaubensvorschriften gestritten, denn die sogenannten „Säulen“ des Islam waren noch nicht endgültig definiert. Ein schönes Beispiel: „Der Dschihad ist Grundpfeiler und höchste Verwirklichung des Islams. “ Dieser Hadith ist

12 Jacob (1897).

13 Ess (2001), 163.

14 Siehe Ess (2001), $163 \mathrm{ff}$. 
eindeutig syrischer Herkunft und stammt aus der ersten Hälfte des 8 . Jahrhunderts. Ein ebenfalls eindeutig syrischer Autor, Ibn al-Mubā$\mathrm{rak}^{15}$, dem die Überlieferung einer Hadithsammlung mit dem Titel Kitäb al-ğihäd zugeschrieben wird, berichtet uns trotz der generellen Tendenz, dem Dschihad den Vorrang einzuräumen, von Traditionen, in denen von der Gleichrangigkeit anderer religiöser Handlungen mit dem Dschihad gesprochen wird. Ein Beispiel: ,[...] wie derjenige, der sich auf dem Wege Gottes bemüht, ist der Fastende $[\ldots]^{\text {“. }} .16$

Im Irak des 8. Jahrhunderts werden solche Überlieferungen mit größerem Aufwand neu gedacht, andere Glaubenspflichten treten hinzu bis hin zu einer Überlieferungsvariante, „derzufolge der Dschihad $\mathrm{na} \mathrm{ch}$ dem Gebet das Wichtigste ist ". ${ }^{17}$ Mekkanische Gelehrte des 8. Jahrhunderts waren noch anderer Meinung, sahen den Dschihad nicht als Pflicht bzw. Notwendigkeit an. Sie sprechen von einem guten, löblichen Handeln, von einem anderen Dschihad ohne Blutvergießen, nämlich dem Hadschdsch der Pilgerfahrt; generell betonten sie die Freiwilligkeit. ${ }^{18}$ Im Maghrib vertreten einige Gelehrte später die Auffassung, der eigentliche Sinn der DschihadVerse sei mit der Eroberung Mekkas erfüllt. ${ }^{19}$

Die medinensische Variante des Dschihad-Verständnisses zeigt ebenfalls eine Variante der Voranstellung des Gebetes in dem Sinne, „daß der Dschihad die beste der Taten nach dem Gebet ist". ${ }^{20}$

Schon dieser kurze historische, philologisch informierte Blick zeigt eine Variationsbreite in der Doktrin des Dschihad, die einer historisch-kritischen Exegese große Möglichkeiten eröffnet und die wir auch in späterer Zeit teilweise berücksichtigt finden. Betrachten wir noch einen anderen Aspekt!

Der Dschihad wurde auch zu einem Teil persönlicher Praxis derjenigen, die sich einer harten Glaubenspraxis unterwarfen ('ubbäd al-hušn): extremem Fasten, dem Verzehren von Staub oder Erde, dem Insistieren darauf, den Lebensunterhalt selbst zu verdienen

15 Er lebte von 716 bis 797; der Dschihad war ihm „Herzensangelegenheit“. Siehe Ess (1992), 552.

16 Ibn al-Mubārak (o.J.), 3.

17 Ess (2001), 165.

18 Ess (2001), 165.

19 Ess (2001), $165 \mathrm{f}$

20 Bredow (1994), 3 (arabischer Text). 
(kasb), dem Ignorieren der Rolle des Kalifen/Imams und der Unabhängigkeit von der muslimischen Gemeinschaft selbst mit dem Ziel, die persönliche vollkommene Reinheit, den individuellen religiösen Verdienst zu sichern. Es blieb die Gehorsamkeit und die Nachahmung des jeweiligen asketischen Meisters, einer der Ursprünge der späteren islamischen Mystik, des Sufismus. Zudem wurden in späterer Zeit Grenzgarnisonen auch zu Orten geistiger Einkehr, verbunden mit sufischen Praktiken. Ergänzen können wir dies mit einer Überlieferung: „Jede Gemeinschaft (umma) hat eine Art des Mönchtums (rabbanniya); das Mönchtum dieser Gemeinschaft ist der Dschihad auf dem Wege Gottes.“21 Das kann zwanglos als eine Befürwortung einer asketischen Grundhaltung verstanden werden, nicht aber unbedingt als Befürwortung militärischen Kampfes.

Während dieser Zeit, aber auch danach blieb der Dschihad eng verbunden mit einem Teil der koranischen Offenbarung, der oft falsch als „Wohltätigkeit“" oder „Almosen“ bezeichnet wird. Wir haben davon schon mit dem Begriff der Großzügigkeit gesprochen. Im Koran und den frühen historiografischen Texten ist das Kämpfen im Krieg Ausdruck der Zugehörigkeit zur muslimischen Gemeinschaft. Im Extremfalle der Charidschiten kann auch der Kampf gegen Muslime mit anderer als der eigenen Ausrichtung dazu zählen. Es ist nichts, wofür man eine Belohnung welcher Art auch immer erhalten würde.

„Bald nach dem Tod des Propheten Muhammad sah sich der siegreiche frühe islamische Staat überflutet mit allen Arten von Reichtümern. Zur selben Zeit mußte er sich mit den weitreichenden Problemen auseinandersetzen, mit denen sich alle großen Reiche auseinandersetzen mußten, einschließlich der Rekrutierung, Bezahlung und Versorgung ihrer Armeen. Während die Umaijaden- und die Abbassidenkalifen verschiedene Lösungen für ihre fiskalen und militärischen Probleme versuchten, bildeten sich langsam die juridischen und theologischen Lehren des entstehenden Islams heraus."22 Sie hatten verschiedene Fragen zu beantworten: „Ist der Militärdienst eine religiöse Pflicht, die jedem Individuum auferlegt ist? Wie kann die zentrale Autorität [...] große Zahlen von Kämpfern rekrutieren und sie mobilisiert halten? Schließlich nahmen diese Fragen 
und Antworten die charakteristischen Formen des klassischen Islams und seiner Dschihad-Lehre an unter Einschluß der Unterscheidung zwischen individuellem und kollektivem Dschihad“, also der Aussage, eine individuelle Verpflichtung zum Dschihad sei nur gegeben, wenn muslimisches Gebiet angegriffen werde, sonst reiche das Bestehen und der Einsatz von Truppen durch den Staat, mit „dem Bestehen auf der religiös korrekten Absicht seitens der Person, die in den Dschihad zieht, dem Bestehen darauf, dass der Imam", also der spirituell-politische Führer, ,oder sein Repräsentant die Oberaufsicht hat, besonders bei offensiver Kriegsführung; aber auch, zur selben Zeit, die geistige Belohnung, die für die Personen bereitsteht, die sich freiwillig für den Kampf melden. All dies war wieder das Ergebnis eines langen Prozesses, dessen zugrunde liegende Spannungen nie vollständig gelöst wurden." ${ }^{\text {23 } 3}$

Bis jetzt ist die Unterscheidung zwischen „,innerem“ und ,äußerem“ Dschihad, dem Kampf gegen die innere Triebseele, dem ,groBen Dschihad“, und dem gegen den äußeren Feind, dem „kleineren Dschihad“, nicht erwähnt worden. Diese Trennung wurde von der modernen westlichen Forschung, durchaus zu Recht, als ein sekundäres Phänomen späterer Zeit beschrieben. Allerdings ist bereits in den frühesten Anfängen der muslimischen Gemeinschaft beides zu finden, der äußere und der innere Kampf. Der in beiden Formen spirituell begriffene Kampf gewinnt im Islam einen deutlich kriegerischen Akzent, aber ein Akzent ist nur ein Akzent.

Historisch sehen wir also immer wieder die Spannung zwischen dem, was Albrecht Noth den „heiligen Krieg“ und den „heiligen Kampf" 24 genannt hat, die spannungsreiche Auseinandersetzung zwischen groß angelegten kriegerischen Operationen von wie auch immer gearteten Staaten und der individuellen Suche nach Verdienst und Gnade, die sich wenig um den Ausgang von Schlachten kümmerte. Diese Spannung finden wir auch in den Formen der militärischen Operationen, die islamische Staaten und Reiche in der Geschichte durchgeführt haben. Von Zeit zu Zeit organisierten sie groBe Eroberungszüge, die zu einer dauernden Erweiterung ihres Herrschaftsraumes führten. Parallel dazu - und vielleicht viel öfter führten diese Reiche auch Beutezüge, Razzien durch, die trotz der 
Hartnäckigkeit der Kämpfenden wenig Ertrag brachten, wenn nicht gar einen Nettoverlust ergaben. Diese Kämpfer konnten auch eine Gefahr für die innere Stabilität islamischer Staatswesen darstellen, die mühsam unter Kontrolle gebracht werden mussten. Ein gutes Beispiel dafür ist das nasridische Granada, das schließlich die unabhängigen nordafrikanischen Glaubenskrieger unter hoheitliche Kontrolle stellte. ${ }^{25}$ Auf dieser praktisch-politischen Ebene wird der Dschihad zu einem Ärgernis, das eigentlich nur in Notzeiten reaktivierbar sein sollte.

Fassen wir zusammen: „Wir können eine angemessenere Interpretation der Lage erreichen, wenn wir anerkennen, dass der Dschihad eine komplexe Doktrin und ein Ensemble von Praktiken ist, die sich - manchmal wörtlich, manchmal in keiner Weise wörtlich - auf Gewalt und Kriegsführung richten. Durch den Dschihad haben zahllose Muslime teilgehabt an einem Gründungsmythos. Dabei haben sie Aktionen sowohl symbolischer als auch praktischer Art durchgeführt. Sie haben an Angriffen und Kriegszügen teilgenommen, die an den nomadischen Lebensstil Altarabiens oder des mittelalterlichen Zentralasiens erinnern [...], sie haben zum Aufbau islamischer Staaten überall in der Welt beigetragen. Sie wurden zu engagierten Gefolgsleuten frommer Heiliger; einige wurden selber zu frommen Heiligen. Mit all diesen Dingen haben sie es erreicht, ihren Wunsch nach Fortsetzung der authentischen Form der islamischen Vergangenheit zu befriedigen, für sie immer das Medina des Propheten.

Zugleich lehren aber das Medina des Propheten und der Koran den Frieden, genauer gesagt: den sozialen Frieden, der durch die Praxis des großzügigen Gebens erreicht wird." ${ }^{26}$ Durch diese Praxis wird Gemeinsamkeit gestiftet, die ihren paradigmatischen Ausdruck in den Riten des Festes des Fastenbrechens am Ende des Fastenmonats Ramadan finden, die den Eintritt in einen neuen Zeitabschnitt markieren, vorgelebt im Fastenmonat, der die Kohärenz der Gemeinschaft in der Familie und darüber hinaus erfahrbar macht und damit potentiell erfahrene Gewalt auslöscht. ${ }^{27}$

Die beiden Elemente Großzügigkeit und Gewalt, Frieden und Krieg, befinden sich so miteinander in einem Spannungsverhältnis, 
das in der Vergangenheit immer wieder ausbalanciert wurde und wieder werden kann.

Nähern wir uns diesem Spannungsverhältnis noch von einer anderen Seite!

\section{Ein sufischer Korankommentar}

Es erscheint inzwischen üblich, die islamische Mystik, den Sufismus, als Gegenpol des militanten Jihadismus zu konstruieren. Lassen wir unbeachtet, dass dies historisch nicht zutreffend ist, können wir einen Blick in sufische Korankommentare werfen, um die Interpretation eines Begriffes wie „Dschihad“ besser zu verstehen. Schauen wir also in einen solchen Kommentar!

Ibn 'Ağiba ${ }^{28}$ schreibt in seinem Kommentar al-Bahr al-madid fi tafsir al-qur'àn al-mağz ${ }^{29}$ zur Sure 2, al-baqara, 35, demjenigen, der den ğibäd gegen die Feinde erfolgreich geführt habe, stehe der Weg bis hin zur Schau Gottes offen. Unter Feinden werden hier Satan, die menschlichen Begierden (hawā) und das Diesseits (dunyaa) verstanden. Im Kommentar zu Vers 62 dieser Sure wird von denjenigen gesprochen, „die es unternehmen, dem din beizustehen und die Scharia der Muslime öffentlich zu vertreten entweder durch die Bekräftigung ihrer Grundsätze oder den Dschihad gegen ihre hartnäckigen Gegner." Im Kommentar zu Vers 190 wird der Dschihad eindeutig in den Zusammenhang des Kampfes gegen militärische Feinde gestellt, Konstantinopel, also Byzanz, wird explizit genannt. Allerdings wird im Kommentar zu eben diesem Vers auch gesagt: „die Frucht der Taten des Herzens [a'mäl al-qulüb] sei berghoch überlegen" den Taten, die mit Körperkraft vollbracht würden, also auch kriegerischen Taten. Zu Sure 2, al-baqara, 216 heißt es, der Dschihad sei den Gläubigen auferlegt. Er sei zwar anstrengend, berge aber großen Verdienst (bair) für die Gläubigen in sich. Auch zu Vers 146 der Sure 3, äl 'imrān, sagt unser Autor, es gehe um den „Dschihad gegen ihre Feinde“, einen Kampf, der, dies zeigt der Kontext, auf dem Schlachtfeld (ma'raka) stattfindet. Im Kommentar zur Sure 9, at-tauba, 25 findet sich eine direkte Ansprache an die Sufis: „Gott hat euch beigestanden, oh Schar der Muriden, im Dschihad gegen eure Triebseelen (nufüs) und

28 Marokkanischer Sufi des 18. Jahrhunderts; zu seiner Biographie siehe Michon (1998), 12 ff.

29 Siehe Ibn 'Ağỉba (o.J.). 
bei der Erleichterung eurer Angelegenheiten“. Bei der Sure 47, muhammad, 4 findet sich die Unterscheidung zwischen großem Dschihad und kleinem Dschihad. Das Ziel des kleinen Dschihad sei die Beendigung des Krieges durch den Islam oder den Frieden, das des großen das Aufgeben der Triebseele (nafs).

Nehmen wir diese Beispiele aus dem Marokko des 18. Jahrhunderts, sehen wir eine Spannung zwischen dem Kampf auf dem Schlachtfeld und dem gegen die Triebseele, der vor dem Hintergrund des physischen Kampfes mit der Waffe stattfinden kann und zugleich dem physischen Kampf gegenüber als höherwertig betrachtet wird.

Ist eine Auflösung dieser zweiten Spannung möglich, die tatsächlich nicht den von Mostafa formulierten Extremen verfällt? Ein möglicher Ansatzpunkt wäre das Konzept der taqiya, häufig als Lizenz zur Lüge gründlich missverstanden. ${ }^{30}$

\section{Das Konzept der taqīya}

Grundsätzlich können wir den Begriff „taqīya“ als einen der Furcht oder Vorsicht verstehen, im weiteren Sinne als „terminus technicus für die entschuldbare Bekenntnisverletzung." ${ }^{31} \mathrm{Zu}$ verstehen ist darunter die Dispensierung der religiösen Vorschriften, wenn äußerer Druck und die Möglichkeit, dass dem Gläubigen Schaden zugefügt wird, dies erzwingen. ${ }^{32}$ Im Sunnitentum wird dieses Prinzip durchaus anerkannt, aber nicht angewandt.

In der schiitischen Strömung des Islam ist das Prinzip der taqiya zur vollen Entfaltung gekommen und hat sich in zahlreichen diesem Prinzip gewidmeten Abhandlungen niedergeschlagen:

„Es ist [...] eine unaufhörliche Klage der unterdrückten Anhänger der Schi'a, daß sie zur takijja gezwungen sind. In einer dem 'Alī zugeschriebenen“ Rede ,wird die Verfolgung der Gläubigen geschildert, wie sie unaufhörlich auf der Flucht sich befinden und wie sie durch die takijja verdunkelt werden. [...] Der innere Kampf, den der durch dies Takijija-Verhalten hervorgerufene falsche Schein dem Gemüt der ehrlichen Gläubigen verursacht, wird dem Religionskrieg gleichgestellt.“ Einer der schiitischen Imame „hat darüber folgende

30 Siehe dazu Lohlker (2007).

31 Goldziher (1906), 216.

32 Strothmann/Djebli (2000), 134. 
Sentenz: ,Der Seufzer des über unsere Unterdrückung Betrübten ist soviel wie die Lobpreisung Gottes, sein Kummer um uns ist Gottesdienst, und das Verbergen seines Geheimnisses ist ğ gihäd ${ }^{k}$. [...] Die takiija steht also zunächst im Dienste des allgemeinen Wohles der unterdrückten Partei und wird nicht durch persönliches Interesse begründet.“"33

Bei den Schiiten ist also taqiya nicht als eine Lizenz zum unbegrenzten Lügen zu verstehen. Das Konzept gründet in der Verfolgung, der sich diese islamische Strömungen ausgesetzt sahen. Wir wollen die zwölferschiitische Position anhand einer zeitgenössischen Abhandlung zum Thema genauer betrachten.

Es handelt sich bei der Schrift, mit der wir uns beschäftigen, um die Abhandlung „Die taqiya im islamische Denken“, die auf einer schiitischen Webpräsenz publiziert wurde, die sich dem Lager um den irakischen religiösen Führer 'Alī as-Sīstānī zurechnet.

Einer der Grundsätze, der für die taqīya von Bedeutung ist und uns genannt wird, ist, dass „der Islam eine Religion der Erleichterung [von Problemen] und des Aufhebens von bedrängenden Umständen ist." Daher sei es demjenigen, der zu unerlaubten Handlungen gezwungen wird und sie verabscheut, erlaubt, von der Scharia verbotene Dinge zu tun. Dies geschehe, um es dem Menschen zu erlauben, ein freies und würdevolles Leben zu führen.

Unter taqīy $a$ sei, so ein führender ältererer schiitischer Religionsgelehrter, das Verbergen des Wahren, das Verhüllen des Glaubens daran zu verstehen, um Schaden abzuwenden. Ein sunnitischer Religionsgelehrter, der in diesem schiitischen Traktat durchaus zitiert werden kann, schreibe, taqiya sei der Schutz seiner selbst vor Strafe ("uqüba), wenn man auch im Inneren das Gegenteil dessen, was man tue oder sage, hege. An diese Definition hielten sich andere Gelehrte. Die Verbindung zwischen taqiya und Widerwillen (ikräh) bestehe nun darin, dass jemand gegen seinen Willen gezwungen sei, etwas zu tun, was der Wahrheit widerspreche. Damit wird eben der Widerwillen so Definitionen, einen anderen zu etwas zu veranlassen, was er nicht billigt, zu einem konstituierenden Element, um überhaupt von taqìya sprechen zu können.

In einem anderen Artikel heißt es summarisch: ,Jemand, der keine taqiya übt, hat keine Religion." 
Betrachten wird das Konzept der taqiya, sehen wir, dass mit diesem Prinzip durchaus gegen die Pflicht zum Dschihad in der Form, in der sie sich in der neuen Dschihad-Theologie ${ }^{34}$ findet, argumentiert werden kann, da hier ein Prinzip entwickelt wird, das den Einsatz für den Glauben in nicht militärischer Form denkbar werden lässt; ja, dies wird geradezu zur Vorbedingung religiöser Identität. Wir sehen also auch hier das Feld zentraler islamischer Begriffe von Auseinandersetzungen - bzw. deren Möglichkeit - durchzogen, die sich nicht in einfache Formeln auflösen lassen.

Erfolgt allerdings keine produktive Auflösung, steht zu befürchten, dass dschihadistische Grundsätze wie der des palästinensischen Dschihad-Theoretikers 'Abdallāh 'Azzām weiter einflußreich bleiben, der sagt, dass alle sunnitischen Rechtsschulen die Auffassung teilen würden, Dschihad sei der Kampf (qitäl) und Hilfe im Kampf (al-'aun fih $\bar{c}) .{ }^{35}$ Dadurch wird seine Interpretation dem möglichen Streit voneinander abweichender Rechtsschulen enthoben und gegen Kritik immunisiert. Im Prinzip sieht 'Azzām zwar die Möglichkeit vor, die von ihm und anderen vertretenen Positionen, die für ihn gleichbedeutend mit „dem Islam“ sind, friedlich zu verbreiten, wenn ihnen kein Hindernis in den Weg gelegt wird. Angesichts der Widerstände, die sich dieser von Gott auferlegten Pflicht seitens der Machthaber, der Reichen u.a. in den Weg stellten, erklärt er, sei es aber eine Notwendigkeit (darūra) zu töten und zu kämpfen. ${ }^{36}$

Die Realisierung theologischer Desiderate wie der Annäherung an die Einsheit Gottes, den taubid, ${ }^{37}$ erfolgt in 'Azzāms Theologie allein durch die praktische, militärische, kämpferische Aktion, durch „die Bekräftigung des taubid auf Erden mit dem Schwert." Sie geschehe, sagt 'Azzām, nicht durch „die Lektüre von Büchern und nicht durch das Studium der Bücher über die Glaubenslehre ['aqida]".38 Es geht also um eine praktische Theologie, die Umsetzung eines „praktischen taubid" (taubid 'amali). ${ }^{39}$ Es gibt, so das Resümee dieser Gedanken, keinen tauhid ohne Schwert. ${ }^{40}$ Und die Gefahr 
ist dann gegeben, um ein Dschihad-Gedicht zu zitieren, wenn „die Jugend $[\ldots] /$ Sie erwacht mit einem Schrei aus langem Schlaf, wiederholt immer wieder:/Gott ist groß und der Dschihad ist unser Pfad/Gott ist unser Helfer gegen jeden Feind“. .11

Die vielfältig sich entwickelnden zeitgenössischen Diskussionen lassen aber auf andere Denkwege hoffen.

Eine solche erneuerte Interpretation zentraler islamischer Glaubenskonzepte wird gewiss nicht den Gedanken des Opfers für den Glauben in Frage stellen, von dem der libanesische Kulturphilosoph Samir Kassir ${ }^{42}$ spricht. Sie wird sich aber bewusst sein, dass eine Rekontextualisierung der heiligen Texte die heute in vielen Religionen so wichtig gewordene ahistorische Lektüre der Schriften aufheben muss. Die Reduktion der heiligen Schriften auf isoliert betrachtete Grundtexte, die durch Buchdruck und elektronische Medien seit geraumer Zeit allgemein zugänglich sind, ist dieser anachronistischen Lektüre gewiss förderlich gewesen. Einwenden lässt sich mit den Worten Angelika Neuwirths:

„Sollte die kanonische Geltung heiliger Schriften aber nicht eher als epistemologischer ,Filter ‘ wirken, der dem Leser zusätzliche Prozesse des Neubedenkens und der Rekontextualisierung abverlangt? Konkret: Ist kanonischen Texten nicht ein besonderer, aus der kultisch-rituellen Praxis hervorgegangener, hermeneutischer Code zu eigen. Der sie vor einer - zu keiner Zeit intendierten - Lektüre im Buchstabensinn bewahrt? "43

Wie in Judentum und Christentum wird im Islam der durchaus Gewalt involvierende Akt des Gründungsgeschehens der Gemeinschaft insbesondere durch die Riten des gemeinsam vollzogenen Mahles nicht aufgehoben, aber entschärft.

„Erzählungen von Gewalt werden [...] durch die Hermeneutik der die Texte rituell und exegetisch mit zusätzlichen Energien aufladenden Liturgien umkodiert. Ein religionswissenschaftlich angemessenes Lesen heiliger Schriften muss dieser ihnen eigenen, von der Tradition gestifteten Vielschichtigkeit Rechnung tragen. Die Kanonizität eines Textes, obwohl sicherlich ein status extra historiam, lässt keine simplistische Deutung zu, sie sperrt sich gegen ihre Un- 
terlegung mit einer zeitlosen und universellen Geltung im politischsozialen Alltag. ."44

Eine Neuaneignung der hermeneutischen Codes der islamischen religiösen Tradition und deren - auch praktische - Rekontextualisierung gegen alle Vereinfachung stehen also an, zu denen reine Textexegese nur einen begrenzten Beitrag leisten kann.

\section{Literatur}

al-Ğibäd țariqunā (o.J.), online unter: http://www.tawhed.ws/r?i=1769 (Zugriff am 11.11.2006).

Assmann, Jan (2000): „Monotheismus und Ikonoklasmus als politische Theologie“" in: Eckhart, Otto, Hg.: Mose, Ägypten und das Alte Testament. Stuttgart: Verlag Katholisches Bibelwerk, 121-139.

Assmann, Jan (2002): „Monotheismus“, in: Jabrbuch Politische Theologie 4, 122132.

'Azzām, 'Abdallāh (1992): Fi 't-tarbiya al-ğihhädìya wa'l-binä'. Band 3. Peshawar.

'Azzām, 'Abdallāh (o.J.): „Fi 'l-ğihād, ādāb wa-ahkām", online unter: http://www.azzambooks.4t.com./Azzambooks/gehad.zip (Zugriff am 4.4.2006).

Bonner, Michael (2006): Jihad in Islamic History. Princeton: Princeton University Press.

Bonney, Richard (2007): Jihäd. From Qur'än to bin Laden. Basingstoke-New York: Palgrave.

Bredow, Mathias von (1994): Der Heilige Krieg (Ğibäd) aus der Sicht der mälikitischen Rechtsscbule. Stuttgart: Steiner.

Ess, Joseph van (1992): Theologie und Gesellschaft im 2. und 3. Jahrbundert Hidschra. Eine Geschichte des religiösen Denkens im frühen Islam. Band 2. Berlin-New York: de Gruyter.

Ess, Joseph van (2001): Der Febltritt des Gelehrten. Die „Pest von Emmaus" und ibre theologischen Nachspiele. Heidelberg: Winter.

Goldziher, Ignaz (1906): „Das Prinizip der takiija im Islam“, in: Zeitschrift der Deutschen Morgenländischen Gesellschaft 60, 213-226.

Hoyland, Robert G. (1997): Seeing Islam as Others Saw It: A Survey and Evaluation of Christian, Jewish and Zoroastrian Writings on Early Islam. Princeton: Darwin Press.

Ibn 'Ağiba (o.J.): „al-Bahr al-madīd fì tafsìr al-qur'ān al-mağîd“, online unter: http:/ /altafsir.net (Zugriff am 31.10.2006).

Ibn al-Mubārak, 'Abdallāh (o.J.): „Kitāb al-ğihād“, online unter: http:// www.tawhed.ws/r?i=1877 (Zugriff am 26.6.2007).

44 Neuwirth (2006), 61. 
Jacob, Georg (21897): Altarabisches Beduinenleben nach den Quellen geschildert. Berlin: Olms.

Kalisch, Muhammad (2006): „Der Monotheismus des Islam und die Problematik von Toleranz und Gewalt", in: Fürst, Alfons, Hg.: Friede auf Erden? Die Weltreligionen zwischen Gewaltverzicht und Gewaltbereitschaft. Freiburg/B.: Herder, 151-165.

Kassir, Samir (2006): Das arabische Unglück. Berlin: Schiler.

Lohlker, Rüdiger (2006a): „Die neue ğihād-Theologie“, in: Wiener Zeitschrift für die Kunde des Morgenlandes 96, 211-240.

Lohlker, Rüdiger (2006b): Islamisches Völkerrecht. Studien am Beispiel Granada. Bremen: Kleio Humanities.

Lohlker, Rüdiger (2007): „Das Prinzip der Taqīya im Islam. Vorwurf der Lüge oder friedliche Bewahrung des Glaubens?", in: Religionen unterwegs $13,4-9$.

Michon, Jean-Louis, Hg. (1998): Ibn 'Ajîba. Deux Traités dur l'Unité de l'Existence. Marrakesch: Al-Quoba Zarqua.

Morabia, Alfred (1993): Le Gihad dans l'Islam médiéval. Paris: Michel.

Mostafa, Nadia Mahmoud (2006): „The Missing Logic in Discourses of Violence and Peace in Islam. The Necessities of a Middle View after the 11th of September 2001“, in: Said, Abdul Aziz/Abu-Nimer, Mohammed/Sharify-Funk, Meena, Hg.: Contemporary Islam. Dynamic, not Static. London: Routledge, 173-188.

Nagel, Tilman (1994): Geschichte der islamischen Theologie. Von Mohammed bis zur Gegenwart. München: Beck.

Neuwirth, Angelika (2006): „Gewalttexte und Versöhnungsliturgien um Judentum, Christentum und Islam“, in: Wulf, Christoph/Poulain, Jacques/Triki, Fathi, Hg.: Europäische und islamisch geprägte Länder im Dialog. Gewalt, Religion und interkulturelle Verständigung. Berlin: Akademie-Verlag, 49-61.

Noth, Albrecht (1966): Heiliger Krieg und heiliger Kampf in Islam und Christentum. Bonn: Röhrscheid.

Orywal, Erwin (1996): Krieg und Frieden in den Wissenschaften, in: Orywal, Erwin/Rao, Aparna/Bollig, Michael, Hg.: Krieg und Kampf. Die Gewalt in unseren Köpfen. Berlin: Reimer, 13-43.

Sayyid, Bobby Salman (22003): A Fundamental Fear. Eurocentrism and the Emergence of Islamism. London: Zed Books.

Scheffler, Thomas (2006): „Messianismus und Gewaltkontrolle. Zur Entschärfung gewaltfördernder religiöser Texte“, in: Wulf, Christoph/ Poulain, Jacques/Triki, Fathi, Hg.: Europäische und islamisch geprägte Länder im Dialog. Gewalt, Religion und interkulturelle Verständigung. Berlin: Akademie-Verlag, 35-47.

Strothmann, Rudolf/Djebli, Moktar (2000): „Taķiyya“, in: Encyclopedia of Islam. Band 10. Leiden: Brill, 134-136. 

Theologie und Volkssouveränität oder Vom Nutzen der

Theologie für die Politik

Mariano Delgado*

\section{Einleitung}

„Aufgabe und Amt des Theologen reichen so weit, daß offenbar kein Gegenstand, keine Untersuchung, kein Gebiet dem Fach und Vorhaben der Theologie fremd ist". ${ }^{1}$ Diese Worte, mit denen Francisco de Vitoria, der Begründer der Schule von Salamanca, zu Weihnachten 1527 seine öffentliche, ,religionspolitologische“ Vorlesung („Relectio“) über die „staatliche Gewalt" einleitete, würden heute im Munde eines Theologen nicht zu Unrecht als unzulässige Anmaßung klingen. Die Welt ist komplizierter geworden, die wissenschaftlichen Disziplinen haben sich seit der Renaissance ausdifferenziert, Philosophie, Geschichte, Politik, Ökonomie und Jurisprudenz von der Theologie emanzipiert. Ich bin dennoch nicht der Meinung derjenigen, die sagen, dass die Theologie bei ihrer eigentlichen Sache, der Rede von Gott Jesu Christi, bleiben soll, ${ }^{2}$ wenn sie sich heute Gehör verschaffen oder ernst genommen werden möchte. Denn was be-

\footnotetext{
* Mariano Delgado ist Professor im Department für Patristik und Kirchengeschichte an der Universität Fribourg (Schweiz) und seit 2003 Präsident der Vereinigung für Schweizerische Kirchengeschichte und Schriftleiter der Zeitschrift für Missionswissenschaft und Religionswissenschaft (ZMR). Zu seinen Forschungsschwerpunkten zählen das Spannungsverhältnis zwischen Theologie und Philosophie sowie das außereuropäische Christentum, zu seinen Publikationen zählt auch eine Werkauswahl von Bartholomé de Las Casas. Der vorliegende Text basiert auf seiner Schwager-Vorlesung vom 10. Oktober 2006 und ist auch als Nr. 11 der Innsbrucker Diskussionspapiere zu Weltordnung, Religion und Gewalt erschienen.

1 Vitoria (1995), 117 (lateinischer Text 116).

2 Kasper (1987), 127.
} 
deutet eigentlich „Rede von Gott Jesu Christi“? Die Fragen von Teil I der Summa Theologiae des Aquinaten, also die strengen dogmatischen Fragen und „Spekulationen“, oder auch die von Teil II, d.h. die Fragen von Gerechtigkeit und Recht in der civitas terrena, also in der Welt und der Gesellschaft, in denen wir jeweils leben und die wir nicht zuletzt von unserem Glauben her mitzugestalten haben? Nun, eines gilt sicher für uns heute wie einst zur Zeit Vitorias oder Thomas' von Aquin: Ernst genommen werden wir als Theologen nur, wenn wir uns zu Fragen von Gerechtigkeit und Recht oder zu „religionspolitologischen“ Fragen mit der dazu nötigen „Sachkompetenz" äußern, nicht mit eitlem und fahrlässigem Dilettantismus. Gewiss, die Theologen aus der Hochscholastik oder aus der spanischen Spätscholastik besaßen diese Sachkompetenz - gilt dies aber auch für uns heute? Ich möchte diese Frage nicht beantworten müssen. Vielmehr möchte ich Ihnen exemplarisch zeigen, wie zwei katholische Theologen, nämlich der Dominikaner Bartolomé de Las Casas (1484-1566) und der Jesuit Francisco Suárez (1548-1617), sich zu einer der wichtigsten religionspolitologischen Fragen der frühen Neuzeit, nämlich zu der Volkssouveränität, äußerten.

Wenn man sich die Lexika-Artikel über Volkssouveränität oder die einschlägige juristische und politologische Fachliteratur anschaut, so wäre man geneigt, einer reivindicatio catholica das Wort zu reden. So wie die Geschichte der Entstehung der Menschenrechte vor allem von der protestantischen Geschichtsschreibung geprägt ist und die Verdienste der Schule von Salamanca oder Bartolomé de Las Casas im 16. Jahrhundert bis vor Kurzem weitgehend ignoriert wurden, hat man in Sachen Volkssouveränität den Eindruck, dass die Geschichte frei nach Hegels Urteil geschrieben wird, wonach die Reformation „die alles verklärende Sonne [...] nach der langen folgenreichen und furchtbaren Nacht des Mittelalters" war. ${ }^{3}$ Von der Volkssouveränität wird nämlich zumeist geschrieben - übrigens auch in katholischen Lexika wie im Staatslexikon der „Görres-Gesellschaft" -, dass es zwar Vorformen moderner Volkssouveränität bei Marsilius von $\mathrm{Pa}-$ dua und den Konziliaristen gab, aber erst mit Althusius und den Monarchomachen „die Gesamtheit aller Bürger als politische Letztinstanz begriffen" wurde. ${ }^{4}$ 
Ich werde zwar nicht so weit gehen, John Locke, Jean-Jacques Rousseau, Immanuel Kant oder gar Jürgen Habermas in Las Casas und Suárez hineinzulesen, ${ }^{5}$ denn diese lebten in einer Übergangszeit, die nicht mehr Mittelalter und noch nicht Neuzeit war, und sind uns daher durchaus fremd. ${ }^{6}$ Aber ich werde zu zeigen versuchen, dass sie so etwas wie einen katholischen Weg zur modernen Theorie der Volkssouveränität eröffnet haben - genauso wie die katholischen Mystiker einige Generationen vor Descartes einen katholischen, theonomen Weg zur modernen Entdeckung des „Ich“ freigemacht haben, der leider verdrängt wurde.

Die Autoren der Renaissance fragten sich, wer das Subjekt der translatio imperii ist und wie sich die Volkssouveränität mit dem biblischen Befund verträgt, wonach es keine Gewalt gibt, die nicht von Gott stammt (Röm 13.1), und alle Könige und Herrscher - also auch die Tyrannen - durch ihn regieren (Spr 8.15). ${ }^{7}$ Wenn man sie liest, so hat man den Eindruck, dass sie mit dieser Frage ringen, ohne die passende Formel klar zu finden. Bedenkt man das nicht, so läuft man Gefahr, scheinbare Widersprüche in ihrem Denken zu vermuten, ${ }^{8}$ wo es sich nur um das zeitbedingte Ringen mit einer Translationstheorie handelt, die sowohl Gott als auch dem Volk, dem göttlichen, dem menschlichen und dem natürlichen Recht gerecht sein will. Erst Suárez, der große Systematiker, wird sich hierzu unmissverständlich ausdrücken, wie wir noch sehen werden.

Ich werde zunächst die Lehren Las Casas' und Suárez' über Volkssouveränität und Zustimmung des Volkes in ihren Schriften programmatischen Charakters (1.) darlegen und in einem zweiten Schritt nach deren Anwendung im Zusammenhang mit der spanischen Expansion in der Neuen Welt (2.) fragen, die, wie mir scheint, die Probe aufs Exempel darstellt, weil es darin nicht um „unsere“ Rechte geht, sondern um die Rechte der ,anderen“. 9

5 So Garzón Valdés (1990), 9.

6 Vgl. dazu Specht (1987), 173.

7 Vgl. Goez (1958).

8 So etwa, wenn manche Autoren eine Spannung zwischen Vitorias Kommentar zur Summa theologiae II-II q.62 a.1 n.21 - vgl. Vitoria (1934), 77-78 - und seiner Vorlesung De potestate civili - siehe Vitoria (1995) - festzustellen meinen, weil an der ersten Stelle die vertragstheoretische Zustimmung des Volkes und an der zweiten eher der Wille Gottes betont werde. Vgl. Deckers (1991), 276-299, besonders 294-296. Darauf hat schon Ulrich Horst hingewiesen. Vgl. Horst (1995), 45, Anmerkung 83.

9 Vgl. dazu Delgado (2001). 


\section{Volkssouveränität und Zustimmung des Volkes bei Bartolomé de Las Casas und Francisco Suárez}

Das Ergebnis meiner Recherchen möchte ich eingangs in einer These festhalten: Für beide Autoren ist die Zustimmung des Volkes bei der Herrschaftsübertragung sehr wichtig. Denn das Volk ist der Träger der Souveränität. Doch während Las Casas auf dem Boden des korporativen Prinzips „Quod omnes tangit“ aus den zivilen und kirchlichen Rechtstraditionen von Spätantike und Mittealter vehement von der Zustimmung aller Betroffenen spricht (,consensus omnium“), favorisiert Suárez die Zustimmung der Mehrheit („consensus maioris partis reipublicae").

\section{Las Casas' Zustimmung aller aus Überzengung}

Ab 1542 wird Las Casas nicht müde, die Zustimmung aller Betroffenen einzuklagen. So in seinem Traktat De regia potestate ${ }^{10}$, der 1571 in Frankfurt am Main posthum erschien, aber um 1554 vor dem unausgesprochenen Hintergrund des encomienda-Problems in SpanischAmerika, als der quasi-feudalen Veräußerung der königlichen Jurisdiktion über die Indios auf die spanischen Eroberer, entstand und als ein grundlegender Traktat politischer Theorie verstanden werden sollte. ${ }^{11} \mathrm{Um}$ die Bedeutung dieses Werkes für die Entwicklung der Theorie der Volkssouveränität zu ermessen, müsste man bedenken, dass Althusius (1563-1638) und die Monarchomachen - Theodor Beza (1519-1605), François Hotman (1524-1590), Jean Boucher (1548-1644) - erst nach der Bartholomäusnacht vom 24. August 1572 und den damit verbundenen Religionskriegen über die Volkssouveränität nachdenken. Auch Les six livres de la République Jean Bodins, die als Meilenstein in der Entwicklung der Theorie des Souveränitätsbegriffs gelten, aber dem Zeitgeist folgend den monarchischen Absolutismus stärken wollen, erscheinen erst 1576.

Die ursprüngliche Freiheit ${ }^{12}$ der Menschen und Völker und die Übertragung ihrer Souveränität auf die Könige in freier und durch einen Herrschaftsvertrag sanktionierter Zustimmung aller Betroffe-

10 Vgl. deutsche Übersetzung des lateinischen Textes mit spanischer Übersetzung in: Las Casas (1988-1998). Band 12, 12-223. Deutsche Übersetzung in: Las Casas (1994-1997). Band 3/2, 187-248.

11 Zur politischen Theorie Las Casas' vgl. Delgado (2001), Delgado (1997), Eggensperger (2000), Pérez Luño (1990) und Pérez Luño (1994).

12 Las Casas (1994-1997). Band 3/2, 197. 
nen sind der cantus firmus dieses Traktats. Wie für die abendländischen Rechtstraditionen ist die Freiheit für Las Casas „kostbarer und unschätzbarer als alle anderen Güter, die ein freies Volk haben kann“,13 sie kann „zu keiner Zeit verjähren“ ${ }^{14}$ und sie ist immer zu vermuten, sodass im Zweifelsfalle zugunsten der Freiheit zu entscheiden sei: ,,in dubio pro libertate“; 15 gestandene Männer geben sie nur mit dem letzten Atemzuge auf. ${ }^{16}$ „Für die Freiheit und für die Ehre darf und muß man das Leben wagen“ - wird später Don Quijote zu Sancho sagen. ${ }^{17}$ Demgegenüber ist die Sklaverei für Las Casas ,akzidentiell, Menschen zufällig und schicksalhaft aufgebür$\operatorname{det}$ " ${ }^{18}$ Sie kann nicht vermutet werden, ,es sei denn, daß derjenige, der es behauptet, den Beweis erbringt", und zu deren Verjährung genügt „die bloße Nachlässigkeit der Nichtbeanspruchung“. ${ }^{19}$

Das Volk ist für Las Casas „erste Quelle und Ursprung aller Gewalten und Jurisdiktionen“, daher auch „Wirkursache der Köni-

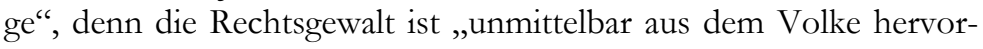
gegangen". ${ }^{20}$ Ausdrücklich bezieht sich Las Casas in diesem Zusammenhang auf die antike demokratische Tradition der translatio imperii a populo in principem, wenn er sagt: ,[D]as römische Volk übertrug dem Fürsten die ganze Gewalt.،"21

Aber obwohl die zitierte Translationsformel von der ganzen Gewalt spricht, versteht sie Las Casas mit gesundem Menschenverstand nicht als Blankoscheck zur absolutistischen Machtausübung. Denn bei der Wahl wurde zugleich ein Herrschaftsvertrag abgeschlossen und ausdrücklich festgehalten, etwa mit welchen Tributen und Abgaben das Volk freiwillig übereinstimmte. Außerdem verzichtete das Volk mit Königswahl und Herrschaftsvertrag auf seine Freiheit nicht, es unterwarf sich nämlich nicht dem Herrscher, ,,sondern dem Gesetz“, dem Herrschaftsvertrag, dem auch der König als Ver-

13 Las Casas (1994-1997). Band 3/2, 213.

14 Las Casas (1994-1997). Band 3/2, 200.

15 Las Casas (1994-1997). Band 3/2, 198 mit Bezug auf die Rechtsregel „Quotiens dubia“ aus den Digesta. Vgl. auch Las Casas' Traktat über die Indiosklaverei, in: Las Casas (19941997). Band 3/1, 59-114.

16 Las Casas (1994-1997). Band 3/2, 198.

17 Cervantes Saavedra (1979), 1203 (Quijote, Zweiter Teil, Kap. 58).

18 Las Casas (1994-1997). Band 3/2, 197.

19 Las Casas (1994-1997). Band 3/2, $199 \mathrm{f}$

20 Las Casas (1994-1997). Band 3/2, 218.

21 Las Casas (1994-1997). Band 3/2, 205, lateinischer Text: „Et populus romanus omnem potestatem in principem transtulit." 
walter (,administrator“) des Gemeinwesens und „Diener des Gesetzes“ („minister legis“) zu gehorchen hatte. ${ }^{22}$ Will der König also über das im Herrschaftsvertrag Vereinbarte hinaus - etwa durch Veräußerung der Jurisdiktion, durch die Einführung von neuen Tributen oder einer neuen minderwertigeren Geldwährung - die Freiheit des Volkes beeinträchtigen, so muss er immer wieder die freiwillige Zustimmung aller Betroffenen einholen. Dieses immerwährende Zustimmungsprinzip im Herrschaftsvertrag ausdrücklich festzuhalten, sei nicht nötig gewesen, denn, so Las Casas mit dem Gesetz „Blanditus“ aus dem Codex, „was implizit dazu gehört, obgleich es nicht ausdrücklich und deutlich gesagt wurde, ändert nichts und fügt nichts hinzu". ${ }^{3}$ Und mit einem weiteren Gesetz aus dem Codex, das er allerdings eigenmächtig interpretiert, untermauert Las Casas die Notwendigkeit der Zustimmung aller, wenn der Herrscher die Freiheit des Volkes beeinträchtigen möchte: „Was allen nutzen soll, ist mit der Zustimmung aller zu tun“, heißt es im Gesetz "Quicumque“. Las Casas formuliert es nun so: „Was allen nutzen soll, aber auch schaden kann, ist mit der Zustimmung aller zu tun““.24 Wenn der König in Angelegenheiten, die allen nutzen oder schaden können, gegen die Zustimmung und den freien Willen bzw. mit „erzwungener $\mathrm{Zu}-$ stimmung" seiner Untertanen handelt, so handelt er gegen das $\mathrm{Na}$ turrecht und gegen das göttliche Recht. ${ }^{25}$ So ist das Einholen der Zustimmung aller Betroffenen für Las Casas eine immerwährende Bedingung für eine gute Regierung.

Um diese Grundprinzipien seiner politischen Theorie zu begründen, akkumuliert Las Casas vor allem Belege aus beiden Rechten und den einschlägigen Kommentaren der Legisten und Kanonisten. Er muss sie aber oft gegen den Strich bürsten, um sie in seinem Sinne interpretieren zu können. ${ }^{26}$ Können wir ihm ein solches Verfahren als unakademisch oder ,ekklektisch“ vorwerfen, wenn sich selbst die renommiertesten spanischen Naturrechtler - jedenfalls vor Ende des Konzils von Trient und der methodischen Erneuerung der ka-

22 Las Casas (1994-1997). Band 3/2, 213.

23 Las Casas (1994-1997). Band 3/2, 206; vgl. Codex 8, 30 (31), 12, in: Corpus Iuris Civilis (1967), 352.

24 Las Casas (1994-1997). Band 3/2, 206; vgl. Codex 11, 59, 7 \$2, in: Corpus Iuris Civilis (1967), 446.

25 Las Casas (1994-1997). Band 3/2, $213 \mathrm{f}$.

26 Vgl. Brieskorn (1996). 
tholischen Theologie durch Melchor Canos De loci theologici27 - durch einen „Quellensynkretismus“ auszeichnen? Das Ziel seines Kampfes ist klar und edel: Las Casas will verhindern, dass die unveräußerlichen Rechte der (indianischen) Völker (Freiheit, Zustimmung, Volkssouveränität) durch eine rücksichtslose imperiale Machtpolitik verletzt werden. Und um dies zu untermauern, klammert er sich an jeden Beleg, den er nur finden kann. Er wollte im Schatten des keimenden Absolutismus mehr Selbstbestimmung begründen, als die abendländischen Rechtstraditionen zugelassen hatten.

\section{Suárez' Absolutismus von des Volkes Gnaden}

Von Suárez wollen wir nun das dritte Buch aus De legibus ${ }^{28}$ untersuchen, eine solide akademische Studie, die nach vielen Vorlesungen und Disputationen zwischen 1607 und 1612 für den Druck überarbeitet wurde, und das dritte Buch aus Defensio fide ${ }^{29}$, eine zwischen 1610 und 1613 in päpstlichem Auftrag - jedenfalls im Auftrag des päpstlichen Nuntius in Spanien und des Ordensgenerals der Jesuiten - verfasste theologisch-politische Apologie der indirekten Gewalt des Papstes im Zeitlichen als Antwort auf die in zeitlicher wie in geistlicher Hinsicht absolutistischen Ansprüche Jakobs I. von England. ${ }^{30}$ In der ersten Schrift begegnet uns die politische Theorie von Suárez in reiner Form, in der zweiten erfährt sie einige Präzisierungen angesichts der englischen Situation. Wir wollen nun konkret seine Translationslehre darstellen, die bei ihm in dankenswerter Klarheit erscheint.

Die Menschen sind von Natur aus frei; wenn eine Menge („multitudo") von ihnen sich durch einen besonderen Willensentschluss oder eine allgemeine Zustimmung (,speciali voluntate seu communi consensu") zusammenschließt, um politisch zu leben, entsteht das Gemeinwesen als Träger der politischen Gewalt. Diese fällt aber dem Gemeinwesen aufgrund der Natur der Dinge und aus der Vorsehung des Schöpfers heraus („ex natura rei et ex providentia auctoris naturae") zu, kommt also in diesem Sinne von Gott, bleibt

27 Cano (1563).

28 Suárez (1975), Kapitel 2-4, 15, 19.

29 Suárez, (1965b), Kapitel 2-3.

30 Zur politischen Theorie Suárez’ vgl. Suárez (1975), Suárez (1977), deutsche Übersetzung: Suárez (2002), Suárez (1965b), Suárez (1978), Suárez (1965a), Elorduy (1965), Pereña (1977a), Pereña (1977b), Abril (1979), Soder (1973) Rommen (1926). 
vermittelbar aber durch den freien Zusammenschluss der Menschen im Gemeinwesen. Diese Gewalt kann das Gemeinwesen kraft Zustimmung (,ex consensu communitatis“, „per consensum communitatis"), aber auch kraft einer anderen legitimen Form ${ }^{31}$ an andere Träger, etwa an Könige, übertragen ${ }^{32}$. So kommt die Gewalt formell gesprochen („formaliter") von Gott, aber die Übertragung an einen konkreten Menschen entspringt der Zustimmung des Gemeinwesens und ist daher menschlichen Rechts.

Mit anderen Worten: Gott verleiht den Königen diese Gewalt mittelbar: erstens weil er sie zuerst unmittelbar dem Volk verleiht, das sie seinerseits an den König überträgt; zweitens weil Gott als erste und universale Ursache zustimmend auch an dieser Übertragung beteiligt ist, die das Volk direkt vornimmt; und schließlich weil er sie approbiert und will, dass sie respektiert wird. ${ }^{33}$ Daher kann Suárez apodiktisch sagen: „Die politische Gewalt, sofern sie auf einen Menschen oder Fürsten legitimer- und ordentlicherweise übertragen wurde, ist immer direkt oder indirekt dem Volk oder der Gemeinschaft entsprungen - und es kann gar nicht anders sein, wenn es ge-

31 Suárez denkt in De Legibus III 4.2-4 - siehe Suárez (1975), 40 ff. - an direkte Einsetzung durch Gott, wie etwa bei Saul und David, was ein außerordentlicher und übernatürlicher Vorgang war (in Defensio fidei III 3.7-8 sagt er allerdings unter dem Einfluss Bellarmins, dass Saul und David nach der göttlichen Einsetzung die Zustimmung des Volkes brauchten und einholten; siehe Suárez [1965b], 38 f.); an die Erbfolge, die nur galt, wenn der erste in der Reihe die Gewalt legitimerweise übertragen bekam; an ungerechte Kriege, die mit der Zeit durch die eventuelle Zustimmung des Volkes eine Herrschaft legitimieren konnten; und schließlich auch an gerechte Kriege, wobei das Volk dann gezwungen war, der neuen Herrschaft zuzustimmen. In Defensio fidei III 2.19-20 werden nur die freiwillige Zustimmung des Volkes (eine langsam mit dem Volkswerdungsprozess wachsende, wie in den patriarchalischen Anfängen des Volkes, oder eine, die sich in der freien Königswahl durch die bereits mit allen Rechten bestehende politische Gemeinschaft ausdrückt, ein für alle Mal geschieht und durch die Herrschaftsfolge implizit weitergegeben wird, diese wäre dann die vernünftigste Form der Zustimmung) und das Kriegsrecht (durch einen gerechten Krieg oder, wie es öfter geschehe, durch einen ungerechten, der aber im Verlauf der Zeit durch die Zustimmung des Volkes legitimiert wird) als Wege zur Herrschaftserlangung genannt. Siehe Suárez (1965b), 31 f.

32 Suárez (1975), 22 (2.3), 32 f. (3.6), 33 (3.7), 39 f. (4.2); Suárez (1965b), 27 (2.13).

33 Suárez (1965b), 27 (2.13): „Mediate autem dicitur Deus dare hanc potestatem regibus, tum quia immediate dedit illam populo, qui in regem illam transtulit; tum quia Deus huic etiam translationi, proxime a populo factae, consentit et cooperatur, tanquam prima et universalis causa; tum denique quia illam approbat et servari vult." Vgl. auch u.a. Suárez (1965b), 28 (2.14): „Deus est qui distribuit regna et principatus politicos, sed per homines seu consensus populorum, vel aliam similem institutionem humanam“. 
recht zugehen soll“. 34 Die Formel „Populus in principem transtulit potestatem", 35 die uns schon bei Las Casas gar mit der Bemerkung begegnete, das Volk sei „Wirkursache“ der Könige, wird von Suárez in den genannten zwei Schriften bis zur Sattheit dekliniert, u.a. auch in Auseinandersetzung mit Francisco de Vitoria, dessen begriffliche Ungenauigkeiten erst hier die nötige Präzisierung erfahren. ${ }^{36}$

Welche Art von Zustimmung des Volkes für eine legitime Herrschaftsübertragung nötig ist, sagt uns Suárez allerdings nicht. Wir können annehmen, dass er eine qualifizierte Mehrheit für ausreichend hält, denn so versteht er die allgemeine Zustimmung im Falle der kollegial-parlamentarischen, nicht monarchischen Regierungsform, wenn er von der Rechtmäßigkeit von Gesetzen spricht. Mit Codex und Digestum sagt er, allgemeine Zustimmung (,unus consensus") sei schon gegeben, wenn zumindest zwei Drittel der Stimmberechtigten anwesend seien und die Mehrheit für ein bestimmtes Gesetz stimme. ${ }^{37}$ Im Falle einer Monarchie genüge aber der Wille des Herrschers für die Rechtmäßigkeit von Gesetzen. ${ }^{38}$ Dies hängt damit zusammen, dass für Suárez die Herrschaftsübertragung an einen König im Prinzip eine absolute ist.

Suárez verweist auf Augustins Rede von einem allgemeinen Vertrag (,„pactum“) am Ursprung der Monarchie;39 auch interpretiert er Ulpianus' Sicht der Lex regia, wonach das Volk seine ganze Gewalt

34 Suárez (1977), 39 (4.2): „[S]equitur ex dictis potestatem civilem, quoties in uno homine vel principe reperitur, legitimo ac ordinario iure a populo et communitate manasse vel proxime vel remote, nec posse aliter haberi, ut iusta sit“. In Defensio fidei III wird diese Denkform im Zusammenhang mit den absolutistischen Ansprüchen Jakobs I. wiederholt: „Nullum regem vel monarcham habere vel habuisse (secundum ordinariam legem) immediate a Deo vel ex divina institutione, politicum principatum, sed mediante humana voluntate et institutione. "Suárez (1965b), 22 (2.10).

35 Suárez (1965b), 26 (2.13).

36 Suárez setzt sich mehrfach mit Vitorias De potestate civili auseinander. Siehe Vitoria (1995). Las Casas wird freilich von Suárez kein einziges Mal erwähnt - sei es aus Unkenntnis, aus akademischer Geringschätzung oder aus realpolitischer Vorsicht, weil Las Casas zu dieser Zeit bereits den Ruf hatte, mit seiner scharfen Kritik an der spanischen Eroberung und Evangelisation der Neuen Welt den Gegnern der spanischen Monarchie Munition geliefert zu haben. Andere zeitgenössische spanische Gelehrte, besonders aus dem Dominikanerorden, werden sich hingegen nicht scheuen, den Bischof von Chiapa als auctoritas zu zitieren.

37 Suárez (1977), 219 (15.4): „Non vero oportet ut omnes consentiant, sed quod maior pars curiae fecerit, perinde habetur ac si ab omnibus factum fuisset (iuxta legem Quod maior, ff. Ad municipalem)".

38 Suárez (1977), 219 (15.4): „,[V]oluntas principis sufficit“.

39 Suárez (1965b), 26 (2.11). 
(,omne suum imperium et potestatem transtulerit“) übertrug, dahin gehend, dass das Volk dem Fürsten zugleich implizit aufbürdete, gut zu regieren und Gerechtigkeit zu üben; der Fürst konnte also die Herrschaftsübertragung nur unter solchen Bedingungen annehmen. ${ }^{40}$ In diesem Vertrag sieht er einen weiteren Beleg dafür, dass die monarchische Institution selbst von den Menschen stammt, denn die ihr übertragene Gewalt kann kleiner oder größer sein, je nachdem wie der Vertrag oder die Vereinbarung ist, die zwischen dem Königreich und dem König geschlossen wurde. ${ }^{41}$ Wird darin aber keine ausdrückliche Einschränkung der übertragenen Gewalt festgehalten oder liegt ein solcher Herrschaftsvertrag gar nicht vor, so ist davon auszugehen, dass der König, wie in den absoluten Monarchien, die Gewalt absoluterweise übertragen bekommen hat, abgesehen von der genannten impliziten Verpflichtung zur guten Regierung und Gerechtigkeit: „Das Volk hat ihm dann die Gewalt absoluterweise und bedingungslos übertragen, wie aus der Regierungsweise solcher Könige hervorgeht, und man kann etwas anderes nicht wahrhaftig behaupten, wenn es aus der Gewohnheit nicht hervorgeht. “42

Aus dem Gesagten sind die zwei größten Unterschiede zwischen Suárez und Las Casas deutlich zu ersehen. Erstens spricht Suárez nirgendwo von der Notwendigkeit einer Zustimmung ,aller Betroffenen" beim Zustandekommen des Herrschaftsvertrags, sondern nur von einer nicht näher definierten Zustimmung des Gemeinwesens, die der - leicht instrumentalisierbaren - „vox populi“ gleichkommt. Und zweitens interpretiert Suárez den Herrschaftsvertrag im Zweifelsfalle als eine absolute Abdankung der Freiheit oder Jurisdiktionsveräußerung des Volkes zugunsten des Königs: „Daher ist die Übertragung dieser Gewalt durch das Volk an den Fürsten keine Delegation, sondern quasi eine Veräußerung oder

40 Suárez (1965b), 26 (2.12): „Ergo intelligi debet constitua per modu pacti, quo populus in principem transtulit potestatem sub onere et obligatione gerendi curam reipublicae et iustitiam administrandi, et princeps tam potestatem quam conditionem acceptavit."

41 Suárez (1975), 43 (4.5): „Cuius etiam signum est quia iuxta pactum vel conventionem factam inter regnum et regem, eius potestas maior vel minor existit. Ergo est ab hominibus, simpliciter locuendo." Vgl. auch Suárez (1965b), 43 (3.13).

42 Suárez (1977), 43 (19.6): „Nam in illum transtulit populus suam potestatem absolute et simpliciter, ut ex ordinario modo regiminis constat, nec aliud verisimiliter affirmari potest nisi ubi ex consuetudine constiterit." 
vollkommene Übertragung der ganzen Gewalt, die die Gemeinschaft besaß“. 43

Dies erklärt, dass für Suárez die Veräußerung der Jurisdiktion durch den König (der Kern des encomienda-Problems im spanischen Weltreich) legitim ist, aber auch, dass das Gesetz allein vom Willen des Königs abhängig ist und der Zustimmung des Volkes nicht mehr bedarf. ${ }^{44}$ Mag Suárez gegenüber dem absolutistischen Jakob I. von Gottes Gnaden immer wieder betonen, dass keine Königswürde direkt von Gott eingesetzt wird, sondern unmittelbar dem menschlichen Willen entspringt, ${ }^{45}$ seine Theorie liegt dennoch im Trend der Zeit und öffnet einem „Absolutismus von des Volkes Gnaden“ Tür und Tor - freilich ein wenig eingeschränkt durch die bereits genannte implizite Pflicht zur guten Regierung, zur Gerechtigkeit und zur Förderung des allgemeinen Wohls ${ }^{46}$ durch die päpstliche, indirekte Gewalt im Zeitlichen und schließlich durch ein Widerstandsrecht, das zwar spekulativ bejaht wird, aber kaum jemals in Wirklichkeit eintreten dürfte, da es - wohl vor dem Hintergrund der heiklen Lage der Katholiken in England unter Jakob I. - von vielerlei Umständen und einer so gut wie nie endenden Unterscheidung der Geister abhängig ist und bei den Katholiken zudem vom Willen des Papstes. ${ }^{47}$

43 Suárez (1975), 49 (4,11): „Quocirca translatio huius potestatis a republica in principem non est delegatio, sed quasi alienatio seu perfecta largitio totius potestatis quae erat in communitate."

44 Vgl. Suárez (1977), 44 (19.7).

45 Suárez (1965b), 22 f. (2.10): „[N]ullum regem vel monarcham habere vel habuisse (secundum ordinariam legem) immediate a Deo vel ex divina institutione, politicum principatum, sed mediante humana voluntate et institutione."

46 Vgl. Suárez (1965b), 34 ff. (3.1-4), wo Suárez Bellarmins Lehre, wonach das Volk nach der Herrschaftsübertragung die Gewalt ,in habitu“ behalte, in diesem Sinne einschränkt.

47 Suárez (1978), 88 (4.17): „Immo addendum ulterius, licet respublica seu regnum hominum, ex sola rei natura spectatum, prout fuit inter gentiles et nunc est inter ethnicos, habeat potestatem, quam disimus, se defendendi a tyranno rege et illum deponendi in eum finem, si necessarium fuerit, nihilominus regna christiana quo ad hoc habere aliquam dependentiam et subordinationem ad Pontificem Summum." Zum Widerstandsrecht und Tyrannenmord bei Suárez vgl. den gut dokumentierten Beitrag von Brieskorn (1990). Dieser kommt zum folgenden freundlichen Urteil: „Während Thomas von Aquin im 6. Kapitel des 1. Buches von De Regimine principum nach einer Reihe von Differenzierungen bald auf die sittliche Pflicht zu sprechen kommt, die Tyrannei zu ertragen, fällt dieses Wort nicht bei Suárez, noch behandelt er so sein Thema. Er erlegt sich und anderen die schwierige Aufgabe der Unterscheidung und des Abwägens auf. Nicht das Annehmen von Zuständen, sondern die ,Unterscheidung der Geister', also eine Methode, ist beherrschend geworden. Ohne ihr zu folgen und nach ihr die Handlungsschritte zu bestimmen, ist mündiges, reifes, menschliches Leben nicht möglich. Das Zitat aus dem Buch der Sprichwörter ,durch mich regieren die Tyrannen` (Spr 8.15) benutzte Suárez nicht zur Begrün- 


\section{Die Anwendung dieser politischen Theorien im Zusammenhang mit der spanischen Expansion oder Die Probe aufs Exempel}

Der gewonnene Eindruck, dass von beiden Autoren Las Casas mit dem Absolutismus am wenigsten und mit der Selbstbestimmung der Völker am meisten anfangen kann, bestätigt sich, wenn wir die Probe aufs Exempel betrachten, nämlich die Anwendung dieser politischen Theorie im Schatten der spanischen Expansion.

\section{Las Casas und die koloniale Frage}

Las Casas konnte eine profunde Kenntnis der Kolonialpraxis für sich reklamieren. ${ }^{48}$ Wenn etwas sein Denken kennzeichnet, so ist dies vor allem das für seine Zeit einmalige Bewusstsein der Notwendigkeit eines reziproken oder interkulturellen Rechtsdiskurses, d.h., die Rechte, die wir für uns beanspruchen, müssen wir auch den anderen zubilligen. Daher lässt seine politische Theorie im Zusammenhang mit der spanischen Expansion vor und nach der Taufe der Indianer letztlich nur diese zwei Grundprinzipien gelten, wenn die Herrschaftsübertragung oder translatio imperii nach dem göttlichen Recht und dem Naturrecht geschehen soll: die freiwillige Zustim-

dung der Passivität und auch nicht, um darauf hinzuweisen, daß Gott wie in allen Dingen, eben auch in der Tyrannei gefunden werden könne und dürfe. Alle Betonung ist auf die Pflicht des Menschen gelegt, sein Gewissen zu informieren, sich an den Maßstäben des ,bonum universalius', der ,Unio' und der, Veritas' auszurichten und diese Werte mit denen der ,Securitas' und der Vermeidung von ,Perturbatio' zu vermitteln. Bereits in der Entscheidungsfindung selbst, nicht erst im Annehmen oder Ablehnen enes Zustandes wird Gott gefunden." Brieskorn (1990), 339. Wie schwierig es letztlich ist, nach Suárez' Unterscheidung der Geister wirklich zum aktiven Widerstand gegen die Tyrannei zu gelangen, belegt meines Erachtens die Haltung der deutschen Katholiken (nicht zuletzt der zum Widerstand neigenden Jesuiten) in Hitlers Drittem Reich. Vgl. dazu Elorduy (1965), XVI.

$48 \mathrm{Im}$ Brief des Jahres 1564 an die Ordensmitbrüder in seinem alten Bistum Chiapa, die seine strenge Sicht des encomienda-Problems nicht teilten, wonach diese koloniale Institution als „intrinsice malum" zu betrachten sei, schreibt der alte Las Casas nicht ohne eine gewisse Enttäuschung: „Es sind [...], meine Patres, einundsechzig Jahre vergangen, seit ich diese Tyranneien beginnen und wachsen sah, und sie haben zugenommen bis auf den Tag. Und ich weiß, dass sie heute noch in ganz Westindien begangen werden, es steht mir hier aufgrund der zahlreichen ständigen Briefe, Berichte und Klagen, die ich hier von vielen Tag für Tag aus diesen Gegenden erhalte (wenn auch nicht aus dieser Provinz, in der sich die encomenderos offenbar wie Heilige benehmen müssen), gegenwärtig vor Augen. So verfüge ich mehr als irgendwer sonst über Kenntnis und Wissen bezüglich der Praxis, und es sind achtundvierzig Jahre, in denen ich schon untersuche und erforsche, um das Recht klar zu beweisen. Wenn ich mich nicht täusche, so halte ich dafür, diese Materie vertieft zu haben und an ihren Grund vorgedrungen zu sein." Las Casas (1994-1997). Band 3/1, 500. 
mung aller Betroffenen und den von beiden Teilen beeideten Herrschaftsvertrag. ${ }^{49}$ In den Traktaten Über die Schätze Perus und Über die zwölf peruanischen Zweifelsfälle, die 1561/1564 entstanden sind und die er sein „Testament“ und sein „Kodizill“ nannte, ${ }^{50}$ werden diese Prinzipien klar begründet.

Die freiwillige Zustimmung ist für Las Casas die wichtigste Wirkursache und der hauptsächliche Rechtstitel für die spanische Herrschaft („consensus illorum est jus et causa efficiens, principatus Regum nostrorum principalius seu principalior" ${ }^{(")}$. Ohne diese $\mathrm{Zu}-$ stimmung kann auch die päpstliche Einsetzung aus der Konzessionsbulle des Jahres 1493 rechtlich nicht greifen. ${ }^{51}$ Die Begründung ist die uns aus De regia potestate bereits bekannte: dass jede Fürstenschaft oder Regentschaft über das Volk von Anfang an, also noch bevor das Reich oder das Fürstentum durch Sukzession übertragen wird, ihren Ursprung in Zustimmung und Wahl des Volkes hat, ${ }^{52}$ dass die Freiheit ein unschätzbares Gut ist und man sie nur mit dem letzten Atemzuge aufgibt, dass jede Herrschaft auch mit Lasten (Tributen usw.) verbunden ist, die die Freiheit beinträchtigen, weshalb die Zustimmung des Volkes nötig ist usw. Gegenüber von De regia potestate wird das Prinzip der Zustimmung aller in diesen Traktaten näher begründet. Die Rechtsregel aus dem sechsten Buch der Dekretalen „Quod omnis tangit, debet ab omnibus approbari“ wird mehrmals angeführt, ${ }^{53}$ eine Regel, die wir vergeblich bei Francisco de Vitoria oder Francisco Suárez suchen werden; aber auch Gesetze von beiden Rechten aus dem Adoptionsrecht, dem Wahlrecht der korporativen Kollegien, dem Vertragsrecht, dem Sklavenrecht, dem Brunnen- und Pachtrecht und gar aus dem Wahlrecht der Bischöfe, deren Einsetzung einst auch der faktischen - nicht bloß rituellen -

49 Vgl. Las Casas (1994-1997). Band 3/1, 279.

50 Las Casas (1994-1997). Band 3/1, 516.

51 Vgl. Las Casas (1988-1998). Band 11/1, 316 f., 320 f., 322 f. Auf den 4. Mai 1493 datierte bekanntlich Papst Alexander VI. seine Bulle Inter ceterae, mit der er den katholischen Königen und seinen Nachfolgern ,aus der Fülle Unserer apostolischen Machtbefugnis [...] für alle Zeiten [...] alle aufgefundenen oder aufzufindenden, alle entdeckten oder zu entdeckenden Inseln und Festländer mitsamt allen Herrschaften, Städten, Lagern, Plätzen und Dörfern und allen Rechten, Gerechtsamen und zugehörigen Berechtrigungen" schenkte, gewährte und übertrug. Vgl. deutsche Übersetzung der Bulle in: Delgado (1996), 73. Zu Las Casas' Interpretation dieser Bulle im Kontext seiner politischen Theorie vgl. Delgado (1997).

52 Vgl. Las Casas (1994-1997). Band 3/1, 287 und 294.

53 Vgl. Las Casas, (1994-1997). Band 3/1, 283, 288; Band 3/2, $301 \mathrm{f}$. 
Zustimmung des Volkes bedurfte, um rechtswirksam zu sein, führt Las Casas an, ${ }^{54}$ genauso wie eine Interpretation des Königtums von Saul und David als eines wesentlich von der Zustimmung des Volkes abhängigen, da Gott selbst das Naturrecht nicht aufheben möchte, das er von Anfang an so geordnet und unwandelbar eingerichtet hat. ${ }^{55}$ Kurz und gut: kein Beleg aus der abendländischen Rechtstradition ist ihm zu schade, wenn er damit sein demokratisches Prinzip der Zustimmung begründen kann.

Mit der Zustimmung ,aller Betroffenen“ meint Las Casas „alle, deren Recht man beschneidet oder denen man einen Schaden zufügt, alle, die aufgrund des Naturrechts, des göttlichen und menschlichen Rechtes die Macht haben, zuzustimmen oder abzulehnen" .56 Und unter Bezug auf das Gesetz „Si unus“ aus dem Sklavenrecht in den Digesten gibt er zu verstehen, dass die Zustimmung nicht gegeben sein kann, solange sich ein Einziger in seinem Recht verletzt fühlt: „Wenn mehrere etwa gemeinsam ein Landgut besitzen und alle außer einem darin Knechte halten wollen, so ist die Zustimmung al-

54 Las Casas zitiert u.a. Kanon „Nulla ratio“ aus dem Decretum: „Keine Begründung erlaubt es, unter den Bischöfen welche zu haben, die weder von den Klerikern gewählt noch vom Volk gewünscht sind' [...] Und wo das Volk nicht zur Wahl gerufen wird, da soll es doch zur Zustimmung der Wahl des Prälaten aufgerufen werden, gemäß der Rechtsregel: ,Was alle angeht, muß auch von allen gebilligt werden' [...] Die Glosse zu Decretum (D.62 c.Nulla ratio) sagt a contrario sensu, wenn das Volk der durch das Kollegium erfolgten Wahl nicht zustimmen wolle, könne die Wahl für ungültig erklärt werden. Und sogar wenn es ohne vernünftigen Grund widerspricht und seine Zustimmung verweigert, muß die Wahl für ungültig erklärt werden, falls sonst ein Ärgernis im Volk entstünde, wie Panormitanus ausgehend von dieser Glosse [...] sagt, daß bei Gefahr eines Ärgernisses für das Volk selbst ein rechtmäßig gewählter nicht über es gesetzt werden soll $[\ldots]$, wenn das Volk einen schon bestallten Bischof oder Prälaten verfolge, dürfe es daran nicht gehindert werden; damit im Volk und in der Kirche wieder Ruhe einkehre, müsse der Prälat zurücktreten oder von seinem Oberen abberufen werden, nachdem man ihn andernorts eine angemessene Stelle zugewiesen habe.“ Las Casas (1994-1997). Band 3/1, 288. Vgl. Decretum Gratiani: D. 62, c. 1, in: Corpus Iuris Canonici (1959), 234. Und Las Casas folgert aus dieser kirchlichen Rechtspraxis mit gesundem Menschenverstand: „Wenn der Bischof den Leuten nicht gegen ihren Willen gegeben werden darf, damit das unwillige Volk den Bischof nicht verachte oder hasse, dann darf noch viel weniger einem freien, fremden, heidnischen und ungläubigen Volke, das seine eigenen, natürlichen Könige hat, die keinen Oberherrn über sich anerkennen, ein weltlicher Regent oder König gegeben werden, den es ja nicht kennt und der ihm verdächtig ist, weil er aus einem anderen Stamm oder einer grausamen Nation stammt; ansonsten entstünde mit Gewißheit schwerstes, nicht zu besänftigendes Ärgernis nicht nur bei einem Volk, sondern unter zahllosen Völkern und unterschiedlichsten Nationen." Las Casas (1994-1997). Band 3/1, 289.

55 Vgl. Las Casas (1994-1997). Band 3/2, $303 \mathrm{f}$

56 Las Casas (1994-1997). Band 3/2, 302. 
ler herbeizuführen; ansonsten macht das Fehlen des einen die Einrichtung ungültig“'.57

Nun, mit der Übertragung solcher Texte auf die Ebene der politischen Zustimmung legt Las Casas bewusst die Latte sehr hoch, denn auch die antike und mittelalterliche Konsenstradition lief letztlich auf eine Mehrheitsentscheidung hinaus. Aber Las Casas würde wohl auch heute eine Mehrheit, die rücksichtslos „obsiegt“ und sich über die berechtigten Einsprüche der Minderheit hinwegsetzt, ablehnen; er würde für eine konsensuale Mehrheit plädieren, die „,̈̈ber-

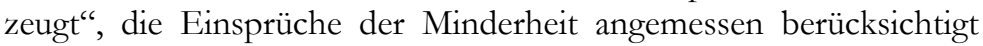
und zu einer Lösung kommt, mit der alle Betroffenen leben können. Ist das nicht demokratischer als der bloße Sieg der Mehrheit? Wäre das aber praktikabel?

Das konsensuale Prinzip der Zustimmung aller Betroffenen ist auch heute in verschiedenen Zusammenhängen von Bedeutung. In der Kirche etwa hat es Papst Johannes Paul II. in seinem Motu proprio Apostolos Suos vom 24. Juli 1998 über „Die theologische und rechtliche Natur der Bischofskonferenzen" betont. Bestimmte Entscheidungen der Bischofskonferenzen bedürfen demnach der $\mathrm{Zu}-$ stimmung aller Betroffenen oder der ausdrücklichen „recognitio“ des Apostolischen Stuhls selbst nach einer Zweidrittelmehrheit in der Vollversammlung. Auch im Rahmen der Europäischen Union oder NATO werden die Entscheidungen nach einem solchen Prinzip getroffen, auch wenn man sich für die Überzeugungsarbeit oder den Ausgleich der verschiedenen Interessen viel Zeit nehmen muss. Andererseits leiden unsere parlamentarischen Demokratien daran, dass immer mehr Entscheidungen über Dinge von allgemeinem Interesse einer kleinen Gruppe von Spezialisten überlassen werden und das Prinzip der Zustimmung aller Betroffenen das Volk nicht einbezieht, sondern höchstens noch die parlamentarischen Volksvertreter, so als ob - frei nach Suárez - mit der Parlamentswahl eine quasi „absolute“ Machtübertragung an Parlament und Regierung vorgenommen worden wäre. Vielfach wächst deshalb die Sehnsucht nach Formen direkter Demokratie, ${ }^{58}$ die dann freilich nicht auf die $\mathrm{Zu}-$ stimmung aller Bürger und Bürgerinnen hinauslaufen kann, denn das würde zur Entscheidungsunfähigkeit führen, sondern auf die $\mathrm{Zu}-$

57 Las Casas (1994-1997). Band 3/1, 284-285. Vgl. Digestum: 8, 3, 19, in: Corpus Iuris Civilis (1967), 148.

58 Vgl. Kaufmann (2006). 
stimmung der Mehrheit unter freier Beteiligung aller stimmwilligen Wahlberechtigten und unter gebührender Berücksichtigung der berechtigten Einsprüche der unterlegenen Minderheit.

Auch Las Casas' Ausführungen über den Herrschaftsvertrag bewegen sich im Rahmen des schon in De regia potestate Gesagten. Ein solcher Vertrag, sagt Las Casas, ist nötig, entspricht dem universalen Gewohnheitsrecht der Völker (,apud omnes populos et gentes") und darf nicht so verstanden werden, als hätte der König freie Hand, über das darin Vereinbarte hinaus die Freiheit des Volkes mit weiteren Lasten zu beeinträchtigen. Für jede neue Maßnahme dieser Art ist die Zustimmung des Volkes einzuholen, auch wenn dies im Herrschaftsvertrag nicht ausdrücklich festgehalten wurde. ${ }^{59}$ Ein solcher Vertrag ist ein gegenseitiger Vertrag, der dem Willen beider Teile entspringt und beide Teile verpflichtet. ${ }^{60}$

Die Beweiskette über die Notwendigkeit der Zustimmung aller Betroffenen und über den Herrschaftsvertrag endet mit den bitteren Worten, dass die spanischen Könige allen Grund haben, ,jede Hoffnung fahrenzulassen, sie möchten jemals das (höchste) Fürstenamt über jene Gebiete in Ruhe und ohne Gewissensbisse innehaben, selbst wenn jene Völker ihre Zustimmung bekunden; denn es kann ja immer die Rechtsvermutung bestehen, sie täten das unter dem Zwang einer überaus berechtigten Furcht" ${ }^{61}$ Daher spricht er den indianischen Völkern ein Widerstandsrecht gegen die als Tyrannen ohne rechten Herrschaftstitel auftretenden Spanier zu. Ein Widerstandsrecht, das nur die zwei klassischen Einschränkungen kennt, die einst Thomas von Aquin formulierte: „es sei denn, dass die unterworfene Menge größeren Schaden aus der folgenden Erschütterung erfährt als aus der Tyrannei“, und „es sei denn, dass ein Treuversprechen gebrochen würde, das auch Feinden gegenüber eingehalten werden müsste" ${ }^{\text {}}{ }^{2}$

59 Vgl. Las Casas (1988-1998). Band 11/1, $306 \mathrm{f}$.

60 „Ecce contratus ultro citroque aut ex utraque parte obligatio, ex uoluntate partium consurgens. Ideo dicimus quod pasciscendo diuersas in unum trahimus uoluntates." Las Casas (1988-1998). Band 11/1, $308 \mathrm{f}$.

61 Las Casas (1994-1997). Band 3/1, 295.

62 Las Casas (1994-1997). Band 3/2, 354. 
Suárez und die koloniale Frage

Wie steht es nun mit Suárez? Auch in der kolonialen Frage liegt er im Trend seiner Zeit. Die zwei gängigsten Argumente zur Legitimation der spanischen Expansion waren um 1600 folgende: erstens die Berufung auf die päpstliche Konzessionsbulle von 1493 als eine Ermahnung zur Wahrnehmung des Missionsrechtes, im äußersten Fall auch mit kriegerischen Mitteln, sollte dies zum Schutz des Lebens der Glaubensapostel nötig sein; und zweitens sagte man - Las Casas' politischer Theorie zum Trotz, wonach der Anspruch auf politische Freiheit nie verjähren könne -, wenn im Zuge der Wahrnehmung des Missionsrechtes fremde Reiche erobert und dabei auch Ungerechtigkeiten begangen worden seien, so seien sie bestimmt schon verjährt, sodass die spanische Herrschaft durch die stillschweigende Zustimmung jener Völker völlig legitim geworden sei. ${ }^{63}$

Es ist klar, dass ein kluger Kopf wie Suárez das erste Argument sehr besonnen darlegt und sich von den rücksichtslosen Hardlinern mit der Bemerkung absetzt, man dürfe durch ein allzu kriegerisches Auftreten nicht den Eindruck erwecken, man wolle fremde Länder besetzen, so als ob unser Glaube uns die Verletzung des Völkerrechts und sogar des Naturrechts gestattete. ${ }^{64}$ Suárez plädiert vielmehr dafür, man solle die heidnischen Fürsten wiederholt und in vornehmer Weise bitten, die Glaubensboten zuzulassen: „Erst wenn alles nichts nütze, dürfe man Gewalt anwenden“. ${ }^{65}$ Der offensichtliche Widerspruch zur apostolischen Kirche wird mit den Worten begründet, die uns auch bei Juan Ginés de Sepúlveda und allen Gegnern Las Casas' begegnen: „Wenn in den Anfängen der Kirche auch diese Art des Zwanges nicht üblich war, so geschah das nicht deshalb, weil es nicht erlaubt gewesen wäre, sondern weil die Kirche damals noch keine weltliche Macht zum Widerstand gegen die Feinde des Glaubens besaß. Christus der Herr wollte im Anfang die Welt mit der Kraft des Wortes und der Wunder besiegen, um seine Macht und die Wahrheit seiner Lehre augenfälliger offenkundig zu machen." 66

63 So z.B. die Argumentation in dem antilascasianischen Pamphlet von 1571 „Die Denkschrift von Yucay", in: Las Casas (1994-1997). Band 3/2, 427-474.

64 Suárez (1858), 440 (n. 8).

65 Höffner (1972), 336.

66 Suárez (1858), 440-441 (n. 10); vgl. Höffner (1972), 336. Dies war schließlich auch die Sicht, die Gregor XIV. im Breve Eximiam potestatem auf Bitten des Jesuiten Alonso 
Über das zweite Argument erfahren wir bei Suárez leider nichts, obwohl dies die Probe aufs Exempel seiner politischen Theorie gewesen wäre, wenn er nicht nur dem Absolutismus Jakobs I., sondern auch der spanischen Expansion Grenzen gesetzt hätte. Hat er vielleicht an die koloniale Rechtstiteldiskussion gedacht, als er für sein Buch Defensio fidei kryptisch geschrieben hat, es sei jetzt nicht die Zeit, der Frage nachzugehen, ob die Juden von den Römern gerechter- und legitimerweise oder ungerechter- und tyrannischerweise unterworfen und zur Entrichtung von Tributen an den Kaiser gezwungen wurden, denn eine solche Frage sei nicht mehr aktuell? ${ }^{67}$ Die spanischen Wörter „iudios“ und „indios“ schreiben sich ja fast gleich. Und hat er vielleicht auch an den kolonialen Kontext gedacht, als er vermerkt hat, der ungerechte Krieg sei zwar der häufigste Weg, auf dem Großreiche entstünden, aber im Verlauf der Zeit treffe ein, dass das Volk seine freie Zustimmung dazu gebe oder die Nachfolger in der Herrschaft guten Glaubens regieren; dann höre die Tyrannei auf und beginne die gute Regierung und königliche Gewalt? Suárez lässt sich anschließend gar zur Schlussfolgerung verleiten, dass die königliche Gewalt so oder so - also durch freie „translatio“ oder Verjährung der gewaltsamen „usurpatio“ - immer kraft eines menschlichen Rechtstitels oder kraft des menschlichen Willens unmittelbar erlangt werde. ${ }^{68}$ Las Casas, für den der Anspruch auf politische Freiheit nie verjährte, wird sich mehrmals im Grab umgedreht haben.

Sánchez und vor dem Hintergrund der philippinischen Kontroverse (ein Bruder Suárez' gehörte zu der von Sánchez angeführten ersten Jesuitengruppe auf den Philippinen) 1591 bestätigte. Darin heißt es, zwar sei das Evangelium in den Anfängen, als die Kirche noch in Windeln lag, ganz nach apostolischer Art ohne den Schutz christlicher Waffen verkündet worden, doch später wurde die Kirche mächtig und militant, so dass ihre erlauchten Söhne, Kaiser, Könige, Fürsten und Herren das Schwert ziehen konnten, um sie zu beschützen und sie stützend unter die Barbaren zu verbreiten. Vgl. Delgado (1995-1996), 760. Was Suárez im Zusammenhang mit dem kolonialen Kontext zu verstehen gibt, steht auch ganz in Einklang mit der „Realpolitik“, die der Jesuit José de Acosta in seinem missionstheologischen Werk De procuranda indorum salute vertritt. Siehe Acosta (1984-1987). Las Casas' politische Theorie, die bis zur Hinrichtung Túpac Amarus 1572 zumindest in Peru eine reale Alternative gewesen ist, wird nunmehr von vielen realpolitisch denkenden Autoren als utopisch und wirklichkeitsfremd diskreditiert.

67 Suárez (1965b), 13 (1.8).

68 „Atque ita semper potestas haec aliquo humano titulo seu per voluntatem humanam immediate obtinetur." Suárez (1965b), 32 (2.20). 


\section{Ausblick}

Las Casas und Suárez haben sich in die Kämpfe ihrer Zeit eingemischt und mit ihren je verschieden akzentuierten politischen Theorien einen katholischen Beitrag zur Begründung der Lehre von der „Volkssouveränität“" geleistet, die der absolutistische Jakob I. von England ironisch ,egregium theologiae axioma“69 nannte. Heute, wo die Theologie an den Universitäten, die sie einst mitgegründet hat, zunehmend unter Legitimationsbedarf gerät, wäre es vielfach angebracht, öfter daran zu erinnern, wie viel die verschiedenen Wissenschaften - so z.B. die politische Theorie - den Theologen eigentlich verdanken.

Es mag gewagt erscheinen, wenn der leidenschaftliche, methodisch eklektische und außerhalb der akademischen Hörsäle wirkende Bartolomé de Las Casas mit dem hochgebildeten Hochschullehrer und Leuchter der spanischen Spätscholastik Francisco Suárez verglichen wird. Aber heute, wo der polemische Schutt, unter dem Las Casas jahrhundertelang begraben war, zum großen Teil abgetragen ist, setzt sich langsam die Ansicht durch, dass sein erster deutschsprachiger Herausgeber, der deutsche Wolfgang von Griesstetter, ${ }^{70}$ durchaus Recht hatte, als er den Bischof von Chiapa 1571 ,einen in allen Wissenschaften sehr versierten Mann" nannte. ${ }^{71}$ Der in Mainz

69 Vgl. Suárez (1965b), 23 (2.10).

70 Immer wieder sind Zweifeln an der Autorschaft des Las Casas geäußert worden. Neuerdings bringt der Historiker Peer Schmidt plausible Argumente dafür, dass Wolfgang von Griesstetter eine fiktive Gestalt war, hinter der sich jemand aus dem Umkreis des Adam von Dietrichstein (1527-1590) versteckte, des Gesandten Maximilians II. am spanischen Hof, dem Sympathien für den „Freiheitskampf“ der Niederlande nachgesagt werden. Warum aber dies Schmidt - ohne jede Textkritik oder ohne jeden Vergleich mit anderen Werken Las Casas' - zur folgenden Schlussfolgerung verleitet, ist wissenschaftlich kaum nachvollziehbar: „Die Zuschreibung des Traktates an Bartolomé de las Casas wird man folglich als eine propagandistische Finte zu bewerten haben." Schmidt (2002), 50. Auch wenn der deutsche Herausgeber Las Casas' Gedanken zu Propagandazwecken missbraucht, ist die Tatsache nicht zu leugnen, dass es eine starke Übereinstimmung zwischen den Aussagen dieses Traktates und der politischen Theorie Las Casas' in seinen Spätwerken Über die Schätze Perus und Über die zwölf peruanischen Zweiffelsfälle gibt. Es ließe sich z.B. leicht nachweisen, dass in diesen Werken dieselben juristischen Autoritäten und Rechtsbelege zitiert werden. Darüber hinaus schrieb Las Casas 1554/1555 vor dem Hintergrund des encomienda-Problems ein Werk, das bisher verschollen ist und folgenden Titel trug: De non alienandis opibus a regia Corona, nec vendendis publicis officiis.

71 So Wolfgang von Griesstetter im Titelblatt des von ihm herausgegebenen Traktats De regia potestate: „D. Bartholomaei de las Casas, episcopi Chiapensis, viri in omni doctrinarum genere exercitatissimi, erudita \& elegans explicatio quaestionis: Vtrum Reges vel Principes iure aliquo vel titulo, \& salua conscientia, Cives ac Subditos a Regia Corona alienare, \& alterius 
lehrende argentinische Rechtsphilosoph Ernesto Garzón Valdés hat - nicht zuletzt wegen des Traktats De regia potestate - nicht gezögert, Las Casas mit Francisco de Vitoria und Francisco Suárez zusammen zu nennen: „Das 16. und der Anfang des 17. Jahrhunderts in Spanien waren geprägt vom Werk dreier großer Theologen und Juristen: Bartolomé de Las Casas, Francisco de Vitoria und Francisco Suárez." 72 Dieses Werk habe, so Garzón Valdés weiter, demokratische Organisationsprinzipien entschieden formuliert, die zwei Jahrhunderte später zum gemeinsamen Erbe des europäischen politischen Denkens werden sollten.

Nach diesem kleinen Vergleich scheint mir aber, dass die Worte, die ein amerikanischer Autor Suárez widmete, als er ihn den ,ersten modernen Demokraten“ nannte, ${ }^{73}$ eher zum Bischof von Chiapa passen. Denn nur seine politische Theorie bestand die Probe aufs Exempel und verteidigte konsequent die Rechte der anderen, wenn sie von uns mit Füßen getreten wurden. Gerade dies ist ein sehr „moderner“ Zug in einer politischen Theorie aus dem fernen 16. Jahrhundert. Der Philosoph Vittorio Hössle hat daher zu Recht Las Casas’ Einmaligkeit hervorgehoben: „Die Assyrer haben ihre Opfer nicht bedauert; Spanien hat, mehr als zwei Jahrtausende später, immerhin einen Las Casas hervorgebracht, und auf den einen Las Casas kann es unendlich stolzer sein als auf alle seine Eroberer." ${ }^{\text {"7 }}$

\section{Literatur}

Abril, Vidal (1979): „Juramento de fidelidad y derechos humanos“, in: Suárez, Francisco: De iuramento fidelitatis. Estudio preliminar. Madrid, 219340.

Acosta, José de (1984-1987): De procuranda indorum salute. Madrid.

Adler, Benjamin (2006): Die Entstehung der direkten Demokratie. Zürich.

Brieskorn, Norbert (1990): „Francisco Suárez und die Lehre vom Tyrannenmord", in: Ignatianisch. Eigenart und Methode der Gesellschaft Jesu. Freiburg/B., 323-339.

Domini particularis ditionis subijcere possint? Antehac nunquam ab vllo Doctorum ita luculenter tractata. Edita cura \& studio Vuolffangi Grießtetteri. Cum gratia \& priuilegio Caesareae Maiestatis. Francofvrti ad Moenum, M.D.LXXI.“

72 Garzón Valdés (1990), 8.

73 So Fichter (1940); hier zitiert nach Elorduy (1965), CXCIX.

74 Hössle (1997), 1042. 
Brieskorn, Norbert (1996): „Las Casas und das römische Recht“, in: Las Casas, Bartolomé de: Werkeauswabl. Band 3/1. Paderborn, 14-32.

Cano, Melchor (1563): De loci theologici. Salamanca.

Cervantes Saavedra, Miguel de (1979): Der scharfsinnige Ritter Don Quixote von der Mancha. Frankfurt/M.

Corpus Iuris Canonici (1959): Decretum magistri Gratiani. Band 1. Graz.

Corpus Iuris Civilis (141967): Volumen secundum: Codex Justinianus. DublinZürich.

Deckers, Daniel (1991): Gerechtigkeit und Recht. Eine historisch-kritische Untersuchung der Gerechtigkeitslehre des Francisco de Vitoria (1483-1546). Freiburg/CH.

Delgado, Mariano (1995-1996): „Las Casas’ posthumer Sieg. Zur Kontroverse über die Missionsart und die Tributfrage im Zusammenhang mit Conquista und Evangelisation der Philippinen", in: Annuarium Historiae Conciliorum 27/28, 737-768.

Delgado, Mariano (1996): Abschied vom erobernden Gott. Studien zur Geschichte und Gegenwart des Christentums in Lateinamerika. Immensee.

Delgado, Mariano (1997): „Universalmonarchie, translatio imperii und Volkssouveränität bei Las Casas oder Das prozeßhafte Entstehen einer politischen Theorie zwischen Mittelalter und Neuzeit", in: Las Casas, Bartolomé de: Werkauswahl. Band 3/2. Paderborn, 161-179.

Delgado, Mariano (2001): „Die Zustimmung des Volkes in der politischen Theorie von Francisco de Vitoria, Bartolomé de Las Casas und Francisco Suárez", in: Grunert, Frank/Seelmann, Kurt: Die Ordnung der Praxis. Neue Studien zur Spanischen Spätscholastik. Tübingen, 157-181.

Dreier, Horst (71988): „Souveränität“, in: Görres-Gesellschaft, Hg.: Staatslexikon. Band 4. Freiburg/B., 1203-1209.

Eggensperger, Thomas (2000): Der Einfluss des Thomas von Aquin auf das politische Denken des Bartolomé de Las Casas im Traktat „De imperatoria vel regia potestate". Eine theologisch-politische Theorie zwischen Mittelalter und Neuzeit. Münster.

Elorduy, Eleuterio (1965): „La soberanía popular según Francisco Suárez“, in: Suárez, Francisco: Defensio fidei III. Madrid, XIII-CCI.

Fichter, J.H. (1940): Man of Spain, Francis Suárez. New York.

Goez, Werner (1958): Translatio imperii. Ein Beitrag zur Geschichte des Geschichtsdenkens und der politischen Theorien im Mittelalter und in der frühen Neuzeit. Tübingen.

Garzón Valdés, Ernesto (1990): „Einführung“, in: Garzón Valdés, Ernesto, Hg.: Spanische Studien zur Rechtstheorie und Rechtsphilosophie. Berlin, 7-46.

Hegel, Gottfried Wilhelm Friedrich (1970): Vorlesungen über die Philosophie der Geschichte. Frankfurt/M.

Höffner, Joseph (31972): Kolonialismus und Evangelium. Spanische Kolonialethik im Goldenen Zeitalter. Trier. 
Horst, Ulrich (1995): „Leben und Werke Francisco de Vitorias“, in: Vitoria, Francisco de: Vorlesungen/Relectiones. Völkerrecht, Politik, Kirche. Band 1. Stuttgart, 13-99.

Hössle, Vittorio (1997): Moral und Politik. Grundlagen einer Politischen Ethik für das 21. Jabrbundert. München.

Kasper, Walter (1987): „Die Weitergabe des Glaubens. Schwierigkeiten und Notwendigkeit einer zeitgemäßen Glaubensvermittlung"“, in: Kasper, Walter: Theologie und Kirche. Mainz, 117-134.

Kaufmann, Bruno (1999): „Die Welt der direkten Demokratie. Ein Überblick", in: Die Zeit 51.

Las Casas, Bartolomé de (1988-1998): Obras completas, 14 Bände. Madrid.

Las Casas, Bartolomé de (1994-1997): Werkauswabl, 4 Bände. Paderborn.

Pereña, Luciano (1977a): „Génesis suareciana de la democracia“, in: Suárez, Francisco: De legibus (III 1-16). Madrid, XVII-LXXVIII.

Pereña, Luciano (1977b): „La obligación política en Francisco Suárez“, in: Surez, Francisco: De legibus (III 17-35). Madrid, XVII-LXIX.

Pérez Luño, Antonio-Enrique (1990): „Democracia y derechos humanos en Bartolomé de las Casas", in: Las Casas, Bartolomé de: Obras completas. Band 12. Madrid, 1*-39*.

Pérez Luño, Antonio-Enrique (1994): Die klassische Naturrechtslehre in 5 Jabrbunderten. Berlin.

Reibstein, Ernst (1972): Volkssouveränität und Freibeitsrechte. Texte und Studien zurpolitischen Theorie des 14.-18. Jabrbunderts. Freiburg/B.-München.

Rommen, Heinrich (1926): Die Staatslehre des Fran₹. Suárez: Mönchengladbach.

Schmidt, Peer (2002): „Freiheit und Herrschaft in las Casas De imperatoria vel regia potestate (1571). Eine propagandistische Finte“, in: Jahrbuch für Geschichte Lateinamerikas 39, 37-50.

Schubert, Friedrich Hermann (1974): „Volkssouveränität und Heiliges Reich“, in: Rausch Heinz, Hg.: Die geschichtlichen Grundlagen der modernen Volksvertretung. Die Entwicklung von den mittelalterlichen Korporationen zu den modernen Parlamenten. Band 2: Reichsstände und Landstände. Darmstadt, 279-314.

Soder, Josef (1973): Francisco Suárez, und das Völkerrecht. Grundgedanken zu Staat, Recht und internationalen Beziehungen. Frankfurt/M.

Specht, Rainer (1987): „Spanisches Naturrecht - Klassik und Gegenwart“, in: Zeitschrift für philosophische Forschung 41, 170-182.

Suárez, Francisco (1858): „De fide“ (Tr. I, disp. 18, sect. 1, n. 8 und n. 10), in: Suárez, Francisco: Opera omnia. Band 12. Paris, 440-441.

Suárez, Francisco (1965a): Ausgewäblte Texte zum Völkerrecht. Tübingen.

Suárez, Francisco (1965b): Defensio fidei III: I Principatus politicus ó la soberanía popular. Madrid.

Suárez, Francisco (1975): De legibus (III 1-16): De civili potestate. Madrid.

Suárez, Francisco (1977): De legibus (III 17-35): De politica obligatione. Madrid. 
Suárez, Francisco (1978): Defensio fidei VI: De iuramento fidelitatis. Documentación fundamental. Madrid.

Suárez, Francisco (2002): Abhandlung über die Gesetze und Gott den Gesetzgeber. Freiburg/B..

Vitoria, Francisco de (1934): „De Justitia “, in: Heredia, Vicente Beltrán, Hg.: Comentarios a la Secunda secundae de Santo tomás. Band 3. Salamanca, 77-78.

Vitoria, Francisco de (1995): „De potestate civili 1“, in: Vitoria, Francisco de: Vorlesungen/Relectiones. Völkerrecht, Politik, Kirche. Band 1. Stuttgart, 114-161.

Vitoria, Francisco de (1995-1997): Vorlesungen/Relectiones. Völkerrecht, Politik, Kirche, 2 Bände. Stuttgart.

Welker, Karl H. L. (1998): „Volkssouveränität“, in: Handwörterbuch zur Deutschen Rechtsgeschichte. Band 5. Berlin, 1006-1010. 

Glaube und Krieg. Gedanken zur Antriebsmotivation zum

Krieg bei den Hussiten und in der New Model Army

Robert Rebitsch*

„Der Glaube kann Berge versetzen“, heißt ein geflügeltes Sprichwort. Die Macht des Glaubens, Berge zu versetzen, findet keine empirische, wohl eher nur symbolhafte Bestätigung. In der Kriegsgeschichte jedoch spielte und spielt der Glaube, die Religion, eine herausragende Rolle für die Kampfmoral eines Kriegers oder Soldaten.

Frappantes Zeugnis glaubensmotivierter Kämpfer legten die Heere in den Hussitenkriegen (1419-1434) ${ }^{1}$ und auch jene des Parlaments im Englischen Bürgerkrieg (1642-1649)2 ab. Sowohl die von

* Robert Rebitsch ist Lektor am Institut für Geschichte und Ethnologie der Universität Innsbruck, wissenschaftliches Mitglied des Herausgeberteams der Innsbrucker Historischen Studien (IHS) und Träger des Theodor-Körner-Preises 2002. Seine Forschungsschwerpunkte liegen in der Konflikt-, Militär- und Politik-Geschichte des 16. und 17. Jahrhunderts und in Biographien. Seit 2005 arbeitet er außerdem im projekt.service.büro der Universität Innsbruck. Der vorliegende Text ist auch als Nr. 6 der Innsbrucker Diskussionspapiere zu Weltordnung, Religion und Gewalt erschienen.

1 Zum Hussitismus und zu den Hussitenkriegen vgl. Seibt (1965a, 1987) und Kaminsky (1957); einen zusammenfassenden Überblick vermittelt Machilek (1986), $710-735$ (mit weiteren Literaturangaben); Šmahel (1985), 215-368 (ein ausgezeichnetes Literaturverzeichnis in Band IV); aus militärhistorischer Perspektive Durdik (1961) sowie Schmidtchen (1990), 79-92 und speziell zur Taktik und Technik der hussitischen Kriegführung 212-220; zum Nachleben der böhmischen Söldnertruppen Tresp (2004); allgemein Fuchs (1972), 156161; zur kriegsrechtlichen Perspektive Schmidtchen (1999), 25-56, besonders 43-52.

$2 \mathrm{Als}$ Überblicksdarstellungen zum militärischen Verlauf des Bürgerkrieges während der Epoche der Englischen Revolution sind folgende Werke zu nennen: der Klassiker von Gardiner (1886-1891), Wedgwood (1958, 1961), Young/Bourne (1959), Roots (1966), 
Jan Žižka von Trocnov ${ }^{3}$ geführten Hussiten als auch Oliver Cromwells ${ }^{4}$ Ironsides zeichneten sich durch eine hohe durch den Glauben motivierte Kampfmoral und durch eiserne Disziplin aus. Obwohl bei Vergleichen immer eine gewisse Vorsicht geboten ist, sind Ähnlichkeiten der beiden Armeen in ihrer Kriegsordnung und in ihren Anschauungen unübersehbar. Die Führer der Glaubenskämpfer, sowohl Žižka als auch Cromwell, beide tragende Figuren ihrer Epoche, stellten dieselben Ansprüche an ihre Untergebenen und forderten ihren Männern ein hohes $\mathrm{Maß}$ an Religiosität und moralischer Integrität ab. Gleichsam galt ihre Linie als Erfolgsrezept; die Armeen dieser beiden Feldherren blieben unbesiegt. Das letztendliche Scheitern beider Konzeptionen hatte andere Gründe als eine entscheidende militärische Niederlage.

Was jedoch unterschied diese beiden Armeen von ihren Gegnern, die selbstverständlich keine „Ungläubigen“ im Sinne von Atheisten waren? Wie gelang es den Führern, ihre Männer bis zum letzen Einsatz zu beflügeln? Worauf basierte also das Erfolgsrezept der „Unbesiegbarkeit“? Fragen, die nicht nur für den Militärhistoriker von Interesse sind, sondern auch in einem beachtlichen Maß für Vertreter der Geistes- und Sozialgeschichte interessant sein könnten.

\section{Verhaltensnormen bei den Hussitenkriegern}

Im Kampf der Hussiten gegen die Reichsheere des römisch-deutschen Kaisers Sigismund (ab dem 28. Juli 1420 gekrönter böhmischer König) ${ }^{5}$ sind verschiedene Motive ausfindig zu machen. Die voneinander zumeist unabhängig operierenden Parteien innerhalb der böhmischen Unabhängigkeitsbestrebung fanden verschiedene Beweggründe zum Krieg, wie schon Ferdinand Seibt in seinen Stu-

Young/Holmes (1974), Manning (1973), Ollard (1976), Ashley (1990), Carlton (1995a), Bennett (1997), Kenyon/Ohlmeyer (1998).

3 Zum hussitischen Heerführer vgl. Heymann (1955), Šmahel (1969) sowie die kurze Beschreibung bei Heymann (1998), 659-660; Seibt (1965a); vieles zu Jan Žižka in Seibt (1965b) und Šmahel (1993).

4 Zum Kavalleriekommandanten des Parlaments und späteren Lord Protector vgl. Ashley (1958), Hill (1970), Gillingham (1976), Morrill (1990), Metz (1993), Gaunt (1996) und Coward (1991).

5 Zu Kaiser Sigismund (1368-1437) vgl. Bezold (1872-1877), Werfers (1989), die Aufsätze bei Macek et al. (1994), die äußerst gehaltvolle Biographie von Hoensch (1996). 
dien eindrucksvoll darlegen konnte. ${ }^{6}$ So standen die von Jan Žižka organisierten Taboriten im Gegensatz zum „rechten“ Prager Flügel einem schon sehr früh artikulierten Nationalismus völlig fern. Die Taboriten suchten vielmehr das Reich Christi auf Erden; sie sahen sich als die eigentliche Streitmacht Gottes und erwarteten das Reich des Herrn: ${ }^{7}$

„Weiter [sagen sie], dass die Taboritenbrüder in dieser Zeit der Rache die Engel sind, die geschickt wurden, um die Gläubigen aus allen Städten, Dörfern und Burgen auf die Berge hinauszuführen wie den Lot von Sodom und dass die Brüder mit ihren Anhängern jener Leib sind, bei dem sich, wo immer er auch sein wird, auch die Adler sammeln werden. Von ihnen heißt es auch: Jeder Ort, auf den euer Fuß tritt, ist euer und wird es sein. Sie nämlich sind das von Gott über die ganze Welt geschickte Heer zur Beseitigung aller Ärgernisse vom Reiche Christi, das die streitende Kirche ist, zur Vertreibung der Bösen aus der Mitte der Gerechten und zur Ausübung der Rache und der Plage über Nationen der Feinde des Gesetzes Christi und ihre Städte, Dörfer und Bollwerke“, so gab einer der bedeutendsten Chronisten Böhmens in der Epoche der Hussitenkriege, Lorenz von Březová, die ursprünglich noch vorhandenen Ideen des radikalen Umbruches, der Wiederkehr Christi, wieder. ${ }^{8}$

Bemerkenswert bei der taboritischen Bewegung war freilich der Umschwung der ursprünglich pazifistisch verstandenen Heilserwartung in einen sozialrevolutionär und aggressiv verstandenen Chiliasmus. ${ }^{9}$ Man erwartete mit der Ankunft Christi nicht das Ende der Welt, sondern vielmehr ein Ende des gegenwärtigen Zeitalters. Es dauerte jedoch nicht allzu lange, bis die eher abstrakten, adventistischen Visionen ,,von dem unerbittlich nahenden Jüngsten Gericht"10 realistischeren Formen und Vorstellungen des Lebens wichen, wobei der durchschlagendste militärische Führer der Hussiten, Jan Žižka, in dieser Frage ohnehin zu den Gemäßigten zählte und späterhin den radikalen Flügel der militanten chiliastischen Taboriten, die so-

6 Vgl. z.B. Seibt (1987), 80-96.

7 Vgl. Šmahel(1996), 191-201 sowie Machilek (1966), 67-94 und Patchovsky (1998), 169195.

8 Bujnoch (1988), 138.

9 Zum Begriff des Chiliasmus vgl. zusammenfassend Konrad (1981), 734-737 und ausführlicher Kaminsky (1957), 43-71.

10 Šmahel (1996), 194. 
genannten Pikarden, liquidierte. ${ }^{11}$ Für den hussitischen Kämpfer aber, so darf doch mit Recht angenommen werden, zählte weit weniger ein abstraktes chiliastisches Theoriegebäude als vielmehr der Gedanke, ein auserwählter Streiter Christi - boží bojovníci (Kämpfer Gottes) - zu sein. Die dahinter stehende Theologie und Philosophie war etwas für die Prager Magister und für intellektuelle Prediger, die Masse der Kämpfer gab sich mit weniger anspruchsvollen Theorien zufrieden. Wichtiger für die Mehrheit waren bestimmt ein klarer, verständlicher Auftrag, ein durchsichtiges Weltbild und ein verständliches wie greifbares Ziel. Aus vielfach einfachen Menschen wurden plötzlich auserkorene Elitekämpfer für die Sache Gottes - ein Faktum, das bisher wohl eher weniger Beachtung fand. ${ }^{12}$ Auch Cromwells Männer, wie unten noch zu zeigen ist, standen im festen Glauben der Auserwähltheit. Dieser Glaube an die Auserwähltheit, zur Vertreibung des Bösen und für die Etablierung des einzigen wahren Reiches zu kämpfen, brachte jedoch auch nicht zu übersehende Brutalität und Kompromisslosigkeit mit sich:

„Nach der gewaltsamen Einnahme der Stadt Prachatitz an der bayerischen Grenze erschlug nämlich eine blutbefleckte Schar der Taboriten auf den Straßen grausam mit Dreschflegeln und mit dem Schwert 135 Menschen wie Schweine und schloß 85 in der Sakristei der Kirche ein, steckte Fässer und Stroh an und verbrannte sie ohne jedes Erbarmen ungeachtet dessen, daß sie mit gebeugten Knien auf der Erde und mit gefalteten, zum Himmel erhobenen Händen herzerweichend flehten, $[\ldots . .]^{\text {" }}, 13$ schilderte der böhmische Chronist eine der vielen Übergriffe der Taboriten auf Zivilisten.

11 Vgl. dazu Patschovsky (1998), 175-176.

12 Zur Einstellung der Krieger Gottes vgl. ihr in Liedern und anderen Schriftquellen hinterlassenes Selbstverständnis bei Macek (1951).

13 Bujnoch (1988), 152. Obgleich Laurentius von Březová ein Gegner der Taboriten war und daher freilich eine propagandistische Berichterstattung nicht ausgeschlossen werden kann, konstatiert auch die neuere Forschung mit Dauer des Krieges eine zum Raub und zur Plünderung neigende hussitische Soldateska. Tresp (2004), 27-28. Ein weiterer Beleg für die gegen Kinder und Frauen gerichtete brutale Kriegführung findet sich in den Denkwürdigkeiten zur Geschichte des Zeitalters Kaiser Sigmunds, siehe Altmann (1893), 120. „[D]o zugen die Behemschen ketzer noch zu dem Dutschen Brod [tschechisch Nemecký Brod; südöstliches Böhmen] und gewonnen die stat und brantent die slügen doinne zu tode manne kinder wiber jung und alt und stalten also grosses jomer und leit do an dem Dutschen cristlichen $\operatorname{volg}[\ldots]$.“ 
Natürlich war die Kriegführung des Mittelalters ${ }^{14}$ grausam und nicht frei von Übergriffen auf die Bevölkerung, natürlich konnten auch die Gegner der Hussiten mit brutaler und rücksichtsloser Kriegführung aufwarten. Die Instruktionen Sigismunds an seinen obersten Hauptmann Kurfürst Friedrich I. von Brandenburg gewährten dem Oberbefehlshaber geradezu freie Hand zu rücksichtslosem Vorgehen gegen die sogenannten „Ketzer“:

,[...] und, ob sy [die Hussiten] in irem unglauben bliben, sy an lib und gut zu straffen $\mathrm{zu}$ pinigen und $\mathrm{zu}$ toden, allerley brandschaczung und ander schaczung zu verdingen und die inczunemen und damit zu tund und zu lassen was er will, allerley gefangen zu scheczen in czyle und tag zu geben oder sy ledig zu lassen gefangen $\mathrm{zu}$ halden oder $\mathrm{zu}$ to ${ }^{\mathrm{e}}$ den wie dann das sin wille und vernunft raten und im gefellig ist, $[\ldots] \cdot{ }^{15}$

Bemerkenswert ist jedoch die Tatsache, dass ein Krieg im Namen und Auftrag Gottes keine Humanisierung mit sich brachte, das Gegenteil war der Fall. Ein ritterlicher Umgang mit dem Feind war nicht mehr vorgesehen, denn der Gegner, namentlich der König, wurde geradezu als der Antichrist schlechthin betrachtet; ${ }^{16}$ und als solcher durfte er keine Gnade mehr erwarten.

Religion und Glaube waren im Mittelalter und in der frühen Neuzeit für jedermann tragende Säulen des Weltbildes - so auch bei den mit dem Kreuzzugspatent ausgestatteten Truppen Kaiser Sigismunds -, jedoch herrschten religiöses Pathos und fanatischer Glaubenseifer, instrumentalisiert zu unbändigem militärischen Tatendrang, bei den Hussitenkriegern noch weit mehr vor als bei den abseits ihres Landes kämpfenden Reichsrittern und den bunt zusammengewürfelten ,internationalen“ Soldtruppen des Königs. Die Bestrafung und Vernichtung dieser Antichristen, wie überhaupt aller bösen und lasterbaften Menschen, waren somit das klar definierte Ziel der Taboriten. ${ }^{17}$

14 Zum Krieg und zur Kriegführung im Mittelalter vgl. Russel (1975); einen Überblick gibt Ohler (1997).

15 Kerler (1883), 184-185 (Nr. 162).

16 Abgesehen von diesen gelehrten Urteilen war Kaiser Sigismund auch beim böhmischen Volk der Antichrist. So riefen die von Sigismund im Kloster Kladrau Eingeschlossenen zum Heer des Königs: „Wo ist der Antichrist, der Ketzerkönig?“ Vgl. Bujnoch (1988), 209.

17 „Überhaupt haben der Bruder Žižka und alle obbenannten Herrn, Ritter, Edlen, Bürger, Handwerker, Landleute und Stadtgemeinden beschlossen, alle bösen und lasterhaften 
Der um 1360 in Trocnov (Südböhmen) geborene, aus einer verarmten landadeligen Familie stammende und im Jahre 1421 völlig erblindete Jan Žižka ${ }^{18}$, selbst vom taboritenfeindlichen Lorenz von Březová als über die Maßen verwegen und tatkräftig ${ }^{19}$ beschrieben, gab seinem Heer das Erfolgsrezept: eine Kriegsordnung, die, auf der causa fidei basierend, den Krieg zur Verteidigung der Sache Gottes, der Wahrheit und der Gerechtigkeit für absolut rechtens hielt. ${ }^{20}$ Der „heilige Kampf um eine gerechtere Welt“ ${ }^{\star 21}$ gegen den Antichristen wurde klaren und unabdingbaren Normen unterworfen, die die Kriegführung prägen sollten. Die Konstruktion eines eindeutigen Feindbildes, des Antichristen, und der Entwurf eines klar artikulierten Willens, nämlich eine gerechte und moralisch geläuterte Welt zu schaffen, waren auch das Ziel Cromwells zwei Jahrhunderte später. Der Gegner, der ja mit einem Kreuzzugspatent im Rücken kämpfte und sich ebenfalls im Dienste des Herrn sah, ${ }^{22}$ wurde ausnahmslos zum Gottlosen stilisiert. Die Hussitenstreiter sahen sich als die einzigen wahren Krieger Gottes. Die im Frühjahr des Jahres 1423 implementierte Kriegsordnung Žižkas spiegelt das hohe Maß an erwünschter und erwarteter Disziplin wider, ${ }^{23}$ da hier Nachholbedarf herrschte. Die Kriegsordnung enthielt Bestimmungen für das Verhalten auf dem Marsch, im Gefecht und beim Wachdienst, also rein auf die Gefechtstechnik ausgelegte Vorschriften, weiters Bestimmungen zur inneren Ordnung im Heer, Bestimmungen über den Umgang mit Deserteuren, Bestimmungen über die Verteilung der Beute, Bestimmungen bezüglich des Gebets als moralische Vorbereitung auf den Kampf sowie Androhungen bei Zuwiderhandeln gegen diese Verordnungen. Strenge bis grausame Strafen waren die Folge bei einem Vergehen. Auffallend bei all diesen Regeln ist zum Ersten

Menschen rächend heimzusuchen, zu peitschen, zu schlagen, zu töten, zu köpfen und henken, zu ersäufen, zu verbrennen und mit allen Strafen zu belegen, welche nach dem Gesetze Gottes die Bösewichter treffen, ohne Rücksicht auf Rang und Geschlecht.“ Aus der Kriegsordnung Jan Žižkas, übersetzt bei Kann (1922), 33-34.

18 Eine Würdigung der Person Jan Žižkas bei Heymann (1955), 444-455.

19 Bujnoch (1988), 77.

20 Vgl. dazu Schmidtchen (1999), 45; die causa fidei auch herausgestrichen bei Seibt (1962), 46.

21 Schmidtchen (1999), 47.

22 Vgl. dazu Hoensch (1996), 290-291 und Anmerkung 20; weiterführend zum Kreuzzug gegen die Hussiten vgl. Heymann (1975), 586-646.

23 Die Kriegsordnung des Jan Žižka von Trocnov (\$1-\$12) bei Heymann (1955), 492-497; die Artikel übersetzt ins Deutsche und kommentiert bei Schmidtchen (1999), 47-52. 
der hohe Stellenwert des bedingungslosen Gehorsams - Todesstrafe bei Ungehorsam - und zum Zweiten der hohe moralische Anspruch an die Truppe:

"Also we do not want to suffer among us faithless men, disobedient ones, liars, thieves, gamblers, robbers, plunderers, drunkards, blasphemers, lechers, adulterers, whores, adulteresses, or any other manifest sinners, men or women; all these will we banish and chase away, or punish them with the help of the Holy Trinity according to the Law of God." 24

Diese Vorschriften stellten durchaus eher unübliche Forderungen dar, zumal die Heere jener Zeit zumeist Soldtruppen waren, deren Disziplin nicht selten zu wünschen übrig ließ und die für ihre ungezügelte wie auch zumeist „gottlose“ Lebensart bekannt waren. ${ }^{25}$ Gewiss bestanden auch die hussitischen Streitkräfte, wenn auch zu einem wesentlich kleineren Teil, aus Söldnern, ${ }^{26}$ jedoch muss in der Lebenseinstellung der große Unterschied gesehen werden. Der Söldner kämpfte üblicherweise des Geldes wegen, für jeden Kriegsherren oder Fürsten. Für den religiös motivierten Streiter des Jan Žižka gab es nur eine Option, nämlich jene auf Seiten des wahren Glaubens. Eine Missachtung der causa $D e \imath^{27}$, ein Verrat an der Sache Gottes, war das schlimmste Verbrechen gegen die gerechte Sache. Selbstverständlich soll mit diesem Vergleich die Effizienz der Soldtruppen nicht in Abrede gestellt werden, schließlich waren diese Männer professionelle Soldaten. Auf Dauer jedoch war und ist Geld nicht immer die beste Motivation, das Leben aufs Spiel zu setzen. Unzuverlässigkeit und Frontwechsel waren für die Soldknechte nicht außergewöhnlich, eine lässige und lockere Lebensweise in moralischer Beziehung an der Tagesordnung. Im Gegensatz dazu stand in den Feldordnungen der sogenannten „Feldbruderschaften“ die moralische

24 So lautet der $\$ 11$ der Kriegsordnung des Jan Žižka. Englisch bei Heymann (1955), 496.

25 In den zeitgenössischen Bild- und Textquellen wurden Soldaten nicht selten als undiszipliniertes Gesindel mit einem Hang zum Würfel- und Kartenspiel, zum Raufen und Saufen, zu Kleiderluxus und ungezügelter Sexualität dargestellt, so ein neuerer Befund allerdings für das 16. Jahrhundert. Vgl. dazu Rogg (2004), 121-144, besonders 136-137. Zu den Soldtruppen des späten Mittelalters allgemein vgl. Schmidtchen (1990), 43-48; Contamine (1992), zusammenfassend Contamine (1995), Mockler (1970) und neuerdings zur Thematik Sikora (2003), 210-238.

26 Vgl. Durdik (1961), 46-47.

27 Zur Rechtfertigung der Hussiten im Krieg gegen den legitimierten Herrscher vgl. Schmidtchen (1990), 79-93 und Schmidtchen (1999), 43-47. 
Integrität des Hussiten an oberster Stelle. Das Gebet war verpflichtend für den Krieger. ${ }^{28}$ Das religiöse Pathos, das Sendungsbewusstsein, zu den auserwählten Streitern Gottes zu gehören, und die daraus resultierende hohe Disziplin und Ernsthaftigkeit gepaart mit den bereits vorhandenen militärischen Fähigkeiten seiner Hussitenstreiter befähigten Žižka ${ }^{29}$, eine neue Gefechtstechnik zu entwickeln: die hussitische Wagenburg. ${ }^{30}$ Sie wurde zur mobilen, für die Reichsheere uneinnehmbaren Festung. ${ }^{31}$ Ohne auf die genaue Technik der speziell gerüsteten, sowohl defensiv als auch offensiv eingesetzten Wagenburg einzugehen, erforderte sie nun einmal ein hohes Maß an Koordination, Disziplin und nicht zuletzt eine gehörige Portion Korpsgeist. Diese Gefechtstechnik konnte nur durch gemeinsames Einüben erfolgreich umgesetzt werden. Daher waren eben nicht nur fanatische Überzeugung und rohe Besessenheit unabdingbare Voraussetzungen für den Erfolg, sondern auch diszipliniertes und geduldiges Verhalten. Das Zusammenwirken der geübten adeligen Reiterei mit waffengeübten städtischen Truppen und meist unerfahrenen bäuerlichen Knechten sowie der gekonnte Einsatz von Feuerwaffen und Artillerie spielte eine wesentliche Rolle im Konzept der Hussiten. So schufen diese Kriegsordnungen eine wohl einzigartige moralische und taktische Disziplin. Dementsprechend hoch war auch das Ausbildungsniveau.

1422, also zwei Jahre nach Ausbruch der ersten Kampfhandlungen, waren die Männer unter dem Kelchbanner schon dermaßen berüchtigt und gefürchtet, dass Papst Martin V. (1417-1431) Sigismund ernstlich ermahnte, effektive Maßnahmen gegen die Unter-

28 „Vor dem Aufbruche, vor jeder Unternehmung, und Befehlsverkündigung, vor jedem Ausfalle aus dem Lager oder der Stadt soll das ganze Heer im Angesichte Gottes und bei Erhebung des Sakramentes auf die Knie sinken und beten, damit der Allmächtige uns seine Hilfe angedeihen, den heiligen Streit zu seinem Ruhme, zur Förderung des Guten, zum Heile der Gläubigen ausfallen lasse.“ Aus der Kriegsordnung Jan Žižkas, übersetzt bei Kann (1922), 32-33.

$29 \mathrm{Zu} \mathrm{Žižkas} \mathrm{Fähigkeiten} \mathrm{als} \mathrm{Stratege} \mathrm{und} \mathrm{Feldherr} \mathrm{immer} \mathrm{noch} \mathrm{interessant} \mathrm{Holý} \mathrm{(1928).}$

30 So stellte auch Uwe Tresp in seiner äußerst fundierten Dissertation neuerdings fest: „Hauptsächliche Grundpfeiler dieser Erfolge waren: die hohe, religiös motivierte Moral der Hussiten, die damit zusammenhängende hohe taktische Disziplin der einzelnen Männer und der geschickte Einsatz neuer technisch-taktischer Varianten in Verbindung mit modernen Waffen." Tresp (2002), 25, weiters zur Disziplin Tresp (2002), 25-28. Diese Dissertation ist inzwischen auch als Tresp (2004) publiziert.

31 Zur Wagenburg vgl. zusammenfassend Schmidtchen (1990), 212-220. 
drückung der Ketzerei in Böhmen zu ergreifen. ${ }^{32}$ Sigismund hatte jedoch bis dahin immer wieder Schwierigkeiten, seine Soldtruppen zu bezahlen und zusammenzuhalten. ${ }^{33}$ Indessen schlugen die Streiter Gottes nicht nur sämtliche eindringenden „Kreuzfahrer“ im eigenen Land, sondern die Kämpfer aus Böhmen leisteten sich auch Raubzüge in die umliegenden Herrschaften.

Das Ende der hussitischen Feldheere wurde trotz aller Bemühungen des Reichsoberhaupts nicht durch auswärtige Truppen besiegelt. Der Zerfall der radikalen hussitischen Bewegung ging letztlich auf die innere Uneinigkeit sowie auf die auswärtige Politik und Diplomatie der Böhmen zurück. Miloslav Polívka resümierte zutreffend: „Der wesentlich geschwächte radikale hussitische Flügel konnte der politischen, militärischen und wirtschaftlichen Macht seiner Gegner in Böhmen und im Ausland kaum länger widerstehen." "34 In der Schlacht von Lipany 1434 siegten schließlich katholische und gemäßigte hussitische Heere gegen die Taboriten und Orebiten. ${ }^{35}$ Nichtsdestotrotz überlebten die hussitische Gefechtstechnik und Taktik im böhmischen Söldnerwesen, sodass Männer aus den Ländern der Wenzelskrone gerne weiterhin für kriegerische Unternehmungen, vornehmlich im Reich, rekrutiert wurden. ${ }^{36}$

\section{Verhaltensnormen bei Cromwells Ironsides}

Machen wir einen Sprung von ca. 220 Jahren in die Wirren der Englischen Revolution ${ }^{37}$. Aufgrund der für die Verhältnisse Englands sehr selbständigen persönlich-monarchischen Politik des englischen Stuartkönigs Karl I. ${ }^{38}$ und der permanenten Missachtung des Parlaments entgegen der englischen Tradition kam es schließlich nach ei-

$32 \operatorname{Kerler}$ (1883), 119 (Nr. 106).

33 Dazu vgl. Hoensch (1996), 293.

34 Vgl. Polívka (1989), 224. Zum Ende der Hussitenkriege vgl. auch Eberhard (1992), 1-43.

35 Zur Schlacht von Lipany vgl. Bartoš (1934), Urbánek (1934) und neue Interpretationen aufnehmend Šmahel (2002). Band III.

36 Dazu die ausführliche Studie von Tresp (2004). Allerdings dürfen die böhmischen, auf den mitteleuropäischen Kriegsschauplätzen operierenden Söldner des 15. Jahrhunderts nicht durchgehend als Hussiten bezeichnet werden.

$37 \mathrm{Zu}$ den zahlreichen Publikationen über die Englische Revolution vgl. nur Saage (1981), Schröder (1986), Wende (1980), Greyerz (1994), Coward (2003), 185-277 und Stone (1983); einen Überblick über die verschiedenen Interpretationsrichtungen vermittelt zusammenfassend Heard (1995), 1-15; weiters Morril (1993), Zagorin (1998), Carlin (1999).

38 Zu Karl I. (1600-1649) vgl. Wende (1998), 111-127, Carlton (1995b) und Asch (1993). 
ner aufgrund leerer Staatskassen notwendigen Einberufung des Ober- und Unterhauses zum Zusammenstoß und unerbittlichen Machtkampf dieser zwei Gewaltenträger. Doch es sollte nicht nur ein politischer Kampf bleiben, England polarisierte sich zwischen der königstreuen staatlich anglikanischen Kirche und dem radikalen Puritanismus, der schon seit der Mitte des 16. Jahrhunderts eine tief greifende Reform der Staatskirche forderte. Weitgehend calvinistisch beeinflusst, versuchten die Puritaner, moralischen Anspruch und Lebensführung in Übereinstimmung zu bringen. ${ }^{39}$ Maßgebend unter den verschiedenen Richtungen der Puritaner wurden die Independenten, auch Kongregationalisten genannt, die sich für eine dezentralisierte Kirchenorganisation und weitgehende Toleranz einsetzten. Sie verstanden sich als eine Versammlung oder eben „Congregation“ der wahrhaft Gläubigen oder Heiligen, bei der es keinen Unterschied zwischen Laien und Geistlichen gab. Hauptexponent der Independenten wurde Oliver Cromwell. Der 1599 geborene, aus ritterlichem Landadel stammende Oliver wurde im puritanischen Glauben erzogen und wuchs im rigiden calvinistischen Ambiente auf. Karl Heinz Metz wies darauf hin, dass bereits in der schulischen Erziehung Cromwells die Existenz des Antichristen, namentlich des römischen Papstes, also die Anwesenheit des Bösen unter den Menschen, eine zentrale Rolle spielte. ${ }^{40}$ Im 1642 beginnenden Krieg gegen die Königspartei wurden die Royalisten, von den Gegnern gerne auch „Papisten" genannt, insgesamt zu Antichristen stilisiert. ${ }^{41}$

Cromwell, der eine ausgesprochene organisatorische Begabung, persönlichen Mut und eine zähe, belastbare Physis hatte, ${ }^{42}$ stellte im August 1642 eine Reiterkompanie von achtzig Mann auf. Es dauerte nicht lange und die Stärke seiner Truppe wuchs. Damit war natürlich auch sein schneller Aufstieg vom Hauptmann zum Obersten verbunden. 1644 war er bereits Generalleutnant (Lieutenant-General) und Befehlshaber der Kavallerie der Ostarmee (Eastern Association $^{43}$ ). Seine gottesfürchtigen Männer - vorwiegend fromme Purita-

39 Zum englischen Puritanismus vgl. Heal (1981), 201-210, Lamont (1969), ferner auch Hill (1968, 1972), Toon (1972), 30-41, Pennington/Thomas (1978)Puritans and Revolutionaries; Collinson (1982), McGregor/Reay (1984); einen Überblick über den englischen Puritanismus bietet Greyerz (2000), 135-154 sowie Collinson (1997), 8-25, besonders 21-24.

40 Vgl. Metz (1993), 32.

41 Vgl. dazu Metz (1985), 43-84.

42 So Metz (1993), 47.

43 Zur berittenen Kerntruppe der New Model Army vgl. Holmes (1974). 
ner, aus East Anglia stammend und Ironsides („Eisenseiten“, gepanzerte Kavallerie) genannt - wurden zur Kerntruppe der berittenen Kontingente des Parlaments, zur Stütze der 1645 ins Leben gerufenen New Model Army. ${ }^{44}$ Aber schon vor der unbedingt notwendigen Reorganisation der Parlamentsarmee genossen Cromwells Ironsides einen ausgezeichneten Ruf:

"Colonell Cromwell is for present at Huntingdon with some five troops to which are added some countrymen of Hunts and other counties; the enemy fled as is conceived to Newarke, upon the noyse of him. The Colonell exercises strict discipline, for when two troopers would have escaped he sent them back, caused them to be whipt at the market place in Huntingdon." 45

Sowohl bei den eigenen Leuten im Parlament als auch bei den „Cavaliers“ - die Bezeichnung für die Royalisten im Englischen Bürgerkrieg, im Gegensatz zu den puritanischen „Roundheads“46 _ konnte sich Cromwell den Ruf, eine disziplinierte und furchtlose Truppe zu führen, erwerben. ${ }^{47}$ Die innere, religiös motivierte Disziplin war ausschlaggebend für die notwendige auf dem Gefechtsfeld erbrachte Disziplin. Edward Hyde, First Earl of Clarendon (16091674), als Kronrat und Schatzkanzler seiner Majestät Karls I. und späterer Lordkanzler Karls II. bestimmt kein Freund des Parlamentskommandanten, beschrieb in seiner Geschichte des Englischen Bürgerkrieges die offensichtlichen Vorteile der Reiterei Cromwells:

"And that difference was observed shortly from the beginning of the war, in the discipline of the King's troops and of those which marched under the command of Cromwell, [...] that though the King's troops prevailed in the charge, and routed those they charged, they never rallied themselves again in order, nor could be brought to make a second charge again the same day: which was the reason that they had not an entire victory at Edgehill: whereas Cromwell's troops, if they prevailed, or though they were beaten and routed,

44 Zur nach der Self-Denying Ordinance reorganisierten Parlamentsarmee vgl. das Standardwerk von Firth (1962), Kishlansky (1979) sowie Gentles (1992).

45 So ein zeitgenössischer Bericht über die Disziplin in Cromwells Truppen: "Special Passages and Certain Informations, April 1643", in: Abbott (1937), 226.

46 Vgl. dazu Hibbert (1993).

47 Zur Disziplin der Ironsides vgl. Gaunt (1996), 50. 
presently rallied again, and stood in good order till they received new orders." 48

Diese Disziplin war es auch schließlich, die den mit Esprit kämpfenden, jugendlichen royalistischen „General of the Horse“, den Pfalzgrafen Rupert ${ }^{49}$, Sohn des unglücklichen Kurfürsten Friedrich V. von der Pfalz und Neffen des englischen Königs Karl I., niederzuringen half. Der impulsive, unkonventionelle, gefechtstechnisch ausgezeichnet operierende Rupert konnte letztendlich gegen die mit eiserner Härte und religiösem Pathos kämpfenden Roundheads keinen Endsieg erringen. Bis zum Sommer 1644 operierte Rupert äußerst erfolgreich, doch bei Marston Moor ${ }^{50}$ stand dem Pfälzer zum ersten Mal Cromwells Reitertruppe unter dem Kommando von Sir Thomas Fairfax, Oberbefehlshaber der Parlamentsarmee, gegenüber; die Royalisten verloren und der Nimbus der Unbesiegbarkeit war zerschlagen. Frank Kitson, ein ausgezeichneter Analytiker der Schlachten des Bürgerkrieges, fasste treffend zusammen:

"In the end their victory [Sieg der Parlamentsarmee, R.R.] was due a combination of Thomas Fairfax's tactical flair, the disciplined excellence of the Eastern Association horse raised, trained and led by Cromwell, and the competence of senior Scottish commanders such as Lumsden and David Leslie, to say nothing of the numerical superiority of the allies and the determination in adversity of some of their foot regiments." 51

Ein Siegeszug des Parlaments folgte. Obgleich Cromwell bestimmt nicht der Soldat der ersten Stunde für das Parlament war, war gerade sein Anteil, seine konfessionell inspirierte Initialzündung von entscheidender Bedeutung. Er erkannte und organisierte das Gewaltpotential des Sektierertums. ${ }^{52}$ Der Aufstieg des Kavalleriegenerals war geradezu „eng mit dem zunehmend sektiererischen

48 Zitat nach Hyde (1958), 45-46; zu Clarendon und seiner Geschichte des Englischen Bürgerkrieges vgl. Harris (1983) sowie Hutton (1982), 70-88.

49 Zum Pfalzgrafen, der General des Englischen Bürgerkrieges wurde, vgl. die Standardbiographie von Morrah (1976); zu Ruperts Engagement im Englischen Bürgerkrieg vgl. die ausgezeichnete Analyse von Kitson (1994) und hauptsächlich aus militärhistorischer Perspektive Rebitsch (2005), 27-41.

50 Zur Schlacht bei Marston Moor vgl. Kitson (1994), 188-205, zur Gesamtproblematik Young (1970), 1644.

51 Zitat nach Kitson (1994), 205.

52 So bereits Delbrück (1920), 216-217. 
Charakter des parlamentarischen Heeres verbunden" ${ }^{53}$ Der spätere Lord Protector schuf eine Truppe mit einer noch höheren Leistungsfähigkeit, Tapferkeit und größerem Siegeseifer als Ruperts Reiterei während der ersten zwei Kriegsjahre. Das Weltbild dieser Truppe war, ähnlich wie bei den Hussiten, von chiliastischen - zumindest jedoch von endzeitlichen ${ }^{54}$ - Vorstellungen geprägt: Das tausendjährige Reich stand ihrer Meinung nach nahe bevor. Um dieses heiß ersehnte Ziel zu erreichen, musste noch der Antichrist ${ }^{55}$, also die Papisten und der König, niedergerungen werden. Der religiöse Eifer und Enthusiasmus der Puritaner gaben ihnen ein, das auserwählte Volk Gottes zu sein. Diese teleologisch strukturierte und rational einsetzbare Vorstellung der Auserwähltheit, der Glaube an die Vorsehung (providence), versah die Soldaten mit der absoluten Siegeszuversicht und zudem mit der unerschütterlichen Überzeugung, ihr Leben für eine gerechte Sache zu riskieren. Die Kreation eines Feindbildes des Anderen, der nicht nur der politische Gegner war, sondern vielmehr den rechten Glauben bedrohte, ein Feind außerhalb der moralischen Norm, war dabei unabdingbar. Die Propaganda des Parlaments stilisierte so auch Rupert von der Pfalz zum wahren Bösen, zum Teufel, der mit seinen Leuten auch vor dem Aufspießen kleiner Kinder nicht zurückschreckte. ${ }^{56}$

Der providentiell geprägte Puritanismus der Independenten bekam durch diese besondere Ernsthaftigkeit und durch seinen rigiden Eifer sein aggressives auf die Liquidierung des Königs ausgerichtetes Glaubensgebäude. Gepaart mit der Disziplin der Truppe und mit handfestem Sendungsbewusstsein erfüllt, warfen sich die Streiter Jehovas, für die sie sich hielten, in den Kampf gegen den Stuart und seine Anhänger. Der Glaubenseifer der independistisch gesonnenen Männer hatte eine äußerst harte und kompromisslose Kriegführung zur Folge. Freilich brach auch Cromwell mit den radikalen chiliasti-

53 Metz (1985), 55; zum Chiliasmus in der Parlamentsarmee vgl. Metz (1985), 54-58.

54 Dass die Endzeiterwartung, wie sie im England des 17. Jahrhunderts weit verbreitet existierte, dogmatisch nicht unbedingt chiliastisch geprägt war, betont Greyerz (2000), 151.

55 Zur Vorstellung des in der Person des Königs vorkommenden „Antichristen“ in England im Zeitalter der Revolutionen vgl. Hill (1971).

56 Vgl. Hibbert (1993), 56 und die Abbildung "Cruelties of the Cavaliers, 1644", 242. Das Propagandaflugblatt zeigt Soldaten des Königs beim Aufspießen von Kindern; ein immer schon beliebter Topos, um den Gegner zu diskreditieren. Vgl. zudem Rebitsch (2005), 3132. 
schen Vorstellungen im Laufe der Zeit, ${ }^{57}$ profanere politische Konzepte schienen effizienter, der religiöse Eifer aber blieb:

"You know how it hath pleased God to beat down your enemies under your feet, both in this kingdom and the kingdom of Scotland; [...] And although God hath used us as instruments for their good, yet hitherto they are not sensible of it, but they are angry that God brought them His mercy at such hand; [...]", verkündete der Lieutenant-General vor Annahme des Kommandos gegen Irland ${ }^{58}$.

So waren Sendungsbewusstsein und religiöser Eifer auch nach dem steten Rückgang der sektiererischen Chiliasten ungebrochen. Dennoch: Obwohl diese „higly trained and expertly skilled Parliamentarian army“ einer der „most aggressive and ambitious forces in Europe" war, wie Tom Reilly feststellte, ließ sich Cromwells Soldateska zu keiner blindwütigen Schlächterei in Irland herab, wie ihr in der Historiographie immer wieder unterstellt wurde. ${ }^{59}$ Bedingungslose Disziplin war eben ein Qualitätszeichen dieser Armee und ihres Kommandanten. Die New Model Army ging gegen feindliche Kombattanten zwar gnadenlos vor, ihren Offizieren gelang es jedoch auch, die für die Kriegführung der damaligen Zeit ansonsten durchaus üblichen Ausschreitungen gegen Zivilisten weitgehend zu unterbinden.

Bei aller tiefen Frömmigkeit und bei allem Glaubenseifer des Oliver Cromwell waren freilich durchwegs rationale Ansätze und wohldurchdachte Ideen bei der Formung seiner Truppe existent. Cromwell wusste sehr wohl das Ideologisch-Religiöse vom Praktischen zu unterscheiden. Nach dem Vorbild des niederländischen Unabhängigkeitskrieges wollte auch er Soldaten formen, die durch höhere Moral und Disziplin, durch eine Selektion, gute Ausbildung,

57 Zum Bruch mit dem Chiliasmus vgl. Metz (1985), 65 und 80-81 sowie auch Hill (1970), 209-241.

58 Vgl. "General Council at Whitehall, 23 March 1648[-9]", in: Abbott (1939), 37.

59 Zum traditionellen Bild der brutalen Irlandexpedition Cromwells vgl. Hill (1970), 112-114 sowie Gentles (1992), 350-384. Zu Cromwells Irlandpolitik im Allgemeinen vgl. Bernard (1975), weiters Berbig (1984), 159-173. Abweichend dazu konnte Tom Reilly anhand einer sehr quellennahen Studie nachweisen, dass die angeblichen Massaker an Zivilisten in Drogheda und Wexford keineswegs den historischen Tatsachen entsprechen. Cromwells Armee ging zwar nach der abgelehnten Übergabe der Städte mit der vollen Härte gegen die Garnisonen und bewaffneten Kombattanten vor, blieb jedoch dabei im Rahmen des geltenden Kriegsrechts und tötete auch keine Zivilisten. Siehe Reilly (1999). 
gute Ausrüstung und regelmäßige Bezahlung den professionellen Söldnern oder, im Falle Englands, den kämpfenden Adeligen, überlegen waren. ${ }^{60}$ Dieses Modell des gut bezahlten, gut ausgerüsteten und relativ gut versorgten Verbandes sollte der gesamten New Model Army zum Vorbild werden. ${ }^{61}$ Das neu formierte Parlamentsheer wurde somit regelmäßig besoldet und hatte zudem die Werkstätten und Arsenale von London auf seiner Seite. All diese Faktoren führten dazu, dass es der Parlamentsfraktion schließlich gelang, sowohl moralisch als auch logistisch und finanziell überlegene Armeen ins Feld zu führen.

Das heißt keineswegs, dass es nicht auch Unzufriedenheit, ja sogar äußerst prekäre Momente und beginnende Meutereien in der Parlamentsarmee gegeben hätte ${ }^{62}$, aber die für jene Zeit relativ guten Rahmenbedingungen und die in der Luft liegenden calvinistischpuritanischen Ideen machten die New Model Army ohne Zweifel zu einem schlagkräftigen Instrument. Natürlich, und hier ist dem englischen Historiker Christopher Hill völlig recht zu geben, waren das ausgeklügelte philosophische und theologische System der in England ohnehin abgeschwächten Prädestinationslehre ${ }^{63}$, die Lehre Calvins und die providentiellen Vorstellungen der Gelehrten jener Zeit für die breite Masse der eher einfachen, aus sozial niederen Schichten kommenden Soldaten des Parlaments nicht ausschlaggebend und bestimmend für ihren Kampfwillen. ${ }^{64}$ Die Moral und das Selbstvertrauen, der psychische und mentale Zustand der Soldaten Cromwells sind viel eher aus dem sie bestärkenden, dem Puritanismus innewohnenden Auserwähltheitsglauben zu erklären denn aufgrund komplexer philosophischer Theoriegebäude. Daraus erwuchs die

60 Vgl. dazu Hill (1970), 76.

61 Vgl. Gentles (1992), 118-119.

62 Vgl. "A Remonstrance from his Excellency Sir Thomas Fairefax, and his Council of War, concerning the late Discontent and Distraction in the Army; with his Excellency's Declaration of himself, and Expectation from the Army thereupon, for the future uniting of the Army, Hertford 14th Nov 1647", in: Abbott (1937), 557-560.

63 Einen globalen, die Zusammenhänge zwischen frühneuzeitlicher Kirchenlehre und dem Entstehungsprozess der Moderne erläuternden Erklärungsversuch, bei dem der Prädestinationsglaube im Mittelpunkt steht, unternahm der deutsche Soziologe Max Weber. Siehe Weber (1922). Auf eine Verknüpfung der Weber'schen Thesen mit der zur Diskussion stehenden religiösen Kampfmoral wird hier bewusst verzichtet.

64 Vgl. dazu Hill (1970), 211-241, besonders 212-213. "But Calvinism did not exist primarily as a philosophical system. It gave courage and confidence to a group of those who believed themselves to be God's elect". 
Kraft der Ironsides und auch der New Model Army. Der Glaube, zu einer elitären, von Gott auserwählten Macht zu gehören, beflügelte die Männer im Krieg gegen den Antichristen und nahm ihnen - bis zu einem gewissen Teil zumindest - die Angst vor dem Kampf gegen das gesalbte Haupt des Königs.

Doch nicht nur die volkstümliche Glaubensvorstellung jener Zeit sorgte für ein harmonisches Gefüge ${ }^{65}$, sondern auch strenge Strafen für besonders ahndungswürdige Delikte waren bestimmend für die Disziplin der New Model Army. Denn neben dem unbestritten hohen Grad an Frömmigkeit, der alle Dienstgrade der 1645 reformierten Parlamentsarmee auszeichnete und der den Zeitgenossen einen einheitlichen und kameradschaftlichen Eindruck der Armee vermittelte, gab es strenge Strafen im Ordnungskatalog. Auf Desertion, Meuterei und Plünderung stand die Todesstrafe, Blasphemie fiel unter den frommen Männern der Ächtung und harter Bestrafung anheim. Und ähnlich den Hussiten galten sonst eher nicht als Verbrechen angesehene Verhaltensweisen, wie Fluchen, übermäßiges Trinken sowie der Verkehr mit Prostituierten, als Verstoß gegen die Integrität der Armee. ${ }^{66}$ Ein moralisch einwandfreies und gottesfürchtiges Leben war somit unabdingbar für den Dienst in der sogenannten „Armee der Heiligen“. Psalmen singend stellten sie sich dem Feind und jagten ihm damit einen gehörigen Schrecken und Respekt ein. ${ }^{67}$

Obzwar die New Model Army in Folge unbesiegt blieb, nimmt ihre Existenz nur eine kurze Periode in der englischen Geschichte ein. Das System des Protektorats von Oliver Cromwell und - in der Endphase des republikanischen Experiments - seines Sohnes Richard verfiel innerlich, wurde von der breiten Masse abgelehnt und war somit untragbar. Olivers Sohn Richard konnte das System nicht mehr aufrechterhalten. Eine Voraussetzung zur Restauration der Monarchie der Stuarts war dann geradezu die Entmachtung und Be-

65 Zum äußeren harmonischen Erscheinungsbild der New Model Army vgl. Gentles (1992), 91-107, vor allem 103.

$66 \mathrm{Zu}$ den Strafen in der Parlamentsarmee vgl. Gentles (1992), 106-107.

67 "Our men went on in several bodies singing Psalms [...] Colonel Cromwell fell with brave resolution upon the Enemy, immediately after Dragooners had given him the first volley, [...]." Abbott (1937), 265. 
seitigung der einst so stolzen Armee der Republik. ${ }^{68}$ Die New Model Armee verschwand im Nebel der Geschichte.

\section{Resümee - Parallelitäten}

Trotz aller unterschiedlicher Ausgangslagen und Zielsetzungen soll resümierend festgestellt werden, dass sowohl bei den radikalen Taboriten als auch bei den Cromwell hörigen Sektierern ein chiliastischer, auf jeden Fall endzeitlicher Anfangsimpuls gegeben war. LieBen die Führer, Žižka wie Cromwell, die radikal-chiliastischen Ideen im Laufe der Zeit auch fallen, so stellten sie doch in der Anfangsphase einen enormen Motivationsschub dar. Auf jeden Fall blieb der für die Kampfmoral so wichtige Glaube an die Auserwähltheit, der Glaube, ein elitärer Streiter Gottes zu sein. Dieser Auserwähltheitsglaube war auch in Hinblick auf den Gegner wichtig, da man gegen keinen Geringeren als den legitimierten, von Gott eingesetzten Herrscher vorging; ein für das späte Mittelalter und für die frühe Neuzeit unerhörter Schritt, war doch der Glaube an das Gottesgnadentum keineswegs nur eine leere Floskel, sondern selbstverständlich Allgemeingut der damaligen Herrschaftsauffassung und Herrschaftslegitimation. ${ }^{69}$ Sigismund, bereits am 8. November 1414 in Aachen zum Römischen König gekrönt, wurde am 23. Mai 1418 durch Papst Martin V. in Konstanz die feierliche Approbation erteilt. Der Colonna-Papst vollzog dort auch die confirmatio electionis, die Bestätigung der Wahl durch das höchste Kirchenoberhaupt. Damit war der Römische König vom Papst legitimiert. Zwei Jahre später, am 28. Juli 1420, schon in Mitten der hussitischen Aufstandsbewegung, wurde der Römische König in Beisein der Mehrheit des böhmischen und mährischen Hochadels im St. Veitsdom mit der Wenzelskrone zum König der böhmischen Länder erhoben. ${ }^{70}$ Dennoch fand der Mörder

68 Zur Endphase des Protektorates vgl. Weinzierl (1979), 48-77; zur Rückkehr Karls II. und zur Wiedereinsetzung der Monarchie in England vgl. Hutton (1985) sowie Morrah (1979).

$69 \mathrm{Zu}$ den Anfängen der monarchischen Herrschaftslegitimation durch das Gottesgnadentum vgl. Kern (1980); zum sakralen Charakter des Königtums vgl. Kantorowicz (1957); weiters Brunner (1968), 160-186; Duchhardt (1983); zusammenfassend Schlinker/Willoweit (1995), 917-920; zum Begriff und Funktion der Monarchie vgl. Boldt (1978), 133-214.

70 Vgl. dazu Hoensch (1996), 156-157 und 293. 
des Jan Hus ${ }^{71}$, wie man ihn in Böhmen zu nennen pflegte, keine Akzeptanz mehr. Karl I. von England, besonders von der Würde seines Amtes und Unantastbarkeit seiner Person überzeugt, rechtfertigte sich schließlich vor Gericht, wo ihm wegen Hochverrats der Prozess gemacht wurde, damit, dass keine irdische Gewalt den von Gott eingesetzten Herrscher zur Rechenschaft ziehen könnte. ${ }^{72}$ Er sah die Monarchie als Stiftung Gottes, eingesetzt zum Wohle und zum Schutz der Menschen. Dass der König von England erhebliche Resonanz als von Gott legitimierter Herrscher, ja sogar Wunderheiler, erhielt, beweist allein schon die Tatsache, dass noch während seiner Gefangenschaft ein beachtlicher Zustrom von Heilungswilligen in sein Gewahrsam herrschte. Den Königen von England wie auch von Frankreich wurde nämlich im Volksglauben die Kraft, Skrofeln - eine tuberkulöse Krankheit - durch ihre wundertätige Berührung zu heilen, zugeschrieben. ${ }^{73}$ Das war in der Tat eine in der volkstümlichen Vorstellung des geheiligten Königtums nicht zu unterschätzende Legitimation seiner Herrschaft. Es gehörte schon, neben aller philosophischer Rechtfertigung ${ }^{74}$, eine gehörige Portion Selbstbewusstsein dazu, einem solchen Monarchen den Krieg zu erklären und im Falle Englands hinzurichten. Der Auserwähltheitsglaube ${ }^{75}$ sowie nicht zuletzt die damit unbedingt notwendige Vorstellung, den Antichristen zu beseitigen und damit eine bessere Welt zu schaffen, waren unabdingbare Voraussetzungen, diese psychologische Hürde mental überwinden zu können. Der Glaubenseifer brachte somit ein hohes $\mathrm{Maß}$ an für die Kampfkraft unabdingbarer Disziplin, aber auch Kompromisslosigkeit gegen Andersdenkende und Andersgläubige mit sich.

Doch die Führer und Kommandanten verließen sich nicht nur auf diesen einzigartigen Motivationsschub oder auf theologisch-

71 Sigismund versicherte dem böhmischen Reformator freies Geleit, dennoch wurde Hus aufgegriffen und zum Tode verurteilt. Vgl. dazu Hoke (1983), 172-193, Seibt (1972) sowie Seibt (1983), 159-171. Grundsätzlich zu Jan Hus die Aufsätze in: Seibt et al. (1997).

72 Vgl. dazu Wende (1998), 125-126; zum Prozess gegen den Stuartkönig vgl. Kelsey (2003).

73 Dazu vgl. Bloch (1998), 393-401.

74 Zur politisch-theoretischen Rechtfertigung des Rump-Parlaments, dem König den Prozess zu machen, vgl. Saage (1981), 115-136; Zum Rump-Parlament vgl. die Studie von Worden (1974).

75 Zur im 17. Jahrhundert weit verbreiteten Vorstellung, England sei eine von Gott auserwählte ,protestantische Nation“, vgl. Firth (1979), 69-110, Christianson (1978), 39-41, Greyerz (2000), 139-140 und 151, Schröder (1986), 27-28. 
philosophische Rechtfertigungslehren, sondern entwarfen auch umfassende Strafkataloge, die ein Übriges für die gute Disziplin taten. So waren in Böhmen als auch in England Verhaltensweisen, die in den damals aufgestellten Söldnerheeren eher als Kavaliersdelikte galten, höchst strafwürdig. Treulose, Säufer, Gotteslästerer, Spieler, Lüstlinge und Ehebrecher waren sowohl bei den Taboriten als auch bei der New Model Army nicht erwünscht, sie untergruben die moralische Integrität der Truppe, die man für die Durchschlagskraft der Armee für unablässig hielt. Im Übrigen waren von diesen Strafen bei moralischen Vergehen alle Dienstgrade betroffen. War der Auserwähltheitsglaube positive Motivation, so stellte der Strafkatalog die negative dar. Wie auch das nicht zu unterschätzende durch den extremen Glauben verinnerlichte metaphysische Gewissen, das eben, kraft der Religion und des Glaubens, ein individuelles Versagen als Abfall von Gott erscheinen ließ. Gegen einen irdischen Strafkatalog zu verstoßen war sicher leichter zu ertragen als gegen die Regeln und gegen die Sache Gottes. Dies war die anerzogene, innerliche und wahre Gottesfurcht. So findet man also metaphysisch bedingte wie auch durchaus rational gehaltene Elemente in den Antriebskräften der religiös motivierten Armeen. Glaubenseifer, strenge moralische Lebensauffassung, Disziplin, taktische Innovation - bei Žižka sicher mehr als bei Cromwell -, ein als Antichrist deklarierter Gegner und vor allem die Vorstellung, elitärer, von Gott auserwählter Krieger zu sein, stellten sich als äußerst effiziente Mischung zur durchschlagenden Kriegführung heraus.

\section{Literatur}

Abbott, Wilbur Cortez, Hg. (1937): The Writings and Speeches of Oliver Cromwell. With an introduction, notes and a sketch of his life. Volume I. 1599-1649. Cambridge/UK.

Abbott, Wilbur Cortez, Hg. (1939): The Writings and Speeches of Oliver Cromwell. With an introduction, notes and an account of his life. Volume II. The Commonwealth 1649-1653. Cambridge/UK.

Altmann, Wilhelm, Hg. (1893): Eberbart Windeckes Denkwürdigkeiten zur Gescbichte des Zeitalters Kaiser Sigmunds. Berlin.

Asch, Ronald G. (1993): Der Hof Karls I. von England. Politik, Provinz und Patronage 1625-1640. Band 3. Köln-Weimar-Wien.

Ashley, Maurice (1958): The Greatness of Oliver Cromwell. New York.

Ashley, Maurice (1990): The English Civil War. Gloucester. 
Ashton, Robert (21989): The English Civil War: Conservatism and Revolution, 1603-1649. London.

Barnard, Toby C. (1975): Cromwellian Ireland. Government and Reform in Ireland, 1649-1660. Oxford.

Bartoš, František M. (1934): Lipany. Prag.

Bennett, Martyn (1997): The Civil Wars in Britain and Ireland, 1638-1651. Oxford.

Berbig, Hans Joachim (1984): „Oliver Cromwells Irlandpolitik“, in: Archiv für Kulturgeschichte 66, 159-173.

Bezold, Friedrich von (1872-1877): Kaiser Sigmund und die Reichskeriege gegen die Husiten, 3 Bände. München.

Bloch, Marc (1998): Die wundertätigen Könige. München.

Boldt, Hans (1978): „Monarchie“, in: Brunner, Otto/Conze, Werner/Kosellek, Reinhart, Hg.: Geschichtliche Grundbegriffe. Historisches Lexikon zur politisch-sozialen Sprache in Deutschland. Band 4. Stuttgart, 133-214.

Brunner, Otto (21968): „Vom Gottesgnadentum zum monarchischen Prinzip“, in: Brunner, Otto: Neue Wege zur Verfassungs- und Sozialgeschichte. Göttingen, 160-186.

Bujnoch, Josef, Hg. (1988): Die Hussiten. Die Chronik des Laurentius von Březová 1414-1421. Graz-Wien-Köln.

Carlin, Norah (1999): The Causes of the English Civil War. Oxford.

Carlton, Charles (1995a): Going to the Wars. The Experience of the British Civil Wars, 1638-1651. London-New York.

Carlton, Charles (21995b): Charles I. The Personal Monarch. London.

Christianson, Paul (1978): Reformers and Babylon. English Apocalyptic Visions from the Reformation to the Eve of the Civil $W$ ar. Toronto.

Collinson, Patrick (1982): The Religion of Protestants. The Church in English Society, 1559-1625. Oxford.

Collinson, Patrick (1997): „Puritanismus I“, in: Theologische Realensyklopädie XXVIII, 8-25.

Contamine, Philippe (31992): La Guerre au Moyen Age. Paris.

Contamine, Philippe (1995): „Söldner, -wesen“, in: Lexikon des Mittelalters. Band VII. München-Zürich, 2030-2034.

Coward, Barry (1991): Oliver Cromwell. London.

Coward, Barry (32003): The Stuart Age. A History of England 1603-1714. London.

Delbrück, Hans (1920): Geschichte der Kriegskunst im Rabmen der politischen Geschichte. Teil IV. Berlin.

Duchhardt, Heinz, Hg. (1983): Herrscherweihe und Königskeönung im frühneuzeitlichen Europa. Stuttgart.

Durdik, Jan (1961): Hussitisches Heerwesen. (Ost-)Berlin.

Eberhard, Winfried (1992): „Der Weg zur Koexistenz: Kaiser Sigmund und das Ende der hussitischen Revolution“, in: Bohemia 33, 1-43.

Firth, Charles H. (41962): Cromwell's Army. London. 
Firth, Katharine R. (1979): The Apocalyptic Tradition in early Protestant Historiography in England and Scotland, 1530 to 1655 . Oxford.

Fuchs, Theodor (1972): Geschichte des europäischen Kriegswesens. Teil 1: Vom Altertum bis zur Aufstellung stehender Heere. Wien.

Gardiner, Samuel Rawson (1886-1891): History of the Great Civil War, 16421649, 3 Bände. London.

Gaunt, Peter (1996): Oliver Cromwell. Oxford.

Gentles, Ian (1992): The New Model Army in England, Ireland and Scotland, 1645-1653. Oxford-Cambridge/MA.

Gillingham, John (1976): Cromwell. Portrait of a Soldier. London.

Greyerz, Kaspar von (1994): England im Jahrhundert der Revolutionen 16031714. Stuttgart.

Greyerz, Kaspar von (2000): Religion und Kultur. Europa 1500-1800. Göttingen.

Harris, Ronald W. (1983): Clarendon and the English Revolution. London.

Heard, Nigel (1995): Stuart Economy and Society. London.

Heal, Felicity (1981): „The Church of England and its Opponents from Reformation to Revolution", in: The Historical Journal 24, 201-210.

Lamont, William M. (1969): Godly Rule. Politics and Religion 1603-1660. London.

Heymann, Frederick G. (1955): John Žižkea and the Hussite Revolution. Princeton/NJ.

Heymann, Frederick G. (1975): „The Crusades against the Hussites“, in: Setton, Kenneth M., Hg.: A History of the Crusades, Volume 3. Madison/WI, 586-646.

Heymann, Frederick G. (1998): „Jan Žižka (von Trocnov)“, in: Lexikon des Mittelalters IX. München-Zürich, 659-660.

Hibbert, Christopher (1993): Cavaliers and Roundheads. The English at War 1642-1649. London.

Hill, Christopher (1968): Puritanism and Revolution. Studies in interpretation of the English revolution of the 17 th century. London.

Hill, Christopher (1970): God's Englishman. Oliver Cromwell and the English Revolution. London.

Hill, Christopher (1971): Antichrist in 17th Century England. London.

Hill, Christopher (1972): The World Turned Upside Down. Radical Ideas during the English Revolution. London.

Hoensch, Jörg K. (1996): Kaiser Sigismund. Herrscher an der Schwelle zur Neuzeit 1368-1437. München.

Hoke, Rudolf (1983): „Der Prozeß des Jan Hus und das Geleit König Sigmunds“, in: Annuarium historiae conciliorum 15, 172-193.

Holmes, Clive (1974): The Eastern Association in the English Civil War. London.

Holý, Kamil (1928): Zižka strateg. Kritické úvahy o jeho tazenich. Prag.

Hutton, Ronald (1982): „Clarendon's History of the Rebellion“, in: English Historical Review 97, 70-88. 
Hutton, Ronald (1985): The Restoration. A Political and Religious History of England and $W$ ales 1658-1667. Oxford.

Hyde, Edward (1958): The History of the Rebellion and Civil Wars in England, Volume IV, Book IX. Oxford.

Kaminsky, Howard (1957): „Chiliasm and the Hussite Revolution“, in: Church History 26, 43-71.

Kaminsky, Howard (1967): A History of the Hussite Revolution. Berkeley-Los Angeles.

Kann, Leopold (1922): Das Feldherrnbild Žǐ̌kas. Mit einigen neuen Streiflichtern. Wien.

Kantorowicz, Ernst H. (1957): The King's Two Bodies. A Study in Mediaeval Political Theology. Princeton/NJ.

Kelsey, Sean (2003): „The Trial of Charles I“, in: English Historical Review $118,583-616$.

Kenyon, John/Ohlmeyer, Jane, Hg. (1998): The Civil Wars. A Military History of England, Scotland, and Ireland 1638-1660. Oxford.

Kerler, Dietrich, Hg. (1883): Deutsche Reichstagsakten unter Kaiser Sigmund 1421-1426, Zweite Abtheilung, VIII. Band. Gotha.

Kern, Fritz (71980): Gottesgnadentum und Widerstandsrecht im frühen Mittelalter. Zur Entwicklungsgeschichte der Monarchie. Darmstadt.

Kishlansky, Mark (1979): The Rise of the New Model Army. Cambridge-New York.

Kitson, Frank (1994): Prince Rupert. Portrait of a Soldier. London.

Konrad, Robert (1981): „Chiliasmus III. Das Mittelalter“, in: Theologische Realensylklopädie VII. Berlin-New York, 734-737.

Lamont, William M. (1969): Godly Rule. Politics and Religion, 1603-60. London.

Macek, Josef, Hg. (1951): Ktoそ̌ jsú bơ̌i bojovnici. Cteni o Tábore v busitském revolučnim hnutí. Prag.

Macek, Josef/Marosi, Ernő/Seibt, Ferdinand, Hg. (1994): Sigismund von Luxemburg. Kaiser und König in Mitteleuropa 1387-1437. Beiträge zur Herrschaft Kaiser Sigismunds und der europäischen Geschichte um 1400. Warendorf.

Machilek, Franz (1966): „Heilserwartung und Revolution der Taboriten“, in: Festiva Lanx. Festschrift Johannes Spörl. München, 67-94.

Machilek, Franz (1986): „Hus/Hussiten“, in: Theologische Realensyklopädie XV. Berlin-New York, 710-735.

Manning, Brian, Hg. (1973): Politics, Religion and the English Civil War. London.

McGregor, J. Frank/Reay, Barry, Hg. (1984): Radical Religion in the English Revolution. Oxford.

Metz, Karl Heinz (1985): „,Providence‘ und politisches Handeln in der Englischen Revolution (1640-60). Eine Studie zu einer Wurzel moderner Politik, dargestellt am politischen Denken Oliver Cromwells“, in: Zeitschrift für historische Forschung 12, 43-84. 
Metz, Karl Heinz (1993): Oliver Cromwell. Zur Geschichte eines schließlichen Helden. Göttingen-Zürich.

Mockler, Anthony (1970): Mercenaries. London.

Morrah, Patrick (1976): Prince Rupert of the Rhine. London.

Morrah, Patrick (1979): Restoration England. London.

Morrill, John, Hg. (1990): Oliver Cromwell. London.

Morril, John (1993): The Nature of the English Revolution. Essays. London.

Ohler, Norbert (1997): Krieg und Frieden im Mittelalter. München.

Ollard, Richard (1976): This War without an Enemy: A History of the English Civil Wars. London.

Parry, Richard H., Hg. (1979): The English Civil War and After. London.

Patschovsky, Alexander (1998): „Der taboritische Chiliasmus. Seine Idee, sein Bild bei den Zeitgenossen und die Interpretation der Geschichtswissenschaft", in: Šmahel, František, Hg.: Häresie und vorzeitige Reformation im Spätmittelalter. München, 169-195.

Paul, Robert S. (1955): The Lord Protector. Religion and Politics in the Life of Oliver Cromwell. London.

Pennington, Donald/Thomas, Keith, Hg. (1978): Puritans and Revolutionaries. Essays in 17th Century History. Oxford.

Polívka, Miloslav (1989): „Böhmen in der Endphase der hussitischen Revolution", in: Historica 29, 161-224.

Rebitsch, Robert (2005): Rupert von der Pfalz 1619-1682. Ein deutscher Fürstensohn im Dienst der Stuarts. Innsbruck-Wien-Bozen.

Reilly, Tom (1999): Cromwell. An Honourable Enemy. The Untold Story of the Cromwellian Invasion of Ireland. London.

Rogg, Matthias (2004): „Gottlose Kriegsleute? Zur bildlichen Darstellung von Söldnern des 16. Jahrhunderts im Spannungsfeld von Lebenswirklichkeit, öffentlicher Meinung und konfessioneller Bildpropaganda“, in: Kaiser, Michael/Kroll, Stefan, Hg.: Militär und Religiosität in der Frühen Neuzeit. Band 4. Münster, 121-144.

Roots, Ivan (1966): The Great Rebellion. London.

Russel, Frederick H. (1975): The Just War in the Middle Ages. Cambridge.

Saage, Richard (1981): Herrschaft, Toleran₹, Widerstand. Studien zur politischen Theorie der Niederländischen und der Englischen Revolution. Frankfurt/M.

Schlinker, Steffen/Willoweit, Dietmar (31995): „Gottesgnadentum“, in: Lexikon für Theologie und Kirche IV. Freiburg/B.-Basel-Rom-Wien, 917920.

Schmidtchen, Volker (1990): Kriegswesen im späten Mittelalter. Technik - Taktik - Theorie. Weinheim.

Schmidtchen, Volker (1999): „Ius in bello und militärischer Alltag - Rechtliche Regelungen in Kriegsordnungen des 14. bis 16. Jahrhunderts", in: Brunner, Horst, Hg.: Der Krieg im Mittelalter und in der Frühen Neuzeit: Gründe, Begründungen, Bilder, Bräuche, Recht. Wiesbaden, 25-56. 
Schröder, Hans-Christoph (1986): Die Revolutionen Englands im 17. Jahrbundert. Frankfurt/M.

Seibt, Ferdinand (1962): „Die Hussitenzeit als Kulturepoche“, in: Historische Zeitschrift 195, 21-62.

Seibt, Ferdinand (1965a): Hussitica. Zur Struktur einer Revolution. Köln-Graz.

Seibt, Ferdinand (1965b): „Žižka v. Trocnov, Jan“, in: Lexikon für Theologie und Kirche 10. Freiburg/B., 1392-1393.

Seibt, Ferdinand (1972): Jan Hus. Das Konstanzer Gericht im Urteil der Geschichte. München.

Seibt, Ferdinand (1983): „Hus in Konstanz“, in: Annuarium historiae conciliorum 15, 159-171.

Seibt, Ferdinand (1987): Hussitenstudien. Personen, Ereignisse, Ideen einer frühen Revolution. München.

Seibt, Ferdinand/Dittrich, Zdenek/Hahn, Karl Josef/Holocek, František/ Kotowski, Norbert/Kucera, Zdenek/Lásek, Jan/Rood, Willem, Hg. (1997): Jan Hus. Zwischen Zeiten, Völkern, Konfessionen. München.

Sikora, Michael (2003): „Söldner - historische Annäherung an einen Kriegertypus", in: Geschichte und Gesellschaft 29, 210-238.

Šmahel, František (1969): Jan Žǐ̌ka z. Trocnova. Prag.

Šmahel, František (1985): La révolution hussite, une anomalic historique. Paris.

Šmahel, František (1993): Husitská revoluce. 4 Bände. Prag.

Šmahel, František (1996): „Tabor als Modell einer Gesellschaftsordnung“, in: Hlaváček, Ivan/Patschovsky, Alexander, Hg.: Reform von Kirche und Reich zur Zeit der Konzilien von Konstanz. (1414-1418) und Basel (14311449). Konstanz, 191-201.

Stone, Lawrence (1983): Ursachen der Englischen Revolution 1529-1642. Frankfurt/M.-Berlin-Wien.

Toon, Peter (1972): „Der englische Puritanismus“, in: Historische Zeitschrift $214,30-41$.

Tresp, Uwe (2002): Söldner aus Böhmen. Entstehung und Organisation böhmischer Söldnerheere im Dienst deutscher Fürsten des 15. Jahrbunderts. Historische Dissertation, Universität Paderborn.

Tresp, Uwe (2004): Söldner aus Böhmen im Dienst deutscher Fürsten. Kriegsgeschäft und Heeresorganisation im 15. Jahrbundert. Paderborn.

Urbánek, Rudolf (1934): Lipany a konec polnich vojsk. Prag.

Weber, Max (1922): „Die protestantische Ethik und der Geist des Kapitalismus“, in: Weber, Max: Gesammelte Aufsätze zur Religionssożiologie. Band 1. Tübingen, 17-236 .

Wedgwood, Veronica C. (1958): The Great Rebellion. The King's Peace, 1637. 1641. London.

Wedgwood, Veronica C. (1961): The Great Rebellion. The King's War, 16411647. London. 
Weinzierl, Michael (1979): „Die Republikaner, die Militärdiktatur 1659 und das Ende der englischen Republik", in: Mitteilungen des Österreichischen Staatsarchivs 32, 48-77.

Wefers, Sabine (1989): Das politische System Kaiser Sigmunds. Stuttgart.

Wende, Peter (1980): Probleme der Englischen Revolution. Darmstadt.

Wende, Peter (1998): „Karl I.“, in: Wende, Peter, Hg.: Englische Könige und Königinnen: von Heinrich VII. bis Elisabeth II. München, 111-127.

Worden, Blair (1974): The Rump Parliament 1648-1653. Cambridge.

Young, Peter (1970): Marston Moor 1644. London.

Young, Peter/Burne, Alfred H. (1959): The Great Civil War. London.

Young, Peter/Holmes, Richard (1974): The English Civil War. A Military History of the three Civil Wars 1642-1651. London.

Zagorin, Perez (1998): The English Revolution. Politics, Events, Ideas. Aldershot. 

Globalisierung von Ausbeutung(ssystemen) im Kongo.

Akteure und Beziehungen im Kontext ,gewalttätigen

Handelns“

Simon Hartmann*

'What was clear from all the trading, however, was that Congo would be exploited for its economic potential" 1

"Exploitation of natural resources of the Democratic Republic of Congo by foreign armies has become systematic and systemic." 2

"I am not the same person now as I was when I walked in here - I have heard stories today that go beyond the imagination..." 3

\section{Einführung}

Der UN-Hilfskoordinator John Holmes legte in seinem Zwischenbericht über die Finanzierung von Hilfsprojekten in aller Welt dar, dass die Vereinten Nationen derzeit die Demokratische Republik Kongo (DRK) als die „hilfsbedürftigste Krisenregion der Welt“ sehen. ${ }^{4}$ Im Kongo ist die MONUC ${ }^{5}$ sowohl personell (mehr als 21.000 Mitarbeiter, davon 16.646 Soldaten) als auch finanziell (Budget von mehr als eine Milliarde Dollar) die aufwändigste Friedensmission der UNO. Das Mandat der MONUC läuft seit 30. November 1999.

Die DRK erschien in der Berichterstattung internationaler Organisationen (u.a. IMF, Weltbank), Nichtregierungsorganisationen (u.a. International Rescue Comitee, Amnesty International) und der internationalen Presse meistens im Zusammenhang mit äußerst gewalttätigen Konflikten (allen voran dem Afrikanischen Weltkrieg)

\footnotetext{
* Simon Hartmann ist seit Juli 2006 Dissertationsstipendiat der Universität Innsbruck und arbeitet im Forschungsfeld „Wirtschafs- und Sozialgeschichte“ der Fakultät für Volkswirtschaft und Statistik an seiner Dissertation zur Wirtschaftsgeschichte des Kongos. Eine frühere Version dieses Textes ist als Nr. 13 der Innsbrucker Diskussionspapiere zu Weltordnung, Religion und Gewalt erschienen.

1 McCalpin (2002), 34.

2 UN (2001), Z 214.

3 John Holms, UN Hilfskoordinator nach einem Besuch im Kongo im September 2007, in: UN (2007).

4 Der Standard (2007).

5 Mission de l'ONU en RD Congo
} 
und anderen humanitären Katastrophen (Hunger und anderen Sozialkatastrophen). Will man dem Phänomen auf den Grund gehen, wird schnell klar, dass man bei dieser Betrachtung nicht nur über den Kongo, sondern auch über Zentralafrika hinausblicken muss. Diese „Verdachtsmomente“ ergeben sich aus wenigstens zwei grundlegenden Tatsachen. Erstens, zeigten unterschiedliche Untersuchungen, dass im Kongo Ausbeutung stattfindet. Allen voran kam ein UN-Expertenteam im Jahr 2001 zu dem Schluss, dass die Ausbeutung der DRK systematisch und systemisch sei. ${ }^{6}$ Zweitens, gilt der Kongo als eine Region, die äußerst reich an natürlichen Ressourcen $^{7}$ ist. In der Vergangenheit und heute sind einige davon (aktuell insbesondere Coltan) für globale Industriezweige und ganze Nationen als strategisch besonders wichtig anzusehen und waren deshalb zumindest zeitweilig von einer stark steigenden Nachfrage an globalen Märkten betroffen.

Zusätzlich deutet bereits ein oberflächlicher Blick auf die Geschichte des Kongos darauf hin, dass die Region in der Vergangenheit bereits viel Gewalt erfuhr. Allein seit der Unabhängigkeit des Kongos im Jahr 1960 fanden mindestens acht gewalttätige Auseinandersetzungen $\operatorname{statt}^{8}$, die je nach Definition entweder als Kriege oder bewaffnete Konflikte wahrgenommen werden ${ }^{9}$. Setzt man die Reise in die Vergangenheit des Kongos fort, stößt man wiederum auf auBerordentlich gewalttätige Ereignisse. Die effektive Okkupation des kongolesischen Hinterlands und in der Folge die juristisch definierten Ansprüche des belgischen Königs Leopold II. und später Belgiens standen im Zeichen von Zwangsarbeit, aber besonders im Fall

6 UN (2001), Z 214.

7 Gold, Industriediamanten, Coltan, Silber, Erdöl, Kobalt, Kupfer, Mangan, Zink, Zinn, Cadmium, Germanium, Beryllium, Methangas, Uran, Edelhölzer, ...

8 Dazu zählen die Katanga-Abspaltung (1960-63), die Kasai-Abspaltung (1960-62), KwiluRebellion (1964-65), die Rebellion im Osten (1964-66), der erste Shaba-Konflikt (1977), der zweite Shaba-Konflikt (1978), die Anti-Mobutu-Rebellion (1996-97) und die AntiKabila-Rebellion (1998-heute). Bei allen Konflikten zusammen, kamen nach Ndikumana/ Emizet (2005), Table 3.1, zwischen 3,9 und 4,8 Millionen (!) Menschen ums Leben.

9 Mit Ausnahme des ersten Shaba-Konflikts (1977 mit 850 bis 1.000 Toten) lag die Anzahl der Toten deutlich über 1.000. Die Katanga-Abspaltung (1960-63) und die Anti-MobutuRebellion forderten nach Ndikumana/Emizet (2005), Table 3.1, bis zu 110.000 bzw. 237.000 Opfer und die Anti-Kabila-Rebellion kosteten nach Coghlan et al. (2006) einer unglaublichen Anzahl von fast vier Millionen Menschen (!) das Leben. Eine sehr treffende Definition von Krieg und Konflikt hat die Arbeitsgemeinschaft Kriegsursachenforschung (AKUF) der Universität Hamburg gegeben. Siehe AKUF (2006). 
des Monarchen auch für massenhaftes Töten. Im Atlantischen Sklavenhandel wurde in mehr als dreieinhalb Jahrhunderten mit Menschen gehandelt, die gezwungen wurden, in den amerikanischen Kolonien der Europäer (insbesondere in Brasilien) zu arbeiten. Diese Indizien lassen ganz allgemein darauf schließen, dass es in der Vergangenheit des Kongos bereits Ausbeutung gab. Weiters ist augenscheinlich, dass es sich um Ausbeutungssysteme handelte, an denen mehrere Akteure beteiligt waren und die in engem Zusammenhang mit unterschiedlichen Formen von Gewalt standen.

Johan Galtung ${ }^{10}$ unterscheidet zwischen direkter und indirekter Gewalt. Erstere weist eine eindeutige Subjekt-Objekt Beziehung auf und kann sich durch Folter, Vergewaltigung und Mord (direkte Gewalt) äußern. Bei indirekter Gewalt unterscheidet er zwischen Gewalt, die durch (komplizierte) Strukturen in ein System (globale Märkte) eingebettet ist (strukturelle Gewalt) und sich u.a. durch Ausbeutung, Unterdrückung, Hunger oder Armut äußert, und Prozessen, welche die Verankerung struktureller und direkter Gewalt legitimieren (kulturelle Gewalt ${ }^{11}$ ). In der Geschichte der Kongoregion sind diese Formen von Gewalt immer wieder zu beobachten und stehen dort oft in engem Zusammenhang mit Ausbeutung.

Die aktuelle Ausbeutung des Kongos steht in engem Zusammenhang mit den vergangenen Ausbeutungssystemen, die ebenfalls nicht völlig unabhängig zu betrachten sind. Im globalen Kontext gesehen, beeinflusst dieses Phänomen seit über 500 Jahren die Region in unterschiedlichen Erscheinungsformen (Sklaverei, Kolonialismus, Kleptokratie ${ }^{12}$ ) immer wieder von Neuem. Ausbeutung gestaltete die Geschichte der Region mit und zeigte sich auch deshalb für die Position des Kongos, in den jeweiligen historischen Weltordnungen, maßgeblich verantwortlich. Die Ausbeutung des Kongos heute kann deshalb ohne die Betrachtung der historischen Ausbeutungssysteme in seinen Ursachen nicht ausreichend erklärt werden. Deshalb kann eine vergleichende Analyse dieser Ausbeutungssysteme dazu beitragen, dieses Phänomen speziell für den Kongo besser zu begreifen. Die Methode könnte ebenfalls als Basis für die Untersuchung von Ausbeutungsphänomenen in anderen Regionen dienen, die bis zu ei-

10 Galtung (1975).

11 Galtung (1990).

12 Diese Bezeichnung wird in der Literatur für die Ausbeutung des kongolesischen Diktators Mobutu Sese Seko (1965-1997) verwendet. 
nem bestimmten Grad ähnlich gelagert sind. Außerdem steht die Ausbeutung im Kongo in engem Zusammenhang mit dem dort aktuell bestehenden Konflikt, weshalb die Analyse zum besseren Verständnis dieser Situation und deshalb zur Beilegung der dort herrschenden Gewalt beitragen kann.

Abbildung 1: Hauptprodukte des Kongos

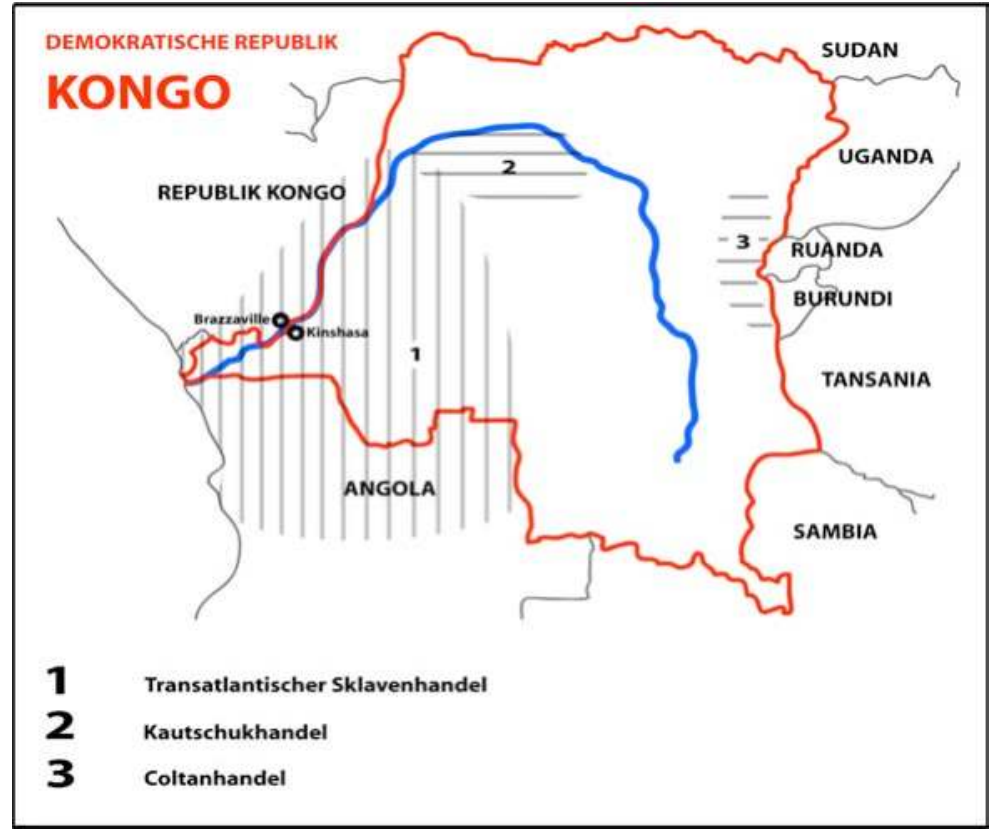

Der Kongo galt für die Europäer spätestens nach den ersten Entdeckungsreisen ins Hinterland (u.a. Cameron, Livingston, Stanley) als besonders ressourcenreich. ${ }^{13}$ Mit den Jahren veränderten sich die Quellen des Reichtums (Sklaven, Elfenbein, Kautschuk, Kupfer,

13 Leutnant Very Cameron berichtete nach einer Reise durch das kongolesische Hinterland, im Jahr 1876 in der Times: „Das Innere ist zum größten Teil ein herrliches und gesundes Land mit unvorstellbaren Reichtümern [...] Darüber bin ich ganz zuversichtlich, dass dort mit einem wohlüberlegten und großzügigen (nicht verschwenderischen) Aufwand an Kapital eines der hervorragensten Binnenschifffahrtssysteme der Welt aufgebaut werden könnte. Bereits nach einem Zeitraum von 30 bis 36 Monaten würde es jedem unternehmungsfreudigen Kapitaleigner gute Rendite abwerfen [...]." Pakenham (1992), 34. 
Diamanten, Coltan), welche als zentrale Gegenstände der Ausbeutungssysteme zu sehen sind. Diese Analyse will untersuchen, wie die Ausbeutungssysteme entstanden und wie sich diese im Kongo etablierten. Es geht darum die Akteure und deren Beziehungen zu charakterisieren. Basierend auf diesen Erkenntnissen soll herausgefunden werden, was sie einerseits zu diesem System beitrugen und andererseits davon betroffen waren.

Bereits kurz nach der Entdeckung des Kongoflusses im Jahr 1482 durch die Portugiesen wurde die Region - mit dem Atlantischen Sklavenhandel - in ein globales Handelsnetzwerk integriert, das in dieser Zeit gerade im Begriff war, sich zu entwickeln. Für einen Wirtschaftshistoriker liegt es nahe, diesen Zeitpunkt als Ausgang für den Prozess der „globalen Integration“ der Kongoregion zu sehen, da aus dieser Sichtweise die Integration der Güter-, Arbeitsund Kapitalmärkte zwischen Regionen als grundlegendes Merkmal für deren Globalisierung gelten. ${ }^{14}$ Es wird angenommen, dass sich sowohl Akteure im Kongo (kongolesische Eliten) als auch Akteure von außerhalb des Kongos (globale Akteure) an der Ausbeutung der Region beteiligten. ${ }^{15}$ Die folgende Analyse konzentriert sich darauf, die Akteure und deren Beziehungen untereinander zu identifizieren, um zu verstehen, wie das Ausbeutungssystem jeweils entstand und funktionierte. Es stellt sich die Frage, ob die Ausbeutungssysteme im Kongo, die seit dem Beginn des globalen Integrationsprozesses entstanden, trotz ihrer zeitlichen Trennung, strukturelle Gemeinsamkeiten aufweisen und ob es sich deshalb um eine Wiederkehr desselben Phänomens handelt. Es ist eine Untersuchung, die sich vorwiegend darauf konzentriert, den Kongo innerhalb einer Weltordnung aus ökonomischen Beziehungen und Gewaltverhältnissen zu analysieren. Ein besseres Verständnis der Ausbeutungssysteme im Kongo könnte als Basis dafür dienen, Lösungsansätze für deren Beseitigung zu entwickeln. Dies soll mittels einer wirtschaftshistorischen Analyse des kongolesischen Sklavenhandels (prekolonial), des Kautschukhandels (kolonial) und Coltanhandels (postkolonial) in Verbindung mit globalen Akteuren und Märkten erfolgen. ${ }^{16}$

14 Bordo et al. (2003), 1-2.

15 Hartmann (2006), Exenberger/Hartmann (2007).

16 Diese drei Beispiele stehen hier nur exemplarisch für die prekoloniale, koloniale und postkoloniale Epoche im Kongo. Es handelt sich um eine beliebige Auswahl von zahlrei- 


\section{Der Atlantische Sklavenhandel}

"If few die the profit is certain, but if many are lost so also is their owner". ${ }^{17}$

Das Kongo-Königreich wurde 1482 durch Portugiesen entdeckt. Die anfängliche Neugierde der Entdecker für diese beeindruckende Gesellschaft wich sehr bald anderen Bedürfnissen. Das Kongo-Königreich besaß neben vielen beeindruckenden Errungenschaften ${ }^{18}$ ein grausames System der Sklaverei und des Sklavenhandels. In erster Linie hielten sich die lokalen Eliten, wie wohlhabende Händler, lokale Stammesführer und der König, Sklaven. Der Großteil der Menschen, die im Kongo versklavt wurden, waren Kriegsgefangene, die aus Kämpfen mit verfeindeten Stämmen oder Königreichen hervorgingen. ${ }^{19}$

Dieses System der totalen Machtausübung über Menschen war für die Europäer zu dieser Zeit aus mehreren Gründen äußerst interessant. Zu dieser Zeit herrschte am ,globalen Arbeitsmarkt" ein äuBerst starker Mangel an Arbeitskräften. Die demographische Struktur Europas war durch die Pestepidemie stark angegriffen. Dazu kam noch, dass die Überfahrt von Europa nach Amerika gefährlich war und viele auch vor exotischen Krankheiten in den Tropen Angst hatten. ${ }^{20}$ Die Kolonien in Amerika waren damals kein besonders beliebter Ort, an dem sich Familien niederließen, sondern vielmehr ein Terrain für Abenteurer und Geschäftsleute, die bereit waren gewisse Risiken einzugehen, um dort Profite zu erwirtschaften. In den amerikanischen Kolonien der Europäer (anfangs Spanier, Portugiesen, später auch Briten und Franzosen) wurde durch den gezielten Einsatz von Krankheitserregern (u.a. Pocken) und Feldzügen mit überlegener Kriegstechnik (insbesondere Feuerwaffen) erreicht, dass die dort heimischen Völker erheblich dezimiert oder ganz ausgelöscht wurden. Dieser Mangel an Arbeitskräften wirkte sich auf die Entwicklungsperspektiven dieser neuen Kolonien besonders negativ aus,

chen Ausbeutungssystemen, die es in diesen drei Phasen des globalen Integrationsprozesses im Kongo augenscheinlich gab.

17 Jose da Silva Lisboa, zitiert in: Miller (1988), 441.

18 Im Kongo-Königreich wurden Kupfer und Eisen geschmiedet, Pflanzen und Tiere domestiziert. Es gab ein Wahlsystem, bei dem der Herrscher von einer Häuptlingsversammlung bestellt wurde. Es existierte eine Zeitmessung nach dem Mondkalender, ein Steuersystem, die Viertagewoche, und es gab Feiertage. Vgl. Hochschild (2002), 17-21.

19 Thornton (1999), 98-99.

20 Klein (1999), 16. 
da dort riesige Landflächen verfügbar waren, aufgrund der Dezimierung der Urvölker und der dünnen Besiedlung durch Europäer jedoch eine Ausbeutung des Ressourcenpotenzials ${ }^{21}$ dieser Errungenschaften nicht umfassend möglich war. Die Tatsache, dass hier Mangel bestand, ließ die Europäer auf Zwangsarbeiter zurückgreifen. Die Portugiesen waren die Ersten, die auf Sklaven aus dem Kongo zurückgriffen. Später transportierten auch die Briten und Franzosen und zeitweilig die Holländer kongolesische Sklaven in die amerikanischen Kolonien. Der Kongo bot sich aus mehreren Gründen an, die benötigten Sklaven zu liefern.

Um vom Abfluss von Arbeitskräften in die amerikanischen Kolonien selbst nicht negativ betroffen zu sein, mussten die kapitalistischen Systeme der Europäer die Zwangsarbeiter von außerhalb beziehen. Hätte man von dort massenhaft Arbeitskräfte herausgezogen, so hätte dies für Europa negative wirtschaftliche Konsequenzen bedeutet.22 Die Kongoregion galt aufgrund der relativ fruchtbaren Böden, im Vergleich zu den kargen Landschaften Nordafrikas, als relativ dicht besiedelt. ${ }^{23}$ In Zentralafrika gab es neben dem KongoKönigreich zahlreiche andere Königreiche und eigenständige Gemeinschaften (nicht staatlich organisierte Waldvölker). ${ }^{24}$ Im Hinterland galten besonders die Region der Lunda und die Gegend um den Sambesi-Fluss als dicht besiedelt und deshalb im Lauf der Zeit als besonders wichtige Quelle für Sklaven im kongolesischen Sklavenhandel. ${ }^{25}$ Weiters sprach für den Kongo, dass der Seeweg nach Brasilien von Zentralafrika weitaus weniger Zeit beanspruchte, als dies von den asiatischen Kolonien (u.a. Indien) aus der Fall gewesen wäre. Die Zwangstätigkeit in Brasilien fand vorerst auf den dortigen Zuckerrohrplantagen statt. Durch die kurze Vorherrschaft der Holländer ${ }^{26}$ in Brasilien fand ein Technologietransfer für die Zuckerpro-

21 In erster Linie lagen die Schätze im landwirtschaftlichen Potenzial der riesigen Landflächen (besonders in der Zuckerproduktion) und den Gold- und Silberminen wie Minas Gerais (Brasilien) oder Potosí (Bolivien).

22 Wallerstein (1986), 120.

23 Miller (1998), 78.

24 Iliffe (1997), 179-180.

25 Miller (1988), 210, 216. Der kongolesische Sklavenhandel wurde großteils über die Umschlagplätze Loango, Mpinda, Luanda und Benguela an der westafrikanischen Küste abgewickelt.

26 Im Jahr 1641 eroberten die Holländer die portugiesischen Stützpunkte im Kongo. Siehe Emmer (1998), 17. Sie dominierten dort bis die Portugiesen Luanda im Jahr 1648 wieder zurückeroberten. Siehe Miller (1976), 91. 
duktion auf die Westindischen Inseln der Briten und Franzosen ${ }^{27}$ statt. In der Folge übernahmen diese die Vorherrschaft in diesem Geschäft.

Abbildung 1: Sklavenpreise in Brasilien (1600-1820)28

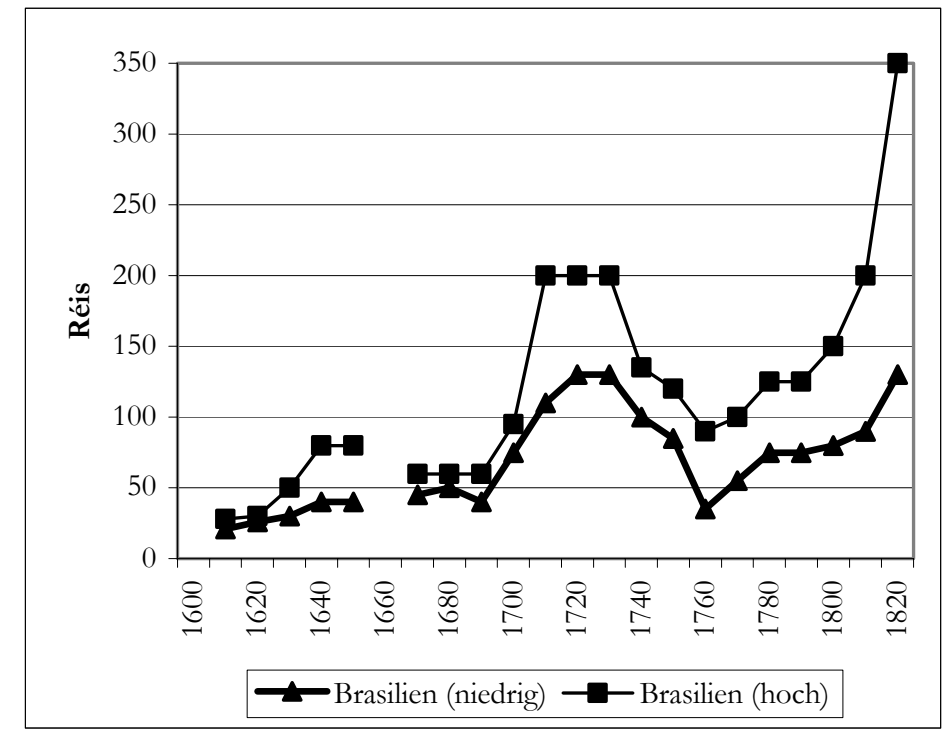

Bei der Arbeit auf den Zuckerplantagen handelte es sich um eine körperlich aufwändige, aber geistig recht anspruchslose Tätigkeit. Die Plantagenbesitzer in den amerikanischen Kolonien lernten sehr schnell die augenscheinlichen Vorzüge der afrikanischen Sklaven, denen sie viel Kraft und Robustheit nachsagten, zu schätzen. Sie seien jedenfalls effektivere Arbeiter als die überlebenden Vertreter der amerikanischen Urvölker. ${ }^{29}$ Adam Smith sah Sklavenarbeit als weitgehend ineffizient an und verwies darauf, dass sie nur bei landwirtschaftlicher Massenproduktion eine erhebliche Senkung der Herstellungskosten bedeute und nur dadurch profitabel sei. Er fügt hinzu, dass „die Zuckerplantagen in den westindischen Kolonien allgemein

27 Französische Inseln - Martinique, Guadeloupe, Saint Domingue; britische Inseln Barbados, Nevis St. Kitt, Jamaika. Siehe Klein (1999), 30, 32.

28 Miller (1986), 63; Grafik vom Autor selbst erstellt.

29 Williams (1966), 9. 
einen viel höheren Gewinn abwarfen, als jede andere landwirtschaftliche Produktionsform zu dieser Zeit" .30

An der Integration des existierenden lokalen Sklavenhandels in das Atlantische System waren mehrere Akteure beteiligt. Wie oben erwähnt, boten überwiegend lokale Eliten Sklaven an. Anfangs befanden sich die wichtigsten Quellen eher in Küstennähe. Mit der Ausweitung des Handels wurden immer größere Teile des Hinterlands in dieses System integriert. Die Europäer mieden es zu dieser Zeit aus mehreren Gründen, selbst in das zentralafrikanische Hinterland vorzudringen. Mythen über schauderhafte Kreaturen, gefährliche Krankheiten (u.a. Malaria, Schlafkrankheit) und kriegerische Stämme ließen die Reise in dieses unbekannte Gebiet als ein äußerst riskantes Unterfangen erscheinen. ${ }^{31}$ So kam es, dass afrikanische Händler den Transport der Sklaven aus dem Hinterland zur Küste organisierten. Dort traten sie in Austauschbeziehungen mit Europäern, die Sklaven gegen europäische Manufakturgüter wie Textilien, Glasperlen, Metallwaren, Alkohol und später auch Feuerwaffen tauschten. ${ }^{32}$ Die Europäer kamen mit eigens dafür gebauten Sklavenschiffen an die Umschlagplätze der westafrikanischen Küste. Für den Kauf von Sklaven waren besonders der Preis und die medizinische Untersuchung durch den Schiffsarzt ausschlaggebend. Zur Zeit des Atlantischen Sklavenhandels dominierten und organisierten die Europäer den Welthandel, da sie über die dafür benötigten Schiffe verfügten. ${ }^{33}$ Diejenigen Sklaven, welche die Tortur der Gefangennahme und des Transportes in die amerikanischen Kolonien überlebten, wurden von Plantagenbesitzern erworben. In deren Betrieben mussten sie ihre Zwangstätigkeit aufnehmen, die für sie in der Regel erst mit ihrem Tod endete. Die Sklavenfahrten waren fast ausnahmslos für alle Afrikaner ${ }^{34}$ eine Reise ohne Wiederkehr.

Nicht jede Unternehmung im Rahmen des Atlantischen Sklavenhandels war per se gewinnträchtig. Der Erfolg hing maßgeblich vom Verhandlungsgeschick an den afrikanischen Küsten, der Mortalität der Sklaven auf See und den Verkaufspreisen in den amerikani-

30 Smith (1978), 319.

31 Hochschild (2002), 14, 21; Miller (1976), 86.

32 Davidson (1966), 139-140.

33 Klein (1999), 55; Borries (1992), 269.

34 Manchmal gelangen Sklavenrevolten, die wenigsten schafften es jedoch, nach Hause zurückzukehren. 
schen Kolonien ab. Außerdem entstanden oft zusätzliche Kosten, da sowohl Kolonialbeamte als auch afrikanische Eliten offiziell Gebühren für den Handel einhoben und in vielen Fällen Schmiergeldzahlungen forderten. ${ }^{35}$ Hinsichtlich der Finanzierung vollzog sich über die Zeit des Atlantischen Sklavenhandels ein Wandel von staatlich monopolisierten zu freien, privatwirtschaftlichen Unternehmungen. Anfänglich war es besonders der Einfluss der europäischen Königshäuser und ihrer jeweiligen Monopolgesellschaften, die den Atlantischen Sklavenhandel maßgeblich prägten. Die riesigen Handelsgesellschaften der Portugiesen, Holländer, Franzosen und Briten wurden alle im Lauf des 17. Jahrhunderts gegründet und verloren aufgrund ihrer ineffizienten Organisation bereits Anfang des nächsten Jahrhunderts ihre dominante Rolle im Atlantischen Sklavenhandel. ${ }^{36}$ Ihre Struktur und Vorgaben hinderten sie daran, auf Veränderungen in der Sklavennachfrage schnell genug zu reagieren. Private Unternehmungen konnten diesbezüglich die Bedürfnisse der amerikanischen Kolonien sehr viel effizienter befriedigen. Bei Bedarf wurden kurzfristig zusätzliche Sklavenfahrten durch den Zusammenschluss mehrerer privater Investoren organisiert. Dadurch erreichten diese eine Streuung ihres Risikos für den Fall, dass eine Unternehmung misslang. ${ }^{37}$ Die Sklaven aus der Kongoregion wurden an den Sklavenmärkten in Brasilien und später auch auf den Westindischen Inseln gehandelt. Infolge des Ausstiegs von immer mehr europäischen Nationen aus dem Sklavenexport schlossen die Sklavenhäfen Brasiliens im Jahr 1851 offiziell $^{38}$ ihre Pforten.

Das Ausbeutungssystem des Atlantischen Sklavenhandels wirkte sich auf die Beteiligten und davon Betroffenen unterschiedlich aus. Über den gesamten Zeitraum dieses globalen Handelssystems wurden nach unterschiedlichen Schätzungen zwischen drei ${ }^{39}$ und über 13 Millionen afrikanische Sklaven ${ }^{40}$ aus dem Kongo exportiert.

35 Miller (1986), 64-65.

36 Klein (1999), 79-82.

37 Wenn es zu Ausfällen aufgrund von Sklavenrevolten oder Unfällen kam. Außerdem wirkten sich außerordentlich hohen Mortalitätsraten aufgrund von Epidemien bei der Atlantiküberquerung negativ auf die Gewinnerwartungen aus.

38 Tatsächlich ging die illegale Sklaverei bis weit in das 20. Jahrhundert weiter. Kevin Bales vermutet, dass heute weltweit noch ungefähr 27 Millionen als Sklaven arbeiten. Siehe Bales (2001), 17.

39 Bobb (1988).

40 Rinchon (1929). 
In dieses Ausbeutungssystem waren mehrere Akteure involviert. Auf globaler Ebene standen sich politische Führer und Geschäftsleute aus Europa und dem Kongo gegenüber. Die afrikanische Seite sorgte für das Angebot an Sklaven, durch das sie die Nachfrage europäischer Plantagenbesitzer in den amerikanischen Kolonien befriedigten. Im Gegenzug bekamen sie prestigeträchtige Tauschgüter sowie Waffen, die ihnen dazu verhalfen, ihre elitäre Position gegenüber der lokalen Bevölkerung zu behaupten. Versklavt wurden große Teile dieser lokalen Bevölkerung in der Kongoregion, die dadurch entweder ihrer Freiheit beraubt wurden oder durch den Prozess der Sklaverei vorzeitig den Tod fanden. Sie waren einerseits Opfer direkter Gewalt, da die Sklavenbesitzer in Afrika und Amerika vor körperlicher Gewalt nicht zurückschreckten, was sich darin zeigte, dass ungefähr 50 Prozent dieser Menschen, vor Antritt ihrer Zwangstätigkeit in den amerikanischen Kolonien, der Gewalt und den Strapazen des Sklavereiprozesses erlagen. ${ }^{41}$ Strukturelle Gewalt wurde vorwiegend auf die afrikanischen Gemeinschaften ausgeübt, aus denen zahlreiche Menschen herausgerissen und versklavt wurden. Die Tatsache, dass große Teile der arbeitsfähigen Bevölkerung im Kongo verschleppt wurden, hatte zur Folge, dass nicht nur Familien, sondern auch Gemeinschaften bis zu ganzen Königreichen (u.a. KongoKönigreich) in ihrer Existenz bedroht waren und in letzter Konsequenz praktisch zerstört wurden. ${ }^{42}$

Im Kongo war demnach die lokale Bevölkerung von der Sklaverei betroffen, indem sie von den kongolesischen Eliten versklavt und globalen Akteuren angeboten wurde. Direkte Gewalt begleitete den ganzen Prozess der Sklaverei und kam sowohl von afrikanischen Eliten als auch den globalen Akteuren. Strukturelle Gewalt erzeugte die Kooperation der afrikanischen Eliten mit den globalen Akteuren, die ihre Triebfeder maßgeblich in der Nachfrage vom amerikanischen Kontinent hatte. Die kulturelle Gewalt bestand in der Legitimation des Sklavenhandels, der zu dieser Zeit sowohl vonseiten der globalen Akteure als auch von den kongolesischen Eliten ausdrücklich erlaubt war. Der Sklavenhandel existierte im Kongo bereits vor der Zeit, in der die Europäer Austauschbeziehungen mit dem Kongo aufnahmen. Das Geschäft nahm mit dem Einstieg der Europäer eine weit- 
aus größere Dimension, mit Millionen Opfern, an, die durch die auBerordentlich starke Nachfrage und deren Organisation des Atlantischen Sklavenhandels erreicht wurde. Für die Idee und Umsetzung eines solchen atlantischen Systems sind die globalen Akteure verantwortlich. Der Sklavenhandel entzog dem Kongo einen großen Teil der arbeitsfähigen Bevölkerung. Die Erlöse aus den Sklavenverkäufen wurden nicht in eine ökonomisch nachhaltige Entwicklung investiert, ${ }^{43}$ sondern dienten fast ausschließlich der privaten Bereicherung der kongolesischen Eliten.

\section{Der Kautschukhandel}

„Der Kautschukhandel ist schuld an diesen Quälereien; darum wollen wir seinen $\mathrm{Na}$ men nicht mehr bören. Soldaten zwangen junge Männer, ibre Mutter oder ibre Schwestern zu töten oder zu vergewaltigen. " 44

Kautschuk wurde für globale Industriebranchen im ausgehenden 19. Jahrhundert eine besonders begehrte Ressource. Die Entdeckung des Vulkanisationsprozesses durch Charles Goodyear im Jahr 1839 machte den Kautschuk ungemein vielseitig nutzbar ${ }^{45}$. Die neuen Verwendungsmöglichkeiten der Ressource inspirierten John Boyd Dunlop zu der Entwicklung des Luftreifens im Jahr 1888. Infolge der Erfolgsgeschichte dieses und anderer Kautschukprodukte stiegen sowohl die globale Kautschukproduktion (bis 1909) als auch der Konsum (bis 1907), vom Jahr 1890 an, jeweils um mehr als das Zweieinalbfache. Global gesehen waren zu dieser Zeit ausschließlich natürliche Kautschukvorkommen von Bedeutung. Damals war bereits bekannt, dass in Asien (Indonesien, Malaysia und Ceylon) Kautschukplantagen, bestehend aus dem brasilianischen Hevea-Baum, im Entstehen waren.

Im Kongo gab es in erster Linie in den heutigen Provinzen Équateur und Kasai (insbesondere Kasai-Flusstal) riesige Vorkommen der Landolphia-Kautschukranke. ${ }^{46}$ Diese Regionen wurden

43 Harms (1981), 43.

44 Mündlich überlieferte Aussage über das Terrorregime im Kongo-Freistaat, zitiert in: Hochschild (2002), 258.

45 Es wurden Schläuche, Rohre, Schuhe, Regenjacken, Strumpfhalter, Ziegel und Isolierungen für elektrische Leitungen, Telegrafen und Telefone und viele andere Produkte aus Kautschuk gefertigt.

46 Loadman (2005), 127 
durch Henry Morton Stanley zum ersten Mal von einem Europäer durchquert. Aufgrund dieser Leistung wurde Stanley vom belgischen König Leopold II. beauftragt, mit den lokalen Stammesführern Verträge abzuschließen, in denen sie ihm ihr Land überschreiben sollten. Die Verträge kamen durch Gewalt und in vielen Fällen durch die List des britischen Entdeckers zustande. Viele der lokalen Größen konnten nicht lesen und verstanden nicht einmal die Sprache, in denen die Verträge verfasst waren. Insgesamt gelang es Stanley, mehr als 450 derartige Vereinbarungen zu treffen, die er mit nach Europa brachte. Dies war einer der zentralen Gründe, dass der KongoFreistaat ${ }^{47}$ auf der Berliner Konferenz 1884/85 der belgischen Krone aus juristischer Sicht als Privatkolonie ${ }^{48}$ zugeschrieben wurde. Der belgische König, der immer seine philanthropischen Motive für seinen Kongo-Freistaat öffentlich herausstrich, war in Wahrheit einzig und allein von seiner Profitgier getrieben. Insgeheim plante er ein Handelsmonopol, welches ihm Anteile an allen Geschäften in seiner Kolonie bringen sollte. ${ }^{49}$

$\mathrm{Zu}$ Beginn war es das Elfenbein, jedoch schon bald darauf der Kautschuk, in dem der König das größte Ausbeutungspotenzial sah. Dies ergab sich aus einem stark ansteigenden Kautschukpreis und den enormen natürlichen Kautschukreserven des Kongo-Freistaats. Im Jahr 1896 machte Kautschuk 50 Prozent und im Jahr 1901 bereits 90 Prozent des gesamten Exportwerts des Kongo-Freistaats aus. $^{50} \mathrm{Zu}$ dieser Zeit war Brasilien der weltweit größte Produzent von Kautschuk. Durch die Erschließung seines Hinterlandes stieg der Kongo sehr bald zum zweitwichtigsten Kautschuklieferanten auf. ${ }^{51}$ Der König fürchtete bereits die drohende Konkurrenz durch Plantagen in Asien, die zu dieser Zeit jedoch noch nicht ihre Erntereife erlangt hatten. So erließ er mehrere Dekrete, die ihm dazu verhalfen, die natürlichen Kautschukreserven seiner Privatkolonie in kurzer Zeit, äußerst gewinnbringend zu verwerten. Kurz nach der Berliner Konferenz forderte er, dass alles Land, was nicht nachweis-

47 Der Kongo-Freistaat war flächenmäßig ungefähr 90-mal größer als Belgien. Der Belgische König war die einzige Privatperson, der im Rahmen der Berliner Konferenz eine Kolonie exklusiv zugesprochen wurde.

48 Dem belgischen König Leopold II. wurde als Einzigem eine afrikanische Privatkolonie zugewiesen. Der Kongo-Freistaat war flächenmäßig um ein Vielfaches größer als Belgien.

49 Hochschild (2002), 111-112.

50 Loadman (2005), 139.

51 Ehrhardt (1903), 9; Jünger (1940), 198. 
lich besetzt oder kultiviert war, in das Eigentum des Freistaats übergeht. ${ }^{52}$ Im Oktober 1891 und Mai 1892 wurden durch den Gouverneur des Freistaats zwei weitere Dekrete erlassen, welche der lokalen Bevölkerung verboten, Elefanten zu jagen und Kautschuk zu sammeln. Von diesen Regelungen wurde nur dann abgesehen, wenn die gesammelten Ressourcen an den Freistaat abgegeben wurden. ${ }^{53}$ Demnach nahm man den Kongolesen nicht nur ihr Land, sondern auch deren Erzeugnisse. Den Kolonialbeamten wurden Bonuszahlungen in Aussicht gestellt, wenn sie es schafften, die begehrten Ressourcen von den Einheimischen zu möglichst niedrigen Preisen zu erwerben. ${ }^{54}$ Sie wurden angehalten alle notwendigen Maßnahmen zu treffen, um dies zu erreichen.

Abbildung 2: Kautschukpreise in Dollar und Pfund (1870-1920) 55

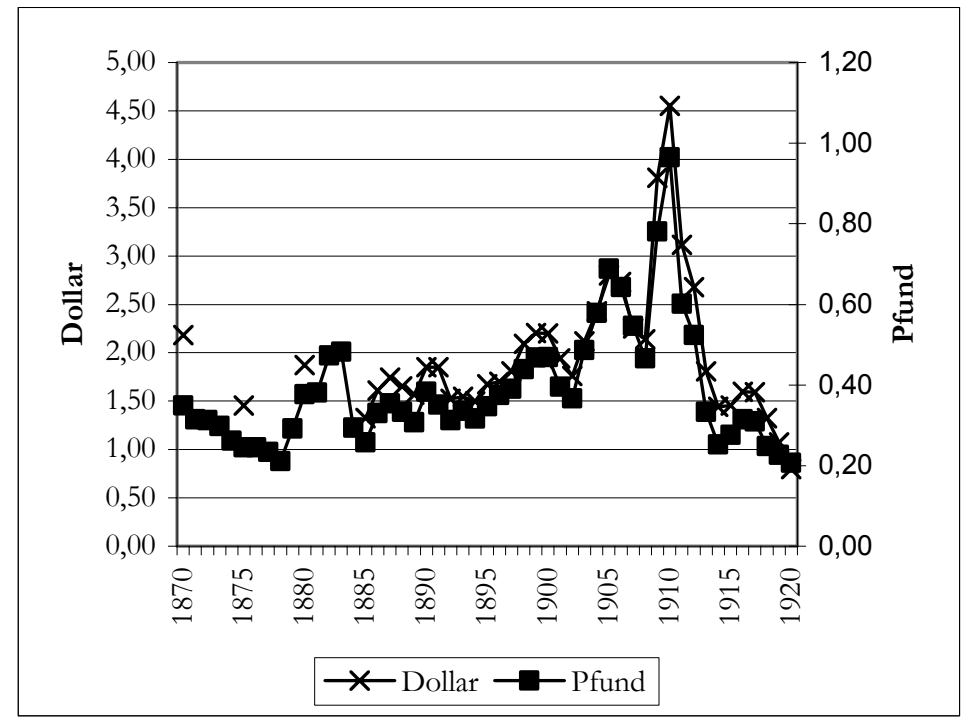

Am 30. Oktober 1892 teilte der König seine Kolonie in drei Zonen auf. Beim ersten Teil handelte es sich um die Domaine Privé, die

52 Doyle (1985), 22.

53 Emerson (1979), 152-153.

54 Morel (1906), 31.

55 International Rubber Study Group (1996), 74-76. 
ausschließlich der Ausbeutung durch den Staat unterlag. Der zweite Teil ging über Konzessionen an Unternehmen, die dadurch in der Lage waren, ein bestimmtes Gebiet der Kolonie inklusive der Bevölkerung auszubeuten. Ein Teil davon wurde im Jahr 1896 als Domaine de la Couronne indirekt dem König von Belgien zugeteilt. An den drei größten Unternehmungen, der A.B.I.R. (Anglo-Belgian Indian Rubber and Exploration Company), der Société Anversoise du Commerce du Congo (Anversoise) und der Compagnie du Kasai, war Leopold II. durch Aktien jeweils zu mindestens 50 Prozent beteiligt. ${ }^{56}$ Der dritte Teil umfasste Regionen, die erst vor Kurzen erschlossen worden waren oder in die Expeditionen geplant waren.

Am weitaus schlimmsten trafen die Bevölkerung jedoch die Steuern, die sie an den Kongo-Freistaat abzuliefern hatten. Die Kolonie besaß keine Geldwirtschaft. ${ }^{57}$ Die lokale Bevölkerung musste die Steuern in Realgütern wie Kautschuk, Elfenbein oder Lebensmitteln abliefern und erhielt für die Produktion, die über den gesetzlichen Abgaben lag, Tauschgüter wie Kupferstäbe und Messer. ${ }^{58}$ Die Vorgaben waren derart hoch, dass Kautschuksammler im Konzessionsgebiet der Anversoise durchschnittlich 24 Tage eines Monats im Regenwald verbringen mussten, um die geforderte Steuer aufbringen zu können. ${ }^{59}$ Damit die männlichen Kautschuksammler nicht einfach verschwanden, wurden deren Familien während dieser Zeit als Geiseln festgehalten. Wurde die geforderte Menge nicht abgeliefert, drohte rohe Gewalt, die für die Menschen im Kongo vielfach den Tod bedeutete.

Zur Durchsetzung der Ansprüche, die der belgische König an die kongolesische Bevölkerung stellte, verhalf ihm eine ungefähr 19.000 Mann starke Privatarmee - die Force Publique. Sie bestand aus wenigen europäischen Offizieren und afrikanischen Söldnern. Die Rekrutierung für diese Truppe verlief für viele Afrikaner nicht freiwillig, da zahlreiche von ihnen verschleppt und zum Dienst gezwungen wurden. Dies zeigte sich darin, dass die Force Publique immer wieder mit einer großen Zahl von Deserteuren zu kämpfen hatte. Ein Teil der Truppe wurde bewusst mit einem Typus Mann besetzt, der augenscheinlich wenig Skrupel vor Gewalt kannte. Wie- 
derum andere versuchten durch den Dienst der Gefahr zu entgehen, selbst ein Opfer der grausamen Beutezüge der Force Publique zu werden. ${ }^{60}$ Die Konzessionsunternehmen hatten ebenfalls ihre privaten Milizen, um die „Produktivität“ der lokalen Bevölkerung ihres Konzessionsgebiets zu garantieren. ${ }^{61}$ In den Regionen mit Kautschukvorkommen wurden die Kongolesen gezwungen, beträchtliche Mengen davon zu sammeln und abzugeben. Der Freistaat erließ immer wieder Anweisungen an seine Beamten und Offiziere, welche das Ziel vorgaben, die Produktionsmengen zu steigern.

Für die Umsetzung der Direktiven erhielten sie keinerlei Einschränkungen, sondern wurden im Gegenteil ermutigt keine Skrupel bei der Durchsetzung der definierten Ansprüche zu kennen. ${ }^{62}$ Sehr viele Hinweise, dass dies tatsächlich geschah, finden sich in den umfassenden Aufzeichnungen von Edmund Dene Morel, Roger Casement, unzähligen Missionaren und der Commission of Enquiry ${ }^{63}$. Diese Schilderungen wiederholten sich besonders in der Beschreibung der unvorstellbaren Grausamkeiten. Es war immer wieder von niedergebrannten Dörfern, Auspeitschung, Kannibalismus, Massenerschießungen, Abtrennung von Gliedmaßen bei Lebenden und Toten $^{64}$, Vergewaltigung und Tötung von Kindern die Rede. Diese Strafen erfolgten meistens, wenn die lokale Bevölkerung den Vorgaben des Freistaats (Steuern, Monopol) nicht Folge leistete. Für die

60 Hochschild (2002), 197.

61 Hochschild (2002), 253.

62 In manchen Anweisungen forderten Vorgesetzte die Verantwortlichen in den Handelsstützpunkten auf, ihre Produktion weiter zu steigern, und schlugen ihnen vor, um dieses Ziel zu erreichen, auch Waffengewalt einzusetzen. Ein Bezirksvorsteher meinte damals, dass man die Menschen in den Dörfern entweder vollkommen unterwerfen oder ansonsten komplett auslöschen sollte. Siehe Morel (1906), 37. Derartige Anweisungen zirkulierten zur Zeit des Kongo-Freistaats massenhaft durch alle Ebenen seiner Hierarchie.

63 Infolge des Casement-Reports forderte die Movement Géographique, den Einsatz einer Kommission, welche die Lage im Kongo-Freistaat bewerten sollte. Die Kommission hielt sich in der Folge drei Monate unter dem Vorsitz des belgischen Richters Emile Janssens im Kongo auf. Weitere Mitglieder waren der italienischen Richters Baron Nisco und Doktor Edmund de Schumacher aus der Schweiz (Marchal 1996, 111). Obwohl die Kommission aufgrund ihrer Zusammensetzung dem belgischen König eher wohl gesonnen sein sollte, fiel deren abschließender Report über den Zustand des Kongo-Freistaats vernichtend für ihn aus.

64 Die Söldner der Force Publique wurden angehalten, für jeden abgegebenen Schuss Nasen, Ohren, Geschlechtsteile oder in den meisten Fällen Hände der Opfer abzuschneiden, um sie ihren Offizieren vorzulegen. Damit sollte vermieden werden, dass Munition vergeudet wurde oder dass Söldner Kugeln für einen möglichen Aufstand beiseite schafften. Siehe Hochschild (2002), 256-257 und 313-314. 
Kautschuksammler wurde es immer schwieriger, diese zu erfüllen, da bereits nach einigen Jahren beträchtliche Teile der Kautschukvorkommen erschöpft waren. Die Arbeit verlagerte sich immer tiefer in die Regenwälder, wurde dadurch noch gefährlicher und nahm immer mehr Zeit in Anspruch. Für die körperliche Bestrafung waren generell die afrikanischen Söldner zuständig.

Die Enthüllungen durch die oben genannten Berichte und das Engagement der von Morel geschaffenen Congo Reform Association, erzeugten erheblichen öffentlichen Druck auf die belgische Krone, die ihre Privatkolonie im Jahr 1908 deshalb Belgien übertrug. Zur selben Zeit war der Zenit der Kautschukproduktion im Kongo bereits überschritten. ${ }^{65}$ Die natürlichen Reserven waren erschöpft und der Abbau von Kautschuk sollte in der Folge nicht mehr lange profitabel bleiben. ${ }^{66}$ Der König starb im Jahr 1909 und die Belgier adaptierten die von ihm geschaffenen Strukturen, um aus der Kolonie wieder Gewinne abschöpfen zu können. Mit der Entdeckung beträchtlicher Mineralienreichtümer (besonders Kupfer) wurde das Ausbeutungssystem auf die neuen Ressourcen hin erfolgreich angepasst.

Die Bilanz der Ausbeutung durch den Handel mit kongolesischem Kautschuk weist für die lokale Bevölkerung eine äußerst düstere Bilanz auf. Sorgfältigen Schätzungen zufolge sollten in den 25 Jahren, in denen der Kongo-Freistaat existierte, dort ungefähr zehn Millionen Menschen der systematischen Ausbeutung zum Opfer gefallen sein. Wie oben erwähnt, kam die direkte Gewalt überwiegend von afrikanischen Söldnern, die teils freiwillig, teils gezwungenermaBen in der Force Publique oder den Armeen der Konzessionsunternehmen dienten. Den Großteil der Opfer forderten Hungersnöte, Erschöpfung und Krankheiten, die durch die äußerst schwierigen Lebensbedingungen, infolge des unerbitterlichen kolonialen Steuersystems, vorherrschten. Das Kolonialregime war eine Fortsetzung der Zerstörung von kongolesischen Gemeinschaften durch massenhaftes Töten und Vertreibung, wie sie bereits im Atlantischen Sklavenhandel betrieben wurde. Die äußerst schlechte Versorgungslage

65 Büchler (1912), 219.

66 Die asiatischen Kautschukplantagen trugen 1908 ungefähr drei Prozent zur weltweiten Kautschukproduktion bei. Bereits im Jahr 1913 überholten sie mengenmäßig die afrikanischen Produzenten und die vormaligen Weltmarktführer in Mittel- und Südamerika. Siehe International Rubber Study Group (1996), 2-5. 
schwächte die Widerstandskräfte der Menschen, die dadurch sehr viel anfälliger für Krankheiten waren. Außerdem gab es im Kongo während der Jahre 1896 und 1903 einen signifikanten Geburtenrückgang. ${ }^{67}$ Den Weg in derart schlechte Lebensbedingungen forcierten die Dekrete und Vorgaben des Kolonialregimes, dem der belgische König Leopold II. vorstand. In diesem System waren der König und dessen Verbündete (u.a. Kolonialbeamte im Kongo, Banken in Europa) die globalen Akteure, welche die Ausbeutung des Kongos vorantrieben. Strukturelle Gewalt wirkte in erster Linie durch diese Akteure, die durch ihre Entscheidungen und Handlungen die katastrophalen Lebensumstände der lokalen Bevölkerung erzeugten. Das koloniale Ausbeutungsregime nahm durch seine zwingende Struktur der Bevölkerung die Freihteit. Zahlreiche Indizien weisen darauf hin, dass der König bei der Ausbeutung seiner Kolonie alle Fäden selbst in der Hand hatte. ${ }^{68}$ Die kulturelle Gewalt, die sich gegen die lokale Bevölkerung des Kongo-Freistaats richtete, wurde durch den Wettlauf um Afrika, der in der Berliner Konferenz seine juristische Legitimation erhielt, forciert. Die Tatsache, dass die Akteure in Berlin die Aufteilung Afrikas unter den Europäern ohne die Anwesenheit eines einzigen Afrikaners beschlossen, war Grundlage der systematischen kolonialen Ausbeutung. ${ }^{69}$

\section{Der Coltanhandel}

'There are plenty of minerals, but we earn nothing. Those who earn are those who don't work." 70

Während der 1990er-Jahre erlebte die Elektronikindustrie einen enormen Aufwärtstrend, der gegen Ende des Jahrzehnts einen vorläufigen Höhepunkt erreichen sollte. Allein zwischen 1997 und 2000 hat sich die Anzahl der weltweit verkauften Mobiltelefone vervierfacht. ${ }^{71}$ Andere Branchen, wie z.B. die Computerindustrie, hatten etwa durch Spielekonsolen und Notebooks ähnliche Erfolge zu verbuchen. Aufgrund der Erfolgsgeschichte des MP3-Musikformats

67 Hochschild (2002), 348-359.

68 Morel (1906), 157-160; Doyle (1985); Hochschild (2002).

69 Katzenellenbogen (1996), 21.

70 Patrice Kyantenge, 17-jähriger Minenarbeiter zitiert in: Johnson/Tegera (2005), 24.

71 Vgl. Gartner (2005). 
werden in großer Zahl tragbare Multimediageräte (mp3-player, i-pods) produziert. Wegen den besonderen Ansprüchen dieser Branchen durchlaufen deren Produkte innerhalb kürzester Zeiträume immer weitere Innovationen, wobei für deren Herstellung ständig Ressourcen benötigt werden. Beim Bau immer kleinerer und leistungsfähigerer Geräte kommt in großem Umfang Tantal zum Einsatz. Dabei handelt es sich um ein Metall, das sich durch seine herausragenden Eigenschaften ${ }^{72}$ für die Produktion von Kondensatoren eignet, die in tragbaren Elektronikprodukten zum Einsatz kommen. Ungefähr 60 Prozent des weltweiten Tantalverbrauchs wird deshalb für die Elektronikindustrie verwendet. ${ }^{73}$ Weitere Anwendungsbereiche für das Metall sind in erster Linie die Waffenindustrie, die Raumfahrtund Medizintechnik. Der weltweit größte Tantalproduzent ist derzeit Australien, wobei Geologen annehmen, dass 80 Prozent der globalen Reserven im Kongo liegen. ${ }^{74}$ Dort kommt das Metall in Form von Coltan (Columbit-Tantalit) vor.

Infolge des Genozids in Ruanda im Jahr 1994 flüchteten ungefähr eine Million Hutu Richtung Westen, was die demographische Zusammensetzung im Osten der DRK massiv beeinflusste. Die Tutsi, die in Ruanda die Macht zurückgewannen, fühlten sich von dieser Situation bedroht und starteten im Jahr 1996 vom Osten aus eine Rebellion in der DRK. Dieser Vorstoß sollte das kongolesische Volk von einem weiteren Ausbeutungssystem, das unter dem Regime des Diktators Mobutu Sese Seko das Land beherrschte, befreien. Die Rebellion der $\mathrm{ADFL}^{75}$ erreichte nach wenigen Monaten die Hauptstadt Kinshasa. Der Diktator wurde vertrieben, das Phänomen der Ausbeutung blieb dem Kongo jedoch erhalten. Die Zerwürfnisse Kabilas mit seinen ehemaligen Alliierten Ruanda und Uganda führten dazu, dass bereits 1998 ein weiterer Konflikt im Osten des Kongos ausbrach, der in der Folge einen großen Teil Zentralafrikas erschüttern sollte. Auf dem Hoheitsgebiet der DRK operierten bis zu

72 Das Metall ist für zahlreiche Industriezweige, aufgrund seiner extremen Hitze- und Korrosionsbeständigkeit (Schmelzpunkt liegt bei fast $3000^{\circ} \mathrm{C}$ ) besonders interessant. Tantal ist gegen chemische Einflüsse immun, leitet und speichert elektrische Energie und ist äußerst dehnbar und biegsam.

73 The DME (2002), 4; USGS (2005a).

74 Nzongola-Ntalajan (2002), 28.

75 Alliance of Democratic Forces for the Liberation of Congo-Zaire. 
sieben reguläre Armeen ${ }^{76}$ von benachbarten Ländern und unzählige Rebellengruppierungen.

Aufgrund seines Einflusses auf Zentralafrika und der außerordentlich hohen Opferzahlen erhielt der Konflikt von der internationalen Presse die Bezeichnung „Afrikanischer Weltkrieg“. Das Motiv der Rebellion der ADFL im Jahr 1996 zielte nicht unbedingt primär auf die Ausbeutung der östlichen Kongoregionen. Aber wie David Keen treffend formulierte, können sich in Konflikten Motive mehrfach ändern. Es kann dazu kommen, dass plötzlich politische Beweggründe von ökonomischen Motiven abgelöst werden. ${ }^{77}$ Der Hauptschauplatz der Auseinandersetzungen, die im Jahr 1998 begannen, war der äußerst ressourcenreiche Osten ${ }^{78}$ des Kongos. Wie um Diamanten, Gold und andere Ressourcen entwickelte sich auch um die Coltanreserven ein Ausbeutungssystem, das sich als Teil der umfassenden Kriegsökonomie im Kongo etablierte. Speziell die riesigen Coltanreserven, die überwiegend in den Kivu-Provinzen, Maniema und Ituri lagern, wurden durch den explodierenden Tantalpreis während der Jahre 1999 und 2000 ungemein wertvoll. Zur gleichen Zeit brandete ein äußerst blutiger Konflikt um die wertvollen Ressourcen des Kongos auf. Die Ausbeutung des Coltans steht hier stellvertretend für andere Ressourcen (u.a. „Blutdiamanten“), die in diesem Konflikt ebenfalls Gegenstand von Ausbeutung waren. Es wird im Folgenden aufgezeigt, wie dieser Prozesss sich auf beteiligte und davon betroffene Akteure auswirkte und wie sich dieser im Zusammenhang mit der kongolesischen Kriegsökonomie darstellt.

Im Kongo wurde die Ausbeutung des Coltans von unzähligen bewaffneten Verbänden (Armeen, Rebellen, Warlords) und skrupellosen Geschäftsleuten vorangetrieben. Diese waren in der Position, Coltan zu beschaffen, und stellten die Verbindung zum Weltmarkt her. Im Kongo wurde infolge des Zusammenbruchs der großen Bergbaukonzerne, während des wirtschaftlichen Niedergangs des Landes unter Mobutu, Coltan hauptsächlich durch artisanal mining gefördert. Dies bedeutet, dass dort in kleinen Gruppen auf eigene Rechnung gearbeitet wurde. Viele dieser artisanal miners („Kleinschür-

76 Angola, Namibia und Simbabwe (anfangs auch Tschad und Sudan) auf ihrem eigenen Staatsgebiet gegen Ruanda und Uganda.

77 Keen (1998), 11.

78 Der Großteil der in der Einleitung erwähnten Ressourcenvorkommen findet sich in den östlichen Grenzregionen des Kongos, die als Teil der „Region der Großen Seen“ gelten. 
fer") betrieben ursprünglich Landwirtschaft und waren infolge des Konflikts gezwungen diese aufzugeben. Die zahlreichen Massaker, welche die Krisenregion erschütterten, trieben die Menschen von ihren fruchtbaren Böden in die Coltanminen. ${ }^{79}$ Große Vorkommen waren bis zu einem gewissen Grad von den dort dominierenden Verbänden bewacht. Dies bedeutete für die Kleinschürfer, dass sie Coltan abbauen konnten, für das sie von den dortigen Händlern, je nach deren Ermessen, zwischen einen und acht Dollar erhielten. 80 Der Zugang zum Coltan wurde in vielen Fällen über einen oder mehrere Zwischenhändler organisiert. Der Preis ergab sich je nach dem Tantalanteil im Coltan. Die Maschinen für derartige Messungen besaßen einige wenige Großhändler, was die Kleinschürfer und Zwischenhändler der vollkommenen Willkür dieser aussetzte. ${ }^{81}$ Manche suchten ihr Glück auch in unbewachten Minen, die weit entfernt im Regenwald lagen, wo jedoch die Gefahr von Überfällen durch bewaffnete Verbände und Banditen lauerte. In den von Ruanda beherrschten Gegenden wurden in großem Stil Häftlinge zum Coltanabbau gezwungen.

Der Zugang zum Weltmarkt wurde von größeren Händlern und militärischen Verbänden, hinter denen Warlords, Rebellenführer oder auch Offiziere von offiziellen Armeen standen, organisiert. Auf der anderen Seite des Weltmarkts standen global agierende Unternehmen, die Tantal förderten. Das Tantalpulver, das für die Kondensatorenproduktion der Elektroindustrie benötigt wurde, produzierten weltweit nur sehr wenige Unternehmen. ${ }^{82}$ Eine UN-Expertenkommission kam nach umfassenden Untersuchungen zu dem Schluss, dass zahlreiche Unternehmen von außerhalb des Kongos mit kongolesischen Coltan handelten oder dieses verarbeiteten und dabei gegen die „OECD Guidelines for Multinational Enterprises“ verstießen. ${ }^{83}$ Sie erwarben die wertvolle Ressource von den oben beschriebenen kongolesischen Akteuren, die Zugang zum Weltmarkt hatten. In einem vorangegangen Bericht kommen dieselben UNExperten zu dem Schluss, dass der Hauptgrund des Afrikanischen Weltkriegs zu diesem Zeitpunkt im Zugang zu wertvollen Ressour-

79 Jackson (2003), 32; Jackson (2005), 157.

80 Johnson/Tegera (2005), 24; Jackson (2003), 27, 33.

81 Johnson/Tegera (2005), 24.

82 Raeymaekers (2002), 20.

83 UN (2002), Annex III. 
cen wie Coltan, Diamanten, Kupfer, Kobalt und Gold lag. ${ }^{84}$ Der Weltmarktpreis für Tantal erreichte im Jahr 2000 einen Jahresschnitt von 591 Dollar pro Kilo. ${ }^{85}$ Ressourcen wie Coltan konnten auch im Kriegszustand profitabel abgebaut werden. Können die Konfliktparteien diese Ressourcen über globale Märkte absetzen, erhalten sie die notwendigen Mittel, um ihre Männer weiterhin mit Waffen zu versorgen. In einer Region, die vom Krieg zerrüttet ist, in der Polizei und Justizsystem nicht mehr funktionieren, kann man seine Position durch Gewalt verteidigen und dadurch seine Ansprüche durchsetzten. Im Kongo wurde der Profit aus dem Verkauf von wertvollen Ressourcen wie dem Coltan großteils dafür verwendet, seine eigene Position zu festigen, indem man sich durch Gewalt den Zugang zu diesen sicherte.

Abbildung 3: Tantalpreise (1964-2004) ${ }^{86}$

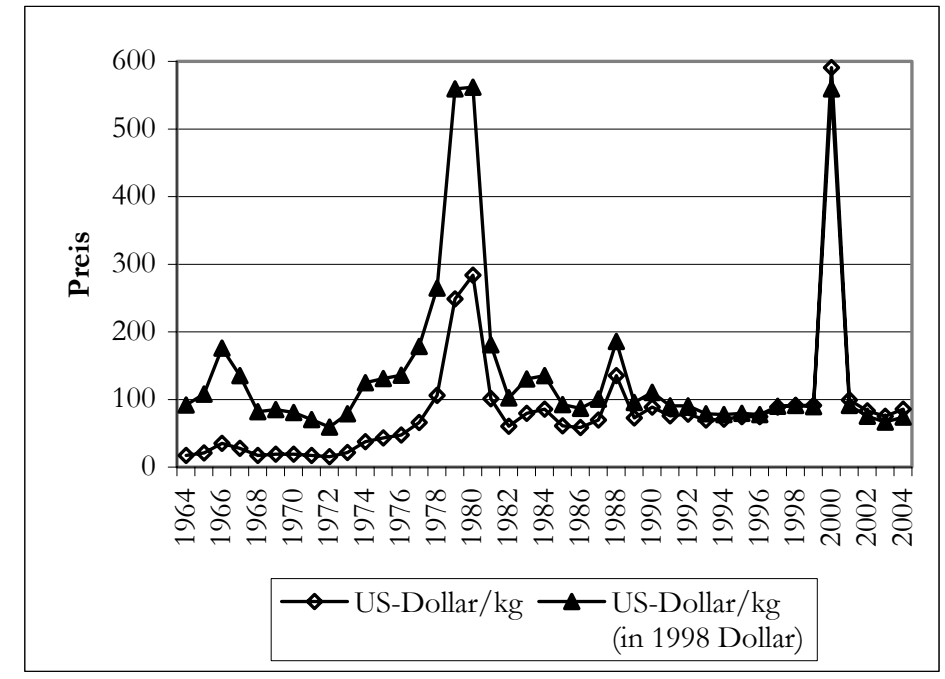

Im Ausbeutungssystem des Coltanhandels im Kongo standen sich mehrere Akteure gegenüber. Bewaffnete Verbände und Großhändler hatten in diesem Ausbeutungssystem eine elitäre Position im Gegen- 
satz zu den Kleinschürfern, da sie durch den Zugang zum Weltmarkt aus dem Coltanhandel relativ hohe Profite ziehen konnten. Ihre privilegierte Position beruhte auf ihrem großen Potenzial an direkter Gewalt, das sie gegen die Kleinschürfer und den Rest der lokalen Bevölkerung in den ressourcenreichen Gebieten einsetzen konnten. Strukturelle Gewalt kam überwiegend von außerhalb des Kongos. Die Unternehmen, kriminellen Kartelle und Regierungen, die als Handelspartner mit den gewalttätigen Eliten im Kongo über globale Märkte in Verbindung traten, trugen durch diese Geldflüsse zur Fortsetzung der direkten Gewalt im Kongo bei. Die Gewalt fand kein Ende, da dort zahlreiche billige Waffen verfügbar waren und gleichzeitig die Institutionen wie Justiz, Polizei und Militär, welche den Menschen in der Krisenregion Schutz bieten sollten, entweder nicht existierten oder sich an der Ausbeutung beteiligten. Im Kongo festigten lokale Eliten ihre Macht durch außerordentlich grausame direkte Gewalt. Die Mittel, die sie dafür benötigten, erhielten sie durch Handelsbeziehungen über globale Märkte, wie sie im Fall des Kongos u.a. der Coltanmarkt bot. Unter Bedingungen, wie sie im Osten des Kongos herrschten, steht und fällt eine elitäre Position damit, ob man durch direkte Gewalt Ansprüche durchsetzen kann. Deshalb stellen die Handelsbeziehungen zwischen globalen Akteuren und den gewalttätigen kongolesischen Eliten strukturelle Gewalt dar, die für die Fortsetzung direkter Gewalt verantwortlich ist. Die Akteure die auf globaler Ebene handeln, zwingt die Bevölkerung in die Situation weiterhin ein Leben ohne Perspektive und unter stetig drohender Gewalt zu führen. Legitimiert wird dieses Ausbeutungssystem durch die globalen Marktmechanismen, über den der Ressourcenhandel abgewickelt wird und der weitgehend keine Einwände gegen die Konsequenzen dieser Handelsbeziehungen hegt. Kulturelle Gewalt entspringt demnach der globalen Organisation des Handels, die derzeit kaum Einschränkungen gegenüber gewalttätigen Akteuren vorsieht.

Im Kongo kämpten immer noch wenigstens 11.000 (vor früher 30.000) Kinder in bewaffneten Verbänden. ${ }^{87}$ Nach Schätzungen des UN Fund for Women werden seit 1998 mehrere Hunderttausend Frauen Opfer von Vergewaltigungen, wobei die UNESCO von bereits „epidemischen Ausmaßen“ spricht. ${ }^{88}$ Im Kongo lebten die 
Menschen bereits infolge der Ausbeutung des Diktators Mobutu in

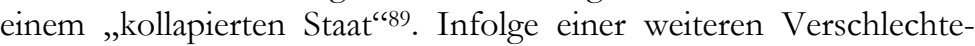
rung der Lebensumstände der lokalen Bevölkerung durch den Konflikt forderten Durchfalls- und Atemwegserkrankungen sowie die Folgen der Unterernährung den weitaus größten Teil der fast vier Millionen Opfer..$^{90}$ Bei ausreichender medizinischer Versorgung hätten schätzungsweise zumindest 40 Prozent dieses gigantischen Ausmaßes an Opfern vermieden werden können. ${ }^{91}$ Diese Umstände sind überwiegend auf strukturelle und kulturelle Gewalt zurückzuführen, da sich die dramatisch schlechten Lebensbedingungen mit direkter Gewalt aus der Finanzierung der Konfliktparteien über Geschäfte an globalen Märkten ergaben. Diese Austauschverhältnisse erzeugten indirekte Gewalt, die sich auf den Kongo verheerend auswirkte. Aufgrund der Krisensituation war kongolesisches Coltan für globale Akteure in vielen Fällen zu Dumpingpreisen erhältlich. Für Unternehmen, die Coltan aus dem Kongo importierten, brachte die Ressource einen strategischen Vorteil im wirtschaftlichen Konkurrenzkampf. Die darin involvierten kongolesischen Eliten benötigten laufend finanzielle Mittel, um durch direkte Gewalt weiterhin ihre Position im Kongo zu behaupten. Dabei spielte für sie der Zugang zu wertvollen Ressourcen (u.a. Coltan) eine besonders wichtige Rolle.

\section{Zusammenfassung und Analyse}

"The natural resources exported from these wars, including oil, diamonds, and coltan, have little intrinsic worth; it is only within the context of the international market that they have value." 92

Was kann man aus der Betrachtung dieser drei Ausbeutungssysteme im Kongo folgern? In allen Systemen wirkten sich die Konsequenzen, die sich aus der Ausbeutung ergaben, generell auf die lokale Bevölkerung negativ aus. Durch die Strukturen des Ausbeutungssystems wirkte auf sie direkte und strukturelle Gewalt. Kulturelle Gewalt legitimierte den Zustand der Ausbeutung. Die Akteure auf globaler

89 René Lemarchand (2003) gibt an, dass der state collapse im Kongo spätestens ab dem Jahr 1992 unaufhaltsam voranschritt.

90 Clark/Koyame (2002), 208; Coghlan et al. (2006), 48.

91 Aoaku (2002), 123.

92 Cater (2003), 33. 
Ebene agierten, sowohl im Fall der Sklaven als auch beim Coltan, über globale Handelsbeziehungen. Auf kongolesischer Seite handelte es sich dabei um Akteure, die eine elitäre Position hatten oder durch die Ausbeutung erlangten (kongolesische Eliten), indem sie an globalen Märkten agierten. Ihnen gegenüber standen politische Vertreter, Geschäftsleute, Unternehmen und kriminelle Organisationen (globale Akteure), die im Atlantischen Sklavenhandel Europäer und beim Coltanhandel hauptsächlich auf den Kontinenten Europa, Asien und Amerika beheimatet waren. Sowohl die kongolesischen Eliten als auch die globalen Akteure konnten von diesen Austauschbeziehungen bis zu einem gewissen Grad profitieren, da die zugrunde liegenden Geschäfte auf Ausbeutung basierten. Bei der Bereitstellung von Sklaven und der Produktion von Kautschuk oder Coltan entstanden verhältnismäßig geringe Kosten, da die Bevölkerung außerordentlich schlecht oder gar nicht bezahlt wurde. Bedeutende Fixkosten waren in erster Linie nur mit dem Transport der Ressourcen verbunden.

Im Gegensatz zum Sklaven- und Coltanhandel kann man beim Kautschukhandel nicht in einer vergleichbaren Form von afrikanischen Eliten sprechen. In der Kolonialzeit waren globale Akteure nicht nur über den globalen Handel in die Ausbeutung des Kongos involviert, sondern sie übernahmen auch offiziell die politische Kontrolle in der Region. Mit der juristisch festgeschriebenen Aufteilung Afrikas im Rahmen der Berliner Konferenz wurde dem belgischen König Leopold II. der Kongo offiziell übertragen. In dieser Zeit, in der der Kautschukhandel alle anderen Geschäfte im Kongo dominierte, kümmerten sich europäische Vertreter direkt um die Ausbeutung der kongolesischen Bevölkerung und Kautschukvorkommen. Sie errichteten Handelsstützpunkte in den ressourcenreichen Regionen und forcierten die Ausbeutung durch ihre ständige Präsenz vor Ort.

Auch die Position der kongolesischen Söldner kann keinem Vergleich mit der der kongolesischen Eliten im Sklaven- und Coltanhandel standhalten. Im Kongo-Freistaat von Leopold II. konnten sich Söldner unter Umständen erhoffen, bis zu einem bestimmten Grad von den Gräueln der Bestrafungsmaschinerie verschont zu bleiben. Sowohl beim Sklaven- als auch Coltanhandel hatten die kongolesischen Eliten zumindest eine Position, die ihnen einen Verhandlungsspielraum gab, und erlangten dadurch zumindest ein gewisses $\mathrm{Maß}$ an Freiheit. Bei beiden Ausbeutungssystemen übernahmen diese privilegierten Kongolesen die Aufgabe, die begehrten Res- 
sourcen bereitzustellen. Beim Kautschukhandel wurden die Söldnern beauftragt, die Zwangssteuern einzutreiben. Im Unterschied zu den anderen Ausbeutungssystemen wurden sie dazu, in vielen Fällen, durch direkte Gewalt gezwungen. Beim Sklaven- und Coltanausbeutungssystem wurde direkte Gewalt in erster Linie von den afrikanischen Eliten auf die lokale Bevölkerung ausgeübt. Für strukturelle Gewalt, die wiederum auf die lokale Bevölkerung wirkte, waren die globalen Akteure in einem bedeutenderen Ausmaß als die kongolesischen Eliten verantwortlich. Im Sklavenhandel organisierten die Europäer den globalen Handel. In allen Ausbeutungssystemen kam die Nachfrage für die jeweilige Ressource von außerhalb des Kongos. Natürlich erzeugten auch die kongolesischen Eliten ein gewisses $\mathrm{Maß}$ an struktureller Gewalt, die auf die lokale Bevölkerung wirkte. Es war jedoch die Nachfrage an den globalen Märkten, welche den Ressourcen erst einen derartigen Wert verlieh, dass sie entsprechend hohe Profite brachten. Aufgrund der Ausbeutungssysteme, die lediglich darauf abzielten, dem Kongo Ressourcen zu entziehen, konnte die lokale Bevölkerung von den wertvollen Ressourcen kaum profitieren. Die Arbeit kongolesischer Sklaven kam nur den amerikanische Kolonien zugute und sowohl Kautschuk als auch Coltan wurden nicht im Kongo verarbeitet, sondern als reiner Rohstoff exportiert. Nur die kongolesischen Eliten konnten durch den Verkauf von Sklaven und Coltan Profite erzielen. Diese stellten im Verhältnis zur lokalen Bevölkerung einen äußert geringen Anteil an der Gesamtbevölkerung dar. Die globalen Akteure konnten durch die Ausbeutung in vielen Fällen wertvolle Ressourcen zu außerordentlich niedrigen Preisen (Dumpingpreisen) erwerben und sich deshalb generell von diesem System die höchsten Profite erwarten.

Die Ausbeutungssysteme des Atlantischen Sklavenhandels, Kautschukhandels und Coltanhandels sind strukturell nicht absolut identisch. Sie weisen jedoch sehr umfassende Ähnlichkeiten auf und jedes von ihnen kann deshalb teilweise als Wiederkehr desselben Phänomens gesehen werden. Im Laufe der Geschichte waren es immer wieder sowohl globale als auch kongolesische Akteure, welche die Ausbeutung des Kongos gemeinsam vorantrieben und dadurch für sich Profite erwirtschafteten. Um diesem Phänomen ein Ende zu bereiten, müssen diese Beziehungen durchbrochen und neu geordnet werden. 


\section{Literatur}

Afoaku, Osita (2002): „Congo's Rebels - Their Origins, Motivations, and Strategies", in: Clark, John F., Hg.: The African Stakes of the Congo War. New York: Palgrave Macmillian, 109-128.

AKUF (2006): „Das Kriegsgeschehen 2005 im Überblick“, online unter: http://www.sozialwiss.uni-hamburg.de/publish/Ipw/Akuf/kriege_ aktuell.htm (Zugriff am 4.12.2007).

Amnesty International (2006): „, Democratic Republic of Congo (DRC): Child soldiers abandoned", online unter: http://web.amnesty.org/ library/index/engafr620192006 (Zugriff am 4.12.2007).

Bales, Kevin (2001): Die neue Sklaverei. München: Antje Kunstmann.

Bennett, Amy (2007): „V-Day and UNICEF urge protection for women and girls in eastern DR Congo“, online unter: http://www.unicef.org/ infobycountry/drcongo_40516.html (Zugriff am 4.12.2007).

Bobb, F. Scott (1988): Historical Dictionary of Zaire. Metuchen/NJ: The Scarecrow Press.

Bordo, Michael/Taylor, Alan M./Williamson, Jeffrey G., Hg. (2003): Globalization in Historical Perspective. Chicago: University of Chicago Press.

Büchler, Max (1912): Der Kongostaat Leopolds II. - Schilderung seiner Entstehung und seiner wirtschaftliche Verhältnisse. Leipzig: Verlag von Rascher \& Cie.

Cater, Charles (2003): „The Political Economy of Conflict and UN Intervention: Rethinking the Critical Cases of Africa“, in: Ballentine, Karen/Sherman, Jake, Hg.: The Political Economy of Armed Conflict - Beyond Greed and Grievance. London: Lynne Rienner Publishers.

Clark, John F./Koyame, Mungbalemwe (2002): „The Economic Impact of the Congo War", in: Clark, John F., Hg.: The African Stakes of the Congo War. New York: Palgrave Macmillan, 201-223.

Coghlan, Benjamin/Brennan, Richard J./Ngoy, Pascal/Dofara, David/ Otto, Brad/Clements, Mark/Stewart, Tony (2006): „Mortality in the Democratic Republic of Congo: a Nationwide Survey“, in: The Lancet 367 (9504), 44-51.

Davidson, Basil (1966): Vom Sklavenhandel zur Kolonialisierung: Afrikanischeuropäische Beziehungen zwischen 1500 und 1900. Reinbek/H.: Rowohlt.

Der Standard (2007): „UNO: Kongo hilfsbedürftigste Region - Somalia vor Hungerkatastrophe“, 17. Juli (online-Ausgabe).

Doyle, Arthur C. (1985): Das Congoverbrechen. Frankfurt/M.: Syndikat.

Ehrhardt, Karl (1903): Die geographische Verbreitung der für die Industrie wichtigen Kautschuk- und Guttaperchapflanzen. Frankfurt/M.: Verlag von Heinrich Keller.

Emerson, Barbara (1979): Leopold II of the Belgians - King of Colonialism. London: Weidenfeld and Nicolson.

Emmer, Pieter (1998): The Dutch in the Atlantic Economy, 1580-1880: Trade, Slavery and Emancipation. Hampshire: Variorum Collected Studies Series. 
Exenberger, Andreas/Hartmann, Simon (2007): The Dark Side of Globalization - The Vicious Cycle of Exploitation from World Market Integration: Lesson from the Congo. Working Papers in Economics and Statistics 31, Universität Innsbruck.

Galtung, Johan (1975): Strukturelle Gewalt - Beiträge zur Friedens- und Konfliketforschung. Reinbek/H.: Rowohlt.

Galtung, Johan (1990): „Cultural Violence“, in: Journal of Peace Research 27 (3), 291-305.

Gartner (2005): „Gartner Says Mobile Phone Sales Will Exceed One Billion in 2009", online unter: http://www.gartner.com/press_releases/asset_ 132473_11.html (Zugriff am 4.12.2007).

Harms, Robert W. (1981): River of Wealth, River of Sorrow - The Central Zaire Basin in the Era of the Slave and Ivory Trade, 1500-1891. London: Yale University Press.

Harms, Robert W. (1983): The World ABIR Made: The Maringa-Lopori Basin 1885-1903. Boston: Boston University Press.

Hartmann, Simon (2006): Historische Betrachtung des Kongo im internationalen Handel: Eine Geschichte kompromissloser Gier. Innsbrucker Diskussionspapiere zu Weltordnung, Religion und Gewalt 13, Universität Innsbruck.

Hochschild, Adam (2002): Schatten über dem Kongo: Die Geschichte eines der großen, fast vergessenen Menschheitsverbrechens. Reinbek/H.: Rowohlt.

Iliffe, John (1995): Africans: The History of a Continent. Cambridge/UK: Cambridge University Press.

International Rubber Study Group (1996): World Rubber Statistics Historic Handbook 1900-1960. Wembley: IRSG.

Jackson, Stephen (2003): „Fortunes of War: the Coltan Trade in the Kivus“, in: Collinson, Sarah, Hg.: Power, Livelihoods and Conflicts: Case Studies in Political Economy Analysis of Humanitarian Action. London: Overseas Development Institute, 21-36.

Jackson, Stephen (2005): „Protecting Livelihoods in Violent Economies“, in: Ballentine, Karen/Nitzschke, Heiko, Hg.: Profiting from Peace - Managing the Resource Dimension of Civil War. Colorado, London: Lynne Rienner Publishers, 153-184.

Johnson, Dominic/Tegera, Aloys (2005): „Digging Deeper: How the DRC’s Mining Policy is Failing the Country - A Pole Institute Report", online unter: http://www.pole-institute.org/documents/regards15_eng.pdf (Zugriff am 4.12.2007).

Jünger, Wolfgang (1940): Kampf um Kautschuk. Leipzig: Wilhelm Goldmann Verlag.

Katzenellenbogen, Simon (1996): „It Didn't Happen at Berlin: Politics, Economics and Ignorance in the Setting of Africa's Colonial Boundaries", in: Nugent, Paul/Asiwaju, Anthony I., Hg.: African Boundaries Barriers, Conduits and Opportunities. New York: Pinter, 21-34. 
Keen, David (1998): The Economic Functions of Violence in Civil Wars. Oxford: Oxford University Press.

Kern Kathleen (2007): „The Human Cost of Cheap Cell Phones“, in: Hiatt Steven, Hg.: A Game as Old as Empire - The Secret World of Economic Hit Men and the Web of Global Corruption. San Francisco: Berrett-Koehler, 93-112.

Klein, Herbert S. (1999): The Atlantic Slave Trade. Cambridge/UK: Cambridge University Press.

Lemarchand, René (2003): „The Democratic Republic of Congo: From Failure to Potential Reconstruction“, in: Rotberg, Robert I., Hg.: State Failure and State Weakness in a Time of Terror. Washington/DC: Brookings Institution Press, 29-70.

Loadman, John (2005): Tears of the Tree. New York: Oxford University Press.

Marchal, Jules (1996): E.D. Morel Contre Léopold II - L'Histoire du Congo 19001910, Volume 2. Paris : Éditions L’Harmattan.

McCalpin, Jermaine O. (2002): „Historicity of a Crisis - The Origins of the Congo War", in: Clark John, Hg.: The African Stakes of the Congo War. New York: Palgrave Macmillan, 33-50.

Miller, Joseph C. (1976): „The Slave Trade in Congo and Angola“, in: Kilson, Marin L./Rotberg, Robert I., Hg.: The African Diaspora - Interpretive Essays. Harvard: Harvard University Press.

Miller, Joseph C. (1986): „Slave Prices in the Portuguese Southern Atlantic, 1600-1830“, in: Lovejoy, Paul E., Hg.: Africans in Bondage. Studies in Slavery and the Slave Trade. Madison: University of Wisconsin Press, 4377.

Miller, Joseph C. (1988): Way of Death. Merchant Capitalism and the Angolan Slave Trade 1730-1830. Madison: University of Wisconsin Press.

Miller, Joseph C. (1998): „The Numbers, Origins, and Destinations of Slaves in the Eighteenth-Century Angolan Slave Trade", in: Inikori, Joseph E., Hg.: The Atlantic Slave Trade - Effects on Economies, Societies, and Peoples in Africa, the Americas, and Europe. Durham: Duke University Press, 77-115.

Morel, Edward D. (2005): Red Rubber: The Story of the Rubber Slave Trade Flourishing on the Congo in the Year of Grace 1906. Honolulu: University Press of the Pacific.

Pakenham, Thomas (1991): The Scramble for Africa 1876-1912, London: Weidenfeld \& Nicolson.

Raeymaekers, Timothy (2002): Network War-An Introduction in Congo's Privatised $W$ ar Economy. Antwerpen: International Peace Information Service.

Rinchon, Dieudonné P. (1929): La Traite et l'Esclavage des Congolais par les Européens - Histoire de la Déportation de 13 Millions 250.000 Noirs en Amérique. Bruxelles: Capucin. 
Smith, Adam (1978): Der Woblstand der Nationen - Eine Untersuchung seiner Natur und seiner Ursachen. München: Deutscher Taschenbuch Verlag.

The DME (2002): „The Tantalum Market (A Micro - Economic Analysis)“, online unter: http://www.dme.gov.za/pdfs/minerals/r37_2002.pdf (Zugriff am 4.12.2007).

Thomas, Dan (2006): „Childhood under Attack in DR Congo“, online unter: http://www.unicef.org/infobycountry/drcongo_35032.html (Zugriff am 4.12.2007).

Thornton, John K. (1999): Africa and Africans in the Making of the Atlantic World, 1400-1800. Cambridge/UK: Cambridge University Press.

UN (2001): „Report of the Panel of Experts on the Illegal Exploitation of Natural Resources and other Forms of Wealth of the Democratic Republic of the Congo“, online unter: http://www.globalsecurity.org/ military/library/report/2001/357e.pdf (Zugriff am 4.12.2007).

UN (2002): „Final Report of the Panel of Experts on the Illegal Exploitation of Natural Resources and other Forms of Wealth of the Democratic Republic of the Congo“, online unter: http://www.naturalresources.org/minerals/law/docs/pdf/N0262179.pdf (Zugriff am 4. 12.2007).

UN (2007): „UN Humanitarian Chief: 'Stories that go beyond the Imagination"“, UN Office for the Coordination of Humanitarian Affairs (OCHA), online unter: http://ochaonline.un.org/OchaLinkClick.aspx ?link= ocha\&docId=1083842 (Zugriff am 4.12.2007).

USGS (2005a): „Historical Statistics for Mineral and Material Commodities in the United States, End-Use Statistics Tantalum", online unter: http://minerals.usgs.gov/ds/2005/140/tantalum-use.pdf (Zugriff am 4.12.2007).

USGS (2005b): „Historical statistics for mineral and material commodities in the United States, Supply - Demand Statistics", online unter: http://minerals.usgs.gov/ds/2005/140/tantalum.pdf (Zugriff am 4. 12.2007).

Wallerstein, Immanuel (1986): Das moderne Weltsystem - Kapitalistische Landwirtschaft und die Entstehung der europäischen Weltwirtschaft im 16. Jahrbundert. Wien: Promedia.

Williams, Eric (1966): Capitalism and Slavery. Chapel Hill: University of North Carolina Press. 
Organisation des Hungers. Ein apokalyptischer Reiter im

Lichte von Weltordnungs- und Globalisierungsprozessen

Andreas Exenberger ${ }^{*}$

„Aber die unten sind, werden unten gehalten, damit die oben sind, oben bleiben." 1

Auf den folgenden Seiten soll dem Zusammenhang zwischen Hunger und Weltordnung nachgegangen werden. Es wird dabei deutlich werden, dass Weltordnung nicht exklusiv im Sinn einer formellen Ordnung verstanden werden kann (wie etwa derjenigen durch die Vereinten Nationen) oder einer gewaltsamen, durch politische oder militärische Machtverhältnisse determinierten Ordnung (wie etwa die Pax Britannica), sondern vielmehr verschiedene Formen annehmen kann, die ich hier unter dem Sammelbegriff „Globalisierung“ fassen möchte (mit Fokus auf seine ökonomische und politische Dimension). Er soll stellvertretend für sehr verschiedene Typen von Weltordnung stehen, die alle ihre Ausdrucksformen in einer globalisierten Welt finden: für die Ordnung durch internationale Organisationen, durch mächtige Staaten, durch finanzkräftige Unternehmen oder durch globale Regimes, die sich in einem komplexen Zusammenspiel verschiedener Faktoren bilden. Im Anschluss an Julian Saurin ist da-

* Andreas Exenberger ist wissenschaftlicher Mitarbeiter am Institut für Wirtschaftstheorie, -politik und -geschichte der Universität Innsbruck im Forschungsfeld „Wirtschafts- und Sozialgeschichte" und Redakteur der Innsbrucker Diskussionspapiere zu Weltordnung, Religion und Gewalt. Der Text stützt sich auf Forschungsergebnisse aus dem vom Jubiläumsfonds der Oesterreichischen Nationalbank (OeNB) geförderten Projekt „Globalisierung des Hungers". Eine frühere Version wurde bei der 14. Klausurtagung der Plattform am 19. Dezember 2005 zur Diskussion gestellt und ist als Nr. 3 der Innsbrucker Diskussionspapiere zu Weltordnung, Religion und Gewalt erschienen.

1 Aus: Die Heilige Johanna der Schlachthöfe (von Berthold Brecht), zitiert in Ziegler (2005), 95. 
bei die Frage zu stellen, ob - bzw. wie - der Hunger in diesem Kontext „organisiert" wird.

Hunger zählt zusammen mit Krieg und Seuchen zu den apokalyptischen Reitern, was auf die historische Normalität dieser Zustände verweist. Dieses menschliche Dreigestirn hat (oft überlappend) eine reiche Ernte an Opfern eingebracht, in den letzten zwei Jahrhunderten ebenso wie davor. Wie seine apokalyptischen Genossen hat der Hunger aber nur wenig ökonomische Forschung nach sich gezogen. Dem will der folgende Text etwas abhelfen, indem er eine Bestandsaufnahme zum globalen Problemkomplex Hunger liefert (wobei auch einige Begriffe zu diskutieren sind), anschließend die historische Dimension von Hunger und Weltordnung (bzw. Globalisierung) darstellt und schließlich die wichtigsten aktuellen Herausforderungen und Entwicklungen aufzeigt.

Vorab noch zwei weitere Bemerkungen: Erstens ist das an den Anfang gestellte Zitat nicht als Ausgangspunkt der Untersuchung zu deuten, sondern stellt sich in bestimmten Zusammenhängen (auf einige davon wird in der Folge näher einzugehen sein) als die offensichtlich beste - teils sogar als die einzig mögliche - Interpretation der Wirklichkeit heraus. Zweitens möchte ich, auch wenn außer Streit steht, dass Hunger angesichts der Zahl der betroffenen Menschen und der Dimension ihres Leidens eines der dringendsten Probleme der Menschheit ist - wie manche meinen, in unsere technologisch hoch entwickelten Welt eigentlich ein „Skandal“ -, die folgenden Ausführungen ohne das Nacherzählen der grauenvollen Details des Hungerns und Verhungerns auf einer möglichst analytischen Ebene ansiedeln. Wer an praktischen Schilderungen interessiert ist, sei auf die Arbeiten von Mike Davis (zu historischen Katastrophen) oder Jean Ziegler (zur Gegenwart) hingewiesen, die zahlreiche Beispiele geben, wie man die alltägliche, stille Katastrophe des Hungers auch in Geschichten, Bilder und Metaphern übersetzen kann. ${ }^{2}$

\section{Bestandsaufnahme}

Derzeit gelten 864 Millionen Menschen, also ein sehr ungleich verteiltes Siebentel der Weltbevölkerung, als chronisch unterernährt und

2 Vgl. etwa Davis (2004) und Ziegler (2005). Vgl. auch Nussbaumer (2000) und Nussbaumer (2003). 
damit akut vom Hungertod bedroht. ${ }^{3}$ Je nachdem, wie man die Hungernden zählt, ergeben sich dabei unterschiedliche Brennpunkte.

Tabelle 1: Länder mit der größten An₹abl an Hungernden 2002-04 4

\begin{tabular}{|c|c|c|c|}
\hline & \multicolumn{2}{|c|}{ Anzahl (Millionen) } & \multirow{2}{*}{$\begin{array}{c}\text { Versorgungsniveau } \\
\text { (kcal pro Kopf und Tag) }\end{array}$} \\
\hline & $2002-04$ & 1979-81 & \\
\hline Indien & 209,5 & 261,3 & 2.470 \\
\hline China & 153,7 & 304,0 & 2.930 \\
\hline Bangladesch & 44,0 & 33,3 & 2.200 \\
\hline DR Kongo & 39,0 & 10,0 & 1.590 \\
\hline Pakistan & 37,5 & 23,6 & 2.320 \\
\hline Äthiopien & 32,7 & $\ldots$ & 1.850 \\
\hline Tansania & 16,4 & 5,2 & 1.960 \\
\hline Philippinen & 14,6 & 12,9 & 2.490 \\
\hline Indonesien & 13,8 & 36,5 & 2.890 \\
\hline Thailand & 13,8 & 10,7 & 2.400 \\
\hline Brasilien & 13,1 & 18,1 & 3.110 \\
\hline Vietnam & 13,0 & 19,7 & 2.630 \\
\hline Nigeria & 11,4 & 23,9 & 2.720 \\
\hline Kenia & 9,9 & 3,3 & 2.150 \\
\hline
\end{tabular}

Tabelle 2: Länder mit dem größten Anteil an Hungernden 2002-04 5

\begin{tabular}{l|r|r|c} 
& \multicolumn{2}{|c|}{ Anteil (\%) } & $\begin{array}{c}\text { Versorgungsniveau } \\
\text { (kcal pro Kopf und Tag) }\end{array}$ \\
\hline Eritrea & $7502-04$ & $1990-92$ & 1.500 \\
DR Kongo & 74 & 31 & 1.590 \\
Burundi & 66 & 48 & 1.660 \\
Komoren & 60 & 47 & 1.770 \\
Tadschikistan & 56 & $\ldots$ & 1.900 \\
Sierra Leone & 51 & 46 & 1.910 \\
Liberia & 50 & 34 & 1.930 \\
Zimbabwe & 47 & 45 & 1.980 \\
Äthiopien & 46 & $\ldots$ & 1.850 \\
Haiti & 46 & 65 & 2.110 \\
Sambia & 46 & 48 & 1.950 \\
Zentralafr. Rep. & 44 & 50 & 1.960 \\
Mosambik & 44 & 66 & 2.080 \\
Tansania & 44 & 37 & 1.960
\end{tabular}

3 Siehe z.B. http://www.fao.org/FAOSTAT/foodsecurity/FSMap1_en.htm für Landkarten (siehe auch http://www.wfp.org/country_brief/hunger_map/map/hungermap.html).

4 Quelle: FAOSTAT (http://www.fao.org/FAOSTAT/foodsecurity/), Versorgungsniveau gemessen als Versorgungspotential gemäß FAO Food Balance Sheet.

5 Quelle: FAOSTAT (http://www.fao.org/FAOSTAT/foodsecurity/), Versorgungsniveau gemessen als Versorgungspotential gemäß FAO Food Balance Sheet. 
Geht man nach der Anzahl (siehe Tabelle 1), liegen die Problemgebiete in Asien (vor allem in Indien und China), geht man nach dem Bevölkerungsanteil (siehe Tabelle 2) oder dem Versorgungsniveau, liegen sie in Afrika.

Die Gesamtzahl der Hungernden blieb während der letzten zwei Jahrzehnte relativ stabil, nachdem sie während der 1970er- und 1980er-Jahre noch gesunken ist, freilich vor allem aufgrund von positiven Entwicklungen in China. Diese Trends zeigt auch Tabelle 3.

Tabelle 3: Unterernährung in den Weltregionen seit $1970^{6}$

\begin{tabular}{l|rrrrr} 
& 1970 & 1980 & 1991 & 1996 & \multicolumn{1}{c}{2003} \\
\hline Entwickelte Länder & $\ldots$ & $\ldots$ & $\ldots$ & 11,7 & 10,9 \\
GUS-Staaten & $\ldots$ & $\ldots$ & $\ldots$ & $\ldots$ & 19,0 \\
Entwicklungsländer & 963,7 & 927,0 & 826,6 & 801,3 & 834,0 \\
$\quad$ Nordafrika & 19,3 & 7,4 & 5,4 & 5,7 & 5,9 \\
Subsaharisches Afrika & 95,0 & 129,5 & 171,9 & 200,2 & 216,4 \\
Lateinamerika/Karibik & 55,3 & 46,2 & 59,5 & 54,7 & 52,2 \\
Ostasien (v.a. China) & 392,7 & 309,1 & 198,7 & 154,8 & 162,9 \\
Südasien (v.a. Indien) & 277,2 & 336,4 & 301,4 & 302,6 & 314,3 \\
Südostasien & 111,6 & 91,6 & 80,1 & 68,1 & 64,0 \\
Westasien & 11,6 & 6,1 & 8,7 & 14,3 & 17,3 \\
Ozeanien & 0,9 & 0,8 & 0,9 & 0,9 & 1,0 \\
\hline Welt & $\ldots$ & $\ldots$ & $\ldots$ & $\ldots$ & 863,9
\end{tabular}

Diese Tendenzen haben internationale Organisationen dazu veranlasst, den Kampf gegen den Hunger auch über konkrete Zielsetzungen in offiziellen Deklarationen zu führen. ${ }^{7}$ Die Food and Agricultural Organisation (FAO) erklärte 1996 im Rahmen des „World Food Summit", die Anzahl der chronisch unterernährten Menschen bis 2015 (bezogen auf 1996) halbieren zu wollen. Und im Jahr 2000 bekannten sich die Vereinten Nationen (UN), Speerspitze der derzeitigen formellen Weltordnung, namens ihrer Mitgliedstaaten zu den Millenniumsentwicklungszielen. Das erste dieser Ziele besteht u.a. darin, den Anteil dieser „Hungernden“ bis 2015 zu halbieren (bezogen auf 1990).

6 Quelle: FAOSTAT (http://www.fao.org/FAOSTAT/foodsecurity/). Ländergruppen gemäß Kategorisierung der UN, Zahlen jeweils im Dreijahresdurchschnitt (plus/minus ein Jahr um das Referenzjahr).

7 Siehe http://www.fao.org/wfs und http://www.un.org/millenniumgoals/. Wer eher gedruckte Quellen schätzt, sei auf FAO (1996) und UNDP (2003) verwiesen. 
Bei genauer Betrachtung sind diese Ziele von FAO und UN natürlich nicht dieselben. Ganz unabhängig davon, wie realistisch ihr Erreichen ist, klaffen sie sogar weit auseinander und das (ältere) FAO-Ziel ist deutlich ambitionierter als das (jüngere) UN-Ziel - ein Unterschied, der vielleicht zunehmenden Realismus spiegelt, vielleicht aber auch eine generelle „Entmenschlichung“ durch eine zu starke Orientierung an „Daten“. Die Millenniumsziele erhöhen generell die Distanz zu den Betroffenen, in diesem Fall den Hungernden: Schließlich steht direkt hinter einer Anzahl, so abstrakt sie auch in ihrer millionenhaften Größe sein mag, eine Menge an Betroffenen, während hinter einem Anteil zuerst weitere Abstraktionen zu passieren sind, ehe man zu den Menschen kommt. Sie machen aber auch in der Größenordnung den zweifellos nicht unbeträchtlichen Unterschied von Leid (oder nicht) für 165 Millionen Menschen, hauptsächlich weil die Weltbevölkerung zwischen 1990 und 2015 von 5,3 auf 7,3 Milliarden anwachsen wird:

\section{Tabelle 4: Hungerreduktionsziele von $\mathrm{FAO}$ und UN im Vergleich \\ Zahl der Hungernden 1996: \\ 820 Millionen \\ FAO-Ziel: Halbieren der Anzahl bis 2015: \\ 410 Millionen \\ Anteil der Hungernden 1990: \\ $5,8 \%=840$ Millionen \\ UN-Ziel: Halbieren des Anteils bis 2015: \\ Differenz: \\ $7,9 \%=575$ Millionen $^{9}$ \\ 165 Millionen}

Vorsicht also vor feinen Unterschieden, die sich übrigens auch in der Sprachregelung von zwei Berichten anderer Organisationen aus derselben Zeit in Bezug auf Armut spiegeln: Während 1997 das Entwicklungsprogramm der Vereinten Nationen (UNDP) seinen Jahresbericht unter das Motto stellte, die Armut (und damit auch den Hunger) „auslöschen“ zu wollen, stand der Jahresbericht der Weltbank

8 Diese Schätzung enthält neben den auch in Tabelle 3 dokumentierten 827 Millionen Hungernden in der sogenannten „Dritten Welt“ eine sehr konservative Schätzung für Hungernde in der „Ersten“ und „Zweiten“ Welt in der Höhe von 13 Millionen. Echte Erhebungen liegen für diese Länder vor den 1990er-Jahren leider nicht vor, die Schätzung ist aufgrund der damals noch relativ guten Versorgungslage in den kommunistischen Ländern aber nicht unplausibel.

9 Wobei ergänzt werden muss, dass das UN-Ziel länderspezifisch zu verstehen ist und die Gesamtreduktion daher (durch einige besonders erfolgreiche Länder) größer ausfallen könnte. Andererseits ist das Bevölkerungswachstum gerade in den von Hunger betroffenen Gebieten besonders hoch, womit sich das Ziel wiederum nach oben verschiebt. 
im Jahr 2001 - man ist versucht, „nur noch“ hinzuzufügen - unter dem Motto der „Attacke“ gegen die Armut. ${ }^{10}$

Immerhin sinkt der Anteil der Hungernden, freilich langsam und sehr uneinheitlich. In manchen Fällen gibt es auch langfristig sehr ungünstige Entwicklungen: Während das durchschnittliche Versorgungsniveau von den 1960er-Jahren bis zu den 1990er-Jahren global von 2.344 auf $2.740 \mathrm{kcal}$ pro Kopf und Tag (jeweils im Zehnjahresschnitt) anstieg, war in mehr als einem Viertel von 154 Ländern, für die Daten vorliegen, die Lage während der 1990er-Jahre sogar schlechter als während der 1960er-Jahre.

Tabelle 5: Langfristige Versorgungstrends 1961-70 bis 1991-2000 11

$\begin{array}{lr}\text { Durchschnittliche Verbesserung: } & +17 \% \\ \text { Länder mit Verbesserung um mehr als 50\%: } & 9 \\ \text { Länder mit Verbesserungen um mehr als 25\%: } & 19 \\ \text { Länder mit Verschlechterungen: } & 41 \\ \quad \text { davon auf relativ niedrigem Niveau (<2.000 kcal): } & 16\end{array}$

Hunger ist heute also global allgegenwärtig, trotz der Versuche, ihn „auszurotten“. Eine Erklärung für diesen offenbar global herrschenden strukturellen Hunger und die immer wieder aufflackernden Katastrophen wird dabei vor allem durch die Frage gesucht, ob Hunger nicht eigentlich Teil des Systems sein kann. Mir ist dabei ein Gedanke aus dem Buch Die Geburt der dritten Welt von Mike Davis in gewissem Sinn Leitidee. Dort ist im Rahmen der Frage, was eine Hungersnot eigentlich ist, und bezogen auf Menschen aus Darfur (schon vor zwanzig Jahren) zu lesen: „[Sie] errichten keine begriffliche Brandmauer zwischen Unterernährung und Hungersnot, Armut und Verhungern. Sie können auch nicht das moralische Kalkül wohlhabender Länder nachvollziehen, die bei ausgewiesenen Hungersnöten umgehend Hilfe leisten, aber chronische Unterernährung, die für die Hälfte der Säuglingssterblichkeit auf dem Planeten verantwortlich ist, gleichgültig ignorieren. Und sie haben zu Recht ein großes Misstrauen gegenüber einer Semantik der Hungersnot, die allzu häufig die ,normale ländliche Armut unsichtbar macht.“12

10 Vgl. UNDP (1997) und World Bank (2000).

11 Quelle: FAOSTAT (http://www.fao.org/FAOSTAT/foodsecurity/), eigene Berechnungen. Insgesamt konnten 154 Länder berücksichtigt werden, die Zahlen beziehen sich auf Zehnjahresschnitte der kcal pro Kopf und Tag (gemäß FAO Food Balance Sheet).

12 Davis (2004), 31, seinerseits in Anlehnung an Arbeiten von Alexander de Waal. 
Die feine, allzu „westliche“ Unterscheidung zwischen Hunger und chronischer Unterernährung ist nicht nur den meisten Betroffenen schwer nachvollziehbar, sondern wird bei etwas Nachdenken auch den Mitfühlenden fremd erscheinen. Tatsache aber ist, dass Organisationen, Staaten und Privatleute viel (wenngleich zu wenig) Energie und Geld investieren, um die akut Lebensbedrohten zu retten, weit weniger aber (zumindest pro Kopf betrachtet) getan wird, um den langsam Sterbenden zu Hilfe zu eilen. ${ }^{13}$ Wichtig ist daher zum einen die Frage, ob Katastrophen Teil der Ordnung sind oder eben gerade nicht, denn das hat wichtige Konsequenzen für die Bekämpfung von akuten Hungerkatastrophen. Wichtig ist zum anderen aber vor allem, welcher Befund für die chronische Mangelversorgung gilt, denn ihr fallen pro Jahr viele Millionen Menschen zum Opfer, insbesondere Kinder. ${ }^{14}$

Um die eben doch wichtigen Unterschiede im Hinblick auf Ursachen und Folgen herausarbeiten zu können, sind daher im Folgenden einerseits „Hunger“ und andererseits „Mangelversorgung“ zu unterscheiden und diese wiederum vom allgemein gebräuchlichen Konzept der „Unterernährung“. All diese Konzepte stellen in unterschiedlicher Weise auf die Versorgung mit Nahrungsenergie (ihrem reinen Brennwert) und auf die Versorgung mit bestimmten Inhaltsstoffen (Vitaminen, Spurenelementen, Fetten usw.) ab, die für eine ausreichende Ernährung wichtig sind (um erst gar nicht von gesunder Ernährung zu sprechen)..$^{15}$

„Hunger“ und „Unterernährung“ gehören dann beide in die Sphäre der primär am Brennwert orientierten Konzepte, während „Mangelversorgung" breiter angelegt ist und auch die unzureichende Versorgung mit Inhaltsstoffen berücksichtigt. ${ }^{16}$ Hunger unterschei-

13 Vgl. Nussbaumer/Exenberger (2006b) für eine systematische Unterscheidung von Katastrophenstrukturen und Katastrophenereignissen, speziell im Hinblick auf die Rezeption von Katastrophen.

14 In manchen Ländern Afrikas liegt, vor allem wegen der Mangelernährung, der Median des Sterbealters nur noch bei drei Jahren, d.h. die Hälfte der Menschen erlebt nicht einmal ihren vierten Geburtstag (selbst in Indien liegt dieses Alter bei annähernd 40 Jahren, in Industriestaaten in der Regel jenseits von 70 Jahren). Vgl. Sen (1999), 128.

15 Dabei ist zu beachten, dass die konkreten Grenzwerte alles andere als unumstritten sind und sie auch sehr stark von der jeweiligen Person abhängen, die in sehr unterschiedlicher Weise in der Lage sein kann, Nahrungsinhaltsstoffe zu verwerten.

16 Man könnte hier noch das Konzept der „Fehlernährung“ einführen, das noch genereller auf negative gesundheitliche Konsequenzen der Ernährung abstellt und daher auch eine Überversorgung mit Nahrungsenergie und Inhaltsstoffen beinhaltet. Für diesen Text ist 
det sich andererseits von Mangelversorgung und Unterernährung in erster Linie dadurch, dass er ein akutes Phänomen ist, das meist mit außergewöhnlichen Naturereignissen (Dürre, Flut) verknüpft ist, wobei ein hoher Grad der unmittelbaren Lebensbedrohung für die davon Betroffenen herrscht, weil in der Regel das Nahrungsdefizit (der Abstand zur Minimalversorgung) sehr groß ist. Mangelversorgung und Unterernährung sind demgegenüber chronische Phänomene, die eher mit generell ungünstigen Naturbedingungen (aridem Klima, hoher Erosionsneigung der Böden) in Zusammenhang gebracht werden (oft auch mit „Überbevölkerung"), wobei zwar ein eher niedriger Grad der unmittelbaren Lebensbedrohung herrscht (und auch ein eher geringes Nahrungsdefizit), aber eine starke und beständige Minderung der Leistungsfähigkeit, die letztlich auch die Lebenserwartung senkt. Auch Hunger kann chronisch werden, wenn er in einem agrarisch prekären Gebiet immer wieder auftritt, das in Zwischenzeiten durchaus Überschüsse erzeugt. Der zentrale Unterschied liegt also in der „Amplitude“ der Versorgungsschwankungen, in der „Volatilität“ der Nahrungszufuhr: Mangelversorgung herrscht in einem Umfeld relativ geringer Schwankungen auf niedrigem Niveau; Hunger herrscht in einem Umfeld relativ großer Schwankungen auf möglicherweise sogar höherem Durchschnittsniveau. ${ }^{17}$

Das entflicht die beiden Phänomene von einem Zusammenhang her, der auf den ersten Blick so zwingend erscheint. Denn so verstanden müssen Gebiete der Mangelversorgung nicht zugleich Hungergebiete sein, auch wenn Gebiete der Mangelversorgung aufgrund der generellen Schwächung der Bevölkerung zweifellos anfälliger für Hunger sind. Das gilt freilich auch für andere Todesursachen: speziell die Trennung zwischen Hungertoten und Seuchentoten ist nicht sauber zu ziehen, wobei in Hungerkrisen fast unweigerlich auch Seuchen wüten. ${ }^{18}$

das aber nicht wichtig, weil es hier nicht um eine Debatte geht, die auch das ständig zunehmende Problem von Übergewicht und Fettsucht berühren soll.

$17 \mathrm{Zu}$ Theorien des Hungers sei vor allem auf die Arbeiten von Amartya Sen verwiesen siehe etwa Sen (1982) oder auch Dréze et al. (1995) - oder auch auf Stephen Devereux siehe etwa Devereux (1992). Beide verweigern sich insbesondere der Interpretation von Hungerkrisen als Angebotskrisen und betonen ihren Charakter als Verteilungskrisen. Eine ausführliche Bestandsaufnahme findet sich auch bei Kracht/Schulz (2005).

18 Nach Young (1992) ist die Beziehung zwischen Unterernährung und Krankheit sogar zyklisch. Sie betont außerdem den sich selbst verstärkenden Charakter der Unterernährung. Vgl. Saurin (1997), 113. 
Man kommt natürlich auch nicht an der sozusagen offiziellen Definition der FAO vorbei, die für die meisten Statistiken zu Ernährung und damit auch Hunger maßgeblich ist. Die FAO betrachtet „Unterernährung“ als einen Nahrungskonsum, der nicht ausreicht, um den Mindestenergieverbrauch eines Menschen sicherzustellen. Da dieser Verbrauch sehr stark von den Lebensumständen abhängt, kann man aber keine allgemeine Regel aufstellen, welches Kalorienniveau etwa diese Bedingung erfüllt. ${ }^{19}$ Das gilt auch, weil der konkrete Verbrauch für bestimmte Tätigkeiten kaum allgemein messbar ist. ${ }^{20}$ Zur Zeit des Welternährungsgipfels 1996 wurde „Unterernährung" als ein Zustand verstanden, in dem ein Mensch, im Durchschnitt über ein Jahr, nicht genug Nahrung zu sich nimmt, um sowohl einer produktiven Tätigkeit nachzugehen wie auch sein Gewicht zu halten. ${ }^{21}$ Bemerkenswert ist, dass dieses Verständnis kaum das Problem der unzureichenden Ernährung aufgrund fehlender Inhaltsstoffe anspricht, sondern lediglich den Mangel an Energiezufuhr. Auch an ,schlechtem“ Essen (etwa weil die primäre Nahrungsquelle Müllhalden sind) sterben aber viele Menschen und bis zu zwei Milliarden sind betroffen, oft von mehreren simultanen Mängeln. ${ }^{22}$

19 Für den „Basalmetabolismus“ einer erwachsenen Frau werden 1.500 Kilokalorien (kcal) pro Tag angenommen, für einen Mann 1.700, Kinder und alte Menschen brauchen weniger, auch die Körpergröße spielt eine Rolle. Diese Werte decken aber nur den Kaloriengrundbedarf ohne jede Aktivität. Sofern auch gearbeitet werden muss, ist von wenigstens 500 bis $1.000 \mathrm{kcal}$ mehr auszugehen, bei Schwerarbeit erhöht sich der Bedarf weiter. Extreme Belastungen (z.B. im Spitzensport) führen sogar zu einem Verbrauch von jenseits von $10.000 \mathrm{kcal}$ pro Tag. Siehe Davis (2004), 48 für einige Beispiele. Die FAO gibt heute - je nach Land unterschiedlich -1.720 bis $2.030 \mathrm{kcal}$ pro Kopf und Tag als Mindestbedarf an. Siehe FAOSTAT (http://www.fao.org/FAOSTAT/foodsecurity/).

20 Vgl. etwa Mason (2003). Da solche Verbrauchsindikatoren, die eine Beurteilung der Ernährungslage im Vergleich mit der grundsätzlich ja messbaren Nahrungszufuhr versucht, daher unzuverlässig sind, werden auch qualitative und anthropometrische Verfahren herangezogen und von den Effekte auf den Grad der Mangelernährung geschlossen: einerseits vom subjektiven Empfinden und der beobachtbaren Aktivität, andererseits von bestimmten messbaren Körpermerkmalen, wie etwa der Körpergröße. Vgl. auch Fogel (2004) für solche Analysen.

21 Vgl. etwa FAO (1996), 3-7 und Appendix 3.

22 Vgl. Ziegler (2005), 110-115. Allein an verschiedenen Formen der Anämie leiden in Entwicklungsländern die Hälfte aller Frauen, ein Drittel aller Kinder (was zu irreparablen Hirnschäden führt) und ein Fünftel aller Männer. 
Dass Hunger in erster Linie ein Versorgungsproblem ist, ${ }^{23}$ ein Problem des unzureichenden Zugangs, der mangelhaften (materiellen und immateriellen) Ressourcen, wird schon darin deutlich, dass Hunger, Unterernährung und Mangelversorgung nicht nur auf der Basis des allgemeinen Wohlstandes der Menschheit oder der verfügbaren Technologien grundsätzlich - sozusagen „technisch“ - vermeidbar wären, sondern schon allein auf Basis der jährlichen Weltnahrungsproduktion. Diese steigt nahezu ständig und entspricht inzwischen einem Versorgungsniveau von mehr als 2.800 Kilokalorien (kcal) pro Kopf und Tag, was weit jenseits aller Mindestversorgungsschwellen liegt, wobei außerdem bei Weitem nicht alle Landressourcen für die landwirtschaftliche Nutzung aktiviert sind.

\section{Historische Anmerkungen zu Hungerkatastrophen und Weltordnung}

Die zwei bevölkerungsreichsten Regionen der Erde, China und Indien, sind nicht nur heute, sondern auch historisch Brennpunkte des Hungers, weil sich dort Nahrungsmittelknappheiten sofort in hohe Totenzahlen übersetzten. Daher bilden sie einen logischen Kristallisationspunkt jeder Auseinandersetzung mit Hunger. ${ }^{24}$ Was bei genauem Hinsehen freilich auffällt, ist nicht nur der Umstand, dass das 19. Jahrhundert in beiden Regionen besonders reich an Katastrophen war, sondern auch, dass die vorangegangenen es nicht waren. So hatten Indien im 17. Jahrhundert und China im 18. Jahrhundert es immer wieder mit vergleichbar ungünstigen Umweltbedingungen zu tun, erlitten aber keine vergleichbaren Katastrophen. Die einhei-

23 Vgl. Saurin (1997), 111-113 vor allem in Anlehnung an Amartya Sen. Für einen kurzen kritischen Überblick über neomalthusianische, nach Sen so bezeichnete „FAD“-Theorien („FAD“ steht für „Food Availability Decline“) vgl. neben Sen (1982), 6-8 und 39-44 auch Devereux (1993), 23-28. Siehe dazu auch Nussbaumer (2003) und Nussbaumer/Exenberger (2006a).

24 Mike Davis erwähnt zusätzlich noch einen dritten Brennpunkt des Hungers Ende des 19. Jahrhunderts, den Sertão in Nordostbrasilien. Dieses Beispiel ist durchaus aufschlussreich, weil es dabei einen klaren Zusammenhang mit Weltordnungsvorstellungen gibt: in Brasilien regierte seit 1888 eine „positivistische“ Republik, deren weltanschauliche Verankerung im Utilitarismus lag, auf den am Beispiel Indien im Text noch zurückzukommen sein wird. Daher waren auch die Effekte durchaus ähnlich: Die Hungernden wurden als Menschen zweiter Klasse angesehen, schließlich sogar als Bedrohung, und die Armee bekämpfte deren aktiven Widerstand gegen die Hoffnungslosigkeit. Vgl. vor allem Davis (2004), 193200. 
mischen Herrscher hatten Mechanismen entwickelt, um die Versorgung der Bevölkerung weit besser sicherzustellen, als dies im 19. Jahrhundert gelang. Erst der Zerfall der staatlichen Macht der Mogulen und der Qing bereiteten dem Massensterben den Weg. ${ }^{25}$

Die schlimmsten Hungersnöte in Indien, wie Mike Davis sehr ausführlich darlegt, ereigneten sich daher nicht, wie gerne behauptet, vor und außerhalb der britischen Herrschaft, und sie wurden auch nicht, wie eine gerne überlieferte Legende erzählt, durch die Eisenbahn gemildert. Vielmehr waren die schlimmsten Hungersnöte in Indien unmittelbar mit britischer Herrschaft verknüpft, vor allem jene allergrößten von 1769/70 und 1866/67 (jeweils Schwerpunkt Bengalen), 1876-78 (Schwerpunkt Südindien) und 1896-1902 (Schwerpunkt Zentralindien), von denen jede in Kombination mit Seuchen wohl mindestens fünf, teils zehn Millionen Tote forderte. ${ }^{26}$ Und die Eisenbahn erleichterte ebenso sehr den Abtransport von Weizen und Reis aus Hungergebieten wie die Zulieferung. ${ }^{27}$

Die „Organisation“ des Hungers durch die Briten in Indien erfolgte auf drei Arten: Erstens wurde das Land in den Weltmarkt eingegliedert; zweitens wurden Indiens Bauern zur Steuerquelle des Empire; und drittens wandten die Briten ihre utilitaristischen Konzepte der Hungerbekämpfung an (die man nach heutigem Verständnis rassistisch nennen muss). ${ }^{28}$ Alle drei miteinander zusammenhängenden Aspekte trugen zur massiven Verschlimmerung der Ernäh-

25 Vgl. ausführlich Davis (2004), 283-313. Dazu kann man noch ergänzen, dass zumindest China vor dem 19. Jahrhundert sogar - wie auch Europa - zumindest partiell von der „kleinen Eiszeit" betroffen war.

26 Eine ähnlich schwere Hungersnot tobte 1942-44 in Bengalen. Auch sie wird oft beschrieben als ein „Verhungern neben der Fülle“ und sie war für Amartya Sen einer der Ausgangspunkte seiner bahnbrechenden Forschungsarbeiten zum Hunger. Vgl. zu dieser „Great Bengal Famine“ etwa Sen (1982), 52-85. Sie ist freilich durch den Zweiten Weltkrieg medial überlagert worden (weswegen sie trotz ihrer Dimension in der öffentlichen Wahrnehmung bis heute kaum existiert), doch ist ihr Ursachenprofil - sehr ähnlich wie das der früheren Hungersnöte - das einer von Dürre ausgelösten, aber durch Kriegswirren und Misswirtschaft massiv verschlimmerten Verteilungskrise. Vgl. dazu auch Nussbaumer (2003), 61-63.

27 Es findet sich statistisch praktisch kein Zusammenhang zwischen verkehrstechnischer Erschlossenheit und Hunger, und wenn, dann eher ein ungünstiger. Davis verweist etwa darauf, dass durch die Eisenbahn weniger die Nahrung, als der Preiseffekt reiste: die Integration verteuerte Nahrung auch dort, wo gar kein Mangel bestand, ohne sie in den Hungergebieten entscheidend zu verbilligen. Vgl. Davis (2004), 147-149.

28 Vgl. ausführlich Davis (2004), 35-68 (für die Hungersnot von 1876-78), 147-181 (für die Hungersnöte von 1896/97 und 1899-1902) und 315-342 (für ein Resümee). 
rungslage bei und führten unmittelbar zu Millionen von Toten. Die Eingliederung des Landes in den Weltmarkt, selten direkt, aber oft durch materielle Zwänge indirekt erzwungen, bedeutete generell eine Umlenkung der Produktion nach den Erfordernissen des Exports. Die im Hinblick auf die Nahrungssicherheit gefährlichsten Effekte waren eine angebotsdämpfende Substitution von Nahrungsmitteln durch andere Agrarprodukte (vor allem Baumwolle) und die generelle Verteuerung von Nahrungsmitteln (der Effekt der Angebotsverknappung wurde durch eine über den Weltmarkt vermittelte Nachfragesteigerung noch verstärkt, zudem mussten - ganz der ökonomischen Logik folgend - die Renditen steigen, um mit der exportgetriebenen Alternative Baumwolle mithalten zu können). Die materiellen Schwierigkeiten, in die viele Bauern und Bäuerinnen dadurch gerieten (vor allem solche, die weiter Nahrungsmittel erzeugten, denn auch für sie stiegen die Pachten), wurden durch steigende Steuerlasten noch verstärkt. Dies war besonders nachteilig, weil die Steuern unabhängig von den Rahmenbedingungen fällig waren und gewaltsam eingetrieben, also auch während der Hungerperioden nicht einmal gestundet wurden. Zudem wurden sie nicht verwendet, um die heimische Infrastruktur zu verbessern (etwa für die Instandhaltung von Bewässerungsanlagen oder das Anlegen von Notfalldepots), sondern vor allem zur Finanzierung imperialer Kriege (Afghanistan, Südafrika). Weltmarktintegration und Besteuerung spielten dann auch zusammen, um die Eigentumsstrukturen in Indien sehr nachhaltig zu verändern. Viele Menschen wurden in unfinanzierbare Kredite gezwungen und verloren ihren Besitz und damit ihre Subsistenzbasis. Massenhafte Verarmung bzw. eine „Modernisierung der Armut" war die Folge. In der Krise kam schließlich noch ein brutales Hungerregime dazu, in dem in schlechtester utilitaristischer Tradition jede materielle Unterstützung (die zudem völlig unzureichend blieb) von in Lagern erpressten Arbeitsleistungen abhängig gemacht wurde, was wiederum akut lebensbedrohend war (auch auf den Märschen in die Lager starben viele). Diese Logik des Massensterbens wurde oft noch auf die Spitze getrieben, wenn die Briten es als „Reinigung“ der Gesellschaft von „unnützen“ Menschen interpretierten und damit teils sogar begrüßten. ${ }^{29}$ Zugleich glaubten die Briten, oft

29 Bezeichnend für dieses Menschenbild ist die zynische Bemerkung des indischen Vizekönigs Lord Lytton 1877 in einem Brief an seine Frau nach einer Reise durch die schlimmsten Hungergebiete: „Aber die fürchterliche Frage ist doch, wie die Regierung von 
durchaus im quasireligiösen Sinn, an die Selbstregelungskräfte des Marktes und die Smith'sche ,unsichtbare Hand“, was in Indien Millionen tötete.

Diese Sicht der Dinge und diese Geringschätzung von Leid und Menschenleben waren in der britischen Kolonialgeschichte freilich nichts Neues. Sie prägten auch die „letzte Schlechtwetter-Ernährungskrise" in der Geschichte Europas, die sich nach 1845 vor allem in Irland verheerend auswirkte. ${ }^{30}$ Eine Kombination aus „schlechtem" Wetter (vor allem kalten Wintern) und einer Pflanzenkrankheit (der Kartoffelfäule) legte die Basis für eine massive Versorgungskrise, die in Irland in den folgenden Jahren wahrscheinlich mehr als eine Million Menschen umbrachte und vor der sich mindestens ebenso viele nur durch Auswanderung nach Amerika retten konnten (wobei viele die Überfahrt auf den „Sargschiffen“ nicht überlebten). ${ }^{31}$ Die Gründe dafür waren sehr ähnliche wie im Fall Indiens, Irland bildete in dieser Hinsicht das Modell späterer kolonialer Abenteuer.

Doch wirkten die Kräfte der Macht (und des Marktes) auch indirekter als durch koloniale Regimes. Dies zeigt sich am Beispiel von China, das während der klimabedingt so verheerenden Jahre zwischen 1877 und 1900 ebenfalls schreckliche Hungersnöte erlebte. ${ }^{32}$ Dort nutzten die Großmächte die schweren, das ohnehin strapazierte Budget des Kaiserreiches über Gebühr beanspruchenden Hungersnöte auch dazu, sich mehr und mehr an den Küsten festzusetzen und in das Hinterland vorzudringen. Diese Aktivitäten öffneten langsam den bislang streng abgeschotteten Markt für den internationalen Warenkreislauf. Die Interpretation der Katastrophe durch die Europäer (und US-Amerikaner), speziell die Briten, war ungeachtet einer christlichen Gesinnung befremdlich rational. Der britische Konsul meinte 1877 etwa: „Die Verteilung von Geldern durch muti-

Madras jemals diese demoralisierten Massen zu wirklich nützlicher Arbeit bewegen kann.“ Zitiert in: Davis (2003), 57. Die furchtbarsten Auswüchse des Regimes zeigten sich auch beim Schiffbruch eines Getreideschiffes während der Hungersnot in Orissa 1866/67: Die Verteilung der Ladung des dort gestrandeten Schiffes an die Hungernden wurde verhindert, weil sie für Kalkutta bestimmt war, sodass sie schließlich verrottete. Siehe Nussbaumer (2003), 55.

30 Vgl. dazu etwa Nussbaumer (2003), 75-85.

31 Die demografischen Folgen waren lange spürbar: Zwischen 1845 und 1910 halbierte sich die irische Bevölkerung auf dann nur noch 4,5 Millionen Menschen. Siehe Nussbaumer (2003), 79.

32 Vgl. ausführlich Davis (2004), 72-87 (für die Hungersnot von 1876-79), 183-193 (für die Not im Umfeld des Boxeraufstandes) und 343-375 (für ein Resümee). 
ge und kluge Männer, die sich in der Hilfe engagieren, wird mehr dazu beitragen, China uns gegenüber zu öffnen, als ein Dutzend Kriege." ${ }^{33}$ Die Chinesen waren, wie Davis ausführt, ob dieser offensichtlichen „Schadenfreude“ der Briten angesichts von millionenfachem Hungertod „angewidert“. Die generelle Meinung der meisten Wirtschaftstreibenden und Politiker im Ausland dürfte sich mit der Ansicht der Missionare aber recht gut getroffen haben. Sie sprachen von einer „wunderbaren Öffnung“ Chinas und erkannten in der Hungerhilfe eine „von Gott gesandte Gelegenheit“: „Man glaubte, damit den archimedischen Hebel gefunden zu haben, um ,alle neun [nördlichen] Provinzen erschließen zu können [...] [." “34 Die christliche Mission war also erfreut (Missionaren verdanken wir übrigens die meisten Berichte speziell über die Hungerkatastrophe in den 1870er-Jahren) und erntete in diesen Jahren viele sogenannte „ReisChristen“. 20 Jahre später freilich waren die meisten davon wieder abgefallen und die Chinesen machten vielfach sogar die Kirchen verantwortlich dafür, dass es nicht regnete. Die Fremdenfeindlichkeit verstärkte sich weiter, weil man die Ausländer auch - und nicht unbedingt zu Unrecht - dafür verantwortlich machte, dass dem Staat das Geld für Investitionen fehlte. Diese Tendenzen gipfelten schließlich im gewaltsam unterdrückten Boxeraufstand, ehe das Kaiserreich schließlich in sich zusammenbrach.

Bei dieser Entwicklung, die natürlich durch Umwelteinflüsse (neben den Dürren wechselte auch der Gelbe Fluss nach 1855 wieder einmal - seinen Lauf) und innenpolitische Entscheidungen mitbestimmt wurde, spielten zwei in unserem Zusammenhang wichtige Faktoren zusammen, die ihrerseits Rückwirkungen auf die Innenpolitik im chinesischen Kaiserreich hatten. Der eine Faktor ist der Einfluss von Handels- und Machtinteressen der Großmächte in China, der ,imperiale Druck“, dem die Qing dadurch permanent ausgesetzt waren und der große Ausgaben für das Militär nötig machte. Der andere Faktor ist das Vordringen des „Weltmarkts“ nach China. Dieser Weltmarkt äußerte sich nun weniger darin, dass billige britische oder US-amerikanische Güter die einheimischen Produkte verdrängten. Das kam auch vor und war vor allem beim Vordringen „indischer“ (eigentlich englischer) Textilien nach China 
verheerend, die manchmal weniger kosteten als die in China billig produzierte Rohbaumwolle. Vor allem aber wuchs die Abhängigkeit der Bauern von Entwicklungen am Weltmarkt. Durchaus im Sinn der Ertragssteigerung für den Staat setzten auch die Qing bereits auf die Förderung von Exportprodukten, viele Bauern entschieden sich aber auch einfach wegen der besseren Renditen für den Anbau dieser cash crops (vor allem Baumwolle, Mohn und Tabak ersetzten als "Geldbringer" die Nahrungsproduktion). Das freilich ermöglichte weniger die Kapitalbildung als die sofortige Umsetzung des Ertrags in Nahrungsmittel und Steuern. Diese schleichende Verknappung führte zu Preissteigerungen bei Nahrungsmitteln, doch auch die Kosten stiegen: Auch in China passten sich die Pachten an das höhere Renditenniveau an, das für den Anbau von cash crops erreichbar war. Die Anfälligkeit für Hunger wuchs damit, jede Preiskrise am Weltmarkt konnte zur Katastrophe führen. ${ }^{35}$ Das galt umso mehr, weil durch die Finanzkrise des Staates zur Abwehr interner Rebellion und externer Intervention nicht nur die Steuern angehoben, sondern vor allem die Ausgaben für Bewässerung, Hochwasserschutz, Binnenverkehr (der Große Kanal versandete im 19. Jahrhundert) und das vorher so leistungsfähige Kornspeichersystem stark vernachlässigt wurden. ${ }^{36}$

Insgesamt veränderte sich in dieser Zeit der Weltagrarmarkt sehr stark, und - wie Harriet Friedmann und Philip McMichael sich ausdrücken - es bildete sich das „erste Nahrungsregime“ “. ${ }^{37}$ Es bestand einerseits in der Vertiefung der kolonialen Beziehungen (wie oben am Beispiel Indien dargestellt), vor allem aber in der Bildung der ersten echten Weltmärkte für Grundnahrungsmittel. Grund dafür war in erster Linie die sogenannte „Transportrevolution“ durch Eisenbahn und Dampfschiffe, die Transportkosten auch für Massengüter drastisch senkte und in vielen Fällen, spätestens mit Entwicklung von Kühlschiffen, auch das Verderblichkeitsproblem eliminierte. ${ }^{38}$ Diese Weltmärkte wurden durch die billigen Getreideange-

35 Vgl. für die Auswirkungen dieser „Kommerzialisierung der Subsistenz“ Davis (2004), 346351

36 Vgl. Davis (2004), 351-356 und 366-375.

37 Vgl. Friedmann/McMichael (1989), 98-103. Auch dieser Ansatz geht auf Polanyi (1978) zurück.

38 Vgl. ausführlich O’Rourke/Williamson (1999), 29-55; auch Borchardt (2001) äußert sich ganz in diesem Sinn. 
bote der europäischen Siedlungsökonomien (USA, Kanada, Australien, Neuseeland, Argentinien) gebildet, die Weltproduktion expandierte größtenteils deswegen zwischen 1840 und 1880 um 50\%.39 In Ländern, deren Regierungen grundsätzlich den globalen freien Warenhandel förderten, führte dies, wenn sie es sich (politisch) leisten konnten (was vor allem in Europa der Fall war), zu protektionistischen Gegentendenzen. ${ }^{40}$ Doch bildeten sich auch engere Beziehungen der Landwirtschaft zur Industrie, nicht nur in dem Sinn, dass Agrarimporte notwendig wurden, um die Ernährung des Industrieproletariats zu verbilligen, sondern auch in Form einer „Agroindustrie“, die sowohl agrarische Produkte verarbeitete und damit weiter verbilligte wie auch weitere Impulse für die Industrialisierung während dieser „ersten Welle“ der Globalisierung (ca. 1870-1914) lieferte. Dass dies auch viele Bäuerinnen und Bauern in Europa um ihr Land brachte und zur Migration in die rasch wachsenden Städte zwang, sei hier nur kurz angedeutet.

Im 20. Jahrhundert waren dann - abgesehen vom global betrachtet stets präsenten strukturellen Hunger - einerseits die Kriegsund Nachkriegszeiten verbreitet Hungerjahre, andererseits ereigneten sich insbesondere im Umfeld totalitärer Regime schwere Hungersnöte. Gerade im Fall der beiden furchtbarsten Hungerkatastrophen des 20. Jahrhunderts - „Stalins Hungersnot“ in der Ukraine 1929-33 und „Maos Hungersnot" während des „Großen Sprungs“ 1958-61 - ist der Zusammenhang mit Weltordnungsvorstellungen und deren Durchsetzung sehr eng. ${ }^{41}$ Strukturell sehr ähnlich ist aber auch gerade der Hunger im Umfeld des Zweiten Weltkrieges, an dem insbesondere der massive Einsatz des Verhungerns als Waffe gegen Feinde und „Untermenschen“ durch die Nationalsozialisten auffällt. Dabei hatte das Hungern im wahrsten Sinn des Wortes Methode und ging bis hin zu Hungerexperimenten, bei denen die Menschen bis zum wissenschaftlichen Exzess entwürdigt und beim gezielt herbeigeführten Sterben genauestens beobachtet wurden. ${ }^{42}$

39 Vgl. Friedmann/McMichael (1989), 100.

40 Vgl. Polanyi (1978), 182-208, der für diese generelle Tendenz den Begriff „Doppelbewegung" geprägt hat.

41 Im kleinen Stil trifft das auch auf Kambodscha 1976-79 und Nordkorea 1995-98 zu.

42 Vgl. etwa Nussbaumer (2003), 185-196 und 210-218. 
Doch bereits in Stalins Hungersnot ${ }^{43}$ wurde Hunger als politisches Kampfmittel eingesetzt, das sich im Rahmen der Zwangskollektivierung gegen die ehemals freien Bauern in der Ukraine richtete und damit diese Störenfriede im Sowjetsystem im wahrsten Sinn des Wortes beseitigen sollte. Sie zeigt auch gewisse Parallelen zu den kolonialen Hungerregimes im Britischen Empire. Stalin forderte zwar keine praktisch nicht bezahlbaren Steuern, aber die Einhaltung völlig unerfüllbarer Planvorgaben. Er nahm damit den Menschen in der Ukraine ohne den Umweg über den Markt, den es in der Sowjetunion ja nicht gab, direkt die zum Überleben notwendige Nahrung. Die mit der Kollektivierung verbundene „Verstaatlichung“ aller Tiere und Pflanzen (so etwas führten auch die Briten - unter ganz anderen Vorzeichen - in Indien durch) wurde notfalls von „Aktivisten“ durchgesetzt: sie durchkämmten die Häuser und Grundstücke nach Essbarem und anderen Wertgegenständen und nahmen meist alles mit. Logische Konsequenz war massenhaftes Verhungern. Bis 1937 starben vermutlich bis zu 15 Millionen Menschen an Hunger und in Lagern. ${ }^{44}$ Oft war es ein Verhungern ,neben der Fülle“: nicht nur war die Ernte an sich gut und daher viele Lagerhäuser in der Ukraine gefüllt, sondern die UdSSR exportierte in diesen Jahren auch massiv Nahrungsmittel. Besonderer Zynismus war also, dass die Nahrung bewusst vorenthalten wurde. Darüber hinaus durfte kein Wort über die Zustände verloren werden und als ab 1932 Berichte in die Weltöffentlichkeit durchdrangen, begegnete man diesen - sehr erfolgreich - mit manipulativer Propaganda. So wurde die Katastrophe verharmlost, für Jahrzehnte erfolgreich verschwiegen und schließlich fast vergessen.

Die Opferbilanz einer anderen kommunistischen Hungersnot ist aber noch weitaus verheerender. Während des „Großen Sprungs““ sind etwa 40 Millionen Menschen (Angaben schwanken zwischen 11 und 75) ums Leben gekommen, in erster Linie infolge von katastrophalem Missmanagement. ${ }^{45}$ Schon der Ansatz war unrealistisch: Die

43 Vgl. zusammenfassend Nussbaumer (2003), 98-105, der im Wesentlichen auf Conquest (1988) zurückgreift. Wie Davis verwendet Robert Conquest den im Amerikanischen allgemeiner verwendbaren Begriff des „Holocaust“ im Kontext von „erzeugtem“ Hunger.

44 Vgl. Conquest (1988), 373.

45 Vgl. ausführlich Nussbaumer (2003), 105-123 und 261 (für Schätzungen zu Opferzahlen). Die Katastrophe ist als extremer Einschnitt in der chinesischen Bevölkerungspyramide immer noch deutlich sichtbar und schlug sich auch in der Entwicklung der Weltbevölkerung messbar nieder. Vgl. zu dieser Hungersnot auch das teils autobiografische jüngste 
Agrarproduktion sollte 1958-68 um jährlich 20\% wachsen, wobei ihr aber gegenüber der Industrieproduktion nur nachrangige Bedeutung beigemessen wurde und massiv Arbeiter aus der Landwirtschaft abgezogen wurden. Der Mangel an Arbeitskräften führte in den ersten drei Jahren der Planperiode daher zu starken Produktionseinbrüchen, die erst 1965 wenigstens wieder kompensiert werden konnten. Schwere ökologische Fehler, die brutale Eintreibung von Produktionsvorgaben und ineffiziente soziale Planung dramatisierten die Lage weiter. Schließlich kam auch noch Dürre hinzu und das Massensterben nahm seinen unaufhaltsamen Lauf. Es war wiederum noch 1958 begleitet von Nahrungsexporten (in die Sowjetunion) und wurde erst 1961 durch Nahrungsimporte bekämpft. Wie Stalin gelang es dabei auch Mao, die Hungersnot bis nach seinem Tod vor der Weltöffentlichkeit zu verbergen, es gab nur eine kurze Phase der internen Kritik.

Zur Hungerkatastrophengeschichte des 20. Jahrhunderts kommt als bemerkenswertestes Aufflammen dessen, was im nächsten Kapitel als „tägliche Katastrophe“ ausführlicher zu besprechen sein wird, die von klimabedingter Dürre ausgelöste weltweite Hungersnot 1983-85 hinzu. ${ }^{46}$ Dieses Ereignis fand - anders als die zuvor geschilderten - unter den Augen der Weltöffentlichkeit statt, was den Betroffenen zwar letztlich geholfen und die Opferbilanz deutlich reduziert hat, das millionenfache Sterben an sich aber auch nicht verhindern konnte. Etwa zwei Millionen Opfer waren bei rund 150 Millionen Betroffenen allein in Afrika zu verzeichnen, während gleichzeitig im Jahr 1984 mit 344 Kilogramm pro Kopf die bis dahin größte Weltgetreideernte nach dem Zweiten Weltkrieg eingebracht wurde. ${ }^{47}$ Diese Hungersnot verweist also nachdrücklich auf das Verteilungsproblem Hunger.

\section{Die tägliche Katastrophe der strukturellen Unterernährung}

Die Dimension der „stillen Katastrophe“ Hunger ist statistisch schwer zu fassen, weil die Zahlenangaben speziell zu Hungertoten

Buch von Jung Chang zur chinesischen Geschichte, Chang/Halliday (2005), in dem die Hungersnot neben anderen Terrormethoden vorkommt, und Becker (1996), übrigens die erste wissenschaftliche Monografie zum Thema.

46 Vgl. Nussbaumer (2003), 71-74 und 130-134 (zu Äthiopien).

47 Nussbaumer (2003), 74. 
aus verschiedensten Gründen sehr ungenau sind. ${ }^{48}$ Über die Unterernährung - trotz aller damit verbundenen Fallstricke - wird seit dem Millenniumsgipfel der UNO immerhin verbindlicher Auskunft gegeben, weil die Erreichung des ersten Millenniumszieles schließlich gemessen werden muss. Die Daten weisen zwar einige erfreuliche Trends auf, geben aber insgesamt kaum Anlass zur Hoffnung, dass die Ziele in der Hungerbekämpfung erreicht werden können, ${ }^{49}$ insbesondere nicht im Lichte der zu erwartenden negativen Auswirkungen der Erderwärmung gerade in den besonders hungergefährdeten Regionen. ${ }^{50}$

Tabelle 6: Absolute Hungertrends während der 1990er-Jahre nach Ländern 51

Zunahme um wenigstens 100.000 dabei wenigstens Verdoppelung der Anzahl

Abnahme um wenigstens 100.000

geringere Veränderung

Zwar sinkt der Anteil der Unterernährten an der Weltbevölkerung, im Hinblick auf das Millenniumsziel aber viel zu langsam (um etwas mehr als $2 \%$ - statt 4 - seit 1990). Die absoluten Zahlen aber steigen eher, und auch die Zahl der betroffenen Länder nimmt nicht ab, wie der folgende Vergleich der Zahlen von 1990-92 (bzw. 1993-95) und von 2002-04 zeigt:

Dieser ambivalente Befund wird weiter bestätigt, wenn man die allerletzten Entwicklungen nach Weltregionen betrachtet, wie sie aus Tabelle 7 hervorgehen. Dabei werden Zahlen für Mitte der 1990erJahre mit den letzten verfügbaren Daten verglichen. Die Regionen sind dabei nach „Erfolg“ gereiht, der in der prozentuellen Reduktion der Zahl der Hungernden gemessen wird.

Die absolute und die relative Dimension des Hungers ist dabei - wie ja auch schon eingangs erwähnt - unterschiedlich in Asien und Afrika lokalisiert. Nahezu alle afrikanischen Länder sind von Hunger

48 Vgl. Nussbaumer (2003), 37-40.

49 Vgl. UNDP (2003), 51 und 54. Ostasien hat zur Jahrtausendwende - wegen China - die Ziele für 2015 schon jetzt erreicht, Lateinamerika ist immerhin ,auf Kurs“, in allen anderen Weltregionen gehen die Tendenzen aber in die falsche Richtung.

50 Vgl. IPCC (2007), 273-313 und UNDP (2007), 90-106.

51 Vergleich der Werte von 1990-92 (bzw. für die Länder des ehemaligen Ostblocks für 1993-95) mit den Werten von 2002-04. Siehe FAOSTAT (http://www.fao.org/ FAOSTAT/foodsecurity/). 
betroffen (teils massiv), es ist hingegen mehr als die Hälfte der Hungernden in Indien, China, Bangladesch oder Pakistan zu Hause.

Tabelle 7: Erfolge und Misserfolge 1994/96-2003 nach Regionen 52

\begin{tabular}{l|rrr} 
& Millionen & \multicolumn{3}{c}{ Veränderung } \\
& Unterernährte & Millionen & $\%$ \\
\hline Positive Entwicklungen & & & \\
\hline Karibik & 6,9 & $-2,1$ & $-23,3$ \\
Südostasien & 64,0 & $-4,1$ & $-6,0$ \\
Südamerika & 32,5 & $-1,6$ & $-4,7$ \\
Transformationsländer & 22,5 & $-0,9$ & $-3,8$ \\
\hline Negative Entwicklungen & & & \\
\hline Südafrika & 36,5 & $+0,0$ & $+0,0$ \\
Nordafrika & 5,9 & $+0,2$ & $+3,5$ \\
Nordamerika & 5,3 & $+0,2$ & $+3,9$ \\
Ostafrika & 91,8 & $+3,5$ & $+4,0$ \\
Südasien & 299,6 & $+12,3$ & $+4,3$ \\
Ostasien & 162,9 & $+8,1$ & $+5,2$ \\
Naher Osten & 32,0 & $+2,4$ & $+8,1$ \\
Westafrika & 37,2 & $+3,4$ & $+10,1$ \\
Ozeanien & 1,0 & $+0,1$ & $+11,1$ \\
Zentralamerika & 7,5 & $+1,0$ & $+15,4$ \\
Zentralafrika & 49,2 & $+10,3$ & $+26,5$
\end{tabular}

Allzu viel hat sich also in den letzten 150 Jahren nicht geändert. Das bestätigt sich auch, wenn man das Verhältnis zwischen den am besten und den am schlechtesten mit Nahrung versorgten Ländern in den letzten Jahrzehnten betrachtet. Abbildung 1 zeigt, dass sich das durchschnittliche Versorgungsniveau der bestversorgten fünf Länder (gestrichelte oberste Linie) wie auch das der schlechtestversorgten fünf Länder (gepunktete unterste Linie) seit 1960 verbessert hat (beides auf der linken Skala abzulesen). Doch das Verhältnis dieser beiden Niveaus (dargestellt durch die dicke Linie in der Mitte und die rechte Skala) schwankt ohne klaren Trend zwischen 2 und 2,2. Es gibt also keinen Aufholprozess, die Versorgungslage der reichen Länder ist konstant etwa doppelt so gut wie die der ärmsten und d.h., sie - obwohl bereits auf sehr hohem Niveau - verbessert sich

52 Quelle: FAOSTAT (http://www.fao.org/FAOSTAT/foodsecurity/). Ländergruppen gemäß Kategorisierung der FAO. Die Zahlen beziehen sich auf die Dreijahresperiode 200204 im Vergleich mit 1993-95 für die Transformationsländer (GUS-Staaten und Osteuropa) und 1995-97 für alle anderen Regionen. 
um mehr als das doppelte Ausmaß pro Jahr als die Lage der armen Länder. Betrachtet man dabei schließlich die Extreme, so stellt man fest, dass ein(e) US-Amerikaner(in) in der Periode 2002-04 mit 3.760 kcal pro Tag das 2,51-fache an Nahrungsenergie im Vergleich mit Schlusslicht Eritrea zur Verfügung hat, dessen $1.500 \mathrm{kcal}$ überdies nur 53\% des Weltdurchschnitts von 2.810 bedeuten und weit unter allen Grenzwerten für ausreichende Versorgung liegen (Österreich liegt in dieser Statistik übrigens mit $3.740 \mathrm{kcal}$ auf Platz 3).

Abbildung 1: Entwicklung der Disparitäten in der Versorgung 1961-2003 53

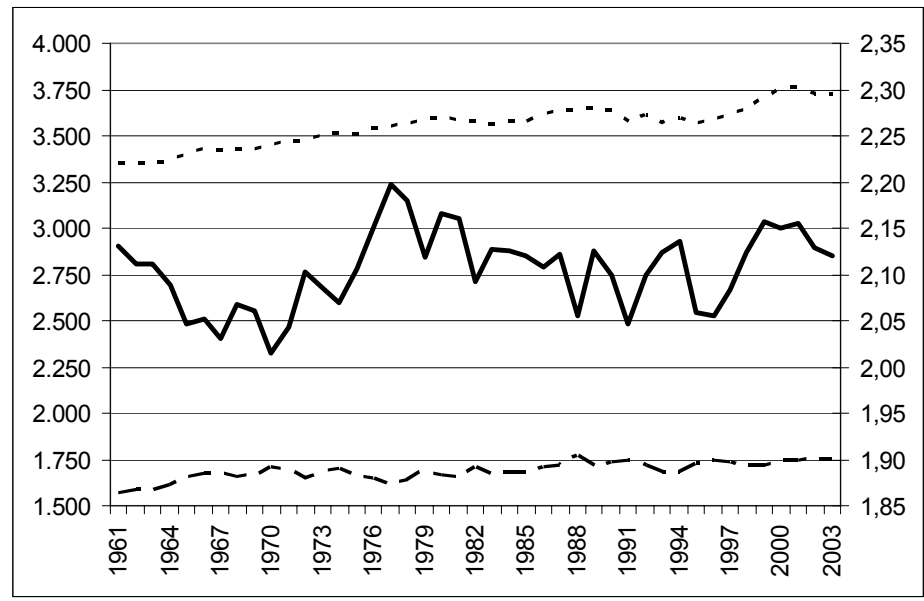

Die Zahl der Hungeropfer schwankt naturgemäß auch mit dem Klima, und offensichtlich tragen auch interne Faktoren viel zu Hungerkrisen bei. Trotzdem (die meisten Unruhen sind ja alles andere als unabhängig von äußeren Einflüssen) ist das Problem als solches offensichtlich strukturell. Minimalbedingungen für die Hungerbekämpfung, die lokal gegeben sein müssen, dabei aber natürlich in einen globalen Kontext einzubetten sind, lassen sich etwa in einem Viereck darstellen: „Nur in der Schnittmenge aus Demokratie (politische

53 FAOSTAT (http://www.fao.org/FAOSTAT/foodsecurity/), Angaben in kcal pro Kopf und Tag. Die Versorgungsdaten sind freilich problematisch, weil sie eigentlich nur das Potential messen (Produktion einschließlich Handelssaldo) und vor allem Verschwendung nicht berücksichtigen. Es handelt sich also nicht um Daten zum tatsächlichen Konsum, sondern lediglich um Niveaus, die theoretisch möglich wären. 
Souveränität der Bevölkerung), Frieden (zumindest Abwesenheit von akuten Konflikten), Ethik (Einhaltung von Menschenrechten und Bewusstsein um die Verantwortung für die natürliche Umwelt und zukünftige Generationen) und einem effizienten Markt (als Synonym für eine Institution, die die Produktion und Distribution von Gütern ökonomisch sinnvoll regelt) kann Hunger beseitigt werden. Fehlt eine dieser Ingredienzien, ist die Hungerbekämpfung unmöglich oder wird unzureichend bleiben. “" 54

Hunger ist also im Übermaß (wenngleich nicht völlig zuverlässig) auch statistisch dokumentiert, wie schon diese kleine Auswahl an Daten zeigt. Zum Hungertod fehlen hingegen zuverlässige Angaben, wobei sich eine Tendenz zur teils dramatischen Überschätzung der tatsächlichen Zahl zeigt. ${ }^{55}$ Freilich sind Hunger und Unterernährung neben Krankheiten die weltweit bedeutendsten Todesursachen und etwa ein Fünftel der gesamten Sterbefälle dürfte auf Hunger als Hauptursache zurückgehen. ${ }^{56}$ Niedrig geschätzt sind es etwa sieben Millionen Menschen pro Jahr, davon zumindest die Hälfte Kinder. Jean Ziegler, der UN-Sonderberichterstatter für das Recht auf Nahrung ${ }^{57}$, gibt die Zahl der Opfer von Hunger und Mangelernährung sowie damit verbundenen Krankheiten im Jahr 2003 mit 36 Millionen an (eine Schätzung an der absoluten Obergrenze des Interpretationsspielraums) und die Zahl der von „verborgenem Hunger“ (also Mangelversorgung) Betroffenen mit zwei Milliarden (also einem Drittel der Menschheit). ${ }^{58}$ Welche Zahl auch immer der Wirklichkeit am nächsten kommt: es handelt sich um eine gewaltige, alltägliche Katastrophe, nur geschieht sie in der Regel im Verborgenen, abseits der Augen der Weltöffentlichkeit.

Man muss an dieser Stelle wohl ausführlicher auf Jean Ziegler eingehen, der sein letztes Buch dem Zusammenhang zwischen Hunger und Weltordnung widmet, wobei er letztere als ein Imperium der

54 Nussbaumer/Exenberger (2006a), 29.

55 Manche Autor(inn)en und sogar Nachschalgewerke schrecken nicht einmal davor zurück, die Zahl der Hungertoten höher anzugeben, als die Gesamtzahl der weltweiten Sterbefälle. Vgl. für einige Zahlen etwa Nussbaumer (2003), 40.

56 Die niedrigste Angabe liefert die WHO (World Health Organisation), die nur eine halbe Million Sterbefälle auf „Verhungern“ (im engsten Sinn) zurückführt, dabei aber u.a. alle hungerbedingten Krankheiten ausblendet. Siehe etwa WHO (2004), 120.

57 Dieses Recht verbrieft etwa schon Artikel 25 (1) der UNO-Menschenrechtskonvention von 1948.

58 Ziegler (2005), 101 und 110. 
Schande (so auch der Buchtitel) analysiert. Nach Ziegler ist diese neofeudale Weltordnung durch „Kosmokraten“ und „Compradores“59 organisiert, die mit ihren eigenen Interessen vor allem jene von Großkonzernen verfolgen, denen auch Staaten kaum Paroli bieten können und denen die Bedürfnisse der riesigen Masse der Menschheit untergeordnet werden. Für uns besonders spannend ist seine Analyse, mit welchem Mittel diese Herrschaft ausgeübt wird, weil sie den Charakter der Ordnung verdeutlicht: es ist der Hebel der internationalen Verschuldung. ${ }^{60}$ Durch sie werden die meisten Länder der Welt (und zumindest indirekt - wenn nicht sogar direkt - auch deren Bevölkerungen) einerseits des materiellen Spielraums beraubt, der die Wahl zwischen politischen Optionen ermöglicht (einige müssen ein Drittel ihres gesamten Staatshaushaltes für den reinen Schuldendienst aufbringen, der anders als in den Industriestaaten fast ausschließlich dem Ausland zugutekommt), und andererseits wird peinlich dafür gesorgt, dass dieses globale Regime nicht kollabiert und die Länder zahlungsfähig bleiben (vorzugsweise nicht tilgungs-, sondern nur dienstfähig, weil das die Abhängigkeit zementiert). Die Verschuldung an sich wird noch flankiert von einem ganzen Regiment „guter Ratschläge“, die von den Hütern des internationalen Kapitalverkehrs im Schoß des Internationalen Währungsfonds kommen und deren Einhaltung unbedingt erwartet wird, wodurch die betroffenen Länder politisch (und ökonomisch) geradezu entmündigt werden. Zieglers Analyse wirkt sehr einfach und ist wohl zu eindimensional, sie ist aber gerade deshalb zugleich auch sehr aufschlussreich: die Verdichtung der hochkomplexen globalen Zusammenhänge auf die wesentlichsten Machtkanäle tut manchmal geradezu Not.

Wir wollen aber noch einige Schritte weitergehen und nach weiteren Gründen fragen. Auf dieser Suche sollten wir beim Weltnahrungsmittelmarkt beginnen. Dort bildete sich nach dem Zweiten Weltkrieg ein „zweites Nahrungsregime“, das sowohl mit einer weiteren Änderung der Handelsströme wie auch mit einer zunehmenden Verflechtung von Agrarsektor und Industrie verbunden war. ${ }^{61}$ Beides ist wichtig für das Verständnis des Zusammenhangs zwischen Hunger und Weltordnung. Die neuen Handelsströme führten zu einer sich ständig vertiefenden Importabhängigkeit vieler Staaten, weil

59 Vgl. Ziegler (2005), 29 und 71-75.

60 Vgl. Ziegler (2005), 69-99 oder auch Chossudovsky (2002), 59-83.

61 Vgl. Friedmann/McMichael (1989), 103-110. 
die Öffnung der Märkte nicht etwa zu einer Kommodifizierung lokaler Produkte beitrug, sondern vielmehr zu einer Ersetzung dieser Produkte durch billige (weil oft massiv subventionierte) Getreidelieferungen (vor allem aus den USA und später auch der EG bzw. EU). ${ }^{62}$ Devereux zeigt dies exemplarisch an Entwicklungen in Zaire in den 1970er-Jahren auf: Dort stieg 1973 die US-amerikanische Firma Continental in den Getreidemarkt ein und hielt 1976 Lieferungen zurück, als das Land wegen eines Verfalls der Kupferpreise am Weltmarkt in Zahlungsverzug geriet; der ungleiche Machtkampf endete mit der Anerkennung einer faktischen Monopolstellung von Continental im nationalen Markt. ${ }^{63}$ Ganz generell sind gerade die ärmsten Länder der Welt, die vorher auch von Agrarexporten lebten, seit der zweiten Ölkrise Nettoimporteure von Nahrungsmitteln. ${ }^{64}$

Diese Tendenzen werden noch verstärkt, weil die Bedeutung der Agroindustrie auf Kosten der konventionellen Landwirtschaft steigt und diese bessere Entfaltungsmöglichkeiten findet, wo schon eine industrielle Basis existiert. Neben der generellen Industrialisierung der Produktion ersetzten industriell erzeugte Produkte (vor allem synthetische Süßstoffe und Fette) traditionelle Güter (Zucker, Öle) und immer mehr Agrarprodukte wurden (und werden) zu Zwischenprodukten (Futtermittel) oder zu industriellen Inputs, neuerdings sogar zu Agrotreibstoffen. Rindfleisch war in diesem Mobilisierungsprozess das „Auto“, Soja und Hybridmais waren das „Öl“. Auch der Markt für haltbare Nahrungsmittel passt perfekt in dieses Bild: ,[...] the shift from farm produce to manufactured foods in the centre during the 1950s and 1960s reflected the larger trend to mass consumption and mass production of standardized products. [...] For farmers all over the world this shift to manufactured foods meant a transformation of markets from either local markets or an anonymous mass of distant consumers, to an oligopolistic relation to corporate buyers of agricultural raw materials." ${ }^{65}$

Drei Aspekte stehen also im „Zweiten Nahrungsregime“ im Mittelpunkt: die Substitution von vormals wichtigen tropischen Exportprodukten durch industrielle Ersatzstoffe; die massive Industrialisierung der Fleischproduktion einschließlich der Futtermittelindus-

62 Vgl. Gresh (2006), 98-101.

63 Vgl. Devereux (1992), 165-166, in Anlehnung an Morgan (1979).

64 Vgl. Gresh (2006), 99.

65 Friedmann/McMichael (1989), 108. Vgl. dazu ausführlich Shiva/Bedi (2001). 
trie als Zulieferer; und schließlich das Naheverhältnis des Agrarsektors zu hoch technisierten Industrien wie der pharmazeutischen und chemischen Industrie (für Medikamente und Düngemittel).66 Das heutzutage immer wichtiger werdende Naheverhältnis zur Gentechnik sei hier nur angedeutet und verschärft das Problem durch steigende Anforderungen an das Technologieniveau noch weiter.

Der Weltagrarmarkt erlebte aber in den letzten Jahren noch einige weitere schwerwiegende Veränderungen. Zentral ist vor allem die totale Veränderung der globalen Eigentumsverhältnisse im $\mathrm{Zu}-$ sammenhang mit Natur, die mit der Möglichkeit der Patentierung von Erkenntnissen über den genetischen Code von Pflanzen und Tieren sowie Manipulationen daran direkt zusammenhängen. ${ }^{67}$ Dies wird oft - wenngleich manchmal zu pauschal - mit dem Begriff „Biopiraterie“ bezeichnet, was darauf hinweist, dass es sich bei dieser Entwicklung immer wieder auch um den regelrechten Raub von bisherigem Gemeineigentum (als „Erbe der Menschheit“ oder „lokalem Wissen") handelt, vor allem auf Kosten von „Entwicklungsländern“ (ein oft geradezu euphemistischer Begriff). ${ }^{68}$ Eine zweite zentrale Änderung ist das Wachstum des industriell kontrollierten Marktes für Saatgut, der von wenigen großen Konzernen kontrolliert wird. Sein Gesamtvolumen beträgt derzeit etwa 21 Milliarden US-Dollar, wovon der größte Akteur (Monsanto) insgesamt etwa ein Siebentel kontrolliert, in manchen Sektoren (z.B. Mais, Bohnen oder Soja) deutlich mehr. ${ }^{69}$ Zudem setzen sich die vorher beschriebenen Tendenzen auch unmittelbar fort, und die Verdrängung der Subsistenzproduktion durch die Weltmarktproduktion hält weiter an, was bisher oft mit einer Abkehr von der Produktion von Nahrungsmitteln und Hinwendung zur Produktion von Futtermitteln einherging. ${ }^{70}$ Zynisch muss man anmerken, dass der aktuelle Weltmarkt das Mästen von Rindern für die industrielle Verwertung (eine vergleichsweise ineffiziente Methode der Übersetzung von Natur in Nahrungsenergie) deutlich höher bewertet als das Einsetzen derselben Ressourcen für die Erzeugung von Nahrungsmitteln, die Leben retten. Harriet Friedman und Philip McMichael sehen diese Änderungen als

66 Vgl. Friedmann/McMichael (1989), 110.

67 Vgl. zusammenfassend Hoppbichler (2005), ausführlicher Klaffenböck et al. (2001)

68 Vgl. zur „Biopiratierie“ ausführlich Shiva (2002).

69 Vgl. ETC Group (2005).

70 Vgl. etwa Barkin et al. (1992). 
besonders gefährlich an, gerade im Hinblick auf Hunger. Ihre Schlussfolgerung lautet: „We conclude that the growing power of capital to organize and reorganize agriculture undercuts state policies directing agriculture to national ends, such as food security, articulated development and the preservation of rural/peasant communities." ${ }^{\text {"71 }}$

Das Gegenstück zu diesem Befund liefert Josef Hoppbichler, wenn er über Patente schreibt: „Patente sind ein Instrument, wenn nicht das wesentliche Instrument, um die Biologie und vor allem auch die Pflanzen als Basis menschlicher Ernährung neu zu kolonisieren und das offene Feld der genetischen Strukturen neu zu vermessen. Alle Gene, aber auch alle Lebewesen, können in ihren genetischen Bestandteilen der kapitalistischen Verwertungslogik zugänglich gemacht werden. Bei dieser Kolonisierung haben nur ganz wenige das Kapital und die Technologie in Händen. Als SiegerInnenpreis winkt ihnen die globale Beherrschung der Ernährung oder zumindest das monopolartige Recht einer Privatsteuer auf jedes Stück Brot, auch auf das ,Brot der Armen'، "72 Diese Prozesse bedeuten insgesamt vor allem zweierlei: ein wachsender Einfluss von Unternehmen auf die Ernährung und Ernährungssicherheit von Menschen (was auf Kosten des Einflusses dieser Menschen selbst und der Staaten geht, in denen sie leben); und eine wachsende Abhängigkeit von vergleichsweise schlecht mit Kapital ausgestatteten Ländern von industrialisierten Ländern, die über die nunmehr zur Agrarproduktion nötige Technologie und andere Produktionsmittel verfügen.

Die zunehmende Kommerzialisierung der Landwirtschaft (die Großkonzerne begünstigt und damit auch zur Abnahme der Produktvielfalt beiträgt) und die Beschleunigung der Wechselwirkungen zwischen Ereignissen am Weltmarkt und lokalen Märkten (was global tätigen Großkonzernen weitere Informations- und damit Wettbewerbsvorteile gegenüber Subsistenzlandwirt(inn)en verschafft) haben massive Rückwirkungen auf den lokalen Konsum und die Produktion, auf die Technologie, die Arbeitsteilung und die Eigentumsstrukturen. Dadurch aber werden Gesellschaften unweigerlich transformiert, nicht nur, aber immer häufiger zu ihrem Nachteil. Besonders problematisch ist dies, weil es dabei um den Zugang zu lebens- 
notwendigen Ressourcen geht, die für die „Entwicklung“ und die Erlangung persönlicher Freiheit so wichtigen entitlements (so der von Amartya Sen in diesem Zusammenhang geprägte Begriff). ${ }^{73}$ Ein weiterer Aspekt der Industrialisierung der Landwirtschaft ist beachtenswert: Durch die Industrialisierung verliert die Nahrungsproduktion nicht nur zunehmend ihre autochtone Reproduktionsfähigkeit (etwa schon durch den Ersatz von Naturdünger durch industriell gefertigten Kunstdünger, vor allem aber im Einsatz von Hybridsorten), sondern die Industrialisierung unterminiert die Basis der Nahrungsproduktion, weil Inputs aus der Landwirtschaft immer mehr durch künstliche, rein industrielle Produkte ersetzt werden, was die (monetären) Kosten erhöht. ${ }^{74}$ Aufgrund solcher Renditeerwägungen werden daher generell Agrarprodukte immer stärker für nichtagrarische Zwecke genutzt oder zumindest für andere Zwecke als Ernährung: als Futtermittel, als Vorprodukte für die Industrie oder neuerdings als Treibstoffe, zudem wird immer mehr Fläche für teils nicht einmal essbare cash crops (z.B. Blumen) verwendet.

Dass dies massive Rückwirkungen auf die Anfälligkeit von Menschen für Hunger hat, ist wohl offensichtlich. Saurin schließt mit: „The globalization of agriculture in essence constitutes the permanent destabilization of food security. " 75 Einen besonderen Beitrag dazu leistet die „Hybridisierung“, also die Erfindung (oder Erschaffung?) von Pflanzen, die nicht mehr fortpflanzungsfähig sind. Sie birgt für sich allein genommen schon zwei große Gefahren: die Anfälligkeit der neuen Sorten für Krankheiten, die nur durch Einkreuzen wilder Arten gemildert werden kann; ${ }^{76}$ und die im wahrsten Sinn des Wortes vitale Abhängigkeit der früheren Subsistenzproduzent(inn)en in aller Welt von technisiertem und damit kommodifiziertem Saatgut.

Einen großen Beitrag dazu, dass sich in den 1990er-Jahren ein „neues internationales Nahrungsregime“ (ein „drittes“?) ausbildete, leistete die Gründung der WTO (World Trade Organisation). Für Anuradha Mittal besteht dieses Regime aus drei Zutaten: dem Abbau von Subventionen und Schutzzöllen (gegen den sich ja die USA, Eu-

73 Vgl. dazu etwa Sen (1982), 1-8 und 45-51 oder ausführlich Sen (1999).

74 Zwei Prozesse, die nach Goodman et al. (1987) „appropriationism“ und „substitionalism“ genannt werden.

75 Saurin (1997), 119.

76 Vgl. dazu ausführlich Fowler (1991). 
ropa und Japan bis heute wehren, andere aber kaum wehren konnten); der zunehmenden Kapitalisierung des Weltnahrungsmarktes durch die Förderung eines globalen „Freihandels“; und der generellen Öffnung von nationalen Agrarmärkten, speziell in der „Dritten Welt" und im ehemaligen Ostblock. ${ }^{77}$ Mittal bezweifelt in seiner Nachlese des Welternährungsgipfels von 1996 generell die einfache Gleichsetzung in diesem Regime, die besagt, dass mehr Handel zu mehr Einkommen führt und dies mehr Sicherheit vor Hunger bedeutet. Eine solche Sichtweise vernachlässigt zumindest die meist ungünstigen Preiseffekte der Marktöffnung, speziell für die Produktionskosten (für Landnutzung und Betriebsmittel), teils aber sogar für die Nahrungsmittel selbst (durch den Wegfall von Subventionen, in Exportländern aber auch einfach durch die Angleichung an den höheren Weltmarkpreis). Dazu kommt noch der Umstand, dass der Verlust der Subsistenzbasis in unvollkommenen Märkten jedenfalls zu größerer potentieller Unsicherheit führt, die in diesem Fall lebensbedrohend sein kann. Diese Entwicklung ist freilich schon älter als die WTO. Sie beginnt spätestens mit den Strukturanpassungsprogrammen von Weltbank und Internationalem Währungsfonds in den 1970er-Jahren, die nahezu direkt von einer zentralen Verschiebung in der Wirtschaftsstruktur der ärmsten Länder begleitet waren. Das Dilemma wird von Stephen Devereux zusammengefasst: „When eight or ten countries raise their output simultaneously, the only winners are the multinationals who buy up a the crop at ,competitive' prices, and consumers in the West who pay less for coffee, chocolate and other commodities because of this induced competition among the exporting economies."

Empirisch ist generell eher ein positiver Zusammenhang zwischen Handelsquoten und Nahrungssicherheit feststellbar, wenngleich mit erheblichen Unschärfen und bei lokal teils sehr unterschiedlichen Auswirkungen. ${ }^{79}$ Insgesamt könnte gerade die WTO zweifellos dabei helfen, insbesondere das für die heimische Produktion extrem schädliche Überschwemmen der Nahrungsmittelmärkte von „Entwicklungsländern“ mit subventionierten industrialisierten Agrargütern zu verhindern, das lokale Märkte zerstört und damit

77 Vgl. Mittal (1997), 36.

78 Devereux (1992), 166

79 Vgl. für die positiven Befunde FAO (2005), 80-97, für kritische Stimmen Shiva/Bedi (2001). 
nicht Entwicklungspotenziale freisetzt, sondern zuallererst Kaufkraft vernichtet und damit Menschen tötet. In Summe aber enthält das WTO-Regime zu viele Fallgruben, die zu einer regelrechten Enteignung gerade der hungergefährdeten Menschen führen. Dies geschieht sowohl unter dem Handelsregime des GATT, das zuerst den agroindustriellen Großbetrieben in die Hände arbeitet und nicht den Subsistenzbauern und -bäuerinnen, mehr noch aber durch die flankierenden Maßnahmen im Rahmen des Dienstleistungsregimes GATS, das günstiger für die derzeitigen Marktführer in diesem Sektor ist, die in den USA und Europa zu Hause sind, und im Rahmen des Eigentumsregimes TRIPS, das teilweise eher Wissensraubzüge legitimiert, als dass es traditionelle Eigentumsrechte bewahren würde. 80

\section{Zusammenfassung und Ausblick}

Prägend für das 19. Jahrhundert sind offenbar imperialistisch bedingte Hungersnöte, die im 20. Jahrhundert durch von totalitären Regimes verursachte Katastrophen abgelöst wurden und schließlich im Phänomen der strukturellen Unterernährung gipfelten, das bis heute Teile der Welt fest im Würgegriff hält. Offensichtlich ist dabei der Zusammenhang zwischen Krieg und Hunger. Wenig überraschend ist der Zusammenhang zwischen Unterentwicklung und Hunger. Kaum zu übersehen ist der Zusammenhang zwischen Totalitarismus und Hunger. Nicht weniger deutlich aber ist der Zusammenhang zwischen Imperialismus und Hunger. Und an vielen Stellen ebenfalls deutlich ist der Zusammenhang zwischen Marktöffnung und Hunger. Insgesamt bestehen also offenbar verschiedene Verbindungen zwischen Weltordnungsvorstellungen und Globalisierungstendenzen und Hunger, die in der Regel ungünstig für die Hungernden wirken.

Die in diesem Kontext denkbare regelrechte „Organisation“ von Hunger - nicht immer, aber oft bewusst - ist am Beispiel Indiens für das 19. Jahrhundert und in den totalitären Katastrophen des 20. Jahrhunderts sehr gut nachvollziehbar, anschließend aber verschleiert worden. Nicht zuletzt durch das WTO-Regime und die

80 Ziegler (2003) widmet sich u.a. ausführlich der WTO. Vgl. FAO (2005) für eine ausführliche Auseinandersetzung darüber, wie und unter welchen Bedingungen Handel den Hungernden helfen könnte. 
darüber oft in erfreulicher Öffentlichkeit geführte Debatte wird sie nun auch für das 21. Jahrhundert wieder deutlicher. Was sich dabei als „,neues Nahrungsregime“ enthüllt, ist freilich beängstigend und fordert zu einer starken Reaktion heraus, weil darin auch die Demokratie weiter ausgehöhlt wird. Für Saurin etwa führt der neoliberale Kurs der Weltwirtschaft zu einer Reorganisation des Hungers zum Nachteil der Betroffenen und letztlich zu einer Privatisierung dieser Organisation. „Whereas with the rise of the modern state the regulation of hunger had been increasingly carried out by state or public authorities on a national-territorial basis, it is increasingly evident that this responsibility has either been dramatically questioned (a matter of legitimacy) or undermined (a matter of capacity). "81 Wenig überraschend ist er daher der Ansicht, dass Weltordnung im Feld der Landwirtschaft heute weniger von Staaten oder internationalen Regimes definiert wird, sondern von Unternehmen: „[W]orld food order - crucial elements of which were instituted by explicit state action - has developed primarily through the operation of global markets, the concentration of capital, and the organization of the agroindustrial complex over which most states have virtually no control. In brief, the world food order can neither be portrayed as a state order, nor can it be analysed primarily in terms of state action." ${ }^{82}$ Untrennbar mit dieser Tendenz verbunden ist die zunehmend wichtige Rolle von Eigentumsrechten an der Natur. „Die Patentierung von Pflanzen und Tieren muss zwar nicht zwingend zum Hunger führen, aber wenn der Zugang zu Saatgut in einem derartigen Ausmaß monopolisiert und die Ernährungssouveränität der Menschen derart untergraben wird, dann steigt das Risiko einer Verstärkung der globalen Hungerproblematik. Regionale Ernährungssysteme werden durch die eindimensionale Ausrichtung ökologisch anfällig und durch das fast zwangsweise Abhängigmachen der Bauern und Bäuerinnen, in Form von patentierten Technologiepaketen, ökonomisch destabilisiert. Patente können also Hunger machen. ${ }^{\text {"883 }}$

Aufgrund der extremen materiellen Lage, in der sich Hungernde unweigerlich befinden, ist zweierlei zentral für die Bekämpfung von Hunger: ein öffentliches Bewusstsein, dass Hunger ein Problem ist, also das konsequente Anerkennen fundamentaler Menschenrech-

81 Saurin (1997), 114-115.

82 Saurin (1997), 119-120. (Hervorhebung im Original).

83 Hoppbichler (2005), Teil 3. 
te auf ein Leben in Würde ${ }^{84}$; und im Anschluss daran die Fähigkeit, organisiert einzugreifen, die staatlich wirksam werden könnte, aber aufgrund des globalisierten Agrarmarktes besser auf globaler Ebene zum Tragen kommen sollte.

Natürlich darf angesichts dieser Umstände, einer ,politischen Ökonomie" des Hungers ${ }^{85}$, nicht wegdiskutiert werden, dass Hunger auch weiterhin einen engen Zusammenhang mit dem Klima aufweist. Gerade das zeigt Mike Davis auf, wenn er ausführlich auf das „Hungerklima“ eingeht, das durch das Zusammenspiel von mit der sogenannten „ENSO“ verknüpften Wettereffekten und den natürlichen Bedingungen in bestimmten Weltregionen (vor allem Nordund Zentralchina, Indien, dem Horn von Afrika, Südafrika und Nordostbrasilien) entsteht. ${ }^{86}$ Das macht Hunger auch zu einem Phänomen der „politischen Ökologie“, das nicht einfach durch monokausale Erklärungen verstanden werden kann, sondern zumindest Kenntnisse über seine ökonomische, politische, soziale, klimatische und geografische Dimension verlangt.

Was es also bräuchte, um den Hunger tatsächlich zu besiegen, wäre eine klare Orientierung globaler Wirtschaftspolitik und der Entwicklungsbemühungen an Zielen, die Nationalstaaten aufgrund radikal geänderter Rahmenbedingungen nicht mehr ohne Weiteres erfüllen können, wie z.B. am Ziel lokaler Nahrungssicherheit. Lippenbekenntnisse werden dazu nicht ausreichen und auch nicht gut gemeinte Ansätze „menschlicher Entwicklung“ im Sinn der Millenniumsziele. Sie werden im nächsten Moment von nicht nachhaltiger Politik der Weltbank, kontraproduktiver Politik des Währungsfonds, gnadenloser Machtpolitik derer, die dazu in der Lage sind, und den profitorientierten Interessen von transnationalen Großkonzernen unterlaufen, hinter denen erheblich mehr Kapital und damit Kraft steht. Gerade diese Globalisierungstendenzen, für die viele ökonomische Analysen blind zu sein scheinen, verhindern auch, dass die Liberalisierung von Märkten ihre positiven Wirkungen nachhaltig entfalten

84 Vgl. etwa FIAN (2005) oder auch Ziegler (2005).

85 Vgl. Nussbaumer (2003).

86 Vgl. Davis (2004), 243-279. „ENSO“ steht für „El Niño“ (die Erwärmung des Meerwassers in bestimmten Regionen des Pazifiks) und „Southern Oscilliation“ (die Oszillation von Luftmassen und Meerestemperaturen im südlichen Pazifik), die nach Ansicht einer zunehmenden Anzahl von Klimatolog(inn)en gemeinsam ein globales Klimamuster ergeben. Vgl. in diesem Zusammenhang kritischer auch Devereux (1992), 35-45. 
kann - unter einem Umstand, der beim Arbeiten in einer oft allzu glatten Modellwelt leicht vergessen werden kann, und zwar demjenigen, dass in der Bekämpfung von Hunger keine Anpassungskosten getragen werden können, weil diese den Tod bedeuten.

Trotzdem könnte die Agroindustrie grundsätzlich - und auch sie selbst wird nicht müde, das zu betonen - durch ökonomisch effizientere und billigere Produktion einiges zur Sicherung der Ernährung der Menschheit beitragen. Bei denen, die über Kaufkraft verfügen, hat sie in den letzten 50 bis 100 Jahren nichts anderes getan, als deren Ernährungslage beispiellos und bis über die Grenze zur Fettleibigkeit hinaus zu verbessern. Dass die vielfältigen ökologischen Probleme (nicht nur Umweltzerstörung, sondern auch Verlust der Artenvielfalt) dabei meist ausgeblendet bleiben, ist wohl sogar weniger bedenklich, als dass diese Industrie diesen Auftrag (so sie ihn denn wirklich erhielte) unter den gegebenen politökonomischen und politökologischen Rahmenbedingungen nicht wird erfüllen können. Damit aber bleibt der Kampf gegen den Hunger ein weiter zu führender, und auch den Profiteuren des gegenwärtigen Systems wird einleuchten, dass uns dieser, wenn er analytisch erfolgreich verläuft, die sonst unvermeidlichen Verteilungskämpfe ersparen könnte.

\section{Literatur}

Arnold, David (1988): Famine. Social Crisis and Historical Change. Oxford: Blackwell.

Barkin, David/Batt, Rosemary/DeWalt, Billie (1992): Food Crops vs. Feed Crops: Global Substitution of Grains in Production. London: Lynne Rienner.

Becker, Jasper (1996): Hungry Ghosts. China's Secret Famine. London: Murray.

Borchardt, Knut (2001): Globalisierung in historischer Perspektive. München: Bayrische Akademie der Wissenschaften.

Chang, Jung/Halliday, Jon (2005): Mao: das Leben eines Mannes, das Schicksal eines Volkes. München: Blessing.

Chossudovsky, Michel (2002): Global Brutal. Der entfesselte Welthandel, die Armut, der Krieg. Frankfurt/M.: Zweitausendeins.

Conquest, Robert (1988): Ernte des Todes. Stalins Holocaust in der Ukraine 19291933. München: Langen Müller.

Davis, Mike (2004): Die Geburt der Dritten Welt. Hungerkatastrophen und Massenvernichtung im imperialistischen Zeitalter. Berlin: Assoziation A.

Devereux, Stephen (1993): Theories of Famine. New York: Harvester Wheatsheaf.

Dréze, Jean/Sen, Amartya/Hussain, Athar, Hg. (1995): The Political Economy of Hunger. Oxford: Clarendon Press. 
ETC Group (2005): „Global Seed Industry Concentration - 2005“, online unter: http://www.etcgroup.org/documents/Comm90GlobalSeed.pdf (Zugriff am 30.11.2007).

FAO (1996): The Sixth World Food Survey. Rom: FAO Publications.

FAO (2005): The State of Food and Agriculture 2005. Agricultural Trade and Poverty: Can Trade Work for the Poor? Rom: FAO Publications.

FIAN (2005): Wirtschaft global - Hunger egal? Für das Menschenrecht auf Nahrung. Hamburg: VSA.

Fogel, Robert W. (2004): The Escape from Hunger and Premature Death, 17002100. Europe, America, and the Third World. Cambridge/UK: Cambridge University Press.

Fowler, Cary (1991): Die Saat des Hungers: wie wir die Grundlagen unserer Ernährung vernichten. Reinbek/H.: Rowohlt.

Friedmann, Harriet/McMichael, Philip (1989): „Agriculture and the State System. The Rise and Decline of National Agricultures, 1870 to the Present", in: Sociologia Ruralis 29 (2), 93-117.

Goodman, David/Sorj, Bernardo/Wilkinson, John (1987): From Farming to Biotechnology: A Theory of Agro-Industrial Development. Oxford: Blackwell.

Gresh, Alain, Hg. (2006): Atlas der Globalisierung. Die neuen Daten und Fakten zur Welt. Berlin: taz.

Heintzman, Andrew/Solomon, Evan (2004): Feeding the Future. From Fat to Famine. How to Solve the World's Food Crisis. Toronto: Anansi.

Hoppbichler, Josef (2005): Patente, Monopole und Hunger (in 3 Teilen), online unter: http://www.paulofreirezentrum.at/index.php?Art_ID=332, Art_ID=333 und Art_ID=334 (Zugriff am 30.11.2007).

IPCC (2007): Climate Change 2007: Impacts, Adaptation and Vulnerability. Cambridge/UK: Cambridge University Press.

Klaffenböck, Gertrude/Lachkovics, Eva/Südwind Agentur, Hg. (2001): Biologische Vielfalt. Wer kontrolliert die globalen genetischen Ressourcen? Frankfurt/M.: Brandes \& Apsel.

Kracht, Uwe/Schulz, Manfred, Hg. (2005): Food and Nutrition Security in the Process of Globalization and Urbanization. Münster: LIT.

Mason, John (2003): „Keynote Paper: Measuring Hunger and Malnutrition“, in: FIVIMS, Hg.: Measurement and Assessment of Food Deprivation and Undernutrition. Rom: FAO Publications.

Mittal, Anuradha (1997): „The Politics of Hunger“, in: Earth Island Journal 12 (2), 36-37.

Morgan, Dan (1979): Merchants of Grain. New York: Viking Press.

Nussbaumer, Josef (2000): Vergessene Zeiten in Tirol. Lesebuch zur Hungergeschichte einer europäischen Region. Innsbruck: Studienverlag.

Nussbaumer, Josef (2003): Gewalt.Macht.Hunger. Band 1: Schwere Hungerkatastrophen seit 1845. Innsbruck: Studienverlag. 
Nussbaumer, Josef/Exenberger, Andreas (2006a): „Erzwungener Hunger, ein globaler Problemkomplex", in: Forum für Kinder- und Jungendpsychiatrie, Psychosomatik und Psychotherapie 16 (4), 3-33.

Nussbaumer, Josef/Exenberger, Andreas (2006b): „Gedankensplitter zu Katastrophen und deren Wahrnehmung“, in: Wissenschaft \& Umwelt INTERDISZIPLIN ÄR 10, 103-114.

O'Rourke, Kevin/Williamson, Jeffrey (1999): Globalization and History. The Evolution of a Nineteenth-century Atlantic Economy. Cambridge/MA: MIT Press.

Polanyi, Karl (1978): The Great Transformation. Politische und ökonomische Ursprünge von Gesellschaften und Wirtschaftssystemen. Frankfurt/M.: Suhrkamp.

Runge, C. Ford/Senauer, Benjamin/Pardey, Philip G./Rosegrant, Mark W. (2003): Ending Hunger in Our Lifetime. Food Security and Globalization. Baltimore: Johns Hopkins University Press.

Saurin, Julian (1997): „Organizing Hunger: Global Organization of Famines and Feasts", in: Thomas, Caroline/Wilkin, Peter, Hg.: Globalisation and the South. London: Macmillan, 106-123.

Sen, Amartya (1982): Poverty and Famines. An Essay on Entitlement and Deprivation. Oxford: Oxford University Press.

Sen, Amartya (1999): Ökonomie für den Menschen. Wege zu Gerechtigkeit und Solidarität in der Mark.twirtschaft. München: Hanser.

Shiva, Vandana (2002): Biopiraterie: Kolonialismus des 21. Jahrbunderts. Münster. Westfälisches Dampfboot.

Shiva, Vandana/Bedi, Gitanjali, Hg. (2002): Sustainable Agriculture and Food Security. The Impact of Globalization. New Dehli: Sage.

UNDP (1997): Human Development Report 1997: Human Development to Eradicate Poverty. Oxford: Oxford University Press.

UNDP (2003): Human Development Report 2003. Millennium Development Goals: A Compact among Nations to End Human Poverty. Oxford: Oxford University Press.

UNDP (2007): Human Development Report 2007/08. Fighting Climate Change: Human Solidarity in a Divided World. Oxford: Oxford University Press.

WHO (2004): The World Health Report 2004. Changing History. Genf: WHO Publications.

World Bank (2000): World Development Report 2000/01: Attacking Poverty. Oxford: Oxford University Press.

Young, Helen (1992): Food Scarcity and Famine: Assessment and Response. Oxford: Oxfam.

Ziegler, Jean (2003): Die neuen Herrscher der Welt und ibre globalen Widersacher. München: Bertelsmann.

Ziegler, Jean (2005): Das Imperium der Schande. Der Kampf gegen Armut und Unterdrückung. München: Bertelsmann. 
Die Informationsrevolution frisst ihre eigenen Kinder.

Internationale Medienpolitik zwischen Terror, Militarisierung und totaler Entgrenzung

Jörg Becker*

Ich möchte im Folgenden in sieben Schritten vom Kleinen zum Großen voranschreiten. Ich beginne mit einem Kapitel über Medien und Terror, komme dann zur Rolle der Medien in den jüngsten Kriegen, frage drittens nach dem, was ich Militarisierung von Kommunikation nenne, schreite weiter zu zwei Kapiteln über zwei sich ergänzende Dimensionen der Kontrollgesellschaft, frage sechstens nach den Folgen einer totalen Entgrenzung von medialer Kommunikation und versuche nach diesem großen Rundumschlag in einem siebten und letzten Kapitel zu retten, was noch zu retten ist.

\section{Medien und Terrorismus}

The Towering Inferno heißt ein Film-Schocker von John Guillermin aus dem Jahr 1974, in dem suizidwillige Muslime einen Großbrand in einem Hochhaus legen. Ein Satz am Ende des Films nimmt den An-

* Jörg Becker ist Geschäftsführer des KomTech-Instituts für Kommunikations- und Technologieforschung in Solingen und seit 1987 Honorarprofessor am Institut für Politikwissenschaft der Universität Marburg. Zudem war er von 1987 bis 1992 Heisenberg-Stipendiat der Deutschen Forschungsgemeinschaft (DFG). Der vorliegende Text basiert auf seiner Schwager-Vorlesung vom 7. April 2005, die sich auf Forschungsergebnisse aus dem von der Deutschen Stiftung Friedensforschung (DSF) in Osnabrück geförderten Projekt „Die Informationskriege um den Balkan seit 1991“ stützte. Eine frühere Version dieses Textes ist als Nr. 2 der Innsbrucker Diskussionspapiere $₹ u$ Weltordnung, Religion und Gewalt erschienen. 
schlag auf das World Trade Center am 11. September 2001 vorweg: „Wir haben heute Nacht noch Glück gehabt mit weniger als zweihundert Toten, aber es werden Zeiten kommen, in denen wir bei einem Hochhaus-Brand Tausende von Opfern haben werden." In John Frankenheimers Schwarzer Sonntag von 1977 setzt eine palästinensische Terroristin einen Piloten unter Druck, einen mit 500 Kilogramm Plastiksprengstoff beladenen Zeppelin in ein voll besetztes Football-Stadium zu steuern. 1998 folgt im Genre solcher Horrorund Desasterfilme der Ausnabmezustand (The Siege) von Edmund Zwick. Eine Serie von Terroranschlägen radikaler Islamisten führt zur Verhängung des Kriegsrechts in den USA. Über die BrooklynBridge rollen Panzer - arabische Amerikaner werden in KZ-ähnlichen Lagern interniert. David Finchers Film Fight Club von 1999 kommt dem Anschlag vom 11. September 2001 noch näher: Eine Gruppe junger Männer gründet unter dem Deckmantel eines Boxervereins flächendeckende Terrorzellen, die den Einsturz eines Zwillingsturmes herbeiführen. In Armageddon (1998) von Michael Bay durchschlägt ein Meteorit tatsächlich das World Trade Center, was den realen Bildern von 2001 erschreckend ähnlich sieht. Erwähnenswert sind auch die Filme Outbreak (1995) von Wolfgang Petersen, der die Katastrophe tödlicher biologischer Angriffe thematisiert, und Independence Day (1996) von Roland Emmerich, in dem Außerirdische ein globales Inferno anrichten.

Man sieht: Weder der terroristische Anschlag auf das World Trade Center vom 11. September 2001 noch dessen massenmediale Inszenierung sind neu. Flugzeugangriffe auf Wolkenkratzer, Krieg gegen radikale Muslime in Afghanistan (so in Rambo III mit Sylvester Stallone von 1987) oder anti-muslimische Vorurteile ${ }^{1}$ : Die US-amerikanische Traumfabrik Hollywood kennt alle drei Momente als ideologische Versatzstücke seit Langem. Das Kino ist vieles gleichzeitig: Phantasie, Regression und Antizipation, Beschleuniger und Katalysator.

Um den Kommunikationsaspekt von Terrorismus verstehen zu können, macht es Sinn, sich diesen Aspekt als ein Dreiecksverhältnis von Terrorist-Opfer-Zielgruppe vorzustellen. Dabei ist das Opfer, das normalerweise in irgendeiner Form mit der Zielgruppe verknüpft ist, eine Art von Instrument, um der Zielgruppe eine ganz spezifi-

1 Vgl. Said (1997) und Shaheen (2001). 
sche Botschaft nahezubringen, also mit ihr zu kommunizieren. Das Opfer des Terrorismus soll die Zielgruppe traumatisieren, demoralisieren, auf alle Fälle irgendwie beeinflussen. Da bei einem terroristischen Akt normalerweise nur zwei der drei Pole dieses Dreiecksverhältnisses anwesend sind, kommt der Kommunikation eine entscheidende Bedeutung zu. Nur Kommunikation ist es, die den dritten Pol des Dreiecks in eine Beziehung zu den anderen beiden Polen einbindet.

Abbildung 1: Terrorismus und Kommunikation

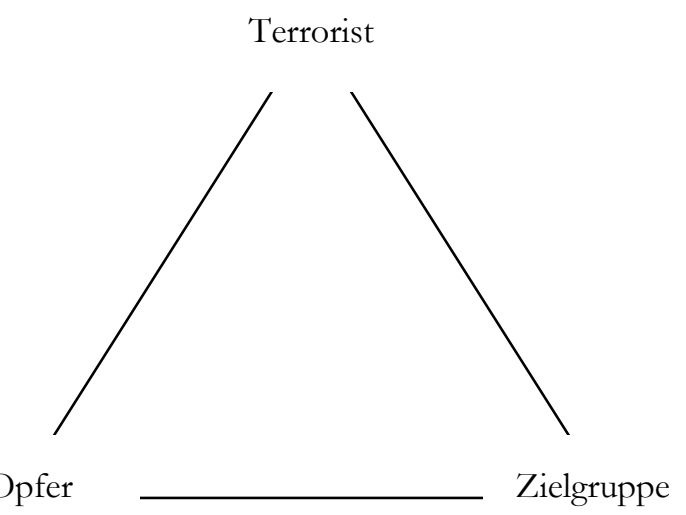

Die Sprache des Terrorismus ist alt. Für einen russischen Sozialrevolutionär im 19. Jahrhundert war dessen Bombe gleichzeitig seine Sprache. In dieser Sprache wehrte er sich gegen eine ungerechte und inhumane politische Ordnung ohne Presse- und ohne Versammlungsfreiheit. Der anarchistisch-terroristischen Bombe eines Attentäters oder eines Kaisermörders im 19. Jahrhundert entsprach eine unregelmäßig und im handwerklichen Druckverfahren hergestellte Zeitung mit kleiner Auflage. Solche Untergrundmedien konnten damals noch durchaus mit offiziellen Medien konkurrieren. Auch viele Zeitungen im 19. Jahrhundert kamen nicht über eine Auflage von einigen 100, bestenfalls einigen 1.000 Stück hinaus, und oft beschränkte sich ihr Umfang auf nur wenige Seiten. Den beiden Größen Medienangebot und Lesermarkt konnte ein einzelner anarchistischer Redner mit einer öffentlichen Rede im Hyde-Park noch Paroli bieten. 
Dieses Verhältnis änderte sich in dem Augenblick, als aus ökonomischen und technologischen Bedingungen heraus nur noch wenige, aber sehr auflagenstarke Zeitungen Millionen von Lesern ansprachen. Ab dem Moment aber, ab dem ein öffentlicher Diskurs in privatwirtschaftlich verfassten Medien stattfand, ab dem es einer Zeitung immer weniger um Leser als um Werbung ging (und aus betriebswirtschaftlichen Gründen auch gehen musste), ${ }^{2}$ konnte ein Terrorist mit normalen Kommunikationsmitteln kein Gehör mehr finden. Wer terroristischer Gegner der vorherrschenden kapitalistischen Kultur war, konnte nicht damit rechnen, dass ihm die Massenmedien Gehör schenkten oder ihm gar Werbeplatz einräumten. Parallel dazu mussten die eigenen Medien der Terroristen klein bleiben; ihre Nischenmedien wurden in der Öffentlichkeit nicht mehr wahrgenommen.

Terrorismus ist eine ganz spezifische Form von Kommunikation. Selbstverständlich verändert sich aber diese Form je nach historischen und kulturellen Bedingungen. Die Ungeheuerlichkeit des terroristischen Anschlags auf das World Trade Center und das Pentagon vom 11. September 2001 gründet darin, dass die USA, die einzig verbliebene Supermacht, auf ihrem eigenen Territorium verwundet wurde, mit hohem Symbolcharakter der beiden zerstörten Gebäude und in der direkten, globalen und zeitgleichen medialen Inszenierung des Geschehens. Die drei eigentlich getrennten Beziehungspole Terrorist, Opfer und Zielgruppe schmelzen sowohl real als auch medial zu einem einzigen Pol zusammen. Anders formuliert: Weil das Fernsehen die Bilder der beiden brennenden Türme des World Trade Center immer wieder zeigte, fungierte es als heimlicher Komplize sowohl der entsetzlichen Bilder als auch der Terroristen.

Wenn sich Kinder die Augenbrauen auszupfen, sich also autoaggressiv verhalten, wenn sie aufhören zu essen oder wenn sie mit dem Gedanken an Selbstmord spielen, dann sind solche Vorgänge oft genug Symptome von Beziehungs- und Kommunikationsstörungen zwischen ihnen und ihren Eltern. Solche Symptome erheischen Kommunikation mit Öffentlichkeit. Ganz ähnlich verhält es sich mit

2 Als „Klassiker“ für diese Argumentation gilt es an dieser Stelle nachdrücklich auf Jürgen Habermas' Strukturwandel der Öffentlichkeit (1962) zu verweisen, auf der Gültigkeit seiner epochalen Analyse zu beharren. Im engeren Fachgebiet der Kommunikationswissenschaft war es der Staatswissenschaftler Karl Bücher, der in seinem Buch Das Zeitungswesen bereits 1906 eine ähnliche Argumentationslinie entworfen hatte. 
dem Phänomen des Terrorismus. Schon 1975 analysierte der amerikanisch-österreichische Psychologe Friedrich Hacker Terrorismus mit den folgenden Worten:

„Der terroristische Akt ist ein Appell an die Umwelt zur Hilfeleistung, ein drastischer Vorwurf an die desinteressierte, blinde und taube Welt, welche die berechtigten Anliegen und Ansprüche der ungerecht behandelten, missachteten Terroristen ignoriert. Blitzartig soll durch die terroristische Aktion ein ins Dunkel des Vergessens verdrängtes Unrecht beleuchtet und sichtbar gemacht werden. Das Signal weist auf den bisher nicht genügend bemerkten Notstand hin und kündigt an, dass die Terroristen nicht mehr gewillt sind, die bisherige Vernachlässigung weiter zu dulden. “3

Der Transfer von einer derartigen Einschätzung zur Medienpolitik liegt auf der Hand. Explizit stellte diesen Bezug z.B. Richard Francis her, früher Abteilungsleiter für Nachrichten und Aktuelles bei der BBC. Seine Analyse der terroristischen Gewalt im NordIrland-Konflikt der 70er-Jahre des 20. Jahrhunderts lautete folgendermaßen:

„Die Geschichte des Rundfunks in Irland und besonders in Nord-Irland zeigt deutlich, dass in den 60er-Jahren [des 20. Jahrhunderts] die bewusste Verbannung von extremen Stimmen aus dem Äther und die sorgfältige Beschäftigung mit den legitimen Zielen der Republikaner uns unglücklicherweise genau die Probleme bescherte, die wir dann in den folgenden zehn Jahren bekamen. [...] Rundfunkleute müssen endlich verstehen, dass Menschen, die ihre legitimen Ziele nicht innerhalb eines demokratischen Systems verwirklichen können, frustrierte Menschen sind und aus dem System herausgedrängt werden. [...] Es besteht die Gefahr, dass in dem Augenblick, in dem niemand auf extreme Stimmen achtet und auf sie hört, sich nicht von ihnen herausgefordert fühlt und sich nicht engagiert, dass sich genau dann diese Stimmen Methoden der Gewalt zuwenden und sich außerhalb des demokratischen System stellen, damit man sie endlich wahrnimmt. “4

Was Richard Francis von der BBC hier als journalistische und politische Maxime schildert, erlangte in Großbritannien sogar gesetzgeberische Qualität. Aufgrund einer 1988 vorgenommenen Geset- 
zesänderung des Rundfunkgesetzes von 1981 war es britischen Radio- und TV-Stationen verboten, Interviews mit IRA-Mitgliedern zu senden.

In einer Welt von Blind- und Taubheit, Desinteresse, Ausklammerung und Vernachlässigung kommunizieren die Terroristen vom 11. September 2001, dass sie an einem Entwicklungspunkt extremer Verzweifelung stehen. Ihre kommunikative Botschaft an die Welt heißt: Interessiert euch für uns, wir wollen von euch nicht länger blind und taub gemacht werden, wir wollen von euch endlich wahrgenommen und gesehen werden. Wir wollen nicht länger ,invisible" sein - so könnte man das Anliegen der Terroristen mit der Botschaft vergleichen, die der afro-amerikanische Autor Ralph Ellison der weißen US-Bevölkerung anbot, als er seinem ungeduldigen Emanzipationsroman den Buchtitel „Invisible Man“ (1952) gab.

In einer Weltunordnung der internationalen Kommunikation, in der sich weit, weit mehr als die Hälfte der Menschheit in den Massenmedien keinerlei Gehör verschaffen kann, entspricht der außergewöhnlichen, singulären und extremen Kommunikationsbotschaft der Terroristen vom 11. September 2001 der normale und alltägliche massenmediale Overkill im reichsten Land der Erde. In den USA gibt es heute 17.000 Zeitungen, 12.000 Zeitschriften, 27.000 VideoVerleihstellen, 350 Millionen TV-Geräte, mehr als 400 Millionen Radiogeräte, werden jährlich 40.000 neue Bücher gedruckt, jeden Tag 41 Millionen Fotos aufgenommen, landen jährlich 60 Milliarden Briefe in den Briefkästen und werden wöchentlich Filme im Ausmaß von 150.000 Programmstunden in den Rest der Welt exportiert, und diese Menge entspricht einer Verfünfzigfachung von Filmausfuhren innerhalb von nur 20 Jahren.

Freilich zeigte die internationale Medienwelt nach dem 11. September 2001, dass dieser mediale Overkill aus den USA gleichermaBen wirkungsmächtig und -ohnmächtig ist. War der AfghanistanKrieg seitens der USA aus Gründen der Zensur absichtlich ein Krieg ohne Bilder, so durchbrach der arabische TV-Sender Al Jazeera die US-amerikanische Bild-Hoheit und Bild-Deutung mit den Videos von Osama bin Laden. Gerade weil es nur wenige Videos von Osama bin Laden gab, gerade auch weil sie von ihrer Bildästhetik her so altmodisch, starr und patriarchalisch wirkten, gerade weil sie in den westlichen Industrieländern nur wenig und oft nur zensiert gezeigt wurden, erlangten sie in der Weltöffentlichkeit eine ikonografische Bedeutung, die weit über dem Bildangebot von $\mathrm{CNN}$ lag. 


\section{Die Rolle der Medien in den jüngsten Kriegen}

Auch wenn es in allen Kriegen eine Korridorbildung in der veröffentlichten Meinungsbildung gegeben hat, und dieses Phänomen auch heute noch besteht, so schält sich in dem Verhältnis von Krieg zu Medien seit dem Zweiten Golfkrieg von 1991 zusätzlich ein neues Phänomen heraus. Das Neuartige liegt darin, dass es staatlichmilitärisch kontrollierte Informationssysteme gibt, die über privatwirtschaftlich arbeitende PR-Agenturen eine bezahlte und bezahlbare Medienöffentlichkeit konstruieren, die einer (Angriffs)kriegsführung aus guten demokratischen Gründen zustimmt. Indem es einem staatlich initiierten, aber privatwirtschaftlich exekutierten KriegsMedien-PR-System sogar gelingt, einige NGOs, Thinktanks, Consulting-Firmen und Teile der Friedensforschung auf seine Seite herüberzuziehen, wird freudestrahlend „die NATO zum militärischen Arm von amnesty international. Vernunft soll herbei gebombt werden" - so Ulrich Beck in einem politischen Essay ${ }^{5}$.

Die Kriegsberichterstattung in den Massenmedien ist inzwischen also das Resultat von Marktbeziehungen zwischen Regierungen und Consulting-Unternehmen, die für ihre Medienmanipulationen bezahlt werden. Die Effektivität medialer Kommunikation bemisst sich nicht länger daran, ob ein Diskurs kommunikativ sinnvoll gestiftet wurde, sondern daran, ob es eine Kongruenz zwischen privatwirtschaftlich vereinbarter und erfolgreich ausgeführter Medienmanipulation gibt. Außer der Privatisierung der Berichterstattung über den Krieg gibt es noch zwei weitere Bereiche der modernen Kriegsführung, die der Staat inzwischen privater Verfügung zuführt. $\mathrm{Da}$ gibt es also neben der Privatisierung von früher öffentlicher Kriegskommunikation durch private PR-Agenturen zweitens das staatliche Gewaltmonopol, das privatisiert wird. Vorbei an parlamentarischen Zustimmungspflichten und Budget-Genehmigungen für einen staatlichen Verteidigungshaushalt externalisiert der Staat seine Kriegsführung an private Militärfirmen (PMF). Drittens schließlich vollzieht sich eine Privatisierungs- und Outsourcing-Strategie in dem Bereich, der früher die ureigenste Domäne staatlicher Politik war, nämlich in der Diplomatie. Lobbying in den Zentren einer fremden Macht, Formulierung von politischen Programmen und internationalen Resolutionen, internationale Vertragsverhandlungen über Krieg 
und Frieden hinter geschlossenen Türen - all das wird nun ebenfalls auf einer marktfähigen Ebene von Angebot und Nachfrage ge- und verkauft. Das privatisierte Dreieck von 1. privatisierter Kriegskommunikation, 2. privatisierter Kriegsaustragung und 3. privatisierter Diplomatie wird die Zukunft von Krieg und Frieden entscheidend verändern und muss theoretisch wie empirisch dringend analysiert werden.

Abbildung 2: Die Privatisierung des Krieges

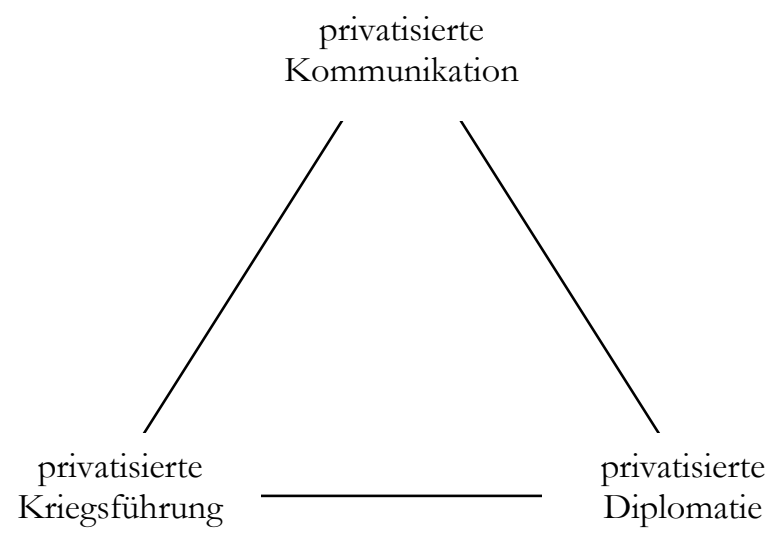

Aus der Sicht der postmodernen französischen Philosophie stehen die „alten Kriege“ der Moderne und ihre entsprechenden Diskurse für das Konzept der Disziplinargesellschaft, so wie es Michel Foucault entfaltet hat, ${ }^{6}$ also einer Gesellschaft, in der alle sozialen Beziehungen nach den beiden Prinzipien von Überwachen und Strafen geregelt werden. Medienbeziehungen im Krieg werden in dieser Disziplinargesellschaft durch das Prinzip der Zensur (Exklusion) geregelt. Demgegenüber stehen die „neuen Kriege“ der Spätmoderne (deren Anfänge im Zweiten Golfkrieg und in den Balkankriegen zu finden sind) und ihre entsprechenden Diskurse für das Konzept der Kontrollgesellschaft, so wie es Gilles Deleuze entfaltet hat, ${ }^{7}$ also ei-

6 Vgl. Foucault (1976).

7 Vgl. Deleuze (1993), 254 ff. Die Übernahme der beiden Termini „Disziplinar-“ und „Kontrollgesellschaft“ impliziert seitens des Verfassers natürlich keine Übernahme der gesamten neueren französischen Theorie der Postmoderne. Was die Kritische Theorie 
ner Gesellschaft, in der die Menschen im vorgegebenen eigenen Interesse gerne und „freiwillig“ mit Polizei und Militär kooperieren, um gegen ihre eigene permanente Lebenskrise und strukturelle Angst vorgehen zu können. Die Notwendigkeit von Bestrafung und Überwachung ist internalisiert worden. Überwachen und Bestrafen werden als nötig, gar als schön empfunden. Medienbeziehungen im Krieg werden in der Kontrollgesellschaft durch das Prinzip der Kooperation (Inklusion) geregelt (embedded journalism, embedded NGOs und embedded Zivilgesellschaft).

Von der Rolle der Medien in ,früheren“ und in ,gegenwärtigen“ Kriegen kontrastiv zu sprechen, unterstellt zeitlich und qualitativ distinkte Entwicklungen und Muster. Solche Unterscheidungen folgen normalerweise verschiedenen Varianten von Evolutionstheorien. Danach haben sich Geschichte und Gesellschaft linear, fortschreitend und zivilisatorisch entwickelt. Hinter diesen Evolutionstheorien stehen relativ simple Annahmen, z.B. die einer Entwicklung von einem früher einfachen zu einem heute komplexen Zustand oder die von einer sich stets verkomplizierenden Entwicklung der Produktivkräfte - daher der landläufige Technikdeterminismus.

Auch die französische Postmoderne folgt genau dieser Annahme. Das wird in Bezug auf die Rolle der Medien im Krieg besonders deutlich bei Paul Virilio. Negativ fasziniert von der waffentechnischen Zerstörungsqualität der US-Waffen im Golfkrieg von 1991 ging er in seinen Essays während dieses Krieges apodiktisch vom Ende des traditionellen Wechselverhältnisses zwischen Krieg und Medien aus. Vollmundig sprach Virilio damals vom „nodalen Krieg“, vom „ersten reinen Medienkrieg“ usw. Still musste eine solche technikdeterministische Position à la Virilio dann aber später bei den darauf folgenden ,normalen“ Söldner- und Guerillakriegen in Ruanda, Bosnien und dem Kosovo bleiben. Im Ruanda-Krieg spielte die „uralte“ Technologie der Radios eine herausragende Rolle und, statt abgefeimte Manipulationsstrategien einzusetzen, wurde in diesen Radios ganz einfach Hass gepredigt. Und im Kosovo-Krieg täuschte die serbische Armee die US-amerikanische Luftwaffe erfolgreich mit Panzerattrappen aus einfachster Pappe in CamouflageBemalung mit der Folge, dass die US-amerikanische Hightech-Luft-

wohl äußere und innere Abhängigkeit und was aus anderer Sicht David Riesman innenund außengeleitet genannt hätte, bringen diese beiden Begriffe von Foucault und Deleuze aber sprachlich und theoretisch sehr fein auf den entscheidenden Punkt. 
waffe während des ganzen Kosovo-Krieges von den vielen hundert serbischen Panzern nur 14 Stück zerstören konnte. Auch im gegenwärtigen Irak-Krieg geht es um das Mit- und Nebeneinander von „steinzeitlichem“ Mann-zu-Mann-Kampf in verwinkelten Hinterhofgassen in Falludscha und kombiniertem Großeinsatz von Hollywood/Pentagon samt Satellitentechnologie. Militärstrategisch formuliert heißt dies im Übrigen, dass die im Jahre 2000 veröffentlichte

Tabelle 1: Alte und neue Medienstrategien in Kriegszeiten

\begin{tabular}{|l|l|}
\hline FRÜHERE KRIEGE & GEGENWÄRTIGE KRIEGE \\
\hline 1. Journalismus & 1. Public Relations \\
\hline 2. räsonierende Öffentlichkeit & $\begin{array}{l}\text { 2. Öffentlichkeit als bezahlte und bezahl- } \\
\text { bare Ware }\end{array}$ \\
\hline $\begin{array}{l}\text { 3. unterschiedliche mediale In- } \\
\text { halte }\end{array}$ & $\begin{array}{l}\text { 3. homogenisierte mediale Inhalte (relativ } \\
\text { unabhängig vom Medium und relativ un- } \\
\text { abhängig vom Land) im Medienmix }\end{array}$ \\
\hline $\begin{array}{l}\text { 4. Inhalte unterschiedlicher Ak- } \\
\text { teure }\end{array}$ & $\begin{array}{l}\text { 4. Inhalte nur weniger und zentral gesteu- } \\
\text { erter Akteure (Nachrichtenagenturen, } \\
\text { CNN, Pentagon, NATO) }\end{array}$ \\
\hline 5. viele Bilder & $\begin{array}{l}\text { 5. sich wiederholende Bilder mit Ikonen- } \\
\text { charakter }\end{array}$ \\
\hline $\begin{array}{l}\text { 6. mal mehr, mal weniger Text- } \\
\text { Informationen }\end{array}$ & $\begin{array}{l}\text { 6. Overkill an stets gleichartigen und sich } \\
\text { dauernd wiederholenden Text- } \\
\text { Informationen }\end{array}$ \\
\hline $\begin{array}{l}\text { 7. keine Ausdifferenzierung in } \\
\text { Mainstream- und Alternativme- } \\
\text { dien }\end{array}$ & $\begin{array}{l}\text { 7. Wachstum von kleinen und billigen Ni- } \\
\text { schen-, Ausweich- und Ersatzmedien } \\
\text { (Comics, Tagebücher, Telefonketten, E- } \\
\text { Mails, Mailinglisten, Chatrooms) als Reak- } \\
\text { tion auf teueren, zentralistischen und sys- } \\
\text { tematischen Infowar }\end{array}$ \\
\hline $\begin{array}{l}\text { 8. Kritische Medienkritik ver- } \\
\text { unsichert die militärische Teil- } \\
\text { offentlichkeit (Exklusion). }\end{array}$ & $\begin{array}{l}\text { 8. Kalkulierte Medienkritik ist Teil der } \\
\text { Kriegsführung (Inklusion). }\end{array}$ \\
\hline
\end{tabular}

Militärdoktrin der USA ,Joint Vision 2020“ mit ihrer Akzententuierung des Einsatzes von Informationstechnologien genauso gültig ist wie die zwei Jahre später veröffentlichte „Doctrine for Joint Urban Operations“. Der Guerilla-Krieg in Hochhaus-Schluchten ${ }^{8}$ wird ge-

8 Notabene: Während die Sowjetunion ein unbemanntes US-amerikanisches Aufklärungsflugzeug über ihrem Territorium abschießt, ihr der erste bemannte Weltraumflug gelingt und die USA Kuba erfolgreich dazu zwingt, sowjetische Raketenbasen abzubauen, während der deutsche Bundeskanzler Konrad Adenauer darauf dringt, dass die Bundeswehr 
nauso zum typischen Kriegsschauplatz des 21. Jahrhunderts wie ein elektronischer Krieg.

Tabelle 2: Krieg und Medien - Struktur und Inbalt in Epochen

\begin{tabular}{|l|c|c|c|c|c|}
\hline EPOCHE & KRIEG & \multicolumn{3}{|c|}{ BEISPIELE } & MEDIEN \\
\hline $\begin{array}{l}\text { Vor- } \\
\text { moderne }\end{array}$ & $\begin{array}{c}\text { Obstrukti- } \\
\text { onskrieg } \\
\text { (Taktik) }\end{array}$ & Chronik & Kreuzzüge & Chronist & Wort \\
\hline Moderne & $\begin{array}{c}\text { Destrukti- } \\
\text { onskrieg } \\
\text { (Strategie) }\end{array}$ & Zensur & $\begin{array}{c}\text { Vietnam- } \\
\text { krieg }\end{array}$ & TV & $\begin{array}{c}\text { Bild \& } \\
\text { Ton }\end{array}$ \\
\hline $\begin{array}{l}\text { Spät- } \\
\text { moderne }\end{array}$ & $\begin{array}{c}\text { Kommu- } \\
\text { nikati- } \\
\text { onskrieg } \\
\text { (Logistik) }\end{array}$ & $\begin{array}{c}\text { Informati- } \\
\text { ons- } \\
\text { manage- } \\
\text { ment }\end{array}$ & $\begin{array}{c}\text { Zweiter } \\
\text { Golfkrieg, } \\
\text { Balkan- } \\
\text { kriege }\end{array}$ & Medien & $\begin{array}{c}\text { Medien- } \\
\text { mix, Tele- } \\
\text { aktion }\end{array}$ \\
\hline
\end{tabular}

Mit den modernen Pionieren der Fortschrittskritik wie Max Weber, Ferdinand Tönnies, Sigmund Freud, Theodor W. Adorno, Max Horkheimer, Herbert Marcuse, Günther Anders oder Hans Peter Dürr sind Moderne und Spätmoderne zutreffend mit dem Gedanken zu charakterisieren, dass es eine „Ungleichzeitigkeit des Gleichzeitigen“9 gibt, eine „strukturelle Heterogenität“, und dass sich diese auf einer Zeitachse der Geschichte stetig, aber immer schneller und umfassender dynamisiert. Globalisierung ist dann eine Phase dieser Entwicklung, die besonders dynamisch ist. Widersprüchlichkeiten und heteronome Entwicklungen sind jetzt besonders scharf sichtbar.

mit Atomwaffen ausgerüstet werden müsse, während also der moderne Krieg überall mit Hightech gleichgesetzt wird, erscheint 1961 in Frankreich das Buch La Guerre moderne von Roger Trinquier. Was dessen Autor damals „modern“ nennt und was wir heute „postmodern" nennen würden, ist eine Anleitung für anti-subversive Kriegsführung. Hier beschreibt ein französischer General - mit Erfahrungen aus den französischen Kriegen in Indo-China und Algerien -, dass die moderne Kriegsführung nichts mit Hightech zu tun habe, wohl aber mit Folter, Erpressung, Repression gegen die Zivilbevölkerung, Standrecht, Todesschwadronen oder dem systematischen Verschwindenlassen von Menschen.

9 Die „Ungleichzeitigkeit der Gleichzeitigkeit“ wurde als „strukturelle Heterogenität“ in den 60er- und 70er-Jahren des 20. Jahrhunderts von den europäischen Übersetzern der lateinamerikanischen Dependenztheoretiker quasi als neues Theorem entdeckt. Es ist der ökonomistischen Blickverengung der Dependenztheoretiker geschuldet, dass sie nicht sehen konnten, dass genau dieses Theorem der „Ungleichzeitigkeit der Gleichzeitigkeit“ als entscheidendes ästhetisches Charakteristikum der Moderne bereits 1926 durch Wilhelm Pinder in seinem Buch Das Problem der Generation in der Kunstgeschichte Europas beschrieben wurde. 
Argumentiert man freilich eindimensional und evolutionär, dann erhält man eine recht simple Parallelität von Kriegs- und Medientechnologien, von Struktur und Inhalt, wie in Tabelle 2 dargestellt. Die Darstellung in dieser Tabelle weist folgende Charakteristika auf.

1. In Überwindung einer reduktionistischen, weil rein contentistischen Feindbild- und Imageforschung des (auch kritischen) Mainstream wird eine Kongruenz von Inhalt und Technik/ Struktur postuliert. Wie vermittelt sich welcher kriegsrelevante Medieninhalt mit welcher kriegsrelevanten Medientechnik?

2. Diese Tabelle unterstellt außerdem, dass es überhaupt so etwas wie geschichtliche Entwicklung gibt. Das ist vielleicht insofern wichtig, als es eine Reihe von Geisteswissenschaftlern gibt, die argumentieren, es hätte sich im Wechselverhältnis Krieg/Medien seit der Antike nichts geändert, damals wie heute ginge es doch nur um Zensur und Lügen und daran könne man auch nichts ändern, zumal ein Sicherheits- und Geheimhaltungsinteresse von Staaten in Kriegszeiten verständlich sei.

3. Ferner unterstellt diese Tabelle, dass es genügend empirisch gesättigte Detailanalysen über das Wechselverhältnis Krieg/Medien in früheren Kriegen gibt, die dann zu den Verallgemeinerungen, wie sie in dieser Tabelle festgehalten sind, führen können. Historische Materialien, Texte, Primär- und Sekundärdokumente (ganz zu schweigen von Bildern, deren Funktion nur sehr unzureichend aufgearbeitet wurde ${ }^{10}$ ) und die politischen Interessen der handelnden Akteure waren und sind jedoch derart disparat und dynamisch-wechselnd, dass der Systematik in Tabelle 2 eigentlich nur heuristischer Wert zugestanden werden kann.

Argumentiert man aber eben nicht evolutionär, sondern multipolar, dialektisch und entlang einer Argumentation der sich dynamisierenden strukturellen Heterogenität, dann kommt man in grafische Darstellungsschwierigkeiten bei den Aussagen von Tabelle 2 - diese einfache Matrix müsste dann eigentlich in Form einer sich um sich selbst drehenden und immer schneller werdenden Spirale visualisiert werden. 


\section{Die Militarisierung von Kommunikation}

Es ist mehr als bezeichnend, dass auch auf dem jüngsten „World Summit on the Information Society" (WSIS) der UN bei der Internationalen Fernmeldeunion (ITU) Ende 2004 ein Thema ausgespart wurde, das eigentlich das Kernstück jeder Diskussion über internationale Medienpolitik bilden müsste, nämlich die Militarisierung von Kommunikation. Diese Thematik ist deswegen nicht ein Teil-, sondern der allerwichtigste Aspekt internationaler Medienpolitik, weil es das Militär und nicht der zivile Sektor ist, das den bei Weitem größten Anteil von Medienressourcen für sich und seine eigenen militärischen Bedürfnisse in Beschlag nimmt. Die militärische Dominanz über die zivile wird dann besonders auffällig, denkt man an die Aufteilung des elektromagnetischen Spektrums und an die von Funkfrequenzen für Satelliten. In diesen beiden Bereichen - den Herz- und Filetstücken jeglichen (!) kapitalistischen Wirtschaftens - dominieren militärische Akteure und militärische Nutzungen die zivilen Akteure und ihre Nutzungen in einem eindeutigen Verhältnis. Während der Anteil von militärischen zu zivilen Satelliten auf ein Verhältnis von $2 / 3$ zu 1/3 geschätzt wird, ist das Verhältnis von militärischer zu ziviler Nutzung des gesamten elektromagnetischen Spektrums en detail unbekannt. Beim NATO-Beitritt Bulgariens 2004 z.B. wurde das Verhältnis von ziviler zu militärischer Nutzung bei Radiofrequenzen der Öffentlichkeit durch Zufall bekannt. Betrug früher dieses Verhältnis in Bulgarien (das übrigens schon zu RGW-Zeiten gute Leistungen im Bereich von Telekommunikation und IT-Technologien vorzuweisen hatte) $32 \%$ militärische zu $68 \%$ zivile Nutzung, so verlangte die NATO 2001 in den Beitrittsverhandlungen von Bulgarien mit Erfolg eine Erhöhung des Militäranteils bei den Radiofrequenzen von 32\% auf 51\%, das bedeutete einen Rückgang der zivilen Ressourcen von $68 \%$ auf $49 \%$.

Meistens sind solche Frequenzaufteilungen jedoch genauso unbekannt wie die Höhe des Anteils des qualitativ wichtigen Hochfrequenz-Bereichs für die Nutzung militärischer Kommunikation. Studien über solche Aspekte sind $\mathrm{m}$.W. nicht vorhanden. Und wissenschaftliche Analysen darüber können nicht angestellt werden, da sie angeblich die jeweilige nationale Sicherheit in Frage stellen. Sicher ist freilich Folgendes: Diese so überaus dominante militärische Ressourcenbindung geschieht erstens auf Kosten des zivilen Sektors und sie entzieht zweitens der Dritten Welt dort dringend benötigte Funkfrequenzen (z.B. bei großen Flächenstaaten). 
Vergleicht man außerdem die politische Kultur der 70er-Jahre des 20. Jahrhunderts mit der gegenwärtigen Diskussionskultur auf dem genannten „World Summit on the Information Society“ (WSIS) der ITU Ende 2004, dann fällt eine starke Entpolitisierung von NGOs auf. Hatten NGOs im Rahmen der UNESCO-Debatten um eine neue internationale Informationsordnung (NIIO) Ende der 70er-Jahre des 20. Jahrhunderts solcherart Fragen nach einer Militarisierung von Kommunikation wenigstens noch thematisiert, so interessierten sich die NGOs auf dem Genfer Weltgipfel für diese Thematik 30 Jahre später in keiner Form mehr.

Militarisierung der Kommunikation meint nicht eine weitere Analyse über mediale vermittelte Inhalte, also Feindbildproduktion oder Militarisierung von Sprache (wie sie von der Kommunikationsund Friedensforschung vorrangig produziert werden), meint vielmehr Struktur, nicht Inhalt, meint also die militärische Kontrolle über Technikgenese, -nutzung, -verbreitung, -zugang und -besitz bei Massenmedien, Informationstechnologien und Telekommunikation. Und auch zu diesen Aspekten sind wissenschaftliche Arbeiten mehr als dünn gesät.

Eine Militarisierung von Kommunikation in dem hier genannten Sinne festzustellen und zu analysieren, ist manchmal einfacher als gedacht - nur im globalen Maßstab und systematisch hat bislang niemand diese Strukturen untersucht. Ich denke hier an ein technologisch so simples Beispiel wie die TV-Technologie. Ist es bereits indikativ, dass im deutschen Faschismus die Verantwortung für die Entwicklung des modernen Mediums Fernsehen bis 1935 nicht im zivilen Propagandaministerium unter Leitung von Joseph Goebbels lag, sondern bei Hermann Göring als dem Oberbefehlshaber der Luftwaffe, ${ }^{11}$ so gilt es für die Gegenwart nüchtern festzuhalten, dass das Militär in vielen Ländern über einen eigenen großen Medienapparat verfügt, über den es sich an „sein Volk“ richtet. So kontrollierte beispielsweise das griechische Militär das öffentliche nationale griechische TV-System von 1951 bis 1982,12 und nach dem Rund-

11 Vgl. Reiss (1979) und Zeutschner (1995).

12 Vgl. Zacharopoulos/Parasxou (1993). Spannend am griechischen Beispiel ist die Tatsache, dass der Kontrollwechsel Militär/Zivil im nationalen Fernsehen Griechenlands nicht parallel zum politischen Wechsel Faschismus/Demokratie verlief, also nicht nach dem Ende der griechischen Militärjunta 1974 stattfand, sondern eben erst acht Jahre später. Als spannend gilt es außerdem festzuhalten, dass Griechenland sein staatliches Militärfernse- 
funkgesetz von 1955 kontrolliert in Thailand das Verteidigungsministerium (Armee, Marine, Luftwaffe) 223 der insgesamt 524 Radiosender, also 42,55\%. In Birma gibt es neben dem (konservativen) staatlichen TV-Kanal MRTV mit Myawady Television seit 1995 eine eigene (moderne) TV-Station der Militärs, ${ }^{13}$ und in der VR China steht mit Liu Chang Le von der Phoenix Satellite Television Holdings Ltd. (ein chinesischer Fernsehkonzern in Hong Kong, an dem auch der Medienkonzern von Rupert Murdoch beteiligt ist) ein ehemaliger Oberst der chinesischen Volksbefreiungsarmee und RadioKriegskorrespondent als Vorstandsvorsitzender an der Spitze eines Fernsehsenders, dessen Publikum in die Billionen geht und der zu den weltweit größten Fernsehsendern zählen dürfte.

Die Militarisierung der gegenwärtigen Informationsgesellschaft lässt sich selbstverständlich noch an weiteren Indikatoren festmachen, von denen hier nur zwei weitere wenigstens kurz erwähnt werden sollen.

Zum einen gilt es hier, auf den steigenden Einfluss von PRAgenturen bei der medialen Vermarktung von Kriegen im Auftrag von Regierungen aufmerksam zu machen. So konnten beispielsweise Mira Beham und Jörg Becker den Nachweis dafür erbringen, dass in den verschiedenen jugoslawischen Kriegen von 1991 bis 2002 USamerikanische PR-Agenturen in 157 Verträgen mit den verschiedenen Regierungen auf dem Balkan (Kroatien, Bosnien-Herzegowina, Slowenien, Montenegro, Serbien, Mazedonien, die Serbische Republik Krajina, der jugoslawische Premierminister Milan Panić, die Republik Srpska, die Bundesrepublik Jugoslawien und die Republik Kosova) das innenpolitische Bild der jugoslawischen Kriege in den USA und damit gleichzeitig das weltöffentliche Bild dieser Kriege im

hen auch noch nach seinem Beitritt zur EU am 1. Jänner 1981 ein ganzes Jahr lang beibehalten konnte und durfte. Der Kontrollwechsel 1982 geschah dann auf Veranlassung der sozialistischen PASOK-Partei. Formal-juristisch war dieser Wechsel von 1982 der vom militärischen zum zivilen Sektor, da die früheren militärischen TV-Sender ET1, NET und ET3 nun zusammengefasst als TV-Kanal ERT 2 einer staatlich-zivilen Aufsicht unterstellt wurden. Inhaltlich war es aber ein Wechsel vom militärischen zum kommerziellen Sektor (allerdings in seiner weichen Variante einer Gemischtfinanzierung von öffentlichen Gebühren plus privatwirtschaftlichen Werbeeinnahmen). Es ist genau dieser Sprung vom militärischen in den Sektor der Kommerzialisierung, der sich nach dem Ende des Ost-WestKonflikts auch in einigen Fernsehsystemen der Entwicklungsländer vollzog und der selbstverständlich unabhängig davon ist, ob die formal-juristische Kontrolle nach dem Wechsel staatlicher, öffentlich-rechtlicher, kommunaler oder regionaler Natur ist.

13 Vgl. U Kyi Win (2001), 326 f. 
Interesse des jeweiligen staatlichen Auftraggebers für ein Auftragsvolumen von insgesamt wenigstens zwölf Millionen US-Dollar mal so oder so präsentierten, eben: „,comme tu veux“ ${ }^{14}$

Zum anderen gilt es, auf die enormen Personalkapazitäten für Medienarbeit in Verteidigungsministerien aufmerksam zu machen. So gibt es beispielsweise im deutschen Bundesministerium der Verteidigung und in der deutschen Bundeswehr rund 2.000 hauptamtliche Vollzeitstellen für Medienarbeit im weitesten Sinne. Dazu rechnen im Ministerium selbst die vielen Hundert Mitarbeiter für Öffentlichkeitsarbeit genauso wie die in der Bundeswehr tätigen Mitarbeiter für eigene Medienprodukte und die Mitarbeiter des Bataillon für Operative Information in Mayen in der Eifel. Würde man diesen rund 2.000 öffentlich bezahlten Medienarbeitern in Sachen Verteidigung und Krieg öffentlich bezahlte Friedensjournalisten gegenüber stellen wollen, um eben auf eine staatlich gewollte Ungleichgewichtung aufmerksam zu machen, so wäre ein solches Verhältnis eben das von $2.000 \mathrm{zu}$ 0, da es ja keine Friedensjournalisten gibt. Ersatzweise sei hier der Vergleich mit Friedensforschern vorgenommen. Den rund 2.000 öffentlich bezahlten und hauptamtlichen Vollzeitstellen in Sachen Verteidigung und Krieg stehen in Deutschland rund 60 (geschätzte) öffentlich bezahlte und hauptamtliche Vollzeitstellen in der Friedensforschung gegenüber. Das heißt: Auf einen öffentlichen Friedensforscher kommen in Deutschland 35 öffentliche PR-Spezialisten für Verteidigungs-, Kriegs- und Aufrüstungsfragen.

\section{Die Kontrollgesellschaft: IT und Kontrolle von oben und außen}

Angesichts einer anvisierten dreifachen technologischen Konvergenz von Informationstechnologien, Telekommunikation und Television $^{15}$ greift Gilles Deleuzes Konzept von der Kontrollgesellschaft sowohl in militärischer als auch in ziviler Hinsicht auf doppelte Weise. Kontrolle von oben und von außen geschieht hierbei eher mittels IT-Technologien - Kontrolle von unten und von innen heraus geschieht eher mit massenmedialer Television.

Informationskontrolle durch Militärs und Nachrichtendienste ist zwar alles andere als ein neuartiges Phänomen, doch erlauben ge- 
genwärtige IT-Technologien eine ungeheuerliche Qualitätssteigerung gerade in diesem Bereich. Paradigmatisch dafür steht das Projekt ECHELON vom Ende der 90er-Jahre des 20. Jahrhunderts. Hierbei handelte es sich um ein Überwachungs- und Kontrollsystem für das routinemäßige und weltweite Abhören von Fax-, Telex-, E-Mailund Telefonverkehr durch die US-amerikanischen Geheimdienste. Bei dem Projekt ECHELON arbeiteten die USA mit den Polizeiund Streitkräften anderer Länder zusammen. Das nach dem 11. September 2001 von der DAPRA (Defense Advanced Research Projects Agency) - der Forschungsagentur des Pentagon - in Auftrag gegebene Projekt „Total Information Awareness“ (TIA) soll sehr viel leistungsstärker als ECHELON werden. Mit diesem neuen weltweiten Abhörsystem sollen alle verfügbaren Informationen nach Hinweisen auf terroristische Umtriebe und Verbindungen durchsucht werden. ${ }^{16}$ Nur am Rande sei hier auf eine spannende These von Geheimdienstexperten verwiesen. Sie selber seien es gewesen, die sich Kommunikation über ein Medium wie Internet richtig gewünscht hätten. Denn Internet sei die Systemantwort darauf, dass in der Grundlagenforschung von Spracherkennung mit keinerlei Fortschritt zu rechnen sei. ${ }^{17} \mathrm{Da}$ demgegenüber Texterkennung sehr einfach sei, sei Internet das ideale Medium für Kontrollsysteme wie ECHELON oder TIA.

Infolge der terroristischen Anschläge vom 11. September 2001 und bei proklamiertem Vorrang nationaler Sicherheitsinteressen vor Menschenrechten wurden und werden alle informationellen Rechte in vielen westlichen Industrieländern erheblich eingeschränkt, greifen zusätzliche staatliche Kontroll- und Repressionsmaßnahmen im gesamten Informationssektor. Freimut Duve, bis vor Kurzem OSZE-Beauftragter für die Freiheit der Medien, kommentierte diese Situation mit folgenden Worten: „Kurz nach dem 11. September war es vorbei mit dem Rechtsstaat in den Vereinigten Staaten und Europa“. ${ }^{18}$ Dazu einige Beispiele:

16 Vgl. Tuschl (2004), $112 \mathrm{ff}$.

17 Notabene: Auch und gerade retrospektiv erweist sich Technikdeterminismus oft genug als empirischer Schwindel. So prognostizierte 1956 ein renommierter US-Wissenschaftler, dass es schon 1961 die ersten funktions- und marktfähigen Übersetzungscomputer geben würde. Vgl. Locke (1956).

18 Zitiert nach Ramonet (2001), 6. 
- Zusätzlich zu den neu vom US-amerikanischen Kongress erlaubten Rechten beim Abhören von Telefongesprächen und dem Mitlesen von E-Mails ist es US-Behörden seit Mitte November 2001 erlaubt, Gespräche zwischen Mandanten und Verteidigern ohne richterliche Genehmigung abzuhören, wenn es begründeten Verdacht dafür gibt, dass man Gewalt oder Terror verhindern kann.

- Neue anti-terroristische Gesetze in den USA erlauben den USStrafverfolgungsbehörden sogar dann den Zugriff auf ausländische Computer-Hacker, wenn diese einen Computer außerhalb der USA attackieren. Die einzige rechtliche Bedingung, die für die Behörden in den USA vorliegen muss, ist die, dass ein Teil der strafbaren Handlung in den USA passiert ist. Dazu reicht es aus, dass das Daten-Routing beim Datentransfer über die USA gelaufen ist. Genau das trifft aber auf mehr als $80 \%$ der gesamten weltweiten Computerkommunikation zu. (Diese neuen Computergesetze stehen in einer langen und unheilvollen USamerikanischen Tradition von nationalen Gesetzen mit extraterritorialer Reichweite.)

- In Großbritannien wurde nach dem 11. September 2001 eine Datenbank geschaffen, die sämtliche Telefon- und Internetkommunikation aller Bürger speichert. Gegen erhebliche Bedenken britischer Datenschützer haben inzwischen fast alle Ermittlungsbehörden einen nahezu uneingeschränkten Zugriff auf die Kommunikationsspuren von Verdächtigen, nicht nur von terroristischen Verdächtigen.

- Seit dem „Patriot Act“ vom Herbst 2001 verlangen die USA von allen Flugpassagieren deren persönliche Reisedaten. Vor dem Hintergrund, dass die US-Fluglinie JetBlue Airways Personendaten von rund 5 Millionen ihrer Flugpassagiere sogar an das Pentagon weitergegeben hat, stimmte die Europäische Kommission in Brüssel diesem US-amerikanischen Verlangen zu, während sich das EU-Parlament (in seiner konstitutionellen Irrelevanz), gespielt empört, dagegen aussprach.

- $\quad$ Seit Anfang 2005 plant (ausgerechnet) das deutsche Justizministerium die verfassungswidrige dreijährige Speicherung aller Verbindungsdaten sämtlicher Telefon-, Fax-, SMS-, Internetund E-Mail-Daten zur Terrorismusbekämpfung. 
Was sich seit dem 11. September 2001 als informationelle Repression durch den Staat zeigt, ist aber nur ein Katalysator von solchen Tendenzen, die es auch ohne dieses Ereignis gibt. Auch dazu einige Beispiele:

- Videokameras überwachen in den nördlichen Industrieländern in stark anwachsendem Ausmaß immer mehr öffentliche Plätze und Räume. Ende der 90er-Jahre des 20. Jahrhunderts dürfte Großbritannien führend in der Videoüberwachung von Städten gewesen sein; bereits 500 Kommunen verfügten über eine flächendeckende Straßenüberwachung. ${ }^{19}$

- Erst vor wenigen Jahren begannen in Deutschland mehrere Firmen mit dem Fotografieren sämtlicher Häuser in ausgesuchten Kommunen und der Speicherung aller Aufnahmen in dreidimensionalen elektronischen Datenbanken.

- Das in Deutschland eingeführte satellitengestützte Mautsystem auf Autobahnen wird nicht nur bei LKWs, sondern auch bei PKWs zu einem System totaler Mobilitätskontrolle führen.

- Hochauflösende Kameras an Bord von Überwachungssatelliten erreichen inzwischen ein Auflösungsvermögen von $1 \mathrm{~m} \mathrm{zu} 1 \mathrm{~m}$, d.h., die im Weltraum positionierte Kamera kann einen Punkt auf der Erde dann erkennen, wenn er vom nächsten Punkt nur einen Meter entfernt ist. Der nachbarliche Garten kann aus dem Weltraum genauso beobachtet werden wie politische Demonstrationen, Verkehrsstaus oder ein Mann-gegen-Mann-Gefecht in der Wüste in einem nächsten Golfkrieg. Der Einsatz von hochauflösenden Kameras an Bord von Überwachungssatelliten erfuhr seine drastische Zunahme nach einem Erlass des USamerikanischen Präsidenten, der 1994 das Satelliten-Privileg des US-Militärs aufhob. Inzwischen gibt es vier privatwirtschaftlich arbeitende Satellitenbetreiber, die Firmen Space Imaging, Earthwatch und Orbimage in den USA und Spot Image in Frankreich, die an jeden zahlungsfähigen Kunden Bilder von jedem wünschbaren Punkt der Erde liefern können. Schon bald werden vermutlich zwanzig solcher Firmen arbeiten; der Einzelumsatz pro Firma wird von einigen Experten auf jährlich drei Milliarden Euro prognostiziert. Die Freigabe dieser Technologien an kommerzielle Kräfte kann aber nur dann Sinn machen, wenn

19 Vgl. ausführlich zur Videoüberwachung K.u.u.g.e.l. (2003). 
man dem militärischen Sektor unterstellt, dass seine eigenen hochauflösenden Kameras an Bord von militärischen Satelliten noch weitaus präziser arbeiten: Die Kameras an Bord der USamerikanischen Militärsatelliten $\mathrm{KH}$ oder Big Bird sollen mit einer Auflösung von etwa zehn Zentimetern arbeiten können, sollen gar die Nase im Gesicht eines jeden Individuums erkennen können. Eine mehr als seltsame Volte in der Privatisierungspolitik der Raumfahrtindustrie schlug freilich die USamerikanische Regierung im Afghanistankrieg im Herbst 2001. Kurz vor Kriegsbeginn bereute man auf einmal die 1994 eingeleitete Privatisierungspolitik, und das Pentagon sicherte sich mit einem Betrag von zwei Millionen US-Dollar monatlich und auf unbegrenzte Zeit alle Rechte an den Bildern, die der weltbeste kommerzielle Ikonos-Satellit der Firma Space Imaging aufnimmt, sozusagen ein exklusives und ewiges Bildmonopol vorbei an allen Marktgesetzen und an allen Vorstellungen über Medienpluralismus.

\section{Die Kontrollgesellschaft: Television und Kontrolle von unten und innen}

Kontrolle durch IT-Technologien und vor allem durch Television findet jenseits der Frage der Herrschaft durch Regierung oder Privatwirtschaft vor allem im Alltag der Menschen statt. In den Industrieländern heißt Sozialisation zu Anfang des 21. Jahrhunderts vor allem Mediensozialisation. Als Sozialisationsagenturen tragen Massenmedien ganz wesentlich dazu bei, dass die Gesellschaftsmitglieder in ihren gesellschaftlichen Lernprozessen vielfältige soziale Normen und Rollenerwartungen erfüllen können. Integration ist ein von Sozialisation kaum zu trennender Begriff. Massenmedien sind die wichtigsten Agenturen für eine Integration von gesellschaftlicher Kommunikation. Dieser Aspekt gilt vor allem auch für viele junge Nationalstaaten, die ihre Unabhängigkeit erst seit den 60er-Jahren des 20. Jahrhunderts erlangten.

Sozialkontrolle durch Television erweist sich als vielfältig bedenklich. Zum einen fördert eine Sozialisationsverschiebung von primären zu sekundären, d.h. medialen Erfahrungen eine Zunahme von Entfremdung, zum anderen erweisen sich die inhaltlichen Medienangebote als ethisch fragwürdig und dysfunktional für demokratische Öffentlichkeiten. So arbeitete schon in den 70er-Jahren des 
20. Jahrhunderts Luis Ramiro Beltrán, der „Vater“ der lateinamerikanischen Kommunikationsforschung, heraus, dass die folgenden zwölf Elemente die Basisnormen im TV-Angebot der meisten Länder seien: Individualismus, Elitismus, Rassismus, Materialismus, Abenteuertum, Konservatismus, Konformismus, Defätismus, Schicksalsgläubigkeit, Autoritätsfixierung, Romantizismus und Aggressivität. ${ }^{20}$ Die große Zunahme von TV-Kanälen durch Kabelund Satelliten-TV seit Anfang der 80er-Jahre des 20. Jahrhunderts hat außerdem zu einer Verstärkung gerade dieser zwölf basalen Medienangebote geführt, nicht zu einer Pluralisierung von Meinungen. Es gehört zu einer ernüchternden Erfahrung, dass die Vermehrung der TV-Kanäle nicht zu einer inhaltlichen Bereicherung, wohl aber zu einer Vervielfältigung des Immergleichen geführt hat. Welche gesellschaftliche Funktion Television erfüllt, hat Noam Chomsky mit dem Titel seines Filmes und Buches Die Konsensfabrik oder dem Begriff „,consent without consent“, den er von dem englischen Soziologen Anthony übernimmt, sprachlich griffig und zutreffend erfasst. $^{21}$

Informationskontrolle ist definitorisch gerade dort besonders schwierig festzumachen, wo sie scheinbar mit Zustimmung der Kontrollierten stattfindet. Aber genau hier greift die Idee der Kontrollgesellschaft von Gilles Deleuze: Die Kontrollierten fühlen sich in der Kontrolle wohl, sie mögen und internalisieren sie. Im Bereich der Television kann man diese verinnerlichte Kontrolle gut an der in den Niederlanden 1999 gestarteten Serie Big Brother klarmachen. Bei dieser Serie registrieren 24 Kameras 24 Stunden am Tag das Leben von „Freiwilligen“ in einer geschlossenen Wohnung. In regelmäßigen Abständen zwingt das zuschauende TV-Publikum per telefonischer Abstimmung und Internet einen der mitspielenden Kandidaten zum Auszug aus der Wohnung, zum Beenden des Spiels. Kontrollieren die TV-Zuschauer das Spiel? Was ist der Unterschied zwischen Spielern und Zuschauern? Wer von beiden ist zynischer?

Erwies sich bis in die 80er-Jahre des 20. Jahrhunderts eine Sozialkontrolle durch Massenmedien als Resultat, Auswirkung und Funktion gewollten politischen Handelns durch Staat und Regierung,

20 Vgl. Beltrán/Fox de Cardona (1980).

21 Vgl. Chomsky $(1996,2002)$. Freilich muss hier auch festgehalten werden, dass Chomskys sprachliche Formeln weitaus besser sind als seine grob-marxistische und doch recht mechanistische Theorie politischer Kommunikationsprozesse. 
so bereitete die Deregulierung der Massenmedien unter dem Vorzeichen des Neoliberalismus diesem Charakteristikum ein Ende. Die Politik der Deregulierung war und ist eine Selbstenthauptung der Politik und eine Übergabe der Massenmedien an die Kontrolle ausschließlich des Marktes.

\section{Entgrenzte Information}

Der Vorstellung von einer räumlich und zeitlich entgrenzten Kommunikation wohnt keinerlei humanitäres Potential inne, vielmehr äußern sich in einer solchen Vision die „soften“ Herrschafts- und Aneignungswünsche einer Kontrollgesellschaft. Setzte die alte Disziplinargesellschaft auf den brachialen Krieg, so baut die neue Kontrollgesellschaft auf die weiche Information. Der Vorstellung von einer Entgrenzung des Informationsfaktors liegen Machbarkeitswahn und Allmachtswünsche zugrunde und die Transformation von humaner Kommunikation in verdinglichte Information. Wo „eine die ganze Welt umfassende Brüderlichkeit“ sich nur über einen Markt von verkaufbaren Informationen realisiert (eventuell auch nur über das Medium Markt realisiert werden kann), da ist bereits die Vision von Brüderlichkeit nur noch Ideologie. Nach Karl Marx wird jener Zustand als Entfremdung bezeichnet, ,in dem die eigene Tat des Menschen ihm zu einer fremden, gegenüberstehenden Macht wird, die ihn unterjocht, statt dass er sie beherrscht". ${ }^{22}$ Es sind aber genau diese Entfernungen von sich selbst, die aus den gegenwärtigen Ungleichheiten und Unverfrorenheiten des globalisierten Informationsmarktes ${ }^{23}$ erwachsen.

Gerade die sozialwissenschaftlichen und politischen Debatten um die gesellschaftliche Relevanz von Kultur und Medien der letzten Dekaden haben den Gedanken einer „soften“ - aber eben doch einer - Herrschaft für Politikstrategien verdeutlicht. Zeichnete sich die alte Disziplinargesellschaft durch Exklusion aus und konnte sich in ihr und gegen sie gerade im Bereich von Kultur und Medien Widerstand gegen zentrale Herrschaftsinstitutionen herausbilden - wobei freilich gerade alle Widerstands- und Alternativkultur permanent Gefahr lief, in die allgemeine Systemherrschaft integriert und pazifiert

22 Marx (1971), 361.

23 Vgl. die folgenden Werke aus der jüngeren Zeit: Ramonet (1999), Leidinger (2003), Pilger (2004), Thomas/Nain (2004) und Becker (2005). 
$\mathrm{zu}$ werden (und genau das ist die nach wie vor zentrale und zutreffende Aussage von Johannes Agnoli in seinem „Klassiker“ Die Transformation der Demokratie ${ }^{24}$ ) -, so inkludiert die gegenwärtige Kontrollgesellschaft Kultur und Medien ganz ohne Widerstand und sie tut es eben „soft“. Paradigmatisch (freilich affirmativ) bestätigte diese theoretischen Erkenntnisse Richard Kühnel, Mitglied des Kabinetts der österreichischen EU-Kommissarin Benita Ferrero-Waldner für Außenbeziehungen und Europäische Nachbarschaftspolitik, in seinem Vortrag „Kultur als Komponente der Außenpolitik von Europa?“ auf der Konferenz „kultur.macht.europa“ im Juni 2007 in Berlin.

Nicht nur finden sich in diesem Vortrag typisch inklusive Begriffe wie „Vermischung“, „Einheit in Vielfalt", „gemeinsame Werte und Vorstellungen“, „Partnerschaft", „gemeinsames Erbe“, „,kulturelle Verbindungen“, „Dialog“ usw. in inflationärem Ausmaß (und demonstrieren sprachlich damit nicht mehr und nicht weniger als die herrschende Inklusionsideologie), sondern vielmehr argumentiert dessen Autor (pseudo)gesellschaftstheoretisch. Er postuliert nämlich: „Mittels der Kultur-Schiene wollen wir nachhaltig und wirksam unsere europäischen Werte und Interessen transportieren. [...] Wir verfolgen dabei einen sanften, aber nachhaltigen Weg der Überzeugung. Damit sei nicht gesagt, dass die EU nicht auch an der Stärkung ihrer ,hard power' weiterarbeiten soll, aber wir sollen unsere ,soft power ${ }^{\varsigma}$ nicht gering schätzen. ,Soft' heisst nicht schwach, und die ,power' ist nicht geringer - im Gegenteil." "25

Die Bestrebungen, Kommunikation in eine Handelsware umzuwandeln, ${ }^{26}$ sei es bei den GATS-Verhandlungen, sei es beim Wettbewerbkommissariat der EU-Kommission, sind der letzte folgerichtige Schritt einer ökonomischen Entwicklung, die sich unter den gegebenen politischen Vorraussetzungen qualitativ nicht aufhalten lassen wird. Und die dagegen anlaufenden Bemühungen liberaler Intellektueller, den Kulturbegriff aus der Umklammerung und Erstickung durch die Ökonomie als autonome Größe noch retten zu wollen, sei es gegenwärtig bei der Arbeit an einer „UNESCO-Konvention zum Schutz der Vielfalt kultureller Inhalte und künstlerischer Ausdrucksformen“ oder in Diskussionen über die ,[k]ulturelle Freiheit in unse-

24 Vgl. Agnoli/Brückner (1968).

25 Kühnel (2007), 1-2.

26 Vgl. (als älteren Titel) Chakravarthi (1990) und (als jüngeren Titel) Smiers (2003). 
rer Welt der Vielfalt“ im jüngsten „Human Development-Report 2004“ sind zum Scheitern verurteilt. Bestenfalls handelt es sich bei diesen Bemühungen um subjektiv gut gemeinte Initiativen - realistischerweise jedoch um Sonntagsrhetorik und damit um Ideologieproduktion.

Im globalen Neoliberalismus produziert der Informationsmarkt eine Unheilsstatistik nach der anderen, und zwangsläufig und systembedingt werden die Informationsreichen immer reicher und die Informationsarmen immer ärmer. Und solche Systemzwänge können nicht einfach voluntaristisch aufgehoben werden, schon gar nicht durch die seit Langem strukturell deformierte sogenannte Entwicklungshilfe. Der Informationsmarkt - das Goldene Kalb der sogenannten Wissensgesellschaft - ist zu einer Art göttlicher Schicksalsinstanz geworden, die darüber urteilt, ob Du ein gottgefälliges Leben führst. Bist Du an diesem Markt erfolgreich, so verfügst Du über Informationen in Hülle und Fülle - bist Du es nicht, verstößt er Dich in die finsterste Hölle der Informationslosigkeit, in die Peripherie, den Rand, die Minderheit.

Die hier vorgetragene Analyse steht zwar quer zur gegenwärtig dominierenden technikdeterministischen Euphorie all derjenigen, die im Internet ein Potenzial zur weltweiten Realisierung einer interaktiven Kommunikationsdemokratie sehen, kann sich historisch aber auf durchaus bemerkenswerte Vorläufer berufen. Alle wichtigen Wissenschaftler des damals noch jungen Faches Kommunikationswissenschaft, sei es Karl Bücher, Otto Groth, Walter Lippmann oder Max Weber, einte die gut begründete Sorge, die ökonomische Eigennutzorientierung der Medien könne deren publizistische Öffentlichkeitsorientierung zerstören.

\section{Gedanken zu einer Medienkultur des Friedens}

Was bleibt nach einem solchen „Kahlschlag“? Was folgt aus einer derartigen Analyse? Welche Handlungsmöglichkeiten gibt es? Dazu einige abschließende Bemerkungen.

Erstens: Wohlweislich wurde zwischen den Begriffen „Kommunikation“ und „Information“ unterschieden. ${ }^{27}$ Aus vielerlei Gründen, die hier nicht en detail entfaltet werden können, entzieht 
sich Kommunikation einer totalen Verformung in marktfähige Ware. Während gegenwärtig Information endgültig zu einer stapel- und marktfähigen Ware verwandelt wird, bleibt Kommunikation von diesem Transformationsprozess zum Teil ausgenommen. Menschen kommunizieren auch außerhalb des Marktes. Sie können sich deswegen nach wie vor verweigern oder Widerstand leisten. Sie können sich aus guten Gründen den „von oben“ verordneten Medien- und Politikmustern entziehen (und genau das tun sie in Westeuropa seit Langem) oder sie können sich aktiv in den Widerstand begeben (und genau das tun sie auch - im Süden mehr als im Norden).

Zweitens: Wo sich die Friedensforschung in einem falschen, d.h. ideologischen Praxisverständnis von ihrer ursprünglich kritischen Herkunft entfernt hat, wo sie also nicht mehr Innovator, Stachel, Kritiker und unbequemer „Rufer in der Wüste“ ist, sondern sich stattdessen unter der Hand und schleichend in eine etatistische Verwaltungswissenschaft zur Herrschaftsstabilisierung verwandelt hat, da bleibt auch deren Forderung nach einer veränderten Medienkultur des Friedens äußerlich.

In genau diesem Zusammenhang sind die acht Forderungen an eine veränderte Medienkultur des Friedens zu sehen, wie ich sie in einem Gutachten an die Deutsche Gesellschaft für Technische Zusammenarbeit (GTZ) ${ }^{28} 2002$ präsentiert habe:

- vermehrte Veröffentlichung solcher Informationen, die eine friedliche Konfliktlösung ermöglichen,

- Abbau den Gegner verteufelnder Vorurteile,

- Sensibilisierung für versteckte Fehlwahrnehmungen gerade bei kontroversen Themen,

- Neu-Definition der Massenmedien als einer Art von sozialem Frühwarnsystem für potenzielle Gefahrenherde,

- Einbezug des Gegners in friedliche Konfliktlösungsvorschläge,

- verstärkte und positive Berichterstattung über Friedensmacher,

- Herstellung eines öffentlichen Klimas im Geiste der Versöhnung,

- Schaffung von Dialog und Kommunikationsmöglichkeiten für die Friedensmacher der gegnerischen Seite.

28 Vgl. Becker (2002b). Meine Kritik an der GTZ habe ich in der gekürzten englischsprachigen Version dieser Studie präzisiert, vgl. Becker (2004), 2, Fußnote 1. 
Solche Forderungen sind nicht falsch. Realisieren lassen sie sich freilich nur dann, wenn sie in solche Medienpolitikstrategien eingebunden werden, die die Medien von ihrer gegenwärtigen privatwirtschaftlichen Verfasstheit in öffentliche Güter zurückverwandeln. Unterbleibt das jedoch, dann gleichen solche Forderungen dem berühmten „Glasperlenspiel“ und man kann sich dann auch etatistischaffirmative Beratungen für eine staatliche Institution wie die GTZ ersparen, so wie ich es nach meinen Erfahrungen mit diesem Gutachten bei der GTZ inzwischen praktiziere. Freilich läuft die Zustimmung zu einer Globalisierung, Privatisierung und totalen Entgrenzung medialer Informationsströme auf das Paradoxon hinaus, dass Massenmedien sowohl Spielball als auch heimlicher Komplize von Terrorismus und PR-manipulierter und bezahlter Kriegsberichterstattung sind und bleiben werden.

Und genau deswegen habe ich diesem Vortrag den Titel „Die Informationsrevolution frisst ihre eigenen Kinder" gegeben. Ich benutze die Wörter „frisst ihre eigenen Kinder" in Paraphrase an Wolfgang Leonhards „Klassiker“ Die Revolution entlässt ibre Kinder (1955) und meine mit „Kinder“ das von Informationsstrategien angestrebte Ziel, also „Aufklärung“. Alle vier (von Informatikern gerne so bezeichneten) kognitiven Revolutionen der Menschheit (Sprache, Schrift, Druck, Computer) waren zwar immer mit dem Versprechen angetreten, dem Menschen nun endlich mehr und bessere Informationen anbieten zu können, aber - je länger, je mehr - konnten sie diesem Anspruch immer weniger gerecht werden. Informationsverschmutzung und nicht etwa Aufklärung wurde zum Normalzustand in der sogenannten Informationsgesellschaft der Gegenwart.

Drittens: Angesichts des kläglichen Versagenmüssens der Mainstream-Medien bei einer Schaffung von Friedenskultur kommt von deren Protagonisten der Ruf nach Alternativmedien wie ein inhaltsleeres Kompensationsritual der eigenen gesellschaftlichen Ohnmacht nur allzu schnell daher. Dieser Ruf übersieht, dass Alternativmedien längst die soziale Funktion Schumpeter'scher Innovationszyklen in einem System stabilisierenden sozialen Diffusionsprozesses à la Everett Rogers erfüllen und sich im Laufe der Zeit überflüssig machen ${ }^{29}$ und außerdem den etablierten Medien gegenüber in ihren Verarbeitungs- und Wahrnehmungsmustern von Krieg, Frieden und interna- 
tionalen Beziehungen eher ähnlich als different sind. ${ }^{30}$ Der Ruf nach Alternativmedien ist nicht falsch und empirisch lässt sich inzwischen sogar gut demonstrieren, dass im Kosovo-Krieg das Internet ein qualitativ hochwertiges und wertvolles Gegenmedium im Vergleich zur Süddeutschen Zeitung und zur New York Times war, ${ }^{31}$ doch wäre dialogisch und kontinuierlich und nur im Kontext sozialer Bewegungen nach solchen alternativen Medienstrategien zu suchen, die sich subversiv einer schleichenden Transformation in Kontrolle und Herrschaft am ehesten verweigern.

Viertens: Dass Kommunikation verbinde und dass die zunehmende Kenntnis des einen über den anderen mittels medialer Botschaften dem Frieden dienlich sei - diese beiden Hypothesen gehören zu den oft völlig unbefragten Annahmen im disziplinären Selbstverständnis sowohl der Kommunikationswissenschaft als auch der Friedensforschung. Längst gibt es empirische Arbeiten, die den Verdacht stärken, dass mediale Kontakte zwischen bis dahin nicht miteinander in Kontakt stehenden Akteuren Vorurteile über den Anderen nicht abbauen, sondern im Gegenteil diese sogar verhärten und verstetigen. ${ }^{32}$ Längst auch, so vermute ich, sind die gesellschaftlichen Bedingungen der Globalisierung derart, dass ein Zuviel an internationalen Informationsflüssen eher kriegsfördernd als kriegsmindernd wirkt. Im Interesse einer Kultur des Friedens brauchen wir nicht mehr, sondern im Gegenteil wahrscheinlich weniger Informationen.

\section{Literatur}

Agnoli, Johannes/Brückner, Peter (1968): Die Transformation der Demokratie. Frankfurt/M.: Europa Verlag.

Bartosch, Andreas (1998): „Das Grünbuch über Konvergenz. Ein Beitrag auf dem Weg in die Informationsgesellschaft", in: Zeitschrift für Urheberund Medienrecht 3, 209-220.

Beck, Ulrich (1999): „Der militärische Euro. Humanismus und europäische Identität", in: Süddeutsche Zeitung, 1. April, 17.

Becker, Jörg (2002a): Information und Gesellschaft. Wien: Springer.

30 Vgl. Becker et al. (2004).

31 Vgl. Krempl (2004).

32 Zunächst einmal sei hier auf einen „klassischen“ frühen Forschungsbericht aus dem Bereich der Vorurteilsforschung verwiesen, vgl. Sola Pool (1965). Ferner sei auf folgende Arbeiten hingewiesen: Popitz (1968), Moore/Tumin (1949), Schneider (1962) und Dörner (1989), 144 ff. 
Becker, Jörg (2002b): Der Beitrag der Medien zur Krisenprävention und Konfliketbearbeitung. Eine Analyse der internationalen Diskussion und Implementierungsmöglichkeiten mit Empfehlungen für die Technische Zusammenarbeit. Arbeitspapier 1/2002 des Sektorberatungsvorhabens Krisenprävention und Konfliktbearbeitung, Deutsche Gesellschaft für Technische Zusammenarbeit.

Becker, Jörg (2004): „Contributions by the Media to Crisis Prevention and Conflict Settlement“, in: Conflict \& Communication Online 3 (1-2), online unter: http://www.cco.regener-online.de/2004/pdf_2004/becker.pdf (Zugriff am 6.12.2007).

Becker, Jörg (2005): Communication and Conflict. Studies in International Relations. New Delhi: Concept Publishers.

Becker, Jörg/Beham, Mira (2006): Operation Balkan. Werbung für Krieg und Tod. Baden-Baden: Nomos.

Becker, Jörg/Carfora, Angelika/Flatz, Christian/Hartlieb, Martin/Lanzinger, Armin/Oberhofer, Thomas/Preglau-Hämmerle, Susanne (2004): „Das Bild des Auslandes und des Fremden in der Alternativpresse“, in: Evangelische Akademie Iserlohn im Institut für Kirche und Gesellschaft, Hg.: Für eine Kultur der Differenzen. Friedens- und Dritte-Welt-Zeitschriften auf dem Prüfstand. Iserlohn: Institut für Kirche und Gesellschaft, 9-76.

Beltrán, Luis Ramiro/Fox de Cardona, Elizabeth (1980): Communicación Dominada. México: ILET-Nueva Imagen.

Bücher, Karl (1906): Das Zeitungswesen. Leipzig: Teubner.

Chakravarthi, Raghavan (1990): Recolonization. GATT, the Uruguay Round and the Third World. London: Zed Books.

Chomsky, Noam (1996): Wege zur intellektuellen Selbstverteidigung: Medien, Demokratie und die Fabrikation von Konsens. München: Marino-Verlag.

Chomsky, Noam (2002): Profit over People. Neoliberalismus und globale Weltordnung. Hamburg-Wien: Europa Verlag.

Deleuze, Gilles (1993): Unterhandlungen: 1972-1990. Frankfurt/M.: Suhrkamp.

Dörner, Dietrich (1989): Die Logik des Misslingens. Reinbek/H.: Rowohlt.

EBU (1978): 37th Meeting of the Television Programme Committee. London: European Broadcasting Union.

Fischbach, Rainer (1998): „Konvergenz - schwacher Begriff, starke Absicht. Eine Herausforderung demokratischer Medien- und Telekommunikationspolitik", in: Blätter für deutsche und internationale Politik 12, 14791488.

Foucault, Michel (1976): Überwachen und Strafen. Die Geburt des Gefängnisses. Frankfurt/M.: Suhrkamp.

Hacker, Friedrich (1975): Terror. Mythos, Realität, Analyse. Reinbek/H.: Rowohlt. 
Habermas, Jürgen (1962): Strukturwandel der Öffentlichkeit. Neuwied: Luchterhand.

Holzer, Anton, Hg. (2003): Mit der Kamera bewaffnet. Krieg und Fotografie. Marburg: Jonas.

Knieper, Thomas/Müller, Marion G., Hg. (2005): War Visions. Bildkommunikeation und Krieg. Köln: Halem.

Kühnel, Richard (2007): Kultur als Komponente der Außenpolitik von Europa?, Vortrag auf der Konferenz „,kultur.macht.europa.“ der Kulturpolitischen Gesellschaft, 7.-8. Juni, Berlin. Unveröffentlichtes Manuskript.

Krempl, Stefan (2004): Krieg und Internet. Ausweg aus der Propaganda? Hannover: Heise.

K.u.u.g.e.l., Hg. (2003): Bildverbot. Wien: Triton Verlag.

Leidinger, Christiane (2003): Medien - Herrschaft - Globalisierung. Folgenabschätzung zu Medieninhalten im Zuge transnationaler Konzentrationsprozesse. Münster: Westfälisches Dampfboot.

Locke, William N. (1956): „Translation by Machine“, in: Scientific American 1, 29-33.

Marx, Karl (1971): Die Frühschriften. Stuttgart: Kröner.

Moore, Wilbert E./Tumin, Melvin M. (1949): „Some Social Functions of Ignorance“, in: American Sociological Review 14, 787-795.

Oy, Gottfried (2001): Die Gemeinschaft der Lüge. Medien- und Öffentlichkeitskritik sozialer Bewegungen in der Bundesrepublik. Münster: Westfälisches Dampfboot.

Paul, Gerhard (2004): Bilder des Krieges - Krieg der Bilder. Paderborn: Schöningh.

Pilger, John (2004): Verdeckte Ziele. Über den modernen Imperialismus. Frankfurt/M.: Zweitausendeins.

Pinder, Wilhelm (1926): Das Problem der Generation in der Kunstgeschichte Europas. Berlin: Frankfurter Verlagsanstalt.

Popitz, Heinrich (1968): Über die Präventivwirkung des Nichtwissens. Tübingen: Mohr.

Ramonet, Ignacio (1999): Die Kommunikationsfalle. Macht und Mythen der Medien. Zürich: Rotpunkt-Verlag.

Ramonet, Ignacio (2001): „Aus einer neuen Welt“, in: Le Monde Diplomatique (dt. Ausgabe), Dezember, 1 und 6.

Reiss, Erwin (1979): Wir senden Frohsinn. Fernsehen unterm Faschismus. Berlin: Elefanten-Press.

Said, Edward W. (1997): Covering Islam: How the Media and the Experts Determine How We See the Rest of the World. New York: Pantheon.

Schneider, L. (1962): „The Role of the Category of Ignorance in Sociological Theory", in: American Sociological Review 27, 492-508.

Shaheen, Jack G. (2001): Reel Bad Arabs. How Hollywood Vilifies a People. New York: Olive Branch Press. 
Smiers, Joost (2003): Arts under Pressure. Promoting Cultural Diversity in the Age of Globalization. London: Zed Books.

Sola Pool, Ithiel de (1965): „Effects of Cross-National Contact on National and International Images", in: Kelman, Herbert C., Hg.: International Behavior. A Social-Psychological Analysis. New York: Holt, Rinehart and Winston, 106-129.

Thomas, Pradip N./Nain, Zaharom, Hg. (2004): Who Owns the Media? Global Trends and Local Resistances. Penang: Southbound.

Trinquier, Roger (1961) : La Guerre moderne. Paris: La Table Ronde.

Tuschl, Ronald H. (2004): Der Informationskrieg der Nachmoderne. Vom Antagonismus der Weltordnung zum permanenten Krieg im kybernetischen Raum. Münster: Agenda-Verlag.

U Kyi Win (2001): „Massenmedien in Birma. Ein Bericht über die aktuelle Situation", in: Internationales Asienforum 32 (3-4), 319-336.

Zacharopoulos, Thymios/Parasxou, Minas (1993): Mass Media in Greece. Westport/CT: Praeger Publishers.

Zeutschner, Heiko (1995): Die braune Mattscheibe - Fernsehen im Nationalsozialismus. Berlin: Rotbuch-Verlag. 
Die Ethik der Technologie im Zeitalter der drohenden
Apokalypse

Jean-Pierre Dupuy*

„Raffiniert ist der Herrgott, aber boshaft ist er nicht." 1
Ein Teil von jener Kraft, die stets das Gute will, und stets das Böse schafft. ${ }^{2}$

\section{Mephisto revisited}

Mit bemerkenswerter Voraussicht schrieb Hannah Arendt in ihrem 1958 erschienen Buch Vita Activa:

„Es zeigt sich nämlich, daß die, Wahrheiten' des modernen wissenschaftlichen Weltbilds, die mathematisch beweisbar sind und technisch demonstrierbar sind, sich auf keine Weise mehr sprachlich oder gedanklich darstellen lassen. [...] Es könnte immerhin sein, daß es für erdgebundene Wesen, die handeln, als seien sie im Weltall beheimatet, auf immer unmöglich ist, die Dinge, die sie solcherweise tun, auch zu verstehen, d.h. denkend über sie zu sprechen. Sollte sich das bewahrheiten, so würde es heißen, daß unsere Gehirnstruktur, d.h. die physisch-materielle Bedingung menschlichen Denkens, uns hindert, die Dinge, die wir tun, gedanklich nachzuvollziehen -

* Jean-Pierre Dupuy ist Professor für soziale und politische Philosophie an der École Polytechnique in Paris und Professor für französische Literatur, Kultur und Sprache an der Stanford University. Er ist außerdem Forschungsrektor am C.N.R.S. (Centre National de la Recherche Scientific) und Leiter der von ihm 1992 gegründeten philosophischen Arbeitsgruppe C.R.E.A. (Centre de Recherche en Épistemologie Appliquée) an der École Polytechnique sowie Forscher am C.S.L.I. (Center of Languages and Information) der Stanford University. Dupuy ist darüber hinaus assoziierter Professor am Institut für Politikwissenschaften der Stanford University. Dem Originaltext (Übersetzung ins Deutsche für diesen Band durch Kristina Stöckl) liegt seine Schwager-Vorlesung vom 25. November 2005 zugrunde, er ist auch unter dem Titel „The Ethics of Technology before the Apocalypse“ als Nr. 4 der Innsbrucker Diskussionspapiere zu Weltordnung, Religion und Gewalt erschienen.

1 Albert Einstein (1921). Zitiert nach Calaprice (2004), 141.

2 Mephisto revisited, frei nach Goethes Faust. Vgl. Goethe (1998), 47. 
woraus in der Tat folgen würde, daß uns gar nichts anderes übrig bleibt, als nun auch Maschinen zu ersinnen, die uns das Denken und Sprechen abnehmen. Sollte sich herausstellen, daß Erkennen und Denken nichts mehr miteinander zu tun haben, daß wir erheblich mehr erkennen und daher auch herstellen können, als wir denkend zu verstehen vermögen, so würden wir uns selbst gleichsam in die Falle gegangen sein, bzw. die Sklaven - zwar nicht, wie man gemeinhin glaubt, unserer Maschinen, aber - unseres eigenen Erkenntnisvermögens geworden sein, von allem Geist und allen guten Geistern verlassene Kreaturen, die sich hilflos jedem Apparat ausgeliefert sehen, den sie überhaupt herstellen können, ganz gleich wie verrückt oder wie mörderisch er sich auswirken möge. “3

Der Ausdruck „,von allem Geist und allen guten Geistern verlassene Kreaturen“, gepaart mit dem Begriff eines „mörderischen“ Apparats, lässt es dem Leser kalt über den Rücken laufen. Wie wir wissen, wurde Arendt drei Jahre später Zeugin des Eichmann-Prozesses in Jerusalem und konnte zur Erklärung von Eichmanns Verantwortung für seine schrecklichen Taten lediglich diesen einen Wesenszug ausmachen: „Gedankenlosigkeit“.

In Anbetracht unserer, wie er es nannte, „Blindheit gegenüber der Apokalypse“ verwies auch Hannah Arendts erster Ehemann, Günther Anders, in seinem herausragenden Buch Hiroshima ist überall (1982) auf die ähnlich gelagerte Diskrepanz zwischen herstellen und vorstellen: unser Vermögen, Dinge herzustellen, zu erzeugen, geht weit über unsere Fähigkeit hinaus, uns dabei gegenwärtig zu halten, was wir eigentlich tun. Arendts Begriff der Gedankenlosigkeit entspricht der von Anders in seiner Analyse aufgezeigten völlig unzulänglichen Vorstellungskraft des modernen Menschen angesichts der Konsequenzen seiner technischen Erfindungen. Im Gefolge von so monströsen Verbrechen wie Auschwitz oder Hiroshima-Nagasaki werden Verbrecher ohne Böswilligkeit und Opfer ohne Hass in Zukunft die normalen Begleiterscheinungen von Unheil und Katastrophenereignissen sein. „Die Technik hat es mit sich gebracht, dass wir auf eine Weise schuldlos schuldig werden können, die es früher, in der technisch noch nicht so vorgeschrittenen Zeit unserer Väter, noch nicht gegeben hatte", 4 schreibt Anders. 
Diese Überlegungen möchte ich nunmehr bei der Betrachtung zweier für unsere Welt bestimmender Ereignisse zum Tragen kommen lassen: 1. der Entscheidung für die Nutzung der Atombombe; 2. des Wandels der Rolle des Wissenschaftlers im Zuge der sogenannten „NBIK-Konvergenz“, des Ineinandergreifens von Nanotechnologie, Biotechnologie, Informationstechnologie und Kognitionswissenschaften. Im ersten Fall geht es um Technologien des Todes, im zweiten um Technologien des Lebens. Das erstaunlichste Merkmal unserer Zeit liegt darin, dass dieser Unterschied keinen Unterschied macht.

Berühmt ist die Antwort des Mephisto auf Fausts Frage, wer er denn sei:

„Nun gut, wer bist du denn? - Ein Teil von jener Kraft,

die stets das Böse will, und stets das Gute schafft."

Diese Definition des Teufels muss aktualisiert werden. Es sollte heißen:

Ein Teil von jener Kraft,

die stets das Gute will, und stets das Böse schafft.

Wenn die Technologien des Lebens genauso gefährlich und mörderisch geworden sind wie die Technologien des Todes, so bringt dies etwas Wesentliches in Hinblick auf die Autonomie der Technik gegenüber den Absichten und dem Willen jener zum Ausdruck, die sie erfinden, hervorbringen und verwenden. Beenden werde ich meinen Aufsatz daher mit einigen Überlegungen zu dieser tragischen Enteignung des modernen Menschen in Anlehnung an Nietzsches Ausspruch vom Willen zur Macht, der ein und dasselbe ist wie der Wille zum Willen.

\section{Aus der Ferne töten}

Im Jahr 1932 schrieb Günther Anders eine Geschichte mit dem Titel Der Blick vom Turm. Hier der Text:

„Als Frau Glü von dem höchsten Aussichtsturme aus in die Tiefe hinabblickte, da tauchte unten auf der Straße, einem winzigen Spielzeug gleich, aber an der Farbe seines Mantels unzweideutig erkennbar, ihr Sohn auf; und in der nächsten Sekunde war dieses Spielzeug von einem gleichfalls spielzeugartigen Lastwagen überfah-

5 Goethe (1998), 47 (Hervorhebung J.P.D.). 
ren und ausgelöscht - aber das Ganze war doch nur eben die Sache eines unwirklich kurzen Augenblickes gewesen, und was da stattgefunden hatte, das hatte doch nur zwischen Spielzeugen stattgefunden.

,Ich geh nicht hinunter!' schrie sie, sich dagegen sträubend, die Stufen hinabgeleitet zu werden, ,ich geh nicht hinunter! Unten wäre ich verzweifelt!" “6

13 Jahre später, am Morgen des 6. August 1945, gab der Pilot Claude Eatherley der Besatzung der Enola Gay das Signal zum Abwurf der Atombombe über der japanischen Stadt Hiroshima. Aus der sicheren Entfernung von zehn Kilometern Höhe sah Hiroshima wie eine Spielzeugstadt aus. Ins Heimatland zurückgekehrt, wurden Eatherley und seine Crew als Helden gefeiert. Eatherley jedoch begann sich für das, was er getan hatte, zutiefst schuldig zu fühlen. Die kognitive Dissonanz zwischen seiner Verzweiflung an sich selbst und der heldenhaften Wahrnehmung seiner Person durch andere wurde unerträglich. Eatherley wollte für sich „das Recht auf Strafe“ in Anspruch nehmen. Er beging eine Reihe von Schein-Überfällen und wurde letztendlich für ,geisteskrank“ erklärt. Anders begann einen Briefwechsel mit Eatherley, bestrebt, ihm klar zu machen, dass sein Verhalten zwar in hohem Maß normal und verantwortungsvoll war, das Ausmaß des Geschehens die Verantwortlichkeit einer einzelnen Person jedoch bei Weitem überstieg. ${ }^{7}$ Anders schrieb sogar an Präsident Kennedy und protestierte dagegen, Eatherleys Anliegen als einen Fall von Wahnsinn abzutun. Er schrieb:

„,Glücklich die Zeit, in der Irrsinnige so reden, unselig die Zeit, in der nur Irrsinnige so reden. ' [...] Nein, Eatherley ist eben nicht der Zwilling von Eichmann, sondern dessen großer und tröstlicher Antipode. Nicht der Mann, der die Maschinerie als Vorwand für Gewissenlosigkeit ausgibt, sondern umgekehrt der Mann, der die Maschinerie als die furchtbare Bedrohung des Gewissens durchschaut."

Der kategorische Fehler lag für Anders darin, dass Nuklearwaffen als strategisches Instrument, als Mittel zum Zweck, betrachtet

6 Anders (1988), 7.

7 Der Briefwechsel erschien auf Deutsch unter dem Titel Off Limits für das Gewissen: Der Briefwechsel zwischen dem Hiroshima-Piloten Claude Eatherley und Günther Anders, 1959-1961siehe Anders/Eatherley (1961) - und wurde 1982 in Hiroshima ist überall erneut abgedruckt - siehe Anders (1982).

8 Anders (1982), 326-327 (Brief an Präsident John F. Kennedy vom 13. Januar 1961). 
werden. Ein Mittel verbindet sich nämlich mit seinem Zweck, es wird von ihm aufgenommen. Die Atombombe ist dafür aber ,absolut zu groß“. Die konkreten, potenziellen und virtuellen Auswirkungen der Atombombe, die bis zur Auslöschung der Menschheit selbst reichen, stehen in keinem Verhältnis zu irgendeinem Zweck oder Ziel, das der Mensch sich zu setzen vermag. „Dasjenige, was uns begrenఇt (das heißt: dasjenige, wogegen wir hilflos bleiben), ist die Unbegrenztheit der Effekte unseres Tuns. Omnipotenz ist unser fatalster Defekt", schrieb Anders 1987. Es ist das schier unübersehbare Ausmaß solcher Folgen, die uns ihnen gegenüber blind werden lassen. Wir sind einfach unfähig, uns emotional und intellektuell zu einer derartig immensen Ungeheuerlichkeit in Bezug zu setzen. Wenn uns gesagt wird, dass unser Staat im Fall des Falles bereit wäre, zwanzig Millionen Kinder in einem anderen Land umzubringen, so rührt uns das nicht. Mit Anders könnte man sagen, dass uns die schiere Unermesslichkeit und Abstraktion der Vorstellung von solchen möglichen Folgen in „emotionale Analphabeten“ verwandelt.

Der Name der B29, an Bord derer an jenem schicksalhaften Morgen des 6. August ein Team von Wissenschaftlern die Folgen der Atombombe beobachtete und auswertete, lautete Necessary Evil. Es handelt sich hier um Details und Feinheiten, wie man sie sich selbst mit viel Phantasie nur schwerlich ausmalen könnte: Der Beitrag der Wissenschaft zum Massaker wurde unter das ehrenvolle Aushängeschild der Ethik und Moralphilosophie gestellt. - Eine Täuschung, eine Travestie.

Tatsache ist, dass bis heute neunzig Prozent der amerikanischen Bevölkerung der Meinung sind, dass die atomare Bombardierung von Hiroshima und Nagasaki der notwendige Preis dafür war, dass eine halbe Million oder mehr amerikanische Soldaten gerettet werden konnten, und, nicht zu vergessen, auch all jene Japaner, die bei der geplanten Invasion von Kyushu am 1. November und von Honshu im darauffolgenden Jahr ums Leben gekommen wären. Um diese vielen Menschenleben zu schonen, war es (mit Sicherheit nicht zum ersten Mal in der Geschichte) gerechtfertigt, die Grundprinzipien der gerechten Kriegsführung außer Acht zu lassen.

Ungünstig für diese Legende ist hingegen, dass die meisten ernsthaften Historiker heutzutage die Ansicht vertreten, dass es, um

9 Anders (1987), 139 (Hervorhebung im Original). 
die Worte eines, der wahrlich nicht als „Revisionist“ bezeichnet werden kann, zu zitieren, „durchaus wahrscheinlich, wenn auch nicht zur Gänze gesichert erscheint, dass eine kombinierte Strategie aus Garantien für die Monarchie, Abwarten des Einmarschs der Sowjets und Beibehaltung der Belagerung das Ende des Krieges noch rechtzeitig vor der Novemberinvasion herbeigeführt hätte. " ${ }^{10}$ Zurückhaltend formuliert könnte man sagen, dass Truman die Mittel zur Beendigung des Kriegs in keiner Weise ausgeschöpft hatte, ehe es zum Abwurf der Atombomben auf Japan kam. Barton Bernstein behauptet sogar, dass die einzige Option, die nicht gesondert geprüft und diskutiert wurde, die Verwendung nuklearer Waffen war - eben weil sie als selbstverständlich galt. Es stellt sich also heraus, dass die wichtigste und epochalste Entscheidung der Neuzeit gar keine richtige Entscheidung war. Anders hatte recht: die Bombe ist kein Mittel zum Zweck, das Essenzielle an der Atombombe ist ihre Existenz, nicht ihre Verwendung.

Die Doktrin der nuklearen Abschreckung, bekannt als $M A D$ (Mutually Assured Destruction, übersetzt als „wechselseitig zugesicherte Zerstörung“ oder „Gleichgewicht des Schreckens“), bringt diese Erkenntnis auf das Vollkommenste zum Ausdruck. Im Januar 2000 bemühte sich der amerikanische Präsident Clinton, seinen russischen Amtskollegen Putin davon zu überzeugen, dass das von den USA geplante Raketen-Abwehr-System Russland nicht davon abhalten würde, die amerikanische Gesellschaft notfalls vernichtend anzugreifen. Das Raketen-Abwehr-System, so Clinton, wäre effektiv in der Abwehr von Boden-Boden-Raketen, die von Schurkenstaaten ausgingen, nicht aber ausreichend zum Schutz vor russischen (oder gar chinesischen) Raketen. Mit anderen Worten, die Doktrin des Gleichgewichts des Schreckens verlangt die Unterlassung militärischer Selbstverteidigung: Die Politik der Abschreckung sieht keine Verteidigung des nationalen Territoriums vor. Im Gegenteil, es ist Teil der Doktrin, dass eine jede Seite die jeweilige Bevölkerung dem Risiko von Angriffen aussetzt und ernsthafte Bemühungen zu deren Verteidigung unterlässt. Sicherheit kann nur immer so groß sein wie der Schrecken. Würde man die Ausmaße des Schreckens verringern indem man, z.B., für einen Großteil der Bevölkerung Atombunker bereitstellt -, so würde damit auch das Ausmaß der Sicherheit ver- 
ringert, denn die gut geschützte Seite könnte in Versuchung geraten, im Vertrauen auf die eigenen „Gewinnchancen“ einen Holocaust zu entfesseln. Das Gleichgewicht des Schreckens verlangt auf eine perverse Art und Weise danach, dass Zerstörung ,gesichert" sein muss, gerade so, als sei unser Ziel nicht die Erhaltung, sondern die Auslöschung der Menschheit.

All diese Merkmale von $M A D$ widersprechen so grundlegend der sehr viel einfacheren, vertrauteren und unserem Empfinden näherstehenden Logik des traditionellen militärischen Denkens - vom Instinkt und gesunden Menschenverstand ganz zu schweigen -, dass die Doktrin der Abschreckung in der Tat während ihrer Wirkungszeit immer wieder von traditionellen militärischen Zielsetzungen in Frage gestellt wurde. Die hart errungenen Nutzen der Politik der Abschreckung waren oftmals bedroht vom Wiederaufleben des alten Wunsches nach Sieg, nach nationaler Verteidigung im herkömmlichen Sinn und nach militärischer Überlegenheit. ${ }^{11}$

Für lange Zeit ging das strategische Denken von einer bestimmten Absicht aus: der Absicht, die ganze Welt in eine apokalyptische Vernichtung zu reißen, sollte der Gegner sich auch nur einen Schritt vorwagen. Es gibt eine Reihe von Unstimmigkeiten in dieser Theorie, ganz abgesehen von ihrer offensichtlichen Immoralität: Ist denn die Bereitschaft, sechzig Millionen unschuldige Menschen zu töten, nicht erschreckend nahe an der Möglichkeit, es tatsächlich zu tun? Doch eines der größten Probleme der Doktrin der Abschreckung hat mit der Frage zu tun, wie glaubwürdig die Bedrohung ist. Jonathan Schell schreibt hierzu:

„Da laut der atomaren Abschreckungstheorie der ganze Zweck der Vergeltungskapazität darin liegt, einen Erstschlag abzuschrecken, müssen wir uns fragen, was es denn noch für einen Sinn hätte, den Vergeltungsschlag zu führen, nachdem der Erstschlag tatsächlich erfolgt wäre. [...] Mithin wird die Logik der Abschreckungsstrategie durch eben das Ereignis - den Erstschlag - aufgehoben, dem sie vorbeugen soll. Sobald die Kriegshandlungen beginnen, ist die ganze Doktrin keinen Schuss Pulver mehr wert. Grundsätzlich beruht die Doktrin auf einem schlimmen logischen Fehler: Man kann einen Erstschlag nicht glaubhaft mit der Androhung eines Vergeltungs- 
schlags abschrecken, dessen raison d'être in dem Augenblick entfällt, da der Erstschlag geführt wird." ${ }^{2}$

Die Lösung wurde in der Begrifflichkeit gefunden: existenzielle Abschreckung. Die Absicht oder die Drohung eines Vergeltungsschlags, der apokalyptische Dimensionen erreicht, ist das Problem? Dann muss diese Absicht beseitigt werden. Zwei namhafte Philosophen haben das so beschrieben: „Die Existenz von nuklearem Rückschlagpotenzial ist zur Abschreckung ausreichend, unabhängig von Bereitschaft, Absicht oder Aussagen einer Nation zur Verwendung von Nuklearwaffen“13; oder: „Was zählt, sind unsere militärischen Kapazitäten, nicht unsere Absichten, Beweggründe oder Deklarationen."14 Abschreckung ist deshalb existenziell, weil die schiere Existenz der Waffen schon abschreckt. Abschreckung ist ein unabdingbares Merkmal von Waffen, denn „die Gefahr einer unendlichen Eskalation ist unvermeidbar." Bernard Brodie beschrieb dies 1973 folgendermaßen:

„Es ist ein bemerkenswertes Paradoxon unserer Zeit, dass einer der Hauptfaktoren für das Funktionieren, genauer für das gute Funktionieren, von Abschreckung eigentlich jene verborgene Angst ist, dass sie im Fall einer ernsthaften Konfrontation versagen könnte. Unter diesen Umständen fordert man sein Schicksal nicht heraus. Wenn wir uns absolut sicher wären, dass nukleare Abschreckung gegen eine nukleare Bedrohung hundertprozentig effektiv ist, dann würde sie wenig bis gar keinen abschreckenden Wert im Fall von nicht-nuklearen Auseinandersetzungen haben." 15

Die Vernunft, die hier am Werk ist, ist nicht etwa Berechnung, sondern eher eine Art von schlichter Vernünftigkeit, bei der der Betroffene über den Abgrund nachsinnt und einfach beschließt, nicht zu nah an ihn heranzutreten. „Man spielt nicht mit dem Feuer - so einfach ist das" ${ }^{16}$ meint David Lewis dazu. Es ist die Wahrscheinlichkeit eines Fehlers, die die Doktrin der Abschreckung so effektiv macht. Aber ein Fehler, ein Unfall oder ein Irrtum, wird hier nicht strategisch verstanden. Es geht nicht darum, dass eine Nation, die unvernünftigerweise inakzeptable Risiken eingeht, einen Krieg ein- 
dämmen und ihren Gegner in Schach halten kann. Eine solche Sichtweise - bekannt als "die Vernunft der Unvernunft“ - wurde 1960 von Thomas Schelling in seinem Buch Strategies of Conflict populär gemacht. Hier hingegen lautet der Schlüsselbegriff „Schicksal“. Der Fehler ist der Zukunft eingeschrieben. Das heißt, es handelt sich hier nicht einfach um die Auseinandersetzung zweier Gegner, sondern um die Konfrontation eines Akteurs, der Menschheit, deren Überleben auf dem Spiel steht, mit ihrem Doppelgänger, nämlich mit der der Menschheit eigenen Gewalt, nach außen projiziert als "Schicksal". Das Feuer, mit dem wir lieber nicht spielen sollten, ist nichts anderes als das Böse in uns, das wir nicht als solches erkennen: als ob wir von einer zunehmend gefährlichen Macht bedroht würden, die außerhalb von uns ist und die keine bösen Absichten gegen uns hegt, doch deren Zerstörungskraft unvergleichlich größer ist als alle Erdbeben oder Tsunamis dieser Welt zusammen.

Martin Heidegger hat bekanntlich gesagt, dass nur ein Gott uns retten könne. Im nuklearen Zeitalter ist dieser (falsche) Gott die externalisierte menschliche Gewalt, deren Auswirkung - der nukleare Holocaust - unserer Zukunft sowohl als Unfall wie auch als Bestimmung auferlegt ist. Günther Anders war davon überzeugt, dass der 6. August 1945 den Anfang der Endzeit in der Geschichte der Menschheit darstellte. ${ }^{17}$ Selbst wenn es uns gelingen sollte, das tragische Ende immer wieder hinauszuzögern, würde sein monströser Schatten auf die Gegenwart fallen und unser Leben in ein Leben auf Zeit verwandeln: „Die Möglichkeit unserer endgültigen Vernichtung ist, auch wenn diese niemals eintritt, die endgültige Vernichtung unserer Möglichkeiten", 18 schreibt Anders als Motto zu Die Atomare Drohung. Unser Leben ist dazu verurteilt, nicht mehr als ein Aufschub zu sein - eine Frist. Wir haben für immer unsere Unschuld verloren. Nicht einmal eine vollständige Abrüstung könnte uns retten: Wir würden dann zwar keine Waffen mehr haben, aber wir würden nach wie vor über das Know-how zu ihrer Herstellung verfügen, und im Fall eines neuen Wettrüstens würde ein jeder versuchen, als Erster im Besitz neuer Atomwaffen zu sein, um den Erstschlag zu führen. Anders zieht folgenden Schluss: Wir sind „die Herren der 
Apokalypse" geworden, wir sind allmächtig, doch ist diese Allmacht eine negative und ununterscheidbar von völliger Ohnmacht. ${ }^{19}$

\section{Aus dem Nichts Leben erzeugen}

„Aus dem Nichts Leben erzeugen“: Es gibt nur wenige „Nanobiotechnologen“, die die Ehrlichkeit oder Kühnheit besitzen zuzugeben, dass dies ihr wahres Ziel ist. ${ }^{20}$ Doch unabhängig davon, ob eine solche Agenda offen ausgesprochen wird oder verborgen bleibt, es steht außer Zweifel, dass genau eine solche Metaphysik die Nanobiotechnologie vorantreibt. Die Vertreter der „NBIK-Konvergenz“ geben vor, der Natur und dem Leben die Arbeit abzunehmen und Ingenieure der Evolution zu werden. Die Evolution war bisher wenig mehr als ein „Herumpfuschen“, sie kann in Sackgassen führen und unerwünschte Ergebnisse hervorbringen. Es ist daher durchaus erstrebenswert für den Menschen, die Rolle, die bisher die Evolution gespielt hat, selbst in die Hand zu nehmen und zum Designer von biologischen und natürlichen Prozessen zu werden. Der Mensch kann an der Erzeugung von Leben teilhaben.

Naturwissenschaftler und Ingenieure, die sich dieser Agenda verschreiben, sind die Erben einer berühmten Mutmaßung, die John von Neumann in seinem klassisch gewordenen Vortrag am California Institute of Technology im Jahr 1948 zum Ausdruck brachte. In dem Vortrag „Die generelle und logische Theorie von Automaten“ stellte Neumann folgende Überlegungen zu Komplexität und sich selbst reproduzierenden Automaten an: ${ }^{21}$

$\mathrm{Zu}$ jener Zeit waren die Thesen von Church und Turing 22 sehr einflussreich, und sie waren durch die Forschung der Kybernetiker Warren McCulloch und Walter Pitts zu den Eigenschaften von neuralen Netzen noch ergänzt worden. Das Credo der Kybernetiker lautete, dass jedes Verhalten, das auf eindeutige Art und Weise in einer endlichen Zahl von Wörtern beschrieben werden kann, von einem Netzwerk formaler Neuronen berechnet werden kann. - Eine er-

19 Anders (2002).

20 Rasmussen et al. (2004).

21 Neumann (1961), 288-326.

22 Dabei handelt es sich um die nach Alonzo Church und Alan Turing benannten Thesen zur Kapazität von Rechenmaschinen, die die Grundlagen für die moderne Informationsund Computertechnologie legten (Anmerkung der Übersetzerin). 
staunliche Aussage, gestand von Neumann ein, machte allerdings folgenden Einwand: Kann man praktisch denn wirklich davon ausgehen, dass komplexes Verhalten in seiner Gesamtheit ohne Widersprüche und unter Verwendung einer endlichen Anzahl von Wörtern beschrieben werden kann? In Einzelfällen durchaus: Unsere Fähigkeit, ein und dieselbe dreieckige Form bei zwei in Linie, Größe und Position unterschiedlichen Dreiecken zu erkennen, kann z.B. so beschrieben werden. Aber wäre es auch möglich, unsere generelle Fähigkeit zum Erstellen „visueller Analogien“ auf diese Art und Weise zu beschreiben? In dem Fall, mutmaßte von Neumann, kann ein Verhalten am besten dadurch beschrieben werden, indem man die Struktur, die es hervorbringt, beschreibt. Unter diesen Umständen ist es bedeutungslos zu „entdecken“, dass ein bestimmtes Verhalten in neuralen Netzen repräsentiert werden kann, kann Verhalten doch nicht anders als durch die Beschreibung des Netzwerks definiert werden.

Mit anderen Worten, von Neumann stellte die Frage nach der Komplexität, vorausahnend, dass dies in Zukunft die große Frage für die Wissenschaft werden würde. Komplexität brachte in diesem Fall mit sich, dass die konstruktive Herangehensweise von McCulloch und Pitts, die Funktion auf Struktur reduzierte, überflüssig war - denn dabei blieb die Frage unberücksichtigt, wozu komplexe Strukturen fähig sind.

Im Zuge seiner Arbeiten zur Theorie von Automaten präzisierte von Neumann diesen Begriff von Komplexität. Er stellte die These auf, dass der Organisationsgrad einer thermodynamischen Größe unterhalb einer gewissen Schwelle degenerativ, d.h. abnehmend, darüber jedoch ansteigend, d.h. zunehmend komplex, ist. Diese Schwelle wiederum war laut von Neumann der Punkt, an dem die Struktur eines Objekts einfacher wird als die Beschreibung seiner Eigenschaften. Schon bald, prophezeite er, würden die Schöpfer von Automaten ihren Kreationen genauso hilflos gegenüberstehen, wie wir es angesichts komplexer natürlicher Phänomene sind. ${ }^{23}$

John von Neumann legte damit den Grundstein zur sogenannten bottom-up-Herangehensweise, die dem NBIK-Programm zugrunde liegt. Entsprechend dieser Philosophie werden die Techniker der Zukunft nicht mehr Erfinder und Designer von Strukturen sein, die 
bestimmte, ihnen zugeschriebene Funktionen erfüllen. Die Techniker der Zukunft werden wissen, dass sie Fortschritte erzielen, wenn sie von ihren eigenen Schöpfungen überrascht werden. Wenn eines unserer Ziele darin liegt, Leben herzustellen, dann muss es möglich sein, eine seiner wichtigsten Eigenschaften zu simulieren, nämlich die Fähigkeit, von sich aus zunehmend komplex zu werden.

Es wäre ein Fehler anzunehmen, dass unsere gegenwärtige Situation in Hinblick auf die Konsequenzen unserer technologischen Weichenstellungen nicht die Frucht eines langen historischen Prozesses darstellt. Diskontinuitäten und Brüche müssen immer vor dem Hintergrund kontinuierlicher Entwicklungen verstanden werden. Kommen wir daher erneut zu Hannah Arendts meisterhafter Untersuchung über die Brüchigkeit menschlichen Handelns, Vita Activa, zurück. In diesem Werk bringt Arendt das grundlegende Paradox unserer Zeit zum Ausdruck: Mit zunehmendem technischem Fortschritt erweitern sich unsere Möglichkeiten, doch sind wir immer weniger imstande, die Folgen unserer Handlungen zu kontrollieren. Ein langer Auszug aus ihrem Buch ist es wert, an dieser Stelle zitiert zu werden, denn seine Relevanz für unser Thema kann man gar nicht genug betonen - ebenso wenig die Tatsache, dass der Text bereits 1958 entstanden ist:

„Eine ähnliche Verlagerung der Fähigkeiten auf ihnen ursprünglich fremde Gebiete scheint heute erfolgt zu sein, als man im Ernst versuchte, das Handeln aus dem Gebiet der menschlichen Angelegenheiten nach Möglichkeit auszuschalten, und diese Angelegenheiten so zu behandeln, als wären sie den Gesetzen des Herstellens unterstellt und könnten mit der gleichen soliden Planmäßigkeit geregelt werden wie die Objekte der gegenständlichen Welt. Der eigentliche Unterschied zwischen der Neuzeit bis in ihre letzten Stadien und der Zukunft, in der wir bereits zu leben begonnen haben, scheint zu sein, dass der Mensch seine handelnden Fähigkeiten, die darin bestehen, spontane Prozesse loszulassen, die ohne ihn niemals entstanden wären, auf die Natur gerichtet hat, der gegenüber er sich bisher im wesentlichen als ein herstellendes und erkennendes Wesen verhielt, insofern er ihr das Material für die Erstellung seiner Dingwelt entnahm, natürliche Vorgänge beobachtete und ihre Gesetze erforschte. $\mathrm{Daß}$ wir uns heute zur Natur als Handelnde verhalten, daß wir wortwörtlich in sie hineinhandeln, darf man vielleicht mit einer Gelegenheitsbemerkung eines dieser ganz modernen Wissenschaftler und Techniker illustrieren, der in allem Ernst gesagt hat, daß ,Grund- 
lagenforschung darin besteht, zu tun und nicht zu wissen, was man tut" [Wernher von Braun, Dezember 1957]. Im Grunde hat dies in die Natur Hineinhandeln bereits mit dem Experiment angefangen, das ja der Natur Bedingungen vorschreibt und natürliche Abläufe provoziert, weil man sich nicht mehr damit zufrieden geben mochte, lediglich zu beobachten, zu registrieren und zu systematisieren, was immer die Natur von sich aus, in ihrem ,natürlichen' Erscheinen, bereit war, dem Menschen an die Hand zu geben und vor das Auge zu legen. Aus dem Experiment hat sich dann eine immer größere Fertigkeit entwickelt, Elementarprozesse los₹ulassen, die ohne den Menschen latent geblieben und vielleicht niemals virulent geworden wären, bis hieraus schließlich eine regelrechte Kunst entstand, Natur, zu machen', nämlich nicht nur natürliche Prozesse aus ihrer Latenz loszulassen, sondern Prozesse, welche die irdische Natur selbst offenbar unfähig ist zu erzeugen $[\ldots]$.

Die Naturwissenschaft ist heute vornehmlich eine Wissenschaft von Prozessen und in ihren fortgeschrittensten Stadien [...] die Wissenschaft von irreversiblen, nicht umkebrbaren Prozessen, von, processes of no return! Diese eigentümliche Sprache, deren sich die Naturwissenschaften heute allgemein bedienen und die wir bis vor wenigen Jahrhunderten nur als die Sprache der Geisteswissenschaften kannten, zeigt bereits an, daß die menschliche Fäbigkeit, die in dieser neuen Art Forschung sich betätigt, auf keinen Fall nur, theoretischer' Natur sein kann, ganz gleich wie viel Intelligenz dazu gehören mag, sich in ihr zu bewegen. So spricht weder die anschauende Kontemplation noch das registrierende Erkennen noch schließlich ein Verstand, der ,mit Folgen rech-

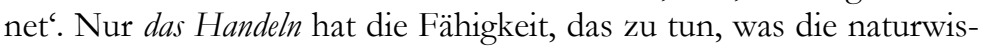
senschaftliche ,Forschung' heute täglich tut, nämlich Vorgänge zu veranlassen, deren Ende ungewiß und unabsehbar ist, Prozesse einzuleiten, die man nicht rückgängig machen kann, Kräfte zu erzeugen, die im Haushalt der Natur nicht vorgesehen sind. Dabei hat sich herausgestellt, daß das Handeln, das ursprünglich auf den Bereich menschlicher Angelegenheiten zugeschnitten ist, seine Eigentümlichkeiten auch dann beibehält, wenn es aus diesem Bereich des Zwischenmenschlichen gleichsam in den Bereich der Natur überspringt. Der Prozeßcharakter des Handelns hat innerhalb der Neuzeit alle anderen dem Handeln zukommenden Eigentümlichkeiten gleichsam aus dem Felde geschlagen, weil nur ihm die ungeheure Erweiterung menschlicher Möglichkeiten und Fähigkeiten zu danken ist; [...] Da zum Wesen dieser Prozesse gebört, daß ibr Resultat unabsebbar ist, spielt in der 
politischen Theorie der Neuzeit nicht so sehr die Brüchigkeit als die Unsicherheit und Ungewißheit menschlicher Angelegenheit die entscheidende Rolle."24

Es besteht kein Zweifel, dass diese Analyse mit bemerkenswerter Voraussicht genau auf die Konvergenz von Nano-, Bio-, Informationstechnologie und Kognitionswissenschaften zutrifft, insbesondere auf zwei Teilaspekte. Erstens, das Bestreben, Natur (neu) zu schaffen, ist eine wichtige Dimension der metaphysischen Fundierung dieses Forschungsfeldes. Zweitens, wie bereits dargestellt, wird es für die Nanotechnologen der Zukunft eine unvermeidbare Versuchung, wenn nicht sogar Aufgabe oder Pflicht, sein, Prozesse in Gang zu setzten, über die sie keine Kontrolle haben.

Für diese Entwicklung bedarf es nicht erst der Drexler'schen self-assemblers ${ }^{25}$ - das Paradigma von komplexen, sich selbst organisierenden Systemen, das von Neumann bereits vorhergesehen hat, breitet sich in raschen Schritten in der Wissenschaft und Technologie aus. Es räumt dabei die alten Metaphern der kybernetischen Ära, welche den Verstand oder das Genom noch als Computerprogramm betrachtet hat, aus dem Weg und ersetzt sie durch neue. So wurde in der Wissenschaft den bislang zentralen Grundsätzen der Molekularbiologie eine Reihe schwerer Schläge versetzt, einmal durch die Entdeckung, dass eine differenzierte Zelle im Genom eines Erwachsenen durch Hinzunahme von mütterlichem Zytoplasma „umprogrammiert" werden kann, sowie durch die Entdeckung von Prionen, die gezeigt hat, dass für Selbst-Reproduktion keine DNA benötigt wird. Im Bereich der Technologie werden jede Woche neue Erfolge bekannt, die deutlich machen, dass wir imstande sind, sich selbst organisierende, komplexe Dinge zu erzengen.

Die Erzählung vom Zauberlehrling muss auf den letzten Stand gebracht werden: Nicht durch einen Fehler oder durch Terror verliert der Mensch die Herrschaft über das, was er geschaffen hat, sondern durch Design.

24 Hannah (1992), 225-227 (Hervorhebung J.P.D.).

25 Der Autor bezieht sich hier auf den amerikanischen Nanotechnologen K. Eric Drexler, der in seinem Buch The Engines of Creation - siehe Drexler (1986) - Systeme beschreibt, die sich ohne Zufuhr von zusätzlicher Energie oder Information als ,self-assemblers“ weiterentwickeln (Anmerkung der Übersetzerin). 


\section{Grenzen setzen}

Die Vorstellung, dass Leben ein Artefakt ist, dass es erzeugt werden kann, hat natürlich weitreichende ethische und epistemologische Implikationen. Interessant ist, zu analysieren, wie die Vertreter der NBIK-Konvergenz den Standpunkt jener wahrnehmen, die sie für ihre „Gegner“, zumindest aber für ihre Kritiker halten. Es sind stets dieselben Ausdrücke, mit denen deren vermeintlicher Standpunkt beschrieben wird: Der Mensch hat nicht das Recht, sich Befugnisse anzumaßen, die alleine Gott vorbehalten sind; Gott zu spielen ist verboten. Oft wird noch hinzugefügt, dass dieses Tabu spezifisch ,jüdisch-christlich" sei. Ein Widerhall dieser Anschuldigung findet sich bei Robert Oppenheimer, der 1956 in einer seiner klarsichtigsten Reflexionen über seine Verantwortung für das Bombardement von Hiroshima und Nagasaki sagte:

„Ich habe einmal gesagt, dass der Physiker [...] auf gewisse Art und Weise Sünde kennt. Ich meinte damit nicht die Tode, die das Resultat unserer Arbeit waren. Ich meinte, dass wir die Sünde des Hochmuts erfahren haben. Wir haben das verwirklicht, was sich in der Geschichte der Menschheit als der Weg der Mehrheit erwiesen hat. Wir waren hochmütig genug zu glauben, dass wir wissen, was gut für den Menschen ist. [...] Das aber gehört nicht zu den natürlichen Aufgaben eines Wissenschaftlers." 26

Der Verweis auf das spezifisch „Jüdisch-Christliche“, fürchte ich, verzerrt jedoch vollkommen die Lehre sowohl des Talmud als auch der christlichen Theologie. Er verwechselt diese nämlich mit dem antiken Begriff des Heiligen: Die eifersüchtigen Götter verfolgen jene Menschen, die des Vergehens der Hybris schuldig geworden sind, durch die Rachegöttin Nemesis. Die Bibel, im Gegenteil, versteht den Menschen als Mit-Schöpfer der Welt. Wie denn auch der Biophysiker und Talmud-Gelehrte Henri Atlan in seiner Analyse der Literatur über den Golem feststellt: „Man findet darin, zumindest in den Anfängen, kein dergleichen negatives Urteil über das Wissen und die kreative Schöpfungskraft des Menschen ,im Ebenbild Gottes' wie in der Faust-Legende. Ganz im Gegenteil, es ist gerade jene kreative Schöpfungskraft, durch die der Mensch seine eigentliche Menschlichkeit erlangt, in Hinblick auf eine imitatio Dei, die es ihm 
erlaubt, im Verlauf einer fortwährenden und verbesserbaren Schöp-

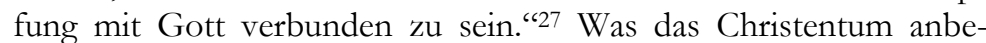
langt, haben es eine ganze Reihe von Autoren, von Max Weber bis Louis Dumont, von Marcel Gauchet bis René Girard, als „die Religion des Endes der Religion“ definiert: Für sie ist das Christentum verantwortlich für die Entsakralisierung der Welt (die berühmte „Entzauberung“) und, dementsprechend, für die fortschreitende Auflösung aller Tabus, Verbote oder Grenzen. Das ist zudem der Grund, warum diese Autoren das Christentum für den Hauptauslöser des wissenschaftlichen und technischen Fortschritts des Westens halten, denn für Wissenschaft und Technik sind gerade Grenzüberschreitungen aller Art unabdingbar.

Es oblag der Wissenschaft selbst, diesen Weg der Desakralisierung der Welt, den die Religionen der Bibel eingeschlagen hatten, zu Ende zu gehen und die Natur all ihrer verordneten und normativen Werte zu berauben. Es ist daher völlig verfehlt, die Wissenschaft in dieser Frage als im Widerspruch zur jüdisch-christlichen Tradition zu bezeichnen. Mit Kant legitimierte sich diese Entwertung der Natur philosophisch, indem sie die Natur als eine Welt ohne Zielsetzungen und Begründungen betrachtete, in der nur Kausalzusammenhänge gelten, und dieser die Welt der Freiheit gegenüberstellte, wo das Handeln durch die Gesetze der Moral bestimmt ist.

Wo liegt hier also das ethische Problem, gibt es überhaupt eins? Es liegt sicher nicht in der Überschreitung irgendwelcher Tabus oder Grenzen, die vom Sakralen vorgegeben sind, denn die wechselseitig bedingte Entwicklung von Religion und Wissenschaft hat das Konzept einer moralischen Grenzziehung und folglich einer Überschreitung nachhaltig entkräftet. Und doch liegt gerade darin das Problem. Denn es kann keine freie und autonome menschliche Gesellschaft geben, die nicht auf einem Prinzip von Selbst-Einschränkung aufbaut, selbst wenn sie der Ansicht ist, dass dieses Prinzip seinen Ursprung in einer wie auch immer gearteten transzendenten Autorität hat. Rousseau und nach ihm Kant haben Autonomie als die Gehorsamkeit gegenüber selbst aufgestellten Gesetzen definiert. Rousseau wollte, dass die Gesetze einer politischen Gemeinschaft dieselbe von außen auferlegte Wirkkraft haben wie die Naturgesetze, ungeachtet der Tatsache, dass die Gesetze einer politischen Gemeinschaft von 
den Menschen selbst aufgestellt werden und sie sich dessen bewusst sind. Doch in einer Gesellschaft, deren Streben darin besteht, Natur nach eigenen Vorstellungen zu verändern und $\mathrm{zu}$ gestalten, verliert der Begriff eines Außen oder einer Alterität jegliche Bedeutung. Dass dabei das Gegebene durch das Gemachte ersetzt wird, ist nur folgerichtiger Bestandteil dieses Prozesses. Aus traditioneller Perspektive liegt die Natur außerhalb der menschlichen Welt mit ihren Sehnsüchten, Konflikten und mannigfachen Unzulänglichkeiten. Wenn aber unser Streben dazu führt, dass Natur zur Gänze das wird, was wir aus ihr machen, dann ist offensichtlich, dass nichts mehr außerhalb bleibt, sondern dass alles in der Welt früher oder später Abbild dessen sein wird, was Menschen tun oder nicht tun, anstreben oder vernachlässigen.

Wie sollen wir Grenzen setzen? Wie werden wir sie begründen, in Anbetracht der Tatsache, dass es keine andere Form von Legitimation geben kann als unser aller Einverständnis? Dies ist die größte Herausforderung unserer Zeit.

Ich kann keine fertige Lösung anbieten. Was ich allerdings mit Sicherheit sagen kann, ist, dass wir immer die Freiheit behalten werden, Grenzen selbst zu setzen. Mit anderen Worten, ich bin gegen jegliche Form von technologischem Determinismus. Nur dann, wenn einige kritische Schwellen überschritten werden, nehmen die Dinge ihren Lauf, als wären wir Marionetten unserer eigenen Schöpfungen. Der Philosoph, der über diese selbst verursachte Entfremdung nachdenkt, muss der Versuchung einer soziologischen Analyse widerstehen. Er bejaht rundweg die Behauptung „Wissenschaft ist nicht neutral“, aber er verleiht diesem Satz eine ganz andere Bedeutung als jene, dass Wissenschaft und Technologie in einen sozialen Kontext eingebettet sind und mit diesem interagieren. Falls Anders recht hat, hätte jeder politische Entscheidungsträger an der Stelle Trumans dieselbe Entscheidung getroffen: die Bombe zu besitzen, hieß, sie auch zu benutzen. Anders war zugegeben ein radikaler Denker, doch selbst ein ausgewogener und moderater Historiker wie Barton Bernstein kommt zu demselben Schluss:

„[Es besteht wenig Grund] zur Annahme, dass die politischen Entscheidungsträger oder die meisten Bürger einer jeden der größeren Kriegsmächte - Großbritanniens, der Sowjetunion, Chinas, Japans oder Deutschlands - versucht hätten, den Abwurf der Bombe auf den Feind und seine Zivilbevölkerung zu vermeiden. Es ist schmerzlich, sich eingestehen zu müssen, dass Amerika vor allem 
deshalb einzigartig war, weil es als einzige Kriegsmacht über die Bombe verfügte und sie auch einsetzte. “ 28

Analog wird es, falls von Neumann recht hat, notwendigerweise einen „sozialen Kontext“" geben, in dem die Entscheidung, ,aus dem Nichts Leben zu erzeugen", erfolgreich sein wird. Unsere höchste Priorität sollte daher meines Erachtens sein, uns selbst zu fragen, ob wir dann noch in der Lage sein werden, genau zu durchdenken, was wir tun. Werden wir nicht unwiederbringlich zu „von allem Geist und allen guten Geistern verlassenen Kreaturen“ geworden sein, so wie es Hannah Arendts größte Sorge war?

\section{Die Neuerschaffung der Welt und das Geheimnis der Liebe}

Nachdem wir in Österreich sind, möchte ich zum Abschluss einem guten Freund von mir Referenz erweisen, dem 2002 verstorbenen Heinz von Foerster, der als jüdischer Immigrant von Wien in die USA auswanderte und dort zum Begründer der Kybernetik zweiter Ordnung wurde, nachdem er als Sekretär bei den Macy-Konferenzen der Geburt der Kybernetik beigewohnt hatte.

Heinz erzählte gerne die folgende wahre Geschichte, welche sich in Wien gegen Ende des Jahres 1945 abgespielt hatte. In der Geschichte geht es um einen anderen Wiener Juden, den Psychiater Viktor Frankl, den gefeierten Autor von Der Mensch auf der Suche nach Sinn. Frankl war soeben aus dem Konzentrationslager AuschwitzBirkenau zurückgekehrt, das er wie durch ein Wunder überlebt hatte, er hatte erfahren, dass seine Frau, seine Eltern, sein Bruder und andere Familienmitglieder alle umgebracht worden waren, und er hatte beschlossen, seine Praxis wieder zu eröffnen.

Dies ist also die Geschichte, wie Heinz sie mir erzählt hat:

Konzentrationslager waren Orte furchtbarer menschlicher Leiden. Man stelle sich nun also das ungläubige Glücksgefühl eines Ehepaars vor, das sich, aus verschiedenen Lagern nach Wien zurückgekehrt, wieder vereint fand. Nur wenige Monate danach aber starb die Frau an einer Krankheit, die sie sich im Lager zugezogen hatte. Der Mann fiel in tiefste Verzweiflung, aus der ihn keiner seiner Freunde herausholen konnte, auch nicht mit dem Hinweis, er möge sich doch vor Augen führen, wie es gewesen wäre, wenn seine Frau 
früher gestorben wäre und sie sich nie wiedergesehen hätten. Schlussendlich konnte er überzeugt werden, Viktor Frankl aufzusuchen, der sich als Helfer für traumatisierte Personen einen Namen gemacht hatte. Sie trafen sich mehrere Male, unterhielten sich lange, und eines Tages fragte Viktor Frankl schließlich: „Nehmen wir an, Gott gäbe mir die Macht, eine Frau wie die Ihre zu erschaffen, sodass Sie keinen Unterschied sehen oder spüren könnten. Ihre äußere Erscheinung, ihr Geschmack, ihr Sprache, ihre Erinnerung, alles wäre wie bei Ihrer Frau. Würden Sie mich bitten eine solche Frau zu erschaffen?" Nach langem Schweigen sagte der Mann: „Nein danke, Herr Doktor!“ Er stand auf, sie schüttelten sich die Hände, der Mann ging nach Hause und begann wieder am Leben teilzunehmen.

Als von Foerster Frankl nach diesem erstaunlichen und einfachen Wandel fragte, erklärte dieser: „Sein ganzes Leben lang hat dieser Mann als Teil der Verbindung dieser beiden Menschen sich selbst mit den Augen seiner Frau gesehen. Als sie starb, war er blind. Als er aber erkannte, dass er blind war, da konnte er sehen! Und so verhält es sich auch mit uns allen: Wir sehen uns selbst mit den Augen des anderen. “29

Das zumindest ist die Lehre, die von Foerster mit Frankl aus dieser Geschichte zog, auf eine typisch kybernetische Art und Weise. Mir scheint aber, dass man noch eine zweite Lehre aus dieser Geschichte ziehen kann, die die erste erweitert. Das Gedankenexperiment, das Frankl seinen Patienten durchspielen ließ, erinnert an einen bekannten griechischen Mythos, jenen von Amphytrion. Um Amphytrions Frau, Alkmene, zu verführen und eine Nacht als ihr Liebhaber mit ihr zu verbringen, nimmt Zeus die Gestalt Amphytrions an. „Die ganze Nacht liebt Alkmene einen Mann, dessen Eigenschaften in jedem Detail identisch sind mit denen ihres Mannes. Ein und dieselbe Beschreibung würde auf beide zutreffen. Alle Gründe, die Alkmene hat, Ampyhtrion zu lieben, sind gleichzeitig Gründe, Zeus zu lieben, der die Gestalt Amphytrions angenommen hat, denn Zeus und Amphytrion können nur numerisch unterschieden werden: sie sind zwei, nicht einer. Und doch ist es Amphytrion, den Alkmene liebt, und nicht der Gott, der seine Gestalt angenommen hat. Wollte man das Gefühl der Liebe durch die Aussagen erklären, die sie rechtfertigen, oder durch die Eigenschaften, die dem Objekt der Liebe

29 Diese Geschichte findet sich abgedruckt in: Förster (1993), 362. 
zugeschrieben werden, welche rationale Erklärung gäbe es dann für dieses „Etwas“, das Amphytrion hat, aber Zeus nicht, und das erklärt, warum Alkmenes Liebe nur ersterem gilt, und nicht letzterem?"30

Wenn man jemanden liebt, dann liebt man keine Liste von Eigenschaften, selbst wenn diese so ausführlich wäre, dass die fragliche Person von jeder anderen Person unterschieden werden könnte. Selbst der perfektesten Simulation fehlt etwas, und es ist dieses „Etwas", das die Essenz von Liebe zum Ausdruck bringt, dieses einfache Wort, das alles sagt und nichts erklärt. Ich habe die große Sorge, dass die spontane Ontologie jener, die am liebsten die Erschaffer oder Neu-Schöpfer der Welt sein möchten, rein gar nichts von den Wesen, die die Welt bewohnen, versteht, sondern sie nur als Listen von Eigenschaften ansieht. Wenn Ethik nur im Geringsten etwas mit Liebe zu tun hat, ist ihre „Supervenienzbasis, um die Sprache der analytischen Philosophie zu bemühen, bei einer solchen Ontologie dazu verurteilt, grundsätzlich unvollständig zu bleiben.

(Aus dem Englischen übersetə̧t von Kristina Stöckl)

\section{Literatur}

Anders, Günther (1982): „Off Limits für das Gewissen“, in: Anders, Günther: Hiroshima ist überall. München: C.H. Beck.

Anders, Günther (1987): Gewalt - ja oder nein. Eine notwendige Diskussion. München: Knaur.

Anders, Günther (31988): Der Blick vom Turm. Fabeln. München: C.H. Beck.

Anders, Günther (61993): Die atomare Drobung. Radikale Überlegungen zum atomaren Zeitalter. München: C.H. Beck.

Anders, Günther (2002): Die Antiquiertheit des Menschen. Band 1: Über die Seele im Zeitalter der zpeiten industriellen Revolution. München: C.H. Beck.

Anders, Günther/Eatherley, Claude (1961): Off Limits für das Gewissen: Der Briefwechsel zwischen dem Hiroshima-Piloten Claude Eatherley und Günther Anders, 1959-1961. Reinbeck/H.: Rowohlt.

Arendt, Hannah (71992): Vita Activa oder vom tätigen Leben. München: Piper.

Atlan, Henri (1999): Les Etincelles de hasard. Tome 1: Connaissance spermatique. Paris: Seuil.

30 Canto-Sperber (2004). 
Bernstein, J. Barton (1995): „Understanding the Atomic Bomb and the Japanese Surrender: Missed Opportunities, Little-Known Near Disasters, and Modern Memory“, in: Diplomatic History 19 (2), 227-273.

Brodie, Bernard (1983): War and Politics. New York: Macmillan.

Calaprice, Alice, Hg. (2004): Einstein sagt. Zitate - Einfälle - Gedanken. München: Piper.

Canto-Sperber, Monique (42004): „Amour“", in: Canto-Sperber, Monique: Dictionnaire d'éthique et de philosophie morale. Paris: Presses Universitaires de France.

Drexler, K. Eric (1986): The Engines of Creation. New York: Anchor Books.

Dupuy, Jean-Pierre (2000): The Mechanization of the Mind. Princeton: Princeton University Press.

Förster, Heinz von (1993): Wissen und Gewissen. Frankfurt/M.: Suhrkamp.

Goethe, Johann Wolfgang von (1998): „Faust. Eine Tragödie“, in: Dramatische Dichtungen I. Band 3. München: Beck, 7-346.

Kavka, Gregory (1987): Moral Paradoxes of Nuclear Deterrence. Cambridge/ UK: Cambridge University Press.

Lewis, David K. (1989): „Finite counterforce“, in: Shue, Henry, Hg.: Nuclear deterrence and moral restraint. Cambridge/UK: Cambridge University Press, 51-114.

Neumann, John von (1961): „The General and Logical Theory of Automata", in: Neumann, John von: Collected Works. Band V. Oxford: Pergamon Press, 288-326.

Rasmussen, Sten/Chen, Liaohai/Deamer, David/Krakauer, David C./Packard, Norman H./Stadler, Peter F./Bedau, Mark A. (2004): „Transitions from Nonliving to Living Matter", in: Science 303, 963-965.

Schell, Jonathan (1982): Das Schicksal der Erde. Gefabr und Folgen eines Atomkriegs. München: Piper. 



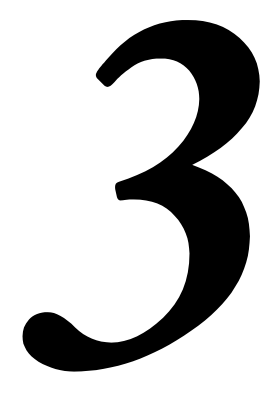



Gewalt und das kulturelle Unbewusste. Eine Archäologie des

Abendmahls

Aleida Assmann*

Dieser Text versteht sich als Beitrag zu einer „Archäologie des Abendmahls". In seiner Intention und methodischen Orientierung folgt er dabei nicht der Ideologiekritik, sondern der kulturellen Gedächtnisforschung. Ideologiekritik richtet sich gegen Ideologien und damit gegen bewusste Inhalte, Programme, Werte; Gedächtnisforschung, wie sie hier betrieben werden soll, zielt demgegenüber auf unbewusste Inhalte, verdrängte Erfahrungen, vergessene Schichten der Traditionen. Während sich Ideologiekritik stets mit deutlicher Selbstgerechtigkeit und Hoheit gegen den anderen und das Andere richtet, versteht sich die kulturelle Gedächtnisforschung gerade auch als eine Form der bewusst machenden Erinnerung, als eine selbstaufklärende und im weiteren Sinne therapeutische Anamnese in Bezug auf problematische Bestände der eigenen Tradition und Kultur.

\section{Schrift und Kult als Medien Gottes}

Theologen und Philosophen haben Gott in aller Regel als das schlechthin Andere des Menschen und seiner Erfahrung beschrieben. Spinoza z.B. hat Gott als „ens absolutissimum infinitum, hoc

* Aleida Assmann ist seit 1993 Professorin für Anglistik und Allgemeine Literaturwissenschaft an der Universität Konstanz. Neben mehreren Gastprofessuren in Princeton und Yale ist sie auch Mitglied der Berlin-Brandenburgischen Akademie der Wissenschaften. Seit 1978 leitet sie gemeinsam mit Jan Assmann den Arbeitskreis „Archäologie der Literatur" zu kulturwissenschaftlichen Themen, aus dem inzwischen mehr als zehn Sammelbände hervorgegangen sind. Der vorliegende Text basiert auf ihrer Schwager-Vorlesung vom 24. November 2005 und ist auch als Nr. 5 der Innsbrucker Diskussionspapiere zu Weltordnung, Religion und Gewalt erschienen. 
est, substantiam" definiert. Absolut und unendlich sind traditionelle Gottesprädikate, weil das eine wie das andere dem Menschen unerreichbar ist. Zusammen machen sie die Substanz, das Wesen Gottes aus, womit zugleich gesagt ist, dass Gott das Wesen schlechthin ist. Wesen, Essenz, ist das Andere nicht nur des Menschen, sondern jedweder Form von Bedingtheit. Auf dieser Ebene der Definition kommt das Sprechen über Gott schnell an sein Ende. Dieses ist erreicht, sobald die traditionellen Absolutheitsprädikate versammelt sind.

Ich werde in meinem Beitrag nicht über Gott, sondern über die Medien Gottes sprechen. Auf diesem Weg folge ich Jochen Hörisch, der den Begriff des Mediums in den theologischen Diskurs eingeführt hat. Ihm fiel auf, dass es im renommierten Handbuch philosophischer Grundbegriffe der Theologie zwischen „Meditation“ und „Medizin“ keinen Eintrag zum Stichwort „Medium“ gibt. Dabei ist das Problem der Medien an fond ein theologisches, denn es entsteht mit der Frage der Vermittlung zwischen den kategorisch getrennten Sphären des Göttlichen und des Menschlichen. Von Gott reden heißt deshalb zugleich, über die Medien zu reden, in denen der Hiat der absoluten Differenz überbrückt, vermittelt wird. Indem ich mich auf diesen Medienpfad begebe, werde ich nicht wie Platon und Augustin von der Frage der Unzugänglichkeit absoluter Wahrheit und göttlicher Wirklichkeit für die beschränkten Möglichkeiten menschlicher Erkenntnis ausgehen ${ }^{1}$, sondern mich dem Thema vom anderen Pol her

1 Die Frage, wie die so in jeder Hinsicht gegensätzlichen Sphären des Göttlichen und Menschlichen überhaupt in eine Relation gebracht werden können, ist der Gegenstand gelehrter philosophischer und theologischer Kontroversen geworden, von denen ich hier nur an das Höhlengleichnis Platons und die Akkomodationstheorie Augustins erinnern möchte. Diese Frage nach einem vermittelnden Brückenschlag zwischen den gegensätzlichen Sphären von Gott und Mensch zielt bereits auf das Problem der Medien, der Mittler. Während bei Platon im Höhlengleichnis die empfangenen Schattenbilder bekanntlich als eine starke Verzerrung der Urbilder dargestellt werden, von denen die Besseren wissen, dass es sich um verminderte Karikaturen handelt, kommt es bei Augustin weniger auf den Substanzverlust in den Bildern an als auf die göttliche Gnade einer Selbstminderung und freiwilligen Herabstufung auf menschliches Maß. Akkomodation bedeutet Selbstanpassung Gottes an die kognitiven und sinnlichen Kapazitätsschranken des menschlichen Geistes. Unser Wissen von Gott ist für Augustin immer schon gebrochen, weil es sprachlich vermittelt ist. Versprachlichung bedeutet narrative Verzeitlichung von Sinn sowie Veranschaulichung des Unbegreiflichen durch Bilder. Er schließt mit seiner Akkomodationstheorie an platonische und neuplatonische Gedanken über die Anpassung des Göttlichen an menschliches Fassungsvermögen an. Bei Platon biegt sich der menschliche Geist das Absolute zurecht bis es auf das Format seiner niedrigen Erkenntnisstufe gebracht ist, 
nähern und nach den unterschiedlichen Medien Gottes fragen, die dieser in der Geschichte der Religionen zur Manifestation und Offenbarung gewählt hat.

Ich werde also versuchen, Gott von den Medien her zu bestimmen, in denen er sich manifestiert, verkörpert und durch die er vergegenwärtigt wird und ohne die das Absolute dem irdischen Menschen nicht begegnen kann. Nach Niklas Luhmann setzen Medien „an den Bruchstellen der Kommunikation“ an und dienen funktionsgenau dazu, „Unwahrscheinliches in Wahrscheinliches zu transformieren". ${ }^{2}$ Wir dürfen diese Mediendefinition erweitern und hinzufügen: Göttliches in Menschliches zu verwandeln. Denn der Begriff der Medien ist nicht auf die neuen Medien und damit auf die technischen Apparate einzuschränken, die seit 1900 im Umlauf sind. Die Medien Gottes übersetzen Transzendenz in Immanenz und stellen damit im prägnanten Sinne einen „Übergang zum Endlichen“ her. ${ }^{3}$

In der hebräischen Bibel wird berichtet, wie sich der Gott Israels Mose oder seinem Volk in einer Fülle von Verkörperungen zur Erscheinung gebracht hat: im brennenden Dornbusch und einer Wolke, die den irrenden Israeliten voran zieht, in einer wunderbaren Begebenheit wie der Teilung der Fluten auf der Flucht vor dem ägyptischen Pharao oder dem Quell, der aus dem Fels geschlagen wird. Aber nicht nur in Wundertaten, auch in längeren und verschlungenen Geschichten schlägt sich das Wirken Gottes in Glück oder Schädigung, in Segen oder Fluch nieder. Die Summe dieser Erfahrungen ist in Geschichten bewahrt, die zusammen mit Geboten und Gebeten gesammelt und schriftlich festgehalten sind. Diejenigen, die nicht selbst Zeugen solcher Interventionen waren, können durch die Schrift zu sekundären Zeugen göttlichen Handelns wer-

bei Augustin biegt Gott sich selber zurecht, bis er ein dem menschlichen Wahrnehmungsvermögen mögliches Format gefunden hat. Der Platon des Höhlengleichnisses hat mit seinen flackernden Schattenbildern der abendländischen Tradition ein kritisch negatives Verhältnis zu Medien überhaupt vorgegeben, die das Eigentliche, das Absolute eher verstellen als zur Ansicht bringen. Der Akkomodationstheoretiker Augustin dagegen hat den Grund für ein positives Verständnis der Medien gelegt, indem er sie als Gnadengeschenk der göttlichen Selbstübersetzung ins menschlich Aufnehmbare bestimmte.

2 Luhmann (1984), 220; zitiert nach Hörisch (1992), 16-17.

3 Diesen Schlüsselbegriff der deutschen Frühromantik verdanke ich ebenfalls Jochen Hörisch, der ihn in seinem poetisch-theologischen Buch Brot und Wein so hervorgehoben hat. Vgl. Hörisch (1992), 195 und Hörisch (1989). 
den. Die einmaligen Ereignisse sind in der Schrift aufgehoben, die die Qualität eines nicht veraltenden Zeugnisses und damit einer dauerhaften Offenbarungsquelle annahm. Die Schrift wurde damit zum exklusiven Medium göttlichen Erscheinens. Deshalb bildet das Medium der Schrift das Zentrum jüdischen Kults und jüdischer Überlieferung. Die Schrift bildet im Judentum mit rituellen Lesungen, geselligem Nacherzählen, dialogischen Verfahren der Auslegung und gesetzeskonformer Lebensführung das Herz religiöser Praxis.

In der christlichen Tradition ist die religiöse Bedeutung der Schrift zurückgestuft worden durch zwei neue Medien Gottes: den inkarnierten Logos als Erfüllung der Schrift und den heiligen Geist als momentane Überwindung und Aufhebung der Schrift. ${ }^{4}$ In welche Überlieferungsformen und in welche kultische Praxis münden nun diese neuen Medien Gottes? Welche neuen kultischen Praktiken entstanden, wo Schrift aus ihrer Zentralstellung entfernt wurde? Kommen wir noch einmal zur zweiten Person der Trinität zurück. Die charismatische Verkörperung Gottes in einer menschlichen Gestalt ist nicht überlieferungsfähig. Die Präsenz des lebendigen Gottessohns verliert ihre Bedeutung, sobald von diesem Mittler nur noch in der vermittelten Form von Geschichten und schriftlichen Zeugnissen berichtet werden kann. Diese Präsenz ist bereits durch den Kreuzestod Christi gebrochen. Mit diesem Tod ändert sich auf eine dramatische Weise das Medium Gottes, der sich fortan in einem bestimmten Leichnam verkörpert. Die prekäre Kollision von lebendigem, ewigem Gott und totem, verweslichen Körper wird durch mythische Bilder wie das leere Grab, über das die Jerusalemer Grabeskirche gebaut ist, sowie die Apotheose des Gekreuzigten in Auferstehung und Himmelfahrt überwunden. Während andere getötete Götter wie Osiris und Dionysos gewaltsam in Stücke gerissen werden und als physische membra disiecta in Fruchtbarkeitskulten zerstreut werden, um eine symbolische Wiederversammlung der Glieder oder Erneuerung des Lebens zu zelebrieren, bleibt vom Körper des getöteten Christus (außer den Abdrücken auf Schweißtuch und Leichentuch) keine materielle Spur zurück. Das Wunder der Auferstehung macht die Inkarnation gewissermaßen wieder rückgängig.

Soll in der Folge die Differenz zwischen Vater und Sohn in der Trinität nicht gänzlich verschwinden, muss der Kult deshalb den As- 
pekt der Leiblichkeit Gottes reaktualisieren. In den Evangelien wird vom letzten gemeinsamen Mahl berichtet, das von Jesus als symbolischer Grundstein einer Erinnerungskultur inszeniert wird. In dieser Szene wird die Umwidmung des Sedermahls, des paradigmatischen jüdischen Gedächtnismahls, in dem zum Pessachfest erzählend, singend und schmeckend an den Gründungsmythos des Volkes Israel, den Auszug aus Ägypten, erinnert wird, zum christologischen Abendmahlskult vollzogen. Der Exodus als eine die kollektive Identität der Juden definierende mythische Erinnerungsfigur wird überschrieben durch das letzte Abendmahl als eine die kollektive Identität der Christen definierende Erinnerungsfigur. Wie sich alle nachgeborenen Juden durch die Tischgemeinschaft des Pessachfestes in die kollektive religiöse Identität des Volkes Israels einreihen, reihen sich alle nachgeborenen Christen durch die symbolische Tischgemeinschaft des Abendmahls in die kollektive religiöse Identität der Christen ein. Meine These, die ich in diesem Text entwickeln möchte, lautet: Bei aller zeitlichen Nähe im Festkalender und strukturellen Entsprechung beider Rituale im Erinnerungs- und Vergemeinschaftungs-Motiv bedeutet diese Umwidmung des jüdischen Festes in ein christliches Fest eine epochale Verschiebung, die ein bis heute weitgehend unbewusst gebliebenes und damit auch nach wie vor unbewältigtes Gewaltpotential birgt.

\section{Religion, unbewusste Tradierung und Gewalt}

Jüdisches Pessachfest und christliches Abendmahl sind darin analog, dass auf der Basis einer geteilten und gemeinsam vollzogenen Erinnerung eine Gemeinschaft begründet wird. Gemeinschaften sind immer auch „Gemeinschaften gegen“, sie entstehen dialektisch durch Integration und Ausschluss. Im jüdischen Pessachfest wird der identitätsfundierende Andere explizit genannt, es sind die Ägypter, die zu einem mythischen Inbegriff von kultureller Fremdheit und politischer Übermacht verdichtet sind. Aufgrund dieser expliziten Nennung des identitätsfundierenden Anderen konnte auf jüdischer Seite dieses Außenverhältnis reflektiert werden und sogar als eine selbstkritische Mahnung für den Umgang mit den Fremden im eigenen Lande ins eigene Selbstbild eingehen: „Bedenke, auch du warst einst ein Fremdling im Lande der Ägypter [...]“, heißt es in der Pessach Haggada. Anders im christlichen Abendmahlsritus. Hier handelt es sich um eine erinnerungsgestützte Gemeinschaftsbildung, bei der das 
Außenverhältnis nicht explizit gemacht wird und kein Verweis auf den identitätsfundierenden Anderen erfolgt. Die Rolle, die beim jüdischen Pessachfest die Ägypter spielen, spielen beim christlichen Abendmahl die Juden. Sie bleiben jedoch ungenannt, was von vornherein eine reflektierte Auseinandersetzung mit diesem Gegenüber ausschließt. Um es auf den Punkt zu bringen: Die Juden kommen in der Geschichte des Abendmahls nicht vor, weil sie der überschriebene und ausgelöschte Grund dieser Geschichte sind. ${ }^{5}$

Mit der martyriologischen Wende vom Gottessohn als inkarniertem Logos zum leidenden, gekreuzigten und gestorbenen Christus ist ein Motiv von Schuld und Rache verbunden, das in der Überlieferung über Jahrhunderte inert blieb, aber unter bestimmten Umständen auch gefährliche Formen annehmen konnte. Mit der Leerstelle des identitätsfundierenden Anderen verknüpft, bildet dieses Motiv eine „Krypta“6 d.h. einen der Reflexion unzugänglichen energetischen Komplex im kulturellen Gedächtnis, der in unterschiedlichen Konstellationen immer wieder reaktivierbar ist. Er ist reaktivierbar im zweitausendjährigen Topos von den Juden als Gottesmördern, der im christlichen kulturellen Unbewussten tief verwurzelt ist. ${ }^{7}$ Diese Grundierung hat auch die Symbolik des Abendmahls mit eingefärbt. Das Abendmahl kann wie das Pessachmahl als ein Gedächtnisritual aufgefasst werden, bei dem die profane Tischgemeinschaft mit Essen und Trinken einer anhaltenden rituellen Erinnerung dient und zur Grundlage von Gemeinschaftsbildung wird. Je stärker jedoch der Körper des Gekreuzigten selbst in den Mittelpunkt dieses Rituals tritt - und genau das passiert im Zuge der bildlichen Ausgestaltung dieses Motivs -, desto deutlicher nimmt es Züge eines Opferrituals an.

5 Während das Pessachmahl die Erlösung von der ägyptischen Übermacht und Repression feiert, feiert das Abendmahl die Erlösung der Menschen von Sünde und Tod auf Golgatha. Aus einer Erinnerungskultur mit engem Gruppenbezug wird dabei eine universelle Erlösungsreligion für die Menschheit. Gleichwohl geht es im Vollzug des Ritus weniger um universelle Botschaften als um emphatische Gruppenbildung und Grenzziehung, dem Pessachritual darin also durchaus analog.

6 Der Begriff „Krypta“ geht auf den ungarischen Psychoanalytiker Nicolas Abraham zurück. Vgl. Abraham/Torok (1978).

7 Dieser Topos geht auf die älteste erhaltene Osterhomilie des Melito, Bischof von Sardes, aus dem 2. Jahrhundert zurück; vgl. Leonhard (2001), 45-47. 


\section{Der Körper der Kirche und die Ambivalenz des Blutes}

Kirche, Staat und andere abstrakte Kollektivkörper haben ganz allgemein gesprochen das Problem, „daß man sie zu wenig sieht.“8 Was man sieht, sind die Rathäuser und Gotteshäuser, aber nicht die communitas der Menschen, die unter diesem Symbol vereinigt sind und auf dieses Symbol einen erheblichen Teil ihrer Identität gründen. Dafür bedarf es Formen der Repräsentation und performativer Riten. Novalis sprach von „Schauhandlungen“; das „Leben des Volkes“ müsse, um sichtbar zu werden, zu einem „Schauspiel“ werden: Entsprechendes gilt für die Kirche, die ebenfalls auf Formen der Repräsentation und Inszenierung, einschließlich der performativen Riten, angewiesen ist. Mit Blick auf diesen notwendig theatralischen Charakter der Religion spricht man auch von „Schaufrömmigkeit“; nicht nur Architektur und Bilder, auch Prozessionen und Riten kommen dem Bedürfnis nach Sichtbarkeit und Sinnlichkeit nach. Der unsichtbare Kollektivkörper der ecclesia wird als Körper Christi vorgestellt. Christus hat nicht nur zwei Naturen, eine menschliche und eine göttliche, sondern auch zwei Körper: einen physischen Körper, der gekreuzigt und begraben wurde, und einen rituellen Körper in Gestalt der Hostie. An die Stelle des entzogenen Leichnams Christi tritt die Hostie als der andere Körper Christi. Dass das Abendmahl mehr als ein Gedächtnisritual ist, das eine Gemeinschaft von Gläubigen stiftet, wurde auf der letzten Bischofssynode im Oktober 2005 in Rom noch einmal bestätigt: Die Eucharistie sei „Quelle und Höhepunkt des Lebens und der Sendung der Kirche“. Essen und Trinken sind also nicht nur memoriale Zeichen für die Gemeinde, sondern auch symbolische Zeichen für die Konstitution und Institution der Kirche. In der Symbolisierung dieses spirituellen Kollektivkörpers spielt nun aber nicht nur die Hostie, sondern vor allem gerade auch das Blut eine außerordentlich bedeutsame Rolle. Diese symbolische Bedeutung des Bluts ist exzessiv und überbordend, sie lässt sich in keiner symbolischen Ordnung kontrollieren, sondern besitzt eine überschüssige und kaum in Schach zu haltende imaginäre Qualität. Das wird nicht zuletzt deutlich in den vielen visuellen Darstellungen von Kreuzigung und Eucharistie, wo das Blut als ein geradezu obsessives Motiv erscheint. Wo immer der unsinnliche Kollektivkörper der Kirche imaginiert werden soll, ist das Blut nicht 
fern, und dieses Blut bedeutet immer zweierlei: Es ist sowohl Garant der Einheit dieses Kollektivkörpers als auch Inbegriff von dessen Bedrohung. (Der symbolische Zusammenhang von Blut und Kollektivkörper überlebte, wie wir wissen, die Säkularisierung und wurde im Nationalsozialismus in einer wahnhaften Rassentheorie zum letzten verbindlichen Kriterium von Einschluss und mörderischem Ausschluss.)

Die Blutspur, die als ein auffälliges ikonografisches Motiv das Christentum begleitet, möchte ich hier nur mit einigen wenigen Bildern aus unterschiedlichen Jahrhunderten andeuten.

Bild 1 und 2: „Krenzzüge“", „,Seligpreisungen“, „V Vaterunser"10
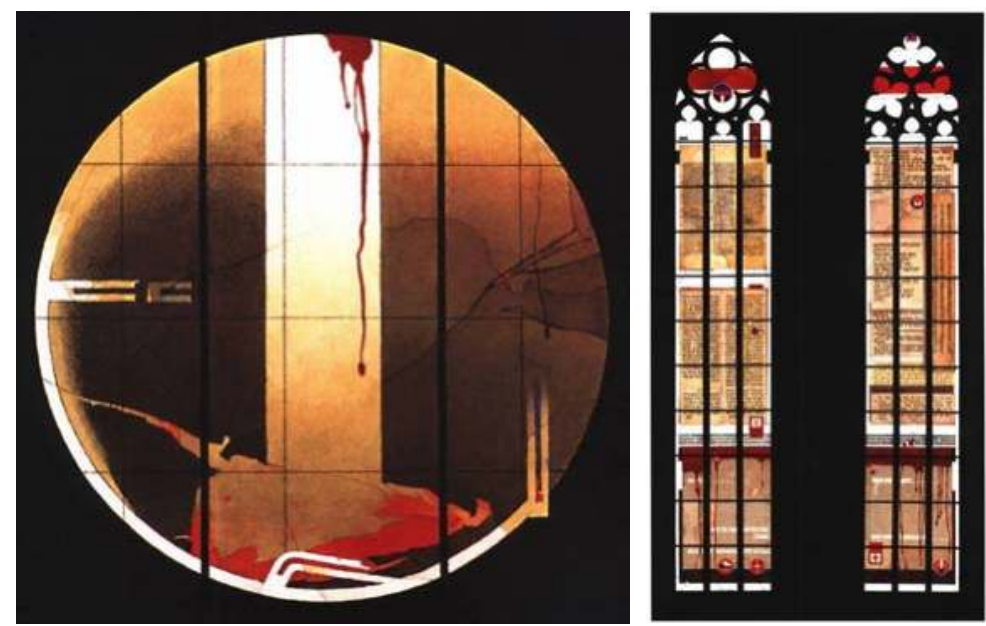

1. Das Blut spielt eine Rolle in den Glasfenstern des Gegenwartskünstlers Johannes Schreiter (siehe Bild 1 und 2 oben). Es findet sich im Glasfenster „Kreuzzüge“ ebenso wie in dem Fenster der Seligpreisungen und dem Vaterunser-Fenster. Hier sind unterschiedliche Sprachen und Schriften montiert, wobei im Fall der Seligpreisungen links besonders auf die aramäischen und hebräischen Urtexte und damit auf die jüdische Herkunft Jesu auf-

9 Sundermeier (2005), 28. Abdruck des Bildes mit freundlicher Genehmigung des Verlags Otto Lembeck.

10 Sundermeiter (2005), 69. Abdruck des Bildes mit freundlicher Genehmigung des Verlags Otto Lembeck. 
merksam gemacht wird. Ein Blutfleck verunstaltet den Text im linken Fenster; eine Blutbahn zieht sich im Sockel durch beide Bildfelder hindurch.

2. Ecclesia und Synagoge (siehe Bild 3 und 4 auf der folgenden Seite). Hier sind Ausschnitte der beiden Personifikationen, die regelmäßig als Paar auftreten, von der Fassade des Straßburger Münsters zu sehen. Der Speer der Synagoge ist gebrochen; ihre Augen sind verbunden, was als „Blindheit" und näherhin als Unglauben zu verstehen ist. Dieser Unglauben verdoppelt sich im Mittelalter: Die Juden glauben nicht an Christus als ihren Messias, und sie glauben nicht an das Wunder der Verwandlung der Hostie.

3. Fra Angelico hat um 1440 im Kloster San Marco in Florenz u.a. Bilder der Kreuzigung als Andachtsbilder an die Wände der Zellen der Mönche gemalt. Das historische Geschehen wird dabei verwandelt in einen Gegenstand der Devotion und Meditationspraxis, die den Gekreuzigten mit dem Mönch auf sehr persönliche und unmittelbare Weise verbindet. Das Medium dieser Verbindung ist das Blut Christi, das aus der Seitenwunde herausspritzt und am Kreuzesstamm herabläuft, wobei es einen direkten, über die Jahrhunderte hinweg unmittelbaren Kontakt mit dem modernen Beter herstellt. ${ }^{11}$

4. Francisco de Zurburáns Darstellung eines gefesselten Lamms mit dem Titel „Agnus Dei“ von 1640 (im Prado, Madrid) vollzieht den Schritt von der Kreuzigung zu einer Ikonografie der Eucharistie; hier fließt noch kein Blut, aber wir wissen, dass das gefesselte Tier im nächsten Augenblick dem Messer des Schlachters erliegen wird. Das Bild ist symbolisch unter- bzw. überbestimmt: Es stellt einfach nur ein Lamm dar, das aber auch ein Pessachlamm ist und aufgrund des liturgischen Textes des Abendmahls („Christe, du Lamm Gottes“) als Körper Christi zu deuten ist. ${ }^{12}$

11 Vgl. Scudieri, (2004), 76 (Zellen 16 und 15).

12 Vgl. Belting (2005). Von Interesse ist hier auch das Bild des Lamms in der Johannes-Apokalypse, das das traditionelle heraldische Tier der königlichen Macht überbietend ablöst. Damit wird nicht nur von einer „Religion der Stärke“ auf eine „Religion der Schwäche“ umgestellt, sondern auch auf eine „Opferreligion“. 
Bild 3: Ecclesia 13

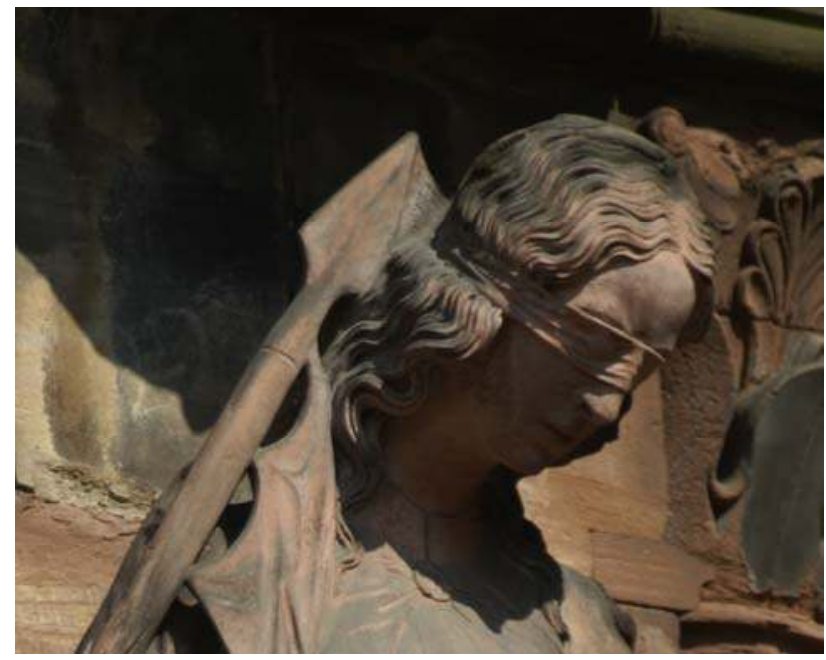

Bild 4: Synagoge 14

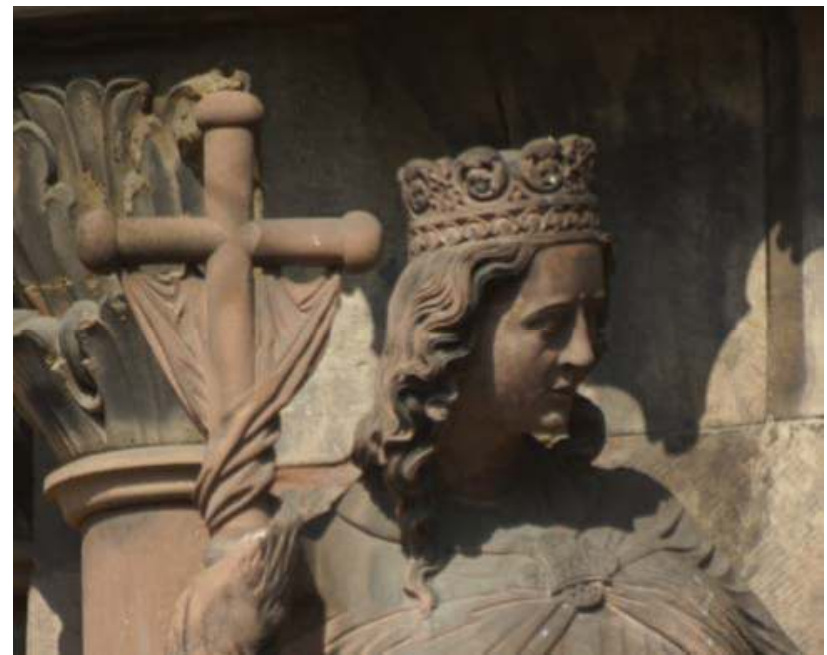

13 Abbildung der Statue der „Ecclesia“ am Münster von Strassburg (C) Christoph Bühler/ landeskunde-online.de.

14 Abbildung der Statue der „Synagoge“ am Münster von Strassburg (C Christoph Bühler/ landeskunde-online.de. 
Die Mediaevistin Caroline Walker Bynum hat auf die ambivalente symbolische Bedeutung des Bluts hingewiesen, die zwischen nährend, fruchtbar, Leben spendend einerseits und Schrecken, Gewalt, Verwundung andererseits changiert. Sie weist dabei auf den mittelalterlichen Umgang mit Reliquien des heiligen Bluts hin, die Spiritualität, Energie und Heilung verheißen und mit denen Politik gemacht und Machtansprüche gerechtfertigt wurden. Das Opferblut Christi hat eine heilende, erlösende Kraft, aber dazu muss es erst einmal vergossen werden, und diese Freisetzung des Opferbluts muss durch andere erfolgen, die damit eine ewige Schuld auf sich laden. ${ }^{15}$ Ohne diese Mitwirkung der Juden am Kreuzigungsgeschehen gäbe es kein göttliches Opfer. Für das Gottesopfer sind die Christen somit auf die Juden angewiesen, was sich in der Geschichte als die Grundlage einer „destruktiven Bindung“ enthüllt hat.

Mit dieser Ikonografie der Eucharistie ist zugleich der Einlass der Affekte in das Sakrament verbunden. Die Kirche entsteht nach dieser Auffassung aus der Wunde Christi und dessen Blut, das sie im eucharistischen Sakrament sozusagen verwaltet. Aus dem historisch einmaligen Ereignis wird durch Überführung in ein Ritual ein Ereignis, das sich ewig wiederholt, ein zeitloser Zustand in ewiger Gegenwart. Das Ritual friert historisches Geschehen bzw. eine Narration ein und transformiert es in ein ewiges Opfer. In dieser Stellung entfaltet sich eine hoch ambivalente Symbolik des Bluts, das sowohl Medium der Erlösung ist als auch Medium der Schuld und der Rache. Matthäus ist der einzige Evangelist, der den in der Wirkungsgeschichte verhängnisvollen Zusammenhang zwischen der Unschuld des Pilatus und der Schuld der Juden hervorkehrt. Sie bekennen sich nach ihm zur Kreuzigung mit einem Satz, in dem sich das Blut der Erlösung in das Blut der Rache verkehrt: „Sein Blut komme über uns und unsre Kinder"“ (Mt 27.25).

\section{Das Abendmahl als Palimpsest}

Um die verschiedenen Schichten dieses Rituals besser verstehen zu können, ist es notwendig, seine Palimpsest-Struktur zu entfalten.

15 In Paul Gerhards Lied „O Haupt voll Blut und Wunden“ heißt es in Strophe 4: „,ich selber bin schuld an Deinem Tod" - freilich nicht im Sinne der Tötung, sondern des Anteils an der Schuld, die Christus auf sich genommen hat. „Ich bin Täter“ heißt hier: Er trägt meine Sünden; es bedeutet nicht: Ich habe ihn umgebracht. 
Der rote Faden ist in diesem Fall eine Blutspur, die vom PessachLamm, das beim jüdischen Frühjahrsfest geopfert wird, zum Kelch des Abendmahls führt. Mit dem Blut des Lamms, das im Buch Exodus als „Blut des Bundes“ bezeichnet wird, werden die Türrahmen jüdischer Häuser eingefärbt, damit der Würgeengel, der als letzte der zehn von Josef prophezeiten Plagen die ägyptische Erstgeburt tötet, an diesen vorüberziehe. (Die englische Übersetzung von pessach, to pass over, bezieht sich auf dieses „Überspringen“ der jüdischen Häuser.) Mit dem Blut des Opfertiers retten sich die Kinder Israels vor ihrem Auszug nach Ägypten. Diese Figur ist im christlichen Ritus umgedreht worden. Jetzt ist es nicht mehr ein Tier, das geopfert wird, um die Juden zu verschonen, sondern ein Mensch, ja der Sohn Gottes selbst, der sich nicht schont und als „Lamm Gottes“ an die Stelle des Opfertiers tritt, um die Menschheit von Sünde und Tod zu erlösen. Das jüdische Tabu des Menschenopfers, das in der Geschichte von der Bindung Isaaks als ein menschheitlicher Fortschritt gefeiert wird, ist gewissermaßen in der Passionssymbolik rückgängig gemacht oder, um mit dem Kunsthistoriker Aby Warburg zu sprechen, „energetisch invertiert“ worden. Beide Elemente, wunderbare Verschonung und Rettung, die beim Pessachfest kommemoriert werden, sowie Martyrium und Opfer, die in der Passionsgeschichte Christi kommemoriert werden, kommen im Wein des Abendmahlssakraments zusammen, der einerseits auf das Trauma der gewaltsamen Tötung verweist und andererseits die erlösende Kraft des Opferbluts als „Blut des neuen Testaments“ hervorhebt. Rituell reinigende Kraft und traumatische Qualität sind im Opferblut in unauflöslicher Ambivalenz miteinander verbunden.

Zum Palimpsest des Abendmahls gehört, dass es in Konkurrenz zu anderen Opferriten steht. Auf der einen Seite musste es über die „Blutopfer“ des Alten Testaments erhoben werden. Es gab hier so etwas wie den Anspruch auf einen zivilisatorischen Fortschritt innerhalb der Religionen, der durch den Blick zurück auf „primitive Riten“ herausgestrichen wurde. Dieser Anspruch ist im Affekt des „,horror cruoris“" zusammengefasst. ${ }^{16}$ Die Tieropfer der Hebräer, die vor der Einführung des synagogalen Wortgottesdienstes im Tempel dargebracht wurden, werden dabei als verabscheuungswürdige „heidnische“ Riten gebrandmarkt. Auf der anderen Seite mussten die 
Grundsubstanzen der Eucharistie, Brot und Wein, sowohl verwandelt als auch besonders konsekriert werden, um das christliche Opfer als ein dem jüdischen überlegenes auszuweisen. Es muss deutlich gemacht werden, dass es hier um etwas ganz anderes und Höheres geht als um das Brot und den Wein, die bei den Juden ja allwöchentlich am Sabbath dem Schöpfer in einem festlichen Ritus geweiht werden. ${ }^{17}$ Überlegenheit und Empfindlichkeit lassen sich aber in diesem psychischen Komplex nicht so klar voneinander trennen. Der jüdische Segen, der über Brot und Wein gesprochen wird, weist sie ausdrücklich als Gottesgaben aus, die als Speisen zum menschlichen Genuss bestimmt sind. Diese Ausdeutung widerspricht eklatant der christologischen Aufladung von Brot und Wein im christlichen Abendmahl. Jeder jüdische Sabbathritus konnte daher von Christen auch als eine Infragestellung und hartnäckige Leugnung des von ihnen praktizierten Abendmahlsdogmas aufgefasst werden.

\section{Zur Geschichte des Abendmahls}

Im christlichen Kult werden Brot und Wein zu den zentralen Medien Gottes, mit denen die christliche Überlieferung befestigt und die massenhafte Teilhabe am zentralen religiösen Mysterium möglich wird. Freilich hat sich das Sakrament der Eucharistie in der Geschichte erst allmählich herausgebildet. Liturgie und Praxis des Abendmahls wandelten sich im Zuge einer neuen Verehrung des Körpers Christi, der als Medium Gottes immer stärker aufgeladen und um den eine neue religiöse Semantik in Bild, Ritual, und Frömmigkeit entwickelt wurde. ${ }^{18}$ Meilensteine in dieser Entwicklung sind eine von Papst Leo 1050 einberufene Synode und das Vierte Lateran-Konzil im Jahre 1215 gewesen, auf dem die Transsubstantiation der Hostie in den Körper Christi als Dogma festgelegt wurde. Mit dieser neuen Lehre forcierte die Kirche ein unsichtbares, unsinnliches Ereignis als Kern des Glaubensinhalts, gleichzeitig entzog sie den Kelch den Laien und vereinnahmte den Ritus damit für sich selbst als Institution. Eine besondere Aufgabe fiel dabei den Priestern zu, die die liturgischen Verwandlungsworte zu sprechen und das

17 Alger von Lüttich nach C. W. Bynum (2001), 91. Alger von Lüttich, Benediktiner und kanonistischer Schriftsteller, starb 1131 in Cluny. Sein Werk De sacramentis corporis et sanguinis Domini libri tres, wurde 1530 von Erasmus in Basel herausgegeben.

18 Rubin (1991). 
Wunder der Verwandlung öffentlich in der Messe zu praktizieren hatten. Mit dieser neuen Glaubensanforderung wuchsen zugleich auch Zweifel und Hysterie. Davon zeugen zwei Zwillings-Phänomene, die mit dem Transsubstantiations-Dogma dialektisch verknüpft sind: Hostienwunder und Hostienfrevel. Ein Priester, der in Bolsena die Messe zu leiten hatte, hegte Zweifel an der Transsubstantiation und wurde durch ein Hostienwunder bekehrt, bei dem ihm Christus in einer Vision als Schmerzensmann erschien. Papst Urban, der in Bolsena Zeuge des Wunders wurde, führte 1264 das Fronleichnamsfest in den kirchlichen Kalender ein. ${ }^{19}$ Seither wird die Hostie in einer Prozession durch die Straßen getragen als Symbol einer von Juden, Ungläubigen und Ketzern bedrohten Kirche. ${ }^{20}$ Raphael hat 1511 ein Bild von der Messe von Bolsena gemalt (siehe Bild 5 gegenüber), in dessen Mittelpunkt die Hand des Priesters mit der blutenden Hostie zu sehen ist.

Auf ungezählten Bildern der selben Zeit sind Juden zu sehen, die sich der Hostien bemächtigen, um diese zu desakrieren, was regelmäßig ein starkes Bluten der Hostien zur Folge hat und die Frevler ihrer Tat überführt. Der erste Vorwurf eines jüdischen Hostienfrevels ist in Paris kurz nach dem Vierten Lateran-Konzil bezeugt, von wo sich das neue Phänomen epidemisch über Europa ausgebreitet hat. Mit der neuen Sakralisierung der Hostie ist die Gefahr ihrer Desakrierung offenbar dialektisch verbunden. Das Bluten der Hostie ist ein zweischneidiges Zeichen: Es bedeutet sowohl Wunder als auch Frevel, denn es quillt aus desakrierten Hostien als Indiz hervor, um die Täter zu beschuldigen.

Der Stress, mit dem hier der Glauben belastet wird - das gilt auch für die Sorgfalt der Priester im Umgang mit dem prekären Gut, denn an einem einzigen Versprecher bei den Verwandlungsworten konnte das Wunder scheitern ${ }^{21}$ - schlägt unmittelbar auf die Juden als die Feinde des Christentums zurück. Ihnen als den verstockt Un-

19 Unter Hostienwunder versteht man ferner unerklärliche Erscheinungen an der konsekrierten Hostie. Dazu gehören auch Blutstropfen, womit das Hostienwunder in einen zu ahndenden Hostienfrevel übergehen kann.

20 Bynum (2001), 103.

21 Camporesi (1989). Als Anglistin verweise ich hier auf die erste Erzählung in James Joyce Dubliners mit dem Titel „The Sisters“. In dieser Geschichte geht es um das dunkle SchuldGeheimnis eines Priesters, der aufgrund einer Parkinson-Krankheit Probleme beim Hantieren mit dem Abendmahlskelch hat - ein traumatisches Ereignis, das sein Lebensende überschattet. 
Bild 5: Raffael, „Die Messe von Bolsena“22

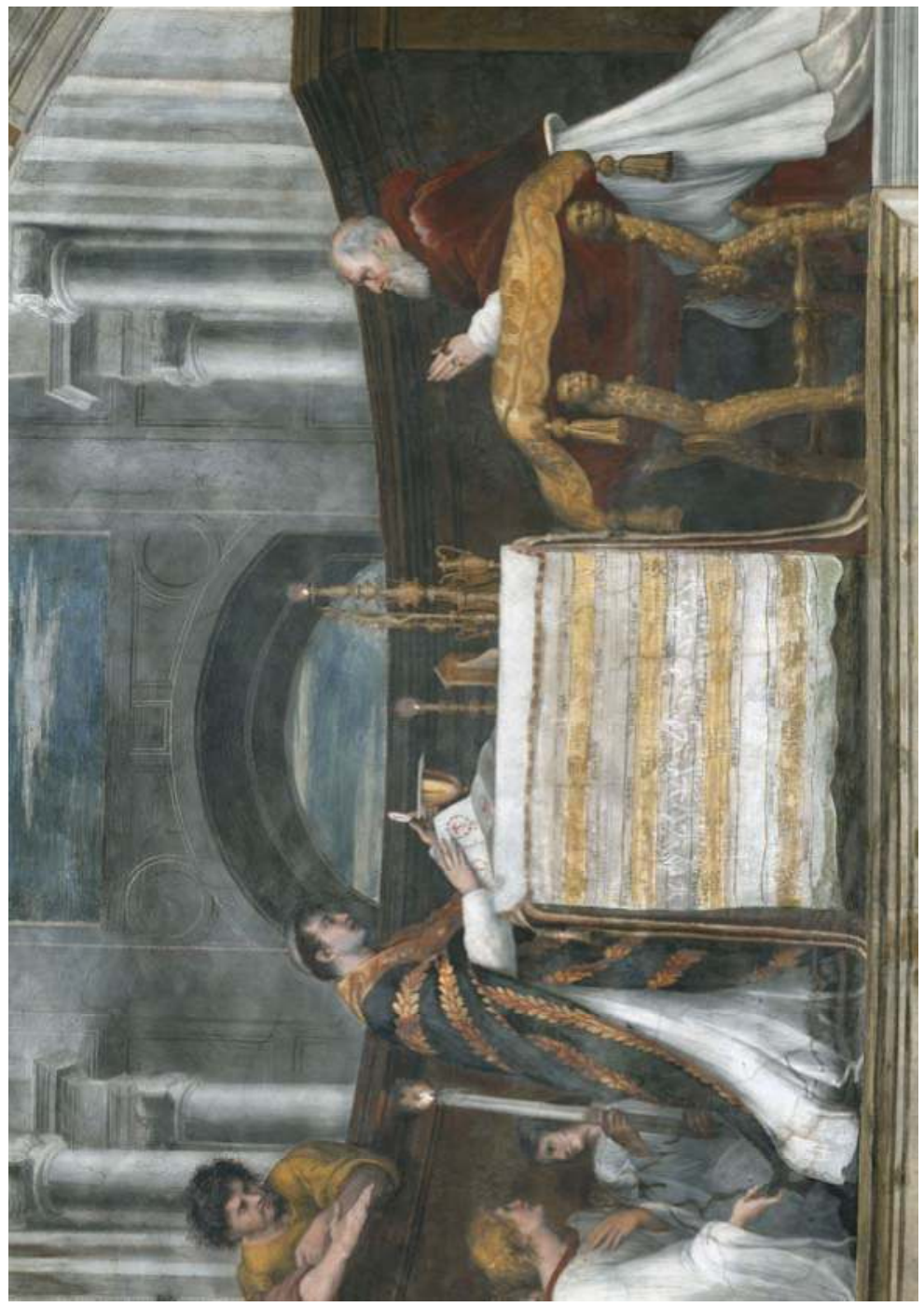

22 Raphael (1483-1520): Miracle of the Mass at Bolsena: central part. Vatican, Stanza di Eliodoro. (C) 1990. Photo Scala, Florence. 
gläubigen wird unterstellt, dass sie den christlichen Gott zum zweiten Mal umzubringen trachten. Nachdem sie geholfen haben, den Gottessohn auszuliefern und ans Kreuz zu schlagen, befürchtet man, dass sie ihre Tat am anderen Körper Christi, der Hostie, wiederholen. Der unausgesprochene Subtext des Abendmahls, der aktive Anteil der Juden an der Ermordung Christi, schlägt durch das Sakrament wieder durch, wobei der verdrängte Anteil, der Vorwurf gegen die Juden, sich nun zu offener Aggression steigert. Gleichzeitig wird damit ein einmaliges historisches Ereignis in die Gegenwart geholt, wo es beliebig oft nachgespielt und wiederholt wird, mit dem Zusatz allerdings, dass man nun aktiv in das religiöse Kerngeschehen der Kreuzigung eingreifen und zurückzahlen kann. Man spricht in dieser Zeit - im 13. Jahrhundert - von einer ,frenetischen“, auf die Passion fixierten „Spiritualität“, die sich gleichwohl einer sinnlich materiellen Grundlage versichern wollte und vom Bedürfnis nicht nur nach spektakulärer visueller Evidenz, sondern auch nach taktiler Unmittelbarkeit getragen war. Hehre Spiritualität und krude Konkretion, Angst und Vorwurf, Empfindlichkeit und Aggression gehen hier eine hoch problematische Verbindung ein und lassen eine destruktive Energie entstehen, die sich im Spätmittelalter in vielen Pogromen entladen wird. ${ }^{23}$ Die Juden, die in der Passionsgeschichte kaum vorkommen (mit Ausnahme der für unseren Zusammenhang entscheidenden und zentralen Stelle Mt 27.25) und auf die die Abendmahlsliturgie mit keinem Wort verweist, erweisen sich in dieser historischen Konstellation als „providentieller Außenfeind“ (Carl Schmitt), als die fundierenden und $\mathrm{zu}$ negierenden anderen einer sich durch das Abendmahls-Sakrament begründenden christlichen Gemeinschaft.

Wie sehr im 13. Jahrhundert, dem Jahrhundert des Transsubstantiations-Dogmas und des Festes Corpus Christi, dem Jahrhundert der Hostienwunder und der Hostienfrevel, die Juden ins kulturelle Imaginäre der Christen vorgerückt sind, bezeugt ein Traktat von Gerhard von Köln, einem Abt von Weingarten aus dem Jahre 1280.24 Gegenstand dieses Traktats ist die Verteidigung der Blutreliquie, das sind „Blutproben“, die die Kreuzfahrer aus dem Heili-

23 Vgl. Nierenberg (1996). Zur Deutung der Pogrome als „Ritualmorde“ vgl. Horkheimer/Adorno (1988), 180. Zum Juden-Bild in der osteuropäischen Volkskultur: Kleinmann (2005), 37-66; Struve (2005), 225-250.

24 Bynum (2001), 97. 
gen Land mitbrachten und die als hoch potente symbol- und machtpolitische Instrumente eingesetzt wurden. Diese Schrift zeigt, wie das Pendel der Eucharistie, das zwischen wertloser Materie und wunderbarer Verwandlung schwingt, auch wieder zum materiellen Pol zurückkehren kann. Transsubstantiation und Transzendenz kehren sich wieder um in physische Materialität. Blut ist ein Stoff, der sich offensichtlich der symbolischen Verwandlung stärker widersetzt und mit einer eigenen Tendenz und Kraft die Symbolordnungen sprengt. Auf diese Weise etablierte sich die Blutverehrung neben der Eucharistie als ein „symbolischer Wildwuchs“, wie man vielleicht sagen darf, der zugleich einen Nährboden für anti-judaistische Stimmungen und Gewalt abgab. In der Schrift Gerhard von Kölns ist zu lesen, dass Christus den Gläubigen nach seinem Tod ein vielfältiges Vermächtnis hinterließ. Dazu gehören - in der von ihm eingeführten Reihenfolge - an erster Stelle die beiden Testamente, also die Bibel, und an zweiter Stelle die Juden selbst, die von der Kirche toleriert werden, um als ewiges Zeugnis von Christi Leiden zu dienen. Als weitere Hinterlassenschaften folgen die Sakramente des Altars, also die Eucharistie, und sodann die Folterwerkzeuge (Kreuz, Nagel, Lanze, Dornen), die ebenfalls die religiöse Lehre ganz auf Passion und Gewalt einstimmen. In dieser Liste erhalten die Juden einen prominenten Platz sogar noch vor dem Sakrament des Abendmahls. Sie sind in diesem Kontext als Gottesmörder stigmatisiert und dienen selbst als ein memoriales Zeichen, das eine Gewalt-OpferRache-Erinnerung instituiert und perpetuiert, die jederzeit aus der symbolischen Sphäre in die Lebenswirklichkeit der Ausgegrenzten und Verfolgten einschlagen kann.

\section{Der Mensch weiß nicht, was er tut. Die kotigen Wurzeln der Kultur: Thomas Mann, Sigmund Freud, Aby Warburg}

In seinem Roman Josef und seine Brüder verwendet Thomas Mann ein Bild für das kulturelle Gedächtnis, das auf seine unbewussten Anteile verweist. Es geht dabei um den Sinn des Pessach-Festes, bei dem in Stellvertretung des erstgeborenen Sohnes ein Widder geopfert wird. Jakkob wird geradezu übel, wenn er den religionsgeschichtlichen Hintergründen oder „Tiefenschichten“ dieser Opfernacht (sozusagen dem horror cruoris) nachgrübelt:

„der Opfernacht, die herankommt, da wir das Schaf schlachten nach Sonnenuntergang und tauchen den Ysopbüschel ins Blut, um 
die Pfosten damit zu bestreichen, damit der Würger vorübergehe. Denn es ist die Nacht des Vorübergehens und der Verschonung um des Opfers willen, und ist das Blut an den Pfosten dem Umhergehenden eine Beschwichtigung und ein Zeichen, daß der Erstling geopfert ist zur Versöhnung und zum Ersatz für Menschen und Vieh, die es ihn zu würgen gelüstet. Darüber fiel ich mehrfach ins Sinnen, denn der Mensch tut manches, und siehe, er weiß nicht, was er tut. Wüßte und bedächte er's aber, so möchte es sein, daß sich das Eingeweide ihm umwendete und ihm das Unterste zuoberst käme in Übelkeit." 25

Jaakob, der hier jenen auch von Freud so stark betonten „Fortschritt in der Geistigkeit" verkörpert, der Zivilisationen als eine innere Tendenz eingeschrieben ist, trägt sich mit dem Gedanken, das Fest als überholt ganz abzuschaffen. Was Thomas Mann hier zum Gegenstand macht, ist das, was Freud die ,archaische Erbschaft" in der Geschichte der Religion und Kultur nennt. Joseph hat einen ganz anderen Blick auf diese archaische Erbschaft als sein Vater, was er mit folgendem Gleichnis zum Ausdruck bringt:

„,Siehe, da ist ein Baum', rief er und wies mit ausgestreckter Hand ins Innere des Zeltes, als wäre dort zu sehen, wovon er sprach, ,prächtig in Stamm und Krone, von den Vätern gepflanzt zur Lust der Späten. Seine Wipfel regen sich funkelnd im Winde, da seine Wurzeln im Stein und Staube haften des Erdreichs, tief im Dunkeln. Weiß wohl auch der heitere Wipfel viel von der kotigen Wurzel? Nein, sondern ist mit dem Herrn hinausgekommen über sie, wiegt sich und denkt nicht ihrer. Also ist's, meines Bedünkens, mit Brauch und Unflat, und daß die fromme Sitte uns schmecke, bleibe das Unterste nur hübsch zuunterst." “26

Mit der „kotigen Wurzel“ ist eine Tiefenschicht der kulturellen Erinnerung angesprochen, die, so Joseph, „hübsch zuunterst“ bleiben möge. Es handelt sich hier um unbewusste Grundlagen der Kultur, die vor einem bewußt machenden Ausbuchstabieren zu schützen sind. Das Erbe, das in diesem Beispiel zugrunde liegt, ist nicht nur einfach obsolet, sondern zum Gegenstand kulturellen Abscheus geworden. Auf die Entdeckung, dass dem gegenwärtigen Fest und seinen Riten eine uralte heidnische Praxis zugrunde liegt wie das Op- 
fer des Erstgeborenen, reagiert Jaakob mit physischem Ekel und dem Wunsch nach Abschaffung dieses Festes. Joseph rät aber, „das Fest zu schonen und es nicht eifernd anzutasten um seiner Geschichten willen, für welche vielleicht mit der Zeit eine andere eintreten könnte“. Das Fest, das dieses Opfer an dem stellvertretenden Widder vollzieht, wird noch seinen Sinn erhalten: für die Juden mit dem Auszug aus Ägypten und für die Christen mit der Kreuzigung und Auferstehung Christi. Deshalb darf es nicht abgeschafft werden. Während Jaakob in die Vergangenheit blickt und die religiösen Untertöne dieses Festes hört, von denen er abgestoßen ist, blickt Joseph in die Zukunft und hört bereits die Obertöne zukünftiger Umdeutungen. ${ }^{27}$

Jaakob und Joseph stehen bei Thomas Mann für zwei unterschiedliche Zugänge zur „archaischen Erbschaft“ im kulturellen Gedächtnis. Wer sich dieser unbewussten Grundlagen bewusst wird wie Jakkob, wird sich lieber heute als morgen von ihnen trennen wollen. Wer dagegen wie Joseph auf die zukünftige Entwicklung schaut und auf der Basis christlicher Figuraldeutung und einer Geschichtsphilosophie argumentiert, die auf dem Vorangegangenen aufruht und es braucht, um es umzudeuten, wird diese archaische Erbschaft verteidigen - mit der Maßgabe freilich, dass das Unterste hübsch zuunterst und die kotige Wurzel des Baumes der Tradition unsichtbar bleiben möge. Thomas Mann schreibt in der ersten Hälfte des 20. Jahrhunderts, in der zur Geschichtsforschung noch zwei neue Instrumente der historischen Selbstaufklärung des Menschen hinzugekommen sind: die Psychoanalyse und die Ethnologie. Sigmund Freud z.B. hat wiederholt auf die „,kotige Wurzel“ des Abendmahls in Gestalt der archaischen Totemmahlzeit aufmerksam gemacht, und auch Mann hat die Entwicklungslinie von der Totemmahlzeit bis zum Abendmahl gezogen, wobei ihn die progressive Entwicklung der Religion als eine Geschichte der Sublimierungen von Tiefenschichten interessierte: vom ursprünglichen Menschenopfer über den Widder als Ersatztier für Isaak bis hin zu Brot und Wein in der Eucharistie.

Den „Fortschritt in der Geistigkeit“ definierte Freud als eine (jüdische) Geschichtsnorm. Dabei war ihm bereits bewusst, dass er damit ein allgemeines menschliches Vermögen überfordere; und er stellte auch fest, dass diese Norm von den Christen mit ihrer Rück- 
kehr zum materiellen Bilder- und Heiligenkult sowie ihrer Fixierung auf das Menschopfer Christi immer wieder unterboten worden sei. Thomas Mann dagegen sah das Christentum als Teil dieser Tradition der fortschreitenden Vergeistigung und Sublimierung, wobei er davon ausging, dass die untersten Schichten des kulturellen Gedächtnisses ein für alle Mal überwunden seien und deshalb auch keiner Bewusstmachung bedürften.

Ich möchte hier abschließend an einen weiteren Zeitgenossen von Mann erinnern, den Kunsthistoriker Aby Warburg. Auch bei Warburg steht das Thema des Fortschreitens in der Geistigkeit im Mittelpunkt seiner Kulturanalyse. Freilich teilt er Thomas Manns positive (hegelianische) Geschichtsphilosophie nicht, der ja auch eine Kulturtheorie des Fortschritts zugrunde liegt. Warburgs Kultur-Modell ist demgegenüber bestimmt durch das bleibende Spannungsverhältnis zwischen Fortschritt und Rückschritt, zwischen Sublimierung und Konkretisierung, zwischen Geistigkeit und Sinnlichkeit. Diese seine skeptische Grundhaltung kommt in seinem Spätwerk, dem sogenannten Mnemosyne-Bilderatlas (siehe Bild 6 gegenüber), noch einmal besonders stark zum Ausdruck, in dem er in einem MontageVerfahren visuelle Arrangements aus Reproduktionen von älteren Stichen und Gemälden und aktuellen Zeitungsausschnitten schuf.

Die vorletzte Tafel des Mnemosyne-Atlas handelt vom „Verzehren Gottes“. Sie enthält Bilder von Hostienwundern und Hostienfreveln, Raphaels Messe von Bolsena sowie Hinweise auf Politik und Kirche im 20. Jahrhundert. Wie für Freud hing auch für Warburg die Zukunft der Kultur von der Fähigkeit der Menschen zur Sublimation ihrer Triebstrukturen ab. Und wie Freud in seinem letzten Buch Der Mann Moses und die monotheistische Religion (1939) setzte sich auch Warburg mit Fragen der Genese des Antisemitismus auseinander. In seinem Todesjahr 1929 machte er sich intensiv Gedanken über das Abendmahl und seine Verwandtschaft mit primitiven Opferkulten. Bekanntlich ist die substantialistische Deutung des Abendmahls, die die ursprüngliche Semantik des Gedächtnismahls durch die Semantik eines Opfermahls ersetzte und zu einem Mysterium des Kults steigerte, in der Geschichte des Christentums nicht unangefochten geblieben. Die Frage, ob Brot und Wein sich im Vollzug des Sakraments konkretistisch in Fleisch und Blut Christi verwandeln oder ob beide symbolischen Charakter haben und als Erinnerungszeichen auf das letzte Abendmahl Jesu und seiner Jünger verweisen, ist, wie die 
Theoretiker der Schule von Port Royal bezeugen, zu einem zentralen semiologischen Problem des Abendlands geworden.

Bild 6: Warburg, „Mnemosyne-Atlas" 28

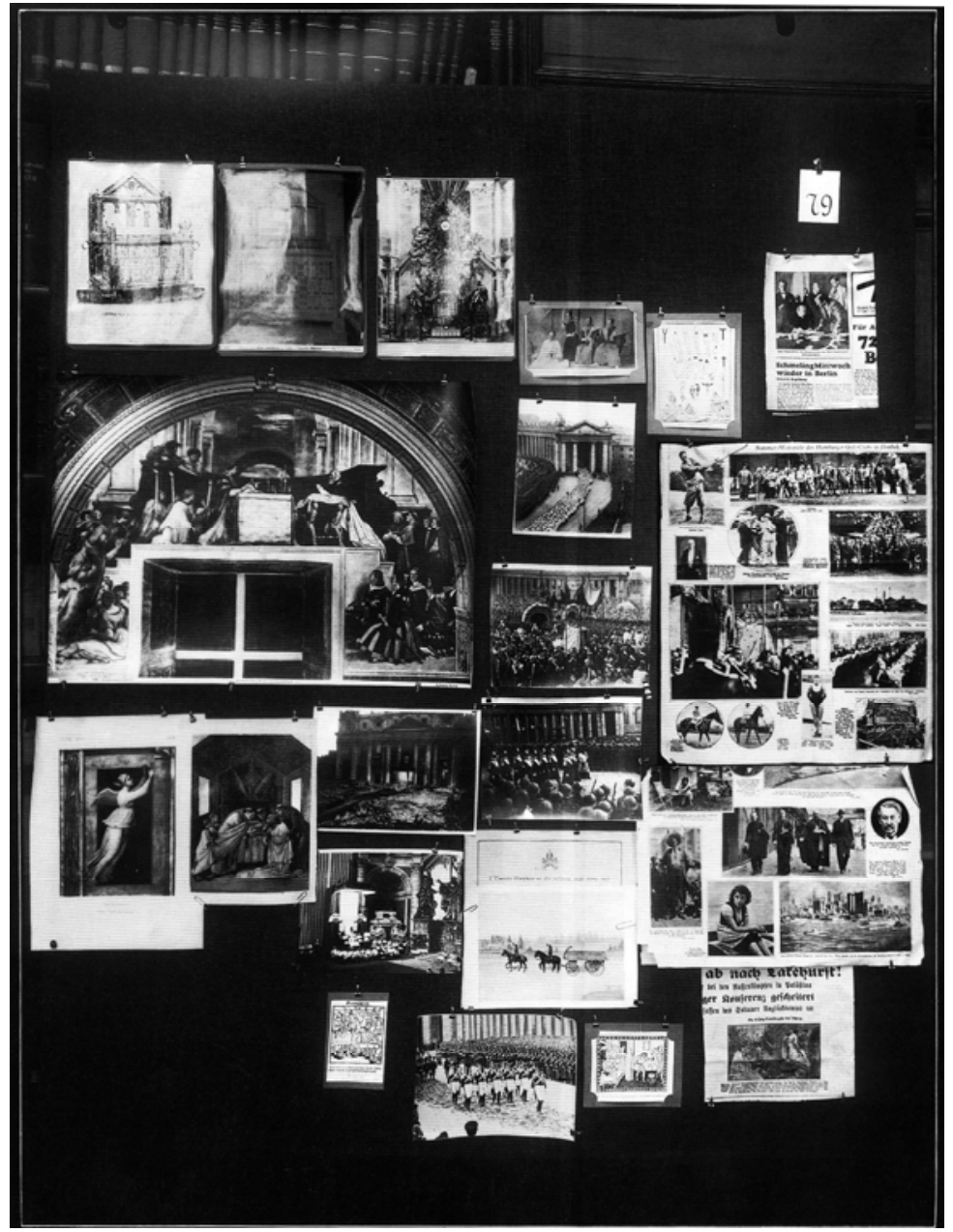

28 Warburg, Mnemosyne Atlas Tafel 79 (1929). (C) The Warburg Institute, London. 
Was Platons Dialog Kratylos für die Antike war, ist der Abendmahlsstreit für die Neuzeit geworden. ${ }^{29}$ In diesen Kategorien der Abendmahlskontroverse entwickelte Warburg seine Diagnose einer spirituellen Krise Europas und seine Perspektive ihrer Überwindung. Im August 1929 schrieb er in sein Tagebuch: „Ich bin weder antikatholisch noch protestantisch, aber ich könnte mir eine zukünftige christliche Religion vorstellen (und wünschen), die sich der Bedeutung des metaphorischen Als $\mathrm{Ob}$ als eines Problems bewußt ist. “"30 In der Auseinandersetzung um Wein und Brot als magisch subtantielle Gegenstände oder verweisend-distanzierende Zeichen erkannte er die menschheitsgeschichtliche Dauerspannung zwischen religiöser Konkretion und wissenschaftlicher Abstraktion wieder. Konkretistische Rituale waren für ihn ebenso unheimlich wie die Überschwenglichkeit eines auf Unmittelbarkeit zielenden Geistes. An die Stelle von Visionen absoluter Präsenz und absoluter Transzendenz stellte er ein Drittes, nämlich die Fähigkeit zur distanzierenden Reflexion. Von ihr erhoffte er sich, dass sie das niemals völlig überwindbare magisch-primitive Erbe der Menschheit in Schach hält, oder er hoffte, mit seinen eigenen Worten, dass „das Chaos der Unvernunft" von „Filtersystemen der Besonnenheit“" gezähmt bleibt. ${ }^{31}$

\section{Zusammenfassung}

Ich fasse zum Schluss die wichtigsten Schritte der Argumentation zusammen:

1. Der Körper Christi ist nicht nur Zentrum der Abendmahlsliturgie, sondern auch zentrales Symbol der Institution der Kirche. Nach der Himmelfahrt, in der die menschliche Natur Christi zugunsten seiner göttlichen Natur überwunden wird, verbleiben zwei Repräsentationen bzw. Manifestationen des Körpers Christi auf der Erde zurück: das sakrale Bild des sterbenden Körpers

29 In Auseinandersetzung mit dem Dogma der Realpräsenz konnte sich eine skeptische Zeichentheorie der metaphorischen Distanzierung entwickeln. In Frankreich haben die Philosophen von Port Royal auf dieser Basis eine neue, moderne Semiotik begründet. Es ist dieser zeichenlogische Zusammenhang, den Jochen Hörisch (1992) in Brot und Wein mit großer Sensibilität für die deutsche Kulturgeschichte nachzeichnet und dabei zum ersten Mal zeigt, welchen wichtigen Anteil gerade auch die Dichter an dieser Geschichte hatten.

30 Schoell-Glass (1999), 636.

31 Schoell-Glass (1999), 639. 
und Leichnams am Kreuz und der sakrale Ritus in den eucharistischen Gaben von Brot und Wein. ${ }^{32}$

2. Brot und Wein symbolisieren die profane Tischgemeinschaft als Erinnerungsgemeinschaft, Fleisch und Blut dagegen verweisen auf die kultische Opfersymbolik, die eine verdrängte traumatisch-gewalttätige Dimension in sich birgt. Das Abendmahl führt dabei drei Dimensionen des jüdischen Kults zusammen: Pessach (das festliche Erinnerungsmahl), Kiddusch (die wiederholte Variante) und Jom Kippur (den Entschuldungsritus).

3. Im Schatten des Abendmahlsritus bildet sich eine Krypta, die tief greifende Verunsicherungen in Form unverarbeiteter Angstund Schuldgefühle in sich aufnimmt. Diese Krypta, die ein konstitutives Element des Abendmahl-Komplexes darstellt, bildet ein Depot negativer Energie, die zur eigenen Entlastung und affirmativen Selbstvergewisserung immer wieder auf andere abgeführt werden muss. Dafür bieten sich - unter den bekannten historischen Voraussetzungen - die Juden an, von denen die Grundstruktur des Ritus übernommen worden ist, der aber in seiner symbolischen Ausarbeitung keine Rolle mehr spielt. ${ }^{33}$ Die Juden haben die Funktion, jene unfassbaren Ängste und Schuldgefühle zu verkörpern, die in der eigenen psychischen Ökonomie nicht adressierbar sind, und werden aus diesem Grund immer wieder zu Opfern von Pogromen und kirchlichen Machtdemonstrationen, deren psychische Grundlage Angst, Unsicherheit und Ohnmacht sind.

Kommen wir noch einmal zu Thomas Manns Bild des Baumes zurück. „Seine Wipfel regen sich funkelnd im Winde, da seine Wurzeln im Stein und Staube haften des Erdreichs, tief im Dunkeln. Weiß wohl auch der heitere Wipfel viel von der kotigen Wurzel? Nein, sondern ist mit dem Herrn hinausgekommen über sie, wiegt sich und denkt nicht ihrer." Auch nach Nietzsche macht es das Wesen des Baumes aus, dass er seine Wurzeln nicht vor sich hat, son-

32 Michalski (1984), 65-85. Es gibt selbstverständlich noch andere Verkörperungen Christi, wie z.B. den konkreten irdischen Menschen selbst, insbesondere die Ärmsten und Geringsten, Leidenden und Verfolgten unter den Mitmenschen, den anderen, auf dessen Antlitz sich das Bild Gottes spiegelt. Für die Symbolik der Kirche als Institution - und nur davon ist hier die Rede - haben diese jedoch keine unmittelbare Bedeutung.

33 Symptomatisch dafür ist, dass in Hörischs (1992) Brot und Wein, das als ein breites kulturtheoretisches Panorama angelegt ist und gelehrte Exkurse in Religions- und Liturgiegeschichte enthält, die Juden nicht vorkommen. 
dern unter sich; genährt und gehalten wird er von ihnen, solange sie tief unter der Erde begraben sind. ${ }^{34}$ Diese naturalistischen Bilder passen nicht unbedingt auf die menschliche Kultur. Auch in der Kultur ist vieles unbewusst und muss wohl auch so bleiben, aber nicht, wenn es ein gefährliches Potential entfaltet. Dann ist es Aufgabe der Kulturwissenschaften, solche „Taschen“ oder Krypten im Kulturellen Gedächtnis aufzuspüren und die verborgenen Depots negativer Energien zu inspizieren. Meine Archäologie des Abendmahls sollte einen kleinen Beitrag zu dieser Aufgabe leisten. „Also ist's“, fährt Thomas Mann fort, „mit Brauch und Unflat, und daß die fromme Sitte uns schmecke, bleibe das Unterste nur hübsch zuunterst." Wo Brauch und Unflat zusammenfallen, kann diese Maxime keineswegs aufrechterhalten werden; solche im Schatten der Transsubstantiationslehre im Volksglauben entstandene Bräuche, wie die von Ritualmord und Hostienfrevel, gilt es - wie dies etwa in Rinn bei Innsbruck in den 1980er-Jahren geschah ${ }^{35}$ - eher heute als morgen abzuschaffen. Grundsätzlich bestehen das Ziel und die Verantwortung kulturwissenschaftlicher Forschung darin, mithilfe einer Durchleuchtung unbewusster und unzugänglicher Traditions-Schichten ihre gefährlichen Gewalt-Potentiale durch eine selbstaufklärende Erinnerungsarbeit zu überwinden.

\section{Literatur}

Abraham, Nicolas/Torok, Maria (1978): L'écorce et le noyeau. Paris: Flammarion.

Assmann, Jan (2006): Mythos und Monotheismus. Religiöse Anthropologie in den Josephs-Romanen Thomas Manns. München: Beck.

34 Nietzsche (1962), 227: „Der Baum fühlt seine Wurzeln mehr, als dass er sie sehen könnte."

35 Der Judenstein bei Rinn galt seit dem 17. Jahrhundert als Tatort eines 200 Jahre zuvor verübten jüdischen Ritualmordes an einem dreijährigen christlichen Knaben, der im 18. Jahrhundert selig gesprochen wurde. Der Festtag des „Anderl (Andreas) von Rinn“ wurde schließlich 1953 vom Innsbrucker Bischof Paulus Rusch aus dem kirchlichen Kalender getilgt; 1994 wurde der Kult um den Judenstein von Bischof Reinhold Stecher offiziell verboten. Obwohl die Darstellung des Ritualmords übermalt und die Kirche in „Mariä Heimsuchung" umbenannt wurde, findet nach wie vor alljährlich eine privat organisierte Wallfahrt von Rechtsextremisten und katholischen Fundamentalisten zum "Judenstein“ bei Rinn statt. Eine vierhundertjährige Tradition lässt sich offenbar nicht so einfach abschaffen. 
Belting, Hans (2005): „Das echte Bild“. Bildfragen als Glaubensfragen. München: Beck.

Biser, Eugen (1990): Die Bibel als Medium. Zur medienkritischen Schlüsselposition der Theologie. Heidelberg: Winter.

Bynum, Caroline W. (2001): „Das Blut und die Körper Christi im späten Mittelalter: Eine Asymmetrie“, in: Grünbein, D., Hg.: Scblaflos in Rom: Versuch über den Satirendichter Juvenal. Berlin: Akademie Verlag, 77-109.

Camporesi, Piero (1989): L'enfer et le fantasme de l'bostie. Une théologie baroque. Paris: Ed. Hachette.

Hörisch, Jochen (1989): Das Abendmabl, das Geld und die neuen Medien. Poetische Korrelation von Sein und Sinn. Bremen: Verlag Bettina Wassmann.

Hörisch, Jochen (1992): Brot und Wein. Die Poesie des Abendmabls. Frankfurt/ M.: Suhrkamp.

Horkheimer, Max/Adorno, Theodor Wiesengrund (1988): Dialektik der Aufklärung. Philosophische Fragmente. Frankfurt/M.: Fischer.

Joyce, James (1968): Dubliners. Harmondsworth: Penguin Books.

Kleinmann, Yvonne (2005): „Blasphemie‘ wider den katholischen Glauben? - Der Fall des jüdischen Schankwirts in Polen 1726“, in: Diner, Dan, Hg.: Synchrone Welten. Zeitenräume jüdischer Geschichte, Göttingen: Vandenhoeck \& Ruprecht, 37-66.

Klinger, Cornelia (2002): „Corpus Christi, Lenins Leiche und der Geist des Novalis, oder: Die Sichtbarkeit des Staates“, in: Belting, Hans/Kamper, Dietmar/Schulz, Martin, Hg.: Quel Corps? Eine Frage der Repräsentation. München: Wilhelm Fink, 219-232.

Leonhard, Clemens (2001): „Pessachhaggada und Osternacht“, in: Kirche und Israel 16, 45-47.

Luhmann, Niklas (1984): Soziale Systeme. Grundriß einer allgemeinen Theorie. Frankfurt/M.: Suhrkamp.

Lüttich, Alger von (1530): De sacramentis corporis et sanguinis Domini libri tres. Basel: Erasmus.

Mann, Thomas (1964): Joseph und seine Brüder, Frankfurt/M.: Fischer.

Michalski, Sergiusz (1984): „Aspekte der protestantischen Bilderfrage“, in: Idea. Jabrbuch der Hamburger Kunsthalle 3, 65-85.

Nierenberg David (1996): Communities of Violence: Persecution of Minorities in the Middle Ages. Princeton: Princeton University Press.

Nietzsche, Friedrich (1962): „Vom Nutzen und Nachteil der Historie für das Leben“, in: Schlechta, K., Hg.: Friedrich Nietzssche: Werke in 3 Bänden. Band 1. München: Hanser.

Rubin, Miri (1991): Corpus Christi. The Eucharist in Late Medieval Culture. Cambridge/UK: Cambridge University Press.

Schoell-Glass, Charlotte (1999): „Aby Warburg's Late Comments on Symbol and Ritual", in: Science in Context 12 (4), 621-642.

Sommerfeldt, John R. (1987): Erudition at God's Service. Kalamazoo: Cistercian. 
Stroumsa, Guy de (2005): La fin du sacrifice. Les mutations religieuses de l'Antiquité tardive. Paris: Odile Jacob.

Struve, Kai (2005): „Ritual und Gewalt - Die Pogrome des Sommers 1941“, in: Diner, Dan, Hg.: Synchrone Welten. Zeitenräume jüdischer Gescbichte. Göttingen: Vandenhoeck \& Ruprecht, 225-250.

\section{Quellennachweise der Bilder}

Bild 1 und 2: Sundermeier, Theo (2005): Aufbruch zum Glauben: Die Botschaft der Glasfenster von Johannes Schreiter, Frankfurt/M. Der Abdruck der Bilder erfolgt mit freundlicher Genehmigung des Verlags Otto Lembeck.

Bild 3 und 4: Abbildungen der Statue der Ecclesia und der Synagoge am Münster von Strassburg. C Christoph Bühler/ landeskunde-online.de

Bild 5: Raphael (1483-1520): Miracle of the Mass at Bolsena: central part. Vatican, Stanza di Eliodoro. (C) 1990. Photo Scala, Florence.

Bild 6: Warburg, Aby M. Mnemosyne-Atlas, Tafel 79 (1926) C Warburg Institute, London. 
Wandlung. Die christliche Eucharistiefeier als Transformation der „kotigen Wurzeln unserer Kultur“. Eine Antwort auf Aleida Assmann

Roman A. Siebenrock, Wolfgang Palaver, Willibald Sandler ${ }^{*}$

„...dass jeder gute Christ bereitwilliger sein muß, die Aussage des Nächsten zu retten als sie zu verurteilen; und wenn er sie nicht retten kann, erkundige er sich, wie jener sie versteht; und versteht jener sie schlecht, so verbessere er ibn mit Liebe; und wenn das nicht genügt, suche er alle angebrachten Mittel, damit jener, indem er sie gut versteht, gerettet werde. "1

Disziplin, wechselseitige Korrektur und Aufmerksamkeit für den ganzen Text von Aleida Assmann waren nötig, damit dieses Leitmotiv des Ignatius von Loyola für die Exerzitienbegleiter auch hermeneutisch zur Geltung kommen konnte. Sehr unterschiedlich waren die Reaktionen auch auf den Text, und ähnlich emotional wie schon nach Assmanns Vortrag haben wir in der Forschungsgruppe „Dramatische Theologie“ an der Theologischen Fakultät der Universität Innsbruck um ein angemessenes Verständnis gerungen. ${ }^{2}$ Das Prädikat „angemessen“ hatte für uns verschiedene Dimensionen. Werden wir dem Anliegen von Aleida Assmann wirklich gerecht? Wie beurteilen wir den Text nach historischen und theologisch-systematischen Kriterien? Kommen wir den für unsere Kultur so wichtigen Fragen, die darin aufgeworfen werden, näher, wie es das Kriterium unseres Forschungsansatzes fordert, nämlich zu einem friedfertigen Umgang miteinander beizutragen; auch im Diskurs innerhalb der Fakultät? Und schließlich, und das war eine wichtige Entde-

* Roman A. Siebenrock, Wolfgang Palaver und Willibald Sandler, alle von der KatholischTheologischen Fakultät der Universität Innsbruck, sind Mitglieder der Forschungsgruppe „Dramatische Theologie“ des theologischen Forschungsschwerpunktes „Religion - Gewalt - Kommunikation - Weltordnung“. Der vorliegende Text ist eine Antwort auf den Beitrag von Aleida Assmann, der sich aus den Kontroversen infolge ihrer SchwagerVorlesung vom 24. November 2005 ergeben hat.

1 Ignatius von Loyola (1993), EB 22.

2 Neben den drei Autoren dieses Beitrags haben vor allem Wilhelm Guggenberger und Petra Steinmair-Pösel schriftliche Vorarbeiten dafür geleistet. 
ckung: Was hat Aleida Assmann uns vermittelt und entdecken gelehrt? Wir dürfen vielleicht hier schon sagen, dass für manche von uns durch diesen Text das Werk und die Person von Aby Warburg eröffnet worden sind. Dafür sind wir dankbar. Was wir aber darin auf einen ersten Blick - entdecken durften, lässt uns auch in Bezug auf diesen Referenzautor von Assmann ganz andere Schlüsse ziehen.

Die Autoren dieser Antwort konnten sich trotz aller Bemühungen in der Einschätzung des Textes nicht in allem einigen, und das wollten wir hier auch nicht verbergen. Deshalb werden manche Erwiderungen und Rückfragen namentlich gekennzeichnet.

Unsere Antwort entfaltet sich in folgenden Schritten. Im ersten Kapitel sollen Vorgehensweise und Hauptthesen ihrer Position kurz referiert werden, damit die Leser(innen) prüfen können, ob wir die Aussagen angemessen verstanden haben. Im zweiten Kapitel wird Wolfgang Palaver den kulturtheoretischen Rahmen klären, und zwar in der Diskussion mit Autoren, die für Assmann wichtig sind - vor allem mit Aby Warburg. Im dritten Kapitel stellt Willibald Sandler die mittelalterliche Eucharistietheologie in den Zusammenhang eines umfassenderen Eucharistieverständnisses, das in der Theologie der frühen Kirche und dann wieder im 20. Jahrhundert deutlich aufscheint. Damit ergibt sich ein deutlich anderes Bild von der Geschichte der Eucharistie, als sie von Aleida Assmann skizziert wird. Im vierten Kapitel wird Roman Siebenrock auf die Wurzeln und Ursachen des christlichen Antijudaismus eingehen, wobei er die christlich-jüdische Diskussion berücksichtigt. Im fünften Kapitel werden noch verschiedene weitere Fragen aufgegriffen und dargestellt. Dabei soll nicht überspielt werden, warum manche These bei uns Kopfschütteln auslösen musste.

\section{Krypta, Palimpsest und die kotigen Wurzeln der Kultur: die Hauptthese und ihre Konsequenzen}

In ihrer theologisch-historischen und künstlerisch-ikonografischen Analyse des Abendmahls erhebt Aleida Assmann den Anspruch, dieses Medium der Vermittlung zwischen dem Absoluten und dem irdischen, endlichen Menschen auf seine verborgenen Voraussetzungen hin zu erhellen. Diese christliche Kultfeier charakterisiert sie als $\mathrm{Pa}-$ limpsest, mit der Begründung, dass sie die Überschreibung einer Krypta, einer Totenstätte also, darstelle, die noch wirksam sei, auch wenn sie weitgehend verborgen bleibe. Diese Krypta, die sich für sie 
im Laufe der Geschichte immer wieder tödlich auswirkt, bestimmt Assmann für das Abendmahl in folgenden Thesen: Während für das Judentum die Schrift das entscheidende Medium gewesen sei, werde für das Christentum zunächst der inkarnierte Logos zum Hauptmedium. Da mit dem Kreuzestod der zweiten göttlichen Person seine Präsenz gebrochen worden sei, würden neue kulturelle Praktiken notwendig. Das entscheidende Medium sei nun ein Leichnam. Das Wunder der Inkarnation werde durch die Auferstehung rückgängig gemacht. Deshalb müsse, damit die Leiblichkeit nicht verloren gehe, der Kult gerade diesen Aspekt betonen. Jener Ritus, der den Gründungsmythos Israels vergegenwärtige, werde in Erinnerung an das letzte Mahl Jesu mit seinen Jüngern weitergeschrieben. Diese Überschreibung führt zur Hauptthese Aleida Assmanns (oben, Seite 256): „Mit der martyriologischen Wende vom Gottessohn als inkarniertem Logos zum leidenden, gekreuzigten und gestorbenen Christus ist ein Motiv von Schuld und Rache verbunden, das in der Überlieferung über Jahrhunderte inert blieb, aber unter bestimmten Umständen auch gefährliche Formen annehmen konnte. Mit der Leerstelle des identitätsfundierenden Anderen verknüpft, bildet dieses Motiv eine „Krypta‘, d.h. einen der Reflexion unzugänglichen energetischen Komplex im kulturellen Gedächtnis, der in unterschiedlichen Konstellationen immer wieder reaktivierbar ist."

Damit wird in den maßgeblichen Tradierungs- und Identitätsritus des Christentums Gewalt eingeschrieben, und zwar deshalb, weil die Freund-Feind-Unterscheidung, die für Assmann jede Gesellschaft konstituiert, im Judentum durch die Nennung der Ägypter ausdrücklich offengelegt wird, im Christentum aber nicht. Die Juden können daher als die identitätsstiftenden Anderen nicht ausdrücklich reflektiert werden. Das bedeutet: Nach Aleida Assmann kommen die Juden im zentralen identitätsstiftenden Ritus der Christen nicht vor. Mit der martyrologischen Wende vom inkarnierten zum gekreuzigten Logos stellt dieser Zusammenhang eine gefährliche Krypta her, deren Abgründe mit dem Bild der kotigen Wurzeln der Kultur nach Thomas Mann und Aby Warburg beschrieben werden. Darüber hinaus behauptet Aleida Assmann, die Bezeichnung der Juden als Gottesmörder, die im christlichen kulturellen Unbewussten fest verankert sei, könne immer wieder gewaltenergetisch auf diese zurückfallen; auch weil durch die Konzentration auf den körperlichen Aspekt des Gekreuzigten das Abendmahl immer stärker den Charakter eines Opferrituals annehme. Die Verdrängung des identitätsstiftenden 
Anderen müsse sich aber immer wieder Bahn brechen. Das markante Zeichen hierfür sei der christliche Antijudaismus. Als besonderes Indiz wählt Assmann die Zeit des 13. Jahrhunderts. Die dogmatische Formulierung der Transsubstantiationslehre auf dem Laterankonzil (1215), im Kontext der gesamtkirchlichen Einführung des Fronleichnamsfestes, verknüpft sie unmittelbar mit dem Anitjudaismus. Ihre Begründung lautet (oben, Seite 264): „Mit dieser neuen Glaubensanforderung [Transsubstantiation] wuchsen zugleich auch Zweifel und Hysterie [...] Der Stress, mit dem hier der Glaube belastet wird [...], schlägt unmittelbar auf die Juden als die Feinde des Christentums zurück."

In ihrer historischen und künstlerischen Aufarbeitung der Geschichte der christlichen Abendmahlpraktik (Palimpsest) erhellt sie ihre These quer durch die christliche Geschichte mit dem Motiv des Blutes, insofern es mit dem Abendmahl zusammenhängt. Hierbei greift sie auf den Bilderatlas von Aby Warburg zurück. Das Abendmahl stellt deshalb für sie den entscheidenden Grund für den christlichen Antijudaismus dar. Da Aleida Assmann aber - das ist entscheidend - den Anspruch auf eine umfassende kulturtherapeutische Anamnese mit therapeutischen Absichten in Bezug auf die eigene Kultur erhebt, fordert sie, gewisse Praktiken - sie nennt Ritualmordlegenden und Hostienfrevel - abzuschaffen. So weit die zusammenfassende Darstellung.

Doch ihr Anspruch reicht unsere Meinung nach weiter. Wenn diese Krypta, wie sie es gerade an dieser Stelle thesenförmig festhält, ein konstitutives Element der Abendmahltradition darstellt und diese Verdrängung der identitätsstiftenden Anderen ein Depot negativer Energie bildet, „das zur eigenen Entlastung und affirmativen Selbstvergewisserung immer wieder auf andere abgeführt werden muss" (oben, Seite 273), dann erscheint uns der eher versöhnliche Vorschlag am Ende des Textes inkonsequent. Faktisch würde dies bedeuten (und so haben wir die Spitze dieses Aufsatzes gelesen), dass das Abendmahl in seinem Gewalt fördernden Potential ein höchstes Risiko in der heutigen Gesellschaft bildet, das abgeschafft werden müsste. Doch trifft diese These zu? Dass Assmann eine wichtige, ja heute notwendige Frage aufgeworfen hat, steht außer Zweifel. Auch wir wollen darauf eine Antwort versuchen: Welches sind die Wurzeln der Gewalt in der sozialen Konstitution der Gesellschaft? Was hat das christliche Abendmahl mit der Gewalt zu tun, in welche die Kirche im Laufe der Geschichte verwickelt war? Welches sind die 
Wurzeln des christlichen Antijudaismus und wie erläutern wir die antijüdischen Gewaltphänomene unserer Geschichte?

\section{Wie mit den kotigen Wurzeln der Kultur umgehen? Thomas Mann - Aby Warburg - René Girard (Wolfgang Palaver)}

Zugegeben, Aleida Assmanns hier zugespitzt formulierte These, dass das katholische Verständnis des Abendmahls mit seiner Betonung des Opfercharakters sowie der Realpräsenz - d.h. der Wandlung von Brot und Wein in Leib und Blut Christi - gewaltgeladen sei und eine deutliche Neigung zum Antijudaismus aufweise, stellt für katholische Theologen eine Provokation dar, die ein sachliches Gespräch schwierig macht. Das ist aber nicht so sehr als Vorwurf gegen Assmann gesagt, sondern zeigt nur, wie unwegsam das Gelände tatsächlich ist, in das uns ihr Beitrag „Gewalt und das kulturelle Unbewusste" führt. Assmanns Provokation ist ein fruchtbarer Anstoß, der es verdient, ernst genommen zu werden. Das Verhältnis von Abendmahl und Gewalt wirft so schwierige Fragen auf, dass eine präzise Auseinandersetzung unabdingbar ist.

Sicherlich ist Aleida Assmann zuerst zuzustimmen, wenn sie Beispiele aus der Geschichte des Christentums nennt, die deutlich machen, wie immer wieder Christen auch durch ein bestimmtes Verständnis der Eucharistie ihre Gewalttaten - oft gegen Juden gerichtet - begründet haben. Ihr Verweis auf die Konflikte, die ausgelöst wurden, als der Innsbrucker Diözesanbischof Reinhold Stecher in den 80er-Jahren des vergangenen Jahrhunderts sich klar vom Volksglauben an die Ritualmordlegende des Anderl von Rinn distanzierte, zeigt, wie sehr solche Probleme bis in unsere eigene Gegenwart hereinreichen. ${ }^{3}$ Die von Assmann genannten historischen Hinweise sind durchaus zutreffend und veranschaulichen das Problem.

Problematischer ist Assmanns These allerdings dort, wo es um den großen kulturtheoretischen Rahmen geht, den sie zur Deutung dieser Belege heranzieht. Gleich zu Beginn ihres Aufsatzes hält sie fest, dass es ihr nicht um "Ideologiekritik“ gehe, sondern um eine „kulturelle Gedächtnisforschung“. Der dabei leitende kulturtheoretische Rahmen selbst wird vor allem in ihrer Gegenüberstellung der Positionen von Thomas Mann und Aby Warburg deutlich. Beide 
wissen einerseits um die gewalttätigen und blutigen Ursprünge menschlicher Kultur, sie unterscheiden sich aber andererseits in ihrer jeweiligen Einschätzung der Position des Christentums gegenüber dem gewaltgeprägten Anfang.

Thomas Mann setzte sich mit den mythischen und gewalttätigen Ursprüngen menschlicher Kultur vor allem in seiner Romantetralogie Joseph und seine Brüder auseinander. Aleida Assmann verdanken wir den interessanten Hinweis auf Manns Einsicht in die „kotige Wurzel“, die zum Baum menschlicher Kultur gehört. Die entsprechende Auseinandersetzung damit bildet das Zentrum des Romanteils „Das bunte Kleid“. Wir finden darin den Dialog zwischen Jaakob, der sich voll Grauen von den blutigen Ursprüngen abwendet und daher sogar alle Feste, die daran erinnern, abschaffen will, und seinem Sohn Joseph, der auf die „kotige Wurzel“ hinweist und im Unterschied zu seinem Vater auf eine vom religiösen Fortschritt getragene Zivilisierung dieser Wurzel setzt. Mehrmals betont Joseph gegenüber seinem Vater, dass es darum gehe, mit Gott über diese Ursprünge „hinaus“zugehen. Ganz ähnliche Formulierungen verwendet Thomas Mann auch, um seine eigene Position gegenüber den mythischen Ursprüngen menschlicher Kultur zu beschreiben. In einem Vortrag zu seinen Joseph-Romanen an der Washingtoner Library of Congress im Jahre 1942 machte er klar, dass diese Haltung des mit der religiösen Entwicklung sich vollziehenden Hinausgehens über die Ursprünge einer „Gottesklugheit“ entspreche, der eine zerstörerische und zur Katastrophe führende „Gottesdummheit" gegenüberstehe. ${ }^{4}$ Letztere identifizierte er natürlich mit dem nationalsozialistischen Versuch, neuheidnisch die blutigen Ursprünge wiederzubeleben. In einer systematisch wichtigen Stelle in diesem Vortrag verbindet er dies mit seiner eigenen Sicht der Überwindung des Menschenopfers, wie sie paradigmatisch in der biblischen Erzählung von der Bindung Isaaks (Gen 22) zum Ausdruck kommt. Nach Mann gibt es eine religiöse Fortschrittsbewegung, die von den blutigen Menschenopfern hin zu unserer modernen Kultur führt. Diese Bewegung beginnt mit der verhinderten Opferung Isaaks und dem damit vollzogenen Bruch mit dem heidnischen Menschenopfer. Nach Assmann sieht Thomas Mann das Christentum in dieser "Tradition einer fortschreitenden Vergeistigung und Sublimierung“". Für 
Mann scheint damit die „kotige Wurzel“ ein für alle Mal überwunden und vergangen zu sein. Sie bedarf genauso wenig einer neuerlichen Bewusstmachung wie auch der Baum nicht mehr ,ihr denkt". 5

Assmann stellt der Position von Thomas Mann jene des Kunsthistorikers Aby Warburg gegenüber. Auch dieser weiß um die blutigen Ursprünge der Kultur oder - um Manns Metapher aufzugreifen - um ihre „kotige Wurzel“. In seiner Einleitung zum Bilderatlas Mnemnosyne spricht er ausdrücklich vom „mörderischen Menschenfraß“ und vom „,menschenopfernden Urtrieb“. ${ }^{6}$ Für Assmann ist vor allem dieses Spätwerk Warburgs interessant. Sie verweist insbesondere auf den Bilderatlas, weil darin dessen Thesen im Kontext des Abendmahlsstreits situiert sind. In seinem Todesjahr 1929 machte er sich intensive Gedanken über die Verwandtschaft des Abendmahls mit primitiven Opferkulten. Assmann stellt fest, dass gegenüber Manns Kulturtheorie des Fortschritts Warburg das „bleibende Spannungsverhältnis zwischen Fortschritt und Rückschritt" betone und für die „Fähigkeit zur distanzierenden Reflexion“ als dritte Möglichkeit gegenüber „Visionen von absoluter Präsenz und absoluter Transzenden z" eintrete. Um Warburgs Position zu verdeutlichen, zitiert sie eine Aussage vom August 1929, in der er seine religiöse Position folgendermaßen umschreibt: „Sagte ihm, daß ich weder antikatholisch noch protestantisch sei, aber ein Christentum der Zukunft denken könne (und erwünsche), daß das die Funktion des metaphorischen ,Wie' als Problem fühle, um das gestritten werden müsse." Warburg eine endgültige Überwindung der heidnischen Ursprünge niemals völlig möglich sein wird, setzte er auf deren Zähmung.

Assmanns Präferenz für die Position Warburgs gegenüber derjenigen von Mann ist positiv hervorzuheben, zeigt sie doch damit, dass sie um die Problematik einer Verdrängung der heidnischen Opferproblematik weiß. Indirekt bewegt sie sich damit sogar in Richtung eines katholischen Abendmahlsverständnisses. Ein genauerer Blick auf Mann und Warburg zeigt allerdings, dass Assmann einer-

5 Mann (1991b), 89.

6 Warburg (2003), 3-4.

7 Warburg (2001), 498 (Tagebuch Band 8/199). Assmann zitiert diese Stelle nach einer früheren englischen Übersetzung von Schoell-Glass folgendermaßen: „Ich bin weder antikatholisch noch protestantisch, aber ich könnte mir eine zukünftige christliche Religion vorstellen (und wünschen), die sich der Bedeutung des metaphorischen Als Ob als eines Problems bewußt ist.“ (Schoell-Glass (1999), 636.) 
seits eine etwas grobe und ungenaue Gegenüberstellung der beiden Kulturtheoretiker vornimmt und andererseits mit ihrer eigenen These hinter Warburg zurückfällt. Assmann ist zwar darin zuzustimmen, dass Mann viel stärker als Warburg von der Fortschrittsidee geprägt ist, ein präziserer Blick zeigt allerdings, dass auch er um die Gefahr wusste, die ein völliges Abkoppeln von der „kotigen Wurzel“ mit sich führen kann. Schon im Gespräch mit seinem Vater Jaakob tritt Joseph gegen die Abschaffung, d.h. „Zerstörung“, des im Menschenopfer wurzelnden Festes ein und plädiert für eine „Verschonung“". ${ }^{8}$ Im dritten Teil der Tetralogie kommt Mann noch einmal auf dieses Gespräch zwischen Jaakob und Joseph zurück. Nun unterstreicht Joseph noch deutlicher als zuvor, wie gefährlich es wäre, den Baum von seiner „kotigen Wurzel“ zu trennen: „Hatten nicht Jaakobs schwermütige Bedenken in Sachen des Festes ihn in die Versuchung gebracht, das Fest und seine Bräuche überhaupt zu zerstören um seiner Wurzeln willen, die wohl sich nähren mochten im untern Unflat? Um Schonung hatte der Sohn ihn bitten müssen fürs Fest der Verschonung, den schattenspendenden Wipfelbaum, der mit dem Herrn hinausgekommen war über die kotige Wurzel, aber dorren mußte, wenn man sie ausrodete. Joseph war für Verschonung, er war nicht fürs Ausroden." Bei allem fortschrittsoptimistischen Idealismus, der bei Mann beim ersten Hinsehen zum Vorschein zu kommen scheint, darf nicht übersehen werden, wie sehr die ganze Tetralogie indirekt auf eine christliche Antwort hinausläuft, die keineswegs oberflächlich bleibt: „Erst das Sohnesopfer Gottes in Christus beendet den Opfer-Mythos endgültig. In Jesus Christus findet die progressive Humantheologie des Romans ihre heilsgeschichtliche und menschliche Mitte." "10 Vor diesem Hintergrund verwundert es nicht, dass der protestantisch erzogene Autor zeitlebens eine groBe Sympathie für den katholischen Ritus hegte. ${ }^{11}$ Während nach Assmann Thomas Mann das Christentum als Fortsetzung der jüdischen Überwindung des Menschenopfers versteht, scheint sie selbst unter Berufung auf Warburg die These zu vertreten, dass mit dem Christentum diese religiöse Entwicklung rückgängig gemacht worden sei: „Das jüdische Tabu des Menschenopfers, das in der Ge-

8 Mann (1991b), 90.

9 Mann (1991a), 215

10 Seibt (2005), 342.

11 Schoell-Glass (1999), 639-640; Braun (2007), 167. 
schichte von der Bindung Isaaks als ein menschheitlicher Fortschritt gefeiert wird, ist gewissermaßen in der Passionssymbolik rückgängig gemacht oder, um mit Aby Warburg zu sprechen, ,energetisch invertiert' worden." (oben, Seite 262) Doch lässt sich Warburg als Stütze für eine solche Behauptung gewinnen? Ein Blick auf seinen wichtigen Kreuzlinger Vortrag von 1923 zeigt die viel subtilere Position Warburgs. Ausgehend von den Schlangenritualen der Hopi-Indianer, die er präzise auf jene „blutigen Wurzeln des Kultes“ zurückführt, die für die heidnischen Menschenopferkulturen charakteristisch sind, stellt er sich die Frage, ob sich solche Ursprünge ein für alle Mal überwinden ließen. ${ }^{12}$ Seine Antwort - wie wir schon durch Assmanns Rekonstruktion wissen können - fällt negativ aus. Immer wieder verweist er auf Spuren eines Aufbrechens jener urtümlichen Hintergründe, die für das Schlangenritual bestimmend waren. Er verweist auf Beispiele im Griechentum, im Alten Testament und in der Geschichte des Christentums. Alle diese Verweise halten ihn aber nicht davon $\mathrm{ab}$, deutlich herauszustreichen, wie sehr dennoch im biblischen Denken eine Ablösung vom Menschenopfer gegeben ist: „Die Erlösung vom blutigen Opfer durchzieht als innerstes Reinigungsideal die religiöse Entwicklungslinie vom Orient zum Okzident." ${ }^{\text {"13 }}$ Im Alten Testament sieht Warburg in der Erzählung vom „ehernen Schlangenidol", das Mose aufrichten lässt (Num 21.4-9), um vom Schlangenbiss zu heilen, einen ,überlebendes Stück Götzendienst“ “. ${ }^{14}$ Doch er betont gleich im Anschluss daran, wie sehr gerade die prophetische Tradition gegen diese Versuchungen angekämpft hat, und erwähnt auch die Tatsache, dass unter König Hiskija - unter Einfluss des Propheten Jesaja - die Schlange des Moses zerschlagen wurde (2 Kön 18.4): „Der Menschen opfernde und Tiere verehrende Götzendienst war ja die feindliche Macht, gegen die die Propheten am erbittertsten kämpften. Und dieser Kampf bildet den Kernpunkt der orientalischen und christlichen Reformation bis in die neueste Zeit hinein."15 Gerade die Anfänge des Christentums waren nach Warburg von diesem Kampf gegen den Götzendienst bestimmt. Er verweist als Beispiel auf Paulus, der eine Viper ins Feuer warf, ohne sich von dieser - wie bei den Heiden oft üblich - sonderlich beein- 
drucken zu lassen (Apg 28.1-6): „Das frühe Christentum - im Kampfe wider den heidnischen Götzendienst - dachte weniger kompromißlich dem Schlangenkult gegenüber. Paulus war in den Augen der Heiden ein gefeiter Sendbote, als er die Viper, die ihn gebissen hatte, ins Feuer schleudern konnte, ohne selbst an dem Schlangenbiß zu sterben." 16 Doch konnte auch eine solche Absage an das Heidentum später bald wieder in eine abergläubische Magie umkippen. Warburg verweist beispielsweise auf maltesische Festlichkeiten, die sich im Anschluss an diese Erzählung über Paulus entwickelten. In der mittelalterlichen Theologie wurde später - anknüpfend an Joh 3.14-15 - auch häufig auf die Geschichte von der ehernen Schlange im Alten Testament hingewiesen, um diese oft unkritisch mit der Erhöhung Christi am Kreuz zu verbinden: „Kaum etwas kann die Unzerstörbarkeit des Tierkultes so zeigen wie diese Verwendung, in der das Wunder der ehernen Schlange hinübergleitet in die christlich-mittelalterliche Weltanschauung. Denn die mittelalterliche Theologie hat diesen Schlangenkult als Objekt der Überwindung so stark in Erinnerung behalten, dass sie aufgrund dieser doch ganz vereinzelten und dem Sinn und der Theologie des Alten Testaments widersprechenden Stelle das Bild der Schlangenverehrung im typologischen Bilderkreis bis an die Kreuzigung selbst heranbringt.“17 Auf derselben Linie liegt auch Warburgs anschließender Hinweis auf die Gegenüberstellung von der Kreuzigung Jesu und der verhinderten Opferung Isaaks. ${ }^{18}$ Aber auch in diesen Hinweisen auf Rückfälle ins Heidentum bleibt Warburg sehr sorgfältig, denn gleichzeitig betont er, dass die Erhöhung der Schlange im Vergleich zur Kreuzigung in der mittelalterlichen Theologie ,ausdrücklich als überwundene Entwicklungsstufe" verstanden wurde. ${ }^{19}$ Für Warburg ist die Schlange ein ,internationales Antwortsymbol“ auf die Frage nach dem Woher von Zerstörung, Tod und Leid und verdient daher ein „,eigenes Kapitel in der Philosophie des ,Als-Ob“. ${ }^{20}$ Für Warburg war einerseits klar, dass die Menschen sich niemals ganz von den heidnischen Kulturen werden lösen können, andererseits sah er groBe Gefahren auf die Menschen zukommen, wenn sie sich ganz auf

16 Warburg (1988).

17 Warburg (1988), 51-52.

18 Warburg (1988), 52.

19 Warburg (1988), 55.

20 Warburg (1988). 
eine Aufklärung in Richtung bloß „mathematischer Zeichen“ und Technik zu verlassen versuchen. Nach Warburg ,zerstört die Kultur des Maschinenzeitalters das, was sich die aus dem Mythos erwachsene Naturwissenschaft mühsam errang, den Andachtsraum, der sich in den Denkraum verwandelte. [...] Telegramm und Telephon zerstören den Kosmos. Das mythische und symbolische Denken schaffen im Kampf um die vergeistigte Anknüpfung zwischen Mensch und Umwelt den Raum als Andachtsraum oder Denkraum, den die elektrische Augenblicksverknüpfung mordet.“21 Mit diesen etwas kryptischen, fragmentarischen und schwer verständlichen Worten endet Warburgs Kreuzlinger Vortrag.

In den letzten Jahren seines Lebens - als er vor allem am Bilderatlas arbeitete - hat sich an dieser Einschätzung von Heidentum, Christentum und moderner Welt nichts Wesentliches geändert. Sein klares Urteil, dass gerade im Christentum der Auszug aus dem heidnischen Opfer gelungen sei, zeigt sich dabei sogar noch deutlicher. Während er im Falle des Judentums - ganz im Unterschied zu Sigmund Freud und seinen vielen gegenwärtigen Nachfolgern - nicht so sicher war, ob dieses nicht bloß unter dem „Zwang der Verhältnisse“ - weil eben der Tempel zerstört war - dem Opfer entsagte, ohne wirklich auf einen „Weg der Vergeistigung“ gelangt zu sein, schätzte er am Christentum dessen „Ablehnung des Opfers“.22 Ein Brief an seine Nichte Gisela vom Frühjahr 1929 zeigt diese Haltung unmissverständlich: „Das Judentum hat in der Entwicklung des Opferkultes (das bei jeder Religion im geheimnisvollen Mittelpunkt steht) eine heroische vermittelnde Aufklärungsstellung dadurch eingenommen, daß Elias den kinderschlachtenden Molochpriestern eine unheilbare moralische Niederlage verschaffte; aber das Tieropfer blieb. Hierin blieben die Juden Heiden am Mittelmeerbecken. Erst die revolutionierenden Erben des Judentums, die Christen, versuchten durch imaginäre Generalablösung des blutigen Opfers, das Gotteshaus vom Qualm des Opferaltars zu reinigen." ${ }^{23}$ Nach seinem Biographen Ernst Gombrich sind hinsichtlich dieser Einschätzung des Christentums vor allem auch Warburgs Interpretationen der Bilder von Raffael bedeutsam. Gombrich verweist dazu sowohl auf Raffaels Opfer von Lystra, das die Ablehnung heidnischer Opfer durch

21 Warburg (1988), 59; vgl. Böhme (2006), 243-247.

22 Gombrich (2006), 369-371.

23 Zitiert nach Raulff (2003), 70. 
die Apostel Paulus und Barnabas (Apg 14.8-18) darstellt, als auch auf Raffaels Messe von Bolsena, das zu jener letzten Tafel des Bilderatlas gehört, auf den Aleida Assmann im Anschluss an Schoell-Glass besonders verweist. ${ }^{24}$ Obwohl das Bild die Legende von der blutenden Hostie aufgreift, drückt es in Raffaels Deutung die Absetzung vom heidnischen Kultus aus, als „Ausdruck eines tiefen geistigen Erlebnisses“: „Wir sehen den Priester in andächtiger Versunkenheit und die Gläubigen im Ausdruck frommer Innerlichkeit aufwärts streben. “25 Warburg unterstreicht diese Deutung gerade in jener Tagebuchaufzeichnung, die von Assmann zwar hervorgehoben, aber gleichzeitig um die genaueren Ausführungen zu diesem Bild verkürzt wird. Die von Assmann zitierte Aufzeichnung setzt sich nämlich so fort: „Vor lauter tätigem ,hoc meum corpus est' vergesse der Norden zu bemerken, wie sich seit Raffaels Messe von Bolsena die Katholische Kirche vom brutal Magischen loszumachen im Begriff sei.“26 Mit dem „hoc meum corpus est" spielt Warburg - das entsprechende Bild findet sich ebenfalls im Bilderatlas - auf jenen modernen Körperkult an, der sich dem Symbol der Eucharistie mit ihrem Wissen um das heidnische Opfer nichts ahnend entgegenzustellen begann. ${ }^{27}$ Diese Gegenüberstellung von Monstranz und modernem Körperkult berührt sich mit Warburgs kritischen Einwänden gegen die moderne Welt der Technik, wie wir sie aus dem Kreuzlinger Vortrag kennen. Ähnlich wie Warburg an der Technik ihren radikalen und nicht ungefährlichen Kampf gegen jede Art von Opfer bemängelt, stellt Warburg auch hier die moderne „Vermeidung des Passionserlebnisses" in Frage. ${ }^{28}$

Aus dieser Skepsis gegenüber bestimmten Momenten der modernen Welt geht zumindest deutlich genug hervor, dass für Warburg eine völlige Loslösung von den heidnischen Wurzeln nicht weniger gefährlich ist als das Verbleiben im heidnischen Mythos. Es verwundert daher auch nicht, dass sich Warburg am Ende seines Lebens so sehr dem Katholizismus geistig annäherte, dass sogar Gerüchte entstanden, dass er konvertiert sei.. ${ }^{29}$ Assmann spart diese

24 Gombrich (2006), 371.

25 Gombrich (2006), 371.

26 Warburg (2001), 498. Vgl. Warburg (2001),141; Schoell-Glass (1999), 636.

27 Vgl. Gombrich (2006), 372-374.

28 Warburg (2001), 498.

29 Warburg (2001), XXX, 476; Gombrich (2006), 375; Negel (2000). 
Annäherung im Anschluss an Schoell-Glass, die mit der katholischen Kirche Schwierigkeiten zu haben scheint, konsequent aus. ${ }^{30}$ Damit beraubt sie sich aber selbst der interessanten und weiterführenden Frage, ob sich nicht gerade von Warburg her eine viel vorsichtigere Beurteilung des katholischen Eucharistieverständnisses ergeben würde. Warburg erkannte -Thomas Mann nicht ganz unähnlich - im katholischen Christentum eine wichtige Brücke zwischen heidnischer Vergangenheit und aufgeklärter Zukunft. Im Ringen um das ,,metaphorische ,Wie' des Abendmahlsstreits ging es ihm um jenen „Denkraum“, der zwischen dem religiös-magischen Weltbild des Heidentums und jener mathematischen Abstraktion gefunden werden muss, die sich vollständig von den heidnischen Wurzeln lösen zu können glaubt. Er sprach von der Notwendigkeit einer „Auffangstelle jener Austauschbewegung von Vergangenheit und Gegenwart", um damit „dem Chaos von Unvernunft ein Filtersystem der retrospektiven Besonnenheit entgegenzusetzen“.31 Wie Thomas Mann die Verschonung dem Ausroden vorzog, so betonte Warburg die Notwendigkeit einer Transformation, die die in den heidnischen Wurzeln enthaltene Energie umformen und nicht ignorieren sollte. „Bin kein revolutionärer Reformator; energetischer Transformator", schrieb er im Juni 1928 von sich. ${ }^{32}$

Aus der Sicht der Innsbrucker Forschungsgruppe legt sich eine Zusammenfassung dieser kritischen Überlegungen zu Assmanns kulturtheoretischem Rahmen aus der Perspektive der mimetischen Theorie René Girards nahe. In deutlicher Nähe zu Mann und Warburg erkennt Girard, dass die menschliche Kultur aus blutiger Gewalt - aus dem Sündenbockmechanismus - hervorgeht. In Judentum und Christentum erkennt auch er den Auszug aus der heidnischen Kultur des Menschenopfers. Vielleicht noch etwas optimistischer als Mann betont er in seinem früheren Werk so sehr den Unterschied zwischen dem Heidentum und den biblischen Religionen Judentum und Christentum, dass er für die Kreuzigung Christi den Begriff „Opfer“ überhaupt ausschließen will. ${ }^{33}$ Später - unter deutlichem Einfluss des Innsbrucker Dogmatikers Raymund Schwager - korrigiert er diese Position, indem er bei Aufrechterhaltung seiner Unter- 
scheidung zwischen heidnischen und biblischen Religionen betont, wie sehr eine völlige Entkoppelung vom heidnischen Opfer der Illusion verfällt, die heidnische Kultur risikolos und fern aller Gewalt verlassen zu können. ${ }^{34}$ Indirekt verweist er damit auf jene von Warburg erkannten Gefahren einer technizistischen Neutralität, die mit dem Heidentum zu brechen versucht, indem es letztlich den Menschen abzuschaffen beginnt. ${ }^{35}$ Heute betont er gerade deshalb die „Einzigartigkeit der Evangelien“ - weil sich diese noch stärker als das Alte Testament auf das heidnische Menschenopfer zurückbeziehen, um in ihrer Darstellung von Tod und Auferstehung Jesu Christi zu einer Überwindung des Menschenopfers zu gelangen, die nicht risikoarm gelang, sondern den grausamen Tod am Kreuz erforderte. ${ }^{36}$ Nur durch die äußerste Angleichung an den heidnischen Gewaltmechanismus gelingt es den Evangelien, diese Opferkulturen von innen her umzuwandeln. Das Kreuzesopfer Christi ist deshalb kein Rückfall ins Heidentum, sondern im Gegenteil die radikale Transformation der mythischen Ursprungsgewalt. ${ }^{37}$ Assmann scheint diese grundlegende Unterscheidung zu unterschätzen und folgt darin dem mehrfach zitierten Medientheoretiker und Literaturwissenschaftler Jochen Hörisch, der trotz seines Hinweises auf Girard den Unterschied zwischen heidnischen Opferkulten und Abendmahl verkennt. ${ }^{38}$

Wie aber erklärt Girard die vielen - auch von Assmann erwähnten - Beispiele christlich legitimierter Gewalt, die sich gerade aus einem bestimmten Opferverständnis ableiteten? Girard negiert diese Phänomene in der Geschichte des Christentums keineswegs, sondern sieht in ihnen die Folgen eines "sakrifiziellen Christentums“, das durch eine opferkultische Deutung der Passion und Erlösung Jesu gekennzeichnet ist. ${ }^{39}$ Der Tod Jesu wird ähnlich wie das Opfer archaischer Religionen gedeutet. Ein Beispiel dafür ist jene in der Christenheit weitverbreitete Theologie, die den Kreuzestod Jesu als ein von Gott gefordertes Opfer versteht, das den Zorn Gottes besänftigen soll. Diese sakrifizielle Interpretation der biblischen Schrif-

34 Girard (1995); vgl. Palaver (2004), 293-310.

35 Vgl. Palaver (2001).

36 Girard (2002), 156-173.

37 Niewiadomski (2001).

38 Hörisch (1992), 93-112

39 Girard (1983), 234; vgl. Palaver (2004), 311-321. 
ten erlaubte es, auch unter Berufung auf diese Texte eine Kultur zu begründen, die sich von herkömmlichen Kulturen nicht sonderlich unterschied. ${ }^{40}$ Das sakrifizielle Christentum bewirkte, dass die zwischenmenschliche Gewalt wieder auf Gott projiziert wurde und sich so die Menschen von der - für alle gleichermaßen bestehenden Verantwortung für die Gewalt entledigen konnten. Wenn aber nicht mehr die Verantwortlichkeit aller für die Gewalt unter den Menschen aufrechterhalten wird, dann führt das sehr rasch zur Jagd nach Sündenböcken, auf die die Gewalt abgeschoben wird. Das Moment der Verfolgung anderer gehört deshalb zu den typischen Merkmalen des sakrifiziellen Christentums. Juden-, Ketzer- und Hexenverfolgungen, Kreuzzüge und Religionskriege waren die direkten Folgen dieser sakrifiziellen Fehldeutung der biblischen Schriften. Deutlich hält Girard den Zusammenhang zwischen sakrifiziellem Christentum und Judenverfolgung im Blick auf das Mittelalter fest: „Der Zerfall eines Christentums, das mehr oder weniger vom Geist der Verfolgung angesteckt ist, ein Christentum als Opferreligion, kann nur zu christlichem Antisemitismus führen." ${ }^{\text {"41 }}$

\section{Eucharistie als Transformation, die an die (kotige) Wurzel geht (Willibald Sandler)}

Aleida Assmann konzentriert sich in ihrer Darstellung der Abendmahlsgeschichte ganz auf eine Epoche - nämlich das Mittelalter, mit Auswirkungen bis zur Gegenwart -, die von einem heutigen theologischen Eucharistieverständnis her in Vielem als defizitär betrachtet werden muss. Um Assmanns Anliegen einer Erinnerungsgeschichte gerecht zu werden, genügt es allerdings nicht, im engen Blick auf mittelalterliche Eucharistietheologie und -praxis deren Defizite zu brandmarken. Es ist auch nötig zu fragen, wie derart weit- und tiefreichende Missverständnisse möglich waren und ob diese vielleicht mit Einseitigkeiten zu tun haben, die an die Wurzel der Eucharistie und damit des Christentums überhaupt - gehen. Das wiederum ist nicht möglich, ohne den Blick zu weiten auf die Bedeutungsdimen-

40 Girard (1983), 188.

41 Girard (2005), 127. Im englischen Originaltext zeigt sich die Position Girards noch prägnanter: ,The disintegration of a Christianity somewhat contaminated with the spirit of scapegoating (sacrificial Christianity) is bound to generate Christian anti-Semitism. " Girard (1996), 220. 
sionen, die in der Eucharistie eigentlich enthalten sind. Außerdem ist zu zeigen, dass die für das Mittelalter charakteristischen Eucharistievorstellungen des Mittelalters nicht nur defizient waren.

Mit den von Assmann herangezogenen Bildern: Wir müssen noch tiefer graben, um zu sehen, ob nur Kot an der christlichen Wurzel ist oder ob die Wurzel sich nicht tiefer in guter Erde vergräbt, sodass der Kot nur eine Zwischenschicht darstellt. Sollte das zutreffen, dann ist nicht nur Aufklärung - im Hinweis auf den Kot an der Wurzel und deren „kotige Auswirkungen“ - gefordert, sondern auch Aufklärung der Aufklärung: damit nicht insgesamt als Ausgeburt von Kot verworfen wird, was vielleicht unverzichtbares Mittel zu seiner heilenden Transformation ist.

Der Blick ist also zu weiten auf die gesamte Eucharistiegeschichte und insbesondere auf ihre heilsgeschichtliche Verankerung im dramatischen Christusereignis. Von hier aus ist die tiefere „gute Erde“, an der sich die Wurzel der Eucharistie nährt, zu erschließen. Damit ich mich nicht in der Fülle des damit anstehenden Materials verliere, werde ich mich zunächst von einer Frage leiten lassen, die Aleida Assmann an den Anfang ihres Beitrags gestellt hat: die Frage der Medialität, die mit Christus als dem authentischen Mittler zwischen Mensch und Gott in seiner sakramentalen Präsenz als Realsymbol Gottes zu tun hat.

Dass das Problem der Medien im Verhältnis zwischen Gott und Mensch theologisch zentral ist, stellt Aleida Assmann selber fest, auch dass hierfür theologisch der Begriff des Mittlers bedeutsam ist (siehe Anmerkung 1 im Beitrag). Wie Assmann weiters richtig bemerkt, wird im Neuen Testament Jesus Christus als Mittler favorisiert, und zwar mit dem Anspruch einer Unmittelbarkeit, die den Mittlerbegriff, der immer auch Distanzierung besagt, an seine Grenzen führt. ${ }^{42}$ Nach christlichem Verständnis ist von Jesus Christus zu sagen: Zwischen Gott und Mensch ist er Mittler ohne jedes Hindernis, restlos adäquate Vergegenwärtigung von Gott selbst für die Menschen. Diese Vergegenwärtigung bezeugen die Evangelien durch die Erfahrung von Menschen, die Jesus begegneten: Für sie galt, was Johannes in einer „Ich-Aussage“ Jesus zuschrieb: „Wer ihn sieht, sieht den Vater“ (vgl. Joh 12.45; 14.8-9). Diese Vergegenwärtigung

42 Vgl. Gal 3.20: „Einen Mittler gibt es jedoch nicht, wo nur einer handelt; Gott aber ist ,der eine'." 
Gottes, um die es zentral in Jesu Gottesreichbotschaft geht, ist keinesfalls nur statisch-kontemplativ zu verstehen. Auch wenn solche Momente beinah ekstatischer Vorwegnahme einer himmlischen Gottunmittelbarkeit wesentlich zur Erfahrung der Christusbegegnung dazugehören, ${ }^{43}$ geschieht dies nicht ohne irdischen Bezug, sondern als Auslöser massiver innerweltlicher Veränderungen. Menschen werden in einen dramatischen, heilsgeschichtlichen Prozess hineingerissen, der bisherige Versuche der Sinn- und Gottsuche mitsamt ihren kulturellen und institutionellen Fixierungen in ihrer Unzulänglichkeit aufdeckt und so Umkehr sowohl möglich als auch notwendig macht. ${ }^{44}$ Der resultierende machtvolle Umkehrruf erfolgt nicht nur individuell, sondern greift tief in gesellschaftliche Formen - etwa die Prinzipien kollektiver Identitätsbildung - ein. Insbesondere werden durch seine radikale Hinorientierung der Menschen auf den unverfügbaren Gott exkludierende Prinzipien kollektiver Identitätsbildung aufgedeckt und erschüttert. Von dieser gesellschaftskritischen Wirkung der Gottesreichbotschaft her sind die enormen Konflikte zu begreifen, die Jesus ausgelöst hat. Von dorther ist Erlösung nach neutestamentlichem und frühkirchlichem Verständnis als ein dramatischer Kampf zu verstehen. ${ }^{45}$ Der frei gewordene Zugang zu Authentischem deckt Unzulängliches in all seinen kollektiven, kulturellen und gesellschaftlichen Verfestigungen auf und kann so extrem destabilisierend wirken. Von hier aus sind paulinische Aussagen, dass die Menschen durch Jesus Christus von einer Gebundenheit an Mächte befreit werden, durchaus nicht als „mythologisch“ zu verstehen. Die Überwindung dieser Mächte erforderte allerdings Jesu Einsatz bis zu seinem Kreuzestod. ${ }^{46}$

In diesem Zusammenhang eröffnet sich ein biblisches Opferverständnis in noch unverkürzter Weise: Das dafür wichtige Wort „paradidónai“ (,übergeben“, „überliefern“; vgl. lateinisch „tradere“) übergreift vier semantische Dimensionen: (1) Der Vater hat den Sohn für uns alle hingegeben (Röm 8.32); (2) der Sohn hat sich

43 Ich denke hier nicht nur an die Erfahrung dreier Jünger von der Verklärung Jesu (Mt 17), sondern an jene vielen nicht näher bestimmten Erfahrungen, die Menschen veranlassten, alles zurückzulassen, um Jesus zu folgen, die sie zum Staunen brachten und die Jesus in Gleichnissen anspricht, z.B. dem Gleichnis vom Schatz und der Perle.

44 Vgl. die summarische Darstellung von Jesu öffentlichem Wirken in Mk 1.15.

45 Dazu immer noch bedeutend: Aulen (1975); vgl. Sandler (1998).

46 Vgl. Schwager (1990). 
selbst hingegeben (Gal 2.20; Eph 5.2); (3) er wurde schuldhaft ausgeliefert von den Menschen (Mk 9.31 u.ä.); (4) dieses Heilsgeschehen wurde vom Vater an den Sohn (Mt 11.27) und dann zwischen den Menschen weitertradiert (1 Kor 11.2; 15.3-5).47 Zum Zusammenhang in Kurzfassung: Die sündige Auslieferung Jesu durch die Menschen (3) wurde von Jesus in Übernahme des göttlichen Heilswillens (1) aus eigenem Wollen heraus (2) von Grund auf transformiert; und dieses Geschehen der Erlösung wird von seinen Zeugen (der Kirche) bekennend weitergetragen (= paradidonai im vierten Sinn). Diese Überlieferung geschieht nicht bloß in Worten. In der Eucharistie ereignet sie sich als „Memoriale“ (J. Jeremias), in einem Geschehen der Erinnerung oder Anamnese, die nicht bloß psychologisch, sondern ontologisch zu verstehen ist: Die feiernden Menschen werden hineingenommen in einen dramatischen Prozess, der geeignet ist, sie von Grund auf - an ihren (kotigen) Wurzeln - zu transformieren.

Die Vergegenwärtigung Jesu Christi geschieht in der Eucharistie in diesem Sinn primär durch die feiernde Gemeinschaft, insofern sie sich in augenfälliger Weise von dieser Veränderung erfassen lässt. Wo sie sich dagegen resistent verhält - durch ein unsolidarisches „Kommunizieren“ - , isst sie sich nach den Worten von Paulus das Gericht: „Denn wer davon ißt und trinkt, ohne zu bedenken, daß es der Leib des Herrn ist, der zieht sich das Gericht zu, indem er ißt und trinkt" (1 Kor 11.29).

„Leib Christi“ hat demnach drei Bedeutungen, die gemäß der beschriebenen Dramatik ursprünglich zusammenhängen: (1) Leib des historischen Jesus, der diesen Prozess der Transformation realgeschichtlich ausgelöst hat; (2) eucharistischer Leib als Zeichen der wirksamen Gegenwart Jesu Christi (wirksam durch die transformative Kraft an Menschen als Gemeinschaft); (3) Kirche, repräsentiert durch die feiernde Gemeinde, die sich in den heilsgeschichtlichen Prozess der Selbsthingabe Jesu Christi hineinziehen lässt und so selber in den Leib Christi transformiert wird: „Ist der Kelch des Segens, über den wir den Segen sprechen, nicht Teilhabe am Blut Christi? Ist das Brot, das wir brechen, nicht Teilhabe am Leib Christi? Ein Brot ist es. Darum sind wir viele ein Leib; denn wir alle haben teil an dem einen Brot" (1Kor 10.16-17). 
Von daher ist die eucharistische Realpräsenz Jesu Christi in den gewandelten Gaben von Brot und Wein ursprünglich eingebettet in eine Aktualpräsen₹: der wirksamen Vergegenwärtigung des heilsgeschichtlichen Tun Jesu Christi. ${ }^{48}$ Entsprechender liturgischer Vollzug ist die Anamnese, eine Erinnerung, die nicht nur ein schwaches Memorieren durch die Feiernden ist, sondern Geschehen einer von Gott ausgehenden Anamnese: Gott erinnert sich unser. - Diese Anamnese mündet in den für das eucharistische Hochgebet eigentlich zentralen Vollzug des Bittens (Epiklese), das untrennbar Bitte um Wandlung der Gaben (Wandlungsepiklese) und Bitte um Wandlung der Feiernden (Kommunionepiklese) ist. ${ }^{49}$ Die Wandlungsworte sind diesem Geschehen begründend zugeordnet. ${ }^{50}$ Weil Jesus sich selbst - symbolhaft verdichtet in Brot und Wein - für die Menschen hingegeben hat und weil er seinen Jüngern den Auftrag gegeben hat, „das zu seinem Gedächtnis zu tun“, dürfen sie dies in Anamnese und Epiklese auch vollziehen. Der Bitte um Wandlung der Gaben sowie der Feiernden ist jene Gewissheit der Erhörung zugesagt, die sich im Johannesevangelium mehrfach in erstaunlicher und provozierender Weise findet. ${ }^{51}$

Gewandelt wird also in eins mit Brot und Wein die feiernde Gemeinschaft. Ausdruck dieses Gewandeltseins ist der gemeinsame eucharistische Lobpreis, der - vereint mit den Engeln und Heiligen die himmlische Liturgie vergegenwärtigt. ${ }^{52}$ In der absichtslos lobpreisenden Ausrichtung auf Gott hin finden Menschen den Grund zu einer Gemeinschaftsbildung, die ohne den Ausschluss von Dritten auskommt. ${ }^{53}$ In dem Maße, wie Menschen sich gemeinsam auf den wahren Gott ausrichten, können sie es wagen, ihre Bitten zu universalisieren, ohne dass dadurch nur identitätsbildende Animositäten als Krypta ins (kollektive) Unbewusste versenkt werden. Diese universale Ausrichtung ist im Heilsuniversalismus des Kreuzestodes

48 Vgl. Betz (1955).

49 „Durch ihn, den du zu deiner Rechten erhöht hast, bitten wir dich: Sende deinen Geist auf diese Gaben herab und heilige sie, damit sie uns werden Leib und Blut deines Sohnes, unseres Herrn Jesus Christus.“ - „Wir bitten dich: Schenke uns Anteil an Christi Leib und Blut und lass uns eins werden durch den Heiligen Geist." (2. Hochgebet).

50 Vgl. Meßner (1995).

51 Vgl. Joh 15.7 u.ä.

52 Vgl. 2. Vatikanum, Liturgiekonstitution 8.

53 Vgl. Sandler (2005). 
Jesu grundgelegt (,gestorben für alle") und kommt im vierten Hochgebet explizit zum Ausdruck. ${ }^{54}$

Die Eucharistie ist also ein komplexes Geschehen, das heilsgeschichtliche und eschatologische, ekklesiologische und soteriologische Dimensionen miteinander verbindet, was in einer reichen Feiergestalt mit Anamnese, Epiklese und Lobpreis zum Ausdruck kommt, in die die Wandlungsworte Jesu integriert sind. Nicht immer in der Geschichte der Kirche konnte diese komplexe Gestalt von Eucharistie adäquat zum Ausdruck gebracht werden. Die frühkirchliche Theologie hatte mit dem Platonismus - mit seinen Konzepten von Anamnesis und Methesis - ein Werkzeug, um eine Repräsentation und Gegenwärtigkeit zu artikulieren, die nicht bloß äußerlichsymbolistisch oder grob-realistisch gedacht wird. Sakrament wurde in diesem Sinn als Mysteriengeschehen gedacht. ${ }^{55}$ Die lateinische Patristik konnte mit dem Begriff ,sacramentum“ daran anknüpfen, wenn auch der Blick auf ein dynamisch-heilsgeschichtliches Geschehen damit weiter verdeckt wurde. ${ }^{56}$ Ein Bruch erfolgte hingegen durch die Übernahme der Eucharistietheologie im fränkisch-germanischen Raum. Die sakramentale Gegenwart Christi konnte nicht mehr - wie in der frühen Kirche - als dynamisch verstandene Vergegenwärtigung in eucharistischer Aktualpräsenz begriffen werden, sondern nur noch in den Alternativen von äußerlich-symbolischem, letztlich allegorischem Verweis oder einem Kapharnaitismus, der davon ausging, dass es Fleisch und Blut des historischen Christus seien, welche die Gläubigen beim Kommunizieren mit ihren Zähnen zermahlen würden. ${ }^{57}$ Die beiden Abendmahlsstreite im 9. und 11. Jahrhundert geben bitteren Aufschluss über diese unglückliche Alternative zwischen Abwesenheit und Anwesenheit. ${ }^{58}$ Hier öffnete erst die Transsubstantiationslehre einen theologisch akzeptablen Ausweg, indem sie mit neu erschlossenen aristotelischen Denkformen ein sensualistisches Präsenzverständnis überwand. Mittels der Unterscheidung zwischen Substanz und Akzidens konnte nun behauptet wer-

54 „Und wenn die ganze Schöpfung von der Verderbnis der Sünde und des Todes befreit ist, lass uns zusammen mit ihr dich verherrlichen in deinem Reich durch unseren Herrn Jesus Christus." (4. Hochgebet).

55 Für die liturgische Erneuerung in der ersten Hälfte des 20. Jahrhunderts war die Wiedergewinnung dieser patristischen Konzepte zunächst leitend. Vgl. Casel (1960).

56 Vgl. Meßner (1989), 92.

57 Vgl. Denzinger/Hünermann (1991), Nr. 690.

58 Vgl. Gerken (1973), 104-112. 
den, dass in der Eucharistie eine substantielle Wandlung von Brot und Wein zu Leib und Blut Christi unter Beibehaltung der akzidentellen Erscheinungsmerkmale erfolgte. Damit konnte eine Gegenwart Jesu Christi und mit ihm Gottes angenommen werden, die nicht mehr sensualistisch greifbar und dennoch real war. Mit dieser konzeptionellen Hilfe konnten die alten patristischen Texte zur Eucharistie wieder rezipiert werden.

Für die Volksfrömmigkeit war dies ein anspruchsvoller Weg an der Grenze zur Überforderung. Es bestand eine unerfüllte Sehnsucht nach greifbaren Ausweisen einer Präsenz des sich hingebenden Christus, die nach anselmianischem Erlösungsverständnis absolut heilsnotwendig war, aber äußerlich nur mehr durch die schlichte Elevation der gewandelten Hostie zum Ausdruck kam. Das Bedürfnis des mittelalterlichen Menschen nach sinnenhaft Greifbarem und Sichtbarem fand zwar durch neue Formen der Frömmigkeit Schaufrömmigkeit, Fronleichnamsfeste, eucharistische Anbetung in eine Richtung, der die Theologie der Transsubstantiation entsprach. Aber in ihrer Verengung auf das Wandlungsgeschehen bot diese eucharistische Frömmigkeit dem Erfahrungsbedürfnis der Menschen zu wenig Anhalt. Daher wurden Legenden über Hostienwunder und Hostienfrevel als Konkretisierungen des sonst Ungreifbaren gierig aufgegriffen - auch gegen die fast durchgängigen Versuche von Bischöfen und Päpsten, solche Unterströmungen, vor allem in ihren antijudaistischen Tendenzen, zu bekämpfen. ${ }^{59}$

Dem heutigen theologischen Rückblick wird die damalige eucharistietheologische Lösung der Transsubstantiationslehre ambivalent erscheinen. ${ }^{60}$ Sie bietet eine einwandfreie Antwort auf eine Frage, die allerdings in verengender Weise gestellt wurde: Wie geschieht es, dass Jesus Christus durch die Wandlungsworte in Brot und Wein gegenwärtig wird? - Die Schwäche der Antwort besteht darin, dass sie die Verengung der Frageperspektive unkritisiert übernimmt. Unangetastet blieb die Fixierung des eucharistischen Geschehens auf die Wandlungsworte, bei zunehmender Konzentration auf den „in persona Christi“" agierenden Priester und Depotenzierung des feiernden Kirchenvolkes zu weitgehend stummer und isolierter „Schaufrömmigkeit" voneinander isolierter Einzelner. Diese Verengung 
wurde erst im 20. Jahrhundert mit Liturgiereform und Zweitem Vatikanischem Konzil überwunden. Viele Jahrhunderte vorher lag ein Schleier über Eucharistieverständnis und Eucharistiepraxis, der uns verwirren und erschrecken kann. Von daher kommt meines Erachtens auf epochaler Ebene - weithin unabhängig von individueller Schuld - in Ansätzen das Verhängnis zum Tragen, das Paulus warnend ausdrückte: „Denn wer davon isst und trinkt, ohne zu bedenken, dass es der Leib des Herrn ist, der zieht sich das Gericht zu, indem er isst und trinkt.“ (1 Kor 11.29) Bei intensivierter Verehrung des eucharistischen Leibes Christi wurde dennoch weithin „nicht bedacht, dass es der Leib des Herrn ist“" zumindest nicht in der bestimmten Hinsicht, dass dieser Leib zugleich der gemeinschaftlichkirchliche Leib ist, der sich einer Wandlung nicht entziehen darf. Wie oben festgestellt wurde, geschieht diese kommuniale Wandlung hin zu einer gemeinschaftlichen Identität, die sich nicht dem exkludierenden Grenzziehen verdankt. Wenn die Rückbindung an den ermöglichenden Grund einer solchen universalen Identität defizitär bleibt, wird der Traum von einer universalen Einheit - der in der Wort- und Bildsymbolik von Kirche und Liturgie dennoch stets präsent blieb - zu einer gefährlichen Schimäre. Unter diesen Bedingungen eines defizitären Vollzugs von Eucharistie trifft auf ihn weitgehend zu, was Aleida Assmann mit Krypta, Palimpsest und inerter Schuld- und Rachemotivik kritisch aufgewiesen hat. Es handelt sich hier um das, was Paulus Gericht nennt und was sich jene zuziehen, die „eucharistisieren“, ohne den Leib des Herrn zu bedenken. Wo ein solches Bedenkensdefizit auf epochaler und struktureller Ebene auftritt, wird sich auch das Gericht auf dieser Ebene auswirken: In diesem Sinn wären die verbreiteten antijudaistischen Profilierungsversuche auf der Ebene des Kirchenvolkes ebenso zu deuten wie die Halbherzigkeit und Erfolglosigkeit, mit der die Kirchenleitung solche exkludierende Identitätsbildungsformen in ihren eigenen Reihen bekämpfte. In diesem Sinn geschah es oft, dass Kirche meinte, andere Menschen (vor allem Juden) im Namen Gottes zu richten, und sich dabei selbst das Gericht sprach, indem sie ihre Sendung, die sie ja immer als universale verstanden hatte, verriet. ${ }^{61}$ Angesichts dieses historischen Versagens ist die einzige Möglichkeit von Kirche, ihre

61 Nach dem Zweiten Vatikanischen Konzil besteht diese Sendung der Kirche darin, dass sie „Sakrament, das heißt Zeichen und Werkzeug für die innigste Vereinigung mit Gott wie für die Einheit der ganzen Menschheit“ ist. Vgl. Lumen Gentium 1. 
Sendung weiter glaubwürdig vertreten zu können, die Umkehr, zu welcher nicht nur eine erneute Hinwendung zu ihrer die Wurzeln transformierenden Quelle gehört, sondern auch das freimütige Eingeständnis ihres Versagens. ${ }^{62}$

Nun zu Aleida Assmanns Ausführungen: Es dürfte deutlich geworden sein, dass ich Assmanns Kritik am eucharistischen Abendmahl nicht rundweg zurückweise, sondern in gewisser Hinsicht sogar für theologisch bedenkenswert halte. Zugleich dürfte deutlich geworden sein, dass eine theologische Rezeption ihrer Überlegungen nicht ohne entscheidende Transformationen möglich ist.

Dies betrifft vor allem ihre zentrale These: „Gemeinschaften sind immer auch ,Gemeinschaften gegen', sie entstehen dialektisch durch Integration und Ausschluss" (oben, Seite 255). Die Innsbrucker dramatische Theologie, von der die obigen Ausführungen geleitet sind, ${ }^{63}$ nimmt die Problematik ,gemeinschaftliche Identität durch Ausschluss" zwar auch in hohem Maße ernst, rechnet aber mit der grundsätzlichen Möglichkeit ihrer Überwindung. ${ }^{64}$ Für Christen ist diese Annahme der Überwindbarkeit einer tief verwurzelten feindbestimmten Identitätsbildung Gegenstand von Glauben und Hoffnung. Im Gespräch mit nichttheologischen Wissenschaften und Gesprächspartner(inne)n kann diese Annahme nur in der Weise einer Hypothese eingebracht werden. Das heißt, sie hat sich im Wettbewerb mit alternativen Grundannahmen zu bewähren. Dazu gehört auch die Kritik von alternativen Grundannahmen. Im Sinn einer solchen Kritik wäre Aleida Assmann zu fragen, ob bei konsequenter Annahme von gemeinschaftlicher Identitätsbildung, ,immer auch [...] durch Ausschluss [... von ...] identitätsfundierenden Anderen“ nicht zwangsläufig - und gewiss gegen Assmanns Intention - die Annahme einer Prinzipialisierung von Feindschaft im Sinn von Carl

62 Vgl. Wandinger (2003).

63 Vgl. Sandler (2005) sowie Scharer/Niewiadomski (1999).

64 „Ein tiefer, echter und dauerhafter Friede zwischen Menschen, der nicht auf Opferung Dritter aufgebaut ist und ohne Polarisierung auf Feinde auskommt, ist sehr schwer erreichbar, ja übersteigt menschliche Kräfte. Wenn er dennoch Wirklichkeit wird, ist dies ein klares Zeichen, daß Gott selber (der Hl. Geist) in den Menschen am Wirken ist. Diese inkarnatorische Logik ist sowohl an der biblischen Botschaft als auch an den zahlreichen ekklesialen ,Zeichen der Zeit" in der menschlichen Geschichte ablesbar.“ Niewiadomski/ Schwager (2003), 64. - Zum Zitat wäre hier hinzuzufügen: diese inkarnatorische Logik ist leitend für das Geschehen der Eucharistie. „Daß Gott selber (der Hl. Geist) in den Menschen am Wirken ist“, ist ausdrücklicher Gegenstand der epikletischen Eucharistiebitte. 
Schmitt folgt: Wenn Gemeinschaften immer auch „Gemeinschaften gegen" sind und folglich ohne identitätsfundierende Andere (in diesem Fall: „Feinde“) nicht auskommen, wenn es weiters fatal (weil eine „Krypta“ bildend) ist, seine Feinde nicht zu nennen, dann muss man sie eben nennen - als Feinde. Zwar ist das Nennen von Feinden noch nicht gleichbedeutend mit ihrer Bekämpfung und Exklusion, vielmehr besteht die Möglichkeit - wie Assmann am Beispiel des jüdischen Passahfestes bemerkt -, dass man die Feindschaft überwindet. Aber wenn das Prinzip stimmt, dass Gemeinschaften immer "Gemeinschaften gegen" sind, dann ist solche Einbeziehung von Feinden stets nur auf Kosten von neuen, anderen „Feinden“ möglich. ${ }^{65}$ Kann Aleida Assmann aber dann noch ohne Inkonsequenz brandmarken, was sie als Ausgeburt spätmittelalterlichen kirchlichen Antijudaismus aufweist, dass nämlich die Juden ,sich in dieser historischen Konstellation als ,providentieller Außenfeind (Carl Schmitt)“ (oben, Seite 266) erweisen? Diese Überlegungen sind nicht als polemische Unterstellung gemeint, dass sich Assmann von Carl Schmitt ja gar nicht so sehr unterscheide, sondern als Argument für eine Modifikation von Assmanns Anfangsthese, dass Gemeinschaften immer auch „Gemeinschaften gegen“ seien. Im Sinn meiner obigen Argumentation glaube ich, dass der definitive Ausschluss der Möglichkeit von alternativen Formen friedlicher Identitätsbildung Assmann in Bedrängnis bringt. Wenn man solche Alternativen hingegen nicht als ausgeschlossen, sondern nur als „sehr schwer möglich" "66 betrachtete, würden diese Konsequenzen vermieden werden, ohne dass ihre nachfolgenden Überlegungen als grundsätəliche ihre Triftigkeit einbüßten.

Allerdings führt dann ihre Anwendung auf die christliche Eucharistie nicht mehr zu deren definitiver Verurteilung. Wenn hier im

65 Daher läge eine kritische Schlussfolgerung ähnlich jener, die Roman Siebenrock am Ende dieses Artikels ziehen wird, tatsächlich nahe: dass nämlich die heutige säkulare Gesellschaft ihre Toleranz gegenüber früher Ausgestoßenen - vor allem den Juden - nur durch das Festmachen neuer „Feinde“ bewerkstelligen könnte. Diese würden nunmehr für das Unheil der Geschichte generalisierend verantwortlich gemacht werden. Der Schritt von einer generellen Disqualifizierung des Abendmahls als des Zentralvollzugs der Christen, wie sie Assmann in ihrem Beitrag unternimmt, zu einer Stigmatisierung der Christen selber wäre unter bestimmten geschichtlichen Bedingungen nur ein kleiner - ähnlich dem kleinen Schritt von einer generellen Desavouierung von jüdischer Religion im Sinn einer Substitutionstheorie zu einer definitiven Judenverfolgung. Dass ein solcher Schritt ein kleiner ist, vertritt ja auch Aleida Assmann mit ihrem Konzept der „Krypta“.

66 Vgl. abermals das Zitat in Anmerkung 64 aus Niewiadomski/Schwager (2003). 
zentralsten Vollzug des letzten Abendmahls keine Feinde genannt werden, obwohl zum Zeitpunkt des Abendmahls für Jesus seine Tötung bereits absehbar war, dann gibt es durchaus einen Anlass zu den von Aleida Assmann genannten Verdachtsmomenten. Eine Universalisierung von Erlösung, wie sie das Christentum tatsächlich mit Blick auf Kreuz und letztes Abendmahl betreibt, muss als Unterfangen erscheinen, an dem Menschen aus eigener Kraft heraus nur scheitern können. In diesem Punkt trifft sich unsere dramatische Theologie mit der Kritik Assmanns. Der Anspruch des Christentums, in seinem gründenden Zentrum auf eine Quelle gestoßen zu sein, die exkludierende Identitätsbildung überwindbar macht und universalen Frieden ermöglicht, muss dennoch nicht a priori verworfen werden. Er ist vielmehr an den ersichtlichen Fakten zu messen, und hier gibt es gewiss auch vieles, das ihn zu falsifizieren scheint. Allerdings: Wenn es eine Quelle für „wahren Frieden ohne Ausschluss Dritter“" geben sollte, dann ist es nur naheliegend, dass sie durch die abgründigen Selbstsicherungsbedürfnisse bestehender exkludierender Identitätsformen ständig verschmutzt wird. ${ }^{67}$ Von hohem Interesse angesichts des Ringens um Frieden in der Welt müssten aber Indizien dafür sein, dass diese Quelle wenigstens manchmal in nachvollziehbarer Weise rein geflossen ist. ${ }^{68}$

Die letzten beiden Abschnitte haben eine Grundannahme Assmanns relativiert, von der aus sie jüdisches Passahmahl und christliches Abendmahl direkt gegeneinander ausspielte. Damit sollte nun der Weg frei sein für eine differenzierte Auseinandersetzung mit ihrer weiteren Kritik. Zentral für Assmann ist der Vorwurf der Überschreibung: „Der Exodus als eine die kollektive Identität der Juden definierende mythische Erinnerungsfigur wird überschrieben durch das letzte Abendmahl als eine die kollektive Identität der Christen definierende Erinnerungsfigur" (oben, Seite 255). Dass Gemeinschaften ihre Identität durch Grenziziehungen bilden und weiterbilden, die stets in großer Gefahr sind, zu Ausgrenzungen von konkreten Personen und Personengruppen zu werden, ist als universales Faktum zuzugestehen. Als solches trifft es allerdings auch schon die jüdische Passahfeier. Auch dieses ist durch Überschreibungen vorausgehender - näher nicht mehr bekannter - heidnischer Riten entstanden. ${ }^{69}$

67 Vgl. Wolfgang Palavers obige Ausführungen zu einem sakrifiziellen Christentum.

68 Vgl. dazu z.B. Sandler (2003).

69 Vgl. Meyer (1989), 58. 
Überschreibungen bestimmen aber nicht nur die Konkurrenz und Ablöse zwischen Religionen und Kulturen, sondern auch ihren inneren Verlauf. So ist z.B. die prophetische Opferkritik als eine massive innerjüdische Überschreibung von jüdischem Opferverständnis zu verstehen. „Darübergeschrieben“ wird soziale Barmherzigkeit, ${ }^{70}$ womit das zugrunde Liegende allerdings auch nicht einfach ausgelöscht wird. Dieser Vorgang innerjüdischen Überschreibens wurde nun vom Christentum in seinen Anfängen durchaus - zunächst noch innerjüdisch! - weitergeführt. Jesu Opferkritik ist zwar scharf, überbietet aber kaum die Opferkritik etwa von Hosea. Und auch von Jesus ist eine Totalverwerfung der Opferinstitution nicht beabsichtigt. Ähnlich erfolgten spätere Überschreibungen in Übernahme und Veränderung, im Bezug auf das Opferverständnis etwa im Hebräerbrief. In diesem Sinn ist nun auch Jesu letztes Abendmahl und damit auch die Eucharistie zu verstehen. Gewiss gibt es Überschreibung, aber auch Übernahme und Kontinuität. Die heilsgeschichtliche Anamnese, die ich oben bereits als essentiell für die Eucharistie genannt habe, umfasst die gesamte Heilsgeschichte und greift damit auch die alttestamentlich-jüdische Geschichte positiv auf. ${ }^{71}$ Allerdings drohten mit einer zunehmenden Verengung der Eucharistie auf das Wandlungsgeschehen diese Momente anamnetischer Kontinuität zum Judentum aus dem Blick zu geraten, auch wenn sie in Ikonografie und biblischen Texten ihre Präsenz niemals völlig verloren. Im 20. Jahrhundert wurde mit der Wiederentdeckung der anamnetischen Dimension für die Eucharistie auch die Verwurzelung der Eucharistie in jüdischen Vollzügen wiederentdeckt. ${ }^{72}$

Ich habe meine eucharistietheologische Skizze mit der von Aleida Assmann aufgeworfenen Problematik von Medium und Mittler begonnen. Nach christlichem Verständnis erwies sich Jesus Christus als Mittler im emphatischen Sinn. In der Eucharistie ereignet sich die Vermittlung der - sündhaft unterbrochenen - Beziehung zwischen den Menschen und Gott als realsymbolische Vergegenwärtigung Jesu Christi in Wort, Tat und - realpräsentisch - Sein. Jesus Christus erweist sich in dieser Sicht als Mittler katexochen, als Ursakrament oder Realsymbol. Ausgehend von dem Geschehen heilshafter Vergegenwärtigung, wie ich es oben skizziert habe, ist die

70 „Liebe will ich, nicht Schlachtopfer, Gotteserkenntnis statt Brandopfer“ (Hos 6.6).

71 Roman Siebenrock wird diesen Aspekt im nächsten Abschnitt deutlicher ausführen.

72 Vgl. Thurian (1963) sowie Meyer (1989), 49-61. 
Theologie auf einen Begriff des Realsymbols verwiesen, der sich von arbiträren Symbolen vor allem dadurch unterscheidet, dass er keine bloß nachträgliche Vermittlung herstellt. ${ }^{73}$ Salopp gesagt: Wenn ich zuerst Gott und dann den Menschen als voneinander unabhängige Wirklichkeiten feststelle, um dann nach der Vermittlung zwischen beiden zu fragen, dann habe ich schon verloren; die versuchte Vermittlung kann dann nur noch scheitern. Christologie und Sakramententheologie stehen und fallen mit einer ursprünglicheren Vermittlung von Gott und Mensch, bei der Einheit und Unterschiedenheit, Immanenz und Transzendenz, göttliche Geheimnishaftigkeit und Selbsterschließung nicht zwangsläufig in einem konkurrierenden, sondern in einem - zumindest der Möglichkeit nach - direkt proportionalen Verhältnis gedacht werden. Nur durch ein solches Verständnis der Vermittlung können die großen Aporien der Eucharistietheologie überwunden werden. ${ }^{74}$ Und nur dadurch kann die Eucharistie adäquat reflektiert werden als ein dramatisches Geschehen, in dem Menschen als Gemeinschaft in die transformative Heilsgeschichte Jesu Christi hineingezogen werden und sich nicht bloß an einer fernen Geschichte erbauen.

Setzt man dieses theologisch gebotene Verständnis von Realsymbol als Maßstab für die Vermittlung von Transzendenz und Immanenz, dann erweisen sich die diesbezüglichen Ausführungen Aleida Assmanns als unzulänglich, bestimmt sie doch die Mediumsfrage ausgehend von einer absolut gesetzten Transzendenz als Problem nachträglicher Vermittlung. Soweit Assmann in der Folge auf dieser Prämisse aufbaut - und sie hat sie bewusst programmatisch an den Anfang gesetzt -, müssen ihre Folgerungen relativiert werden. Sie gewinnen dann folgende Form: Soweit Christen ein tieferes Verständnis von Medialität - im Sinn von Realsymbol und sakramentalem Heilsmysterium - verloren haben, stehen sie in höchster Gefahr, in die von Assmann aufgewiesenen Fallen zu gehen. Wie wir gesehen haben, ist ein solch reduziertes Medialitätsverständnis charakteris-

73 Vgl. Rahner (1960).

74 Z.B. ist im Hinblick auf das Verständnis der Messe als Opfer die Aporie zwischen einmaliger Selbsthingabe Jesu Christi vor zweitausend Jahren und ihrer vielmaligen Vergegenwärtigung im eucharistischen Opfergeschehen zu lösen; weiters die Aporie zwischen Jesus als dem eigentlichen Akteur des versöhnenden Opfers und der feiernden Gemeinde mit dem Priester als dieses Opfer Vollziehenden. Vgl. dazu Balthasar (1967). 
tisch für die Kirche des Mittelalters, also jener Epoche, aus der Assmann hauptsächlich ihre Indizien zur Kritik bezieht.

Für die Gegenwart droht ein Verlust des Verständnisses für Realsymbolik von neuer Seite. Das digitale Denken in strikter JaNein-Logik schwächt die Sinne für differenzierte Vermittlungen und droht das Eucharistieverständnis in ähnliche Aporien zu treiben, wie wir sie von den mittelalterlichen Abendmahlsstreitigkeiten kennen. ${ }^{75}$ Ist es nicht dieser Verlust realsymbolischen Denkens und Wahrnehmens, den Aby Warburg beklagt, mit seinem Horror vor den „elektrischen Augenblicksverknüpfungen“, die den Raum als Andachtsraum oder Denkraum morden?76

\section{Das einzige „Neue Volk Gottes“: Wurzeln und Ursachen des christlichen Antijudaismus (Roman Siebenrock)}

Aleida Assmann stellt in ihrer Analytik des christlichen Antijudaismus eine These auf, die kontradiktorisch zu allen Analysen ist, die im jüdisch-christlichen Dialog, auf den sie nie Bezug nimmt, konsenshaft vertreten werden. Während sie behauptet, dass die entscheidende kulturtheoretische Problematik darin liege, dass die Juden im zentralen Abendmahlritus nicht vorkämen, besteht der Konsens darin, dass die Problematik darin liegt, wie die Juden in der christlichen Tradition vorkommen. Zudem wird die Frage der Eucharistielehre gegenüber bestimmten eucharistischen Praktiken als sekundär eingestuft. Deshalb ist zunächst in aller Kürze über diesen jüdisch-christlichen Prozess zu informieren. Daraus ergibt sich eine andere, mich viel mehr überzeugende Sicht auf jene historischen Anlässe, die Assmann bearbeitet. Und diese Sicht ist auch von höchstem kulturtheoretischem Interesse. Schließlich möchte ich zu einigen Details dadurch Stellung beziehen, dass ich über die wahren Sachverhalte informiere.

Die innerkirchliche Revolution im Verhältnis zum Judentum nach einer fast jährigen Entfremdungsgeschichte, die nicht nur als Gewaltgeschichte interpretiert werden kann, auch wenn die Juden in erschreckendem Maße immer wieder zu Sündenböcken geworden sind, hat eine solche Qualität erreicht, dass erstmals eine Gruppe

75 Die teilweise harten Alternativbildungen in der Argumentation von Assmann erscheinen mir wie ein Symptom eines solchen Blickverlusts.

76 Vgl. dazu den vorhergehenden Abschnitt von Wolfgang Palaver. 
von jüdischen Gelehrten, die fast alle Richtungen des Judentums repräsentieren, diese ernsthafte Erneuerung anerkannt und eine neue Qualität der Beziehungen festgestellt hat, und zwar in dem bemerkenswerten Text „Dabru Emet". ${ }^{77}$ Dieser Text reagiert darauf, wie innerhalb der katholischen Kirche vor und nach dem Zweiten Weltkrieg das Verhältnis zum Judentum sich dadurch auch neu konstituieren konnte, dass nach den Ursachen und Wurzeln des christlichen Antijudaismus gefragt wurde, und zwar in einem Prozess partizipativer Forschung, weil zunächst die jüdischen Partner hier gehört wurden. ${ }^{78}$ In diesen Prozess sind bis heute Persönlichkeiten von besonderem Gewicht eingebunden, die in die katholische Kirche konvertiert sind und ausdrücklich zu ihrem jüdischen Erbe gestanden sind bzw. stehen. Aus dem großen Kreis, Edith Stein ist vielleicht die bekannteste, möchte ich für das Zweite Vatikanische Konzil Johann Österreicher nennen und für die letzten Jahrzehnte Kardinal Lustiger, den ehemaligen Erzbischof von Paris, der in diesem Jahr gestorben ist. Nicht unerwähnt darf bleiben, dass Johannes Paul II., der diese Wende unauslöschlich in das Gedächtnis der Kirche eingeschrieben hat, z.B. ein Leben lang in Freundschaft mit jüdischen Mitschülern stand. Allein aus solcher Nähe wächst wahres Verständnis, weil die Nähe die Schuld und die Verletzung mit erfahren lässt. ${ }^{79}$ Dieser Prozess wurde gesamtkirchlich wirksam mit dem Zweiten Vatikanischen Konzil.

Das Konzil sah sich mit einer langen Geschichte des Antijudaismus konfrontiert, die im 20. Jahrhundert in der Schoah ihren entsetzlichen Höhepunkt hatte. Dabei musste die Frage beantwortet werden, welche Verantwortung die Kirche und der christlich-motivierte Antijudaismus - neben, mit oder in anderen Gründen - für den nationalsozialistischen Vernichtungswahn hatten. Worin bestand der kirchliche Antijudaismus? Er „äußerte sich ab dem 2. Jahrhundert n. Chr. [...] in ziemlich gleichbleibenden Slogans: Die Juden sind Christus- und damit Gottesmörder. Sie weigern sich böswillig, sich Christus und seiner Botschaft zu beugen. Sie bringen durch ihre

77 Vgl. Kampling (2003).

78 Dieses Prinzip des Forschungsprozesses der kommunikativen Theologie ist meiner Ansicht nach das entscheidende methodische Defizit von Assmann. Siehe das Grundsatzpapier: Kommunikative Theologie - Forschungskreis (2006).

79 Zur gesamten Konzilsdiskussion siehe meinen Kommentar: Siebenrock (2005). Den aktuellen Stand des Dialogs fasst zusammen: Henrix (2006). 
ärgerniserregende Lebensweise Unruhe und Unsicherheit in die Kirche hinein und sind daher die ,Urketzer'. Sie unterminieren die christliche Gesellschaft (Brunnenvergifter, Hostienschänder). Man muß sie daher als gestraftes Volk und als widerwillige Zeugen der Wahrheit des Christentums in eine gedemütigte Lebensweise abdrängen (Augustinus von Hippo) und mit ,scharfer Barmherzigkeit ${ }^{\varsigma}$ gegen sie vorgehen (Martin Luther). “80 Als Ursache hierfür und für die mangelnde Widerstandskraft gegenüber dem Vernichtungswahn des NS-Regimes wird die Substitutionstheorie, als die entscheidende theologische Wurzel, angesehen. ${ }^{81}$ Diese Vorstellung besteht wesentlich darin, dass das jüdische Volk alle Verheißungen des Bundes an das „Neue Volk Gottes“, die Christen, verloren hätte. Die Juden wären nicht mehr das Volk der Verheißung und daher nicht mehr im Bund. Als Begründung werden in unterschiedlicher Weise die oben angeführten Faktoren genannt: Sie seien schuld am Tod Christi und daher auch als „Gottesmörder“ qualifizierbar, hätten den Glauben abgelehnt und seien daher, ungläubig' (perfidei judaei') und von Gott in alle Welt zerstreut worden. Nach dieser traditionellen Position verstanden sich die Christen als die wahren Juden dem Glauben nach. Das gegenwärtige Judentum diente nur zur pädagogischen Illustration christlicher Überlegenheit. Dies besagt, dass das Judentum innerhalb des Christentums immer präsent gehalten wurde und deshalb mit einer ,eingeschränkten Toleranz ${ }^{6}$ rechnen konnte. ${ }^{82}$ Eine besondere Variante dieser verwickelten Beziehung ist das Verhältnis der doppelten Schutzherrschaft, das in Rom von den Päpsten praktiziert wurde. ${ }^{83}$ Warum die päpstlichen Schutzerlässe, insbesondere

80 Petuchowski/Thoma (1989), 18. Dieses Lexikon ist von einem Juden und einem Christen geschrieben.

81 Petuchowski/Thoma (1989), 20.

82 Die geschichtliche Verwicklung bis zur Neuzeit fasst zusammen: Angenendt (2007), 485533.

83 Brechenmacher (2004), kurz: Brechenmacher (2005). Die These dieser historischen Arbeit ist höchst bemerkenswert. Das Verhältnis der katholischen Kirche zu den Juden war über Jahrhunderte theologisch genau geregelt. Die Päpste erfüllten gegenüber Juden und Christen eine doppelte Schutzverpflichtung: Sie hatten einerseits die Christen vor ,verderblichem Einfluss" der Juden, andererseits die Juden vor Übergriffen durch die Christen zu schützen. Seit dem 16. Jahrhundert wurde diese „doppelte Schutzherrschaft“ jedoch immer einseitiger zuungunsten der Juden gewichtet, umso mehr, je mehr sich die katholische Kirche durch Reformation, Aufklärung und Moderne in die Defensive gedrängt sah. Der dogmatische Anspruch, die Juden zu beschützen, und das tatsächliche, gegen die Juden gerichtete Handeln klafften immer weiter auseinander. Die Kirche wurde schließlich, vor 
auch die Ablehnung der Ritualmordlegenden durch Rom, ${ }^{84}$ fast ohne Wirkung blieben, nicht immer und dann - vor allem im 14. und 15. Jahrhundert - wenig Wirkung zeigten, wäre eigens zu untersuchen. Jedenfalls kann ohne Zweifel gesagt werden, dass das Judentum immer in der christlichen Erinnerung präsent war - bis in das Ritual der Messe hinein. Die wichtigsten Gedächtnisformen sollten kurz beschrieben werden.

Schematisch lassen sich drei Stufen unterscheiden, die die „UnBeziehung“ zwischen Kirche und Synagoge unheilvoll prägten. Im Neuen Testament sind polemische Aussagen zum Judentum, insbesondere im Johannesevangelium, festzustellen, die den allmählichen Ablösungsprozess des jungen Christentums von seiner jüdischen Herkunft bezeugen. Die zweite Stufe bilden die „Adversus-IudaeosTexte" der Kirchenväter, die zunächst eine reale Auseinandersetzung und Kontroverse dokumentierten, später jedoch zu klischeehaften Polemiken und entsprechenden jüdischen Antworten ohne direkte Beziehung degenerierten. Gerade weil sie auch in diesem Stadium in der literarischen Form des Dialogs oder der Disputation geschrieben wurden, sind sie Dokumente eines verweigerten oder zerstörten Gesprächs. Diese Texte führten zu oder bestärkten Verdächtigungen und Verleumdungen, die sich z.B. künstlerisch im Gegensatzpaar Kirche und Synagoge, in der Volksfrömmigkeit in den Ritualmordlegenden, dem Hostienfrevel oder der Brunnenvergiftung ${ }^{85}$ und gesellschaftspolitisch in verschiedenen Stigmatisierungen mit den entsprechenden Stereotypen und blutigen Verfolgungen in Krisenzeiten äußerten. Die Kleiderordnung des vierten Laterankonzils, die Pogrome, die Vertreibung oder durch massiven Druck bewirkte Taufe der Juden nach der Eroberung Granadas 1492 in Spanien sowie vielfältige Diskriminierungen und Einschränkungen in Europa bis zur Toleranzgesetzgebung der Aufklärung sind die in der Erinnerung zu Bu-

allem im 19. Jahrhundert, anfällig für den Antisemitismus. Erst mit dem Zweiten Vatikanischen Konzil gelang eine neue theologische Grundorientierung.

84 Joop van Banning SJ weist nach, dass die päpstlichen Reaktionen auf Ritualmordlegenden im Mittelalter (im Gegensatz zur Neuzeit) klar und entschieden ablehnend waren und die Integrität der Juden und die Duldung ihrer Riten ausdrücklich einschärften. Er untersucht in allen Details die Päpste Innozenz IV. (1243-1254) und Gregor X (1271-1276), also Päpste zu jener Zeit, die Assmann behandelt. Diese Klarheit sei noch bei Martin V. (14171431) und Paul III. (1534-1549) festzustellen. Siehe Banning (2003).

85 In der allgemeinen Forschung wird dieser Vorwurf, der vor allem nach der Pest 1348 die Oberhand gewinnt, als wesentlich verheerender angesehen als die beiden anderen. 
che schlagenden antijüdischen Maßnahmen in christlichen Gesellschaften. Das entscheidende theologische Problem aber war: Die christliche Theologie hatte keine Antwort auf die Frage der Bedeutung des gegenwärtigen Judentums in der einen Heilsgeschichte. Deshalb wurde in der Karfreitagsliturgie bis 1960 für die ,perfidi Judaei“, die ungläubigen Juden, gebetet.

Die Präsenz der Juden war sehr vielfältig; auch wenn es im Lebensraum gar keine Juden gab. Die traditionelle Liturgie, nicht nur die Messfeier, findet in einem Kirchenraum statt, der ikonografisch die Gemeinde in die Gegenwart der Heilsgeschichte setzt. Ich kenne keine mittelalterliche Kirche der Gotik, in der Repräsentanten Israels nicht vorkommen. Dass das christliche Königtum sich bis auf David zurückführte, ist an jeder Königsgalerie zu erkennen. Es gab die negative Ikonografie in der Entgegensetzung von Synagoge und Ecclesia, und zwar in fast allen Medien: von Skulpturen in Kirchen bis zu Zeichnungen in Handschriften. Israel ist aber auch präsent durch seine Psalmen und seine Schriften in der gesamten Liturgie des Kirchenjahres, vor allem in der Osternacht und im Brevier, dem Stundengebet der Kirche.

Im römischen Messkanon, dem Herzstück der Messe oder des Abendmahls, den Assmann aber nie erkennbar konsultiert, ist das Judentum selbstverständlich ausdrücklich gegenwärtig. Im anamnetischen Teil des Kanons heißt es in der typischen Abbreviatur dieses schönen Textes: „Blicke versöhnt und gnädig darauf nieder und nimm sie an wie einst die Gaben deines gerechten Dieners Abel, wie das Opfer unseres Vaters Abraham, wie die heilige Gabe, das reine Opfer deines Hohenpriesters Melchisedeck." Damit sind die allgemeine und der Beginn der speziellen Heilsgeschichte in Israel genannt und ist zugleich die Brücke zur Theologie des Heiligen Paulus geschlagen. Israel ist also mit Abraham ausdrücklich genannt. Wenn zudem noch wahrgenommen wird, dass in diesem Kanon die Kirche allein und ausschließlich das Opfer des Lobes darbringt, sonst aber diese Feier ein Gedäcbtnis des Todes und der Auferstehung ist, dann wird wohl unbestreitbar deutlich, dass auch in der Mitte der Messe die heilsgeschichtliche Einheit von altem und neuem Bundesvolk genannt ist.

Wie sind aber dann jene Vorgänge zu erklären, auf die Assmann abhebt? Hans Hermann Henrix, einer der profiliertesten Vertreter der katholischen Kirche im jüdisch-christlichen Dialog, sieht verschiedene Faktoren am Werk, die zusammengespielt haben müssen. 
„Außertheologische Faktoren waren neben theologischen Legitimationen für das Auf und Ab verantwortlich. Sozialpsychologische Motive spielten wie ökonomische vielfach in die Verhältnisse hinein. Der mittelalterliche Mensch suchte unter seinesgleichen eine Identität zu finden. Die Identitätsfindung wurde oft begleitet vom Argwohn gegenüber Fremden und ethnischen, kulturellen oder religiösen Minderheiten. Der Fremdenhass wurde im Verhältnis zur jüdischen Minderheit durch wirtschaftliche Gründe zusätzlich angestachelt. [...] Und doch war der religiöse Aspekt wohl von größerem Gewicht: Die als fremd empfundenen religiösen Vorschriften der Juden fanden in Lebensformen ihren Ausdruck, die der christlichen Mehrheit als Herausforderung ihres Christentums erschienen und diesem den Anspruch von absoluter Wahrheit und Geltung bestritten. So wandte sich in labilen Situationen, die durch Missernten, Hungersnöte, Kriege oder Seuchen sowie durch soziale Spannungen ausgelöst wurden, das Bedürfnis nach Sündenböcken oft genug gegen die jüdischen Minderheiten. In solchen Konstellationen wurden die Klischees und Stereotypen antijüdischer Theologie abgerufen. "86 Das bedeutet, dass die theologischen Klischees zu Stigmatisierungen führten, die sich erst in einer Krisensituation zu verheerenden Gewalttätigkeiten verdichteten. Dabei wurde das Eingreifen der Obrigkeit gelähmt oder wesentlich geschwächt.

Ich kenne schließlich einen Aufsatz, der die Blutsymbolik aufgreift und in etwa in Assmanns Richtung argumentiert. Christina von Braun hat die Ambivalenz des Blutsymbols im Kontext der Transsubstantiationslehre und des Antisemitismus mit einigen bemerkenswerten Quellenangaben dargestellt. Der entscheidende Unterschied ihrer These zu Assmann aber lautet: „Der Jude wurde fortan als sichtbarer - d.h. in der Sprache der Transsubstantiation: als realer - ,Anderer ${ }^{6}$ gebrandmarkt. Seine Sichtbarkeit stellte gleichsam das

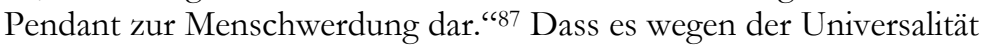
und unvermeidbaren Vieldeutigkeit dieses Symbols nicht leicht ist, begründete Schlussfolgerungen und Entwicklungslinien über Jahrhunderte hinweg zu ziehen, sei zugestanden. Solche Symbole greifen immer zurück auf die „kotigen Wurzeln“ unserer Kultur, der gegenüber selbst ein unfehlbarer Papst wie ein Schifflein im Orkan er- 
scheint. Dennoch wird insbesondere die römisch-katholische Tradition dadurch deshalb nicht entlastet, weil sie gerade durch das Lehramt - insbesondere den Papst - eine Instanz kennt, die gerade in diesen Streit der Interpretationen definitiv hätte eingreifen können. Solch klares und dezidiertes Eingreifen geschah jedoch erst in der jüngeren Zeit mit dem Zweiten Vatikanischen Konzil und ohne Kompromiss im Pontifikat von Johannes Paul II.

Darin kam nicht etwas völlig Neues zur Geltung, sondern, wie schon Jules Isaak, der große Anreger des jüdisch-christlichen Dialogs, meinte, die verschüttete eigene Tradition zu Ehren. Deren Bedeutung sei an jenen Stellen verdeutlicht, die Assmann nach ihrem Vortrag - in schriftlicher Weise auf Anfragen antwortend - in ihren Beitrag eingearbeitet hat. In Anmerkung 15 interpretiert sie die Strophe 4 gegen deren Text. Im Lied „Oh Haupt voll Blut und Wunden“ heißt es ausdrücklich: „Nun, was du, Herr, erduldet, ist alles meine Last, ich hab es selbst verschuldet, was du getragen hast.“ Die darin liegende Tradition, den Tod Jesu selber verschuldet zu haben, kann mit zwei weiteren Beispielen verdeutlicht werden. In Bachs Matthäuspassion ist der Verrat Petri mit der Tonfolge „B-A-C-H“ vertont. Und ausdrücklich heißt es im Catechismus Romanus (dem sogenannten „Trienter Katechismus“ von 1566) zur Frage, wer denn Schuld am Tode Jesu habe und wie das Handeln der Juden einzuschätzen sei: „Und es müssen dieser Schuld alle teilhaftig erachtet werden, welche öfters in Sünden fallen; denn da unsere Sünden Christus den Herrn bewogen haben, den Kreuzestod auf sich zu nehmen: so kreuzigen wahrlich jene, welche sich in Schandtaten und Lastern wälzen, von neuem (Hebr 6,6), soviel an ihnen ist, ,in sich selbst den Sohn Gottes und machen ihn sich zum Gespötte'. Und dieser Frevel wird bei uns um so schwerer erscheinen, als er bei den Juden war, weil jene nach dem Zeugnisse desselben Apostels ,den Herrn der Glorie niemals gekreuzigt hätten, wenn sie ihn erkannt hätten“ (1 Kor 2,8), wir aber das Bekenntnis ablegen, ihn zu kennen, und doch durch unsere Werke ihn verleugnen und so gewissermaßen gewaltsame Hand an ihn zu legen scheinen." ${ }^{\text {"88 }}$

Als Antwort auf unseren Hinweis in der Diskussion auf die Gerichtsrede Jesu im Matthäusevangelium (Mt 25) antwortet Assmann: „Es gibt selbstverständlich noch andere Verkörperungen Christi, wie 
zum Beispiel den konkreten irdischen Menschen selbst, insbesondere die Ärmsten und Geringsten, die Leidenden und Verfolgten unter den Mitmenschen, den anderen, auf dessen Antlitz sich das Bild Gottes spiegelt. Für die Symbolik der Kirche als Institution - und nur davon ist hier die Rede - haben diese jedoch keine unmittelbare Bedeutung“ (oben, Anmerkung 32 auf Seite 273). Wenn man die vielfältigen Anspielungen auf die „Ecclesia“ seit der Väterzeit kennt, ${ }^{89}$ ist es nicht leicht, die Aussage „Symbolik der Kirche als Institution" $\mathrm{zu}$ interpretieren, zumal es sehr lohnenswert wäre, den Implikationen der von ihr eingestandenen universalen Präsenz Christi mehr Gewicht zu verleihen. Hier liegt ein Ansatz zur Universalisierung des Christentums vor. Wie aber symbolisierte sich die Kirche, auch als Institution? Seit Laktanz und Leo dem Großen ist die Präsenz Christi in den Armen ausdrückliche kirchliche Lehre, die Wirkungsgeschichte - auch institutionelle - geschrieben hat. Die Vorschriften der Benediktregel und die generelle Orientierung an den sieben Werken der Barmherzigkeit ${ }^{90}$ werden auch wegen der Präsenz des leidenden Christus in den Armen wirksam - vor allem in der franziskanischen Bewegung. Auch in Tirol gibt es zahlreiche Darstellungen dieser Werke in Kirchen und Kreuzgängen. Die mittelalterlichen Hospitäler legen bis in ihre Inschriften hinein davon Zeugnis $a b,{ }^{91}$ und in besonderer Weise ist diese Armensorge in der Gestalt des Heiligen Martin volkstümlich und Symbolausdruck der Kirche bis in das letzte Dorf hinein geworden. Ohne die Wohltätigkeit und Armenpflege in der Antike zu negieren, schreibt Paul Veyne, dass das Christentum eine ganze Gesellschaft für die Armen zu sensibilisieren vermocht hat.92 Der genannte Text (Mt 25) hatte gerade während und nach der NS-Herrschaft auch eine eminent kritische Bedeutung für die christlichen Kirchen. Denn die ,geringsten Brüder“ Jesu sind die Juden. Damit aber steht, wie Schalom ben Chorim sagt, eine christliche Welt unter dem Gericht.

89 Siehe Rahner (1964).

90 Den sechs Werken, die im Evangelium (Mt 25.31-46) genannt werden (Hungrige speisen, Durstige tränken, Fremde beherbergen, Nackte kleiden, Kranke pflegen, Gefangene besuchen), wurden das Begraben der Toten und sieben geistige Werke der Barmherzigkeit hinzugefügt: Unwissende lehren, Zweifelnden raten, Irrende zurechtweisen, Trauernde trösten, Unrecht ertragen, Beleidigungen verzeihen, für Lebende und Tote beten.

91 Luz (1997), 521-522.

92 Siehe Angenendt (1997), 585-598. 


\section{Einige methodische Rückfragen}

Wie kann es zu einem so unterschiedlichen Verständnis kommen? Wir meinen, ${ }^{93}$ dass hier methodische Vorgaben ausschlaggebend sind. Diese wollen wir in Form von Rückfragen so kurz als möglich ansprechen. Einige Themenkreise scheinen angesprochen werden zu können. Dabei gehen wir von folgenden Voraussetzungen aus: Der Text von Assmann erhebt zum einen den Anspruch, den theologischen Diskurs adäquat zu rezipieren. Zum anderen ruft er dazu auf, in zentrales kirchliches Handeln einzugreifen.

\section{Methode und Anspruch}

Das Gott-Welt- bzw. Gott-Mensch-Verhältnis wird mit einem narrativen Verweis auf Platon und einem nicht weiter belegten Zitat von Spinoza als durch Medien vermitteltes charakterisiert. ${ }^{94}$ Gerade manche Aussagen von letzterem (z.B. „deus sive natura") würden eher das Gegenteil nahelegen, weil der Pantheismus gerade die Frage nach einem speziellen Medium unterläuft. Diese Bestimmung ist deshalb von Bedeutung, weil sie die Voraussetzung für die Bedeutung der Medien Gottes darstellt. In dieser Hinsicht darf an einige hilfreiche Unterscheidungen aus der philosophisch-theologischen Tradition erinnert werden. Wird der Bezug des Menschen auf Gott als den absoluten Grund eher gegenständlich gefasst, dann ist stets diese Gegenständlichkeit kritisch zu reflektieren, um nicht in falsche Vorstellungen abzugleiten. Dabei kommt der Reflexion auf die Mittel dieser Vergegenwärtigung („Medien“) immer eine besondere Bedeutung zu! In der Tradition der klassischen Gotteslehre wie auch in der analytischen Religionsphilosophie des 20. Jahrhunderts wird besonders aufmerksam die Weise unseres Sprechens von Gott in der Lehre von der Analogie oder der Eigenart religiöser Sprache bedacht. ${ }^{95}$

Wie aber steht es um die Methode der Gedächtnisforschung, die sich im Rahmen einer Kulturtheorie neu zu etablieren versucht? Das Vorgehen der Gedächtnisforschung wird im Text von Ideolo-

93 In diesem Abschnitt werden einige Rückfragen und Einwände gesammelt, die in der Gruppe diskutiert worden sind.

94 Wir nehmen an, dass sie sich auf folgende Aussagen bezieht: "Per Deum intelligo ens absolute infinitum hoc est substantiam constantem infinitis attributis quorum unumquodque æternam et infinitam essentiam exprimit.” (Ethica, Pars prima: De Deo. VI.)

95 Muck (1983). 
giekritik durch den Hinweis unterschieden, dass Ideologien bewusste Gehalte besitzen würden, während Gedächtnisforschung aufmerksam mache auf unbewusste Gehalte und verdrängte Erfahrungen. Durch bewusstmachende Erinnerung habe sie eine aufklärende und therapeutische Aufgabe. Was die angeführte Unterscheidung zwischen Ideologiekritik und Gedächtnisforschung betrifft, wäre aber zu klären, wie die Meinung von Ideologiekritikern gesehen wird, welche die Ideologie keineswegs als bewusste Täuschung verstehen, sondern als durch verschiedene verzerrende Faktoren bestimmte spontane Weisen der Auffassung und des Handelns (z.B. bei Ernst Topitsch). Was ist deshalb zur Behebung dieser Schwierigkeit nötig? Genügt Bewusstmachung und Aufklärung oder ist darüber hinaus Weiteres vonnöten, wie z.B. Modelle einer Alternative und einer Motivation durch bessere Verwirklichung umfassenderer Ziele bzw. Hilfen? Die methodische Bedeutung, welche dabei dem Beachten der kleinen Differenzen späterer gegenüber früherer Formen zukommt, um die Spannung zu erklären zwischen dem bewusst Aufgefassten und Angezielten einerseits und dem faktisch doch auch im Handeln damit Verbundenen andererseits, das der früheren, „überwundenen“ Form entsprechen würde. Dieser Aufweis dient zunächst wohl dazu, die Spannung zwischen bewusst Angezieltem und tatsächlich damit Verbundenem (das dem bewusst Angezielten widerspricht und deshalb als Problem empfunden wird) von einem Entstehungszusammenhang her zu erklären. Auf welcher Grundlage kann vorausgesetzt werden, dass gegenwärtiges Bewusstsein gültig und ihm Widersprechendes nicht gültig ist? Hier wären noch viele Fragen zu klären.

\section{Umgang mit den Quellen}

Da Therapie Anamnese voraussetzt, impliziert der Text eine Erkenntnisposition, die den Anderen besser zu verstehen behauptet, als er sich selbst versteht. Warum kommt dann keine maßgebliche Quelle der christlichen Tradition, eine theologische, dogmatische, praktische oder liturgische, zur Sprache? Das bedeutet, dass die Therapeutin die Anamnese eines Patienten erhebt, ohne auch nur einmal auf den „Klienten“ wirklich gehört zu haben. Dabei ist von besonderem kritischem Gewicht, dass sie auf zentrale (kommunikative) Aspekte des Patienten, in dem hier erörterten Fall: den Vollzug und Text der Messe, nicht Bezug nimmt. Wie können aber Sinngehalt und Ausdruck eines Rituals geprüft werden, wenn seine wesentlichen Elemente nicht wahrgenommen werden? Eine solche Vorgehens- 
weise steht immer in Gefahr, gegenüber den eigenen und kollektiven Vorurteilen keine kritische Distanz einnehmen zu können.

Im Anschluss an die Eucharistie und im Sinn von Aby Warburg wird auf die Spannung verwiesen zwischen religiöser Konkretion mit magisch substantieller Gegenständlichkeit (absoluter Präsenz zugeordnet) und wissenschaftlicher Abstraktion mit verweisend-distanzierenden Zeichen (absoluter Transzendenz entsprechend). Was wohl gesucht wird, ist eine Aufdeckung und Zähmung des „Chaos der Unvernunft" durch ein „Filtersystem von Besonnenheit“, als Frucht der „Fähigkeit zur distanzierenden Reflexion“. Dies wird als die Aufgabe gesehen, sich der Bedeutung des metaphorischen Als$\mathrm{ob}$ als eines Problems bewusst zu werden. Mit welchen Mitteln geht das? Geht das ohne theologische Untersuchung der Geltungsfrage? Welcher Rahmen ist nötig, um das „Chaos der Unvernunft“ als solches zu beurteilen - mit welcher Vernunft? - mit unreflektierten Voraussetzungen des Gegenwartsbewusstsein? Mit welcher Personengruppe? Bedarf es dafür nicht des Rahmens der Geltungsfrage und unseres Bezugs zur Gottesfrage - gerade wegen jenen „kotigen Wurzeln unserer Kultur", die wir nicht hinter uns lassen können und die daher einer steten Wandlung, d.h. Transformation, bedürfen?

\section{Literatur}

Angenendt, Arnold (1997): Geschichte der Religiosität im Mittelalter. Darmstadt: Wissenschaftliche Buchgesellschaft.

Angenendt, Arnold (2007): Toleran₹ und Gewalt. Das Christentum zwischen Bibel und Schwert. 2. Auflage. Münster: Aschendorff.

Assmann, Jan (2006): Thomas Mann und Ägypten. Mythos und Monotheismus in den Josephsromanen. München: Verlag C.H. Beck.

Aulén, Gustav (1975): Christus Victor. An historical study of the three main types of the idea of the Atonement. London: S. P.C. K. Large Paperbacks.

Banning, Joop van SJ (2003): „Der Vatikan und der Ritualmord“, in: Buttaroni, Susanna/Musial, Stanislaw, Hg.: Ritualmord. Legenden in der europäischen Gescbicbte. Wien-Köln-Weimar: Böhlau, 61-84.

Balthasar, Hans Urs von (1967): „Die Messe, ein Opfer der Kirche?“ in: Balthasar, Hans Urs von: Skižen zur Theologie III. Einsiedeln: Johannes Verlag, 166-217.

Betz, Johannes (1955): Die Eucharistie in der Zeit der griechischen Väter. Band I,1: Die Aktualpräsenz der Person und des Heilswerkes Jesu im Abendmabl nach der vorephesinischen griechischen Patristik. Freiburg/B.: Herder.

Böhme, Hartmut (2006): Fetischismus und Kultur. Eine andere Theorie der Moderne. Reinbek/H.: Rowohlt Taschenbuch Verlag. 
Braun, Christina von (1995): „Viertes Bild: ,Blut und Blutschande‘. Zur Bedeutung des Blutes in der antisemitischen Denkwelt", in: Schoeps, Julius H./Schlör, Joachim, Hg.: Antisemitismus. Vorurteile und Mythen. Frankfurt/M.: Piper, 80-95.

Braun, Michael (2007): „Audienz der Autoritäten: Deutsche Schriftsteller und der Papst“, in: Orientierung 71 (15-16), 166-167.

Brechenmacher, Thomas (2004): Das Ende der doppelten Schutzherrschaft. Der Heilige Stubl und die Juden am Übergang zur Moderne (1773-1870). Stuttgart: Hiersemann.

Brechenmacher, Thomas (2005): Der Vatikan und die Juden. Geschichte einer unbeiligen Beziehung. München: C.H. Beck.

Casel, Odo (1960): Das christliche Kultmysterium. Regensburg: Pustet.

Denzinger, Heinrich/Hünermann, Peter, Hg. (371991): Kompendium der Glaubensbekenntnisse und kirchlichen Lehrentscheidungen. Freiburg/B.: Herder.

Gerken, Alexander (1973): Theologie der Eucharistie. München: Kösel.

Girard, René (1983): Das Ende der Gewalt. Analyse des Menschbeitsverbängnisses. Freiburg/B.: Herder.

Girard, René (1995): „Mimetische Theorie und Theologie“, in: Niewiadomski, Józef/Palaver, Wolfgang, Hg.: Vom Fluch und Segen der Sündenböcke. Raymund Schwager zum 60. Geburtstag. Thaur: Kulturverlag, 15-29.

Girard, René (1996): The Girard Reader. New York: The Crossroad Publishing Company.

Girard, René (2002): Ich sah den Satan vom Himmel fallen wie einen Blit:. Eine kritische Apologie des Christentums. München: Hanser.

Girard, René (2005): Die verkannte Stimme des Realen. Eine Theorie archaischer und moderner Mythen. München: Hanser.

Gombrich, Ernst H. (2006): Aby Warburg. Eine intellektuelle Biographie. Hamburg: Philo \& Philo Fine Arts.

Henrix, Hans Hermann (2004): Judentum und Christentum. Gemeinschaft wider Willen. Kevelaer: Topos-Taschenbuch.

Henrix, Hans Hermann, Hg. (2006): Nostra aetate - ein zukunftsweisender Konzilstext. Die Haltung der Kirche zum Judentum 40 Jahre danach. Aachen: Einhard.

Hörisch, Jochen (1992): Brot und Wein. Die Poesie des Abendmabls. Frankfurt/ M.: Suhrkamp.

Ignatius von Loyola (1989): „Geistliche Übungen“, in: Peter Knaur, Hg.: Ignatus von Loyola: Gründungstexte der Gesellschaft Jesu. Deutsche Werkausgabe Band 2. Würzburg: Echter Verlag.

Kampling, Rainer, Hg. (2003): Dabru emet - redet Wabrheit. Eine jüdische Herausforderung zum Dialog mit den Christen. Gütersloh: Kaiser.

Katechismus (1970): Katechismus nach dem Beschlusse des Konqils von Trient für die Pfarrer. Kirchen: Sieg.

Kommunikative Theologie - Forschungskreis/Communicative Theology Research Group (2006): Kommunikative Theologie. Selbstvergewisserung un- 
serer Kultur des Theologietreibens. Communicative Theology. Reflections on the Culture of Our Practice of Theology. Münster: LIT.

Luz, Ulrich (1997): Das Evangelium nach Matthäus. Band 3, Mt 18-25. Evangelisch-Katholischer Kommentar zum Neuen Testament Band 1. Zürich-Düsseldorf: Neukirchener.

Mann, Thomas (1991a): Joseph und seine Brüder. Der dritte Roman: Joseph in Ägypten. Frankfurt/M.: Fischer Taschenbuch Verlag.

Mann, Thomas (1991b): Joseph und seine Brüder. Der zweite Roman: Der junge Joseph. Frankfurt/M.: Fischer Taschenbuch Verlag.

Mann, Thomas (1996): Essays. Band 5: Deutschland und die Deutschen 19381945. Frankfurt/M.: Fischer Taschenbuch Verlag.

Mann, Thomas (1999): Selbstkommentare: ,Josef und seine Brüder“. Frankfurt/ M.: Fischer Taschenbuch Verlag.

Meßner, Reinhard (1989): Die Meßreform Martin Luthers und die Eucharistie der Alten Kirche. Ein Beitrag zu einer systematischen Liturgiewissenschaft. Innsbruck-Wien: Tyrolia.

Meßner, Reinhard (1995): „Einige Probleme des eucharistischen Hochgebets“, in: Messner, Reinhard/Nagel, Eduard/Pacik, Rudolf, Hg.: Bewahren und Erneuern. Studien zur Meßliturgie. Innsbruck-Wien: Tyrolia, 174-201.

Meyer, Hans Bernhard (1989): Eucharistie. Geschichte, Theologie, Pastoral. Handbuch der Liturgiewissenschaft. Teil 4. Regensburg: Pustet.

Muck, Otto (1983): Philosophische Gotteslehre. Düsseldorf: Patmos.

Negel, Joachim (2000): „Distanz und Bedeutung: Biographische Notizen zu Aby Warburgs Religionsbegriff“, in: Theologie und Glaube 90 (4), 575601.

Niewiadomski, Józef (1985): „Kirche und Ritualmord“, in: Publik-Forum 17, 31-32.

Niewiadomski, Józef (2001): „Transzendenz und Menschwerdung. Transformationskraft des Opfers im Fokus österlicher Augen“, in: Dieckmann, Bernhard, Hg.: Das Opfer-aktuelle Kontroversen. Religions-politischer Diskurs im Kontext der mimetischen Theorie. Deutsch-Italienische Fachtagung der Guardini Stiftung in der Villa Vigoni 18.-22. Oktober 1999. Münster: LIT, 293-306.

Niewiadomski, Józef (2003): „Gottesmörder und Mörder der Kinder Gottes? Eine theologische Analyse aus der Perspektive der Dogmatik“, in: Buttaroni, Susanna/Musiał, Stanislaw, Hg.: Ritualmord. Legenden in der europäischen Geschichte. Wien: Böhlau, 41-60.

Niewiadomski, Józef/Schwager, Raymund, Hg. (2003): Religion erzengt Gewalt - Einspruch! Münster: LIT.

Palaver, Wolfgang (2001): „Globalisierung und Opfer. Carl Schmitts Lehre vom Nomos“, in: Dieckmann, Bernhard., Hg. (2001): Das Opfer-aktuelle Kontroversen. Religions-politischer Diskurs im Kontext der mimetischen Theo- 
rie. Deutsch-Italienische Fachtagung der Guardini Stiftung in der Villa Vigoni 18.-22. Oktober 1999. Münster: LIT, 181-206.

Palaver, Wolfgang (2004): René Girards mimetische Theorie. Im Kontext kulturtheoretischer und gesellschaftspolitischer Fragen. Münster: LIT.

Petuchowski, Jakob Josef/Thoma, Clemens (1989): Lexikon der jüdischchristlichen Begegnung. Freiburg/B.-Basel-Wien: Herder.

Rahner, Hugo (1964): Symbole der Kirche. Die Ekklesiologie der Väter. Salzburg: Müller.

Rahner, Karl (1960): „Zur Theologie des Symbols“, in: Rahner, Karl: Schriften zur Theologie IV. Einsiedeln-Zürich-Köln: Benziger.

Raulff, Ulrich (2003): Wilde Energien. Vier Versuche zu Aby Warburg. Göttingen: Wallstein.

Rose, Gillian (1992): The Broken Middle: Out of Our Ancient Society. Oxford: Blackwell.

Sandler, Willibald (1998): „Was ist dramatische Theologie?“, in: Tschuggnall, Peter, Hg: Religion - Literatur - Künste. Aspekte eines Vergleichs. Anif: Müller-Speiser, 41-57.

Sandler, Willibald (2003): „Das Friedensgebet der Religionen in Assisi“, in: Schwager, Raymund/Niewiadomski, Józef, Hg.: Religion erzengt GewaltEinspruch! Münster: LIT, 78-97.

Sandler, Willibald (2005): „Kirche als Sakrament des Heilsdramas Jesu Christi“", in: Siebenrock, Roman/Sandler, Willibald, Hg.: Kirche als universales Zeichen. In memoriam Raymund Schwager SJ. Münster: LIT, 101139.

Scharer, Matthias/Niewiadomski, Józef (1999): Fasæinierendes Geheimnis. Neue Zugänge zur Eucharistie in Familie, Schule und Gemeinde. Innsbruck-Wien: Tyrolia.

Schwager, Raymund (1990): Jesus im Heilsdrama. Entwurf einer biblischen Erlösungslehre. Innsbruck-Wien: Tyrolia.

Schwager, Raymund (2005): „Erlöser des Menschen. Soteriologie in der Verkündigung von Johannes Paul II. und die Herausforderungen unserer Zeit", in: Siebenrock, Roman/Sandler, Willibald, Hg.: Kirche als universales Zeichen. In memoriam Raymund Schwager SJ. Münster: LIT, 6398.

Schoell-Glass, Charlotte (1999): „Aby Warburg's Late Comments on Symbol and Ritual“", in: Science in Context 12 (4), 621-642.

Seibt, Gustav (2005): „Der Roman von Gott. Mythos und Monotheismus in Thomas Manns ,Joseph'-Tetralogie“, in: Sinn und Form 57 (3), 331-343.

Siebenrock, Roman (2005): „,Theologischer Kommentar zur Erklärung über die Haltung der Kirche zu den nichtchristlichen Religionen Nostra aetate", in: Herders Theologischer Kommentar zum Zweiten Vatikanischen Konzil. Band 3. Freiburg/B.-Basel-Wien: Herder, 591-693.

Verweyen, Hansjürgen (1991): Gottes letətes Wort. Grundriß der Fundamentaltheologie. Düsseldorf: Patmos. 
Wandinger, Nikolaus (2003): „,Wir vergeben und bitten um Vergebung“. Kommentar zu den kirchlichen Schuldbekenntnissen und Vergebungsbitten des Ersten Fastensonntags 2000“, in: Schwager, Raymund/Niewiadomski, Józef, Hg.: Religion erz̨engt Gewalt - Einspruch! Münster: LIT, 143-179.

Warburg, Aby Moritz (1988): Schlangenritual. Ein Reisebericht. Berlin: Klaus Wagenbach.

Warburg, Aby Moritz (2001): Tagebuch der Kulturwissenschaftlichen Bibliothek Warburg. Mit Einträgen von Gertrud Bing und Fritz, Saxl. Berlin: Akademie Verlag.

Warburg, Aby Moritz (2003): Der Bilderatlas Mnemosyne. Berlin: Akademie Verlag. 


\section{Ursprünge der Gewalt. Eine kritische Auseinandersetzung mit der Theorie matriarchaler Gesellschaft aus Sicht der mimetischen Theorie}

Wilhelm Guggenberger, Wolfgang Palaver, Willibald Sandler, Petra Steinmair-Pösel*

Die zumindest im deutschsprachigen Raum zentral mit dem Namen Heide Göttner-Abendroth verbundene Theorie der matriarchalen Gesellschaft und die mimetische Theorie René Girards stellen zwei Ansätze dar, die sich intensiv mit den Bedrohungspotentialen moderner Gesellschaften auseinandersetzen. Beide erkennen ein in der Gegenwart geradezu apokalyptisch zugespitztes Zerstörungspotential jener sozialen Spannungen, Rivalitäten und Konflikte, die alle uns vertrauten, historiografisch erfassten Kulturen durchziehen. Die Feststellung einer annähernd flächendeckenden Präsenz offener oder subtiler, direkter oder struktureller Gewalt in menschlichen Gesellschaften wirft die Frage nach den Ursprüngen und Wurzeln dieser Gewalt auf. Sowohl die Matriarchatsforschung als auch die mimetische Theorie versuchen im Interesse der Gestaltung von Gegenwart und Zukunft eine Antwort auf diese Frage zu geben, wobei sich sowohl Überschneidungen und Parallelen als auch deutliche Differenzen zwischen den beiden Ansätzen zeigen.

* Wilhelm Guggenberger, Wolfgang Palaver, Willibald Sandler und Petra Steinmair-Pösel, alle von der Katholisch-Theologischen Fakultät der Universität Innsbruck, sind Mitglieder des Clusters „Anthropologie und Gewalt“ im Rahmen der Forschungsplattform „Weltordnung - Religion - Gewalt“. Der vorliegende Text ist eine Gemeinschaftsproduktion für die 15. Klausurtagung der Plattform am 7. April 2006, die auch als Nr. 8 der Innsbrucker Diskussionspapiere $z u$ Weltordnung, Religion und Gewalt erschienen ist. 
Bei unserer Auseinandersetzung mit der Theorie matriarchaler Gesellschaften aus der Sicht der mimetischen Theorie werden wir nach einer kurzen methodologischen Anmerkung in drei Schritten vorgehen.

Zunächst wollen wir unser Verständnis der Geschlechterdifferenz bzw. Geschlechtergleichheit im Hinblick auf die Gewaltthematik anhand einer Autorin verdeutlichen, die einerseits eine Klassikerin feministischen Denkens und eine große Gestalt der Frauenbewegung ist, andererseits aber auch in großer Deutlichkeit Elemente mimetischen Verhaltens anspricht, weshalb sie von René Girard immer wieder als Referenzautorin herangezogen wird. ${ }^{1}$ Gemeint ist die britische Schriftstellerin, Essayistin, Literatur- und Kulturkritikerin Virginia Woolf (1882-1941). Girard selbst betont besonders in Bezug auf ihren Roman Die Wellen (The Waves) ihre fundamentale Einsicht in mimetische Zusammenhänge. ${ }^{2}$ Der amerikanische Literaturwissenschaftler William Johnsen hat eine solche Nähe zu Einsichten der mimetischen Theorie auch in Bezug auf ihre beiden für die Frauenbewegung zentralen Schriften A Room of One's Own (dt. Ein eigenes Zimmer) und Three Guineas (dt. Drei Guineen) herausgearbeitet. ${ }^{3}$ Der Rückgriff auf Woolf soll zeigen, dass der mimetische Ansatz nicht in grundsätzlichem Widerspruch zu feministischem Denken steht oder gar frauenfeindlich ist.

Im zweiten Schritt wollen wir untersuchen, inwiefern die für Girard so zentrale Sündenbocktheorie mit der Matriarchatsthese kompatibel ist. Hier werden sich durchaus Anschluss-, aber auch Differenzpunkte finden. Es wird sich zeigen, dass beide Ansätze eine gesellschaftliche Marginalisierung von Frauen beobachten und beklagen, dafür aber unterschiedliche Ursachen nennen.

Der dritte Schritt, in dem es zentral um die anthropologischen Ursprünge von Gewalt im menschlichen Zusammenleben geht, wird schließlich das Thema Mimesis als positives aber auch latent gefährliches Potential des Menschen in den Mittelpunkt der Argumentation stellen. In diesem Kontext werfen wir auch einen vergleichenden Blick auf die Zukunftsvisionen der beiden Theorien.

1 Vgl. Girard (1997), 153-154, Girard (1978), 309, Girard/Golsan (1993), 133-134, Girard/ Palaver (2001), 762 und Bailie (1997), 135-139.

2 Vgl. im Anschluss an Girard auch Keukelaere (2006).

3 Vgl. Johnsen (2003). 


\section{Methodische Analogien zwischen Matriarchatsforschung und mimetischer Theorie}

Zuallererst ist auf drei grundsätzliche methodologische Ähnlichkeiten zwischen der Theorie matriarchaler Gesellschaften und der mimetischen Theorie hinzuweisen, die einerseits das Gespräch erleichtern sollten, anderseits freilich auch Anlass und Begründung präziser Unterscheidung in inhaltlichen Einzelfragen darstellen.

Beide Zugänge sind erstens durch eine „Hermeneutik des Verdachts" gegenüber herrschenden gesellschaftlichen Strukturen gekennzeichnet. Während die mimetische Theorie die Aufdeckung des verdrängten Gründungsmordes und seiner bis in die Gegenwart nachwirkenden Gewaltdynamik betreibt und dabei ganz allgemein von einer Perspektive der Opfer ausgeht, ist die Matriarchatsthese um die Aufdeckung der Realität eines ursprünglich vorherrschenden, historisch aber verdrängten Matriarchats bemüht, wobei ebenfalls die Perspektive der Opfer (primär Frauen, zumindest indirekt aber auch der männliche Teil der Menschheit, ja die gesamte außermenschliche Natur) eingenommen wird.

Eine zweite Gemeinsamkeit zeigt sich hinsichtlich der Mythenanalyse. Beide Theorien verstehen Mythen als geschichtliche Zeugnisse. Mythen enthalten demnach einen wahren historischen Kern. Immer wieder hat Girard beispielsweise auf die realen Opfer hingewiesen, die sich in mythologischen Erzählungen zumindest spurenhaft erkennen lassen. Sein vor Kurzem erschienenes Buch Die verkannte Stimme des Realen verweist bereits im Titel auf dieses Bemühen, hinter mythischen und literarischen Texten konkrete Realitäten zu entdecken. Heide Göttner-Abendroth weist am Beispiel von Johann Jakob Bachofen ${ }^{4}$ und Robert von Ranke-Graves, zwei wichtigen Vorläufern der Matriarchatsthese, darauf hin, wie sehr diese gegen ästhetisierende romantische Mythostheorien Mythen als geschichtliche Zeugnisse verstanden haben. Als Beispiel kann ein Zitat von Robert Ranke-Graves dienen:

„Es ist ein Unglück, dass das Wort ,mythisch', trotz des starken mythischen Elements im Christentum, heute nur noch soviel heißt wie ,phantastisch, absurd, unhistorisch'; denn Phantasie spielte eine geringe Rolle in der Entwicklung der griechischen, lateinischen, palästinensischen und keltischen Mythen, bis die normannischen- 
französischen trovères [Troubadours] sie zu unverantwortlichen Ritterromanzen verarbeiteten. Sie alle waren ernste Berichte über alte religiöse Bräuche und Ereignisse, und sie sind als Geschichte recht zuverlässig, sobald man nur ihre Sprache versteht und Transkriptionsfehler, Missverständnisse der alten Riten und willkürliche, aus moralischen oder politischen Gründen eingefügte Änderungen berücksichtigt.“"5

Drittens weisen beide Ansätze eine grundsätzlich interdisziplinäre Ausrichtung auf. Die Fragestellung ist jeweils derart umfassend, dass ihre Abarbeitung sich nur schwer in Übereinstimmung mit der extremen Arbeitsteilung des traditionellen Fächerkanons der disziplinären Wissenschaften bringen lässt. Archäologie, Geschichtswissenschaft, Anthropologie, Ethnologie, Sozialwissenschaft, Literaturwissenschaft, Theologie etc. liefern wesentliche Beiträge für die beiden Theorien. Diese Breite ermöglicht nicht nur die Entwicklung einer umfassenden Theorie, sondern verursacht auch immer wieder Kritik der Fachwissenschaften, die die von ihnen angezielte Präzision in Gefahr sehen. Wissenschaft, die lebensdienlich sein will, muss aber wohl gerade dort, wo es um den Menschen geht, den Schritt zum Paradigma wagen, das aufs Ganze zielt.

\section{Virginia Woolf, Feminismus und mimetische Theorie}

Virginia Woolf ist eine Autorin, die gerade durch ihr feministisches Interesse und ihre Beschäftigung mit Geschlechterfragen auf mimetische Zusammenhänge stößt. Eine ausführlichere Auseinandersetzung mit ihr könnte für den Dialog zwischen feministischen Ansätzen im Allgemeinen und der Matriarchatsthese im Besonderen einerseits und der mimetischen Theorie andererseits durchaus fruchtbar sein. Wir beschränken uns hier auf eine Behandlung der beiden Essays Ein eigenes Zimmer und Drei Guineen.

Methodologisch arbeitet Woolf in beiden Essays mit Geschichten, die sie erfindet, um ihre Leserschaft ihren Erkenntnisprozess mit- bzw. nachvollziehen zu lassen. Mit anderen Worten: Indem sie

5 Ranke-Graves (1985), 14; Göttner-Abendroth (1995), 94. Die historische Leseweise von Mythen war und bleibt umstritten. Vgl. Hinweise auf die Ablehnung von Bachofens Vorgangsweise in der wissenschaftlichen Community seiner Zeit in Wesel (1999), 12 und 55. Zur historischen Bedeutsamkeit von Mythen vgl. auch Mulack (2003), 57-60. Alles entscheidend bleibt freilich die Frage, wie man die Sprache der Mythen richtig entschlüsselt. 
Geschichten erzählt, stellt sie Theorien über historische Ereignisse und menschliches Verhalten auf und gewährt dabei nicht nur Einblick in die Ergebnisse ihrer Reflexionen, sondern erlaubt es den Leser(inne)n auch, ihren Überlegungen von Grund auf zu folgen, denn: ${ }^{6}$

„Man kann seinen Zuhörerinnen nur die Gelegenheit geben, ihre eigenen Schlüsse zu ziehen, während sie die Grenzen, die Vorurteile, die Abneigungen der Rednerin wahrnehmen. Die Erfindungen der Literatur enthalten in dieser Hinsicht wahrscheinlich mehr Wahrheit als Wirklichkeit.“"7

Woolf geht also davon aus, dass in den Geschichten, die sie in Ich-Form erzählt, Wahres über das Verhältnis zwischen Männern und Frauen, über die historische und aktuelle Stellung der Frauen, über Geschlechterdifferenz und den Beitrag der Frauen zu einer friedlichen und gerechten Gesellschaft vermittelt wird. Was ist nun diese Wahrheit, die Woolf in ihren literarischen Erfindungen mitteilen will?

\section{Ein eigenes Zimmer}

In ihrem 1929 erstmals erschienenen Essay A Room of One's Own (Ein eigenes Zimmer) setzt sich Woolf mit der Rolle von Frauen in der britischen Gesellschaft am Beginn des 20. Jahrhunderts ebenso auseinander wie mit der Geschichte dieser Rolle und mit jenen Frauen, die es ihr selbst ermöglichten, als Schriftstellerin tätig zu sein und als Frau ihre eigenständige Meinung zu dieser Frage zu vertreten.

Als Anlass ihrer Überlegungen nennt Woolf eine Vorlesung zum Thema Frauen und Literatur, die sie vor Studentinnen eines Frauencolleges halten soll. Doch anstatt eine Abhandlung über dieses Thema vorzutragen, erzählt sie Geschichten über ihre Erlebnisse beim Schreiben des Vortrags. Dabei ändert sie auch den Hauptfokus ihrer Überlegungen: es geht ihr vor allem um die Bedingungen, unter denen Frauen intellektuell tätig sein können, und um das damit zusammenhängende Thema Frauen und Armut.

Ein zentrales, immer wiederkehrendes Motiv ist dabei die Erfahrung des Ausschlusses von Frauen aus verschiedenen gesellschaftlichen Bereichen, wie etwa dem guter universitärer Bildung. 
Woolf stellt sich die Frage, warum Frauen nicht (wie Männer dies für ihre Söhne tun) mehr Geld für die Ausbildung ihrer Töchter zur Verfügung stellen bzw. gestellt haben. Die Antwort liegt auf der Hand: Weil Frauen arm sind. Der Blick auf die Mutter von Mary Seton, der fiktionalen Hauptperson ihrer Geschichte, liefert ihr eine erste Begründung für diese Armut: Weil Frauen in der Vergangenheit damit beschäftigt waren, viele Kinder zu gebären und aufzuziehen, hatten sie nicht die Möglichkeit, einen Beruf auszuüben und Geld zu verdienen. Und weil das Gesetz den Frauen verbot, Geld zu besitzen, war es für sie auch gar nicht interessant, Geld zu verdienen - es waren sowieso ihre Männer, die dann über das Geld nach ihrem Gutdünken verfügen konnten. ${ }^{8}$

Woolf beschreibt in der Folge, wie sie sich, von diesen ersten Wahrnehmungen getrieben, aufmacht, um in der Bibliothek des British Museum, die auch für Frauen offen steht, eine Antwort auf die Frage zu finden, warum Frauen arm sind. Die Beobachtungen, die sie dabei macht, sind höchst aufschlussreich: Sie bemerkt, dass es unzählige Bücher über Frauen gibt, die jedoch alle von Männern geschrieben sind:

„Haben Sie eine Vorstellung, wie viele Bücher über Frauen im Laufe eines einzigen Jahres geschrieben werden? Haben Sie eine Vorstellung, wie viele von Männern geschrieben sind? Ist Ihnen bewusst, dass Sie vielleicht das am häufigsten abgehandelte Tier des Universums sind? ${ }^{(\omega)}$

Weiters bemerkt sie, dass es für sie, die keine Universitätsausbildung genossen hat, sehr schwierig ist, sich in den Literaturmassen zurechtzufinden, während der Student am Nebentisch scheinbar alle 30 Sekunden höchst zufrieden eine neue Erkenntnis aus seiner Lektüre niederschreibt, was sie zu einem neidvollen Blick auf ihren männlichen Kollegen veranlasst. Im Gegensatz zum Studenten am Nachbartisch ist sie selbst von der Bibliothek enttäuscht, denn sie hat nichts wirklich Passendes zu ihrem Thema gefunden. Statt Schlussfolgerungen aus der Lektüre zu notieren, zeichnet sie deshalb, während sie noch grübelt, eine Skizze:

„Ich hatte ein Gesicht gemalt, eine Gestalt. Es war das Gesicht und die Gestalt des Professor X. bei der Niederschrift seines monu- 
mentalen Werks Die geistige, sittliche und körperliche Unterlegenheit des weiblichen Gescblechts. Es war auf meinem Bild kein Mann, der auf Frauen anziehend wirkte. Er war untersetzt; er hatte große Kinnbacken; zum Ausgleich hatte er sehr kleine Augen; er war sehr rot im Gesicht. Seine Miene verriet, wie er unter einem Gefühl litt, das ihn dazu trieb, mit seiner Feder auf das Papier einzustechen, als tötete er beim Schreiben ein schädliches Insekt, aber auch, als er es getötet hatte, befriedigte ihn das nicht; er musste fortfahren, es zu töten; und selbst dann blieb ein Grund für Zorn und Beunruhigung. Konnte es seine Frau sein, fragte ich, mein Bild betrachtend? War sie in einen Kavallerieoffizier verliebt? [...] Was immer der Grund war, der Professor sah auf meiner Skizze sehr zornig und sehr hässlich aus, während er sein großes Buch über die geistige, sittliche und körperliche Unterlegenheit der Frauen schrieb. [...] Doch gerade in unserer Muße, in unsern Träumen kommt die versunkene Wahrheit manchmal an die Oberfläche. Eine sehr elementare Übung der Psychologie, die den erlauchten Namen Psychoanalyse nicht verdient, zeigte mir beim Betrachten meines Notizbuchs, dass die Skizze des zornigen Professors im Zorn angefertigt worden war." ${ }^{\prime 10}$

Woolf bemerkt also ihren eigenen Zorn, den die These von der Unterlegenheit der Frauen bei ihr ausgelöst hat, und sie wird sich rasch bewusst, dass dieser Zorn nur den Zorn des Professors widerspiegelt. Neugierig geworden, sucht sie weiter nach Gründen für diesen Zorn der Männer („Patriarchen“). Einen Grund dafür vermutet sie in deren Angst, die Frauen könnten sich ihre Positionen aneignen - eine Befürchtung, die sie aus der Rivalität zwischen Reichen und Armen auf das Geschlechterverhältnis überträgt: „Reiche Leute zum Beispiel sind oft zornig, weil sie befürchten, dass die Armen sich ihren Reichtum aneignen wollen." 11

Einen anderen, subtileren Grund für die Betonung der männlichen Überlegenheit sieht Woolf jedoch darin, dass Männer aus der Illusion ihrer Überlegenheit über die Frauen jenes Selbstvertrauen schöpfen, das sie so dringend brauchen, um im Leben und im Konkurrenzkampf mit anderen Männern bestehen zu können. Dieser leidenschaftliche, auf mimetischer Rivalität beruhende Konkurrenzkampf, in dem die Frauen als Vergrößerungsspiegel für das männli- 
che Selbstbewusstsein wirken, ist nach Woolf auch der Antriebsmotor der Kultur:

„Frauen haben seit Jahrhunderten als Spiegel gedient, Spiegel mit der magischen und erhebenden Kraft, die Gestalt des Mannes in doppelter Größe wiederzugeben. Ohne diese Kraft wäre die Erde wahrscheinlich immer noch Sumpf und Urwald. [...] Welchen Nutzen sie in zivilisierter Gesellschaft auch immer haben mögen, Spiegel sind für alle grausamen und heroischen Taten unabdingbar. [...] Das erklärt zum Teil, wie unentbehrlich Frauen oft für Männer sind. Und es erklärt, wie empfindlich Männer gegen ihre Kritik sind; [...] Denn wenn sie anfängt, die Wahrheit zu sagen, schrumpft seine Gestalt im Spiegel; seine Lebenstüchtigkeit wird vermindert."12

Solange Frauen jedoch von Männern abhängig sind, können sie kaum zu einer eigenen, unabhängigen Meinung gelangen und ehrliche Kritik äußern, sondern sind dazu gezwungen, Männern als Spiegel zu dienen. Vor diesem Hintergrund misst Woolf dem unabhängigen Einkommen für Frauen eine noch größere Bedeutung zu als dem Frauenwahlrecht. Sie beschreibt, wie eine Erbschaft, die ihr ein lebenslanges, gesichertes Einkommen verschafft, sie aus der Dynamik von Konkurrenz und Zorn befreit und in ihr einen bemerkenswerten Stimmungswechsel gegenüber Männern hervorgerufen hat:

„Keine Macht der Welt kann mir meine fünfhundert Pfund wegnehmen. Nahrung, Haus und Kleidung sind für immer mein. Deswegen hören nicht nur Mühsal und Fron auf, sondern auch Hass und Bitterkeit. Ich brauche keinen Mann zu hassen; er kann mir nicht schaden. Ich brauche keinem Mann zu schmeicheln; er kann mir nichts geben. Und so gelangte ich unmerklich zu einer neuen Haltung gegenüber der anderen Hälfte der Menschheit. Es war absurd, irgend einer Klasse oder einem Geschlecht als ganzem die Schuld zu geben. [...] Zwar besaßen sie [die Männer] das Geld und die Macht, aber nur um den Preis, in ihrer Brust einen Adler, einen Geier zu beherbergen, der für alle Zeit die Leber herausreißt und auf die Lunge einhackt - der Drang nach Besitz, die Gier nach Erwerb, die sie dazu treibt, fortwährend die Äcker und Güter anderer Menschen zu begehren. [...] In der Tat enthüllte die Erbschaft meiner Tante mir den Himmel und setzte an die Stelle der großen und im- 
posanten Gestalt eines Herrn, den Milton mir zu immerwährender Anbetung empfahl, den Anblick des offenen Himmels."13

Dieser Stimmungswandel führt Woolf zuerst zu Mitleid und Nachsicht dem anderen Geschlecht gegenüber und dann zu dem, was sie als „die größte aller Befreiungen“ empfindet, „nämlich [zu der] Freiheit, über die Dinge als solche nachzudenken" ". ${ }^{4}$ Aus dieser Freiheit heraus, die nicht mehr durch Zorn oder Rivalität getrübt ist, kann sie aufzeigen, welche Geschichte ihrer Einsicht vorausgegangen ist und welche Kämpfe ausgefochten worden sind, ohne sich selbstgerecht über ihre Vorfahren zu erheben. Aus dieser Freiheit heraus kann sie auch eine Zielvision für das $\mathrm{Zu}$ - und Miteinander von Männern und Frauen entwerfen: Dass Frauen wie Männer leben, aussehen oder schreiben, erscheint ihr nicht als Ziel, das fände sie „unendlich schade“. Vielmehr solle „die Erziehung eher die Unterschiede als die Ähnlichkeiten hervorkehren und verstärken" "15, ohne dass dabei das Geschlechtsbewusstsein immer im Vordergrund stehe $^{16}$. Der Idealzustand bestünde nach Woolf darin, dass Männer für Frauen nicht mehr Gegner sind und Frauen keine Zeit damit verschwenden, gegen sie zu Felde zu ziehen, sondern dass die Geschlechter sich gegenseitigen ergänzen und zusammenarbeiten.

\section{Drei Guineen}

In ihrem Essay Three Guineas, der neun Jahre nach $A$ Room of One's Own erschienen ist, geht Woolf nochmals einen Schritt weiter: Was in Ein eigenes Zimmer als Lösung des Problems erscheint - ein gesichertes Einkommen und ein eigenes Zimmer - ist nun durch die politische Situation, durch die faschistischen Regime in Italien und Deutschland und den drohenden Krieg, in Frage gestellt. In einem fiktiven Briefwechsel beantwortet Woolf die Frage, wie Frauen dazu beitragen können, eine friedliche und gerechte Gesellschaft zu verwirklichen.

Woolf geht davon aus, dass es jener Frauen bedarf, die sich eine eigene, unabhängige Meinung bilden können und die in der Folge auch den gesellschaftlichen Einfluss besitzen, diese zur Geltung zu bringen. Deshalb argumentiert sie im ersten Abschnitt von Three 
Guineas, dass Frauen eine entsprechende Ausbildung benötigen, um eine Arbeit zu bekommen, die ihnen ein eigenes Einkommen und eine eigene Meinung ermöglicht. Dann können Frauen ihre unterschiedliche Sichtweise in den gesellschaftlichen Diskurs einbringen, die durch ihre spezifische Geschichte, ja ihre Außenseiterinnenrolle entstanden ist: dadurch, dass sie - im Unterschied zu den Männern keinen Besitz und keine Macht gehabt haben, nicht integriert gewesen sind, in das komplexe, durch Konkurrenz und Rivalität gekennzeichnete Rangsystem, das durch verschiedene Roben, Titel und Ämter strukturiert ist. Der Wert des Beitrags der Frauen zu einer friedlichen und gerechten Gesellschaft liegt dabei nach Woolf gerade in dieser unterschiedlichen Sichtweise, die gleichsam einen Blick von außen auf die patriarchal strukturierte Gesellschaft ermöglicht, begründet:

„Jede Hilfe, die wir Ihnen zuteil werden lassen können, muss sich von der unterscheiden, die Sie sich selbst geben können, und vielleicht liegt der Wert unserer Hilfe gerade in der Tatsache dieses Unterschieds." "17

Doch sind Frauen nicht gerade dann, wenn sie sich - wie die Männer - in Bildung und Beruf zu bewähren und zu behaupten suchen, in der Gefahr, diese unterschiedliche Sichtweise zu verlieren und selbst in eine Konkurrenz- und Rivalitätssituation mit Männern und untereinander zu geraten? Woolf sieht die Gefahr,

„dass die Berufe eine gewisse unleugbare Wirkung auf diejenigen haben, die sie ausüben. [...] Denken wir dann nicht zu Recht, dass wir, wenn wir dieselben Berufe ergreifen, dieselben Eigenschaften übernehmen werden? Und führen diese Eigenschaften nicht zu Kriegen? Werden wir in einem weiteren Jahrhundert oder so, wenn wir die Berufe auf dieselbe Weise ausüben, nicht ebenso besitzergreifend sein, ebenso eifersüchtig, ebenso streitsüchtig, ebenso selbstherrlich $[\ldots] .{ }^{\prime \prime 18}$

Aber sie ist sich auch dessen bewusst, dass der erneute Rückzug von Frauen in die Privatsphäre keine Lösung darstellt. Vielmehr schlägt sie vor, dass Frauen Berufe ausüben und Geld verdienen, allerdings unter bestimmten Bedingungen, die eine vollständige Anpassung an die Dynamik der Konkurrenz verhindern. Als solche Be- 
dingungen nennt Woolf: 1. Armut (genug Geld, um davon gut und unabhängig leben zu können, aber nicht mehr), 2. Keuschheit (Weigerung, den Verstand um des Geldes willen zu verkaufen), 3. Verachtung (Verzicht auf Ruhm, Lob und Anerkennung, Vorzug von Lächerlichkeit und Anonymität) und 4. Freiheit von unechten Loyalitäten (Befreiung von Nationalstolz, religiösem Stolz etc.). ${ }^{19}$

Woolf ist der Ansicht, dass Frauen nicht von Natur aus selbstloser sind als Männer, sondern ihre größere Widerstandskraft gegen gewisse Zwänge der Konkurrenz und der Rivalität den genannten Bedingungen verdanken, die ihnen aufgrund ihrer gesellschaftlichen Situation zu Lehrmeisterinnen geworden sind. ${ }^{20}$ So schlägt Woolf schließlich vor, dass Frauen eine (gänzlich unbürokratische, auf Reichtum und Titel verzichtende) Gesellschaft der Außenseiterinnen begründen sollen, um mit ihren eigenen Methoden für Frieden, Gleichheit und Freiheit zu arbeiten. Konkret würde das für Frauen bedeuten, sich zu weigern, die oben beschriebene Spiegelfunktion zu erfüllen, also durch ihre Bewunderung (oder auch durch engagierte Opposition) die Dynamik von Konkurrenz und Rivalität unter den Männern weiter anzuheizen.

\section{Systematischer Ertrag}

Was lässt sich nun in systematischer Hinsicht anhand der beiden „feministischen“ Schriften Virginia Woolfs über eine Positionierung der mimetischen Theorie im Bereich der Genderthematik lernen?

Liest man die beiden Essays, bemerkt man sehr rasch, dass Woolf sich der mimetischen Struktur menschlichen Begehrens und Handelns und der damit verbundenen Konfliktneigung zutiefst bewusst ist. Die erzählten Geschichten machen die Benachteiligung von Frauen sehr deutlich. Daraus folgt die Forderung nach Gleichberechtigung, was zunächst bedeutet, Rechte für Frauen einzufordern, welche die Männer bereits haben. Damit geraten Frauen jedoch sowohl historisch als auch strukturell in eine Position der Konkurrenz, der Rivalität und der Verspätung. ${ }^{21}$ Deutlich wird dies in der Passage über Woolfs Beobachtungen im British Museum: Der neidvolle Blick, den sie ihrem männlichen Kollegen zuwirft, weist

19 Vgl. Woolf (2001), 223-224.

20 Vgl. Woolf (2001), 246.

21 Vgl. Johnsen (2003), 110. Einen immanenten Kampf um Rechte innerhalb der herrschenden Strukturen kritisiert auch Werlhof (2003), 17. 
bereits auf diese Rivalität hin, und die folgende Auseinandersetzung mit den Ursprüngen ihres eigenen Zorns ist sehr erhellend: Ihre Analyse zeigt klar, dass sie die Ursache für den Zorn in mimetischen, nicht in instinkthaften Zusammenhängen sieht. Ihr Verhalten gründet im Verhalten anderer, nicht in den Vorgaben der Natur: Sie wird zornig, weil der Professor zornig ist. Ihr Zorn entspringt einer mimetischen Ansteckung mit seinem Zorn. ${ }^{22}$

Auf mimetische Zusammenhänge weist auch Woolfs Analyse der „Spiegelfunktion“, die Frauen oft erfüllt haben, hin. Wie ist das zu verstehen? Der amerikanische Literaturwissenschaftler W. Johnsen zeigt auf, dass es hier um negative Reziprozität geht: Es handelt sich dabei um negatives Feedback (in diesem Fall der Männer an die Frauen), das andere (die Frauen) dazu benutzt, den Betrachter (den Mann) als bewundernswertes Modell der Nachahmung und Rivalität zu bestätigen. Tatsächlich tendiert diese Konstellation aber dazu, gewalttätiges Verhalten hervorzurufen: ${ }^{23}$ Es handelt sich um einen mimetischen double bind, bei dem das männliche Vorbild (unbewusst) zugleich zwei konträre Botschaften aussendet: (1) Ich bin höchst nachahmenswert! und (2) Wehe, du ahmst mich nach! Das bewunderte Vorbild verwandelt sich so - wie Girard vielfach aufgezeigt hat - nur allzu rasch in einen verhassten Rivalen.

Die konkrete Befreiung aus den Verstrickungen in die Dynamik von Rivalität und Konkurrenz und aus den damit einhergehenden irrationalen Emotionen von Eifersucht und Zorn beschreibt Woolf als Befreiung von diesem männlichen Vorbild, das gleichsam als Götze präsentiert wird und als Enthüllung des Himmels. Diese Befreiung hat zur Folge, dass sie Männer nicht mehr bekämpfen muss, dass sie gänzlich aus diesem Rivalitätsverhältnis ausgestiegen ist. Diese Befreiung bedeutet auch, dass Woolf die Wurzeln des Feminismus bis ins Patriarchat zurückverfolgen und aufzeigen kann, dass auch das Patriarchat, wenn auch in relativ geringem Maß, Frauen gefördert hat. ${ }^{24}$

22 Vgl. Johnsen (2003), 114. Nach Johnsen geht Woolfs Analyse des Zorns so tief, dass sie nie wirklich weiter verfolgt wurde. Zorn wird immer als primäre Emotion verstanden, als Hypothese, die alles Weitere erklärt. Woolf hingegen schlägt vor, dass das Faktum des Zornes entmythologisiert werden sollte. Vgl. Johnsen (2003), 116-117.

23 Vgl. Johnsen (2003), 117.

24 Vgl. Johnsen (2003), 134. 
Woolf erkennt und überwindet damit ein Kernproblem von Emanzipationsbewegungen: Diese müssen nämlich - um in einem Rechtssystem Gerechtigkeit zu erlangen - andere anklagen. Aber gleichzeitig bedeutet diese Anklage eine Verstrickung in Ressentiments, die davon abhält, ,über die Dinge als solche nachzudenken“. ${ }^{25}$ Mit diesem Ausstieg aus der Dynamik von Rivalität und Konkurrenz eröffnet Woolf eine Form des Feminismus, die nicht in eine Sündenbockjagd auf die Patriarchen verfällt. Sie weigert sich, einer Klasse oder einem Geschlecht als Ganzem allein die Schuld an den ungerechten Strukturen der Gesellschaft zuzuschieben. Deshalb bezeichnet Johnsen Woolfs Denken als „postsakrifiziell“: Woolf weigert sich sowohl, selbst zum Sündenbock gemacht zu werden, als auch, andere zum Sündenbock zu machen, denn „sie wissen nicht, was sie tun“. Damit bereitet sie den Weg für einen Feminismus, der frei ist von Rivalität und Gewalt und auch die positive Rolle der Väter sehen kann.

Virginia Woolf formuliert unseres Erachtens wesentliche Erkenntnisse, die uns auch bei einer Auseinandersetzung mit der Theorie matriarchaler Gesellschaften leiten sollen: Die Realität der als patriarchal bezeichneten Gesellschaften ist bis in die Gegenwart vielfach ungerecht und destruktiv, weil von ausufernder Konkurrenz und Konflikt geprägt. Die anthropologischen Grundlagen dieser Realität sind aber nicht spezifisch männlicher Natur - wir finden sie auch im Verhalten von Frauen. Dadurch verlieren die Begriffe Matriarchat und Patriarchat freilich einiges an Erklärungskraft. Ihre AuBenseiterposition in der männlich dominierten Gesellschaft macht Frauen aber in besonderer Weise sensibel und hellsichtig für Unrechtsstrukturen und die von ihnen geforderten Opfer. ${ }^{26}$ Diese Perspektive muss im Interesse der Gesamtgesellschaft, ja der gesamten Schöpfung deutlich zur Sprache gebracht werden, um Grundlage einer besseren, friedlicheren Gesellschaftsordnung zu werden. Dazu können in besonderer Weise auch Erfahrungen des Empfangens beitragen, die jenseits erkämpfter und immer neu zu erkämpfender Machtpositionen gemacht werden. Bei unserem Bemühen um eine

25 Vgl. Johnsen (2003), 140-141.

26 Die Sensibilisierung einer Gesellschaft für die Position der Opfer kann selbst nochmals pervertiert werden, wenn die Opferrolle zum subtilen Machtinstrument gemacht wird oder als Ressentiment in Erscheinung tritt, das erlittene Verletzungen als Speerspitze gegen andere richtet. 
gerechtere Gesellschaftsordnung müssen wir aber damit rechnen, dass wir es nicht nur mit üblen Strukturen zu tun haben, die es zu überwinden gilt, sondern mit einer allgemeinmenschlichen Problematik, die wir als mimetische Rivalität bezeichnen, die aber nicht mit einer quasi-naturgegebenen und naturnotwendigen Gewalttätigkeit gleichgesetzt werden darf.

\section{Kulturgründung und Sündenbock}

\section{Ausgeblendete Gründungsgewalt in der Matriarchatsthese?}

Die Matriarchatsthese sieht am Beginn menschlicher Kultur eine lange Periode mutterzentrierter Gesellschaften, deren egalitäre, friedvolle Lebensweise gewaltsam von außen zerstört wurde. Hier zeigt sich nun ein deutlicher Unterschied zum Verständnis kultureller Entwicklung, wie es die mimetische Theorie vertritt. Um diesen Unterschied deutlich herauszuarbeiten, versuchen wir zuerst skizzenhaft die Matriarchatsthese nachzuzeichnen.

Heide Göttner-Abendroth versteht unter Matriarchat „,von Frauen geschaffene und geprägte Gesellschaften, in denen sie dominieren, aber nicht herrschen" ${ }^{27}$. An dieser Definition zeigt sich, dass das Matriarchat nicht wie das Patriarchat mit Herrschaft verbunden ist. ${ }^{28}$ Aus der Sicht der Matriarchatsthese hat sich Herrschaft geschichtlich erst später entwickelt. Mit dem Begriff arché ist deshalb auch nicht Herrschaft, sondern Anfang, also die Mutter bzw. das mütterliche Prinzip gemeint. Die Position der Matriarchatsthese entspricht den Schlussfolgerungen der Archäologin Marija Gimbutas über das alte, matriarchale Europa:

„Die Kultur, die Alteuropa genannt wird, war gekennzeichnet von der Dominanz der Frau in der Gesellschaft und der Verehrung der Göttin, welche das kreative Prinzip verkörpert, denn sie ist die Quelle und Geberin von allem. In dieser Kultur repräsentiert das männliche Element Mann und Tier die spontane und lebensstimulie-

27 Göttner-Abendroth (1995), 9

28 Sprachlich zeigt sich dabei aber, wie schwierig es ist, diesen Sachverhalt überhaupt zum Ausdruck zu bringen. Denn auch das im Lateinischen wurzelnde „dominieren“ bleibt natürlich noch an männliche Herrschaftsformen gebunden. Das könnte natürlich auch damit zusammenhängen, dass das Patriarchat sich so sehr durchgesetzt hat, dass die geschichtlich gebräuchlichen Sprachen das Matriarchat völlig ausblenden. 
rende Seite, aber nicht die lebensspendenden Kräfte. Diese Kultur, die vor den indoeuropäischen Eroberungen lag, war matrifokal und matrilinear, eine Agrikultur mit Sesshaftigkeit, egalitär und friedlich. Sie kontrastiert sehr scharf mit der nachfolgenden indoeuropäischen Kultur, welche patriarchal war." ${ }^{29}$

Der Hinweis auf die Verehrung der Göttin zeigt deutlich, dass diese matriarchalen Kulturen auch religiös geprägt waren. Über 20.000 Jahre soll es Göttinverehrung gegeben haben. ${ }^{30}$ Die massenhafte Verbreitung von entsprechenden Frauenstatuetten ist ein Beleg dafür. ${ }^{31}$ Gemäß der Matriarchatsthese wurden diese friedlichen und egalitären Kulturen durch Indoeuropäer - eine maskuline Kultur, die aus der russischen Steppe kam - zerstört. ${ }^{32}$ Als klassisches Beispiel einer matriarchalen Gesellschaft gilt die minoische Kultur Kretas, die von Eindringlingen aus dem Osten zerstört worden sein soll. ${ }^{33}$

Im Unterschied dazu geht die mimetische Theorie davon aus, dass alle uns bekannten Kulturen aus einer mit Gewaltmitteln operierenden Eindämmung ausufernder zwischenmenschlicher Gewalt entstehen. Girard spricht von einem Gründungsmord, der Teil eines kollektiven Sündenbockmechanismus ist. Die Problematik der Gewalt steht damit am Beginn aller Kultur, da sie nicht von außen an sie herangetragen wird, sondern ihr gleichsam inhärent ist. Diese Sichtweise dient nicht der Rechtfertigung gewalttätiger Strukturen, wohl aber einem besseren Verständnis von deren sozialer Funktion.

Aus einer Gegenüberstellung von mimetischer Theorie und der Theorie matriarchaler Gesellschaften stellt sich daher die Frage, ob die Matriarchatsthese nicht durch eine Ausblendung des internen Konfliktpotentials jener untergegangenen Gesellschaften gekennzeichnet ist, die sie als Vorbilder für eine Gesellschaftsordnung der Zukunft präsentiert. Liegt in diesem Ansatz nicht eine Versuchung zum Neo-Rousseauismus, der historisch Vergangenes idealisiert, um

29 Göttner-Abenroth (1995), 108. Das Zitat gibt eine Aussage Gimbutas aus ihrem Werk The Godesses and Gods of Old Europe wieder.

30 Vgl. Göttner-Abendroth (1995), 108.

31 Vgl. Göttner-Abenroth (1995), 18.

32 Vgl. Göttner-Abenroth (1995), 110 und 56. Marija Gimbutas Geschichtsthese wurde allerdings inzwischen auch von feministischer Seite deutlich kritisiert: Röder et al. (1996), 273-298; vgl. auch die Auseinandersetzung mit der Matriarchatskritikerin Cynthia Eller in: Marler (2003), 120-127.

33 Vgl. Eisler (1993). 
damit nicht in letzter Konsequenz „über die Dinge als solche“34 nachdenken zu müssen?

Einige konkrete Beispiele lassen sich als Argumente für die Berechtigung einer solch kritischen Anfrage aufführen. Die These von einer angeblich gewaltfreien minoische Kultur in Kreta etwa wurde durch den Fund eines Menschenopfers in den 1980er-Jahren nachhaltig erschüttert. Riane Eislers Erklärung, hier handle es sich im Sinne einer Ausnahme um ein Menschenopfer angesichts einer bedrohlichen Naturkatastrophe, ${ }^{35}$ überzeugt nicht wirklich. Wird in einer Krisensituation auf blutige Opferrituale zurückgegriffen, stellt sich die Frage nach ursprünglicheren Mustern für solche Rituale. ${ }^{36}$ Auch Kretas Mythen (Stieropfer, Stierspringer, die Sage vom menschenfressenden Minotaurus) weisen eher auf das Vorhandensein eines ursprünglichen Opfermechanismus hin. ${ }^{37}$

Ein weiteres Beispiel findet sich in Ranke-Graves Hinweis auf die Riten der „Heiligen Hochzeit“, in denen jährlich ein Mensch geopfert wurde. Göttner-Abendroth zitiert die folgende Passage, ohne das Faktum des Menschenopfers zu kommentieren oder es systematisch in Beziehung zur Behauptung der strukturellen Gewaltfreiheit matriarchaler Gesellschaften zu stellen: „Die Stammesnymphe oder Königin wählte aus ihrem Gefolge junger Männer den Liebhaber für ein Jahr, um ihn dann bei Jahresende zu opfern. " ${ }^{38}$ Noch deutlicher wird diese Vorstellung in der Paraphrasierung von George Frazer, der darauf hinweist, dass der „Heilige König“ als Gatte der kosmischen Göttin für die Aufrechterhaltung der Harmonie verantwortlich ist. „Entsprechend hart ist die Bestrafung des Königs, wenn durch ein Unwetter erwiesen ist, dass seine zauberische Magie versagt hat. Es drohen Prügel, Absetzung oder der sofortige Tod.“39 Carola Meier-Seethaler hält angesichts solcher Beobachtungen sogar fest, dass Tier- und Menschenopfer in matrizentrischen Frühkulturen eine zentrale Rolle spielten und Adressat solcher - sowohl

34 Woolf (2001), 43.

35 Vgl. Eisler (1993), 360-362.

36 Vgl. Schwager (1992), 365-366.

37 Vgl. Wolf (1983), 58-69.

38 Ranke-Graves (1985), 13-14; Göttner-Abendroth (1995), 95.

39 Göttner-Abendroth (1995), 85. Auch im Falle des Erfolgs ist dem König freilich der Tod sicher, denn damit wird seine rituelle Wiedergeburt ermöglicht. 
männlichen als auch weiblichen - Opfer die „Große Göttin“ als Herrin über Leben und Tod war. ${ }^{40}$

Schließlich ist auch die selektive Rezeption von Christian Sigrists Buch Regulierte Anarchie durch die Vertreterinnen der Matriarchatsthese von einer gewissen Ausblendung kollektiver Gewaltmuster geprägt. Sigrists Werk gehört zu den marxistischen Zugängen, die für die Matriarchatsthese wichtig geworden sind. Nach Sigrist gab und gibt es Kulturen, die keine Herrschaft im Sinne der Soziologie Max Webers kennen. Autorität als Führung müsse demnach klar von einer mit Befehlen verbundenen Herrschaft unterschieden werden. So sehr die Beobachtungen Sigrists in Afrika zutreffen und es tatsächlich Kulturen gibt, die keine Herrschaft in unserem neuzeitlichen Verständnis kennen, so sehr wäre aber die These falsch, dass diese segmentären Gesellschaften von allen gewaltgeprägten Ordnungsmustern frei wären. Sigrist selbst weist beispielsweise auf Formen kollektiven Neids hin, die in solchen Kulturen zu beobachten sind und eine wichtige Rolle zur Aufrechterhaltung sozialer Ordnung spielen. ${ }^{41}$ Egalität kann dabei mitunter geradezu als Folge gesellschaftsweit dominierenden Neids interpretiert werden. ${ }^{42}$ Der mit Formen des kollektiven Neids einhergehende Gruppendruck lässt die Gewalt erahnen, die solche Ordnungsmuster einerseits zwar bändigen, aber andererseits auch weiter fortschreiben. Ausdrücklich hebt Sigrist hervor, dass die rechtliche Selbststeuerung in segmentären Gesellschaften zwar auf Gleichgewichtsmodelle zurückgreift, diese aber keine „harmonistischen Gesellschaftsideale“ voraussetzen, sondern durchaus als „Konfliktmodelle“ verstanden werden können. ${ }^{43}$ David Signers aktuelle Arbeit über das Hexenwesen in Afrika zeigt die Zusammenhänge solcher Neidmuster mit dem Sündenbockmechanismus. Die Schwierigkeit, die Gewalt in diesen Kulturen zu erkennen, hängt vor allem damit zusammen, dass sie ganz vom Bemühen geprägt sind, die interne Gewalt vor ihren eigenen Mitglie-

40 Vgl. Meier-Seethaler (1992), 81-82. Die Autorin meint, die Grausamkeit der Opfer in matriarchalen Kulturen sei dadurch relativiert, dass sie freiwillige Selbstopfer zum Wohl der Gemeinschaft gewesen seien.

41 Vgl. Sigrist (1979), 190-197.

42 Vgl. Wesel (1999), 94: „Die Lele, matrilineare Ackerbauern im westlichen Kongo, sagen von sich, sie seien sehr neidisch und duldeten keine Ungleichheit.“

43 Vgl. Sigrist (1979), 116. 
dern zu verbergen ${ }^{44}$ - nur die eingeweihten Heiler wissen um sie -, während unsere moderne Kultur gerade durch eine immer größere Sichtbarkeit der Gewalt gekennzeichnet ist.

Natürlich weist auch Göttner-Abendroth auf Ordnungsmuster hin, die für solch herrschaftsfreie Gesellschaften typisch sind. Sie kommt in ihrer Darstellung der Sündenbocktheorie sogar sehr nahe, wenn sie aufbauend auf Sigrist vom notwendigen „Ausschluss“ von „egoistischen Normbrechern“ spricht. Den Zusammenhang von Ordnung und Ausschluss problematisiert sie aber nicht, sondern gleicht sich in ihrer Position erstaunlicherweise eher jenen bürgerlichen Anschauungen an, für die Verbrecher einfach Verbrecher und damit auszusondernde Störfaktoren sind, ohne dass die Sündenbockdimension und die damit zusammenhängende Abschiebung von gesellschaftsweit zirkulierender Gewalt auch nur andeutungsweise in den Blick kämen.

„Ihre innere Ordnung halten herrschaftslose Gesellschaften aufrecht durch Selbststeuerung und Selbsthilfe. Selbststeuerung ist, wenn ein Normbrecher, der sich um die sozialen Spielregeln der Gegenseitigkeit nicht kümmert und egoistisch nur für sich sorgt, auch bald von der Gegenseitigkeit der anderen ausgeschlossen wird. Da die Gruppe der einzige Schutz ist, bedeutet Ausgeschlossensein Gefahr fürs Überleben. Bei Selbststeuerung bleibt die Gruppe passiv. Selbsthilfe ist dagegen aktiv. Der Normbrecher, der sich der Pflicht zum Teilen entzogen hat, riskiert Übergriffe auf sein Eigentum, sei es, dass seine Felder oder Herden geschädigt werden, sei es, dass er selbst oder seine Verwandten Prügel bekommen. Er soll damit materiell geschwächt werden, um seine Überhebung über die Gruppe rückgängig zu machen, und er soll davor gewarnt werden, es zu weit $\mathrm{zu}$ treiben. Hier wird offensichtlich, dass die Gleichheit der Mitglieder dieser Gesellschaften nicht ein unbewusstes Naturgeschenk ist, sondern ein bewusstes Streben nach Aufrechterhaltung dieser Gleichheit." 45

Das systematische Grundproblem in Göttner-Abendroths Auseinandersetzung mit herrschaftsfreien Gesellschaften zeigt sich in ihrer Ausblendung der inneren Konfliktpotentiale dieser Gesellschaf-

44 Rosny (1999), 341 zur traditionellen afrikanischen Gesellschaft: „Die Gesellschaft ist so aufgebaut, dass sie vor ihren Mitgliedern die Gewalt verbirgt, die jederzeit zwischen ihnen zum Ausbruch kommen kann.“"

45 Göttner-Abendroth (1995), 58-59. 
ten. Herrschaft entwickelte sich historisch ihrer Meinung nach als Ausnahmefall. Auch hier berührt sie indirekt die Sündenbocktheorie, die ebenfalls eine Ausnahmesituation am Ursprung annimmt. Doch für Göttner-Abendroth kommen solche Ausnahmesituationen durch „äußeren Druck“ zustande, während die mimetische Theorie immer wieder die interne Konfliktneigung in den Vordergrund stellt. Wo Göttner-Abendroth von inneren Spannungen spricht, sind diese immer schon Ergebnisse einer von Herrschaft geprägten Kultur:

„Äußerer Druck, der verändernd auf die gleichheitsbewussten Gentilgesellschaften wirkt, entsteht [...] durch die menschliche Umgebung. Denn Völker mit Zentralinstanz üben Druck auf andere Völker aus, die nicht durch Herrschaft und die Doppelheit von Befehl und Gehorsam schlagkräftig organisiert sind. Völker mit einer Zentralinstanz sind strategisch überlegen. Und diese strategische Überlegenheit gegenüber anderen Völkern nutzen die Herrschenden meist aus, um von den inneren Spannungen im eigenen Volk, die durch die Verschärfung von Herrschaft entstehen, abzulenken. Innere Spannungen und Probleme werden nach außen auf andere Völker projiziert und damit der Boden zu Eroberung geschaffen." ${ }^{\text {"46 }}$

Diese Ausblendung interner Gewaltpotentiale zeigt sich auch an Göttner-Abenroths Auseinandersetzung mit dem „Inzest-Tabu“. Die mimetische Theorie und die Matriarchatsthese stimmen zwar darin überein, dass sich dieses Tabu nicht durch angebliche biologisch-negative Folgen erklären lässt. Doch während Girard es als Schutzmechanismus gegen die zur Gewalt neigenden mimetischen Rivalitäten in Verwandtschaftsgruppen interpretiert, sieht GöttnerAbendroth im „so genannten ,Inzest-Tabu““ nur eine „christlichpatriarchale Erfindung “47.

\section{Die Stellung von Frauen am Ursprung menschlicher Kultur}

Auch wenn also matriarchale Gesellschaftsformen, deren Reste sich noch heute finden lassen, nicht bloße Utopie sind, sondern über eine lange Phase menschlicher Geschichte hinweg tatsächlich weltweit bestanden haben sollten, stellt sich die Frage, ob diese wirklich frei von Herrschaft und massiver struktureller Gewalt waren. 
Wir versuchen in diesem Kontext aus der Perspektive der mimetischen Theorie eine alternative Interpretation jener Belege, die von den Vertreterinnen der Matriarchatsthese für die Existenz mutterzentrierter Gesellschaften angeführt werden.

Die weitverbreitete Verehrung von weiblichen Gottheiten lässt sich aus dieser Sicht nicht nur als Hinweis auf eine gesellschaftlich dominierende Rolle von Frauen lesen, sondern auch als Hinweis darauf, dass Frauen bevorzugt zu Sündenböcken gemacht wurden. Girard spricht immer wieder davon, dass Weiblichkeit ein typisches Opferzeichen ist, sodass durch die gesamte Geschichte hindurch Frauen in überproportionalem Ausmaß zu den Sündenböcken zählen. ${ }^{48}$ Dieser Sachverhalt wurzelt sehr wahrscheinlich in der geringeren körperlichen Spontankraft und größeren Verletzbarkeit von Frauen - wie sie etwa durch Schwangerschaft und Stillzeit bedingt ist -, woraus sich eine niedrigere soziale Position ergab. ${ }^{49}$ Dürften Frauen somit als „schwächeres“ Geschlecht schon immer gefährdet gewesen sein, eher als Männer in die Sündenbockrolle zu geraten, scheint sich ihre Situation durch das Sesshaftwerden und die Umstellung von Jägergesellschaften auf Ackerbau weiter verschlechtert zu haben. Das könnte damit zusammenhängen, dass Kinder und damit auch die Frauen als deren Gebärerinnen aufgrund der steigenden Bedeutung von Arbeitskraft in zunehmendem Maße als Besitz der Männer betrachtet wurden. Dadurch werden Frauen in verstärktem Ausmaß zum Objekt der Rivalität und Konkurrenz, das heißt auch zum Auslöser von Konflikten, ${ }^{50}$ wodurch sie neuerlich in die Rolle der Schuldigen an sozialen Konflikten gedrängt wurden. Girard führt das häufige Vorkommen von archaischen Göttinnen ausdrücklich auf die Tatsache vieler ursprünglicher weiblicher Sündenböcke zurück. In zahlreichen Mythen lassen sich vergöttlichte Frauen entdecken, die ihren Kulturen als Sündenböcke dienten. ${ }^{51}$

Frauen wurden so buchstäblich marginalisiert, wie es sich in vielen Kulturen beobachten lässt. Dort, wo sich die gewalttätigen

48 Siehe Girard (1987), 209, Girard (1983), 229 sowie Girard (1988), 32 und 76.

49 Vgl. Wesel (1999), 85-90.

$50 \mathrm{Vgl}$. Wesel (1999), 96.

51 Vgl. Girard (1988), 75-76; Girard (1996), 118-141 und 276. Selbst die Verehrung einer Erd- bzw. Muttergottheit, die nicht nur stets neu das Leben hervorbringt, sondern es auch immer wieder verschlingt, indem sie die Toten in sich aufnimmt, könnte auf die Sündenbocklogik verweisen. Derjenige, dem die Schuld am Unheil (Tod) zugewiesen wird, gilt letztlich auch als Heilbringer. 
Konflikte unter Männern zuspitzten, verließen die Frauen oft als Schwächere den Schauplatz des Geschehens und flüchteten an den Rand ihrer Dörfer oder Siedlungen. Ethnologische Befunde geben diese Tendenz deutlich wieder. Girard verweist u.a. auf den Grundriss der südamerikanischen Dörfer der Bororo. ${ }^{52}$ Im Zentrum des Dorfes befindet sich das Männerhaus, zu dem Frauen keinen Zugang haben. Die Frauen wohnen in den kreisförmig um das Männerhaus herum errichteten Häusern am Rande des Dorfes, die sie eigentlich nie verlassen. Während in dieser strengen Immobilität früher ein Indiz für das Matriarchat gesehen wurde, sieht Girard darin nicht den Ausdruck für eine Vorherrschaft der Frauen, sondern für deren passive Rolle in einer von männlicher Gewalt dominierten Kultur.

Dieser tendenzielle Ausschluss der Frauen aus der kulturellen Ordnung ist nun aber seltsamerweise mit der Neigung der Mythen verbunden, den Frauen im Unterschied zu den Männern ein besonderes Naheverhältnis zur kollektiven Gewalt nachzusagen. Zahllos sind die mythischen Beispiele, in denen Frauen als blutrünstige Hetzmeute dargestellt werden. Die germanischen Walküren, die Amazonen, die rächenden Erinnyen, die Mainaden, die Orpheus töten, und schließlich vor allem die Bakchen, die im dionysischen Rausch den König Pentheus töten, können hier u.a. aufgezählt werden. Das Beispiel der gewalttätigen Bakchen nimmt Girard zum Anlass, nach der Ursache für die Verweiblichung der kollektiven Gewalt in der Überlieferung vieler Kulturen zu fragen. ${ }^{53}$ Seiner Ansicht nach handelt es sich dabei „um eine mythische Stellvertretung des männlichen Geschlechts durch das weibliche in Bezug auf die Gewalt".54 Der Mythos schiebt den Frauen jene Gewalt zu, für die vor allem die Männer die Verantwortung tragen.

\section{Woher die Gewalt - woher ihre Überwindung?}

Selbst wenn Girards Interpretation archäologischer und mythologischer Zeugnisse als zutreffend anerkannt wird, ist die Frage nach

52 Vgl. Girard (1987), 207-208; Girard (1996), 276.

53 Vgl. Girard (1987), 206-210. Vgl. für die anderen Beispiele Girard (1990), 43 und 187-192.

54 Girard (1987), 206. Selbst mythische Erzählungen von matriarchalen Gesellschaften können als subtile Rechtfertigung von Männerdominanz und Männergewalt in der jeweiligen Gegenwart dienen. Vgl. Wesel (1999), 60-64. 
dem Ursprung gesellschaftlicher Gewalt, die wir nicht als unabänderliche Naturgegebenheit verstehen, nach wie vor ungeklärt. Bevor wir jedoch versuchen, eine Antwort auf diese Frage aus Sicht der mimetischen Theorie zu geben, sei darauf hingewiesen, dass Matriarchatsforschung unseres Wissens eine solche Antwort bislang ebenfalls schuldig geblieben ist. ${ }^{55}$

Übereinstimmend mit anderen Matriarchatsforscherinnen vertritt Göttner-Abendroth, dass es (1) matriarchale Gesellschaften gegeben hat und dass diese (2) den patriarchalen Gesellschaftsformen durchwegs geschichtlich vorausgegangen sind. Damit verbunden ist die These, dass (3) matriarchale Gesellschaften von Patriarchaten verdrängt wurden, und zwar durch eine gewaltsame Bemächtigung von außen.

Werden alle drei Behauptungen konsequent vertreten, ergibt sich ein logisches Problem: Wenn Matriarchate grundsätzlich Patriarchaten vorausgegangen sind und durch „Patriarchate von außen“ erobert wurden, woher kommen dann diese Patriarchate? Entweder (1) waren diese selber ursprünglich Matriarchate, die durch andere Patriarchate erobert wurden, aber wo kommen dann diese her? Oder (2) es gab doch Gesellschaften, die von Anfang an patriarchale Herrschaftssysteme waren, oder (3) es waren Matriarchate, die durch innere Krisen zu Patriarchaten wurden. Die erste Alternative verschiebt das Problem nur; die zweite Alternative könnte von einer Matriarchatstheorie vielleicht zugestanden werden, widerspricht aber dem Ansatz, dass matriarchale Strukturen naturnäher sind und Patriarchate defiziente Gesellschaftsformen darstellen. Es bleibt daher ungeklärt, wie es zu ,jenem eigentlichen Sündenfall“ unserer Geschichte kommen konnte, in dem ein von Männern erfundenes Herrschaftssystem sich gewaltsam durchgesetzt hat. ${ }^{56}$ Ohne plausibles Tatmotiv „aber könnte nur ein biologisch verankertes Aggressionspotential der Männer als Ursache aller Übel gelten, eine wenig hoffnungsvolle Perspektive, welche die Frauen erneut zum schwa-

55 Der angekündigte Band IV der Buchreihe über das Matriarchat von Heide GöttnerAbendroth über die Entstehung des Patriarchats wird dazu wohl etwas sagen müssen, ist bislang aber leider noch ausständig.

56 Vgl. Werlhof (2003), 23. Evolutionäre Erklärungsversuche des Patriarchates, auch jene, die von Vertreter(inne)n der Matriarchatsforschung vorgebracht werden, stehen für Werlhof im Gegensatz zur Tatsache gewaltsamer Zerstörung der meisten matriarchalen Kulturen. Vgl. Werlhof (2003), 24. 
chen Geschlecht deklariert" ${ }^{\text {" }}{ }^{57}$ Die dritte Alternative entspricht der mimetischen Theorie, die das interne Konfliktpotential von Gesellschaften in den Vordergrund ihres Forschungsinteresses stellt.

Allerdings scheint nicht erst die Behauptung, alle Gesellschaften wären ursprünglich herrschaftsfrei matriarchal gewesen, sondern schon die Behauptung, dass es überhaupt herrschaftsfreie Gesellschaften gegeben hat, in Widerspruch zur mimetischen Theorie zu stehen, insofern diese durchgängig von einem Gründungsmord als Ursprung von Kultur ausgeht. Wir wollen daher im Folgenden die These der mimetischen Theorie von einem generellen Ursprung der Kultur im gewaltsamen Geschehen eines Gründungsmordes diskutieren, um sie auf eine differenziertere Sichtweise hin zu öffnen. Diese wollen wir dann neuerlich mit der Matriarchatsthese ins Gespräch bringen.

\section{Ontologisierung der Gewalt in der mimetischen Theorie?}

Girards These von der Verwurzelung aller Kulturen in einem Gründungsmord kann nicht nur unterboten, sondern auch überspitzt werden. Dies ist der Fall, wenn man unterstellt, dass alle menschlichen Gesellschaften und Kulturen infolge ihrer Verwurzelung im Gründungsmord vollkommen und unentrinnbar von Gewalt geprägt sind. Das würde bedeuten, dass menschliche Gesellschaften ohne Sündenbockmechanismus oder funktionale Äquivalente dafür, die ebenso gewalttätig sind, grundsätzlich nicht überlebensfähig wären. Eine intrinsische Gewalt könnte so immer nur verschoben, nie aber überwunden werden. Die Unterstellung einer solchen „Ontologisierung der Gewalt“ wird von Girard und den Innsbrucker Vertreter(inne)n der mimetischen Theorie zurückgewiesen. ${ }^{58}$ Wollte man sie postulieren, würde die mimetische Theorie in sich widersprüchlich werden. Denn zu ihren zentralen Elementen gehört die Annahme einer geschichtlich erfolgten Aufdeckung, Durchbrechung und ansatzweisen Überwindung dieser Gewaltstrukturen durch die jüdisch-

57 Meier-Seethaler (1992), 12.

58 Vgl. Palaver (2004), 57. Damit ist auch die Kritik von Werlhof hinfällig, die sich auch gegen die mimetische Theorie richtet „Ich habe nie daran geglaubt, dass Gewalt etwas Naturgesetzliches sei, das ,den Menschen' angeblich ,immer schon' prägt, wie uns das von allen Seiten ständig eingehämmert wird. Ich habe mich also in die Welt aufgemacht, um eine Erklärung für die Frage der Gewalt zu finden.“ Werlhof (2003), 13-14. 
christliche Offenbarung und insbesondere durch das Christusereignis.

Da Girard eine überaus tiefe Verflechtung menschlicher Gesellschaften in Sündenbockmechanismen annimmt, führt deren Aufdeckung und Durchbrechung durch die jüdisch-christliche Offenbarung nicht zu einer problemlosen und raschen Überwindung von Gewaltstrukturen, sondern in einen krisishaften weltgeschichtlichen Prozess der Verschärfung, der durch mannigfache Verdrängungen, Verschiebungen und eskalierende Ausbrüche von Gewalt gekennzeichnet ist. ${ }^{59}$ Denn die biblische Aufdeckung des Sündenbockmechanismus beraubte uns zunächst archaischer Formen der Gewalteindämmung, ohne dadurch garantieren zu können, dass sich die Menschen deswegen schon an der Aufforderung zur Gewaltfreiheit in der Bergpredigt orientieren werden. Dennoch sind für Girard schrittweise Veränderungen gewalttätiger gesellschaftlicher Strukturen eine geschichtliche Realität, eine bleibende Möglichkeit und damit auch eine stets drängende Verpflichtung. Die mimetische Theorie ist keine fatalistische Geschichtsphilosophie, sondern offen für ein dramatisches Ringen um eine bessere Form menschlichen $\mathrm{Zu}-$ sammenlebens.

Dazu muss aber festgehalten werden, dass die Verwurzelung menschlicher Gesellschaften im Sündenbockmechanismus zwar tief, aber keinesfalls total ist. Diese - zugegebenermaßen subtile - Unterscheidung wird durch ein differenzierteres Verständnis der Mimesis ermöglicht.

Die Identifikation und Opferung bzw. Ausstoßung von Sündenböcken stellen für Girard ein Handlungsmuster dar, in dem sich Kollektive durch die Strukturierung von Gewalt vor einer Zerstörung durch ein allgemeines Gewaltchaos schützen. Die These von der Universalität des Gründungsmordes kann daher so verstanden werden, dass vorstaatliche Gesellschaften, die nicht über politische und juridische Instrumente der Gewaltbegrenzung verfügen, in mimetische Destabilisierungen hineinrutschen können, die zwangsläu-

59 Vgl. etwa Schwager (1978), 162-163. Eine Aufdeckung von Sündenbockstrukturen, die mit einer Entmythologisierung des Opfers als allein schuldiges Subjekt einhergeht, beraubt den Mechanismus zumindest teilweise seiner Effizienz. Das kann in paradoxer Weise zu einer Steigerung der Dosis dieses höchst zweischneidigen Heilmittels für soziale Krisensituationen führen. Vgl. Girard (1996), 16-17. 
fig zu ihrer Zerstörung führen würden, ${ }^{60}$ es sei denn, die mimetische Krise des Jeder-gegen-jeden kippt um in das Alle-gegen-einen des Sündenbockmechanismus. Dadurch kommen dem Sündenbockmechanismus und seiner rituell transformierten Weiterführung in mythosgeprägten Kulturen eine relativ positive Funktion zu. Daraus ergibt sich freilich keine Rechtfertigung solcher Strukturen: Der Kulturbegriff der mimetischen Theorie bleibt vielmehr ausgesprochen ambivalent.

Als Ursprung von Zuständen allseitiger Gewalt nennt Girard mimetische Konflikte. Diese entzünden sich, wenn eine durch Mimesis - also die spontan-vorbewusste interpersonale Orientierung des menschlichen Begehrens - verursachte Rivalität um materielle oder immaterielle Objekte eskaliert. Unausweichlich zur menschlichen Natur gehört dabei für Girard einzig das mimetische Verhalten.

„Diese Betonung der Nachahmung darf aber nicht in einem engen oder oberflächlichen Sinn verstanden werden. Es geht Girard nicht um eine anthropologische Karikatur des Menschen, die diesen als ein nachäffendes Wesen beschreibt, sondern um die Erkenntnis, dass sich im mimetischen Begehren eine grundsätzliche und extreme Offenheit aller Menschen auf andere hin ausdrückt." ${ }^{\text {"6 } 1}$

Diese anthropologische Grundkonstante wird vom Begründer der mimetischen Natur explizit als ,,intrinsisch gut“" und als Ermöglichung von Freiheit und Menschlichkeit bezeichnet. ${ }^{62}$ Mimesis kann aber auch zur Quelle von Rivalität und Konflikt werden, wenn sie in einer vom Aneignungsbegehren geprägten Form auftritt. Ihre verheerende Wirkung liegt dann darin, dass sie sich mit der ihr eigenen selbstverstärkenden Ansteckungskraft unvorhersehbar in Dynamiken steigern kann, in denen die heilenden Kräfte guter Mimesis nicht mehr wirksam zu werden vermögen.

Dass mimetisches Begehren faktisch häufig in Konfliktivität abdriftet, schließt nicht aus, dass es auch eine nichtkonfliktive, ja sogar konfliktüberwindende Mimesis gibt. ${ }^{63}$ Nachgeahmt kann auch

60 Die Zerstörung der Gesellschaft kann durch ein Überborden innerer Gewalt (z.B. Blutrache) erfolgen, aber auch durch eine derartige konfliktbedingte Minderung von Kooperation und Selbsterhaltungskräften der Gesellschaft, dass sie den Herausforderungen des Überlebens nicht mehr gewachsen ist.

61 Palaver (2004), 58.

62 Girard (2002), 31.

63 Vgl. z.B. Girard (2002), 34 
ein ,gutes“ Begehren werden, z.B. das Begehren zu danken, zu segnen oder zu helfen. Dass Mimesis Gemeinschaften und ganze Gesellschaften destabilisieren und in die Gewalt treiben kann, ist nicht gleichbedeutend mit der Annahme, dass sie zwangsläufig destruktiv ist. Das mimetische Begehren ist „für das Beste wie für das Schlimmste in uns verantwortlich" " ${ }^{4}$ wie Girard betont.

Nehmen wir den Gründungsmord mit darauf folgender gesellschaftlicher Installierung von Opfermechanismen als Indiz für eine herrschaftsorientierte Gesellschaft, ${ }^{65}$ dann kann die mimetische Theorie durchaus zugestehen, dass es auch herrschaftsfreie Gesellschaften gegeben hat. Sie wird allerdings damit rechnen, dass die Überlebenschancen solcher Gesellschaften stets prekär waren. Gefährdet waren sie nicht nur von außen - durch Gesellschaften, die infolge eines Gründungsmordes aggressive Strukturen aufwiesen -, sondern auch von innen durch eine Mimesis, die nicht von Natur aus destruktiv ist, aber immer auch ein hohes Destabilisierungspotential aufweist.

So verstanden lässt die mimetische Theorie durchaus Raum für zentrale Anliegen der Matriarchatsforschung. Matrifokale Gesellschaften mit herrschaftsfreien Formen der Autoritätsausübung, wie sie von Matriarchatsforscherinnen beschrieben werden, erscheinen hier nicht als a priori unmöglich. Eine Theorie der positiven Mimesis macht sogar die gesellschaftsstrukturierende Wirksamkeit von Mutter-Kind-Verhältnissen plausibel. Die Erfahrung eines vorbehaltlosen Beschenktseins wird zum ersten Ort mimetischer Nachahmung. Auch die Annahme, dass friedfertige Gesellschaften von aggressiveren Nachbargesellschaften überrannt wurden, ist im Rahmen der mimetischen Theorie plausibel. Darüber hinaus rechnet sie allerdings mit der hohen Wahrscheinlichkeit innerer Destabilisierung, wobei diese durchaus durch friedlichen Kontakt mit aggressiveren Nachbarstämmen ausgelöst werden kann. Denkbar ist freilich auch das Aufbrechen eines Geschlechterkonflikts, der durch Rivalität um die entscheidende Macht über das Leben (Gebären bzw. Töten) verursacht ist, wie Meier-Seethaler annimmt. Rechnet man mit der Möglichkeit innerer Destabilisierung, kann der oben vorgebrachte logi-

64 Girard (2002), 32.

65 Das wird nahegelegt durch die Kulturentwicklungen, die Girard auf der Grundlage des Gründungsmordes entwickelt, und die von Matriarchatsforscher(inne)n durchwegs als patriarchal bezeichnet würden. 
sche Einwand gegen das Zerbrechen matriarchaler Strukturen vermieden werden.

Mit Christa Wolf, die sich von der Annahme friedlicher matriarchaler Kulturen abwandte, als sie während einer Kreta-Reise mit dem schon erwähnten Fund eines Menschenopfers konfrontiert war, geht es uns angesichts aktueller Gewaltbedrohungen aber primär nicht darum, eine friedlichere Vergangenheit zu rekonstruieren, die in irgendeinem Goldenen Zeitalter zu finden sein könnte, sondern die Frage der Gewalt als gegenwärtige und zukünftige Aufgabe ernst zu nehmen. Gerade in unserer apokalyptischen Lage wird eine Orientierung an Modellen der Gewaltfreiheit, wie wir sie in der Botschaft Jesu finden, immer notwendiger. Es geht heute vorrangig darum, Formen des sozialen Zusammenlebens zu stärken, die weder auf Opferungen Dritter noch auf die Polarisierung gegen äußere Feinde angewiesen sind. ${ }^{66}$

\section{Ökonomie des Schenkens in Matriarchatsforschung mimetischer Theorie}

Diesem zukunftsorientierten Anliegen der mimetischen Theorie kommt der Ansatz von Geneviève Vaughan, der Einladenden zum zweiten Weltkongress der Matriarchatsforschung 2005 in Texas, entgegen. Seit den 1970er-Jahren entwickelt sie eine Ökonomie des Schenkens, ${ }^{67}$ die - ausgehend vom „Mothering“" und „Nurturing“" von Müttern gegenüber ihren Kindern - sich wesentlich von einer Ökonomie des Tausches unterscheidet, in der gegeben wird, um zu bekommen. Dieser Ansatz wurde von prominenten Vertreter(inne)n der Matriarchatsforschung überaus positiv aufgenommen. So schreibt Heide Göttner-Abendroth:

„Die Arbeiten der Geneviève Vaughan halfen mir die matriarchale Ökonomie genauer zu formulieren. Die matriarchale Ökonomie lässt sich am allerbesten mit der Begrifflichkeit der, Ökonomie des Schenkens' beschreiben. Mit keiner anderen ökonomischen Theorie lässt sich das so beschreiben. Ich selbst war auf den Begriff ,Ausgleichsgesellschaft' gekommen. Denn mit der Zirkulation der Güter stellen sie in den Matriarchaten ständig eine ökonomische Balance her, zwischen den Clans und damit allen Mitgliedern einer 
Gemeinschaft. Von Geneviève Vaughan lernte ich, dass diese Balance auf Schenkebene basiert." "68

Nun schließt das Schenken keineswegs aus, dass die freie Gabe mit freier Gegengabe beantwortet wird - darin besteht ja gerade die Ökonomie des Schenkens. ${ }^{6}$ Von außen betrachtet kann solches Wechselspiel des Schenkens einer Ökonomie des Tausches zum Verwechseln ähnlich sehen.

„Der entscheidende Unterschied besteht darin, dass die Gabenökonomie eine Wirtschaftsform ist, in der die am Austauschprozess Beteiligten in einer Beziehung wechselseitiger Verpflichtung stehen. Die Wiederherstellung der gemeinsamen gesellschaftlichen und natürlichen Lebensumwelt ist wichtiger als der individuelle Erfolg der einzelnen Wirtschaftssubjekte. Demgegenüber stellt der Warenaustausch zwischen den Beteiligten keine verpflichtende Beziehung her, und die Dynamik der Akkumulation sprengt prinzipiell und tatsächlich alle Solidarität mit der natürlichen und gesellschaftlichen Lebensumwelt." "70

Der Unterschied zwischen beidem ist wesentlich, aber zugleich sehr subtil. Durch minimale Verschiebungen kann ein freies Wechselspiel von Gabe und Gegengabe in ein System von Erwartungen und Verpflichtungen abrutschen. ${ }^{71}$ Die Frage, ob eine matriarchale Gesellschaft auch von innen destabilisiert werden kann, muss im Blick auf die Ökonomie des Schenkens wohl mit ja beantwortet werden. Mit dem Gegensatz zwischen einer Ökonomie des Schenkens und einer Ökonomie des Tausches beschreibt Vaughan - mit nachdrücklicher Zustimmung anderer Matriarchatsforscherinnen einen Gegensatz zwischen matriarchalen und patriarchalen Gesellschaftsformen, der zweifellos essentiell ist, der aber im Konkreten nicht einfach eindeutig zugeordnet werden kann. Frauen können

68 Heide Göttner-Abendroth, zitiert in: Madeisky (2006). Claudia von Werlhof über Geneviève Vaughan: „Sie geht sogar über das hinaus, was wir bisher entwickelt haben. Sie vertieft die Analyse. Sie setzt nämlich nicht einfach bei den Frauen an, sondern bei den Müttern! Dadurch schaut man dann wirklich vom Leben selbst her, so wie es entsteht, und wie dann damit umgegangen wird! Mehr in die Tiefe kann man gar nicht gehen. Durch diese Vertiefung ist es eine Erweiterung der Analyse." Zitiert in: Madeisky (2006).

69 Vgl. Vaughn (2004).

70 Gutmann (2001), 210.

71 Die mimetische Theorie vermag solche Verschiebungen im Wechselspiel (präverbaler) Kommunikation mit ihrer interpersonal-gesellschaftlichen Ansteckungskraft zu beschreiben. 
nicht weniger als Männer durch eine Pervertierung der Ökonomie des Schenkens tief in eine Ökonomie des Tausches hineingezogen werden; anderseits können auch Männer zu Trägern einer Ökonomie des Schenkens werden. Diese Behauptung nivelliert nicht die Differenzen zwischen Mann und Frau; der Matriarchatsforschung kann darin zugestimmt werden, dass die mütterliche Erfahrung des Bergens und Nährens von Kindern einen primären Quellort für die Rückkehr zu authentischem Schenken darstellt.72

Schließlich bietet die Ökonomie des Schenkens als Grundlage für ein Zusammenleben, das frei von destruktiver Rivalität ist, auch eine Basis, auf der die verschiedenen ideellen und religiösen Hintergründe von mimetischer Theorie und Matriarchatsforschung miteinander ins Gespräch gebracht werden können. Eine zentrale Schwierigkeit für einen Dialog zwischen beiden Ansätzen liegt ja darin, dass das für die mimetische Theorie zentrale Christentum für Vertreter(innen) der Matriarchatsforschung als wesentlich herrschaftlich und patriarchal beurteilt wird. Das muss aber bei näherer Betrachtung nicht so gesehen werden. Vielmehr gilt für uns die Feststellung: „In der jüdischen und christlichen Tradition ist die ganze Welt, insofern sie eben Schöpfung ist, eine Gabe. ${ }^{\text {"73 }}$ Die materielle und geistige Erfahrung des Beschenkt- und Begabtseins kann nur gemacht werden, wenn das Empfangene nicht als etwas Verfügbares wahrge-

72 Die Frage, wie gesellschaftliche Systeme, die von negativer Mimesis geprägt und deshalb potentiell gewalttätig sind, zu Systemen positiver Mimesis, d.h. zur wechselseitigen mimetischen Verstärkung von lebensförderlichen Bestrebungen zurückgeführt werden können, ist auch für die mimetische Theorie ein wichtiger Punkt. Aufgrund der Dynamik einer wechselseitigen mimetischen Verstärkung reichen unter Umständen kleine Anstöße dazu aus. Diese sind den in negativer Mimesis Verstrickten aber oft nicht mehr möglich. Die selbstlose und hingebungsvolle Beziehung der Mutter zu ihrem Kind könnte infolge ihrer naturmäßigen Verankerung ein bedeutendes Reservoir für solche Anstöße sein. Es ergibt sich somit im Hinblick auf die Mutter-Kind-Beziehung eine besondere Bedeutung von Frauen für die positive Transformation von Gesellschaften. Dieser Vorzug bedeutet aber auch eine erhöhte Gefahr. Mutter-Kind-Beziehungen können pervertiert werden zu einer mütterlichen Dominanz, welche die Bedeutung von Vätern und anderen Bezugspersonen herabsetzt und das Kind in einer symbiotischen Abhängigkeit hält. Rivalisierende und potentiell gewalttätige Strukturen werden durch pervertiertes „Mothering“ nicht nur nicht überwunden, sondern über die Generationen verstärkt weitergegeben, z.B. in einer Verachtung von Vätern, die aus Töchtern Mütter macht, die gegenüber ihren Kindern wiederum die Väter herabsetzen, und aus Söhnen Väter, die infolge einer Missachtung ihres eigenen Vaters selber nur mehr defizient Vater sein können. Solche Kritik setzt den hohen Wert, den Vaughan dem „Mothering“" und „Nurturing“ zuschreibt, in keiner Weise herab. Im Gegenteil! Sie folgt dem Grundsatz: corruptio optimi pessima.

73 Joas (2004), 21. 
nommen wird. Damit legt sich aber der Gedanke eines Gebers nahe, der in seinem Geben frei und daher liebende Person ist, nicht einfach eine sachlich-natürliche Quelle, in der Leben und Tod ewig in der Schuld des jeweils anderen stehen. Das biblische Verständnis des Sündenfalls, der das menschliche Zusammenleben in Konflikt und wechselseitige Zerstörung treibt, lebt gerade auch von der Unterscheidung zwischen empfangener Gabe und angeeignetem Raub. Handlungen freien Gebens und Schenkens können Nachahmungsprozesse auslösen, die Alternativen zu Formen gewaltsamer Gewaltreduktion wie dem Sündenbockmechanismus ermöglichen. ${ }^{74}$ In der Unterscheidung zwischen einer Ökonomie des Schenkens und einer Ökonomie des Tausches könnte also ein Ansatz für einen beiderseits fruchtbaren Dialog zwischen Matriarchatsforschung und mimetischer Theorie bestehen.

\section{Zum Abschluss}

Kehren wir zuletzt noch einmal zu Virginia Woolfs Verständnis einer Rolle der Frauen im Bemühen um die Überwindung patriarchaler Gesellschaftsstrukturen zurück. Um nicht selbst in die Dynamik von Rivalität und Gewalt zu verfallen, empfiehlt sie als Schutz die Tugenden Armut, Keuschheit, Verachtung und Freiheit von falschen Loyalitäten. Diese Tugenden stehen in großer Nähe zu den sogenannten „Evangelischen Räten“ Armut, Keuschheit und Gehorsam in der christlichen Tradition. Dabei könnte man dem Rat der Armut auch die Woolf'sche Verachtung (derision) zuordnen, da es bei dieser jesuanischen Empfehlung darum geht, irdische Güter - sowohl materielle als auch immaterielle wie Ansehen, Ruhm etc. - nicht überzubewerten und auf jeden Fall nicht um ihrer selbst willen anzustreben. Woolfs Verachtung meint gerade, Ruhm und Anerkennung abzulehnen bzw. Lächerlichkeit und Anonymität vorzuziehen. Der christliche Gehorsam steht insofern der Freiheit von falschen Loyalitäten nahe, als der Gehorsam gerade als Schutz vor spontanen Loyalitäten und Abhängigkeiten dienen sollte. Woolf bringt zwar selbst die von ihr empfohlenen Tugenden (Lehrmeisterinnen) nicht explizit in Verbindung mit der christlichen Tradition. Da sie aber in einem

74 Das lässt sich theologisch (Gnadentheologie!) ebenso aufweisen wie religionsphilosophisch. Zu letzterem vgl. die Phänomenologie der Gabe bei Jean-Luc Marion. 
ähnlichen Zusammenhang positiv auf Christus als ,große Autorität in Sachen menschliches Leben" 75 anspielt, ist eine auch von ihr intendierte Nähe zur christlichen Tradition nicht auszuschließen.

Die Evangelischen Räte wurzeln in der Erfahrung, dass uns Menschen ein Leben geschenkt ist, das nicht im Wettkampf um Besitz und Anerkennung erst errungen zu werden braucht. Die intensive Verflechtung in die gewaltsamen oder zumindest gewaltgefährdeten Strukturen unserer Gesellschaft kann den Blick auf diese Erfahrung leicht verstellen. Eine Position am Rande der Gesellschaft, am Rande von Macht und Anerkennung muss nicht notwendigerweise, kann aber diesen Blick gnadenhaft neu eröffnen. Hinzu kam sowohl für Virginia Woolf als auch für Geneviève Vaughan die Erfahrung einer unerwarteten wirtschaftlichen Absicherung ihrer Existenz, die eine gewisse Distanz zum Kampf um materielle Güter erlaubte, im Falle Vaughans auch die Möglichkeit des freizügigen Weiterschenkens eröffnete. Im Licht der Chancen, die eine kritische Distanz zu etablierten Strukturen bietet, wurden Frauen die ersten Zeuginnen des christlichen Evangeliums, ${ }^{76}$ in diesem Licht empfindet auch Woolf sich als Trägerin einer besonderen Wahrheit.

\section{Literatur}

Bachofen, Johann Jakob (1975): Das Mutterrecht. Eine Untersuchung über die Gynaiokratie der alten Welt nach ibrer religiösen und rechtlichen Natur. Eine Auswabl. Frankfurt/M.: Suhrkamp.

Bailie, Gil (1997): „The Vine and Branches Discourse: The Gospel's Psychological Apocalypse“, in: Contagion 4, 120-145.

Eisler, Riane (1993): Kelch und Schwert. Von der Herrschaft zur Partnerschaft. Weibliches und männliches Prinzip in der Geschichte. München: Goldmann Verlag.

Girard, René (1978): „Narcissism: The Freudian Myth Demythified by Proust", in: Roland, A., Hg.: Psychoanalysis, Creativity and Literature. New York, 293-311.

Girard, René (1983): Das Ende der Gewalt. Analyse des Menschbeitsverbängnisses. Freiburg/B.: Herder.

Girard, René (1987): Das Heilige und die Gewalt. Zürich: Benziger.

Girard, René (1988): Der Sündenbock. Zürich: Benziger.

Girard, René (1990): Hiob - ein Weg aus der Gewalt. Zürich: Benziger.

75 Woolf (2001), 211.

76 Vgl. Palaver (2004), 385 sowie Girard (2002), 160. 
Girard, René/Golsan, Richard J. (1993): „Interview“, in: Golsan, Richard J.: René Girard and Myth: An Introduction. New York-London: Garland, 129-149.

Girard, René (1996): The Girard Reader. New York: The Crossroad Publishing Company.

Girard, René (1997): Wenn all das beginnt ... Dialog mit Michel Treguer. Münster: LIT.

Girard, René (2002): Ich sah den Satan vom Himmel fallen wie einen Blitr. Eine kritische Apologie des Christentums. München-Wien: Hanser.

Girard, René (2005): Die verkannte Stimme des Realen. Eine Theorie archaischer und moderner Mythen. München-Wien: Hanser.

Girard, René/Palaver, Wolfgang (2001): „Gespräch mit René Girard“, in: Sinn und Form 53 (6), 760-774.

Göttner-Abendroth, Heide (31995): Das Matriarchat I. Geschicbte seiner Erforschung. Stuttgart: Verlag W. Kohlhammer.

Gutmann, Hans-Martin (2001): „Der gute und der schlechte Tausch. Das Heilige und das Geld - gegensätzliche ökonomische Beziehungen?“, in: Jürgen Ebach/Gutmann, Hans-Martin/Frettlöh, Magdalene L., Hg.: „Leget Anmut in das Geben“-Zum Verbältnis von Ökonomie und Theologie. Gütersloh: Kaiser, 162-225.

Joas, Hans (2004): „Die Logik der Gabe und das Postulat der Menschenwürde“, in: Gestrich, Christof/Bolz, Norbert, Hg.: Gott, Geld und Gabe. Zur Geldformigkeit des Denkens in Religion und Gesellschaft. Berlin: Wichern Verlag, 16-27.

Johnsen, William A. (2003): Violence and Modernism. Ibsen, Joyce, and Woolf. Gainesville: University Press of Florida.

Keukelaere, Simon de (2006): „What Is Deviated Transcendency? Woolf's The Waves as a Textbook Case“, in: Contagion 12-13, 195-218.

Madeisky, Uschi (2006): „Schenken als Grundlage unseres Seins“, online unter: http://www.ab40.de/seiten/archiv_skizzen/06_1/06_1_4a.html (Zugriff am 3.12.2007).

Marler, Joan (2003): „Der Mythos vom ewigen Patriarchat. Eine kritische Antwort auf Cynthia Ellers: Der Mythos von der matriarchalen Frühgeschichte“, in: Werlhof, Claudia von/Meier-Seethaler, Carola/Mullack, Christa/Göttner-Abendroth, Heide/Spretnak, Charlene/Marler, Joan/Derungs, Kurt, Hg.: Die Diskriminierung der Matriarchatsforschung. Eine moderne Hexenjagd. Bern: edition amalia, 109-129.

Meier-Seethaler, Carola (1992): Ursprünge und Befreiungen. Die sexistischen Wurzeln der Kultur. Frankfurt/M.: S.Fischer.

Mulack, Christa (2003): „Die Matriarchatsforschung in der Diskussion - eine Verteidigung“, in: Werlhof, Claudia von/Meier-Seethaler, Carola/ Mullack, Christa/Göttner-Abendroth, Heide/Spretnak, Charlene/ Marler, Joan/Derungs, Kurt, Hg.: Die Diskriminierung der Matriarchatsforschung. Eine moderne Hexenjagd. Bern: edition amalia, 41-62. 
Palaver, Wolfgang (22004): René Girards mimetische Theorie. Im Kontext kulturtheoretischer und gesellschaftspolitischer Fragen. Münster: LIT.

Ranke-Graves, Robert von (1984): Griechische Mythologie. Quellen und Deutung. Reinbek/H.: rowohlts enzyklopädie.

Ranke-Graves, Robert von (1985): Die Weiße Göttin. Sprache des Mythos. Reinbek/H.: rowohlts enzyklopädie.

Röder, Brigitte/Hummel, Juliane/Kunz, Brigitte (1996): Göttinnendämmerung. Das Matriarchat aus archäologischer Sicht. München: Droemer Knaur.

Rosny, Eric de (1999): Die Augen meiner Ziege. Auf den Spuren afrikanischer Hexer und Heiler. Wuppertal: Peter Hammer.

Schwager, Raymund (1978): Brauchen wir einen Sündenbock? Gewalt und Erlösung in den biblischen Schriften. München: Kösel.

Schwager, Raymund (1992): „Rückblick auf das Symposium“, in: Niewiadomski, Józef/Palaver, Wolfgang, Hg.: Dramatische Erlösungslehre. Ein Symposion. Innsbruck: Tyrolia, 338-384.

Schwager, Raymund/Niewiadomski, Józef, Hg. (2003): Religion eræengt Gewalt - Einspruch! Innsbrucker Forschungsprojekt, Religion - Gewalt - Kommunikation - Weltordnung؛ Münster: LIT.

Signer, David (2004): Die Ökonomie der Hexerei oder Warum es in Afrika keine Wolkenkratzer gibt. Wuppertal: Peter Hammer.

Sigrist, Christian (1979): Regulierte Anarchie. Untersuchungen zum Feblen und zur Entstehung politischer Herrschaft in segmentären Gesellschaften Afrikas. Frankfurt/M.: Syndikat.

Vaughan, Geneviève (2004): „Das Schenken und die Göttin, Eine Philosophie des sozialen Wandels“, online unter: http://www.gift-economy. com/articlesAndEssays/dasSchenken.html (Zugriff am 3.12.2007).

Werlhof, Claudia von (2003): „Gewalt und Geschlecht“, in: Werlhof, Claudia von/Meier-Seethaler, Carola/Mullack, Christa/Göttner-Abendroth, Heide/Spretnak, Charlene/Marler, Joan/Derungs, Kurt, Hg.: Die Diskriminierung der Matriarchatsforschung. Eine moderne Hexenjagd. Bern: edition amalia, 13-33.

Wesel, Uwe (81999): Der Mythos vom Matriarchat. Über Bachofens Mutterrecht und die Stellung von Frauen in frühen Gesellschaften vor der Entstehung staatlicher Herrschaft. Frankfurt/M.: Suhrkamp.

Wolf, Christa (1983): Voraussetzungen einer Eræäblung: Kassandra. Frankfurter Poetik-Vorlesungen. Darmstadt: Luchterhand.

Woolf, Virginia (2001): Ein eignes Zimmer. Drei Guineen. Zwei Essays. Frankfurt/M.: S.Fischer. 

Satanologie angesichts der Apokalypse. Wovon René Girard (nicht) spricht und was daraus folgt

Claudia von Werlhof*

Als Mitglied einer Gruppe der Innsbrucker Forschungsplattform „Weltordnung - Religion - Gewalt“, die zum Thema „Matriarchatsthese/Patriarchatskritik" arbeitet, wurde ich anlässlich einer Klausurtagung aufgefordert, mein Unbehagen gegenüber Girard zu formulieren. Der vorliegende Text ist die Überarbeitung des Vortrages, den ich 2006 dazu in Innsbruck gehalten habe.

Beim Lesen von René Girard hatte ich immer schon Schwierigkeiten. Ich verstand nicht, was er eigentlich will. Ich ärgerte mich, weil er den Wald vor Bäumen nicht sieht, wie ich fand. Ich fühlte mich von ihm nicht im Geringsten angesprochen, er ließ mich völlig kalt. Ich empfand ihn als lieb- und humorlos und äußerst aggressiv, was mich wunderte, weil er angeblich gegen Gewalt und für Jesus ist. Außerdem langweilte ich mich, paradoxerweise, weil er aus meiner Sicht über die „Nebenkriegsschauplätze“ nicht hinauskommt.

Ich war kurz davor, aus Desinteresse das Handtuch zu werfen. Schließlich entschloss ich mich, ihm noch einmal Zeit zu widmen,

* Claudia von Werlhof ist seit 1988 Professorin für Politisches System Österreichs unter besonderer Berücksichtigung der Frauenforschung (Frauenforschungslehrstuhl) am Institut für Politikwissenschaft der Universität Innsbruck. Sie beschäftigt sich in erster Linie mit Globalisierung und alternativen zivilgesellschaftlichen Ansätzen, insbesondere der Matriarchatsforschung. Der vorliegende Text ist eine gekürzte Fassung (redaktionelle Bearbeitung für diesen Band durch Andreas Exenberger) eines als Nachlese zur Kontroverse um die Matriarchatsthese anlässlich der 15. Klausurtagung der Forschungsplattform am 7. April 2006 entstandenen Textes. 
allerdings nicht dem gesamten Werk. So konzentriere ich mich hier neben Das Heilige und die Gewalt vor allem auf Ich sah den Satan vom Himmel fallen wie einen Blit: Eine kritische Apologie des Christentums.

Dabei wurde mir klar, warum ich solche Probleme mit dem Lesen von Girard habe und was das mit seiner „mimetischen Theorie“ zu tun hat: Sie ist nämlich eine „Satanologie“. Um das zu verdeutlichen, ist fünferlei von Interesse, von dem Girard nicht spricht: der Satan, die Frauen, der Mensch als Maschine (weswegen bei ihm speziell die Mimesis zwischen Mutter und Kind ausgeblendet bleibt), der heutige Opfermechanismus und die matriarchalen Mythen. Für diesen Text möchte ich mich auf den ersten und die beiden letzten Aspekte konzentrieren, die wohl am besten in den Kontext dieses Bandes passen. Eine vollständige und noch ausführlichere Auseinandersetzung wird 2008 an anderer, wenn auch nicht ganz anderer Stelle zu veröffentlichen sein. ${ }^{1}$

\section{Wovon René Girard (nicht) spricht - vom Satan}

René Girard spricht vom Satan, und wovon er nicht spricht, ist auch der Satan. Dahinterzukommen ist mir schwergefallen. Wenn ich Sa$\tan$ - was immer „er“ auch sei - überhaupt sehen würde, dann in unserem Gesellschaftssystem, und zwar gerade in seiner heutigen Gestalt als kapitalistisches Patriarchat bzw. dessen kriegerische „Globalisierung" durch den Neoliberalismus. ${ }^{2}$ Girard dagegen sieht ihn dort gerade nicht. ${ }^{3}$

Daher spricht Girard nicht davon, wie die Welt, auch ohne Sa$\tan$ zu bemühen, erklärt werden könnte, und zwar die ganze. Denn dass auch die übrige Wissenschaft ein Problem mit der Erklärung der Welt und der Gewalt in ihr hat, insbesondere heute, wo die Moderne trotz bzw. wegen ihrer „Globalisierung“ einem durchaus unrühmlichen und überaus gewalttätigen Ende entgegengeht, ist inzwischen offensichtlich. ${ }^{4}$ Anstatt aber an diesem Manko anzusetzen, tut

1 In: Zivilisationspolitik, Band 1, hg. vom Cluster „Matriarchatsthese/Patriarchatskritik“ im Peter Lang Verlag (Frankfurt/M.-Paris-New York), zugleich Nr. 23 der Reihe „Beiträge zur Dissidenz".

2 Vgl. Werlhof (2007a).

3 Vgl. Girard (2002), 208 f. und $211 \mathrm{f}$.

4 Vgl. Wallerstein (1979), Bourdieu et al. (1997), Tarnas (1999), 558 f., Chossudovsky (2002, 2003), Mies (2004), Diamond (2005) und Wright (2006). 
Girard etwas ganz anderes. Denn gerade den Versuch, die Welt „säkular" zu erklären, hält er für illusorisch. ${ }^{5}$ Demgegenüber baut er auf eine andere Illusion bzw. eine Fiktion, die seinem „Theorie“Gebäude zugrunde liegt: das angeblich immer schon entscheidende Wirken eines sogenannten „Satans“ in der Welt. So ist die Globalisierung für ihn durchaus keine vor allem ökonomische Frage, sondern - ganz im Gegenteil - eine der globalen „Sorge um die Opfer". 6

Girard geht in diesem Zusammenhang vielmehr vom Kommen der christlich prophezeiten „Apokalypse“ aus. ${ }^{7}$ Erscheinen ihm daher das - durchweg menschengemachte - Elend und der beginnende Zusammenbruch der Welt in politökonomischer wie sozioökologischer Hinsicht nur als „logisch“? Jedenfalls findet er, man müsse nun wählen zwischen der „Wahrheit“ der Apokalypse und dem „Weltfrieden". 8 Wäre der Frieden demnach die Unwahrheit, die Enthüllung der Wahrheit aber der Krieg?

Gesellschaftliche Verhältnisse sind für Girard nichts weiter als kollektiv organisierte religiöse Opferrituale ${ }^{9}$ oder - in der Moderne „Institutionen“, die an deren Stelle nämlich als „Gesetz gegen Mord" 10 - anstatt, wie früher, für ihn - getreten. Was diese Institutionen bedeuten, wie sie entstanden und warum sie überhaupt da sind sowie alles, was an gesellschaftlichen Verhältnissen darüber hinaus existiert, ist für ihn keine Frage der Analyse, sondern wird als gegeben vorausgesetzt. So ist Girard vor allem mit den - bzw. manchen - Mikroverhältnissen in dieser Welt bzw. in ihren „,westlichen“ Teilen, noch genauer in den USA, in denen er ja die meiste Zeit verbracht hat, beschäftigt und nimmt sie als pars pro toto.

Generell setzt er eine Verfasstheit aller Gesellschaften, ob der „archaischen“ oder heutigen, in Form von Herrschaft und Hierarchien seitens „der Mächte“11 als Normalität voraus. Dass er damit nur von Patriarchaten spricht, ${ }^{12}$ interessiert ihn nicht. Er erklärt, ,,die Mächte“ in der Gesellschaft seien auch nicht „blindlings zu verurtei-

5 Vgl. Girard (2002), 50 ff., 227 und 235 ff.

6 Vgl. Girard (2002), $221 \mathrm{f}$.

7 Girard (2002), 230.

8 Girard (2002), 232.

9 Vgl. Girard (2002), 84 ff., 104 und 109 ff.

10 Girard (2002), 112 und 118.

11 Girard (2002), 126

12 Vgl. Werlhof (2006). 
len“, denn sie sorgten schließlich für „die Aufrechterhaltung der Ordnung" ${ }^{13}$ Ihre Genese und deren Zusammenhang mit den von ihm beobachteten Phänomenen analysiert er nicht. Er hat also weder eine Geschichts- noch Gesellschaftstheorie, in der es mehr als bloße religiöse Gewalteindämmungs- und Opfermechanismen bzw. säkulare Institutionen gäbe, ja, die Gesellschaft resultiert bei ihm lediglich „aus den Beziehungen zwischen den Menschen“.14 Er hat aber auch keine „säkulare“ Theorie darüber, warum es immer wieder zu Gewalt in Form eines „mimetischen Furors“ und der „mimetischen Ansteckung “ ${ }^{\prime 15}$ hysterischer ${ }^{16}$ und gewaltgieriger Massen im „Lynchmord mit nackten Händen“17, im Opfer eines „Sündenbocks“ oder im wiederholten Blut-Ritual eines „Gründungsmords" $" 18$ als überhistorische „Normalität“ kommt bzw. all dies in persönlichen Gewaltverhältnissen der Menschen untereinander wiederkehrt.

Zentral ist dabei Girards „Mimesis“-Begriff. In der MimesisDiskussion bedeutet „Mimesis“ generell etwa „Nachahmung“ oder „Anverwandlung“" und bezeichnet die Art, wie Lebewesen - gerade auch gefühlsmäßig - mit der Außenwelt in Verbindung sind bzw. treten, ${ }^{19}$ also was der lebendige Zusammenhang oder die „Verbundenheit alles Seins" 20 für das einzelne Lebewesen bedeuten und worauf sich insbesondere seine Gefühle und Empfindungen richten. Im Anschluss an Platon, der die Mimesis abwertend dem Tierreich zuordnet, wird der Mimesis-Begriff vor allem in der Ästhetik- und Kunst-Theorie, später aber auch für weitere gesellschaftliche Vorgänge verwendet. ${ }^{21}$

Das Besondere an Girard ist, dass er die Mimesis nicht als prinzipiell positive Lebensäußerung, ja, -gabe versteht, sondern in den einseitigen und krass negativen Zusammenhang mit "Satan“ und dessen Gewalt bringt. Demnach ist „Mimetik“ so etwas wie Mimesis an Satan; seine Nachahmung und seine „Hineinnahme“ ins Innere des Menschen. Nach Girard okkupiert Satan förmlich die menschli-

13 Girard (2002), 128.

14 Girard (2002), 63.

15 Girard (2002), 16 und 235.

16 Vgl. Girard (2002), 143.

17 Girard (2002), 87.

18 Girard (2002), 10 und 61.

19 Vgl. Genth (2002), 26 f.

20 Werlhof (2007b).

21 Vgl. Gebauer/Wulf (1992). 
chen Gefühle, und Menschen richten ihr Gefühlspotential auf Satan und an ihm aus. „Mimetische Rivalität“, „mimetisches Begehren“, „mimetische Konkurrenz“, „mimetische Ansteckung“ und „mimetischer Furor" haben als Begriffe der Mimetik bei Girard immer einen einzigen Inhalt: das Empfinden von Gewalt, brennender Gewalt. Die Gewalt als unmittelbare und „heiße“ hat bei ihm eine kollektive wie individuelle Seite, andere Formen von Gewalt kommen bei ihm nicht vor, z.B. eine „kalte“, rationale, wie etwa die Eichmanns oder wie die der Kriegsvorbereitung, der organisierten Ausbeutung, systematischen Unterdrückung bzw. Herrschaft, des geplanten Raubes sowie von deren ,wissenschaftlicher“ Begleitung.

Girard behauptet, dass die von ihm thematisierte „heiße“, affektive Gewalt - ebenso wie ihre angeblich organisierte, allerdings nur vorübergehend wirksame „Befriedung“ durch den kollektiven „Opfer-Mechanismus“ im „mimetischen Zyklus“22 - nicht durch die

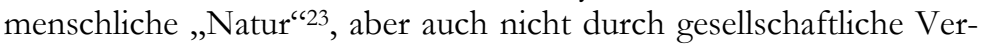
hältnisse verursacht sei, etwa durch Herrschaft, Unterwerfung, Ausbeutung und Krieg. Denn je länger diese dauerten, desto eher sei ihr „Einrücken“ von außen ins Innere, ihre „Internalisierung“ zu beobachten. Affektive Formen menschlicher Gewalt definiert er als von „Satan“ in uns ausgelöste, „personifizierte“ und bösartige, als gewaltorientierte „Mimetik“24, eine Art ansteckende „Krankheit“"25.

Gleichzeitig, so Girard, sei es aber derselbe Satan, der uns diese Gewalt im Sündenbockopfer ,zyklisch“ immer wieder austreibe. Genau diese Eigenschaft Satans, gewissermaßen auch sein eigener Exorzist zu sein, sei nämlich sein „Geheimnis“.26 Dadurch würde vermieden, dass die gesellschaftliche Ordnung immer wieder im Chaos eskalierender Gewalt versänke, ${ }^{27}$ denn Satan habe ein Interesse an der Aufrechtherhaltung dieser Ordnung als seiner „Welt", in der er der „Herrscher“ sei. ${ }^{28}$ Damit wäre Satan der Organisator und Manipulator ${ }^{29}$ der Gewalt ebenso wie ihrer vorübergehenden Eindämmung und anschließenden Wieder-Anfachung. Satan ist dem-

22 Girard (2002), 15, 35 ff. und 93.

23 Girard (2002), 229.

24 Girard (2002), 114.

25 Girard (2002), 228.

26 Girard (2002), 53.

27 Vgl. Girard (2002), 56, 104 und 106.

28 Vgl. Girard (2002), 227.

29 Vgl. Girard (2002), 93. 
nach Krisenproduzent ebenso wie Krisenmanager, und zwar auf der persönlichen Ebene ebenso wie auf der „gesellschaftlichen“ (im Sinne der kulturell-religiösen).

Das in gegenseitiger bösartiger Nachahmung - Mimetik - zum Ausdruck kommende „Begehren“ hat nach Girard allerdings auch ursprünglich die „Erhebung“ des Menschen aus dem Tierreich und dem „Animalischen“ ermöglicht und zur menschlichen Kultur geführt. ${ }^{30}$ Wo sich aber der Unterschied zwischen Mensch und Tier verlöre, erklärt er, sei dies ,immer mit Gewalt verbunden“.31 Deshalb sei dann gerade ein „Gründungsmord“ notwendig, um menschliche Kultur zu erfinden, ${ }^{32}$ einschließlich der angeblichen Notwendigkeit seiner ständigen Wiederholung im Opferritual. Wieso hat also die Erhebung über das Tierreich den Menschen nicht weniger Gewalt gebracht, sondern im Gegenteil diese auch noch systematisiert? Was ist der Unterschied zwischen „Aggressoren“, die sich in „,kollektiver Hysterie“ wie „Raubtiere aufführen“, 33 und letzteren? Schließlich töten Raubtiere nur, wenn sie Hunger haben, und nicht, um Gewalt auszuüben.

Wenn das „Begehren“ sowohl für „das Beste wie für das Schlimmste in uns verantwortlich ist" "34 dann entnehme ich dem „guten“ Begehren einerseits also eine grobe und unreflektierte $\mathrm{Na}$ turverachtung, andererseits vermisse ich im Weiteren die Berücksichtigung dieser positiven Seite des Begehrens bzw. der damit verknüpften Mimesis/„Mimetik“. Nur im Zusammenhang mit dem Wirken Jesu scheint dieses positive Begehren, paradoxerweise allerdings vor allem in Gestalt des Verzichtes, wieder eine Chance zu haben, wenn auch nicht überall. Denn der Verzicht auf Gewalt bzw. deren Verbot dürfte, wenn der Drang nach Gewalt so menschlich ist, dass er geradezu das Kennzeichen der conditio bumana ist, lediglich in den Untergrund führen.

Gerade in oder um uns Menschen herum sei Satan jedenfalls permanent anzutreffen. Er erscheint als Teil von uns selbst und unserer Gewalt in Form unserer diversen Mimetiken und insbesondere 
auch unserer „Konkurrenz“35, unseres „Neides“, unserer „Eifersucht“, unserer „Anklage“, unserer „Sündenböcke“ und all dessen, was wir uns gegenseitig kollektiv oder individuell Grässliches antun. Dies ist das zentrale Thema bei Girard, denn, apodiktisch: „Der gegenseitigen Gewalt kann keine noch so stabile Herrschaft und keine Versöhnung je ein Ende setzen. “"36

Gewalt ist demnach die entscheidende anthropologische Konstante in uns! Da gibt es nur noch: „No exit!“ Wir scheinen gefangen in der ständig brodelnden Gewalt-Hölle des Irdischen. Von einem etwa über diese angeblich in uns wirkende Dauer-Gewalt des Satanischen hinausgehenden menschlich Positiven ist dabei eher nicht die Rede $^{37}$ und auch nicht von so etwas wie eventuellen ,satansfreien Zonen“ im Menschen und um ihn herum, etwa am Berg oder im Kinderzimmer. Im Gegenteil, eine satanische TranszendentalAnthropologie ${ }^{38}$ definiert uns: Zum „Menschen“ gehört Satan als eine Art „Dämon“ dazu, sozusagen in „Personalunion“, und dies in der besonders modern formulierten Variante einer dämonischen „Mechanik“ oder Automatik, sozusagen statt deus nun diabolus ex bzw. in machina.

Nun weiß ich immerhin, warum Girard so aufgeregt ist, ja geradezu beleidigend wird, indem er den Menschen einen immer noch existierenden, offenbar furchtbaren ,animalischen Herdeninstinkt“"39 - er kann Tiere auf den Tod nicht ausstehen - unterstellt, die Menge „brutal und dumm“40 nennt, das menschliche Begehren als „Krankheit“41 bezeichnet, allen Menschen einen „Hunger nach Gewalt“42 unterstellt, sie in einer „seit Anbeginn bestehenden Knechtschaft“43 sieht und ihnen keine Möglichkeit zur „Selbstbefreiung“"44 attestiert. Besonders fällt immer wieder die Dämonisierung der Tiere und unseres „tierischen Erbes“ auf, die auch schon in der Antike, zu Zeiten der Hexenverfolgung und später gerade seit der Aufklärung zu beob-

35 Girard (2002), 95.

36 Girard (1994), 454.

37 Vgl. Girard (2002), 237.

38 Vgl. Girard (2002), 93.

39 Girard (2002), 217 und 238.

40 Girard (2002), 216.

41 Girard (2002), 228.

42 Girard (2002), 115 und 196.

43 Girard (2002), 175.

44 Girard (2002), 64. 
achten sind. ${ }^{45}$ Girard scheint auch davon auszugehen, dass der Mensch als Individuum, also ohne Gemeinschaft und Beziehungen, leben könne bzw. sogar solle. Aber wer plant eigentlich die Gewalt, wer schafft den Hunger (nicht den nach Gewalt, den anderen), wer beutet Menschen aus? Girard behauptet, es gebe heute keine Sklaven und Leibeigenen mehr - welch eine Unkenntnis -, der Westen kämpfe gegen die „Unterentwicklung“ - jene, die er seit Jahrhunderten überall selbst erschafft? -, er sei weniger ,ethnozentristisch“ als alle Vorgänger - das Wort Rassismus kennt Girard nicht -, er habe die Welt sogar „geeint“ - vielleicht in der Monokultur von Coca Cola \& Co - und er verspüre eine „Furcht, Gesellschaften zu demütigen, die nicht zur privilegierten Gruppe gehören" ${ }^{\text {"46 }}$ - in Afghanistan, im Irak und im Kongo scheint das ja am meisten zuzutreffen.

Jedenfalls ist in diesen Groß- und Entwicklungstaten des Westens, wie Girard sie sieht, der Satan gerade abwesend. So sei „die westliche Welt bis in unsere Tage hinein den zwingenden Formen der wesenhaften Gewalt [...] entgangen“".47 Jedoch war keine Zivilisation je so global gewalttätig wie die moderne - westlich-christliche. ${ }^{48}$ Gerade da müsste daher doch Satan mitgewirkt haben, oder? Aber Girard warnt uns eindringlich vor der Allgegenwart des Leibhaftigen überall sonst und vor denen, die ihn partout, vor allem an/ in sich selbst, nicht wahrhaben wollen.

Girard hat ein hermetisch geschlossenes Begriffs- und Denksystem geschaffen in dem Sinne, dass man, wohin man innerhalb dieses Systems auch schaut, auf Satan stößt. So soll das Wirken Satans vor allem in uns persönlich - paradoxerweise auch im Westen genau beschrieben werden, und dabei soll angeblich nichts ausgelassen werden, keine Räume, keine Dimensionen und keine Zeiten. So „systematisch“ hier alle Menschen angesprochen werden, so systematisch wird aber gleichzeitig übergangen, dass diese Menschen nicht nur Individuen sind, sondern auch in einem GesellschaftsSystem leben und überhaupt - eben wie Wölfe oder Bienen - nur in Gemeinschaft überleben können. Gesellschaft ist also weit mehr als ein Opferritual-Zusammenhang bzw. dessen heutige Auflösung und Ersetzung durch angeblich opferferne „Institutionen“. So ist „Sys- 
tem“ für Girard alles Mögliche, nur nicht die Gesellschaftsordnung, in der wir alle versammelt sind. Es ist also zu fragen: Warum soll eine allgemeine Theorie über menschliches Fühlen und Handeln ohne eine ordentliche Gesellschaftsanalyse auskommen? Warum soll die Analyse der Mikro- ohne die der Makroverhältnisse möglich sein? Warum soll eine Anthropologie, Kulturtheorie oder Religionswissenschaft - gerade in Zeiten der „Globalisierung“ - den gesamtgesellschaftlichen, politischen, ökonomischen, sozialen, geschlechtsspezifischen, technologischen, militärischen und ökologischen Rahmen außer Acht lassen bzw. bloß als gegeben voraussetzen? Soll das alles durch Satan ersetzt werden?

Nach Girard resultiert die Gesellschaft jedenfalls aus nichts anderem als den „Beziehungen zwischen Menschen“,49 und als „Hindernis auf dem Weg zum Heil““ sieht er lediglich die „sündige Menschheit“, „zwischenmenschliche Beziehungen“ und eine „konfliktuelle Mimetik“. ${ }^{50}$ Mit Jesus ist für Girard hingegen die Befreiung von negativer Gewalt - es gibt ja, wie gesagt, angeblich auch eine positive, nämlich die mit „besänftigender Wirkung“"51 - in der Welt erschienen, und zwar auch noch zum ersten Mal in der Menschheitsgeschichte ${ }^{52}$ - welch kühne These angesichts der Dauer dieser Geschichte, in der Jesus bestenfalls eine junge Erscheinung ist.

Es ist offensichtlich nicht im Interesse von Girard, die Geschichte zu „periodisieren“ und vor- und nichtpatriarchale, nämlich „matriarchale" - und d.h. nicht etwa frauenbeherrschte, sondern am „mütterlichen Anfang“ (mater arche) bzw. einer „mütterlichen Ordnung" orientierte - Gesellschaften zur Kenntnis zu nehmen, die zum Teil immer noch existieren..$^{53}$ Stattdessen sind für Girard alle vorchristlichen Gesellschaften „heidnisch“ und das heißt bei ihm: nur mühsam gebremst satanischer Gewalt verfallen. ${ }^{54}$ Daher nimmt er die aus nichtpatriarchalen Gesellschaften hervorgegangenen Traditionen von Gewaltlosigkeit, Herrschaftsfreiheit, All- und Naturverbundenheit, Gerechtigkeit, Gegenseitigkeit, Friedlichkeit, freundli-

51 Girard (2002), 227 und Girard (1994), 66.

$52 \mathrm{Vgl}$. Girard (2002), $174 \mathrm{ff}$.

53 Vgl. Göttner-Abendroth (1988), Göttner-Abendroth (2006).

54 Vgl. Girard (2002), 138. 
cher mimetischer „Anverwandlung“55 und „Satansfreiheit“ - von Indigenen bis zu Gandhi - einfach nicht zur Kenntnis. Liebe und Gewaltfreiheit sind für ihn erst mit Jesus erfunden worden. ${ }^{56}$ Eine „ideale Gesellschaft“" habe sowieso „,nie existiert“, beauptet Girard. ${ }^{57}$ Er negiert damit alles, was nicht zu seiner These passt. Dazu gehören insbesondere mütterliche Traditionen und entsprechende Kulturen seit unvordenklichen Zeiten, ${ }^{58}$ wie ideal oder nicht ideal sie auch gewesen sein mögen.

Erst das christliche „Kreuz“ habe, so Girard, die Welt verändert, nämlich ,auf den Kopf gestellt“"59 - in der Tat, nicht auf die Füße! Daraus erklärt sich auch, warum das Positive bei ihm durchaus nicht allgemein in den Menschen, jedenfalls nicht in ihnen als „Masse“, zu erwarten ist. Askese ist also angesagt (wie originell!). Gnostisch, so vermutet Sloterdijk im Nachwort ${ }^{60}$, könne Girards Werk genannt werden, und Sloterdijk versteht darunter Weltflucht und -fremdheit - einen „heiligen Protest gegen Welt und Leben“, die „Sezession vom Seienden überhaupt“, ein „phantastisches Abseits, links von der Schöpfung, fern von den Mächten des Kosmos" und in „der Fülle des Nichts an Welt und Wirklichkeit“. ${ }^{61}$ Wer könnte sich einen solchen „Geist der großen Verneinung" "62 wohl leisten? Eine Mutter mit Kindern vielleicht? Warum sollten die Massen sich mittels Askese von Satan befreien wollen, anstatt direkt ein gewaltfreies Miteinander im Hier und Jetzt zu schaffen, wozu vor allem das Verlassen seines „Reichs“, der Herrschaftsordnung des Patriarchats, gehört?

Und woher kommt eigentlich der „Hunger“ nach Gewalt? Wer ist denn wie „Achill, das Vieh“, den Christa Wolf in Kassandra ${ }^{63}$ beschreibt und der bei Girard eine Art überhistorisches Massenphänomen zu sein scheint? Immerhin haben schon die alten Griechen das Böse im „Animalischen“ gesehen. Aber wodurch wird man wieder? - zum „Vieh“? Durch Satan? Christa Wolf ist ohne Satan

55 Genth (2002), 25.

$56 \mathrm{Vgl}$. Girard (2002), $203 \mathrm{ff}$.

57 Girard (2002), 203.

58 Vgl. Todorov (1985), Amadiume (1997), Biegert (1991), Liedloff (1980) und Somé (2000).

59 Girard (2002), 180.

60 Vgl. Sloterdijk (2002), 251.

61 Sloterdijk (1991), $18 \mathrm{f}$. und 21.

62 Sloterdijk (1991), 30.

63 Vgl. Wolf (1994). 
ausgekommen: Achilles ist das scheußlichste, perverseste und grauenerregendste Produkt schlechthin von Patriarchat und Krieg. Aber die kommen bei Girard nicht in diesem Zusammenhang oder überhaupt nicht vor, weil er Satan gerade dort nicht ansiedelt. Oder liegt es daran, dass der Krieg zum „Heilsplan“ gehört?

Dave Grossman, immerhin ein ehemaliger Oberstleutnant der US-Armee, beschreibt, wie schwierig es für das Militär aller Zeiten war, den Soldaten das Töten beizubringen. ${ }^{64}$ Das schildert auch schon Sunzi für die chinesische Armee im Jahre 500 v. Chr. ${ }^{65}$ Es gibt nämlich ein uraltes Tötungstabu und so schossen sie in allen Armeen lieber daneben, bis man ihnen Tötungs-Maschinen, d.h. Distanz zum Gegner, geben ${ }^{66}$ bzw. sie selbst in Killer-Maschinen verwandeln konnte. ${ }^{67}$ Wieso weiß Girard davon nichts, und wo kommt dieses Tabu lange vor Jesus bereits her? Stattdessen hungern bei Girard die Massen immer schon nach Blut und sättigen sich an ihm wie die sogenannten „Kannibalen“. ${ }^{68}$

Satan ist also ausgerechnet der Militärforschung zufolge gerade nicht immer schon mit den Menschen verbunden gewesen, wie Girard behauptet, ${ }^{69}$ sondern erst, seitdem das Tötungstabu gebrochen ist - nämlich seit dem Patriarchat, mit dem der Krieg beginnt. ${ }^{70}$

Heute sind diejenigen mit dem „Furor“ vor allem die Veteranen, die aus den in der Welt verstreuten Kriegen von Girards Wahlheimat, den USA, zurückkommen und diese Heimat in eine neue Front verwandeln. ${ }^{71}$ Benötigt man Satan, um die post-traumatic stress disorder (PTSD) der Veteranen zu erklären, ${ }^{72}$ das Wüten, die Schlaflosigkeit, das Schuldbewusstsein, die Morde und Selbstmorde daheim? Es ist das, was die Kriegs-Maschine und die total rational und ohne den geringsten Furor kalkulierenden Befehlshaber aus den Soldaten gemacht haben. ${ }^{73}$ Aber Girard sieht den Satan nur „hinter“

64 Vgl. Grossman (1996), 249 ff.

65 Vgl. Sun/Clavell (2001).

66 Vgl. Grossman (1996), 156.

67 Vgl. Grossman (1996), 262 ff.

68 Vgl. Girard (2002), 10 f. Das Argument kennen wir schon, nämlich als Projektion von Kolonisatoren und Missionaren auf die angeblich „Primitiven“ in Übersee; siehe Stüben (1985).

69 Vgl. Girard (2002), $110 \mathrm{ff}$.

70 Vgl. Dieckvoss (2003).

71 Vgl. Girard (1994), 66.

72 Vgl. Grossman (1996), $281 \mathrm{ff}$.

73 Vgl. Grossman (1996), 249 ff. 
den „Mächten“ ${ }^{74}$ nicht aber ganz konkret auch in ihnen, den Generalen, Präsidenten und Waffenproduzenten. Ist das der Fall, weil hier mehr als nur ,zwischenmenschliche Beziehungen“ und „,konfliktuelle Mimetik" eine Rolle spielen?

Man kommt am Ende nicht umhin, Satan und Jesus als - „mimetische"? - Rivalen zu sehen, fast wie im - typisch patriarchalen Kampf unter Männern, in diesem Falle besser „Geistern“: Dort siege Satan immer noch und sei auch noch zum Nachahmer Jesu geworden, wodurch er viele Leute gerade heute erneut hinters Licht führe, ${ }^{75}$ wie Girard beklagt. Ahmt Jesus umgekehrt auch Satan nach, wenn er „die Menschen krank macht, um sie anschließend zu heilen"?76 Langsam hat man Probleme, zwischen Jesus und Satan überhaupt noch zu unterscheiden.

Angesichts der Satans-Gefahren will Girard uns aber ordentlich wachrütteln! Von seiner eigenen Besessenheit ausgehend macht er aus Satan eine Art Schablone, eine „, formale Form“777, die er uns allen überstülpt, um uns in der Manier einer self-fulfilling prophecy reduktionistisch zu bändigen. Was darüber hinaus existieren könnte, wird systematisch weggelassen.

\section{Wovon Girard gerade nicht spricht - von der wahren Gewalt als dem heutigen „Opfer-Mechanismus“}

Ob bewusst und gewollt oder nicht, ,der Mensch“ überhaupt ist bei Girard mit dem Dämon unterwegs. Dabei wird - ganz modern - der Mensch als „Maschine“, leere Hülle/Apparat, homo vacuus ${ }^{78}$, gesehen, der jeder Tiefe, Fülle, jedes eigenständigen Innenlebens, jedes selbstbestimmten und von anderen unabhängigen Wollens, also jeder Eigenmächtigkeit und gewissermaßen der Seele entbehrt. Diese(r) Maschinen-Mensch/Mensch-Maschine ${ }^{79}$ wird über die Mimetik, also die gewaltbereite Übernahme des Begehrens anderer, dazu veranlasst, nicht seinen „Trieben“, etwa im Sinne eines eigenen, inneren 
Begehrens, zu folgen, sondern: „Der Nächste ist das Vorbild unserer Begehren" $" 80$.

Wer hat dann aber eigentlich überhaupt noch einen freien, von Satan unbeeinflussten Willen, ein eigenes Innenleben, eine Seelentiefe, und wer ist überhaupt ein guter Mensch nach Girard? Man müsste sie suchen unter denen, von denen er nicht spricht. Wer kommt bei ihm nicht vor?

1. Die Frauen, insbesondere als Mütter. Die kämen infrage, aber sie sind gewiss nicht gemeint, wie an anderer Stelle ausführlich festzustellen sein wird. ${ }^{81}$

2. Die weltlich Herrschenden, die sich als Herren der Welt fühlen bzw. sich so aufführen. Es sind allerdings diejenigen, die ohne jeden „Furor“ eiskalt Kriege und Ausbeutung planen und durchführen lassen, töten und töten lassen in aller Welt und damit am laufenden Band Blutopfer fordern und neue „Gründungs"-Morde begehen. ${ }^{82}$ Hat Satan mit denen (übrigens sind die allermeisten davon Männer) nichts im Sinn, obwohl es ja offensichtlich ganz und gar sein Reich ist, in dem diese anderen Herren agieren und regieren? Von diesen Leuten ist keine (analysierende) Rede bei Girard, es sei denn am Rande und in positivem Ton. ${ }^{83}$ Hier klafft eine riesige Lücke. Was wirklich böse genannt werden kann und muss (z.B. bestimmte „Global Players"), taucht bei Girard gar nicht erst auf.

Es sind hie die Reduzierung der Gewalt auf grauenhafte Lynchmorde und ihre Dämonisierung, bei gleichzeitiger Verniedlichung des wirklich umfassenden, systematisch durchgesetzten Bösen, und da seine „Banalisierung“" sowie die Aufbauschung von vergleichsweise harmlosen Affekten wie Neid und Eifersucht, die bei Girard so ärgerlich machen. Von den keineswegs blutrünstigen oder im Affekt geschehenden, mimetisch aufgeladenen, sondern rational geplanten und durchgeführten täglichen Verbrechen gegen Menschen, Leben und die Erde spricht er nicht oder nicht in negativer bzw. systematisch-analytischer Weise: ${ }^{84}$ vom Krieg, Kolonialismus,

80 Girard (2002), 24.

81 Hier sei nochmals auf die ausführlichere Version dieses Textes verwiesen, die zu einem späteren Zeitpunkt veröffentlicht wird.

82 Vgl. Chossudovsky (2002), Mies/Werlhof (2003), Mies (2004), Perkins (2004) und Werlhof (2007a).

83 Vgl. Girard (2002), 202, 208 und 212 f.

84 Vgl. Girard (2002), 213. 
Kapitalismus, Patriarchat und von der Globalisierung, in der dies alles zur ganz säkular herbeigeführten „Apokalypse“ kulminiert. Soll das Scheitern des christlichen Abendlandes in Gestalt der westlichen Zivilisation nun also gar als ominöser Plan Gottes ausgelegt und „erklärt“ werden?

So spricht Girard insbesondere nicht von einem Gesellschaftsund Wirtschaftssystem, das seine Mitglieder alltäglich zum Bösen, nämlich zur Konkurrenz, zur Unterwerfung und Ausbeutung, zum Betrug, zum Mitmachen und zur Lüge zwingt, von Abermillionen täglichen Opfern der Profitwirtschaft und Spekulation, den Zigtausenden, die täglich verdursten und verhungern, ${ }^{85}$ den überall vergewaltigten und ermordeten Frauen, denen, die in heutigen Kriegen umkommen, zu 80 bis 90\% Zivilisten, vor allem Frauen und Kinder, denen, die in vorsätzlich angelegten Minenfeldern verstümmelt werden, die durch Folter, Zwangsprostitution, buchstäbliche Leibeigenschaft, Zwangsarbeit und Sklaverei gehen, ${ }^{86}$ die Girard ja ignoranterweise als abgeschafft betrachtet. Er spricht nicht von denen, die mutwillig oder so nebenbei radioaktiv verseucht werden ${ }^{87}$ oder einfach „nur“ dem allgemeinen „Fortschritt“, z.B. im Verkehr, zum Opfer fallen.

Noch nie hat es Hunderte Millionen Sklaven auf der Welt und Dutzende von Kriegsschauplätzen auf einmal gegeben, noch nie so viele Tote täglich, bloß weil ihnen der Zugang zu Boden, Wasser und Nahrungsmitteln inzwischen versperrt ist. Girard redet auch nicht von den Menschen, die seit Jahrhunderten im Namen der „Entwicklung" vertrieben und enteignet werden von Land, Produktionsmitteln, Selbstversorgung und den Existenzmöglichkeiten selbst. ${ }^{8} \mathrm{Da}$ von ist heute weiterhin nicht weniger als die Hälfte der Menschheit bedroht, nämlich drei Milliarden noch existierende Kleinbauern auf der Welt. ${ }^{89}$

Am allerwenigsten redet Girard davon, dass und wie diese Gewalttaten direkt geplant und organisiert werden, nämlich von weltweit operierenden Institutionen, die extra dafür geschaffen wurden, wie dem Bankensystem und den Konzernvereinigungen, der WTO, 
dem IWF und der Weltbank, von den Einzelregierungen einmal abgesehen. ${ }^{90}$ Aber Girard behauptet, heutige Institutionen seien frei von Mimetik und Opfer. ${ }^{91}$ Er redet auch nirgendwo davon, dass diese Gewalt, die wahre Gewalt, nicht zufällig vor allem von ganz rational denkenden und wahrscheinlich überhaupt nichts empfindenden, völlig gleichgültigen Bürokraten ohne jeden Bezug zu irgendeiner Masse begangen wird. ${ }^{2}$ Die „Ordnung“, die das hervorbringt, ist eine katastrophale Un-Ordnung. Das Chaos, das Girard beim Zusammenbruch dieser Ordnung aufgrund des fehlenden Opfermechanismus heute, der offenbar durch das „private" Quälen von Frauen und Kindern nicht wettgemacht wird, befürchtet, ${ }^{93}$ ist durch diese „Ordnung“ selbst längst eingetreten.

Wie kann Girard das Opfer heute mit seiner Theorie erklären? Gar nicht, denn es gibt für ihn heute weder Opfermechanismen noch gesellschaftliche Verhältnisse außerhalb davon, die die Opfer erklären könnten. Heutige „Institutionen“ seien ja, so Girard, sogar zur Opfervermeidung da. ${ }^{94}$ Das hat man von der Inquisition auch schon behauptet. Warum hat er dazu nicht Ivan Illich gelesen, der die „Kontraproduktivität“ moderner Institutionen erklärt, die nämlich immer das Gegenteil von dem hervorbringen, was sie selbst angeblich - anstreben?95

So bleibt der Gewaltbegriff bei Girard in unerträglicher, selbst direkt gewalttätig wirkender Weise eingeschränkt. Weder von direkter ökonomischer, politischer und religiöser ${ }^{96}$ noch von indirekter, „struktureller“ und im System selbst angelegter Gewalt ${ }^{97}$ hat er scheinbar je gehört, von Massenvernichtung und Krieg gerade heute zwar am Rande, ${ }^{98}$ aber ohne dass das für seine Analyse Folgen gehabt hat. Nimmt er sie nicht zur Kenntnis, weil er gerade gegen die bisherigen und zugegebenermaßen unzureichenden Erklärungsversuche von Gewalt eine andere Theorie entworfen hat - oder weil er sie als gottgewollte „Apokalypse“ definiert? Ist es ein Trick, Aufstieg

90 Vgl. Chossudovsky (2002).

91 Vgl. Girard (2002), 204 und 208.

92 Vgl. Perkins (2004).

93 Vgl. Girard (2002), 189.

94 Vgl. Girard (2002), 207 f.

95 Vgl. Illich (2006).

96 Vgl. Widerspruch (1993).

97 Vgl. Galtung (1982).

98 Vgl. Girard (2002), 208. 
und Niedergang der westlichen Moderne, an denen das Christentum von Anfang an prominent und federführend beteiligt war, jetzt auf einmal zur Apokalypse zu (v)erklären, um nicht zur Verantwortung gezogen zu werden?

Ist auch das gemeint, wenn es heißt, „das lügnerische Religiöse“ bewahre „,vor dem Chaos" ${ }^{\text {"99 }}$ und man nehme, wenn die Menschen „die Unwissenheit verlieren“, „,der menschlichen Gewalt den letzten Hemmschuh"? 100 Wie, wenn darunter heute auch das christlich Religiöse fiele und die religiösen und anderen „Mächte“ lediglich eine panische Angst davor hätten, dass die Wahrheit über ihre eigene Gewalt die Augen der ehemals Gläubigen öffnete? Welch einer Wut, und zwar einer gänzlich unsatanischen, würden sie da begegnen?

Girard hat zur Gewalt nur Dogmatisches, Dämonisches, Individuelles, Eklektisches, Satans- oder Gottgewolltes und, was die westliche Gesellschaft als Ganzes angeht, sogar fast nur Positives zu sagen. Ausgerechnet der technische Fortschritt, die kapitalistische Wirtschaft und die Globalisierung - die die Eckpfeiler der besten aller Gesellschaften seit je - sind auf dem institutionellen Weg unterwegs in eine vielleicht sogar jesusgemäße Zukunft. ${ }^{101}$ Widersprüche, wie die angeblich gleichzeitige „Entgrenzung der Opferlogik“ und die dadurch geschehende „Zerschlagung“ des „modernen“ Staates durch die Globalisierung, ${ }^{102}$ bleiben einfach so im Raum stehen.

Die Natur, schließlich, kommt bei Girard auch nicht als Opfer systematischer Gewalt vor, von einem Nebensatz abgesehen, ${ }^{103}$ selbst wenn es noch so viele ökologische Probleme, Klimawandel, ausgerottete Fauna und aussterbende Flora gibt. Da sieht er auch keinen Zusammenhang mit den Zerstörungen durch Industrialisierung sowie Fortschritt der Maschinerie und modernen Warenproduktion. Im Gegenteil, die scheinen ja die mimetische Rivalität sogar zu besänftigen. ${ }^{104}$ Kultur ist eben Naturbeherrschung, Macht über das böse Leben, die bösen Tiere und den bösen Tod. Wie kann ohne Schaden für die Analyse „des Menschen“ und der Gesellschaft die 
Natur als Grundlage unserer Existenz einfach unter den Tisch fallen, und dies in Zeiten nahender „Apokalypse"?

Daher noch einmal zu den heutigen Opfern. Die von Girard so genannte „Sorge um die Opfer"105 ist ja vor allem deswegen da, weil es trotz aller eventuellen „Sorge“ immer mehr werden. Wie, wenn das dadurch geschieht, dass gerade die modernen, säkularen Institutionen, z.B. „der Markt“, Opfer „verlangen“ und genauso undurchschaut wirken wie ihre religiösen Vorgänger? Und wer sagt, dass an diese Opfer nicht geglaubt werde? An das moderne Menschenopfer in Medizin und Arbeitsprozess, durch neoliberale Wirtschaftspolitik, „humanitäre Interventionen“, Hilfs- und Friedensmissionen, technischen Fortschritt, Entwicklung, Warenproduktion, Wachstum, Folter und Krieg? Heißt es nicht ständig, für den Fortschritt müssten Opfer gebracht werden, und zwar Menschenopfer? Und Opferriten gibt es auch: Sport- und andere Heldenkulte, nächtliche Organtransplantationen, die Zerstückelung der Vorgänge um die Hervorbringung neuen Lebens in der Petrischale und anderswo, generell die Rituale um das in Ökonomie, Politik, Wissenschaft, Krieg und Kunst gebrachte, meist unsichtbar bleibende Lebens- und vor allem Frauenopfer ${ }^{106}$ sowie die Feier der "Global-Players“ jährlich in Davos, die Feier des „großen Fressens"107.

Vielleicht sind ja die Institutionen und das System von heute gar nicht so säkular? Vielleicht hat das religiöse Opferritual, die heidnische „Opfermaschinerie“, gar nicht wirklich aufgehört zu wirken? Vielleicht leben wir ja, umgekehrt, gerade in einer wie nie zuvor durch und durch vom Opfer - das übrigens oft nur als „Kollateralschaden" gilt - geprägten und durch dieses Opfer geradezu definierten Gesellschaft?108 Dann wäre dieses Opfern auch gar kein ,,heidnisches“, sondern ein christliches. Die christliche „Sorge um die Opfer" seitens der Institutionen wäre dann nur Ideologie, Aushängeschild, Lippenbekenntnis, und in Wirklichkeit ginge es um das Gegenteil. Vom Resultat her gesehen ist dies jedenfalls der Fall. So hat Entwicklung bei uns bis jetzt immer Unterentwicklung anderswo bedeutet. ${ }^{109}$ Sollen wir davon ausgehen, dass das nicht gewollt

105 Girard (2002), $202 \mathrm{ff}$.

106 Vgl. Bergmann (1996), Bergmann (2000).

107 Vgl. Werlhof (2007a).

108 Baecker (2003).

109 Vgl. Frank (1968). 
war? ${ }^{110}$ Wenn ja, dann hätten wir auf diese „Entwicklung“ eben verzichten müssen. Weil das aber gerade nicht geschah, war es selbstverständlich gewollt. Es wurde nur nicht eingestanden.

Da sind überall Zusammenhänge, die geradezu auf ein systematisches Opfer(n), ein Opfer(n) als „System“, hinweisen. Aber Girard ficht das nicht an. Seine Art angeblicher Interdisziplinarität nimmt dies alles nicht zur Kenntnis. Dabei wäre es ja erklärbar, warum es heute mit den Opfern nicht besser, sondern immer schlimmer und auch noch global geworden ist, und das nicht wegen einer fehlenden, sondern umgekehrt wegen einer immer „durchschlagenderen“ Opfer-,„Maschinerie““.111 Vielleicht ist also dieses Opfern ja, statt des Jesusglaubens, wirklich die neue Religion geworden, ${ }^{112}$ und sie wäre weder heidnisch noch christlich im Sinne Girards, sondern christlich im Sinne einer Moderne des Patriarchats, die als säkularisiertes Christentum zu verstehen wäre, d.h. in diesem Falle als eine säkulare Ordnung, die durch und durch christlich - wenn auch sicher nicht jesuanisch - geprägt ist.

Für Girard, jedoch, ist die Auflösung der Ordnung durch das Fehlen eines Opfer-,„Mechanismus“ - wie er ihn versteht - zu erklären. Ein kommendes Chaos ist vor der patriarchalen Art von Ordnung, ob modern oder ,archaisch“, nicht bekannt, im Gegenteil. Vor diesem Hintergrund sind die Phänomene der systematischen Gewaltanwendung als Opfermechanismen ganz anders zu verstehen. Sie legitimieren und erhalten die Un-Ordnung und sind damit ein ebenso säkularer wie religiöser Betrug. Ebendeshalb sollen sie gerade auch heute nicht durchschaut werden. Dazu trägt Girard bei, indem er das heutige, in seiner Weite und Tiefe noch gar nicht begriffene Desaster nicht dem christlichen Westen anlastet, sondern vor allem als Kommen der schon mehrmals angekündigten Apokalypse, also als göttlichen Plan, deutet.

Girard sieht also nicht, dass die Herrschafts-, Religions- und Gewaltordnung selbst sowohl für die kommende Apokalypse wie auch für die Verzweiflung, Perversion und Gewalttätigkeit der Menschen sorgt, die gezwungen sind, in ihr zu leben. Und er sieht kaum, dass ihre Gewalt meist gerade noch nicht einmal im Furor ausgetobt wird, sondern in der krankmachenden Mittäterschaft bei der kalten 
Gewalt, im Gehorchen und Sich-Fügen, im Sich- und andere Beherrschen und Unterdrücken - im Nicht-mehr-Leben(-Lassen) -, ob mimetisch ausgelöst oder nicht. Girard will jedenfalls den Menschen nur die eine Gewalt ohne die andere austreiben und den Grund für beide unbehelligt lassen. Die Frage ist also: Wer hindert eigentlich die Menschen daran, friedlich zu kooperieren und verantwortungsvolle Gemeinschaft zu sein? Sie sich selber?

\section{Wovon Girard spricht - den patriarchalen - und wovon nicht - den matriarchalen Mythen. Die Folge: Verbot der „Anklage“}

Da Girard nur die patriarchale Gesellschaftsordnung kennt, die er allerdings nicht als solche benennt, weil das nur möglich ist, wenn man ein Gegenteil dazu sieht, nimmt er auch nur patriarchale $\mathrm{My}$ then zur Kenntnis. Diese haben selbstredend einen „Gründungsmord" zum Inhalt, ${ }^{113}$ eben weil die patriarchalen Gesellschaften überall mit dem Überfall, der Eroberung und der Ermordung der „Großen Mutter und Göttin“ sowie der sich auf sie berufenden Gesellschaften beginnen. ${ }^{114}$ Dafür braucht es eine Rechtfertigung und die ist der Inhalt der patriarchalen Mythen. Girard aber wundert sich: „Die eigentlich religiöse Dimension lässt sich mit einer mütterlichen Substanz, einer ursprünglichen Gebärmutter vergleichen, deren sich die Riten im Verlauf der Zeit entledigen, um sich in entritualisierte Institutionen zu verwandeln. " ${ }^{115}$ Er kann dies aber nicht erklären.

Die matriarchalen Mythen - sowie die kritische Patriarchatsbzw. Matriarchatsforschung - können das sehr wohl. ${ }^{116}$ Denn hier wird ja offensichtlich ein Mutter- und Göttin-Mord beschrieben. Das passt aber nicht in Girards Bild, weil er behauptet, dass das Blut-Opfer als „Gründungsmord“ vor dem Entstehen der Götter und Göttinnen komme und die letzteren erst aus dem Mordopfer als „vergöttlichte“ hervorgingen. Göttinnen seien daher ursprünglich „Sündenböcke“ in ihren Kulturen gewesen. ${ }^{117}$ Demnach hätte es also nicht darum gehen können, sich „der mütterlichen Substanz zu

113 Girard (2002), $109 \mathrm{ff}$.

114 Vgl. Weiler (1991).

115 Girard (2002), 121.

116 Vgl. Göttner-Abendroth (1988), Treusch-Dieter (2001), James (2003) und Tazi-Preve (2004).

117 Vgl. Palaver (2003), 382. 
entledigen“, sondern diese wäre als „,vergöttlichte“ bzw. „Göttin“ erst das Resultat des Opferrituals gewesen. Hierbei wird unterschlagen, dass die „Grosse Göttin“ ebenso wie der all-mächtige monotheistische All-Gott seit unvordenklichen Zeiten ebenfalls als AllGöttin bzw. „All-Mutter“ verstanden wird: als Göttin, die nicht nur unabhängig vom Opfer ist, sondern im Gegensatz zu ihm steht, gleichzeitig aber nicht ,über“ allem waltet, sondern dieses All selbst und damit auch ,in allem“ ist, weil sie es hervorbringt. Allein, dass Girard dieses Göttin-,Konzept“ der „Alten“ nicht berücksichtigt, ist ein Mutter- bzw. Göttin-Mord. ${ }^{118}$

Die Dinge sind einfach zu klären: Es kommt eben nicht der Mord vor der Geburt. Und was die frühe „Kultur“ hervorbringt und eint, ist die Selbstorganisation um die Geburt herum: die „mütterliche Ordnung“ und/als deren Einbettung in die „kosmische“ AllMutter-Ordnung, später auch Göttin genannt. Wie die Geburt kommt auch die „Göttin“ lange vor den patriarchalen Mordtaten, ${ }^{119}$ die sich der Göttin entledigen müssen, um selbst scheinbar an deren Stelle treten zu können. Das ist der wirkliche Betrug im wiederholten Gründungsmord-Opferritual: dass es nur eine(n) Ersatz-Gott/-Göttin „schafft“, dem/der als „Schöpfer(in)“ einer „Ordnung“" gehuldigt wird, die nicht auf der Feier des Lebens, sondern der der Gewalt beruht. Schließlich kann diese Ordnung nicht ohne Gewalt auskommen, da sie mittels ihrer die „Macht-über“ geschaffen hat und ohne sie nicht bleiben kann.

Es ist daher offenbar „,notwendig“, von der matriarchalen Ordnung - so nebenbei - zu behaupten, sie „wurzele im Opfermechanismus“ ebenso wie die patriarchale. ${ }^{120}$ Andernfalls wären „der Mensch“ bzw. „die Frau“ nicht in allererster Linie böse, gefährlich und gewalttätig, und dann würde das ganze Gebäude der „mimetischen" und anderer patriarchaler Theorien in sich zusammenfallen.

Der Mythos von Thiamat und Marduk ist ein Beispiel für einen patriarchalen Göttin-Gründungsmord aus dem 2. Jahrtausend v. Chr. in Babylon, das Girard erwähnt, aber ohne seinen patriarchalen Charakter zu bemerken. ${ }^{121}$ Dieser Mythos erklärt, wie die mesopotamische Despotie entstand, und rechtfertigt sie nachträglich, 1000 
Jahre nach ihrer Etablierung. Das Beispiel zeigt auch, dass davor eine andere Gesellschaft und „Religion“, ebendie der „Grossen Göttin“, - und keineswegs ein lediglich blutrünstiges „Heidentum“ existiert haben müssen, deren Existenz vernichtet und deren Reichtum angeeignet wurden. Dementsprechend geht es auch im Mythos um Gewalt und Raub, das Prinzip des "Teile und Herrsche“ sowie die angeblich mögliche „Schöpfung aus Zerstörung“, das alte und neue Motto patriarchaler Gesellschaft bis heute. So wird Thiamat, die unvordenklich alte Groß- und Welt-Göttin getötet - aber nicht im Anschluss an ihre Ermordung erst „erfunden“ - und ihr Leichnam, die „Mutter-Materie“ schlechthin, ${ }^{122}$ wird ,zerstückelt“, in Erde und Himmel, oben und unten geteilt und als Lebensgrundlage herrschaftlich angeeignet.

Dass das Opfer Thiamats - die u.a. übrigens mit „Chaos“ übersetzt wird - rituell wiederholt und - auf der Seite der Eroberer auch einmütig gefeiert wird, dürfte klar sein. Eine solche „Einmütigkeit“, von der Girard in Bezug auf das „archaische“ Opfer(n) immer wieder spricht, ${ }^{123}$ kann aber bei den Eroberten, von denen Girard nicht spricht, nicht angenommen werden. So dürfte auch der Mord an Jesus sicher nicht der erste gewesen sein, der nicht einmütig hingenommen wurde, wie Girard behauptet, und darum die ganze Opferei im Prinzip beendet haben soll. Es ist ja geradezu das Gegenteil der Fall.

Dass die Eroberer, die das Patriarchat als regelrechte, auf Dauer gestellte Gesellschaftsordnung auf den eroberten matriarchalen Gesellschaften erst aufbauen, daher die Teilung und Spaltung, die Dichotomisierung der Gesellschaft und die Dualismen von Gut und Böse, Oben und Unten, Männern und Frauen, Form und Stoff, Geist und Materie etc. einführen bzw. erfinden, die es vorher nicht gab, ergibt sich aus der Tatsache der Eroberung und anschließenden Etablierung einer Fremdherrschaft. ${ }^{124}$ Natürlich muss so die „Gleichheit“, die frühere Egalität, als äußerste Bedrohung angesehen werden, wie dies auch Girard tut. ${ }^{125}$ Denn für ihn ist die Gleichheit nicht mit der herrschaftlichen „Normal“-Ordnung vereinbar. Die

122 Vgl. Girard (1994), 94.

123 Vgl. Girard (2002), 14, 81, 107 und 120.

124 Vgl. Werlhof (2006).

125 Vgl. Girard (2002), 77 ff. und 88. 
Bedrohung gibt es also nur für die Sieger. Denn durch „Gleichheit“ wäre es ja mit der Herrschaft wieder vorbei.

Die patriarchale Negation der matriarchalen Gesellschaft als derjenigen, auf der noch jedes Patriarchat „aufsitzt“, und die Verweigerung einer „Periodisierung“ der Geschichte über das Patriarchat hinaus sind bei Girard vorausgesetzt, obwohl er mit der Existenz matriarchaler Kultur, ja Hochkultur, viel mehr hätte erklären können, als er es ohne sie tut, z.B. die Tatsache des Frauenopfers im Patriarchat generell, die er ja mit der „weiblichen Schwäche“ begründet. ${ }^{126}$ Treusch-Dieter und andere haben nachgewiesen, dass das Frauenopfer die ganze Antike und ihre „Mysterien“ (sic!) begleitet und zugleich Holocaust, also Brandopfer, ist, ${ }^{127}$ wie wir es bei der Verbrennung von Ketzern, Hexen und Juden sowie der Sati, der traditionellen indoeuropäischen Witwenverbrennung, und bei den modernen Mitgiftbrandmorden an indischen Ehefrauen wiederfinden. ${ }^{128}$ So kommt das Frauen- und Blutopfer - nicht das Menstruationsblutopfer! - ursprünglich aus dem Krieg, dem Eroberungskrieg der sich patriarchalisierenden Kriegerhorden gegen unbewaffnete matriarchale Völker und ist nicht etwa ewiger Begleiter menschlicher Kultur, wie Girard immer noch annimmt. ${ }^{129}$

Die matriachalen Mythen erzählen entsprechend auch nicht vom Opfer, sondern sie sind allesamt - umgekehrt - Geburts-, Abkunfts- und Abstammungsmythen, Mythen über die Verbundenheit aller Lebewesen durch die Urmutter, konkretisiert in der Gestalt eines Gestirns, eines Muttertiers, einer Pflanze, Landschaft oder Menschenfrau. ${ }^{130}$ Es kommt eben nicht der Mord vor der Geburt wie bei Girard, und menschliche Kultur begann dementsprechend um das mater arche, den Lebensanfang aus den Müttern (arche = Anfang, Beginn, Ursprung, Gebärmutter), und nicht um einen „Gründungsmord“. Dementsprechend musste „das Heilige“ auch nicht erfunden werden, schon gar nicht durch eine Gewalttat, sondern in matriarchalen Gesellschaften gilt alles Vorhandene als „heilig“, es sind „sakrale" Gesellschaften. ${ }^{131}$ 
Ich frage mich, warum Girard hier Georges Bataille nicht erwähnt, mit dem er ja viel gemeinsam hat. ${ }^{132}$ Denn Bataille hat die Ambivalenz des (patriarchalen) Heiligen als gleichzeitig „Verfemter“ in einer Weise herausgearbeitet, der man noch ansehen kann, dass hier möglicherweise eine Entwicklung zugrunde liegt, in der das Heilige ursprünglich keineswegs verfemt und auch nicht von einem Nicht-Heiligen getrennt war. ${ }^{133}$ Bei Girard indessen scheidet diese Möglichkeit schon dadurch aus, dass das Heilige - bei den vorchristlichen Religionen - erst aus dem Verfemten entsteht. Dadurch ist die vollständige Verkehrung des Heiligen ins Verfemte, dem die Gewalt gilt, bzw. der Gewalt ins Heilige vollzogen. Damit sind wir bei Girard ohne Übergang mitten im Patriarchat, das die Opfer seiner Kriege und Gewalttätigkeiten nachträglich „heiligt“" damit sie weitergehen können. Dass davor ein anderes Heiliges unabhängig von der Gewalt existiert hat, das inzwischen durch den Göttin-/Muttermord unsichtbar gemacht worden ist, ist nur bei Bataille noch erahnbar.

Die Gewalt ist eine mögliche menschliche Verhaltensweise, die natürlich auch in matriarchalen Gesellschaften vorkommt, aber sie tritt aus deren Verständnis nicht ein wegen Satan, sondern weil in der Gemeinschaft - und nicht bloß beim Einzelnen - Konflikte aufgetreten sind, die nicht oder nicht rechtzeitig bemerkt wurden. Matriarchale Menschen wissen, wie sie damit umgehen können. Sie lösen Konflikte, indem sie gemeinsam die Verantwortung übernehmen und um Wiedergutmachung bemüht sind, also gerade ohne Gewalt und Bestrafung vorgehen. ${ }^{134}$ Die Gewalt auch noch zum System zu machen, ist für sie gerade ausgeschlossen. Dies wäre der äußerste Tabubruch.

Christlich gesehen ist etwa der Mensch - wie in jeder Herrschafts-Ordnung - grundsätzlich schlecht, übrigens gerade auch als matriarchaler (trotz bzw. gerade wegen der „Großen Göttin“ jedenfalls als „heidnisch“ bezeichneter) Mensch. Daher wird von christlicher Seite immer so darauf beharrt, dass die matriarchale Gesellschaft, wenn überhaupt davon die Rede ist, auch, ja gerade als ,ar-

132 Vgl. Bataille (1997).

133 Vgl. Bataille (1975).

134 Vgl. Göttner-Abendroth (1991), Lauderdale (1996), Göttner-Abendroth/Derungs (1997) und Göttner-Abendroth (2000). 
chaische“ besonders gewalttätig war. ${ }^{135} \mathrm{Da}$ wird so getan, als hätten die Frauen die Schrecken der Herrschaft und des Blutopfers geradezu erfunden, die man bei Männern für ganz normal, ja unverzichtbar hält. Niemand, weder „die Mächte“ noch die „Masse“, ist hingegen schicksalhaft zur Gewalt gezwungen. Eine Gesellschaftsordnung, die das anerkennt und Gewalt vermeiden will, führt keinen Krieg, erfindet keine Klassen oder den Krieg gegen die Frauen und die Tiere, keine Herrschaft als System und auch keine Theorien, dass der Mensch ebenso wie Satan und die Natur insgesamt im Prinzip notwendig böse und gewalttätig sei.

Für Gandhi war hingegen ,jede Art von Gewalt [...] unwahr", 136 Gewaltlosigkeit bestand für ihn in „satyagraha“, der Suche nach Wahrheit. Denn die Gewaltanwendung verschweigt einen zugrunde liegenden Widerspruch. Daher rief er zum gewaltfreien Widerstand auf. Das scheint Girard nicht kennen zu wollen, denn für ihn gibt es auch eine „gute“ Gewalt, außerdem ist Gandhi kein Christ, und drittens ist Girard auch gegen jeden Widerstand. Dies belegt seine, d.h. die christliche Ablehnung der „Anklage“, die Satan vorbehalten ist, ${ }^{137}$ um das Opferritual und die Ermordung des nach Jesus - unschuldigen Opfers zu inszenieren. Die „Anklage“ ist also angeblich allein dem patriarchalen Opferritual zuzuordnen und in ihrem Charakter, ,satanisch“.

Ein solcher Reduktionismus und Automatismus sind abzulehnen. Eine Anklage führt keineswegs unausweichlich zum Tod Unschuldiger, wie Girard behauptet, sondern kann auch zur gemeinsamen Erkenntnis von Schuld, zur Beendigung des schuldhaften Verhaltens und zum Versuch einer Wiedergutmachung dieser Schuld führen. Diese Praxis ist sehr alt, aber eben nicht patriarchal, und nur durch sie ist auch eine wirkliche Versöhnung möglich. Diese kann aber nicht auf einer Illusion, der Erwartung, dass das Opfer einfach vergibt, oder der Erzwingung einer solchen Vergebung beruhen, sondern nur auf der gemeinsamen Erkenntnis der Ursachen einer Gewalttat und der Bereitschaft, in Zukunft von ihr abzulassen.

Auf das Heute angewandt: Sollen wir warten, bis die letzten Wälder gerodet, die letzten Kulturen und Arten ausgerottet und das Erdklima für immer und ewig gekippt ist? Wo liegt denn hier die

135 Vgl. Guggenberger et al. (2006) und Palaver (2003), 381 ff.

136 Gandhi (2000), 84.

137 Vgl. Girard (2002), 227 
Gewalt? In der Vernichtung oder in der Empörung darüber? Müssen wir nicht genau dies tun: die Waldvernichter und Klimazerstörer eben jetzt anzeigen, gegen sie Anklage erheben und ihnen gemeinsam das Handwerk legen? Sie sollen ja dafür nicht zum Tode verurteilt werden. Aber unschuldig sind sie auf gar keinen Fall. Sie könnten sich ja etwa an der Wiederaufforstung beteiligen, finanziell, organisatorisch und/oder physisch. Und vor allem müssten sie mit der fortgesetzten Vernichtung von „Mutter Erde“ aufhören, anstatt weiter ihren unendlichen Produktions- und Wachstumswahn zu befriedigen.

Das negative Menschenbild des Patriarchats, des Christentums und Girards kommt daher, dass der Aufstand gegen die Herrschaft immer befürchtet werden muss und daher aller Anklage der Aufstand unterstellt wird. Indem Herrschaft eine „Fehlform“ ist, ${ }^{138}$ muss sie das Böse von sich auf die Beherrschten projizieren. Ohne Herrschaft gibt es keine Notwendigkeit für ein Bild vom Menschen als schlechtem, sündigem oder niedrigem. Herrschaft legitimiert sich, weil sie eben nicht gewollt wird, und dafür muss sie sich systematisch als besser, höher und edler darstellen als die Beherrschten und als die alte Herrschaftsfreiheit. ${ }^{139}$ Dasselbe gilt natürlich für das Geschlechterverhältnis im Patriarchat. Man(n) stelle sich vor: die Frauen klagen an! Da fürchten die Männer, dass sie mit ihnen dasselbe machen wollen, was sie mit den Frauen gemacht haben. Plötzlich „wissen“ sie um das, was sie sonst dauernd leugnen, bagatellisieren oder unsichtbar machen: Mutter- und Göttinnenmord, Kindsmord, Folter, Missbrauch, Vergewaltigung, Unterdrückung und Ausbeutung sowie generell (Todes)strafen für Frauen auch ohne Gerichtsurteile, ${ }^{140}$ im Opferritual oder ohne es. Männer projizieren ihre eigene Gewalttradition auf die Frauen - was sogar Girard bemerkt, aber nicht analysiert ${ }^{141}$ - und können sich einfach nicht vorstellen, dass es nicht darum geht, „den Spieß umzudrehen“, sondern darum, an den besseren Traditionen menschlicher Kultur wieder anzusetzen. Etwas anderes ist nach den Gewaltorgien des Patriarchats heute sowieso nicht gefragt, jedenfalls gerade nicht bei den Beherrschten.

138 Vgl. Ernst (1996).

139 Vgl. Clastres (1976), Clastres (1981) und Sigrist (1994).

140 Vgl. Werlhof (1996a).

141 Vgl. Girard (1994), 209. 
In Matriarchaten ist das Herrschen ein Tabu. Die Gleichheit als materielle wie die Egalität der Rechte und Pflichten darf auf keinen Fall durchbrochen werden. Deshalb und nicht, weil es immer ein Opfer geben muss wie bei Girard, wird der bedroht, der sich über die Gleichen erhebt. ${ }^{142}$ Er wird auf diese Weise daran erinnert, dass er seine vorübergehend andere Position als König, Kazike, Häuptling etc. nicht missbrauchen darf für egoistische Zwecke. Diese Position dient nämlich hier der Aufrechterhaltung der egalitären Ordnung, nicht ihrer Zerstörung. Auch nichtpatriarchale Menschen wissen um die Gefahren der Macht, und sie gehen so damit um, dass sie sie vermeiden können. ${ }^{143}$

Pierre Clastres, den Girard nicht zitiert, obwohl er als französischer Anthropologe so gearbeitet hat, dass Girard ihn unmöglich hat übersehen können, nennt die angeblich „primitiven“ staatslosen und egalitären Gesellschaften „Staatsfeinde““.144 Manchmal wird dort der Ungleiche nur eingesetzt, um die Gemeinschaft an die Gefahr der Macht zu erinnern und sie nicht aufkommen zu lassen. Denn dort ist man nicht naiv. Niemand soll sie ausbreiten wollen, denn Macht ist gefährlich und macht arm. So wird der vorübergehend Mächtigere und Wohlhabendere zum Häuptling gewählt, gerade um ihm dadurch alle Macht und allen Reichtum wieder zu entziehen. Für die sogenannten Primitiven ist daher nicht eine archaische Ursprungsmacht, sondern deren Ablehnung kennzeichnend. ${ }^{145}$

Der Muttermord gilt in matriarchalen Gesellschaften als abscheulichstes aller Verbrechen (vgl. Orest) und die Autorität der Mütter, aber auch von Männern, bemisst sich nach ihrer Lebenserfahrung, Kompetenz und Weisheit. Bei den Tolteken in Mexiko etwa ist das Wort für Gerechtigkeit dasselbe wie für Schönheit, die „Macht“ ist die Eigenmächtigkeit der Lebewesen und wird beschrieben als „Blume, die in den Händen der Menschen spazieren geht" ${ }^{\text {"146 }}$ (da scheint es ja sehr gewalttätig zuzugehen). Frauen sind in solchen Gesellschaften ökonomisch nicht von Männern abhängig. Ihre Kultur ist lebensorientiert, sieht das Diesseits als in das All eingebettet an und nicht von einem sogenannten Jenseits getrennt. Da geht es 
auch nicht darum, zu opfern, sondern zu schenken und zu (ver)teilen. ${ }^{147}$

Patriarchat enthält immer Reste des vorherigen Matriarchats als „zweite Kultur“. ${ }^{148}$ Die Mutter-Kind-Mimesis gehört dazu; und von ihr stammen nach wie vor Liebe, Freundschaft und Gegenseitigkeitsverhältnisse, das Gefühl der Verantwortung und das Sich-umeinander-Kümmern. Dass all dies auch heute noch vorkommt, ist gewiss kein Verdienst des Patriarchats und auch nicht des Christentums.

Jedenfalls hat Jesus die patriarchale Gesellschaftsordnung Roms sehr wohl thematisiert, ja auf das Schärfste angegriffen, ${ }^{149}$ und er hat sehr wohl das Gute in den Menschen, gerade in den sogenannten Sündern und Frauen, gesehen, angesprochen und darauf gebaut. Er hat ihnen ihre Würde wieder gegeben. Satan hat er aber nicht verabsolutiert. Auch deswegen ist Jesus u.a. in viel älteren matriarchalen Traditionen anstatt im Gnostizismus patriarchaler Weltverleugnung anzusiedeln.

\section{Schluss im Angesicht der „Apokalypse“: Wovon Girard (noch?) nicht spricht - von der Logik eines allgemeinen Exorzismus als Opferritual auf individueller Basis und Ersatz für die Abschaffung des Patriarchats}

In der Logik Girards muss das Böse, das in allen von uns wirkt, in und aus uns beseitigt werden, sonst kommen wir nie zum Frieden Jesu. Wäre nach der Logik Girards dazu nicht gerade die „Teufelsaustreibung", der Exorzismus, geeignet? Exorzismus wäre eine Hilfeleistung für Jesus, und eine solche wäre gerade heute nötig, weil ja - nach Girard - die „Selbstaustreibung“ Satans nicht mehr stattfindet, ${ }^{150}$ Satan also selbst nicht mehr als sein eigener Exorzist wirken kann. Denn da das Opferritual heute angeblich abgeschafft ist, sind wir - nach Girard - Satan nun auch noch pausenlos, ohne die vorübergehend angeblich „Frieden“ stiftende und „versöhnende“ Unterbrechung und „Entspannung“ durch das Opfer ausgeliefert. 
Das Fehlen des Opferrituals führe aber, so Girard, auf die Dauer zum Zusammenbruch der allgemeinen Ordnung - und ist diese nicht gerade auch die Satans als des sogenannten „Herrschers der Welt“"151? Dann wäre das die Lösung! Mit der allgemeinen Ordnung müsste auch Satan dran glauben: „Satan wird sein Reich zerstören und sich selbst vernichten"152. Wir geben die Ordnung auf, und Satan muss weichen. Wunderbar: kein Patriarchat und kein Satan mehr weit und breit.

Genau diese Schlussfolgerung kommt bei Girard natürlich nicht vor. Denn für ihn ist der Zusammenbruch der Ordnung verbunden mit einem Untergang in der Expansion der „raubtierhaften“153 Gewalt von jedem gegen jeden (welch ein Kompliment an die Menschheit!). Es bliebe dann das Problem, ob der individuelle Exorzismus Satan auch nur vorübergehend oder für immer austriebe. Jedenfalls stünde der Christenheit eine große Aufgabe bevor. Vor allem würde diese nie aufhören, zumindest, was die Frauen angeht, sofern es nicht gelänge, die Frauen - das ist ja das große Projekt des Patriarchats - durch Reproduktionsmaschinen zu ersetzen. Weil dies aber bisher nicht möglich war, war es nie ein Zufall, dass der Exorzismus fast immer an Frauen vollzogen wurde.

Wie wird das also in Zukunft sein? Im Anschluss an den „GroBen Exorzismus“ (1614), das Rituale Romanum, und die Hexenverfolgung gab es, als die Frauen ca. ab dem 18. Jahrhundert statt auf den Scheiterhaufen in die Psychiatrie gebracht wurden, ${ }^{154}$ eine neue Art der „Behandlung“. Wie ist also der Übergang vom alten OpferMechanismus und dem alten Exorzismus sowie dem Scheiterhaufen als bereits modernem Opfer-Mechanismus über die Psychiatrie in den neuen Exorzismus zu denken? Auf jeden Fall würde mit dem neuen Exorzismus verhindert werden, dass Unschuldige geopfert werden „müssen“, vorausgesetzt, es stirbt niemand (mehr) dabei und man glaubt mit Girard, dass es heute auch sonst kein Opfer(n) mehr gebe.

Anders formuliert: Wenn man die Apokalypse doch „verzögern“, den „Weltfrieden“ vor der „Wahrheit“ retten (wie eingangs erwähnt) und auch ohne unmittelbar drohenden Weltenbrand in die 
Zukunft gehen möchte, dann wäre vielleicht der Exorzismus zu propagieren als die einzige Möglichkeit, die sich noch auftäte.

Der Exorzist würde also an die Stelle Satans treten. Das heißt, man müsste Satan in seiner „positiven“ Gewalt neu erfinden und gewissermaßen einüben. In Wirklichkeit würde allerdings auf diese Weise das Opfern auch noch verdoppelt, und unter Katholiken wäre letztlich niemand vom Exorzismus ausgenommen. Dennoch würde auch der Exorzismus nicht endgültig helfen, da auch er uns Satan anschließend erneut ausliefern würde. Der Verdacht drängt sich auf, dass es kein Entkommen geben soll, sondern immer nur eine Rückkehr - in den „Schoss der Kirche“ wie in den - wenn auch er einen hätte - Satans. Eine Rückkehr in die Arme von Mutter Erde ist da jedenfalls nicht vorgesehen, obwohl wir damit den ganzen Spuk hinter uns lassen könnten, wie ich es, natürlich im Gegensatz zu Girard, sehe. Denn nach ihm ist ja Mutter Erde, das irdische Leben selbst, das eigentliche Problem. Girards Analyse hat jedenfalls zum Ergebnis, dass wir nicht die Gesellschaft, sondern uns selbst ändern sollen.

Allein noch das säkular daherkommende Projekt der Moderne, nämlich die Welt insgesamt technisch in ihr Gegenteil, nämlich ins „Höhere“, zu transformieren, tatsächlich „,auf den Kopf zu stellen“, wäre dann statt des Exorzismus eventuell geeignet, eine angebliche „Höherentwicklung“ einzuleiten, ja ein neues „Paradies“ und gar einen womöglich gänzlich post-satanischen „,neuen Menschen“ zu schaffen. Dieses Projekt, das ja wirklich existiert, ${ }^{155}$ müsste von Girard eigentlich sogar als positiver Weg in Richtung Jesus betrachtet werden. Denn was würde die prophezeite Apokalypse in diesem $\mathrm{Zu}$ sammenhang bedeuten? Wäre sie nicht ein Moment, in dem die Zerstörung der „sündigen Welt und Menschheit“ und ihre Transformation sowie ihre Neuschöpfung als eine Welt und eine Menschheit „nach der Sünde“ ansteht? Kann also die Apokalypse als alchemistisches Wunder einer zweiten Geburt der Erde und Menschheit bzw. Post-Menschheit - verstanden werden? Und wären eventuell der säkulare und der christliche Post-Humanismus nicht sogar sehr gut damit vereinbar? Oder bedeutet „nach dem Menschen“, dass es nicht eine neue conditio bumana gibt, die „der Mensch“ und Gott womöglich gemeinsam - jedenfalls diesmal ganz ohne Frauen - erschaffen hätten, sondern einfach gar keine mehr? Jedenfalls hätte Sa- 
tan erst dann ausgespielt, wenn die angepeilte unirdische und leiblose Welt da wäre, und/oder natürlich dann, wenn es die Welt überhaupt nicht mehr gäbe. Aber das gälte dann für alle anderen Beteiligten auch. Schließlich kann es kein Leben ohne Leben geben. Das ist der Widerspruch, um den auch Girard nicht herumkommt.

Der von Raymund Schwager zitierte Ulrich Horstmann sieht ja das Ende der Menschheit vorher. ${ }^{156}$ Es wäre das letzte große, allgemeine, in säkularisierter Form dargebrachte Opfer, das zu verhindern, wie ich es verstehe, Jesus - wenn auch nicht das Christentum! $!^{157}$ - ja eigentlich angetreten war. Aber nach Girard ist Jesus ja sowieso anders zu interpretieren, und es geht heute um den NeuAnfang einer geläuterten Menschheit, wenn nicht der ganzen, dann immerhin einer ,hellsichtigen Minderheit“.

Wie aber, wenn die Apokalypse - umgekehrt dazu - deshalb einträte, weil Christentum und Patriarchat gerade aufgrund ihrer Leib- und Lebensfeindlichkeit einen solchen Rückzug des Lebens von der Erde produziert und provoziert hätten, dass insbesondere gnostische Heilige dies wegen ihrer ja durchaus intendierten Lebensuntüchtigkeit nicht überleben würden? Bliebe als Alternative, sich vor, während oder nach der Apokalypse auf das matriarchale Erbe des Westens, z.B. „Alt-Europas“158, zurückzubesinnen? Das kommt natürlich für Girard nicht infrage, denn er erkennt die Gewalt ja nicht als Ergebnis des Patriarchats, sondern sieht in ihr eine geradezu „universelle“ und „absolute“ Macht. Für ihn wird „das Spiel der Gewalt $[\ldots]$ zum Spiel des Universums insgesamt". 159

Der Göttin sei dank, des ungeachtet sind anderswo die Menschen längst dabei, die Befreiung von Patriarchat, Kapitalismus und Gewalt eigenhändig in die Tat umzusetzen. ${ }^{160}$ Und so könnte Satan am Ende besiegt werden, wenn es ihn denn gäbe, weil die Menschen ohne Herrschaftsordnung - ganz im Sinne Jesu (?), aber nicht im Sinne Girards - nicht mehr prinzipiell schlecht gemacht werden, zu machen sind. Doch nicht Befreiung von Patriarchat und Gewalt,

156 Vgl. Horstmann (1985).

157 Das Tragische ist, dass Jesu Religion ausgerechnet zu der Roms wurde, des damaligen patriarchalen Imperiums, worunter sie schwer gelitten haben muss. Vielleicht hat Jesu Tradition in den 1700 Jahren seitdem deshalb nicht gesiegt.

158 Vgl. Gimbutas (1996)

159 Girard (1994), 144.

160 Vgl. Deloria (1978), Mies (2002), Werlhof et al. (2003), Shiva (2005), Korten (2006), Mouratidi (2006) und Holloway (2006). 
sondern Erlösung zum „opfer"losen Leiden ist Girards Devise zum „Leben“ als Verzicht, und das angeblich ohne Opfer. Wie das wohl gehen mag?

(Redaktionell bearbeitet von Andreas Exenberger)

\section{Literatur}

Amadiume, Ifi (1997): Reinventing Africa. Matriarchy, Religion and Culture. London: Zed Books.

Amin, Samir (2004): „Die neue Agrarfrage. Drei Milliarden Bäuerinnen und Bauern sind bedroht", in: Widerspruch, Hg.: Widerspruch, Heft 47: Agrobusiness - Hunger und Recth auf Nahrung. Zürich, 25-30.

Arlacchi, Pino (1999): Ware Mensch. Der Skandal des modernen Sklavenhandels. München-Zürich: Piper.

Baecker, Dirk, Hg. (2003): Kapitalismus als Religion. Berlin: Kulturverlag Kadmos.

Bales, Kevin (2001): Die neue Sklaverei. München: Antje Kunstmann Verlag.

Bammé, Arno/Feuerstein, Günter/Genth, Renate, Hg. (1983): MaschinenMenschen - Mensch-Mascbinen. Grundrisse einer sozialen Beziebung. Reinbek/ H.: Rowohlt.

Bataille, Georges (1975): Das theoretische Werk. Die Aufhebung der Ökonomie. Der Begriff der Verausgabung. Der verfemte Teil. Kommunismus und Stalinismus. Paris: Rogner und Bernhard.

Bataille, Georges (1997): Theorie der Religion. München: Matthes \& Seitz.

Bergmann, Anna (1996): „,Auf Teufel komm raus“ - Moderne Technologie und Exorzismus im Kreißsaal", in: Werlhof, Claudia von/Schweighofer, Annemarie/Ernst, Werner, Hg.: Herren-Los. Herrschaft - Erkenntnis - Lebensform. Frankfurt-Paris-New York: Peter Lang, 189-203.

Bergmann, Anna (2000): „Chimärenzeugungen: Prinzipien des Zerstückelns und Neuzusammensetzens in der Transplantationsmedizin“, in: Wolf, Maria, Hg.: Optimierung und Zerstörung. Intertheoretische Analysen zum menscblich Lebendigen. Innsbruck: Studia Universitätsverlag, 135-159.

Biegert, Claus, Hg. (1991): Der Erde eine Stimme geben. Indianische Welten. Reinbek/H.: Rowohlt.

Bourdieu, Pierre, Hg. (1997): Das Elend der Welt. Zeugnisse und Diagnosen alltäglichen Leidens an der Gesellschaft. Konstanz: Universitätsverlag Konstanz.

Chossudovsky, Michel (2002): Global Brutal. Der entfesselte Welthandel, die Armut, der Krieg. Frankfurt/M. Zweitausendeins.

Chossudovsky, Michel (2003): War and Globalization. The Truth behind September 11. Quebec: Global Outlook. 
Clastres, Pierre (1976): Staatsfeinde. Studien zur politischen Anthropologie. Frankfurt/M.: Surhkamp.

Clastres, Pierre (1981): „Freiheit - Fatalität - Namenlos“, in: Pflasterstrand. Band 8. Berlin, 85-99.

Deloria, Vine jr. (1978): Nur Stämme werden überleben. München: Lamuv.

Derungs, Kurt (2003): „Die Natur der Göttin“, in: James, Edwin O.: Der Kult der Grossen Göttin. Bern: Amalia.

Diamond, Jared (2005): Kollaps. Warum Gesellschaften überleben oder untergehen. Frankfurt/M.: Fischer.

Dieckvoss, Gerd (2003): Wie kam Krieg in die Welt? Ein archäologisch-mythologischer Streifzug. Hamburg: Konkret Literatur Verlag.

Eisler, Riane (1993): Kelch und Schwert. Von der Herrschaft zur Partnerschaft. Männliches und weibliches Prinzip in der Geschichte. München: Frauenoffensive.

Ernst, Werner (1996): „Metapsychologie und ,egologisches Subjekt““, in: Werlhof, Claudia von/Schweighofer, Annemarie/Ernst, Werner, Hg.: Herren-Los. Herrschaft - Erkenntnis - Lebensform, Frankfurt-Paris-New York: Peter Lang, 80-110.

Fester, Richard/König, Marie/Jonas, F. Doris (2000): Weib und Macht. Fünf Millionen Jahre Urgeschichte der Frau. Frankfurt/M. Fischer.

Frank, Andre Gunder (1968): Kapitalismus und Unterentwicklung in Lateinamerik.a. Frankfurt/M.: EVA.

Galtung, Johan (1982): Strukturelle Gewalt. Beiträge zur Friedens- und Konflik.tforschung. Reinbek/H.: Rowohlt.

Gandhi, Mahatma (2000): Die Kraft der Gewaltlosigkeit. Gütersloh: Kiefel.

Gebauer, Gunter/Wulf, Christoph (1992): Mimesis. Kultur - Kunst - Gesellschaft. Reinbek/H.: Rowohlt.

Genth, Renate (1996): „Matriarchat als zweite Kultur“, in: Werlhof, Claudia von/Schweighofer, Annemarie/Ernst, Werner, Hg.: Herren-Los. Herrschaft - Erkenntnis - Lebensform. Frankfurt-Paris-New York: Peter Lang, 17-38.

Genth, Renate (2002): Über Maschinisierung und Mimesis. Erfindungsgeist und mimetische Begabung im Widerstreit und ihre Bedeutung für das Mensch-MaschineVerbältnis. Frankfurt-Paris-New York: Peter Lang.

Gimbutas, Marija (1996): Die Zivilisation der Göttin. Die Welt des Alten Europa. Frankfurt/M.: Zweitausendeins.

Girard, René (1994): Das Heilige und die Gewalt. Frankfurt/M. Fischer.

Girard, René (2002): Ich sah den Satan vom Himmel fallen wie einen Blitr. Eine kritische Apologie des Christentums, München-Wien: Carl Hanser.

Göttner-Abendroth, Heide (1988): Das Matriarchat. Band 1: Geschichte seiner Erforschung. Stuttgart: Kohlhammer.

Göttner-Abendroth, Heide (1991): Das Matriarchat. Band II,1: Stammesgesellschaften in Ostasien, Ozeanien, Amerika. Stuttgart: Kohlhammer. 
Göttner-Abendroth, Heide (2000): Das Matriarchat II,2: Stammesgesellschaften in Amerika, Indien, Afrika, Stuttgart, Kohlhammer.

Göttner-Abendroth, Heide, Hg. (2006): Gesellschaft in Balance. Dokumentation des 1. Weltkongresses für Matriarchatsforschung 2003 in Luxemburg. Stuttgart: Kohlhammer.

Göttner-Abendroth, Heide/Derungs, Kurt, Hg. (1997): Matriarchate als herrschaftsfreie Gesellschaften. Bern: Amalia.

Greco, Monica (2000): „Homo Vacuus. Alexithymie und das neoliberale Gebot des Selbsteins“, in: Bröckling, Ulrich/Krasmann, Susanne/ Lemke, Thomas, Hg.: Gouvernementalität in der Gegenwart. Studien zur Ökonomisierung des Sozialen. Frankfurt/M. Suhrkamp, 265-285.

Grossman, Dave (1996): On Killing. The Psychological Cost of Learning to Kill in War and Society. Boston-New York-London: Little, Brown and Company - Back Bay Books.

Guggenberger, Wilhelm/Palaver, Wolfgang/Sandler, Willibald/SteinmairPösel, Petra (2006): Ursprünge der Gewalt: Eine kritische Auseinandersetzung mit der Theorie matriarchaler Gesellschaft aus der Sicht der mimetischen Theorie. Innsbrucker Diskussionsbeiträge zu Weltordnung, Religion und Gewalt 8, Universität Innsbruck.

Günther, Siegwart (2000): Uran-Geschosse: Schwergeschädigte Soldaten, missgebildete Neugeborene, sterbende Kinder. Freiburg/B.: Ahriman Verlag.

Holloway, John (2006): Die Welt verändern ohne die Macht zu übernehmen. Münster: Westfälisches Dampfboot.

Horstmann, Ullrich (1985): Das Untier. Frankfurt/M. Suhrkamp.

Illich, Ivan (2006): In den Flüssen nördlich der Zukunft. Letəț Gespräche über Religion und Gesellschaft mit David Cayley. München: C.H. Beck.

James, Edwin O. (2003): Der Kult der Grossen Göttin. Bern: Amalia.

Kimmerle, Gerd (1980): Hexendämmerung. Studie zur kopernikanischen Wende der Hexendeutung. Tübingen: Konkursbuchverlag.

Korten, David (2006): The Great Turning. From Empire to Earth Community. San Francisco: Berrett-Koehler \& Kumarian.

Lauderdale, Pat (1996): „Indigene nordamerikanische Alternativen zur Vorstellung von Recht und Strafe in der Moderne: Was die Natur uns lehrt", in: Werlhof, Claudia von/Schweighofer, Annemarie/Ernst, Werner, Hg.: Herren-Los. Herrschaft - Erkenntnis - Lebensform. FrankfurtParis-New York: Peter Lang, 133-156.

Liedloff, Jean (1980): Auf der Suche nach dem verlorenen Glück. Gegen die Zerstörung unserer Glücksfähigkeit in der frühen Kindheit. München: Beck.

Meier-Seethaler, Carola (1992): Von der göttlichen Löwin zum Wabrzeichen männlicher Macht. Zürich: Kreuz.

Mies, Maria (1985): „Erwünschte Frauen - unerwünschte Frauen“, in: Beiträge zur feministischen Theorie und Praxis 14. Köln, 37-48.

Mies, Maria (1992): Wider die Industrialisierung des Lebens. Pfaffenweiler: Centaurus. 
Mies, Maria (2002): Globalisierung von unten. Der Kampf gegen die Herrschaft der Konzerne. Hamburg: EVA.

Mies, Maria (2003): „Über die Notwendigkeit, Europa zu entkolonisieren“, in: Werlhof, Claudia von/Bennholdt-Thomsen, Veronika/Faraclas, Nicholas, Hg.: Subsistenz, und Widerstand. Alternativen zur Globalisierung. Wien: Promedia, 19-40.

Mies, Maria (2004): Krieg obne Grenæen. Die neue Kolonisierung der Welt. Köln: PapyRossa.

Mies, Maria/Shiva, Vandana (1993): Ökofeminismus. Zürich: Rotpunkt.

Mies, Maria/Werlhof, Claudia von (2003): Lizenz, zum Plündern. Das Multilaterale Abkommen über Investitionen - MAI - Globalisierung der Konzernherrschaft und was wir dagegen tun können. Hamburg: EVA.

Mouratidi, Katharina (2006): Venceremos! Die andere Globalisierung. Bönningheim: Wachter Verlag.

Palaver, Wolfgang (2003): René Girards mimetische Theorie. Im Kontext kulturtheoretischer und gesellschaftspolitischer Fragen. Münster: LIT.

Perkins, John (2004): Confessions of an Economic Hit Man. San Francisco: Berrett-Koehler.

Rifkin, Jeremy (1986): Genesis zwei. Biotechnik - Schöpfung nach Maß. Reinbek/ H.: Rowohlt.

Schirrmacher, Frank (2001): Die Darwin AG. Wie Nanotechnologie, Biotechnologie und Computer den neuen Menschen träumen. Köln: Kiepenheuer \& Witsch.

Shiva, Vandana (2005): Earth Democracy. Cambridge/UK: South End press.

Sigrist, Christian (1994): Regulierte Anarchie. Untersuchungen zum Feblen und zur Entstehung politischer Herrschaft in segmentären Gesellschaften Afrikas. Hamburg: EVA.

Sloterdijk, Peter (1991): „Die Wahre Irrlehre. Über die Weltreligion der Weltlosigkeit", in: Sloterdijk, Peter/Macho, Thomas, Hg.: Weltrevolution der Seele. Ein Lese- und Arbeitsbuch der Gnosis. Band 1. Gütersloh: Artemis \& Winkler, 17-56.

Sloterdijk, Peter (2002): „Erwachen im Reich der Eifersucht. Notiz zu René Girards anthropologischer Sendung“", in: Girard, René: Ich sab den Satan vom Himmel fallen wie einen Blitæ: München-Wien: Carl Hanser, 241-254.

Somé, Malidoma Patrice (2000): Die Kraft des Rituals. Afrikanische Traditionen für die westliche $W$ elt. München: Diederichs.

Straube, Ingrid (2001): Die Quellen der Philosophie sind weiblich. Aachen: einFACH-verlag.

Stüben, Peter E. (1985): „Strangers in Paradise. Phantasieren, Beschreiben, Beherrschen - Zur Entdeckungs-, Wissenschafts- und Eroberungsgeschichte der lateinamerikanischen Regenwälder", in: Stüben, Peter E., Hg.: Kahlschlag im Paradies. Die Vernichtung der Regenwälder - das Ende der Stammesvölker. Gießen: Focus, 163-188.

Sun, Wu/Clavell, James (2001): Sunzi. Die Kunst des Krieges. München: Droemer Knaur. 
Tarnas, Richard (1999): Idee und Leidenschaft. Die Wege westlichen Denkens. München: DTV.

Tazi-Preve, Irene (2004): Mutterschaft im Patriarchat. Mutter(feind)schaft in politischer Ordnung und feministischer Theorie - Kritik und Ausweg. FrankfurtParis-New York: Peter Lang.

Todorov, Tzetvan (1985): Die Eroberung Amerikas. Das Problem des Anderen. Frankfurt/M.: Suhrkamp.

Treusch-Dieter, Gerburg (2001): Die Heilige Hochzeit. Studien zur Totenbraut. Herbolzheim: Centaurus.

Vaughan, Genevieve (1997): For-Giving. A Feminist Criticism of Exchange. Austin/TX: Plain View \& Anomaly.

Wallerstein, Immanuel (1979): „Aufstieg und künftiger Niedergang des kapitalistischen Weltsystems", in: Senghaas, Dieter, Hg.: Kapitalistische Weltökonomie. Kontroversen über ihren Ursprung und ibre Entwicklungsdynamik. Frankfurt/M.: Suhrkamp, 31-67.

Weiler, Gerda (1991): Der enteignete Mythos. Eine feministische Revision der Archetypenlebre C.G. Jungs und Erich Neumanns. Frankfurt/M.: Campus.

Werlhof, Claudia von (1996a): „Das Rechtssystem und der Muttermord“, in: Werlhof, Claudia von: Mutter-Los. Frauen im Patriarchat zwischen Angleichung und Dissiden₹: München: Frauenoffensive, 27-60.

Werlhof, Claudia von (1996b): „Fragen an Ramona. Die Zapatisten, die indianische Zivilisation, die Matriarchatsfrage und der Westen“, in: Werlhof, Claudia von: Mutter-Los. Frauen im Patriarchat zwischen Angleichung und Dissiden₹: München: Frauenoffensive, 189-224.

Werlhof, Claudia von (2006): „Das Patriarchat als Negation des Matriarchats. Zur Perspektive eines Wahns“, in: Göttner-Abendroth, Heide, Hg.: Gesellschaft in Balance.. Stuttgart: Kohlhammer, 30-41.

Werlhof, Claudia von (2007a): „West End? Die weltvernichtende Globalisierung des Neoliberalismus und Antworten ,von unten“", in: Eberharter, Alexander/Exenberger, Andreas, Hg.: Globalisierung und Gerechtigkeit. Eine transdisziplinäre Annäherung. Innsbruck: Innsbruck University Press, 107-126.

Werlhof, Claudia von (2007b): „The Interconnectedness of All Being. A New Spirituality for a New Civilization“, in: Kumar, Corinne (Hg.): Asking, we walk. The south as new political imaginary. Volume 2. Bangalore: Streelekha, 249-268.

Werlhof, Claudia von/Bennholdt-Thomsen, Veronika/Faraclas, Nicholas, Hg. (2003): Subsistenz, und Widerstand. Alternativen zur Globalisierung. Wien: Promedia.

Widerspruch, Hg. (1993): Widerspruch, Heft 26: Religion und Gewalt. Zürich.

Wolf, Christa (1994): Kassandra. Neuwied: Luchterhand.

Wright, Ronald (2006): Eine kurze Geschichte des Fortschritts. Reinbek/H.: Rowohlt. 
Ziegler, Jean (2004): „Das tägliche Massaker des Hungers“, in: Widerspruch, Hg.: Widerspruch, Heft 47: Agrobusiness - Hunger und Recth auf Nabrung. Zürich, 19-24. 
Besessenheit und Exorzismus. Gedanken zu einem
psychiatrisch (und theologisch) obsoleten Thema

Hartmann Hinterhuber ${ }^{*}$

\section{Einführung}

1976 schrieb Karl Rahner: „Wie wir heute auch als orthodoxe Gläubige ohne Hexen ,auskommen', so könnte man auch ohne Besessenheit ,auskommen'. Selbst wenn man einen Einfluss solcher bösen Mächte und Gewalten als denkbar annimmt, wäre dieser uns empirisch in dem, was wir schlicht Krankheit nennen und unter diesen Voraussetzungen durchaus mit irdischen Mitteln bekämpfen können." 1

Trotz dieser klaren Aussage sind auch in der Postmoderne bei Fundamentalisten der großen christlichen Kirchen wie auch der freikirchlerischen und pfingstlerischen Gemeinschaften längst überwunden geglaubte Abwehrmechanismen des Mittelalters aktiv. In der Besessenheit artikuliert sich eine vorwissenschaftliche Vorstellung von Krankheit und Leiden, es manifestiert sich ein Gottes- und Menschenbild, das weit im Heidentum und in frühchristlichen Häresien wurzelt. Das Gottes- und Menschenbild der Exorzisten ist - um es gleich zu sagen - konträr zu jener großartigen Vision, die Papst Be-

\footnotetext{
* Hartmann Hinterhuber ist Leiter der Klinischen Abteilung für Allgemeine Psychiatrie an der Medizinischen Universität Innsbruck. In seiner Arbeit beschäftigt er sich auch mit den Wechselwirkungen der Interpretation des „Geistes“ mit der Gesellschaft. Der vorliegende Text basiert auf einem Impulsreferat, das er bei der 16. Klausurtagung der Plattform am 3. Juli 2006 gehalten hat. Eine frühere Version ist als Nr. 10 der Innsbrucker Diskussionspapiere zu Weltordnung, Religion und Gewalt erschienen.

1 Rahner (1976), 721-722.
} 
nedikt XVI. kürzlich in seinem Rundschreiben „Deus caritas est“ entworfen hat. Der Titel ist dem ersten Johannesbrief 4.8 entnommen: ,[...] denn Gott ist die Liebe“. ${ }^{2}$

Jeder Mensch, ob krank oder gesund, besitzt eine unantastbare Würde: Er ist in der jüdisch-christlichen Tradition immer Gottes Ebenbild. Christus hat sich mit den leidenden Menschen identifiziert: Von den Heilungsberichten des Neuen Testamentes wissen wir, dass er nicht nur psychisch Kranke, sondern auch Epileptiker (Mt 17.15), Stumme (Mt 9.32, Lk 11.14), Mehrfachbehinderte (Mt 12.22), Blutflüssige und Gichtkranke (Lk 13.15) geheilt hat, indem er aus diesen die personifizierten Krankheitserreger vertrieben hat. Kein Exorzist würde heute daran denken, einen der letztgenannten Leidenszustände als Besessenheit zu definieren und diesem mit seinem Ritual zu begegnen.

Menschen mit psychischen Erkrankungen wurden zu allen Zeiten und in allen Ländern diskriminiert und stigmatisiert. Auch heute leiden psychisch Kranke - wie Musil es formulierte - an einer ,minderwertigen Erkrankung“, sie werden emarginiert, diskriminiert und stigmatisiert. In der Vorstellungswelt der Exorzisten begegnet uns eine furchterregende Abwertung und Diskriminierung psychisch Kranker. Patienten leiden in dieser Sichtweise nicht nur an einer „minderwertigen Diagnose“, sondern verlieren ihre Personalität, sie verlieren sogar ihre Seele: An die Stelle der anima immortalis tritt die beherrschende Macht des personifizierten Bösen, der Teufel.

\section{Psychiatrie und Besessenheitsphänomene}

Welche Haltung nehmen heute die medizinischen Wissenschaften insbesondere die Psychiatrie - den Besessenheitsphänomenen gegenüber ein?

Die Weltgesundheitsorganisation hat in der Tat in ihrer „Internationalen Klassifikation psychischer Störungen“ in der 10. Version im Jahr 1991 unter der Codierung F44.3 die „Trance- und Besessenheitszustände“ aufgenommen. ${ }^{3}$ Diese Erkrankungen scheinen im Rahmen der „dissoziativen Störungen“ auf. Sie werden wie folgt definiert: 
„Störungen, bei denen ein zeitweiliger Verlust der persönlichen Identität und der vollständigen Wahrnehmung der Umgebung auftritt; in einigen Fällen verhält sich ein Mensch so, als ob er von einer anderen Persönlichkeit, einem Geist, einer Gottheit oder einer ,Kraft ${ }^{`}$ beherrscht wird. Aufmerksamkeit und Bewusstsein können auf nur ein oder zwei Aspekte der unmittelbaren Umgebung begrenzt und konzentriert sein, und häufig findet sich eine eingeschränkte, aber wiederholte Folge von Bewegungen, Stellungen und Äußerungen. Hier sollen nur Trancezustände einbezogen werden, die unfreiwillig oder ungewollt sind und die in die täglichen Aktivitäten einbrechen, die also außerhalb religiöser oder anderer in diesem Sinn kulturell akzeptierter Situationen auftreten (oder höchstens im Anschluss an diese).

Hier dürfen keine Trance-[und Besessenheits-]zustände klassifiziert werden, die während schizophrener oder akuter Psychosen mit Halluzinationen oder Wahn oder im Rahmen einer multiplen Persönlichkeit auftreten. Diese Kategorie ist nicht zu verwenden, wenn der Trancezustand mit einer körperlichen Krankheit (wie etwa Temporallappenepilepsie oder einer Kopfverletzung) oder mit einer Intoxikation durch psychotrope Substanzen in Zusammenhang steht.“

In den Erörterungen ist zu lesen:

„Diese Störungen wurden früher als verschiedene Formen der Konversionsneurose oder Hysterie klassifiziert. Heute jedoch erscheint es günstig, den Terminus Hysterie wegen seiner vielen unterschiedlichen Bedeutungen so weit wie möglich zu vermeiden. Die hier beschriebenen dissoziativen Störungen werden als psychogen angesehen. D.h., es besteht eine nahe zeitliche Verbindung zu traumatisierenden Ereignissen, unlösbaren oder unerträglichen Konflikten oder gestörten Beziehungen."

In der vorausgegangenen 9. Version findet sich die Diagnose "Trance- und Besessenheitszustände“ nicht: Sie wurde erst in der 10. Auflage unter dem Druck von Psychiatern aus der Dritten Welt aufgenommen.

Das DSM-IV, eine Ausgabe des diagnostischen und statistischen Manuals der APA, der Amerikanischen Psychiatrievereinigung, zählt die Annahme, besessen zu sein, zur „,nicht näher be- 
zeichneten dissoziativen Störung“ ${ }^{4}$ Die „dissoziative Trance-Störung" wird wie folgt definiert:

„Einzelne oder wiederkehrende Störungen des Bewusstseins, der Identität oder des Gedächtnisses, die in bestimmten Gebieten oder Kulturen verbreitet sind. Dissoziative Trance beinhaltet eine eingeschränkte Bewusstheit von unmittelbaren Umgebungsbedingungen oder stereotypes Verhalten oder Bewegungen, die erfahren werden als seien sie außerbalb der eigenen Kontrolle. Besessenheitstrance beinhaltet das Ersetzen der normalen Erfahrung persönlicher Identität durch eine neue Identität, die auf den Einfluss eines Geistes, einer Macht, einer Gottheit oder anderen Person zurückgeführt wird und mit stereotypen ,unwillkürlichen' Bewegungen oder Amnesie verbunden ist. Die Dissoziative oder Trance-Störung ist kein normaler Teil akzeptierter kollektiver, kultureller oder religiöser Praktiken.“

Im Anhang des DSM-IV finden sich „Kriterienlisten, die für weitere Forschung vorgesehen sind“. Hier werden die Merkmale der „dissoziativen Trance-Störung“ folgendermaßen beschrieben:

„Das Hauptmerkmal ist ein unwillkürlicher Trancezustand, der innerhalb des Kulturkreises der Person kein normaler Bestandteil allgemeiner kultureller oder religiöser Riten ist und der in klinisch bedeutsamer Weise zu Leiden oder zu Funktionsbeeinträchtigungen führt. Diese vorgeschlagene Störung sollte nicht bei Personen erwogen werden, die sich willentlich und ohne darunter zu leiden in $\mathrm{Zu}$ stände von Trance oder Besessenheit begeben, die im Rahmen kultureller oder religiöser Riten von der kulturellen Gruppe, der die Person angehört, allgemein akzeptiert sind. Solche willentlichen und nichtpathologischen Zustände kommen häufig vor und bilden die überwältigende Mehrheit der Zustände von Trance oder Besessenheits-Trance, die in verschiedenen Kulturkreisen praktiziert werden. Jedoch können Betroffene, die sich kulturell akzeptierten Tranceoder Besessenheitszuständen unterziehen, Symptome entwickeln, die $\mathrm{zu}$ Leiden oder Beeinträchtigungen führen, und so für diese vorgeschlagene Störung in Betracht kommen. An bestimmten Orten auftretende Fälle von dissoziativer Trancestörung zeigen eine beträchtliche transkulturelle Variation in Hinblick auf die spezielle Art der Verhaltensweisen, die während des veränderten Zustandes gezeigt werden. Hierzu zählen das Vorhandensein oder Fehlen von dissozia- 
tiven sensorischen Veränderungen (z.B. Blindheit), die Art der Identität, die während dieser Zustände angenommen wird, und der Grad der erlebten Amnesie nach dem veränderten Zustand.

In Trance geht der Verlust der gewohnten Identität nicht mit dem Auftreten von veränderten Identitäten einher, und die Handlungen während des Trancezustandes sind im Allgemeinen nicht komplexer Art (z.B. konvulsive Bewegungen, Fallen, Laufen). In Besessenheits-Trance treten eine (oder mehr) abgrenzbare Identitäten mit charakteristischen Verhaltensweisen, Gedächtnisinhalten und Einstellungen auf, und die vom Betroffenen ausgeführten Handlungen tendieren zu mehr Komplexität (z.B. zusammenhängende Unterhaltungen, charakteristische Gesten, Gesichtsausdrücke und bestimmte Verbalisierungen, die kulturell tradiert einem BesessenheitsAgens [treibende Kraft] zugeordnet werden). Von einer vollständigen oder partiellen Amnesie wird regelmäßiger nach einer Episode von Besessenheits-Trance als nach einer Trance-Episode berichtet (obwohl Berichte von Amnesie nach Trance nicht ungewöhnlich sind). Viele Betroffene mit dieser vorgeschlagenen Störung zeigen Merkmale von lediglich einem Trance-Typ, manche aber stellen sich mit gemischter Symptomatik vor oder fluktuieren im Zeitverlauf zwischen Trancetypen entsprechend lokaler kultureller Bedingungen."

Die Autoren des DSM-IV führen noch „[z]ugehörige Merkmale“ an:

„Varianten dieser Zustände wurden in fast jeder traditionellen Gesellschaft auf jedem Kontinent beschrieben. Die Prävalenz scheint mit zunehmender Industrialisierung abzunehmen, wird aber durch traditionelle ethnische Minderheiten in den industrialisierten Gesellschaften hochgehalten. Es gibt beträchtliche örtliche Unterschiede hinsichtlich Alter und Art des Beginns. Der Verlauf ist typischerweise episodisch mit variabler Dauer der akuten Episoden von Minuten bis zu Stunden. Es wurde berichtet, dass die Personen während eines Trancezustandes eine höhere Schmerzschwelle haben können, ungenießbare Materialien essen (z.B. Glas) und eine gesteigerte Muskelkraft erleben können. Die Symptome einer pathologischen Trance können als Reaktion auf Hinweisreize aus der Umgebung und durch Mithilfe anderer verstärkt und reduziert werden. Das vermutete Agens der Besessenheit ist üblicherweise spiritueller Natur (z.B. Totengeister, übernatürliche Wesen, Götter, Dämonen) und wird häufig als fordernd oder feindlich erlebt. Betroffene mit ei- 
ner pathologischen Besessenheits-Trance erleben typischerweise eine begrenzte Anzahl von Agentien (eine bis fünf), die sich nacheinander, nicht gleichzeitig ausdrücken. Zu den Komplikationen zählen Suizidversuche, Selbstverstümmelung und Unfälle. Von plötzlichen Todesfällen wurde berichtet, die möglicherweise auf eine Herzarrhythmie zurückzuführen sind.“

Zum Verständnis dieser Störungen ist ein knapper Exkurs in die Psychopathologie und Psychiatrie notwendig.

Schon 1917 stellte Karl Bonhoeffer fest, dass das menschliche Gehirn auf eine Vielzahl von äußeren wie inneren Störungen nur mit einer kleinen Zahl von psychischen Symptomen reagieren kann. ${ }^{5}$ Auf eine Schädel-Hirn-Verletzung, eine Vergiftung, eine lang anhaltende Narkose, auf metabolische Entgleisungen oder krankheitsbedingte, psychotische Veränderungen der Wahrnehmung und der Informationsverarbeitung kann der Mensch nur mit einer begrenzten Anzahl von Verhaltensmustern reagieren: Es sind dies die Gereiztheit, die Depression und die Euphorie, das sich bis zu Verfolgungsideen steigernde Misstrauen, Wahnbilder und Trugwahrnehmungen. ${ }^{6}$

Eine gute Einsicht in psychische Störungen, besonders in das schizophrene Anderssein, bietet eine kurze Darstellung der Ich-Psychologie und der Ich-Psychopathologie: Christian Scharfetter hat in seinem Buch Schizophrene Menschen eine sehr prägnante Übersicht geboten. ${ }^{7}$ Dieser seiner Sichtweise schließe ich mich an.

Jeder Mensch besitzt - und kennt - fünf basale Dimensionen des Ich-Bewusstseins:

- die Gewissheit der eigenen Lebendigkeit: die ICH-VITALITÄT

- die Gewissheit der Eigenbestimmung des Erlebens, Denkens, Handelns: die ICH-AKTIVITÄT

- die Gewissheit eines kohärenten Lebensverbandes: die ICHKONSISTENZ

- die Begrenzung des Eigenbereiches: die ICH-DEMARKATION

- die Gewissheit der eigenen personellen, physiognomischen, sexuellen, biographischen Identität: die ICH-IDENTITÄT

5 Bonhoeffer (1917).

6 Siehe auch Hinterhuber/Fleischhacker (1997).

7 Scharfetter (1995). 
Belastungen und Krankheiten können diese für den Menschen existenziell bedeutsamen Gewissheiten erschüttern. Eine solche Erschütterung stürzt den Betroffenen in größtes Leid sowie in unsägliche Not und Verzweiflung. Scharfetter bietet eine erschütternde Übersicht:

Störung der ...

... ICH-VITALITÄT $\rightarrow \quad$ Angst vor oder Erleben von dem eigenen Absterben, Tod, Untergang, Nicht-mehr-Sein, Weltuntergang, Untergang anderer Menschen. $\ldots$ ICH-AKTIVITÄT $\rightarrow \quad$ Fehlen der Eigenmächtigkeit im Handeln und Denken. Fremdsteuerung, -beeinflussung, Kontrolle im Handeln, Erleben, Fühlen, Denken. Lahmgelegtsein. Besessensein.

... ICH-KONSISTENZ $\rightarrow \quad$ Änderung der Beschaffenheit des Leibes. Aufhebung des Zusammenhangs des Leibes oder seiner Teile, der Gedanken-Gefühlsverbindungen, der Gedankenketten, der Willens- und Handlungsimpulse, der Seele, der Welt, des Universums.

$\ldots$ ICH-DEMARKATION $\rightarrow \quad$ Unsicherheit, Schwäche oder Aufhebung der Ich-Nicht-Ich-Abgrenzung, Fehlen eines (privaten) Eigenbereichs im Leiblichen, im Denken und im Fühlen. Störung der Innen-, Außenund Eigen- Fremd-Unterscheidung.

... ICH-IDENTITÄT $\rightarrow \quad$ Unsicherheit über die eigene Identität, Angst vor Verlust der eigenen Identität. Verlust der Identität. Physiognomische und Gestaltänderung, Geschlechtsänderung, Verwandlung in ein anderes Wesen, Änderung der Herkunftsidentität.

In Schizophrene Menschen schildert Scharfetter die Störung der IchAktivität folgendermaßen:

„Wenn die eigene Ich-Aktivität verloren gegangen oder schwer herabgesetzt ist, so wird das Eigene als von Fremden überwältigt, gesteuert, manipuliert erfahren. Der eigenen Ohnmacht entspricht die Übermacht der anderen. Die Thematisierung dieser Erfahrung ist dann der Fremdbeeinflussungswahn: Bewegungen, Denken, Fühlen, Wahrnehmen, Sprechen, Schreien etc. werden nicht mehr als eigene Leistungen erfahren, sondern als von anderen manipulierte, gesteuerte, gemachte. Da die Beeinflussung meist als etwas Bedrängendes, Unheimliches, Unfrei-Haltendes, Nötigendes und Überwältigendes 
erfahren wird, liegt die Interpretation dieser Erfahrung als Verfolgung nahe (Verfolgungswahn). Auch als Besessenheitswabn kann sich das austragen: in der Überzeugung, von fremden Mächten (meist von bösen Mäcbten, der desegoifizierten eigenen Aggressivität) besessen zu sein.

Abgespaltenes Eigenes wird als Fremdes, unter Umständen besessen Haltendes erfahren: psychotische Besessenheit. Meist sind es das als übermächtig und nur negativ erlebte Sexuelle und die Aggression - die Besessenheit vom Teufel. Das Gute und Trostvolle erscheint dann nur mehr als gelegentlicher Zuspruch Gottes oder seiner Engel oder ist entschwunden. 'B

Aus einer Vielzahl von Krankengeschichten wählt Scharfetter einige Protokollbelege der gestörten Ich-Aktivität aus. Ich erwähne einige markante Beispiele:

- „Ich muss ständig die Faust schließen und öffnen, damit ich weiß, dass ich mich noch bewegen kann.“

- „Ich kann mein Denken und Handeln nicht mehr selbst bestimmen."

- „Was andere tun, überträgt sich auf mich: Wenn ich jemanden hinken sehe, muss ich auch hinken.“

- „Ich bin mechanisiert.“

- „Ich bin gesteuert durch Hypnose, Magie.“

- „Der Teufel hält mich besessen, macht die Bewegungen.“

- „Nicht ich schreie, das sind Einwirkungen auf meinen Stimmnerv."

- „Man kann es einem schlimm machen durch Einsetzen im Gehirn.“ (Gemeint ist das Einsetzen eines Mikrosenders)

- „Meine Gedanken sind gemacht, gelenkt, eingegeben, werden gestoppt, abgezogen."

Bei den quälenden Störungen des Ich-Bewusstseins mit dem vorherrschenden Gefühl des Gemachten und Gelenkten handelt es sich in den meisten Fällen um Symptome einer schizophrenen Störung. Klaus Conrad beschrieb sehr akribisch die initiale Symptomatik einer schizophrenen Psychose: Als Trema bezeichnete er das Gefühl einer sich anbahnenden Katastrophe. Verschiedene Anmutungserlebnisse können zur Gewissheit überleiten, von Mächten des Bösen beherrscht zu werden. ${ }^{9}$ 
Von dämonischen Bildern geprägte Halluzinationen können aber auch nach Konsum von psychotropen Substanzen wie LSD oder Psilocybin auftreten und gegebenenfalls auch im Rahmen eines Flashbacks oder einer drogeninduzierten Psychose fortbestehen. ${ }^{10}$

Eine psychische Störung ist immer die Resultante aus dem Zusammenwirken verschiedenster Faktoren: Die Kultur einer Region und einer Zeit definiert das psychopathologische Verhalten und legt den inhaltlichen Kontext fest. ${ }^{11}$ Die Ausgestaltung der Wahnformen ist somit stets abhängig von Überzeugungen, Traditionen, Mythologien und religiösen Inhalten, die in der betreffenden Bevölkerung vorherrschen. Darüber hinaus wird der Wahn vom Lebensalter, der Schulbildung, von tradiertem magisch-mystischem Denken und der kulturell begründeten Notwendigkeit einer rationalistischen Erklärung des Erlebens geprägt. ${ }^{12}$

Die Ausgestaltung einer psychischen Erkrankung ist somit immer abhängig von den aktuellen Zeitthemen, von den familiär tradierten Werten und den in der jeweiligen Population bestehenden Vorstellungen, wie sich seelische Ausnahmezustände erklären lassen.

Es ist eine nicht bestrittene Feststellung der Medizin- bzw. der Psychiatriegeschichtsschreibung, dass die Psychiatrie und die psychiatrischen Erkrankungen in ganz besonderer Weise von den herrschenden Ideen einer Epoche beeinflusst werden. Die psychiatrische Wissenschaft und die psychischen Erkrankungen sind direkte Spiegelungen der philosophischen und religiösen Grundanschauungen sowie der sozialen Zustände der betreffenden Zeit. Darüber hinaus reflektieren beide die politischen Strukturen eines Landes mit eindrucksvoller Deutlichkeit. ${ }^{13}$

10 Die besonders in den USA immer noch gestellte Diagnose einer „multiplen Persönlichkeit“" beruht häufig auf einer vom Psychiater oder Psychotherapeuten induzierten Gewissheit, in sich verschiedene abgrenzbare Persönlichkeiten aufzuweisen. In der europäischen diagnostischen Tradition würde diese Störung primär als histrionische Persönlichkeitsvariante bezeichnet werden - vorausgesetzt, eine schizophrene Störung konnte ausgeschlossen werden. Die Diagnose einer „multiplen Persönlichkeit“ kann allenfalls bei schwer traumatisierten Menschen als dissoziative Identitätsstörung gestellt werden.

11 Hinterhuber (1987).

12 Hinterhuber et al. (1995).

13 Heinrich (1965). 


\section{Überlegungen zur Pathoplastik psychischer Erkrankungen}

Im Rahmen der Innsbrucker transkulturell-historischen Vergleichsuntersuchung versuchten wir, die Inhalte und die Ausprägung von Wahn- und Trugwahrnehmungen in einen Bezug zu den vorherrschenden kulturellen Werten und zum Zeitgeschehen zu stellen. ${ }^{14}$ Insgesamt wurden 100 männliche und 100 weibliche Patienten in unsere Studie aufgenommen. Wir haben - beginnend im Jahr 1904 in Zehn-Jahres-Abständen die Krankengeschichten von jeweils 20 erstmals an der Universitätsklinik für Psychiatrie Innsbruck aufgenommenen schizophren Erkrankten - jeweils zehn Frauen und zehn Männer - eingehend nach einem festgelegten Schema analysiert.

Abbildung 1: Wabnthemen: Religion, Politik/Gesellschaft, Technike ${ }^{15}$

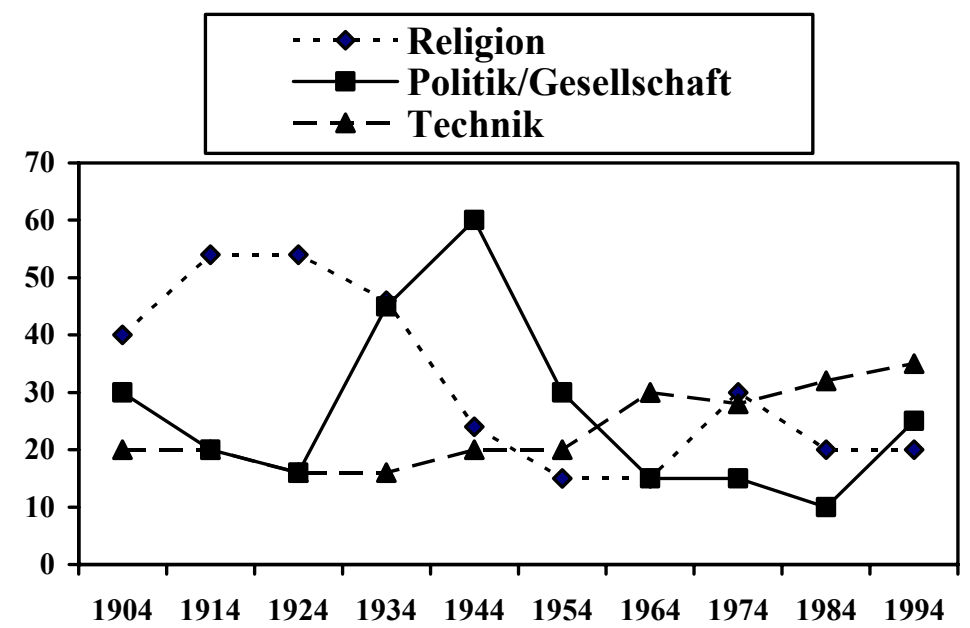

Während Verfolgungsideen über die Jahrzehnte konstant blieben, nahmen in unserem Kollektiv Wahnvorstellungen und Trugwahrnehmungen religiösen und politischen Inhaltes deutlich ab, wurden technisch-naturwissenschaftliche Deutungen häufiger.

Ein Vergleich der verschiedenen Wahninhalte über die Jahrzehnte zeigt eindrucksvoll bei jenen mit Bezug zu „Politik/Gesellschaft" einen Gipfel in den Jahren 1934 bis 1954: Die politisch tur- 
bulente Zeit fand rasch Eingang in die Wahninhalte und verdrängte die bis 1924 dominierenden religiösen Themen. Auffallend ist auch eine weitgehend gleichmäßige Aufwärtsentwicklung ,technischer Wahnvorstellungen" von 1904 bis 1994: die rasante technologische Entwicklung in den letzten 100 Jahren hat darin einen kontinuierlichen Niederschlag gefunden. Es zeigt sich somit aufgrund der Abnahme anderer Wahnthemen seit 1964 ein Überwiegen von jenen mit technischen Inhalten.

Abschließend und zusammenfassend kann festgehalten werden, dass ein psychotischer Zusammenbruch zu allen Zeiten und in allen Kulturräumen dann auftritt, wenn Anforderungen an eine genetisch belastete Person herangetragen werden, die größer sind als ihre Fähigkeit, mit diesen Problemen zurechtzukommen. Immer stehen die primären Krankheitssymptome (primäre Pathoplastik) im Vordergrund. Die soziokulturell determinierte Erscheinungsform (sekundäre Pathoplastik) variiert in den einzelnen Jahrzehnten, sie ist jedoch selbst für die Diagnose einer Schizophrenie von geringer Relevanz.

Als Ergebnis unserer transkulturell-historischen Forschung kann nicht nur für die schizophrenen Psychosen, sondern auch für alle psychischen Ausnahmezustände festgehalten werden, dass die kulturellen Traditionen den Inhalt einer psychischen Störung bestimmen können: Eine an dämonische Besessenheit glaubende Gesellschaft wird bei Ihren Mitgliedern auch Besessenheitssymptome erzeugen.

Bezüglich der Pathoplastik, der umweltbedingten Ausformung definierter Verhaltensmuster in psychischen Ausnahmesituationen, schrieb schon Voltaire im „Dritten Brief über die Quäker“ in den Briefen aus England aus dem Jahr 1731 Folgendes: „Fox hielt sich für erleuchtet. Folglich glaubte er, auf andere Art als andere Menschen reden zu müssen; er fing an zu zittern, sich zu krümmen und zu grimassieren, seinen Atem anzuhalten und ihn heftig auszustoßen; die delphische Priesterin hätte es nicht besser gekonnt. In kurzer Zeit hatte er viel Routine mit der Erleuchtung, und bald darauf stand es kaum noch in seiner Macht, anders zu sprechen. Dieses war die erste Gabe, die er seinen Schülern mitgab. Sie schnitten guten Glaubens alle Grimassen ihres Meisters und zitterten mit aller Kraft bei der Erleuchtung und daher erhielten sie den Namen Quäker, was Zitterer heißt. Die kleinen Leute vergnügten sich, sie nachzumachen. Man 
zitterte, man sprach durch die Nase, hatte Gliederzucken und war überzeugt, den Hl. Geist in sich zu haben." ${ }^{16}$

\section{Vorstellungen über die Ursachen psychischer Erkrankungen}

In allen Kulturräumen bestehen - häufig auch gleichzeitig - konkrete Vorstellungen bezüglich der Genese psychiatrischer Erkrankungen, wobei neben natürlichen Ursachen (Vererbung, körperliche Beeinträchtigungen, Ansteckung u.Ä.) auch übernatürliche Erklärungsmodelle herangezogen werden.

Der große Lehrmeister der transkulturellen Psychiatrie, Wolfgang M. Pfeiffer, gliedert die übernatürlichen Ursachen psychischer Störungen in folgende Gruppen: ${ }^{17}$

1. Der Verlust von Lebenskraft (beispielsweise der „Seelenverlust“ oder das „Mitnehmen der Seele“ bei amerikanischen Indianern).

2. Die Besessenheit: Der Betroffene vermutet durch eine geistige Macht in Besitz genommen worden zu sein. Der Glaube, von Geistern besessen zu sein, ist bei Patienten in Afrika südlich der Sahara, in den mediterranen Ländern, auf den Pazifischen Inseln fast ubiquitär, er ist aber auch in Südamerika bei $50 \%$, in Nordund Mitteleuropa bei 20 bis 30\% der Bevölkerung vorhanden.

3. Das Eindringen eines schädlichen Agens in den Körper: Das schädliche Agens ruft nicht Besessenheit, sondern Erkrankung hervor.

4. Der Bruch eines Tabus: Ein schweres Vergehen führt entweder unmittelbar zur geistigen Störung oder durch den dadurch ausgelösten Zorn der Götter.

5. Die Störung in der Beziehung zum Doppelgänger: In zahlreichen Kulturen - von Westafrika über Indonesien bis Australien - wacht bei jedem Menschen ein geistiger Doppelgänger über sein rechtes Handeln. Eine Störung in dieser Beziehung führt zu Unglück und psychischer Störung.

6. Die magischen Einwirkungen

o durch Zauber

- durch Fluch

○ durch den bösen Blick 


\section{Besessenheitsphänomene in der psychiatrischen Literatur}

Die im 14. Jahrhundert Europa heimsuchende Pest entfachte in Europa den Hexenglauben in einer ungeahnten Dimension. Auch der Besessenheitswahn entwickelte sich zu einer psychischen Epidemie, die alle Kennzeichen einer Massenpsychose aufweist. Gustave Le Bon definierte ein Massenphänomen durch folgende Kriterien: Verlust der Kritikfähigkeit, Wegfall von Hemmungen, hysterische Verhaltensmuster, Nivellierung der seelischen Vollzüge und das Gefühl der Depersonalisation. ${ }^{18}$

Es war in der Tat besonders die französische Psychiatrie, die sich sehr früh den unterschiedlichen Erscheinungsformen psychiatrischer Erkrankungen im Laufe der Geschichte widmete. So finden wir schon im bahnbrechenden Lehrbuch Maladies mentales von Esquirol (1772-1840) ein Kapitel, das er der „démonomanie“ und dem Hexenwahn widmete. ${ }^{19} 1845$ veröffentlichte Calmail eine Geschichte der Massenpsychosen, auch er berücksichtigte eingehend die Besessenheitsepidemien und Hexenverfolgungen. 1887 stellte Charcot die protokollarisch festgehaltenen Symptome sogenannter Besessener jenen gegenüber, die an einer ,grande hysterie“ litten. Sigmund Freud und viele andere Schüler Charcots veröffentlichten historische Berichte von Exorzismen und verglichen deren Symptome mit jenen der Hysterie.

Hysterien treten besonders häufig in Gesellschaftsformen auf, die wenig Organisationsstruktur aufweisen, in denen die Beziehungen der Menschen zueinander direkt, spontan und infolgedessen oft auch distanzlos und unberechenbar sind. In den industriell entwickelten Staaten sind alle menschlichen Beziehungen strukturiert und bis ins Letzte organisiert. Für die Theatralik der hysterischen Verhaltensweisen fehlt hier weitgehend der Boden: Die Neurose wendet sich von der „Gebärde“ hin zur „Beschwerde“. ${ }^{20}$

Infolgedessen begegnen uns heute stark ausgeprägte typische „hysterische“ Phänomene kaum noch bei der „einheimischen“ Bevölkerung, sondern wesentlich häufiger bei Migranten aus den Ländern der Dritten Welt. Für die „Besessenheit“ gilt Ähnliches. 
Traugott Konstantin Österreich konnte 1921 in seinem großen Werk Die Besessenheit nachweisen, dass in fast allen Kulturen zu allen Zeiten Menschen negative Ereignisse wie Krankheiten und Unglücksfälle dem Werken böser Geister zugeschrieben haben. ${ }^{21}$ Diese dienten in einer vorwissenschaftlichen Welt auch als Erklärung der unvermittelt auftretenden und oft dramatisch verlaufenden psychischen Störungen: Ein böser Geist sei in den Leib des Kranken eingefahren und beherrsche nun anstelle der menschlichen Seele den Körper. ${ }^{22}$ Pfeiffer fand in allen Kulturen Hinweise auf Besessenheitsvorstellungen, unbekannt sind sie - nach seinen Feldforschungen - nur bei Pygmäen und Buschmännern und bei verschiedenen Indianervölkern. ${ }^{23}$

Cécile Ernst befasste sich eingehend mit den überlieferten, sehr ausführlichen Protokollen von Exorzismen von 13 Personen aus dem 16. und 17. Jahrhundert. ${ }^{24}$ Indem viele Exorzisten über ihre Bemühungen ein äußerst genaues, oft wortgetreues Protokoll führten (oder durch einen Notar führen ließen), schrieben sie die ersten, ausführlichen psychiatrischen Krankengeschichten: Oft umfassen diese mehrere Hundert Druckseiten. Es entsteht so ein sehr lebendiges, aber immer sehr tragisches Bild vom Kranken, dessen akribisch aufgezeichnete Symptomatologie auch heute noch in vielen Fällen eine exakte Diagnosestellung erlaubt. Aus den Protokollen ist ferner ersichtlich, wie sich der Exorzist und der der Besessenheit beschuldigte Kranke sich wechselseitig beeinflussen, wie die Erwartungen der Zuschauer die Dynamik mitgestalten und wie politische und soziale Gegebenheiten die Aussagen und den Verlauf prägen.

Erlauben die Protokolle (bei aller Vorsicht) eine Diagnose, so scheinen am häufigsten histrionische Persönlichkeitsstrukturen vorzuliegen. Bei 10 bis 20\% der auswertbaren Fälle liegt unter der Anwendung moderner Diagnosekriterien das Vorliegen einer Schizophrenie und bei einem gleichen Prozentsatz jenes einer manischdepressiven Erkrankung nahe. 


\section{Der theoretische Hintergrund der Besessenheit: Der Teufel und die Dämonen}

Bereits bei den Sumerern, den Hethitern und den Assyrern sowie in vielen Stammes- und Naturreligionen spielte der Glaube an Dämonen eine zentrale Rolle. Religionsgeschichtlich sind die dem Teufel unterstellten Dämonen älter als der Teufel selbst.

Homer verstand unter Dämonen noch die Götter in ihrer übermenschlichen Wirksamkeit. Seit Hesiot mutierten sie zu Zwischenwesen zwischen Göttern und Menschen: Die Dämonen konnten in gutem oder bösen Sinn auf die menschlichen Geschicke einwirken.

Der Dämonenglaube war omnipräsent: Der Großteil aller Krankheiten, Schicksalsschläge und Unglücksfälle wurde auf die Dämonen zurückgeführt. Diese waren aber auch für deren Heilung bzw. Abwendung verantwortlich.

In der hebräischen Bibel, dem Alten Testament, finden sich nur wenige und untergeordnete Hinweise auf Teufel und Dämonen: Jahwe war der Schöpfer des Guten und des Bösen, für den Teufel gab es infolgedessen keinen Platz. Der Teufel wird bei Hiob $1.6 \mathrm{zu}$ den „Söhnen Gottes“ gerechnet. Er ist weder von Gott abgefallen noch von diesem verstoßen. Das hebräische Wort „satan“ stammt aus der Juristensprache und bedeutet so viel wie „Ankläger vor Gericht" und ist somit auch der „Widersacher". Im Griechischen wird aus „,satan“ „diabolos“, der „Verführer“ oder der „Verleumder“. In der Tat fühlt sich der Mensch rasch verleumdet, wenn etwas gegen ihn vorgebracht wird.

Das Alte Testament bezeichnet nur im Ersten Buch der Chronik, 21.1 den Satan als Anstifter einer Sünde. Die Parallelstelle (2 Sam 24.1) erwähnt aber Gott selbst, der David zur Sünde verleitet. ${ }^{25}$ Die dualistische Gegenüberstellung Gott/Satan findet sich in der Tat erst im jüdischen Schrifttum der letzten zwei Jahrhunderte vor Christi Geburt: der Teufel tritt nun als Gottes Gegenspieler und Herrscher über das Dämonenvolk auf. Um Gott - und den Menschen - von allem Bösen dieser Welt zu entlasten, wird Satan immer mächtiger.

Im Spätjudentum wird auf Henoch, den siebten der zehn Urväter, eine reiche apokalyptische Literatur zurückgeführt. In deutlicher Anlehnung an entsprechende Erzählungen der griechischen Mythologie lässt man Henoch von der Verbindung himmlischer Männer 
mit irdischen Frauen, die zum Engelfall führt, berichten (siehe dazu auch Gen 6). Aus der genannten Vereinigung sollen die Dämonen entstanden sein. Der Satan wird nun als der Anführer der gefallenen Engel bezeichnet. Herbert Vorgrimler bezeichnet den aus außerbiblischen jüdischen Schriften stammenden und in den Spätschriften des Neuen Testamentes (2 Petr 2.4) aufgenommenen Engelsturz als „Mythos“.26 Auch ist Vorgrimler überzeugt, dass bezüglich des Teufels ,in den Ausgestaltungen durch Seelsorge und Volksglauben sich unglaubliche Phantasien [äußern]“. ${ }^{27}$ Folgenschwer sind nach Vorgrimler die von kirchlichen Autoritäten vorgenommenen oder tolerierten Identifizierungen des Teufels mit bestimmten Volksgruppen und Emarginierten sowie mit dem Antichrist, wie bei Hilarius von Poitiers († 367) oder Johannes Chrysostomus († 407): „Hintergründe und Auswirkungen des Glaubens an den Teufel werden im Hexenwahn deutlich. Aggressivität gegen Außenseiter und Fremde, Abwälzung eigener Schuldkomplexe auf Minderheiten, vermeintliche Schaffung sicherer Lebensräume durch deren ,Ausrottung', Beherrschbarkeit der Geschichte usw. “28 Im Teufel sieht er nur „eine mit extrem negativen Eigenschaften ausgestattete Symbolgestalt, die generell der Verarbeitung von Erfahrungen des Bösen dient, wobei Probleme und Konflikte nicht rational angegangen, sondern auf eine mythische Personifikation projiziert werden." ${ }^{29}$

Für Carl Gustav Jung gehört das Böse zum Göttlichen. Die christliche Trinität stellt für ihn nur ein Symbol dar, das durch die Verdrängung des vierten Prinzips entstanden ist. „Die christliche Trinität besteht aus drei menschlichen Personen, und der Vierte, der Teufel, erscheint nur mehr als Halbtier. Die Quaternität des Alten Testamentes verhält sich somit komplementär zur Trinität des Neu-

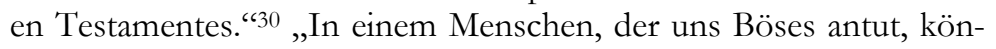
nen wir nicht zugleich den Helfer erwarten. Jahwe aber ist kein Mensch; er ist beides, Verfolger und Helfer in Einem, wobei der eine Aspekt so wirklich ist wie der andere. [...] Jahwe ist nicht gespalten, sondern eine Antinomie, eine totale innere Gegensätzlichkeit, die unerlässliche Voraussetzung seiner ungeheuren Dynamik, seiner All-

26 Vorgrimler (2000).

27 Vorgrimler (2000), 613.

28 Vorgrimler (2000), 613.

29 Vorgrimler (2000), 613.

30 Jung (1982), Band 10, 85. 
macht und Allwissenheit.“31 C.G. Jung vergleicht Gut und Böse mit den beiden Händen Gottes, mit denen dieser die Welt regiert. Rechts ist dabei das Gute, links hingegen das Böse. Damit wird nach C.G. Jung versucht, die Kluft zwischen der alttestamentlichen Auffassung von einem jähzornigen Gott und der christlichen Auffassung von einem guten Gott zu schließen. Ein böser Gott ist aber verachtenswert, ist eine Contradictio in se: Nur ein heiliger Gott ermöglicht nach Albert Görres - eine menschenwürdige Religion. ${ }^{32}$

Im Neuen Testament sind Dämonen primär Schadens- und Krankheitsgeister. Die Synoptiker berichten, dass Christus häufig Dämonen ausgetrieben hätte. Bei Markus, 9.38-39 und in der Apostelgeschichte, 19.13-16 lesen wir, dass auch jüdische Exorzisten Dämonen im Namen Christi ausgetrieben haben.

Das Neue Testament berichtet uns von etwa dreißig Krankenheilungen, bei denen ein historischer Kern vermutet werden kann. Zwischen Krankheit und Dämonenbesessenheit wurde (und wird oft auch heute) aufgrund eines fehlenden oder mangelhaften naturwissenschaftlichen Verständnisses der Medizin nicht unterschieden. Auch die Berichte der Evangelien (beispielsweise Mt 4.24 und Mk 1.34) schwanken zwischen ,besessen“ und „krank“. Eine Analyse der beschriebenen Heilungen ergibt folgende Diagnosen:

- $\quad$ Epilepsie (Mt 17.15, Mk 9.13, Lk 9.37)

- $\quad$ Stummheit (Mt 9.32, Lk 11.14)

- Blindheit und Stummheit (Mt 12.22)

- $\quad$ Gicht (Lk 13.15)

- $\quad$ Schizophrenie (Mt 8.28, Mk 5.1, Lk 8.26)

Die Berichte der Krankenheilungen zeigen vor allem eines auf: Das Wunder der Liebe Gottes. Hinter all den Krankenheilungen, von denen die Evangelisten berichten, steht die Menschenfreundlichkeit Christi. Mit Sicherheit hat er nicht allen die Gesundheit zurückgegeben, wohl aber ihre Würde und ihre Rechte. Er führte die durch Krankheit Emarginierten sowie die durch Vorurteile Diskriminierten zurück in die menschliche Gesellschaft, er begegnete allen Ausgegrenzten und allen Randgruppenangehörigen mit Wertschätzung und Achtung: Darin liegt der tiefe Gehalt der Heilungsberichte. 
Dem gegenüber steht diametral die Haltung des Exorzisten, der den tiefen Sinngehalt dieser Berichte nicht versteht und in wörtlicher Auslegung die schlimmste aller möglichen Diskriminierungen eines Kranken begeht: Er sieht im Patienten einen Menschen ohne Seele: einen vom Teufel Besessenen.

In diesem Punkt schließe ich mich - ausnahmsweise - Uta Ranke-Heinemann an, die schreibt, die Wundergeschichten hätten den Blick auf Jesus nicht geöffnet, sondern versperrt. ${ }^{33}$

Darüber hinaus müssen wir uns immer vergegenwärtigen, dass nicht Gott oder sein postulierter Gegenpart uns in Versuchung führt: Wir selbst sind es, die den Egoismen erliegen, wir selbst führen uns in Versuchung. Deshalb beten die in apostolischer Tradition lebenden indischen Thomaschristen im Vaterunser: „Und führe uns, wenn wir in Versuchung kommen. "So lesen wir auch im Jakobusbrief, 1.13: „Denn Gott [...] führt auch selbst niemand in Versuchung.“"

Rudolf Bultmann konnte schlüssig aufzeigen, dass die Berichte der Austreibungen von Dämonen durch Christus und in Christi Namen eindeutig mit der blühenden hellenistischen und spätjüdischen Tradition der Besessenenheilung zusammenhängen. Es scheint somit unerlässlich, sich kurz mit der Bedeutung des daimon auseinanderzusetzen.

Als daimon bezeichneten die Griechen etwas Göttliches, die gute innere Stimme des Menschen. Später mutierten die Dämonen zu Schadensgeistern und zu personifizierten Krankheitserregern. In der Urkirche hatte jeder Christ die Macht (und auch das Recht), Krankheitsdämonen zu vertreiben und somit zu heilen. Erst die Kirchenväter setzten dämonische und teuflische Einflussnahme gleich. In der frühchristlichen Kirche galten die heidnischen Götter als Dämonen. Auch die vorchristlichen, spätantiken Praktiken der Dämonenaustreibung wurden im Exorzismus fortgeführt. Das eigentliche Exorzistenamt entstand im 3. Jahrhundert: Vor seiner Weihe erhält auch heute noch jeder katholische Priester die niedere Weihe des Exorzistats. Dabei handelt es sich - leider - nicht um eine Befähigung, Heil und Heilung zu vermitteln und zu bewirken, sondern dezidiert um jene, teuflische Mächte auszutreiben. Auch heute begegnen uns im Rahmen einer religiös getönten Wahnwelt Archetypen des personifizierten Bösen, die entweder als Dämon, Teufel oder 
böse Geister identifiziert werden. Menschen islamischer Tradition gebrauchen dafür den Terminus „dschinne“.

In ungezügelter phantastischer Vorstellungskraft trieb und treibt der Dämonenglaube immer buntere Blüten: Don Gabriele Amorth glaubt alle unterschiedlichen Erscheinungsbilder des Teufels in dieser Welt zu kennen: Schon 1988 waren es 1.758.640.176! ${ }^{34}$ Wesentlich dramatischer erscheint aber folgende Aussage: Im Anschluss an den Todesfall der Studentin Anneliese Michel 1976 in Klingenberg äußerte sich Rudolf Graber, Bischof von Regensburg, mit den Worten: „Wenn es keinen Teufel gibt, dann gibt es keinen Gott.“ (Ich kenne einige Theologen, die ihr Lehramt wegen Äußerungen verloren haben, die im Vergleich zu dieser monströsen dualistischen Aussage geradezu harmlos sind.) Es gibt eine - wie Manfred Scheuer bekennt - unchristliche und unberechtigte Aufwertung des Teufels und des Bösen. ${ }^{35}$ Dies ist dort der Fall, wo die Macht des Bösen als gleichrangige Macht neben der Macht Gottes gesehen wird, sodass ein ständiger Kampf zwischen Gut und Böse mit einem ungewissen Ausgang herrscht. Unchristlich ist es, wenn der Teufel in den Mittelpunkt des Interesses und der Aufmerksamkeit rückt.

Nicht nur bei Don Gabriel Amort und bei Bischof Graber, sondern bei vielen Besessenheitsgläubigen dominieren die Faszination des Grauens und die Anziehungskraft des Okkulten. Zu diesem Thema schreibt Vorgrimler: „Weder die biblischen noch die kirchlich-amtlichen Texte erlauben es, wie das im volkstümlichen Glauben meist der Fall ist, die Eigenart und das Wirken der Dämonen auszumalen und in ihnen überaus mächtige Gegner Gottes zu sehen. “"36

Abschließend möchte ich nochmals Vorgrimler zitieren: „Die heutige Auffassung der Besessenheit in den Kirchen ist von weitgehender Überlagerung einer Reliktmentalität durch wissenschaftliche Erkenntnisse gekennzeichnet. Keine Manifestation vermeintlicher Besessenheit nötigt dazu, das Phänomen theologisch als Auseinandersetzung mit einem personalen Bösen anzugehen; es gehört allenfalls in den Bereich der Theodizee. In wissenschaftlicher Sicht handelt es sich um interdisziplinär anzugehende psychische Erkrankungen, vor allem Schizophrenie, Neurosen, Depressionen und zum

34 Amorth (2000), Amorth (2001) und Amorth (2002).

35 Scheuer (o.J.).

36 Vorgrimler (2000), 121. 
Teil auch Epilepsie, mit der Zuständigkeit von Psychologie und Psychoanalyse, auch Parapsychologie, Psychopathologie und Psychiatrie. Vielfach ist die vermeintliche Besessenheit auf Fehlverhalten der Verantwortlichen in der religiösen Sozialisation und in den Phasen sexueller Entwicklung zurückzuführen [...] nachweisbar ist auch die gezielte Beeinflussung Kranker in ihrer Meinung, sie seien vom Teufel besessen, durch selber kranke Personen der Umgebung und durch ,Seelsorger"“. 37

Unbeschadet der großartigen Leistungen der Aufklärung und der den Alltag durchdringenden naturwissenschaftlichen Erkenntnisse sowie der kritisch-historischen Bibelwissenschaften haben sich auch bis in die Gegenwart Vorstellungen von Besessenheit, von Hexerei und negativen Kräften erhalten.

\section{Der Exorzismus}

Im Zuge der Notwendigkeit, nach der Reformation die Riten zu kodifizieren, entstand 1614 die bis in die jüngste Vergangenheit gültige Form des „ritus exorzitandi obsessos a daemonio“ als Teil des Rituale Romanum (Tit. XI, Kap. 1-3). ${ }^{38}$ Der große „exorzismus solemnis expulsivus" darf nur von einem Priester mit bischöflicher Erlaubnis bei sogenannter Besessenheit angewendet werden. Neben der Form „possessi“" kennt das Rituale auch noch den Terminus „obsessi“. Vom großen Exorzismus werden der Taufexorzismus und der kleine Exorzismus für „circumsessi“ unterschieden. Letzterer Begriff steht für Menschen, von denen angenommen wird, dass sie von Dämonen belagert und bedroht sind.

Erwähnt wird auch ein Zustand der „latenten Besessenheit“, während dem der Betroffene körperlich oder psychisch krank erscheint. Durch einen „exorzismus probativus“ wird der Teufel gezwungen, sich in einer „Krise“ zu manifestieren: Dabei soll das Vollbild der Besessenheit auftreten.

Im Körper des Kranken haust somit der Teufel - nach der immer noch gültigen Vorstellung - in Art einer Zweitseele, die sich wie im Rituale genannt - durch übernatürliche Kräfte und übernatürliches sprachliches und anderes Wissen manifestiert.

37 Vorgrimler (2000), 91.

38 Ecclesia Catholica (1999). Eine offizielle deutsche Übersetzung des Rituale Romanum liegt nicht vor. 
Spricht der böse Geist aus dem Patienten, kann der Besessene über Himmel und Hölle Dinge offenbaren, die die Menschen ,in ihrem natürlichen Zustand“ nicht wissen können. Bereits im Markusevangelium erkennen und bekennen die Teufel Jesus als Gottes Sohn. Der Teufel, der aus dem Besessenen spricht, hat infolgedessen eine apologetische Funktion. So schreibt der Kirchenvater Tertullian (150-225), dass die Teufel durch die Besessenen bekennen, alle heidnischen Götter, inklusive des heilkräftigen Äskulaps, seien Dämonen (Tert. Apol. 23) ${ }^{39}$. Die Teufel, die durch die Besessenen sprechen, äußern sich auch sehr prononciert und kenntnisreich zu den aktuellen innerkirchlichen Diskussionen: Ein Teufel offenbarte dem Bischof Ambrosius von Mailand, der die Arianer bekämpfte, dass alle, welche die Trinität leugnen, zur Hölle fahren werden. „Besessene“ unterstützten die katholische Position gegenüber den calvinistischen Bibelinterpretationen. Italienische Teufel verfluchten nach der Einnahme Roms 1870 den laizistischen italienischen Staat.

Die apologetische Funktion des Teufels bereitet aber theologische Schwierigkeiten. Im Johannesevangelium, 8.44 bezeichnet Jesus ja den Teufel als Mörder, Lügner und Vater der Lügner. Es ergibt sich somit die alles bestimmende Frage, wann lügt der Teufel und wann spricht er die Wahrheit: Der Kirchenvater Cyprian (200-258) glaubte, dass der Teufel im Exorzismus dann wider Willen die Wahrheit sagt, wenn er durch Beschwörungen oder durch Folter dazu gezwungen wird. Auch Duns Scotus lehrte, dass Schläge nicht den Besessenen treffen, sondern den Teufel.

Diese Überzeugung zieht sich durch die Jahrhunderte, sie wurde auch in der jüngsten Vergangenheit von Menschen geteilt, die sich besonders eng mit der kirchlichen Lehrmeinung verbunden glaubten. 1966 wurde die 17-jährige Bernadette Hasler durch Stockschläge zu Tode gebracht, von sechs religiösen Fanatikern, die alle, wie sie vor den Geschworenen sagten, nicht auf das Mädchen eingedroschen haben, sondern auf den Satan.

Eine Täterin erklärte: „Das sündhafte Mädchen hat weder mit Weinen noch mit Schreien auf die Prügel reagiert, weil es die Prügel nicht gespürt hat, weil die Prügel den Teufel getroffen haben." ${ }^{\text {(40 }}$ Und Josef Stocker, ehemaliger Angehöriger des Pallotiner-Ordens 
und Anführer der „Teufelsaustreiber von Ringwil“, führte aus: „Bernadette hat den Teufel herbeigerufen, aus eigenem, freiem Willen, hat sich also mit ihm als freier Mensch in böser Absicht verbunden." ${ }^{\prime 1}$

In der Gegenwart entwickelt die Dämonologie der Exorzisten immer neue, gefährliche Formen. So wurde in Klingenberg die „Sühnebesessenheit“ kreiert, ein Phänomen, von dem sich Anneliese Michel und ihre „Dämonen“ überzeugen ließen. Ute Leimgruber interpretiert diese Vorstellungen der Exorzisten dahingehend, dass „mit der Besessenheit der konkreten Person (zugelassen durch Gott!) die Sünden anderer Menschen gesühnt werden müssten, was wiederum bedeutet, dass diese Art der Besessenheit nicht heilbar ist, schließlich handle es sich um Gottes Willen, der bis zum Tod der Besessenen hin erfüllt werden müsste. “42

Ähnlich äußerte sich 2005 der orthodoxe rumänische Mönch Daniel Corogeanu nach dem exorzismusbedingten Tod der jungen Nonne Irina Cornici. ${ }^{43}$

Können wir italienischen Medien Glauben schenken, wurde selbst an einer der herausragendsten Gestalten der katholischen Welt des 20. Jahrhunderts ein Exorzismus vollzogen: Mutter Teresa von Kalkutta musste sich wenige Monate vor ihrem Tod im Jahr 1997 einer herzchirurgischen Intervention unterziehen. Postoperativ trat wie bei älteren Patienten sehr häufig - ein nächtlicher Verwirrtheitszustand auf, den der Erzbischof von Kalkutta Henry Sebastian D'Souza als „Nachstellung des Teufels“ deutete und den italienischen Salesianerpriester Rosario Stroscio beauftragte, den Exorzismus durchzuführen. Viele heilige Personen seien Nachstellungen des Teufels ausgesetzt gewesen, so Stroscio, darunter auch körperlichen und sichtbaren, die unter Umständen gerade nachts aufgetreten seien, genau wie bei Mutter Teresa. Darum sei D’Souza der Meinung, dass es sich auch in diesem Fall um einen Angriff des Teufels handeln müsse und ein Exorzismus notwendig sei. ${ }^{44}$ Pater Rosario Stroscio konnte mit seinen Gebeten Mutter Theresa beruhigen, er aber war überzeugt, dass es ihm gelungen sei, „den Teufel zu ver-

41 Diggelmann (1969), 19.

42 Leimgruber (2004), 66.

43 So meldete die Tiroler Tageszeitung am 20. Februar 2007 unter dem Titel „Haft für Exorzisten in Rumänien“.

44 Stroscio (2001). 
treiben, woraufhin dann die Nonne endlich einschlief". Die immer wieder geforderte Beiziehung eines Facharztes scheint bei Mutter Teresa unterblieben zu sein, sonst wäre ihr die monströse Unterstellung, den Teufel in oder um sich gehabt zu haben, erspart geblieben!

Der Verlauf der Besessenheit folgt auch heute noch (!) in der Diktion des Rituale Romanum einem genauen Schema. Die Besessenheit weist ein Vorstadium, die „circumsessio“ auf: Die Dämonen belagern das Opfer und warten auf eine günstige Gelegenheit zur Einfahrt. Die Symptome der „circumsessio“ sind:

- Halluzinationen aller Sinnesorgane

- depressive Verstimmungen

- Verhaltensstörungen

- Aufmerksamkeitsstörungen mit Neigung zu Unfällen

- besonders schwere Versuchungen

Fährt nun der Teufel oder die Teufelschar in das Opfer ein, wird aus der „circumsessio“ die „possessio“ bzw. die „obsessio“. Das Hauptsymptom der „possessio“ ist ein rascher Wechsel zwischen Erregungszuständen und Stupor und eine vollständige Abwendung von der Außenwelt. Soll nun ein Exorzist den Teufel austreiben, sieht das Rituale Romanum folgende Praxis vor:

- Dem Dämon sind keine unnötigen Fragen zu stellen.

- Er ist daran zu hindern, Allotria („nugae“, „risus“, „ineptiae“) zu treiben.

- Notwendig sind die Fragen

- nach der Zahl und dem Namen der Teufel,

- nach der Zeit ihres Ausfahrens und

- nach der Ursache der Besessenheit.

- Besonders wichtig ist die Frage, ob der Teufel den betreffenden Körper wegen einer „opera magica“ (wegen der Zauberkunst einer Hexe oder eines Hexenmeisters) besessen hält.

- Der Dämon wird aufgefordert, Zaubermittel, die der Besessene verschluckt hat, zu erbrechen.

- Der Dämon wird aufgefordert, Zaubermittel, die außerhalb des Besessenen versteckt sind, zu nennen, um diese verbrennen zu können.

- Sollte auch der Besessene angeben, dass er durch ein „maleficium", ein Hexenwerk, besessen sei, soll sich der Exorzist dennoch nicht um einen Gegenzauber an eine Hexe wenden. 
Nach erfolgter Austreibung sollte sich ein tiefer Schlaf einstellen. Das Rituale Romanum schreibt noch unter Canon 1152: „Exorcismi a legitimis ministris fieri possunt non solum in fideles et catechumenos, sed etiam in acatholicos vel excommunicatos." Exorzismen sind also auch bei Nichtkatholiken und Exkommunizierten möglich. - Während meiner Arbeit an diesem Text fand ich keinen Hinweis, dass ein Exorzist je versucht hätte, das Böse beispielsweise aus Adolf Hitler oder Joseph Stalin und deren Mitläufer und Schergen auszutreiben. Diese Beobachtung scheint nicht für den Mut der Exorzisten zu sprechen, sie konzentrieren sich anscheinend lieber auf die Ärmsten der Armen, wahrhaftig auf die ,armen Teufel“ in unserer Gesellschaft.

Nach dem Rituale Romanum ist der Exorzismus - wie wir gelesen haben - vor dem Hintergrund des Hexenwahnes (und der Hexenverfolgungen) zu sehen. Hexenwahn und Besessenheitsglaube haben eine gemeinsame Grundlage: Einmal den Glauben an den Pakt eines Menschen mit dem Teufel, das andere Mal das angenommene leibhaftige Innewohnen des Teufels im Besessenen. So haben nachweislich Besessene häufig Hexenverfolgungen ausgelöst. Selten wurden dagegen Besessene beschuldigt, selbst Hexen zu sein.

Das beschämende Handbuch des Hexenrichters Malleus Maleficarum (Hexenhammer) der beiden Inquisitoren Insistoris und Sprenger beschreibt die Teufelsbesessenheit in einer kaum zu überbietenden Menschenverachtung: Züge dieses Pamphletes finden sich noch im bis in das Jahr 1999 gültigen Rituale Romanum sowie in der derzeitigen Fassung des „Exorzismus“! Johannes Paul II. ließ 1999 den entsprechenden Passus des Rituale Romanum überarbeiten und unter dem Titel De Exorzismis veröffentlichen. ${ }^{45}$

In diesem Zusammenhang gebührt drei Männern höchste Anerkennung und Würdigung. ${ }^{46}$ Großartiges leistete der Tiroler Landesbischof Georg Golser von Brixen, indem er sich 1486 gegen den Hexenwahn stellte und ein mutiges Zeugnis eines christlichen $\mathrm{Hu}-$ manismus ablegte: Er stellte bei den Inquisitoren Insistoris und Sprenger die Diagnose einer „Altersparanoia verbunden mit Schwachsinn" und wies sie außer Landes. 
Ein anderer war der calvinistische Arzt Johannes Weyer, der 1550 eine exakte Beschreibung der Hysterie bot, die sich phänomenologisch nicht von den klassischen Schilderungen Charcots, Freuds und moderner Autoren unterscheidet. Entsprechend aktuell sind auch seine therapeutischen Empfehlungen, er verbot, den „verrückten Schreikrämpfen der besessenen Nonnen“ irgendwelche Aufmerksamkeit zu schenken und verschickte die kranken Frauen voneinander getrennt - aufs Land, wo sie prompt - ohne Teufelsaustreibungen oder andere therapeutische Maßnahmen - von allen Besessenheitssymptomen geheilt waren.

Nicht die notwendige Beachtung fand zu seiner Zeit - und auch in der Gegenwart - das Buch Cautio Criminalis, das Gewissensbuch von Prozessen gegen die Hexen. Leibniz soll es 1710 „das männlichste Buch, das jemals der Feder eines Kämpfers für Wahrheit und Recht, gegen Lüge und Unrecht entflossen ist", genannt haben. Der Autor, der 1591 geborene Jesuit Friedrich Spee von Langenfeld, hat wie kaum ein anderer die Psychopathologie der Inquisition und des Hexenwahns erkannt und gegen diese gekämpft. Er hätte eine Heiligsprechung wahrlich verdient.

In den Praenotanda der neuen Exorzismusempfehlungen aus dem Jahr 1999 wird die Notwendigkeit des Rituals dadurch begründet, dass wohl der einzelne Mensch durch die Taufe vom Bösen befreit worden sei, dass jedoch bestimmte Männer und Frauen vom Teufel in besonderer Art und Weise gequält werden könnten.

Auch der neue Exorzismus kennt Anzeichen, die für Besessenheit sprechen (das Verstehen fremder Sprachen, das Wissen um geheime und verborgene Dinge, das Verfügen über außergewöhnliche Kräfte, die feindliche Reaktion auf heilige und geweihte Dinge). Theologisch gibt es aber keine Kriterien, nach denen eine Besessenheit festgestellt werden könnte.

Unter dem Titel „Der einfache Exorzismus der Taufe“ müssen wir in den Absätzen Nr. 1237 und Nr. 1243 die fatalen Sätze lesen, dass alle Kinder vor der Taufe vom Teufel besessen seien: Erst durch den Taufexorzismus würden sie Kinder Gottes! Die Taufe ist das Sakrament der Aufnahme eines Menschen in die Gemeinschaft der Christen. Die „abrenuntiatio satanae“, die Absage an den Teufel, wird im Taufritual kaum noch verstanden: Der Taufexorzismus und das Taufgelübde entsprechen nicht mehr dem überwiegenden Verständnis der Gläubigen und werden auch von der Mehrheit der Theologen nicht mehr nachvollzogen. Auch Vorgrimler vertritt die 
Sichtweise, wonach die erstrangige Wirkung der Taufe in der Eingliederung in die Kirche liegt. ${ }^{47}$

Der Exorzismus berücksichtigt meines Erachtens wesentliche Aussagen der Bibel nicht: Lukas (Lk 10.18) und Matthäus (Mt 12.28) bekennen, dass die Dämonen entmachtet sind, und im Ersten Johannesbrief, 3.8 heißt es: „Der Sohn Gottes aber ist erschienen, um die Werke des Teufels zu zerstören."

Die kirchliche Lehrtradition hält im Katechismus aus dem Jahr 1993 folgendes fest: „Wir müssen uns nicht vor jenen fürchten.“48 Auch das Resümee der interdisziplinären Tagung zum Thema „Wie können Menschen vom Bösen befreit werden“ vom Oktober 2004 konstatiert: „Dank der Entmachtung des Bösen durch Jesus Christus ist für den Menschen ein Sieg über das Böse möglich.“49

Vorgrimler unterzieht die Exorzismen Christi einer historischkritischen Analyse, wenn er schreibt: „Da im Frühjudentum zur Zeit Jesu die Überzeugung verbreitet war, der Messias werde die bösen Mächte definitiv besiegen, zeichnen die synoptischen Evangelien in christologischer Absicht Jesus als Exorzisten.“ Er setzt fort: „In der kirchlichen Tradition ist der Exorzismus seinem Wesen nach ein fürbittendes Gebet, das zu den Sakramentalien gerechnet wird. (,Teufelsaustreibung ${ }^{6}$ in der Form eines Befehls lässt einen abergläubischen Hintergrund erkennen). “50

Befürworter des Exorzismus - beispielsweise Klaus Berger ${ }^{51}$ vertreten sehr häufig auch ein dualistisches Weltbild, dem Herrschaftsbereich Gottes ist ein solcher des Teufels gegenübergestellt. Damit verlassen sie das Lehrgebäude des Christentums.

\section{Kurzer Exkurs in die Pastoralmedizin}

Albert Niedermeyer behandelt in seinem Handbuch der speziellen Pastoralmedizin ${ }^{52}$ alle nur möglichen Formen der Besessenheit und der Hexeneinwirkung. So lesen wir im Band $\mathrm{II}^{53}$, dass beispielsweise

47 Vorgrimler (2000), 610.

48 Ecclesia Catholica (1993), Nr. 2.850.

49 Niemann/Wagner (2005).

50 Vorgrimler (2000), 187.

51 Berger (2002) und Berger (2005).

52 Niedermeyer (1949-1952).

53 Niedermeyer (1950). 
auch die Impotenz ein Hexenwerk sein kann. Zur Frage, ob es eine impotentia ex maleficio gibt, zitiert Niedermeyer eine Reihe theologischer Autoren:

„Rossi: ,Impotentia oriri potest ex maleficio.

Sanchez lib. VII, disp. XCIV an. 6. signa maleficii ita statuit: maleficii signum est, quando coitum quis appetit, et virgam erigit, ita ut ad copulam aptus sit; et cum ad vas foeminium penetrandum appropinquat, relaxantur organa nec potest complere atque iterum rigent, et si iterum copulari nitatur, denuo laxantur [...] Praeterea maleficii signum est, si vir ille ad unam ligatus sit, potens autem ad alias $[\ldots]$ Tandem ex modis, quibus impotentia effici solet ex maleficiis, [...] erit optimus cognoscendi modus an ex maleficio viri consurgat impotentia, v. g. si vir appetens coitum, subito accedere tentans exhorrescat, nec accedere possit. ${ }^{6}$

Gasparr $^{54}$ : ,Demum (sc. impotentia) potest provenire ex causa naturali $[. .$.$] alia ex causa supranaturali id est ex maleficio de quo ca-$ nones et Aa. passim.

Ad rem Feije [...]: ,posse ex maleficio impotentiam oriri absque temeritate negari nequit, cum concilia innumera, ipsi quoque Romani Pontifices hoc ponant [...] At vero huiusmodi maleficia non facile adstruenda esse nemo non videt, et ex signis, quae Aa. indicare solent, plura possunt, absque ulla ope daemonis, a causis naturalibus provenire. “ $“ 55$

Niedermeyer widmete den „dämonischen Erscheinungen“ insgesamt zehn Seiten: Es bleibt kaum eine Erkrankung, die nicht möglicherweise von Dämonen ausgelöst werden kann. Sein Handbuch erschien zu einer Zeit, in der die moderne Medizin bereits seit Langem einen hohen Wissensstand erreicht hatte: Niedermeyers Pastoralmedizin atmet einen überwunden geglaubten Geist.

\section{Die christliche Deutung des Bösen in der Welt}

Die christliche Theologie findet im Geheimnis des Bösen drei Wurzeln:

- die persönliche Sünde als Freiheitstat des Menschen,

54 Pietro Gasparri, der Autor des 1932 in Rom erschienen zweibändigen Tractatus canonicus de matrimonio, war Kardinal der römischen Kirche, von 1914 bis 1930 Staatssekretär und der eigentliche Schöpfer des Codex Juris Canonici.

55 Niedermeyer (1950), 282. 
- die überindividuelle Sündenmacht, die als Erbsünde bezeichnet wird, und

- den Teufel, ein geschaffenes, personales Geistwesen, das sich aus freiem Willen von Gott abgewandt hat.

Nach Manfred Scheuer ${ }^{56}$ hält die Kirche an den genannten drei Momenten der einen Antwort auf die Frage nach dem Bösen fest, die komplementär zu verstehen sind:

- Die kirchliche Lehre spricht von der Sünde.

- Die kirchliche Lehre vom Bösen spricht nicht nur von der persönlichen Sünde des Einzelnen, sondern im Anschluss an das Neue Testament (bes. Röm 5) von der Macht der Sünde, unter der die Menschheit insgesamt steht und die jeden Menschen vorgängig zu seiner eigenen Entscheidung qualifiziert. Diese biblische Lehre von der überpersonalen Macht der Sünde wurde später als Lehre von der Erbsünde weiter entfaltet und definiert.

- Schließlich spricht die kirchliche Lehre vom Teufel, vom Satan, von den bösen Mächten und Gewalten. ${ }^{57}$

Manfred Scheuer zählt moderne Erscheinungsbilder des Bösen auf: Qualen, welche Menschen einander zufügen, Psychoterror, den viele sehr verborgen zu erleiden haben, Einsatz von Massenvernichtungsmitteln, Genozid, Massensterben durch Hunger.

Die Wurzeln der christlichen Vorstellung des Bösen liegen sehr tief und gründen großteils in der frühchristlichen häretischen Bewegung der Marcioniten.

Marcion (85-160) fühlte sich als Schüler des Apostels Paulus und verkündete in den jungen Christengemeinden seine Interpretation der heiligen Schriften, er trennte nicht nur das Alte und das Neue Testament, sondern auch den Gott Mosis und den Gott Christi. Der bekannte, der alte Gott hat die Welt geschaffen: Er ist der Demiurg. Der unbekannte, neue Gott hat seinen Sohn gesandt, er ist der ,gute Fremde“. Der Demiurg ist der Vater des Bösen, der Herr der Erde. Auch Augustinus lehrte (im Einklang mit fast allen Kirchenvätern), dass das Reich der Welt ein „magnum latrocinium“, eine große, von Dämonen regierte Räuberhöhle sei. Dem Manichäismus hing Augustinus († 430) neun Jahre lang an. 
Nach Marcion ist der Gott Christi, der fremde Gott, der gute Gott. Durch Marcions Schüler Apelles wurde der Demiurg zu Luzifer, dem gefallenen Engel: Durch seinen Fall hat er die Welt geschaffen! Die Welt ist des Teufels.

Der Manichäismus war eine systematisch entworfene gnostische Religion mit einem konsequenten Dualismus von Gut und Böse, Licht und Finsternis, Geist und Materie: Die Bewegung der Marcioniten war nicht eine Sekte, sondern eine mächtige Gegenkirche, die im 2. Jahrhundert mit der werdenden katholischen Kirche um die Vorherrschaft kämpfte. Der christliche Kanon entstand als Reaktion auf die Lehre Marcions. Nicht weniges ist auch in das Neue Testament eingeflossen. So heißt es beispielsweise im 1. Johannesbrief: „So jemand die Welt lieb hat, in dem ist nicht die Liebe des Vaters $[\ldots]$, denn alles, was in der Welt ist, $[\ldots]$ ist nicht vom Vater, sondern von der Welt." (1. Joh 2.15) Und die Welt ist des Teufels.

Auch sollen die Glaubenden nicht ,von der Welt" sein (1. Joh 18.36), diese Welt hat einen eigenen Fürsten (1. Joh. 12.31, 14.30, 16.11) oder die Welt hat einen eigenen Gott (2. Kor 4.4). Die Lehren Marcions sind nur in Bruchstücken bekannt, wir können sie jedoch aus den Schriften von Irenäus, Justinus, Clemens Alexandrinus und Tertullian rekonstruieren. Seine mächtige Gegenkirche hielt sich bis in das 6. Jahrhundert, die Lehre Marcions verschmolz dann weitgehend mit dem Manichäismus.

Marcionitische Gedanken wurden nicht nur von den Manichäern und den Priszillianern, sondern selbst von den Albigensern und den Katherern übernommen: Auch in deren Lehre wurde alles Böse durch die Wirkung des Teufels erklärt, der als selbständiges Prinzip des Negativen und als Schöpfer der Materie gesehen wurde. Gegen diese Überzeugung wandte sich die Synode von Braga (561-564) und später auch das 4. Laterankonzil aus dem Jahr 1215.

Von Marcion geprägt ist die Überzeugung, die Welt sei von Anfang an derart verdorben worden, „dass sie bis tief in den materiellen Bereich hinein von einer Unheilsgeschichte geprägt ist, die sich gegen ihre eigenen schöpfungsmäßigen Strukturen und Bestimmungen richtet". ${ }^{8}$ Durch die Vorstellung der Macht des Teufels, der Bosheit der Welt und den Anfeindungen durch die Dämonen wirkt der Häretiker Marcion aber immer noch in der Kirche weiter. So erklärt 
aufbauend auf Formulierungen des 4. Laterankonzils das römische Dokument „Christlicher Glaube und Dämonologie“ im Jahr 1975, dass die Existenz der bösen Geister und damit des Teufels der konstante Glaube der Kirche sei und daher als dogmatische Tatsache zu gelten habe. ${ }^{59}$ Bereits wenige Jahre vorher hat Papst Paul VI. sich in einer Ansprache zur Existenz der Teufel und Dämonen geäußert und festgestellt, dass, wer sich weigere, diese Realität anzuerkennen, den Boden der biblischen und kirchlichen Lehre verließe.

1993 widmete sich auch der Weltkatechismus der Frage der Personalität des Bösen. Bezüglich der Beglaubigung des personalisierten Bösen durch die Offenbarung wählt der Weltkatechismus eine sehr zurückhaltende Formulierung. Die Theologin Marion Wagner stellt sich in diesem Zusammenhang die Frage, ob es sich bei der Lehre über den Teufel grundsätzlich um eine Aussage handelt, deren Verbindlichkeit unterhalb der Verbindlichkeit einer Glaubenswahrheit anzuordnen ist. Sie hält fest, dass der Begriff der Person im Zusammenhang mit dem Teufel nirgendwo lehramtlich umschrieben oder definiert ist und dass auch nach traditioneller theologischer Lehre der Teufel keineswegs als individuelle personale Gestalt verstanden werden muss, sondern sich ins Unfassbare entzieht. ${ }^{60}$

Auch Karl Rahner glaubt in seinen Reflexionen Über Engel, dass man heute die Frage offenlassen muss, ob die Annahme von Engeln und Dämonen zum verbindlichen Glaubensgut der Kirche gehört. Unter der Voraussetzung, dass es solche Wesen tatsächlich gibt, wendet er sich gegen die Vorstellung von Engeln als reinen Geister: „Zunächst einmal sei ein Protest gestattet gegen die landläufige Meinung in der Angelologie und Dämonologie, diese geschaffenen ,Geister müssten als ,reine' Geister ohne einen ihnen notwendig zukommenden Wesensbezug zur Materie gedacht werden. ,Reine Geister mögen diese Wesen sein, insofern sie weder bloß materielle Wirklichkeiten sind noch jene Materialität haben, die dem Menschen durch seine Leiblichkeit gegeben ist. Dass darüber hinaus die Engel und Dämonen ,reine' Geister seien, mag neuplatonische Philosophie sein, ist aber weder glaubensverbindliche Lehre der Kirche noch logisch dadurch gegeben, dass diese Wesen keinen Leib haben von der Art, wie er im Menschen gegeben ist." ${ }^{\text {"61 }}$

59 Scheffczyk (1975).

60 Wagner (2005).

61 Rahner (1978), 403. 


\title{
Versuche, das Böse zu erklären
}

\author{
„Die Linie, die Gut und Böse trennt, verläuft nicht \\ zwischen Klassen und nicht zwischen Parteien, \\ sondern quer durch jedes Menschenher:. \\ Diese Linie ist beweglich, sie schwankt im Laufe der Jahre. \\ Selbst in einem vom Bösen besetzten Herzen bält sich ein \\ Brückenkopf zum Guten, selbst im gütigsten Herzen- \\ ein uneinnehmbarer Schlupfwinkel des Bösen. "62
}

Die das gesamte menschliche Leben durchdringende negative Dimension stellt nicht nur für Theologen, Philosophen, Anthropologen, Juristen und Psychologen eine Herausforderung dar, sondern gerade auch für Psychiater und Psychotherapeuten.

Unter dem Begriff „das Böse“ werden alle möglichen Formen des Verwerflichen, Schlechten, Infamen und Niederträchtigen sowie der Destruktivität, der Boshaftigkeit und des Willens zur Selbst- und Fremdvernichtung subsumiert. Dem Bösen begegnen wir tagtäglich in den aggressiven und verantwortungslosen Handlungen von Menschen mit geringer Frustrationstoleranz und fehlendem Schuldgefühl. Psychiater stellen in diesen Situationen die Diagnose einer antisozialen, gefühlsarmen Persönlichkeitsstörung mit Defiziten der Impulskontrolle und belegen das Böse mit unterschiedlichen Begriffen und erklären es durch Destruktivität und Aggression, durch Frustration und repressive Strukturen, durch Sachgesetzlichkeiten und Zwänge. Die Realität des Bösen wird aber weder heruntergespielt noch verharmlost. Für Wyss existieren drei Grundformen des radikalen Bösen: die Verblendung, der Fanatismus und die Abstumpfung. ${ }^{63}$ Fanatismus wird häufig mit dem Bösen gleichgesetzt. Etymologisch leitet sich dieses Wort von „fanatici“ ab, also von der lateinischen Bezeichnung für Menschen, die von einer fremden Gottheit besessen sind.64 Der Ausdruck ,fanatici“ findet sich über dem Umweg „fanatic“ in „Fans“ wieder, also in der Bezeichnung für all jene, die in blinder Verehrung einer Person oder einer Sache verharren und sich für sie bedingungslos einsetzen.

Ausdrucksformen der Bosheit haben den Menschen durch seine Geschichte begleitet: Homo homini lupus - für den englischen Phi-

62 Motto zum 2. Band von Alexander Solschenizyns Archipel GULAG.

63 Wyss (1997).

64 Hole (1995). 
losophen Thomas Hobbes ist jeder Mensch dem anderen ein reiBender Wolf. Das Programm der Aufklärung ist die Entzauberung der Welt. Das Übernatürliche, die Geister und die Dämonen, werden von da an als Projektionsfläche gesehen, derer sich die Menschen bedienen, die durch die Auswirkungen der Naturgewalten in Angst und Schrecken versetzt worden sind. Immanuel Kant sieht den Ursprung des Bösen in der menschlichen Natur. Das Böse ist deshalb in der Welt, da der Mensch seine Freiheit missbraucht. Goethe lässt im Faust Mephistopheles als lichtscheuen Fürsten der Unterwelt auftreten, der in sich die Prinzipien Negation, Entwertung und Zerstörung vereint. Das Negative wird bei Hegel zur Triebkraft des Fortschritts der Geschichte.

Mit Leibniz setzt eine teleologische Funktionalisierung des Bösen ein. Leibniz bezeichnet in seiner Theodizee (\$21) als „malum physicum“ („Übel“) jene Erfahrung des Zerstörerischen und des Leidens, für die niemand unmittelbar verantwortlich gemacht werden kann. Als „malum morale“ wird hingegen jenes Böse angesprochen, das aus dem Handeln bzw. der Freiheit des Menschen resultiert, beispielsweise Mord, Lüge, Ausbeutung, Diebstahl etc. Damit ist aber nicht sofort eine Schuld- und Verantwortungszuweisung verbunden.

Das „malum metaphysicum“ wird als Wesenseigenschaft einer endlichen, von vielfältigen Unzulänglichkeiten geprägten Welt verstanden. In Verbindung mit dem „malum morale“ ergeben sich Fragen nach der Ursache und der Verantwortlichkeit für ebendiese $\mathrm{Zu}$ stände. In diesem Kontext taucht dann nach Raymund Schwager und Roman Siebenrock ${ }^{65}$ auch außerhalb der spezifisch religiösen Tradition die Rede von dem Bösen bzw. dem Teufel auf. Als „das Böse“ wird jene Macht bezeichnet, die das Leben zerstört, in all seinen Formen und in höchst unterschiedlichen Vorgehens- und Erscheinungsweisen. Das Böse ist zunächst - auch nach Schwager und Siebenrock - immer im menschlichen Herzen und in den zwischenmenschlichen Beziehungen zu suchen.

Als Fortentwicklung der Idee des individuellen Bösen erscheinen in der säkularisierten Gegenwart konkrete Personen als Inkarnationen des Bösen: Die Diktatoren des 20. Jahrhunderts werden als die Verkörperung des Bösen schlechthin gesehen. Erschreckend tritt uns auch die „biedermännische Banalität des Bösen“ entgegen, die 
sich in unreflektiertem Pflichtbewusstsein und todbringendem Gehorsam der bürokratischen Schreibtischtäter manifestiert. ${ }^{66}$

Die Einengung des Begriffs „Mensch“ auf Angehörige derselben Sippe, Kaste oder Nation mit der Aberkennung der Menschenrechte und der Menschenwürde aller nicht zu diesem Verbund zählenden „Barbaren“ senkt und senkte zu allen Zeiten und bei allen Völkern die Aggressions- und Tötungsschwelle sehr.

Für einen „Massenmord ohne Schuldgefühl“ bedarf es nicht primär ,williger Henker“ - wie es Daniel Goldhagen, ein amerikanischer Soziologe, in seinem umstrittenen Buch formuliert. ${ }^{67}$ Dazu genügte und genügt immer noch die Schaffung von entsprechenden gesellschaftlichen Bedingungen. In der Nachfolge der Theorie der „Degradierungszeremonien“ postuliert Troy Duster sechs Voraussetzungen für Massenmord ohne Schuldgefühl. ${ }^{68}$ Die wichtigste Maßnahme besteht darin, dem Opfer die menschliche Würde zu nehmen. Alle totalitären Gesellschaften bedienten sich zur sozialen Ausgrenzung dieser perfiden Propagandainstrumente. „Leere Menschenhülsen“, „hirnlose Monster“" „Lebensunwerte Existenzen“ und andere ähnliche Formulierungen ermöglichten die Ermordung nicht nur von psychisch Kranken und anderen „Volksschädlingen“ in Nazideutschland, sondern auch im ehemaligen Jugoslawien, in Kambodscha, in Ruanda und an vielen anderen Orten in der Alten und in der Neuen Welt. Ähnliche Argumente sind heute auch in der von Peter Singer eingeleiteten Euthanasiediskussion zu hören. Die niederländischen Formulierungen in Bezug auf den „Gnadentod“ erinnern in erschreckender Weise an eine Diktion einer überwunden geglaubte Epoche. ${ }^{6}$

Grausame Kriege und verordneter Völkermord sind jene Aktionsfelder, die bestimmten Menschen Gelegenheit bieten, ihre Aggressionstendenzen und ihre Destruktivität umzusetzen und ihnen freien Lauf zu lassen. Diesbezüglich stellt Wolfgang Sofsky fest, dass die Anführungskraft der Meute nicht unterschätzt werden dürfe, denn in ihrer Mitte fühle sich noch der Kleinmütigste zu allem er-

66 Payk (2006). Vgl. Hannah Arendts Ausspruch von der Banalität des Bösen im Zusammenhang mit dem Eichmann-Prozess: Arendt (1995).

67 Goldhagen (1996).

68 Duster (1990).

69 Hinterhuber/Meise (2003). 
mächtigt. ${ }^{70}$ Folgerichtig stellen Michael Osterheider und Andreas Mokros die Frage, ob das Böse demnach eher ein soziales als ein individualpsychologisches Problem sei. Bestimmen die Umstände, in denen wir handeln, den Grad unserer Bosheit, weniger unser Charakter?

Laut Osterheider und Mokros erlauben bisher durchgeführte sozialpsychologische Experimente ${ }^{71}$ den Schluss, dass unter bestimmten Bedingungen viele Menschen fähig sind, Böses zu tun. Demnach erübrigt sich die Frage nach einer eindeutigen, dauerhaften und personenimmanenten Unterscheidung in gute und böse Menschen.

Zunehmende Gewalterfahrungen und kontinuierlich dargebotene reelle oder fiktive Gewaltdarstellungen verändern negativ das Sozialverhalten disponierter und labiler Menschen. Darüber hinaus können sie, wie epigenetische Studien nahegelegt haben, auch zu Impulskontrollstörungen bei nachfolgenden Generationen führen. Sie bedingen auch sehr bedenkliche moralische Umwertungen wie den Ruf nach „neuen Formen des alten Scheiterhaufens“: Friedmann Pfäfflin und Thomas Ross finden dies in den USA in einer hohen Akzeptanz der Todesstrafe und in Europa im immer stärker werdenden Plädoyer für das lebenslange Wegsperren von aggressiven

70 Sofsky (1996).

71 Gemeint sind hier sozialpsychologische Experimente nach Danley Milgram. Im Jahr 1963 ließ der Sozialpsychologe Milgram unauffällige, ganz normale Bürger von New Haven (Connecticut) an einem Lernexperiment teilnehmen: Als „Lehrer“ hatten sie die Lernleistungen ,ihrer Schüler“ zu überwachen. Sobald der „Schüler“ (ein Mitarbeiter des Projektteams) einen Fehler machte, konnte ihn der „Lehrer“ mit einem Stromstoß bestrafen. Die Intensität der Stromstöße stieg mit jedem Fehler an. Das (simulierte) Schreien, Flehen, Wimmern und Brüllen der „Schüler“ wurde den „Lehrern“ durch Lautsprecher übermittelt: Die Männer, die als Lehrer wirkten, waren überzeugt, dass sie in der Tat Stromstöße verabreichen, die bei ,ihren Schülern“ Schmerzen und auch schwere Behinderungen - gegebenenfalls mit Todesfolgen - auslösen. Fast zwei Drittel dieser Männer erfüllten ihren Auftrag bis zur maximalen - lebensbedrohlichen - Stärke von 450 Volt. Siehe Milgram (1974). 1993 wiederholte Paul Matussek das Milgram-Experiment in München und erzielte idente Ergebnisse. Siehe Matussek (1993). An der Stanford University modifizierte kurze Zeit später Philip Zimbardo das Milgram-Experiment, indem er 24 Freiwillige durch Zufall in die beiden Gruppen „Gefangene“ und „Wärter“ aufteilte. Da die „Wärter“ im Schein-Gefängnis rasch dazu übergingen, die „Gefangenen“ in einem bedrohlichen Ausmaß zu misshandeln, musste der Versuch schon nach sechs Tagen beendet werden, die Laufzeit hätte zwei Wochen betragen sollen. Die Übergriffe erfolgten besonders in der Nacht, da die „Wärter“ annahmen, die einzelnen Überwachungskameras wären zu dieser Zeit nicht in Betrieb. Siehe Zimbardo (2002), Zimpardo (2006). 
Menschen bestätigt. ${ }^{72}$ Dieser Sachverhalt könnte auch erklären, dass in einem Rückgriff auf uralte Rituale vermehrt nach dem Exorzismus gerufen wird.

In diesem Sinne werden Menschen wieder ihres Mensch-Seins beraubt. Der von den Medien als „Profiler“ stilisierte Kriminalpsychologe Thomas Müller spricht schon gar nicht mehr von Menschen, sondern gleich von der „Bestie Mensch“. ${ }^{73}$ Die Tendenz zu einer Brutalisierung schreitet fort: Im Vorwort seines Buches schreibt Robert Hare: „Psychopathen sind soziale Raubtiere.“74

Da der Mensch es selten verkraftet, sich einzugestehen, Urheber des Bösen zu sein, entwickelt er Projektionsfiguren, denen er unterschiedliche Namen gibt und kreiert somit einen Sündenbock, den die Griechen als „Pharmacon“ bezeichneten: Der Sündenbock ist das Heilmittel! $!^{75}$

Wenn ein Teufel benötigt wird, um das real existierende Böse dieser Welt zu erklären, dann finden sich vor allem Mechanismen der Entlastung, der Verdrängung und der Projektion, des Splittings und der Rationalisierung. So ist Herbert Haag zuzustimmen, der festgehalten hat, dass der Teufel für die Erklärung des Bösen in der Welt nicht nur unbrauchbar, sondern auch unnötig ist, weil man dieses ebenso gut, ja noch besser ohne Rückgriff auf den Teufel erörtern kann. ${ }^{76}$

\section{Die Psychiatrie und das Böse}

Die Psychiatrie bedient sich eines multifaktoriellen Krankheitsbegriffes, in dem nicht nur organische Störmomente, sondern ganz besonders ein weitgefasstes psychologisches Verständnis vom Gestörtsein einfließt. Psychiater halten sich davon zurück, eine moralische Wertung und Bewertung von Gut oder Böse durchzuführen. Der einzelne Psychiater wird aber besonders in der forensischen Gutachtens-

72 Pfäfflin/Ross (2006).

73 Müller (2006).

74 Hare (2005), XI.

75 Auch René Girard beschäftigt sich mit der Manifestation des Bösen. Girard spricht seit seinem Werk Das Heilige und die Gewalt mit schonungslosem Realismus immer wieder über das Problem der Gewalt. Die Gewaltneigung des Menschen gründet im mimetischen Begehren und wird aus dieser Quelle ständig reproduziert. Girard sieht in deren Eindämmung und Bändigung die hauptsächliche Aufgabe jeder Kultur bzw. der Religionen.

76 Haag (1976), Haag (1990). 
praxis immer wieder mit Menschen und Situationen konfrontiert, die er als böse bezeichnen muss.

Unter dem vermeintlichen Druck der Operationalisierbarkeit und Quantifizierbarkeit aller Bereiche entwickelte Michael Stone 1993 die Messskala „Creation of Evil“, die Abstufungen des Bösen. ${ }^{77}$ Die Randbereiche der Skala sind definiert: Tötung aus Notwehr rangiert am unteren Ende, am oberen Ende finden wir den psychopathischen Mörder, der sein Opfer vor der Ermordung möglichst lange und möglichst intensiv leiden lässt. Über Umfragen im World Wide Web versuchte auch der Psychiater Michael Welner das Böse messbar und somit auch vergleichbar zu machen. ${ }^{78}$ Zurzeit arbeitet er noch an der Erstellung seiner „Skala der Verderbtheit“.

Eine unwidersprochene Einteilung von Menschen in gute und schlechte kann - wie wir darzulegen versucht haben - nicht erfolgen. Definierte Verbaltensweisen und Handlungsabläufe können aber sehr wohl als gut oder böse beschrieben werden. ${ }^{79}$

Allem voran müssen wir festhalten, dass Handlungen und Verhaltensweisen nicht an sich für böse erklärt werden können, wenn sie von Menschen verübt werden, die im Rahmen einer psychiatrischen Erkrankung an Wahrnehmungsstörungen und Beeinträchtigungen der Realitätserfassung leiden oder ein intellektuelles Defizit schwerer Ausprägung aufweisen. 80 Schuldunfähig sind auch jene Straftäter, bei denen der Gesetzgeber eine „schwere andere seelische Abartigkeit" annimmt. Bei Menschen mit einer gravierenden Persönlichkeitsstörung oder einer sexuellen Deviation können die Wahlfreiheit und das Urteilsvermögen in einem Ausmaß eingeschränkt sein, das einem Psychosekranken entspricht.

Verhaltensforscher kennen die bei höheren Tieren entwickelte Demutsgebärde, die eine instinktive Tötungshemmung zur Folge hat. Beim Homo sapiens übernehmen Überich-Instanzen die Aggressionshemmung: Das Gewissen ersetzt den Instinkt. Der Mensch entwickelte im Laufe der Geschichte Regeln und Gesetze, die das Zusammenleben erleichtern sollten. Vorbedingung einer Aggressionskontrolle sind aber intakte Hirnfunktionen. Sind diese gestört, 
können dissoziale Impulse das Verhalten eines Menschen kennzeichnen. ${ }^{81}$

Welche verbrecherischen Verhaltensweisen empfinden wir als besonders böse? Michael Osterheider et al. versuchen, darauf eine Antwort zu geben: Eine Tat erscheine umso böser, je höher der Planungsgrad sei, je mehr instrumentelle Gewalt darin zum Einsatz komme und je schwerwiegender die Konsequenzen für die Opfer seien. Als Anzeichen einer höheren Tatplanung gälten u.a. die Beschaffung von Tatmitteln im Vorhinein, Maßnahmen zur Identitätsverschleierung und der Einsatz von Hilfsmitteln zur Aufrechterhaltung der Kontrolle über das Opfer. ${ }^{82}$ Instrumentelle Gewalt ist stets sehr kalkuliert und willentlich auf ein Ziel gerichtet, die Ausübung von Gewalt ist von vornherein geplant. Derjenige, der wiederholt Böses tut, zeigt in der Regel nach Osterheider eine „Ausschließlichkeit der eigenen Perspektive und eine „Unbedingtheit des eigenen Wollens." Wer Böses tue, sei gegenüber dem Empfinden seines Opfers blind. Diese Blindheit könne durch konstellative Faktoren herbeigeführt oder zumindest begünstigt werden wie im Experiment von Milgram; sie könne aber auch Folge eines Defektes in der Entwicklung der Persönlichkeit sein wie im Falle der Psychopathie. Die Entwicklung von mitleidlosen, gefühlskalten Persönlichkeitstypen beruht in der Regel auf genetischen, angeborenen oder früh erworbenen Ursachenkonstellationen. ${ }^{83}$

Die (Kriminal)psychologie und die Psychiatrie mit der Subdisziplin der forensischen Psychiatrie versuchen eine Erklärung zu finden, warum bestimmte Individuen leichter dazu tendieren, böse Handlungen zu setzen. Hare hat diesbezüglich das Konstrukt der „Psychopathy“ vorgestellt.8 ${ }^{84}$ Unter Psychopathy versteht er eine schwere Persönlichkeitsstörung mit erhöhter Gewaltbereitschaft und Rücksichtslosigkeit. Hare rechnet zu diesem Syndrom u.a. Verant-

81 Neurowissenschaftliche Untersuchungen zu destruktivem Verhalten belegen, dass Störungen der Impulskontrolle, gemeinschaftsgefährdendes Sozialverhalten und viele Formen der Gewalt auf neurobiologische Ursachen zurückgeführt werden können. Siehe Anderson et al. (1999, 2000), Blair (2006), Damasio et al. (1994), Müller (2006a, 2006b), Müller et al. (2001), Müller et al. (2003), New et al. (2002), Osterheider/Mokros (2006), Pietrini et al. (2000), Raine et al. (2000), Raine et al. (2003), Raine et al. (2004), Soderstrom et al. (2002) sowie Yang et al. (2005).

82 Osterheider/Mokros (2006).

83 Hinterhuber/Fleischhacker (1997).

84 Hare (1991), Hare/Neumann (2005). 
wortungslosigkeit, ein Fehlen von realistischen, langfristigen Zielen, ein Bedürfnis nach permanenter Stimulation, einen oberflächlichen Charme, verbunden mit Grandiosität und einem Mangel an Empathie. Psychopathische Persönlichkeiten im Sinne von Hare zeigen somit eine Mischung von Dissozialität, affektiver Unbeteiligtheit, emotionaler Kühle, manipulativen Fähigkeiten und von extremem Egozentrismus. Die Delikte der Psychopathen im Sinne von Hare sind in der Tat von jenen zu unterscheiden, die von nicht psychopathischen Tätern verübt worden sind. Von Psychopathen nach Hare durchgeführte Delikte sind besonders kalkuliert und grausam, die Gewalt wird ganz gezielt eingesetzt. Diese Delinquenten werden häufiger und schneller rückfällig.

Robert I. Simon hat sich eingehend mit dem Dilemma der Abspaltung des sogenannten „Bösen“ beschäftigt. ${ }^{85}$ Nach seiner Hypothese wird das Unerklärbare, das wir rational nicht erfassen können, dämonisiert. Grund dafür scheint die Tatsache zu sein, dass eine Auseinandersetzung darüber gemieden wird, da immer auch etwas „Böses“ in den eigenen Vorstellungen und Gedanken präsent ist. Simon schließt mit dem Gedanken, dass sich der Mensch mit dem „subjektiven Bösen“ nur widerwillig und ungern auseinandersetzt.

\section{Schlussbemerkungen}

„Prïfet alles, und das Gute behaltet!“ (1 Thess 5.21)

Im sechsbändigen, ab 1949 im Herder-Verlag Wien erschienenen Handbuch der speziellen Pastoralmedizin lesen wir: „Pseudomystik spekuliert auf Leichtgläubigkeit und Wundersucht, den ,Mirakulismus' der Menge. Die Wundersucht ist aber oft die größte Gegnerin wahren Glaubens. Wahrer Glaube sucht nicht und verlangt nicht fortwährend, Wunder"“. .86

Die Kirche benötigt heute nicht eine immer größere Schar von Heiligen mit deren Wundertaten, sondern eine „Theologie der Befreiung", eine Befreiung von vorwissenschaftlichen Vorstellungen, eine Befreiung von abergläubischer Volksfrömmigkeit, eine Befreiung von unchristlicher Dämonenvorstellung. 
Dramatisch - und auch heute oft noch tödlich - ist die Überzeugung, den Teufel in sich zu haben. Die archaischen - und unchristlichen - Lehren einer ausufernden Dämonologie können einem Kranken beim Vorliegen einer psychotischen oder schweren neurotischen Ich-Störung die subjektive Gewissheit der Besessenheit vermitteln: Diesen Kranken ist jede psychiatrische, psychotherapeutische und seelsorgerische Hilfe und Begleitung zu gewähren. Ein Exorzismus verbietet sich, einerseits infolge der dargestellten grundsätzlichen Bedenken, andererseits aufgrund der Festigung krankhafter Überzeugungen: In der Krankensalbung steht diesen Menschen wie allen Kranken - die Heilsvermittlung der Kirche offen.

Die Fortschritte der Neurowissenschaften, der gewaltige Erkenntniszuwachs der Psychiatrie und der psychotherapeutischen Medizin sowie die historisch-kritischen Bibelwissenschaften fordern in Verbindung mit dem heutigen Menschen- und Gottesbild ein endgültiges Abrücken von der dämonischen Tradition des Christentums. ${ }^{87}$ Schon vor mehr als 50 Jahren stellte Rudolf Bultmann fest, der Geister- und Dämonenglaube sei durch die Kenntnis der Kräfte und Gesetze der Natur erledigt. ${ }^{88}$

Die Glaubensinhalte müssen kompatibel sein mit dem Stand der naturwissenschaftlichen Erkenntnisse und auch mit den Ergebnissen einer kritisch-historischen Bibelwissenschaft.

Dietrich Bonhoeffer, vor hundert Jahren geboren und am 9. April 1945 hingerichtet, warnte eindringlich vor einer Infantilisierung des Glaubens. Durch die Infantilisierung der Glaubensinhalte und der Glaubensvermittlung verliert die Kirche gerade in der modernen Wissens- und Kommunikationsgesellschaft Boden, Glaubwürdigkeit und Zukunft.

Die Zukunft gehört mit Sicherheit jener Gottesvorstellung, die Benedikt XVI. charismatisch mit dem Kürzel „Deus caritas est“ umrissen hat.

\section{Literatur}

Amorth, Gabriele (2000): Neue Berichte eines Exorzisten. Stein/R.: ChristianaVerlag.

Amorth, Gabriele (2001): Ein Exorzist erzählt. Stein/R.: Chrisiana-Verlag.

87 Hinterhuber et al. (2003).

88 Bartsch (1950). 
Amorth, Gabriele (2002): Exorzisten und Psycbiater. Stein/R.: ChristianaVerlag.

Anderson, Steven W./Bechara, Antoine/Damasio, Hanna/Tranel, Daniel/ Damasio, Antonio R. (1999): „Impairment of social and moral behavior related to early damage in human prefrontal cortex", in: Nature Neuroscience 2 (11), 1032-1037.

Anderson, Steven W./Bechara, Antoine/Damasio, Hanna/Tranel, Daniel/ Damasio, Antonio R. (2000): „Acquisition of social knowledge is related to the prefrontal cortex", in: Journal of Neurology 247 (1), 72.

Arendt, Hannah (1995): Eichmann in Jerusalem. Ein Bericht von der Banalität des Bösen. München-Zürich.

Bartsch, Hans-Werner (1950): Kerygma und Mythos. Hamburg: Reich \& Heidrich.

Benedikt XVI. (2006): „Deus caritas est “Typis Vaticanis.

Berger, Klaus (2002): Wozu ist der Teufel da? Gütersloh.

Berger, Klaus (2005): „Fromm sozialisiert - fromm therapierbar. Teufel und Dämonen im Neuen Testament", in: Niemann, Ulrich/Wagner, Marion, Hg.: Exorzismus oder Therapie? Ansätze zur Befreiung vom Bösen. Regensburg: Verlag Friedrich Pustet, 7-31.

Blair, R. J. R. (2006): „The emergence of psychopathy: implications for the neuropsychological approach to developmental disorders", in: Cognition 101 (2), 414-442.

Bonhoeffer, Karl (1917): „Die exogenen Reaktionstypen“, in: Archiv für Psychiatrie und Nervenkrankbeiten 58, 50-70.

Bultmann, Rudolf (1961): Die Geschichte der synoptischen Tradition. Göttingen: Vandenhoeck \& Ruprecht.

Conrad, Klaus (2003): Die beginnende Schizophrenie. Versuch einer Gestaltanalyse des Wabnsinns. Bonn: Edition Das Narrenschiff.

Damasio, Hanna/Grabowski, Thomas/Frank, Randall/Galaburda, Albert M./Damasio, Antonio R. (1994): „The return of Phineas Gage: clues about the brain from the skull of a famous patient", in: Science 264 (5162), 1102-1105.

Diggelmann, Walter Matthias (1969): Hexenprozeß. Die Teufelsaustreiber von Ringwil. Bern: Benteli Verlag.

Dilling, Horst, Hg. (1991): Weltgesundheitsorganisation: Internationale Klassifikation psychischer Störungen. ICD-10 Kapitel V (F), klinisch-diagnostische Leitlinien. Bern-Göttingen-Toronto: Verlag Hans Huber.

Duster, Troy (1990): Backdoor to Eugenics. New York: Routledge.

Ecclesia Catholica, Hg. (1993): Katechismus der Katholischen Kirche. MünchenWien: Oldenbourg.

Ecclesia Catholica (1999): Rituale Romanum ex decreto Sacrosancti Oecumenici Concilii Vaticani II instauratum auctoritate Ioannis Pauli PP II promulgatum. De exorcismis et supplicationibus quibusdam. Editio typica. Rom: Typis Vaticanis. 
Ernst, Cécile (1972): Teufelaustreibungen. Die Praxis der katholischen Kirche im 16. und 17. Jahrbundert. Bern: Verlag Hans Huber.

Ernst, Klaus/Kind, Hans/Rotach-Fuchs, Margit (1968). Ergebnisse der Verlaufsforschung bei Neurosen. Berlin-Heidelberg-New York: Springer.

Esquirol, Jean Etienne Dominique (1838): Des maladies mentales. Paris: Tircher.

Esser, Gerhard, Hg. (1916): Tertullians Apologetische, dogmatische und montanistische Schriften. Kempten-München: Kösel.

Gasparri, Pietro (1932): Tractatus canonicus de matrimonio. Rom: Typis Polyglottis Vaticanis.

Görres, Albert/Rahner, Karl (1982): Das Böse. Wege zu seiner Bewältigung in Psychotherapie und Christentum. Freiburg/B.: Herder, 237.

Goldhagen, Daniel J. (1996): Hitlers willige Vollstrecker. Berlin: Wolf Jobst Siedler Verlag.

Haag, Herbert (1976): „Ein fragwürdiges römisches Studiendokument. Zum Thema Teufel“", in: Theologische Quartalschrift 156, 28-34.

Haag, Herbert (1990): Abschied vom Teufel. Vom christlichen Umgang mit dem Bösen. Zürich: Benziger.

Hare, Robert D. (1991): Manual for the Hare Psychopathy Checklist - Revised, Toronto: Multi-Health Systems.

Hare, Robert D. (2005): Gewissenlos. Die Psychopathen unserer Zeit. Wien-New York: Springer.

Heinrich, Kurt (1965): „Die Bedeutung der Stammesgeschichte des menschlichen Erlebens und Verhaltens für Neurologie und Psychopathologie", in: Homo 16, 65.

Hinterhuber, Hartmann (1987): „Transkulturelle Psychiatrie“, in: Zeitschrift für Allgemeinmedizin 63 (35-36), 1047-1053.

Hinterhuber, Hartmann (2001): Die Seele. Natur- und Kulturgeschichte von Psyche, Geist und Bewusstsein. Wien-New York: Springer Verlag.

Hinterhuber, Hartmann/Fleischhacker, Walter W. (1997): Lehrbuch der Psychiatrie. Stuttgart: Thieme.

Hinterhuber, Harmann/Heuser, Manfred/Meise, Ullrich (2003): Bilder des Menschen. Innsbruck: Verlag Integrative Psychiatrie.

Hinterhuber, Hartmann/Madlung-Kratzer, Ekkehard/Waibl, Elmar (1995): „Menschen, Mächte und Maschinen: Die Pathoplastik schizophrener Psychosen im Licht der soziokulturellen Entwicklung der letzten 100 Jahre“, in: Zapotoczky, Hans Georg/Hinterhuber, Hartmann/Heuser, Manfred/Pöldinger, Walter, Hg.: Mensch, Macht, Maschine. InnsbruckWien: Verlag Integrative Psychiatrie, 40-74.

Hinterhuber, Hartmann/Meise, Ullrich (2003): „Die Psychiatrie darf nicht schweigen: Gedanken zu den Euthanasiegesetzen in Belgien und den Niederlanden“, in: Neuropsychiatrie 17 (1), 29-34. 
Hinterhuber, Hartmann/Scheuer, Manfred/van Heyster, Paul (2006): Der Mensch in seiner Klage. Anmerkungen aus Theologie und Psychiatrie. Innsbruck: Tyrolia.

Hobbes, Thomas (2004): Leviathan. Hamburg: Felix Meiner.

Hole, Günter (1995): Fanatismus: der Drang zum Extrem und seine psychologischen Wurzeln. Freiburg/B.-Wien: Herder.

Jung, Carl Gustav (1982): Gesammelte Werke. Olten: Walter-Verlag.

Kasper, Walter (1979): „Die Lehre der Kirche vom Bösen“, in: Schnakkenburg, Rudolf, Hg.: Die Macht des Bösen und der Glaube der Kirche. Düsseldorf: Patmos, 68-84.

Le Bon, Gustave (151982): Die Psychologie der Massen. Stuttgart: Kröner.

Leimgruber, Ute (2004): Kein Abschied vom Teufel. Eine Untersuchung zur gegenwärtigen Rede vom Teufel im Volk Gottes. Münster: LIT.

Matussek, Paul (1993): „Analytische Psychosentherapie in neuer Sicht“, in: Nervenarzt 64 (11), 696-705.

Milgram, Stanley (1974): Das Milgram-Experiment. Zur Gehorsamsbereitschaft gegenüber Autorität. Reinbek/H.: Rowohlt.

Müller, Jürgen L. (2006a): „Neurobiologie des Bösen“, in: Neurotransmitter Sonderheft 2, 24-30.

Müller, Jürgen L. (2006b): „Bedeutung neurobiologischer Faktoren bei der Aggressionsgenese I. Genetische und neurochemische Aspekte“, in: Nervenbeilkunde 25 (11), 953-961.

Müller, Jürgen L./Schuierer, Gerhard/Marienhagen, Jörg/Putzhammer, Albert/Klein, Helmfried E. (2001): „Psychopathie und Hirntrauma. Ein Beitrag zur Neurobiologie der Gewalt“, in: Nervenheilkunde 40, 330-338.

Müller, Jürgen L./Sommer, Monika/Wagner, Verena/Lange, Kirsten/ Taschler, Heidrun/Roder, Christian H./Schuierer, Gerhard/Klein, Helmfried E./Hajak, Göran (2003): „Abnormalities in emotion processing within cortical and subcortical regions in criminal psychopaths: evidence from a functional magnetic resonance imaging study using pictures with emotional content", in: Biological Psychiatry 54, 152-162.

Müller, Thomas (42006): Bestie Mensch. Reinbek/H.: Rowohlt.

New, Antonia S./Hazlett, Erin A./Buchsbaum, Monte S./Goodman, Marianne/Reynolds, Diedre/Mitropoulou, Vivian/Sprung, Larry/Shaw, Robert B./Koenigsberg, Jr., Harold/Platholi, Jimcy/Silverman, Jeremy S./Siever Larry J. (2002): „Blunted prefrontal cortical 18fluorodeoxyglucose positron emission tomography response to meta-chlorophenylpiperazine in impulsive aggression", in: Archives of General Psychiatry 59, 621-629.

Niedermeyer, Albert (1949-1952): Handbuch der speziellen Pastoralmedizin. Wien: Verlag Herder.

Niemann, Ulf/Wagner, Marion, Hg. (2005): Exorzismus oder Therapie? Ansätze zur Befreiung vom Bösen. Regensburg: Verlag Friedrich Pustet.

Österreich, Traugott Konstantin (1921): Die Besessenheit. Langensalza. 
Osterheider, Michael/Mokros, Andreas (2006): „Die Forensische Psychiatrie und das Böse", in: Neurotransmitter Sonderheft 2, 9-14.

Payk, Theo R. (2006): „Psychopathologie des Bösen“, in: Neurotransmitter Sonderbeft 2, 16-20.

Pfäfflin, Friedmann/Ross, Thomas (2006): „Ist das Böse psychotherapiefähig?", in: Neurotransmitter Sonderheft 2, 21-23.

Pfeiffer, Wolfgang M. (1994): Transkulturelle Psychiatrie. Stuttgart: Thieme.

Pietrini, Pietro/Guazzelli, Mario/Basso, Gianpaolo/Jaffe, Karen/Grafman, Jordan (2000): „Neural correlates of imaginal aggressive behavior assessed by positron emission tomography in healthy subjects", in: The American Journal of Psychiatry 157, 1772-1781.

Rahner, Karl (1976): „Besessenheit und Exorzismus“, in: Stuttgarter Zeitung 194, 721-722.

Rahner, Karl (1978): „Über Engel“, in: Rahner, Karl: Schriften zur Theologie. Band 13. Köln-Einsiedeln-Zürich: Benziger, 381-428.

Raine, Adrian/Lencz, Todd/Bihrle, Susan/Lacasse, Lori/Colletti, Patrick (2000): ,Reduced prefrontal gray matter volume and reduced autonomic activity in antisocial personality disorder", in: Archives of General Psychiatry 57, 119-127.

Raine, Adrian/Lencz, Todd/Taylor, Kristen/Hellige, Joseph B./Bihrle, Susan/Lacasse, Lori/Lee, Mimi/Ishikawa, Sharon/Colletti, Patrick (2003): „Corpus callosum abnormalities in psychopathic antisocial individuals", in: Archives of General Psychiatry 60, 1134-1142.

Raine, Adrian/Ishikawa, Susan/Arce, Estibaliz/Lencz, Todd/Knuth, Kevin H./Bihrle, Susan/Lacasse, Lori/Colletti, Patrick (2004): „Hippocampal structural asymmetry in unsuccessful psychopaths", in: Biological Psychiatry 55, 185-191.

Ranke-Heinemann, Uta (2004): Nein und Amen. München: Wilhelm-HeineVerlag.

Roth, Gerhard (22006): „Willensfreiheit und Schuldfähigkeit aus Sicht der Hirnforschung“", in: Roth, Gerhard/Grün Klaus-Jürgen, Hg.: Das Gebirn und seine Freiheit. Göttingen: Vandenhoeck \& Ruprecht, 9-27.

Roth, Gerhard (2003): Füblen, Denken, Handeln. Wie das Gebirn unser Verbalten steuert. Frankfurt/M.: Suhrkamp.

Saß, Henning/Wittchen, Hans-Ulrich/Zaudig, Michael, Hg. (1996) Diagnostisches und Statistisches Manual Psychischer Störungen. DSM-IV. GöttingenBern-Toronto-Seattle: Hogrefe-Verlag für Psychologie.

Schallenberg, Peter (2006): „Die Sünde als Dämon“, in: Neurotransmitter Sonderheft 2, 60-69.

Scharfetter, Christian (41995): Schizophrene Menschen. Weinheim: Beltz-Psychologie-Verlags-Union.

Scheffczyk, Leo (1975): „Christlicher Glaube und Dämonenlehre“, in: Münchner Theologische Zeitschrift 16, 387-396. 
Scheuer, Manfred (o.J.): Da steckt der Teufel dabinter. Erste Assoziationen mit dem Thema. Unveröffentlichtes Manuskript.

Schwager, Raymund/Siebenrock Roman A. (2006): Das Böse/Der Teufel. Theologische Orientierungen. Innsbrucker Diskussionspapiere zu Weltordnung, Religion und Gewalt 9, Universität Innsbruck.

Simon, Robert I. (1996): Bad Men Do What Good Men Dream - A Forensic Psychiatrist Illuminates the Darker Side of Behavior. Washington/DC: American Psychiatric Press.

Soderstrom, Henrik/Hultin, Leif/Tullberg, Mats/Wikkelso, Carsten/Ekholm, Sven/Forsman, Anders (2002): „Reduced frontotemporal perfusion in psychopathic personality", in: Psychiatry Research 114, 81-94.

Sofsky, Wolfgang (1996): Traktat über die Gewalt. Frankfurt/M.: Fischer Verlag.

Stone, Michael H. (1993): „Long-term outcome in personality disorders“, in: The British Journal of Psychiatry, 299-313.

Stroscio, Rosario (2001): „Der Teufel quälte Mutter Theresa. Ich habe sie vom Teufel befreit", in: Oggi, 19. September 2001.

Voltaire (1994): Briefe aus England. Zürich: Diogenes.

Vorgrimler, Herbert (32000): Neues Theologisches Wörterbuch. Freiburg/B.Basel-Wien: Herder.

Wagner, Marion (2005): „Personalität des Bösen? Zur ,Funktion“ und zum Gebrauch der Rede vom Teufel“, in: Niemann, Ulf/Wagner, Marion, Hg.: Exorzismus oder Therapie? Ansätze zur Befreiung vom Bösen. Regensburg: Verlag Friedrich Pustet, 32-48.

Welner, Michael (2002): „Indexing Evil“, in: Psychology Today 35 (1), 15-16.

Wyss, Dieter (1997): Kain. Eine Phänomenologie und Psychopathologie des Bösen. Würzburg: Königshausen \& Neumann.

Yang, Yaling/Raine, Adrian/Lencz, Todd/Bihrle, Susan/LaCasse, Lori/ Colletti, Patrick (2005): „Volume reduction in prefrontal gray matter in unsuccessful criminal psychopaths“, in: Biological Psychiatry 57, 11031108.

Zimbardo, Philip G. (2002): „The Stanfort Prison Experiment. A Simulation Study of the Psychology of Imprisonment Conducted at Stanford University", online unter: http://www.prisonexp.org/ (Zugriff am 6.12.2007).

Zimbardo, Philip G. (2006): „On rethinking the psychology of tyranny: the BBC prison study“, in: British Journal of Social psychology 45 (1), 47-53. 
Zur Rede vom Bösen, Dämonen und dem Teufel in der Theologie. Eine theologische Orientierung zum Text von Hartmann Hinterhuber

\author{
Roman A. Siebenrock ${ }^{*}$
}

Der umfassende Aufsatz von Hartmann Hinterhuber nennt aus der Sicht des Psychiaters und Therapeuten viele berechtigte Aspekte, die es geraten sein lassen, auf die Rede vom Teufel gänzlich zu verzichten. Er weist vor allem auch darauf hin, dass selbst im neuen Katechismus der katholischen Kirche die Rede von Dämonen oder vom Teufel keine - einmal quantitativ gesehen - bedeutende Rolle spielt. Mir ist es nicht möglich, auf diese Kritik aus eigener Kompetenz zu antworten. Im ersten Teil dieser Orientierung möchte ich daher einen Text zitieren, den eine Gruppe von Theologinnen und Theologen zusammen mit dem Therapeuten Niemann verfasst hat. Dieser Text spricht für sich und stellt eine Antwort auf die Einwände dar, weil er einen verantwortbaren Umgang mit „Besessenheit“ aufzeigt. Menschen, die in dieser Sprache ihre Lebensnot und Ohnmacht ausdrücken, kann nur geholfen werden, wenn sich der Therapeut mit ihnen und damit auch mit ihrer Vorstellungswelt verbindet. Außerdem zeigt diese Orientierung, dass bereits jetzt in der realen Praxis

* Roman A. Siebenrock ist nach mehrjähriger Tätigkeit an der Katholisch-Theologischen Fakultät der Universität Innsbruck seit 2006 Professor für Dogmatik am Institut für Systematische Theologie und Sprecher des Forschungsschwerpunktes „Religion - Gewalt Kommunikation - Weltordnung“ der Fakultät. Seine Arbeitsschwerpunkte sind der interreligiöse Dialog, vor allem im Zusammenhang mit J. H. Newman, Karl Rahner und dem Zweiten Vatikanischen Konzil, und er betreut das Karl-Rahner-Archiv. Der vorliegende Text ist eine Reaktion auf den Text von Hartmann Hinterhuber, der auch an die Diskussionen während der 16. Klausurtagung der Plattform am 3. Juli 2006 anknüpft. 
viele Forderungen eingelöst sind, die kritisch gegen die exorzistische Praxis erhoben worden sind (und werden).

Meine eigene Orientierung, die ich im zweiten Teil darlege, hat eine geringere Absicht: Ich möchte zeigen, dass die Frage nach dem Teufel bzw. nach Dämonen oder - abstrakter formuliert - nach dem radikal Bösen nicht überholt ist, sondern sich uns heute noch unausweichlicher stellt, als hier angedeutet wird. Mit einigen Hinweisen auf die aktuelle Diskussion soll dies auch belegt werden.

\section{Stellungnahme zum Thema „Das Böse und die Befreiung vom Bösen"1}

1. Die Rede vom Teufel ist vielfältig vorbelastet und kann leicht missverstanden werden. Sie stößt heute häufig auf Unverständnis.

2. Gleichwohl spielt die Kategorie des Bösen in der Lebenswelt der Menschen eine große Rolle. Menschen erfahren das Böse nicht selten als eine Macht, der sie ohnmächtig ausgeliefert sind.

3. Wenn in diesem Zusammenhang von der Personalität des Bösen bzw. vom Satan oder vom Teufel die Rede ist, so ist Folgendes zu beachten:

○ Im Alten Testament kommt der Teufel kaum vor. Die Dämonen spielen - vor dem Hintergrund des Ringens um Monolatrie und Monotheismus - keine Rolle.

- Im Neuen Testament begegnet der Teufel (diabolos) unter vielen Namen:

- Satan (hebr.: der Widersacher, Verfolger, Feind), der Versucher, Beilial/Beliar, Fürst dieser Welt usw. Hier handelt es sich um Umschreibungen und Metaphern, die zeigen, dass eine gewisse Scheu besteht, das Abgrundböse auf einen bestimmten Namen festzulegen. Das Neue Testament spricht in verschiedenen Kontexten vom Sieg über den Teufel und verbindet diesen Sieg untrennbar mit der Person Jesu Christi. Dabei bleibt der „Teufel“ aber schillernd und unfassbar. Er entzieht sich jeder Fixierung.

1 Abgedruckt in: Niemann/Wagner (2005), 137-141. Unterzeichnet von: Marion Wagner; Ulrich J. Niemann SJ; Antonio Autiero; Klaus Berger; Medard Kehl SJ; Ute Leimgruber; Manfred Probst SAC; Klemens Richter. 
○ Eben weil das Abgrundböse schillernd ist und unfassbar bleibt, kann es bei der theologischen Rede vom Teufel nur um die sprachliche und bildhafte Bewältigung sowie Vertiefung der Erfahrung des Abgrundbösen gehen. Wenn man theologisch von der Personalität des Bösen spricht, wird dadurch festgehalten und klargestellt:

- Das Böse ist eine furchtbare Realität. Es ist nicht notwendig, sondern kontingent. Es hat mit dem Phänomen der menschlichen Freiheit zu tun, d.h. mit der grundsätzlichen Fähigkeit des Menschen, zwischen Gut und Böse zu unterscheiden und sich dann diesbezüglich zu entscheiden. Das Böse zeigt mitunter eine eigentümliche Logik und Raffinesse. Es ist eine sich vom einzelnen Menschen unterscheidende Macht, aber der Mensch kann sich ihm widersetzen. Dank der Entmachtung des Bösen durch Jesus Christus ist für den Menschen ein Sieg über das Böse möglich.

4. Die Grenzen des theologischen Sprechens über das Böse sind einzugestehen und zu wahren: Die Rede vom Teufel oder von der Personalität des Bösen ist der Versuch, über jene furchtbare Realität des Abgrundbösen etwas mehr auszusagen als nichts.

5. Wenn bezüglich des Bösen in Ermangelung eines besseren Begriffs von Person gesprochen wird, kann es sich bestenfalls um eine analoge Aussage im Sinne der klassischen Analogielehre handeln. Das heißt: Bei dieser Aussage ist die Unähnlichkeit größer als die Ähnlichkeit. Es wäre daher ein Missverständnis, die Personalität des Bösen mit menschlicher Personalität gleichzusetzen.

6. Die Rede vom Teufel ist eine Verstehenskategorie und Deutungshilfe, die bei der Verständigung über Ursprung, Wesen und Bewältigung des Bösen helfen kann. Der Geheimnischarakter des Bösen wird durch die Rede vom Teufel nicht aufgelöst, sondern im Gegenteil im Bewusstsein gehalten. Hier kommt das zum Ausdruck, was die Möglichkeiten menschlichen Sprechens übersteigt und letztlich unsagbar ist.

7. Ziel theologischen Nachdenkens und Sprechens muss eine pastoral verantwortete Rede vom Bösen sein, die vermittels ihrer metaphorischen Kraft das jedem Menschen begegnende Böse in seiner individuellen, personalen und subjektiven (situativ-einmaligen) wie auch in seiner überindividuellen, überpersonalen und objektiven Form zu identifizieren vermag. 
○ Das heißt: Theologie und Verkündigung müssen in einer Weise vom Bösen sprechen, die deutlich macht, dass das Böse zwar von Menschen begangen wird, dass böse Zustände aber - auch wenn sie von den menschlichen Tätern nicht zu trennen sind - über die individuelle Täterschaft hinausweisen und zu strukturellen Konstellationen einer kollektiven Bosheit (z.B. Hiroshima, Auschwitz, Archipel Gulag etc.) werden, gegenüber denen sich einzelne Menschen machtlos fühlen. Ebendieses Miteinander und Ineinander von individuellem Tun und überindividueller Macht bringt die Rede vom Teufel zur Sprache.

8. Immer wieder gibt es Menschen, die sich als „besessen“ erleben oder bei denen andere Symptome angeblicher „Besessenheit“ zu erkennen meinen.

9. $\mathrm{Ob}$ es etwas wie eine dämonische Besessenheit gibt, ist weder zu beweisen noch zu widerlegen. Nach Auskunft der Humanwissenschaften handelt es sich bei dem auftretenden Phänomen um ein in religiös-terminologische, theatralisch-gebärdenhafte Sprache gefasstes psychodynamisches und psychopathologisches Syndrom.

- Unter humanwissenschaftlicher Perspektive gibt es also keine Besessenheit, sondern nur besondere Persönlichkeitskonstellationen und eventuell Krankheitssymptome, die in einem bestimmten religiösen Kontext in dieser Weise gedeutet werden können.

○ Theologisch kann die Möglichkeit von Besessenheit nicht ausgeschlossen werden. Sie gilt als sententia certa.

- Allerdings dürfte es im konkreten Fall schwierig sein, eine moralische Gewissheit darüber zu erlangen, ob Besessenheit vorliegt (vgl. CIC e. 1172 \2). Es gibt keine theologischen Kriterien für Besessenheit.

- Die immer wieder genannten Anzeichen (das Verstehen fremder Sprachen, das Wissen um geheime und verborgene Dinge, das Verfügen über außergewöhnliche Kräfte, die feindliche, aggressive Reaktion auf heilige und geweihte Dinge) können auf dem Hintergrund heutiger humanwissenschaftlicher Erkenntnisse - selbst in der Summe - keine hinreichende Gründe für die Konstatierung von Besessenheit sein. 
- Daher sind Menschen, die sich für besessen halten oder vermeintliche Besessenheitsphänomene zeigen, einer entsprechenden neurologisch-psychiatrischen und/oder einer klinischpsychologischen Diagnose und einer eventuellen Therapie zuzuführen.

10. Die medizinische und die religiöse Deutung der Phänomene schließen einander nicht aus und treten nicht in Konkurrenz zueinander. Sie stellen jeweils eigenständige und jeweils begrenzte Deutungsdimensionen dar.

o Der Humanwissenschaftler erhebt einen ärztlich-medizinischen und klinisch-psychologischen Befund. Der Theologe stellt die auf diese Weise (nach derzeitigem humanwissenschaftlichem Kenntnisstand mehr oder weniger) erklärbaren Phänomene in einen Gesamtzusammenhang, der die humanwissenschaftliche Dimension transzendiert. Er konstatiert, dass sich hier im Leiden eines Menschen jene Isoliertheit und Kommunikationslosigkeit, jenes Chaos und Tohuwabohu, jene Lebensfeindlichkeit manifestieren, die gottwidrig sind und als Charakteristikum des Bösen gelten.

11. Wie jeder Kranke hat auch der Mensch, der sich vom Bösen in besonderer Weise bedrängt fühlt, ein Anrecht auf ärztlich-medizinische bzw. klinisch-psychologische und seelsorgerliche Betreuung. Dabei ist seiner subjektiven Überzeugung von der religiösen Dimension seiner bio-psycho-sozialen Befindlichkeit angemessen Rechnung zu tragen, ohne sie in irgendeiner Weise zu bestätigen und zu verstärken.

- Der traditionelle Große Exorzismus als Gebet über Besessene und Befehl an den Satan, aus dem Kranken auszufahren oder von ihm abzulassen, kann zumindest in unserem Kulturkreis nicht mehr als angemessene Form liturgischer Hilfe gelten. Dies hat bereits 1984 eine von der Deutschen Bischofskonferenz eingesetzte Kommission konstatiert und anstelle dieses Exorzismus eine „Liturgie zur Befreiung vom Bösen" vorgeschlagen, denn die Erfahrbarmachung der Liebe Gottes, die Zuwendung zum bedrängten Menschen und die eschatologische Deutung dieser Zuwendung sind keineswegs überholt. Diese Zuwendung ist ein wichtiger Teil des Heilsdienstes der Kirche, in ihr wird zeichenhaft deutlich, dass das Reich Gottes bereits angebrochen ist und 
dass in Jesus Christus der Sieg über das Böse bereits errungen ist.

- Mit dem Hilfsbedürftigen und für ihn um die Befreiung vom Bösen zu beten, kann daher als Teil der Reich-GottesVerkündigung bzw. Nachahmung der Reich-Gottes-Praxis Jesu gelten und sollte damit eine wichtige Aufgabe der Kirche sein.

- Seelische Not, körperliches Leiden, Angst, Verzweiflung, Aggression, Negativismus - jene vielfältigen Manifestationen des Abgrundbösen - sollten beim Namen genannt werden, damit „Befreiung“ möglich wird.

○ Zu vermeiden ist daher die seit dem Mittelalter in der Westkirche anzutreffende imprekative (imperative) Form des Befreiungsgebetes sowie die direkte Anrede des Teufels bzw. das Erfragen der Namen von Teufeln und Dämonen.

- Das imprekative (imperative) Gebet fördert das Missverständnis, die Befreiung vom Bösen lasse sich durch Exorzismus magisch erzwingen, und kann gegebenenfalls den „Trotz" der Betroffenen hervorrufen.

- Bei dem Gebet um Befreiung handelt es sich um Liturgie, also um einen Dialog zwischen Mensch und Gott. Von daher verbietet es sich - unabhängig von der theologischen Frage ihrer Existenz -, Teufel und Dämonen in einer gottesdienstlichen Feier anzusprechen. Adressat des Gebetes um Befreiung kann nur Gott sein. Deshalb ist die deprekative (fürbittende) Form dem Gebet um Befreiung als einer liturgischen Handlung angemessen. Die Freiheit und Würde des betroffenen Menschen erfordern aber gleichzeitig sein aktives, möglichst freies Mitbeten. Die conprekative Form des Gebetes entspricht der Förderung der Liturgischen Konstitution des II. Vatikanischen Konzils nach einer ,actuosa participatio" (aktiven Teilnahme im Hier und Jetzt) in der erneuerten Liturgie.

\section{Vom Umgang mit der Frage nach dem radikal Bösen}

Die Theologie hat es zentral mit Fragen und Erfahrungen zu tun, die wir nicht hinter uns lassen können, wenn wir human die Zukunft gestalten wollen; es sind jene Fragen, die der conditio bumana eingeschrieben worden sind. Zu diesen Fragen gehören - nicht an erster, 
aber auch nicht an letzter Stelle - die Fragen nach dem Bösen in all seinen sprachlichen Varianten: Dämonen, Teufel, Geister, Mächte und Gewalten. Diese Themen sind in allen Kulturen zu finden; und auch die Ausdrucksformen hierfür sind nicht völlig verschieden. Die Theologie wollte in den letzten Jahrzehnten diese Fragen als überwunden hinter sich lassen. Doch die große Entmythologisierung hat uns zwar darauf aufmerksam gemacht, dass die verschiedenartige Rede von Dämonen und bösen Geistern nicht über die Ontologie, sondern allein über die menschliche Erfahrung angegangen werden kann, sie hat aber auch gezeigt, dass wir diese Rede (und auch die Bilder, die im kollektiven Gedächtnis der Menschheit tief verankert sind) nicht einfach hinter uns lassen können, sondern verantwortlich auslegen müssen - gerade dann, wenn sie sich ungewollt einstellen. ${ }^{2}$

Aus verschiedenen Gründen sind die verabschiedeten Themen wieder da: Im politisch-philosophischen Denken, in ethnologischen Untersuchungen, aber auch in den Medien, der Kunst und der Musikszene sind diese Fragen präsent. Besonders die Philosophie, und keineswegs die theologisch inspirierte, hat diese Frage erneut aufgeworfen. ${ }^{3}$ Der Grund für diese Renaissance kann nicht in der Verkündigung der Kirche oder ihren Strategien liegen. Sie muss mit Grunderfahrungen des Menschen zu tun haben, mit der Erfahrung des Ganzen der Welt und unserer Selbst, mit der Frage nach den Mächten, die unser Dasein bestimmen, und nach der Weise, wie wir solche Urerfahrungen in Worten, Gleichnissen und Bildern ausdrücken können. ${ }^{4}$ Eine gewisse Rolle spielt auch die Tatsache, dass sich die nichteuropäischen Kulturen nicht mehr vorschreiben lassen, wie sie ihre eigenen Erfahrungen und Traditionen auszulegen haben. ${ }^{5}$

Die Erfahrung des Bösen, der Wider- und Abergeister gegen das Leben, der Todesmächte und Verstrickungsgewalten schafft sich

2 Die viel zitierte Studie von Herbert Haag (1969 und 1978) kommt ebenfalls zu dem Schluss, dass wir diese Frage nicht hinter uns lassen können, auch wenn viele Bilder und Vorstellungen im damaligen Weltbild verankert sind und so heute nicht wiederholt werden können. Die in der Theologie damals geführte Debatte ist dokumentiert in: Kasper/Lehmann (1978). Ausführlich aufgearbeitet und neu geklärt bei: Claret (1997). Eine bedeutende Deutung und Auslegung darf genannt werden: Ricoeur (1971).

3 Safranski (2000), Arendt (2006) und vor allem: Neiman (2004) sowie Horster (2006).

4 Siehe Hofgärtner (1985) und Wenisch (1989).

5 Die neue Diskussion um den Exorzismus wird in der katholischen Kirche stark von nichteuropäischen Kulturen angestoßen und forciert. Bemerkenswerte Annäherungen werden in folgenden Untersuchungen dokumentiert: Signer (2004) und de Rosny (1999). 
auf verschiedene Weise Ausdruck. Es können drei Erfahrungsbereiche ausgemacht werden: persönlich-individuelle, systemisch-strukturelle und die neue Undurchsichtigkeit und Bedrohtheit des Ganzen durch die „Entwicklungslogik“ einer vielfältig dynamisierten Welt. Zunächst mögen persönliche Fragen wie Angst, Erfahrung von Gewalt und Unrecht, von Unglück und Tragödien diese Frage aufwerfen und sich auch in der beschriebenen Weise ausdrücken - das aber nicht nur bei pathologisch zu bezeichnenden Personen. Nachhaltiger meldet sich die Rede vom Bösen als Deutung von Systemen und Strukturen, die machtvoll uns faszinieren, aber Todes- und Vernichtungsmächte darstellen. ${ }^{6}$ Im 20. Jahrhundert scheint sich in dieser Hinsicht eine metaphysische Deutung geradezu aufzudrängen. ${ }^{7} \mathrm{Heu}-$ te stellt sich für viele angesichts des nicht mehr von einzelnen Personen oder Gruppen steuerbaren, aber neue apokalyptische Ängste hervorrufenden Gesamtzusammenhangs unserer sich beschleunigt verändernden Welt das Bild von den dämonischen Mächten und Gewalten ein.

Aber: Sind wir solchen Erfahrungen einfach nur ausgeliefert, oder liegt nicht in der Versprachlichung der erste Schritt zur Distanzierung und damit zur möglichen Befreiung, weil in diesem Akt der Sprache eine erste Differenz eröffnet und die bloße Ohnmacht überwunden wird? Vor allem, wenn das Unheil nicht mehr individualisiert werden kann, stellt sich die Frage nach der Verantwortung noch vehementer. Was liegt dann näher als die Versuchung, hierfür einzelne Menschen und/oder Gruppen als Sündenböcke abzustempeln? In dieser Situation wird zu den alten Mustern der Deutung - und zwar aus allen Weltkulturen - gegriffen. In der höchsten Not stellen sich solche Bilder ein: individuell und kollektiv, höchst ambivalent und gefährlich. Die Frage wird unausweichlich, wie wir damit umgehen können und sollen, ja müssen. Ausreden lassen sich die Menschen ihre Ängste nicht. In Korrektur von Rudolf Bultmann muss darauf hingewiesen werden, dass selbst Menschen in einer hoch technisierten und verwissenschaftlichen Zivilisation zu solchen Deutungen greifen. Der in Abschnitt zwei abgedruckte Text soll den

6 In der jüngsten Diskussion wird dabei gern auf die Systemtheorie von Niklas Luhmann zurückgegriffen. Siehe Ruster (2006).

7 Gerade in der Interpretation des NS-Regimes sprach Eugen Kogon, der das System der Konzentrationslager aus eigener Erfahrung analysierte, von einer Metaphysik des Bösen. Siehe Kogon (1964). 
Umgang mit der persönlichen Erfahrung und die angemessenen therapeutischen Vorgehensweisen in diesem Zusammenhang zeigen.

Für die Ansätze im Forschungsschwerpunkt RGKW hat die Kulturtheorie René Girards eine besondere Bedeutung und Deutungskraft. Dabei wird die Beobachtung wichtig, dass in Girards Theorie das Satanische in seiner Mächtigkeit beschrieben und enthüllt wird, ohne dass er sich dabei auf eine ontologische Position festlegen müsste. ${ }^{8}$

Darüber hinaus erscheint mir folgende Perspektive hilfreich zu sein. Die Erfahrung des Bösen, des radikal Bösen zumal, gehört als Mysterium iniquitatis zu den schmerzlichsten und dunkelsten Fragen des Menschen. Sie zeigt sich in ihrer Entwicklungsstruktur darin, dass unter der Vorgabe der Verheißung und Faszination Menschen in ihren Bann gezogen werden. In dem sich darin entwickelnden Mechanismus werden Menschen zu Tätern und Opfern. Gegen eine Kultur der bloßen Anklage entzieht sich der einzelne Mensch (vom Ergebnis her gesehen) der „Verteufelung“, auch wenn das Ergebnis teuflisch ist: die schlichte Katastrophe, oder: eine Erfahrung des Bösen und der Ungerechtigkeit, die nach der Hölle schreit - nach purem Nein! Dieser Protest kann nach dem 20. Jahrhundert niemandem abgesprochen werden. Daher gehört solch Böses zur Wirklichkeit, und vielleicht haben wir noch gar keine philosophische Orientierung hierfür, die nicht einfach von der menschlichen Freiheit aufgearbeitet werden kann. Andererseits aber, und das ist die Maxime des Evangeliums Jesu Christi, ist von diesem Bösen nur zu sprechen im Kontext seiner Entmachtung und Überwindung. Deshalb ist eine individuelle und gesellschaftliche Umkehr nicht nur unabdingbar, sondern möglich. Wir sind diesen Mechanismen niemals nur ausgeliefert, und seien es scheinbar noch so unumstößliche systemische Notwendigkeiten. In den bildhaften Erzählungen vom Ursprung des Bösen im Engelsturz und seiner Überwindung am Ende der Zeiten im Bild der Frau, die vor dem Drachen flieht - jenem Drachen, der im Zeichen des Lammes nach der Offenbarung des Johannes überwunden wird -, bleibt dies bis heute inspirierend ausgedrückt. Dadurch werden gerade die Unverständlichkeit und die mögliche Entmachtung des Bösen angesagt. ${ }^{9}$ Und gerade diese Unfassbarkeit gibt 
$\mathrm{zu}$ denken und warnt uns davor, die anderen zu stigmatisieren. Wir alle sind darin verstrickt, aber nicht notwendig oder gar unausweichlich. Eine Forschungsplattform, die sich auch mit den ungeheuerlichen Bedrohungen heute auseinandersetzt, kann sich gerade dieser doppelten Botschaft der Bilder nicht entziehen. Wir machen die Erfahrung, dass im Prozess der Aufklärung und der in ihr sich zeigenden Dialektik jene Fragen sich verstärkt einstellen, von denen uns diese zu befreien vorgibt. In einem Zeitalter der Wissenschaft und Technik, der Möglichkeit zur Selbstvernichtung in ,sanft-schleichender" und heißer Form und in der Erfahrung der Undurchsichtigkeit und Unübersichtlichkeit wird die Rede von Dämonen und dem Mechanismus des Satanischen beklemmend aktuell.

\section{Literatur}

Arendt, Hannah (2006): Über das Böse. Eine Vorlesung zu Fragen der Ethik. München: Piper.

Claret, Bernd J. (1997): Geheimnis des Bösen. Zur Diskussion um den Teufel. Innsbruck-Wien: Tyrolia Verlag.

Colpe, Carsten/Schmidt-Biggemann, Wilhelm, Hg. (1993): Das Böse. Eine historische Pbänomenologie des Unerklärlichen. Frankfurt/M.: Suhrkamp.

Haag, Herbert (1969): Abscbied vom Teufel. Einsiedeln: Benzinger.

Haag, Herbert (1978): Vor dem Bösen ratlos? München: Piper.

Hofgärtner, Irmingard (1985): Teufel und Dämonen. Zugänge zu einer verdrängten Wirklichkeit. München: Pfeiffer.

Horster, Detlef, Hg. (2006): Das Böse neu denken. Hannah-Arendt-Lectures und Hannah-Arendt-Tage 2005. Weilerswist: Velbrück.

Kasper, Walter/Lehmann, Karl, Hg. (1978): Teufel - Dämonen - Besessenheit. Zur Wirklichkeit des Bösen. Mainz: M. Grünewald.

Kogon, Eugen (1946): Der SS-Staat. Das System der deutschen Konzentrationslager. Frankfurt/M.: Heyne.

Neiman, Susan (2004): Das Böse denken. Eine andere Geschichte der Philosophie. Frankfurt/M.: Suhrkamp.

Niemann, Ulrich/Wagner, Marion, Hg. (2005): Exorzismus oder Therapie? Ansätz̨e zur Befreiung vom Bösen. Regensburg: Pustet, 137-141.

Ricoeur, Paul (1971): Symbolik des Bösen. Phänomenologie der Scbuld II. Freiburg/B.-München: Alber.

Rosny, Eric de (1999): Die Augen meiner Ziege. Auf den Spuren afrikanischer Hexerei und Heiler. Wuppertal: Peter Hammer Verlag.

Ruster, Thomas. (2006): Von Menschen, Mächten und Gewalten. Eine Himmelslebre. Mainz: M. Grünewald. 
Safranski, Rüdiger (32000): Das Böse oder der Preis der Freibeit. Frankfurt/M.: Hanser.

Schwager, Raymund (1997): Erbsünde und Heilsdrama. Im Kontext von Evolution, Gentechnologie und Apokalyptik. Thaur-Münster: LIT.

Signer, David (2004): Die Ökonomie der Hexerei oder Warum es in Afrika keine Wolkenkratzer gibt. Wuppertal: Peter Hammer Verlag.

Wenisch, Bernhard (21989): Satanismus. Schwarze Messen - Dämonenglauben Hexenkulte. Mainz: M. Grünewald. 



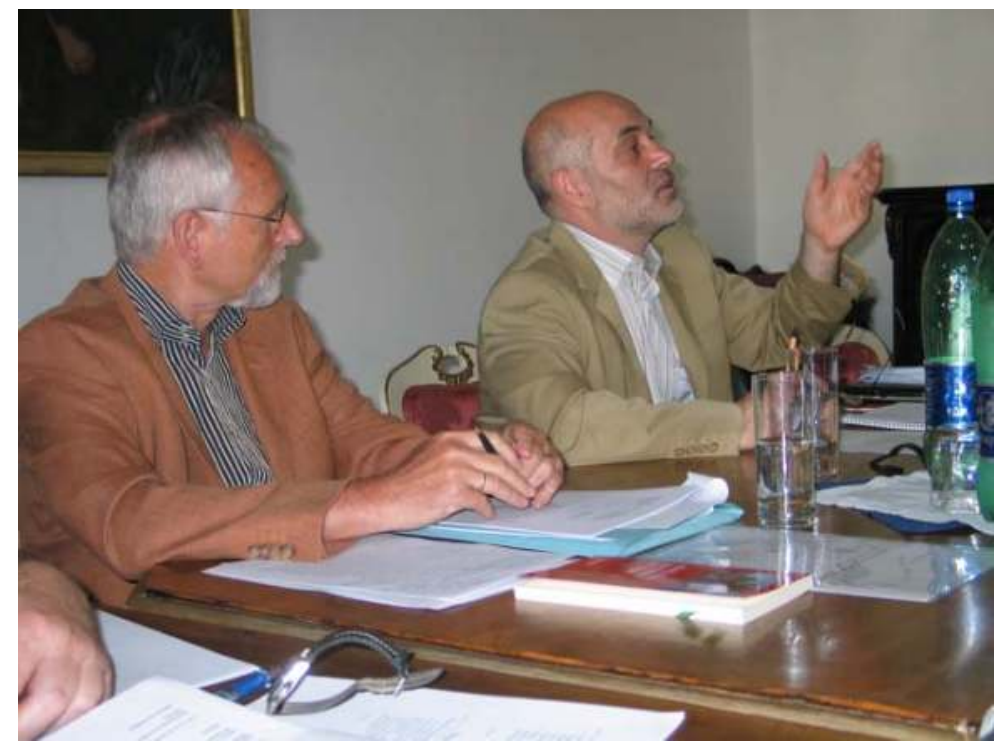

\section{Ankündigung}

Band 2 der Edition Weltordnung - Religion - Gewalt

Westliche Moderne, Christentum und Islam: Gewalt als Anfrage an monotheistische Religionen

Hg. von

Rüdiger Lohlker, Wolfgang Palaver und Roman A. Siebenrock

Mit Beiträgen u.a. von

Arnold Angenendt, Ednan Aslan, Hanna-Barbara Gerl-Falkovitz, Otto Kallscheuer und Jürgen Manemann.

Erscheint 2008 bei innsbruck university press. 
